\title{
INSTRUMENTO DE AUDITORIA DE SEGURANÇA VIÁRIA PARA PROJETOS RODOVIÁRIOS BRASILEIROS
}

\author{
LUCINEI TAVARES DE ASSUNÇÃO \\ ORIENTADORA: MICHELLE ANDRADE
}

DISSERTAÇÃO DE MESTRADO EM TRANSPORTES

DEPARTAMENTO DE ENGENHARIA CIVIL E AMBIENTAL

\section{FACULDADE DE TECNOLOGIA}

UNIVERSIDADE DE BRASÍLIA 
UNIVERSIDADE DE BRASÍLIA

FACULDADE DE TECNOLOGIA

DEPARTAMENTO DE ENGENHARIA CIVIL E AMBIENTAL

PROGRAMA DE PÓS-GRADUAÇÃO EM TRANSPORTES

INSTRUMENTO DE AUDITORIA DE SEGURANÇA VIÁRIA PARA PROJETOS RODOVIÁRIOS BRASILEIROS

LUCINEI TAVARES DE ASSUNÇÃO

ORIENTADORA: MICHELLE ANDRADE

PUBLICAÇÃO: T.DM-012/2015

BRASÍLIA / DF: JULHO/2015 
UNIVERSIDADE DE BRASÍLIA

FACULDADE DE TECNOLOGIA

DEPARTAMENTO DE ENGENHARIA CIVIL E AMBIENTAL

PROGRAMA DE PÓS-GRADUAÇÃO EM TRANSPORTES

\section{INSTRUMENTO DE AUDITORIA DE SEGURANÇA VIÁRIA PARA} PROJETOS RODOVIÁRIOS BRASILEIROS

\section{LUCINEI TAVARES DE ASSUNÇÃO}

DISSERTAÇÃO DE MESTRADO SUBMETIDA AO PROGRAMA DE PÓS-GRADUAÇÃO EM TRANSPORTES DO DEPARTAMENTO DE ENGENHARIA CIVIL E AMBIENTAL DA FACULDADE DE TECNOLOGIA DA UNIVERSIDADE DE BRASÍLIA COMO PARTE DOS REQUISITOS NECESSÁRIOS PARA A OBTENÇÃO DO GRAU DE MESTRE EM TRANSPORTES.

APROVADA POR:

Profa. Michelle Andrade, Dra. (ENC-UnB)

(Orientadora)

Profa. Maria Alice Prudêncio Jacques, PhD (ENC-UnB)

(Examinadora Interna-PGGT-UnB)

Profa. Christine Tessele Nodari, Dra. (PPGEP-UFRGS)

(Examinadora Externa)

BRASÍLIA/DF, 15 DE JULHO DE 2015. 


\section{FICHA CATALOGRÁFICA}

\section{DE ASSUNÇÃO, LUCINEI TAVARES}

Instrumento de Auditoria de Segurança viária para projetos rodoviários brasileiros [Distrito Federal] 2015.

xiii, 337 p., 210x297 mm (ENC/FT/UnB, Mestre, Transportes, 2015).

Dissertação de Mestrado - Universidade de Brasília. Faculdade de Tecnologia.

Departamento de Engenharia Civil e Ambiental.
1. Auditoria
2. Segurança viária
3. Projetos rodoviários
4. Acidentes de trânsito
I. ENC/FT/UnB
II. Título (série)

\section{REFERÊNCIA BIBLIOGRÁFICA}

DE ASSUNÇÃO, L. T. (2015). Instrumento de auditoria de segurança viária para projetos rodoviários brasileiros. Dissertação de Mestrado em Transportes. Publicação T.DM012/2015. Departamento de Engenharia Civil e Ambiental, Universidade de Brasília, Brasília, DF, 337 p.

\section{CESSÃO DE DIREITOS}

AUTOR: Lucinei Tavares de Assunção

TÍTULO: Instrumento de auditoria de segurança viária para projetos rodoviários brasileiros.

GRAU: Mestre

ANO: 2015

É concedida à Universidade de Brasília permissão para reproduzir cópias desta dissertação de mestrado e para emprestar ou vender tais cópias somente para propósitos acadêmicos e científicos. $\mathrm{O}$ autor reserva outros direitos de publicação e nenhuma parte dessa dissertação e mestrado pode ser reproduzida sem autorização por escrito do autor.

Lucinei Tavares de Assunção

e-mail: lucaengenharia@hotmail.com

Telefone: (61) 8623-0943

Brasília/DF 
"Para realizar grandes conquistas, devemos não apenas agir, mas também sonhar; não apenas planejar, mas também acreditar". (Anatole France) 


\section{DEDICATÓRIA}

Dedico esta dissertação a minha mãe Maria Tavares de Assunção, pela sua simplicidade de mulher e mãe. E pelo seu amor incondicional e torcida pela minha vida pessoal e profissional. 


\section{AGRADECIMENTOS}

Ao meu querido Deus.

A família Tavares e Assunção que tanto amo, em especial minha MÃE MARIA, meus irmãos Rubens, Reinaldo, Roberto, Almir e Adalberto (in memoriam), minhas irmãs Luciéte, Lucidéa, Lucineia, Lúcia, Liliane (in memoriam), Leidiane e meus adoráveis sobrinhos e sobrinhas. Em especial as sobrinhas Lorena e Lubya que estavam presente, principalmente, na fase final desta dissertação.

O meu singelo agradecimento à professora Michelle Andrade, pela sua dedicação, que foi dedicação de mãe e amiga nos momentos de orientação e dificuldades. Agradeço também pelo carinho e pela confiança depositada em desenvolver o tema desta dissertação.

Agradeço aos demais professores do PPGT que contribuíram na minha formação: Adelaida, Aragão, Alan, Carlos Henrique, Fabiana, José Matsuo, Farranha, Maria Alice, Pastor, Sérgio e em especial aos professores Paulo Cesar e José Augusto.

Aos professores da Faculdade Ideal-PA, em especial a Hito Braga e João Luiz, pelas cartas de recomendações.

Agradeço imensamente a professora Maria Alice pela contribuição repassada desde os seminários 1 e 2, e ainda no momento da banca final e a professora Christine Nodari pela participação e contribuição na banca.

À minha amiga Rafaela Silveira e meu amigo Chico pela dica de vir para Brasília e depois conhecer o mestrado da UnB. Além de todo o apoio na minha chegada a Brasília, que era para passar apenas seis meses e neste momento já se foi seis anos (ano de 2015).

Aos amigos do PPGT meus agradecimentos pelo carinho e amizade, em especial a turma 2013, que considero ímpar, Aline Maia, Gerardo Sousa, Glaucemaria (Gal), Walysson, Emmanoel, Adriana Souza, Jean Marlo, Leonel, Edwin, Wesley, Rony, Hudson e William Marques. E aos amigos que fiz disciplinas no mestrado e outros que conquistei no decorrer do mestrado, meu simbólico agradecimento e carinho transmitido nessa fase: Noêmia, Áurea, Lourdes, Romea, Érica, Ronny, Juan Pablo, Giovana, Júlio Cesar, José Melquiades, Eliezé, Marcus, Expedito, Rodrigo, Marcelinho, Thárcia, Abimael, Juan, Zuleide, Márcia, Janneth, Carlos, Grazi, Janaína Cardoso e demais colegas do PPGT que direta e indiretamente me incentivaram na finalização do Mestrado.

Aos meus amigos da Agência Nacional de Transporte Terrestre-ANTT que me deram as primeiras oportunidades de cursar o mestrado. Em especial ao meu amigo Josias, Janaína e minha amiga Cinthia Sobreia e sua mãe pelas dicas e revisão do texto desta dissertação. E a minha amiga e irmã Robertinha.

Aos amigos do Departamento Nacional de Transporte Terrestres-DNIT que também me proporcionaram a oportunidade de finalizar o mestrado, em especial Fábio, Rodrigo, André, Daiane, Carlos Abramides, Nilo Junior, Olímpio e Sandro. Além do incentivo especial de Rogério Lezino, Júlio Pelisson e Sergio Campos. 
A Lucinete Pereira, que será minha eterna amiga secretária do PPGT (risos), pessoa ímpar que fico sem palavras para descrever tanto agradecimento que tenho a fazer, obrigada Lú pela amizade e carinho.

A Camila (secretária) meu muito obrigado pelo carinho e discernimento em me orientar nos momentos que precisei da secretária do PPGT.

Agradeço também a Itamá Filho que na hora de configurar as planilhas foi importantíssimo, além de me dar força na revisão final desta dissertação.

Agradeço ainda aos técnicos que responderam o meu instrumento de ASV, que não estão listados em nomes, mas pelos órgãos que pertencem: DNIT, ANTT, DER, Concessionárias de rodovias e consultores de segurança viária, obrigada!

Obrigada, simplesmente obrigada a todos! 


\title{
RESUMO
}

\section{INSTRUMENTO DE AUDITORIA DE SEGURANÇA VIÁRIA PARA PROJETOS RODOVIÁRIOS}

\author{
Autor: Lucinei Tavares de Assunção \\ Orientadora: Michelle Andrade \\ Programa de Pós-Graduação em Transportes, julho de 2015
}

A segurança rodoviária é fundamental, sendo necessário que seja tratada desde a fase de planejamento até a fase de operação para reduzir a necessidade de futuras revisões de projetos, o que resulta em gastos extras aos departamentos de transportes. Após ampla revisão bibliográfica identificou-se a experiência internacional da aplicação de auditoria de segurança viária (ASV) em projetos rodoviários por meio de listas de verificação. A ASV é uma técnica que visa identificar pontos propícios a acidentes de trânsito, além de auxiliar os profissionais a avaliar a segurança viária nos projetos rodoviários. Neste contexto, foi possível elaborar um instrumento adaptado para os projetos rodoviários brasileiros para ser aplicado no estudo de viabilidade, projeto básico e projeto executivo com vista à segurança viária. Realizou-se a revisão bibliográfica e foram selecionados 04 (quatro) manuais internacionais que subsidiaram a elaboração do instrumento proposto nesta dissertação. $\mathrm{O}$ instrumento é composto por três níveis de categorias, divididos em: nível 1 - macrocategoria, nível 2 - mesocategoria e nível 3- microcategoria. Esses níveis foram analisados quanto à forma de apresentação, conteúdo e quanto à frequência de abordagem nos manuais e linguagem técnica dos projetos brasileiros. O instrumento proposto foi avaliado por técnicos com experiência, principalmente, em planejamento, fiscalização e segurança de rodovias, com intuito do aprimoramento e verificação quanto à sua aplicabilidade nos projetos rodoviários brasileiros (estudo de viabilidade, projeto básico e projeto executivo). A colaboração dos técnicos foi relevante em apontar que o instrumento proposto é viável para ser usado em diferentes fases do processo de auditorias de segurança viária, com potencial para auxiliar a melhoria dos projetos sob o aspecto da segurança, reduzindo a ocorrência de locais propícios a acidentes de trânsito nas rodovias brasileiras. Contudo, foi levantada a dificuldade na montagem de equipes independentes e multidisciplinares para atuação na ASV, devido o rodízio dos técnicos nos setores dos órgãos ou a probabilidade de serem cedidos para outros órgãos.

Palavras-chave: Auditoria de segurança viária, Segurança viária, Projetos rodoviários, Acidentes de trânsito. 


\title{
ABSTRACT \\ ROAD SAFETY AUDIT TOOL FOR ROAD PROJECTS
}

\author{
Author: Lucinei Tavares Assunção \\ Supervisor: Michelle Andrade \\ Postgraduate Program in Transport, July 2015
}

Road safety is important, and needs to be treated from the planning phase to the operational phase to reduce the need for future design reviews, which results in extra costs for transport departments. After extensive literature review identified the international experience of the application of road safety audit (RSA) in road projects through checklists. The RSA is a technique that aims to identify favorable points to traffic accidents, and help professionals to evaluate road safety in road projects. In this context, it was possible to draw up an instrument adapted to the Brazilian road projects to be applied in the feasibility study, basic design and executive project for the road safety. We conducted a literature review and 04 were selected (four) international manuals that supported the elaboration of the instrument proposed in this dissertation. The instrument consists of three levels of categories, divided into: Level 1 - macrocategory, level 2 - mesocategory and level 3 microcategory. These levels were analyzed for form of presentation, content, and on the approach frequency in the manuals and technical language of the Brazilian projects. The proposed instrument was assessed by technicians with experience mainly in planning, supervision and road safety, with the aim of improving and verification as to its applicability in Brazilian highway projects (feasibility study, basic design and executive project). The collaboration of technicians was relevant to point out that the proposed instrument is feasible to be used at different stages of the road safety audit process, with the potential to help improve projects under the aspect of safety, reducing the occurrence of potential sites to accidents traffic on Brazilian highways. However, it was raised the difficulty in assembling independent and multidisciplinary teams to operate in RSA, because the rotation of technicians in the fields of organ or likely to be transferred to other organs.

Keywords: road safety audit, road safety, road projects, traffic accidents. 


\section{ÍNDICE}

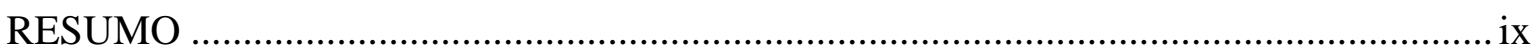

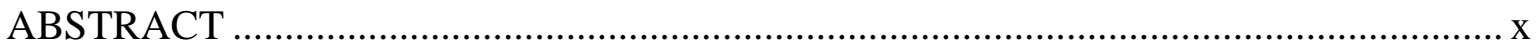

1 INTRODUÇÃ

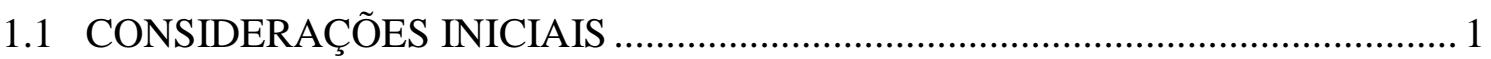

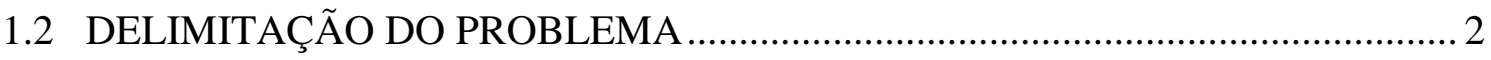

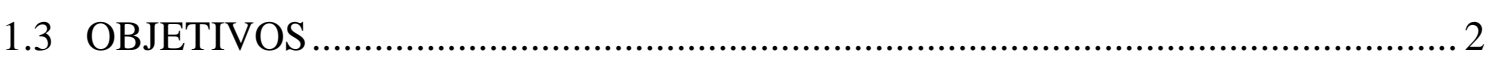

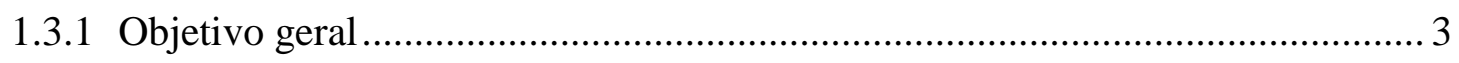

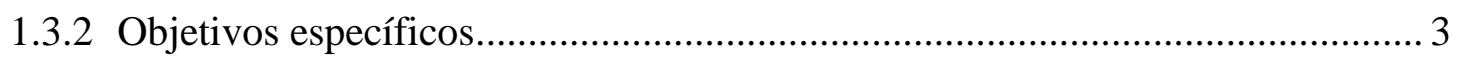

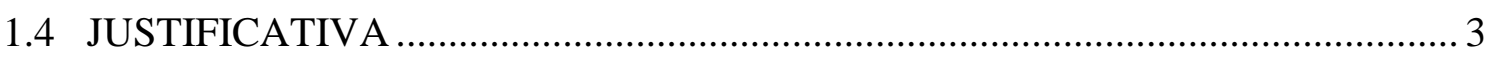

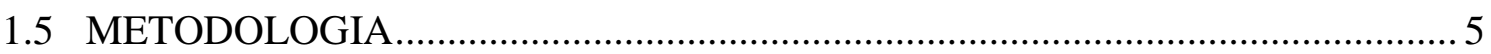

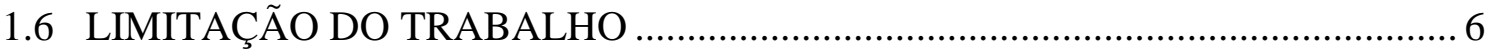

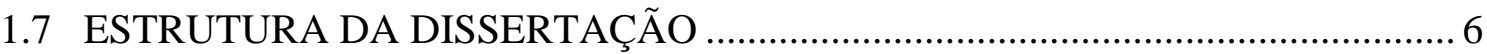

2 CONTEXTUALIZAÇÕES: ACIDENTE DE TRÂNSITO, SEGURANÇA VIÁRA E

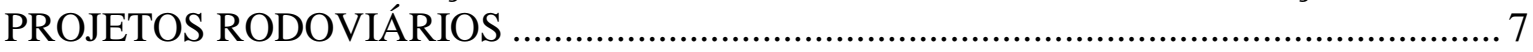

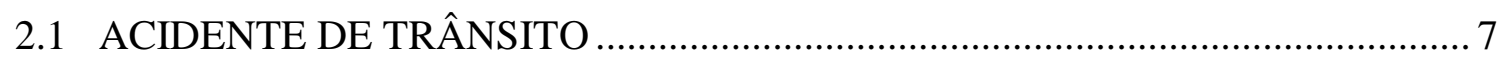

2.1.1 Fatores contribuintes para o acidente de trânsito ........................................... 8

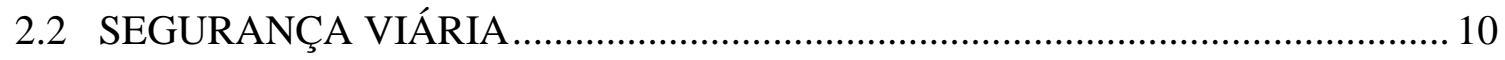

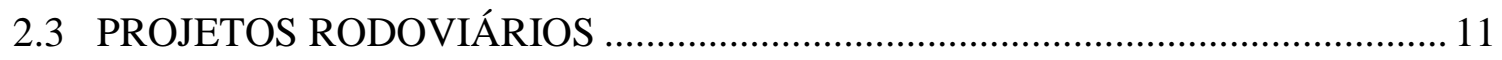

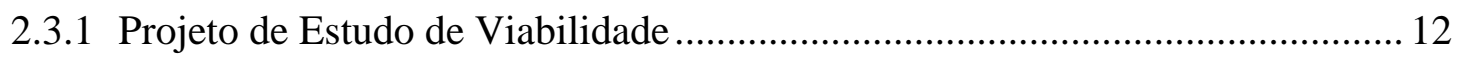

2.3.2 Projeto Básico e Projeto Executivo ...................................................................... 13

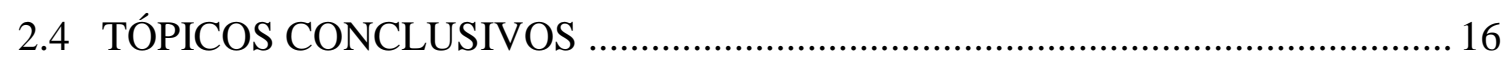

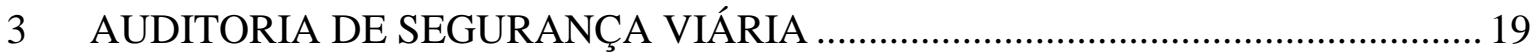

3.1 DEFINIÇÕES DA AUDITORIA DE SEGURANÇA VIÁRIA .............................. 19

3.2 OBJETIVOS DE AUDITORIA DE SEGURANÇA VIÁRIA ................................ 20

3.3 FASES DE APLICAÇÃO DA AUDITORIA DE SEGURANÇA VIÁRIA ........... 21

3.4 EQUIPE DA AUDITORIA DE SEGURANÇA VIÁRIA …................................. 22

3.5 EXPERIÊNCIAS DA AUDITORIA DE SEGURANÇA VIÁRIA ........................ 23

3.5.1 Auditoria de Segurança Viária na Nova Zelândia, Austrália, Canadá, Chile e

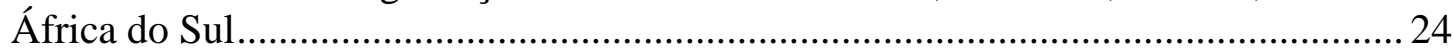

3.5.2 Auditoria de Segurança Viária no Brasil........................................................ 27

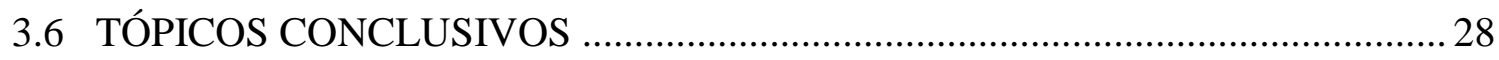

4 INSTRUMENTO DE AUDITORIA DE SEGURANÇA VIÁRIA PARA PROJETOS

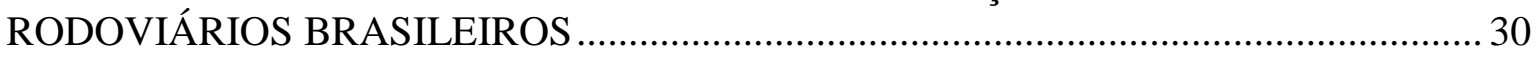

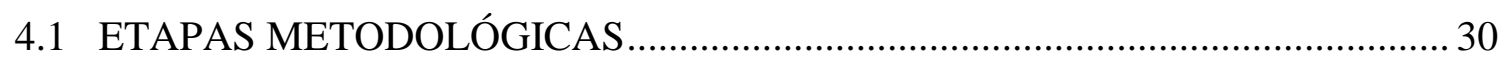

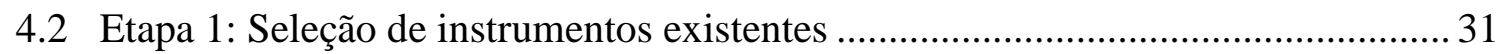

4.3 Etapa 2: Revisão e análise comparativa de instrumentos existentes ....................... 34 
4.3.1 Análise comparativa de instrumentos existentes quanto à apresentação 35

4.3.2 Análise comparativa de instrumentos existentes quanto ao conteúdo 38

4.3.2.1 Análise comparativa quanto ao conteúdo - Macrocategoria - do Instrumento de ASV do Estudo de viabilidade 40

4.3.2.2 Análise comparativa quanto ao conteúdo - Macrocategoria - Instrumento do Projeto Básico. .42

4.3.2.3 Análise comparativa quanto ao conteúdo - Macrocategoria - Instrumento do Projeto Executivo

4.3.2.4 Análise comparativa quanto ao conteúdo - Mesocategorias - Instrumento do Estudo de Viabilidade.

4.3.2.5 Análise comparativa quanto ao conteúdo - Mesocategorias - Instrumento do Projeto Básico.

4.3.2.6 Análise comparativa quanto ao conteúdo - Mesocategorias - Instrumento do Projeto executivo. .51

4.3.2.7 Análise comparativa quanto ao conteúdo - Microcategorias - Estudo de viabilidade

4.3.2.8 Análise comparativa quanto ao conteúdo - Microcategorias - Instrumento do Projeto básico .58

4.3.2.9 Análise comparativa quanto ao conteúdo - Microcategorias - Projeto executivo 59

4.4 Etapa 3: MATERIALIZAÇÃO do instrumento proposto 73

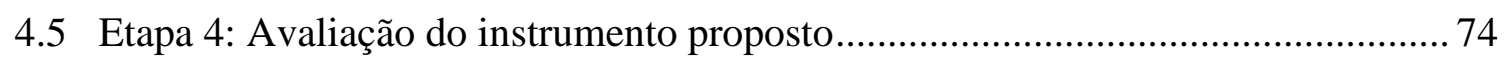

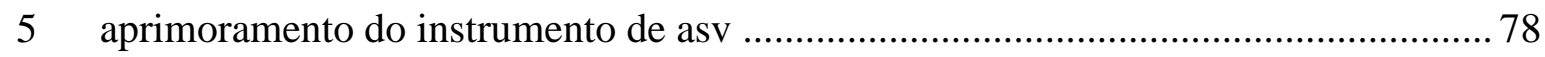

5.1 Etapa 5: Aprimoramento do Instrumento de ASV proposto .................................. 78

5.1.1 Aprimoramento do instrumento adaptado do estudo de viabilidade .................. 79

5.1.1.1 Aprimoramento do instrumento do estudo de viabilidade .................... 79

5.1.1.2 Aprimoramento do instrumento do projeto básico............................... 85

5.1.1.3 Aprimoramento do instrumento de projeto executivo............................ 88

5.1.1.4 Resumo da avaliação dos técnicos .................................................. 96

6 CONCLUSÕES E SUGESTÕES DE TRABALHOS FUTUROS ........................... 98

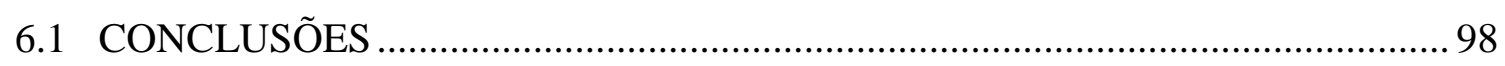




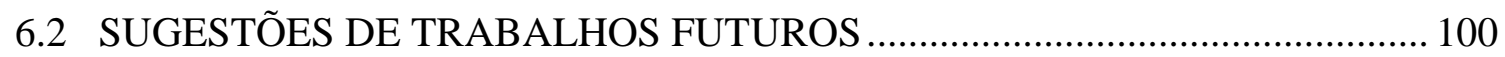

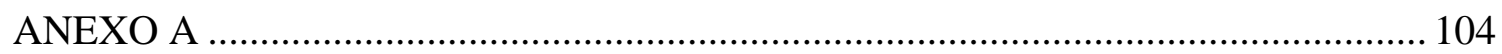

LISTA DE VERIFICAÇÃO DE HILDEBRAND E WILSON (1999)......................... 104

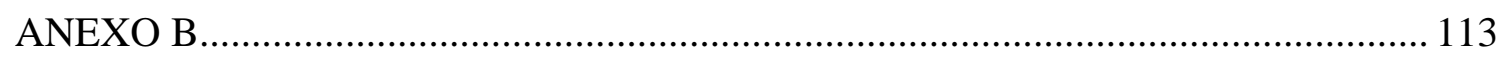

LISTA DE VERIFICAÇÃO DE CASTRILLÓN E CANDIA (2003)............................ 113

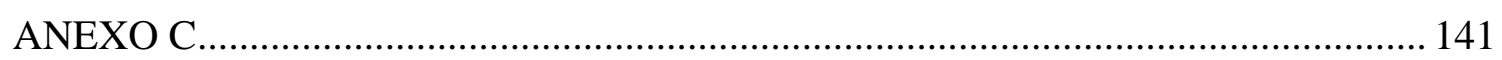

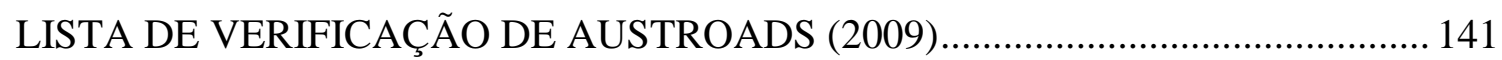

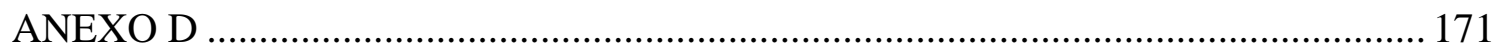

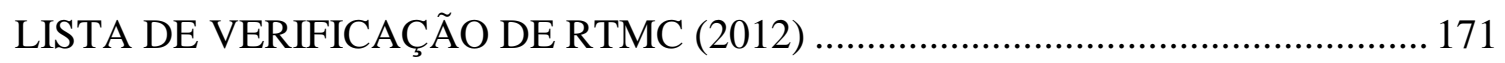

APÊNDICE A1 - MACROCATEGORIA - Estudo de Viabilidade -Análise de

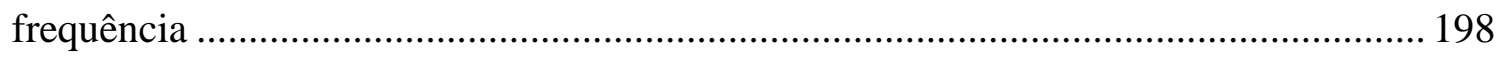

APÊNDICE A2 - MACROCATEGORIA - PROJETO BÁSICO -Análise de frequência 199

APÊNDICE A3 - MACROCATEGORIA - PROJETO executivo -Análise de frequência 200

APÊNDICE B1 - MESOCATEGORIA - Estudo de Viabilidade - análise de frequência 201

APÊNDICE B2 - MESOCATEGORIA - Projeto Básico - Análise da frequência...... 203

ANEXO B3 - MESOCATEGORIA - Projeto Executivo - Análise da frequência ....... 207

APÊNDICE C1 - Análise da frequência - MICROCATEGORIA - Estudo de

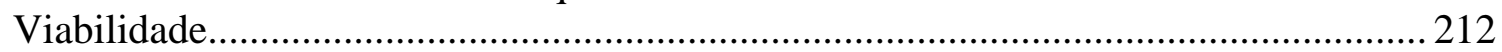

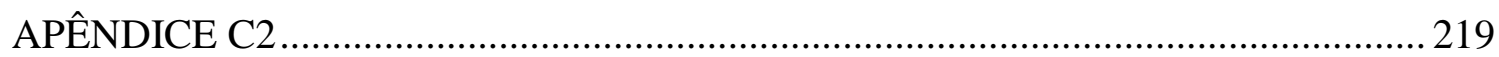

- MICROCATEGORIA - PROJETO BÁSICO - ANÁLISE DE FREQUÊNCIA ....... 219

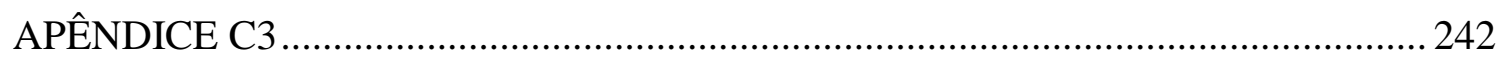

- MICROCATEGORIA - PROJETO EXECUTIVO - ANÁLISE DE FREQUÊNCIA 242

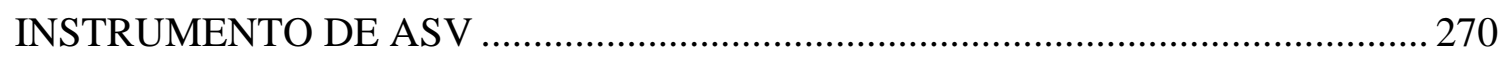

- ESTUDO DE VIABILIDADE - VERSÃO PRELIMINAR ……………………........ 270

INSTRUMENTO DE ASV - PROJETO BÁSICO - VERSÃO PRELIMINAR ........... 277

INSTRUMENTO DE ASV - PROJETO EXECUTIVO - VERSÃO PRELIMINAR. 289

INSTRUMENTO DE ASV - ESTUDO DE VIABILIDADE - VERSÃO FINAL .... 303

INSTRUENTO DE ASV - PROJETO BÁSICO - VERSÃO FINAL ………………..... 309

INSTRUMENTO DE ASV - PROJETO EXECTIVO - VERSÃO FINAL ................... 321 


\section{LISTA DE FIGURAS}

Figura 4.1: Estrutura Metodológica da elaboração do instrumento de ASV proposto ....... 30

Figura 4.2: Forma de apresentação da lista de verificaçãode Hildebrand e Wilson ........... 36

Figura 4.3: Forma de apresentação da lista de verificação de Castrillón e Candia............. 37

Figura 4.5: Forma de apresentação da lista de verificação de RTMC (2012).................... 38

Figura 4.6: Legenda de frequência adotada na comparação dos instrumentos existentes.. 39

Figura 4.7: Processo da análise da frequência................................................................ 40 


\section{LISTA DE QUADROS}

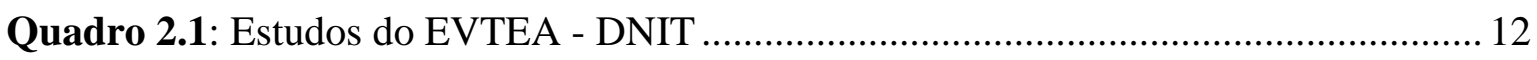

Quadro 2.2 - Conjunto do Projeto Executivo da ANTT ................................................... 15

Quadro 2.3: Conjunto do Projeto Executivo do DER/SP ................................................ 16

Quadro 2.4; Resumo dos projetos abordados no instrumento de ASV proposto............... 18

Quadro 4.1: Referências de pesquisa relacionadas à auditoria de segurança viária ........... 31

Quadro 4.2: Fases de aplicação de ASV nos estudos pesquisados ................................... 32

Quadro 4.3: Listas de verificação selecionados para a análise comparativa ..................... 33

Quadro 4.4: Níveis do instrumento proposto nesta dissertação ........................................ 35

Quadro 4.5: Macrocategorias do Estudo de Viabilidade................................................. 41

Quadro 4.6: Macrocategorias da fase de Projeto Básico ................................................. 43

Quadro 4.7: Macrocategorias do Projeto Executivo ....................................................... 44

Quadro 4.8: Mesocategorias do Estudo de Viabilidade .................................................... 46

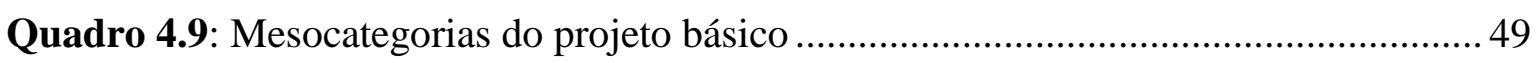

Quadro 4.10: Mesocategorias da fase do projeto executivo ............................................ 54

Quadro 4.11: Representação comparativa da análise das microcategorias ......................... 57

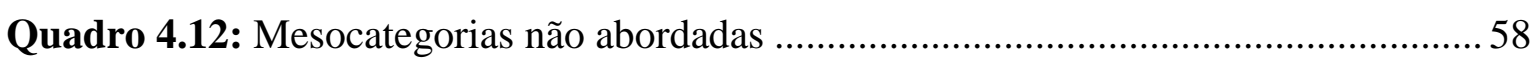

Quadro 4.13: Quantidade de itens abordados por categoria .......................................... 74

Quadro 4.14 : Órgãos versus região de atuação dos técnicos ............................................ 76

Quadro 5.1: Avaliações dos técnicos - Estudo de Viabilidade - macrocategoria "tópicos

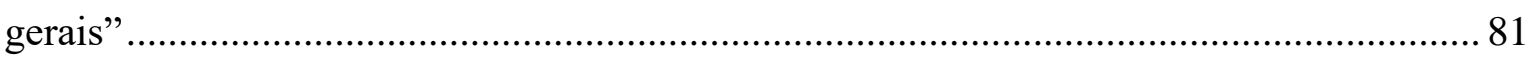

Quadro 5.2: Avaliações dos técnicos - Estudo de Viabilidade - macrocategoria "geometria"

Quadro 5.3: Avaliações dos técnicos - Estudo de Viabilidade - macrocategoria "interseções"

Quadro 5.4: Avaliações dos técnicos - Estudo de Viabilidade - macrocategoria “obstáculos fixos"

Quadro 5.5: Avaliações dos técnicos - Estudo de Viabilidade - macrocategoria "Aspectos Ambientais. 84

Quadro 5.6: Avaliações dos técnicos - Estudo de Viabilidade - macrocategoria "Outros aspectos de segurança não considerados

Quadro 5.7: Avaliações dos técnicos - Projeto Básico - macrocategoria "tópicos gerais" 
Quadro 5.8: Avaliações dos técnicos - Projeto Básico - macrocategoria "geometria”..... 86 Quadro 5.9: Avaliações dos técnicos - Projeto básico - macrocategoria - "obstáculos fixos", "usuários da rodovia", "sinalização e iluminação"

Quadro 5.10: Avaliações dos técnicos - Projeto básico - macrocategorias - "gestão de tráfego e "perguntas adicionais". 88

Quadro 5.11: Avaliação dos técnicos - Projeto executivo - macrocategoria - Tópicos gerais .88

Quadro 5.12: Avaliações dos técnicos - Projeto executivo - macrocategoria "geometria" 90

Quadro 5.13: Avaliações dos técnicos - Projeto executivo - macrocategoria "interseções"

Quadro 5.14: Avaliações dos técnicos - Projeto executivo - macrocategoria Obstáculos fixos 93

Quadro 5.15: Avaliações dos técnicos - Projeto executivo - macrocategoria "usuários da rodovia" 94

Quadro 5.16: Avaliações dos técnicos - Projeto executivo - macrocategoria "Sinalização e iluminação" .95

Quadro 5.17: Avaliações dos técnicos - Projeto executivo - macrocategoria "perguntas adicionais" 96 


\section{INTRODUÇÃo}

\subsection{CONSIDERAÇÕES INICIAIS}

O número crescente de acidentes de trânsito, entre diversos problemas relativos à área de transportes tem sido destaque e motivo de ações para a redução desses acidentes. Em 2009, a Organização Mundial de Saúde (OMS) registrou 1,3 milhão de mortes por acidente de trânsito em 178 países e, se nenhuma ação mundial for empreendida, este número poderá chegar a 1,9 milhão de mortes até 2020 (ONU, 2010). Baseada nesses dados, a Organização das Nações Unidas (ONU) estabeleceu o período de 2011 a 2020 como a Década Mundial de Ação de Segurança no Trânsito. Para tanto, foram convocados todos os países signatários, e o Brasil foi um deles, para um esforço mundial, de desenvolver ações para a redução de 50\% de mortes em acidentes de trânsito em 10 anos (DENATRAN, 2011).

No Brasil, o Ministério da Saúde, em 2011, registrou 43.250 óbitos e 179.000 feridos hospitalizados em 2012, em decorrência de acidentes de trânsito. O seguro de Danos Pessoais Causados por Veículos Automotores de Vias Terrestres - DPVAT, em 2013, menciona que foram 54.000 indenizações por morte e 444.000 por invalidez. Dessa forma, o Brasil ocupa a quinta posição no ranking de países que registram mais óbitos relacionados a acidentes de trânsito (VIAS SEGURAS, 2014).

As rodovias são responsáveis por uma parcela das estatísticas de acidentes de trânsito, demandando assim, medidas voltadas à redução dos índices de acidentes. Nesse sentido, um dos mecanismos utilizados em todo o mundo para atuar na prevenção de acidentes, tanto em ambientes urbanos como rurais, é a técnica de auditoria de segurança viária - ASV.

No Brasil os estudos e ferramentas de auditoria de segurança viária - ASV, no modelo de lista de verificação, vem sendo desenvolvidas e aplicadas em rodovias em operações, conforme os trabalhos desenvolvidos por Schopf (2006) e Rodrigues (2010). Ressalta-se que esses trabalhos foram aplicados nas rodovias da região sul e da região sudeste, respectivamente.

São necessárias medidas proativas para a redução de acidentes e de custos referentes ao retrabalho para correção de defeitos após a implantação dos projetos de rodovias. Nesta 
perspectiva de ações proativas a ASV aplicada em projetos rodoviários (estudo de viabilidade, projeto básico e projeto executivo) devem ser estudadas e aplicadas nos projetos rodoviários brasileiros. Conforme a revisão da literatura brasileira os estudos relacionados à ASV com aplicação em projetos rodoviários ainda são incipientes.

Assim, baseados nos estudos de ASV a presente dissertação propõe o desenvolvimento de um instrumento para Auditoria de Segurança Viária (ASV) de projetos rodoviários brasileiros, para aplicação no Estudo de Viabilidade, Projeto Básico e Projeto Executivo.

\subsection{DELIMITAÇÃO DO PROBLEMA}

Diante do elevado número de acidentes de trânsito registrado a cada ano nas rodovias brasileiras, ações proativas foram necessárias, no intuito de evitar e reduzir a acidentalidade no trânsito, assim proporcionando maior segurança aos usuários das rodovias. No contexto das ações proativas têm-se a aplicação da técnica de ASV.

Há pesquisas acadêmicas que mostram estudos voltados para ASV do tipo lista de verificação em trechos de rodovias em operação. Como os estudos de Schopf (2006), que propôs um instrumento de ASV para trechos de rodovias em operação em pista simples, e Rodrigues (2010), que propôs uma lista de ASV para aplicação em trechos de autoestrada e trechos de rodovias em pista simples, também em rodovias em operação.

Na junção do número elevado de acidentes de trânsito e da técnica de ASV como ação proativa na perspectiva de diminuir esse número de acidentes, esta dissertação propõe a aplicação da ASV nos projetos das rodovias brasileiras. Ressalta-se que no Brasil, a dificuldade do uso de ASV, ainda na elaboração de projeto, é a falta de um instrumento consolidado para a linguagem técnica dos projetos brasileiros, bem como de equipe que possa vir a atuar na ASV.

Neste contexto, tem-se a seguinte questão de pesquisa: É possível construir um instrumento de ASV para aplicação em projetos rodoviários nas fases de estudo de viabilidade, projeto básico e projeto executivo adaptado à realidade brasileira?

\subsection{OBJETIVOS}




\subsubsection{Objetivo geral}

O objetivo geral desta dissertação é elaborar um instrumento de ASV adaptado para projetos rodoviários brasileiros para ser aplicado no Estudo de Viabilidade, Projeto Básico e Projeto Executivo.

\subsubsection{Objetivos específicos}

Os objetivos específicos desta dissertação são:

a) Identificar os instrumentos de auditoria de segurança viária do tipo lista de verificação estruturada para projetos rodoviários;

b) Definir metodologia de adaptação de instrumentos de auditoria de segurança viária do tipo lista de verificação para o uso em projetos rodoviários brasileiros;

c) Verificar a percepção dos técnicos brasileiros em relação a instrumento de auditoria de segurança viária do tipo lista de verificação.

\subsection{JUSTIFICATIVA}

Toda ação no sentido de evitar e mitigar os acidentes de trânsito é benéfico para os usuários de rodovias, principalmente no Brasil, o qual possui índices elevados de acidentes de trânsito. Esses índices representam perdas irreparáveis de vidas, o que reflete diretamente em perdas financeiras significativas para a economia brasileira quando se trata de indenizações pelas perdas humanas e por revisões de projetos para adequações de locais críticos propícios para acidente de trânsito.

Não importa o quanto se estude ou que se venha a aprender sobre a ocorrência de acidentes e suas medidas mitigadoras, nunca será possível prever onde, como, ou quando, exatamente um evento desses ocorrerá. Por outro lado, com base no histórico de acidentes, podem ser identificados os locais críticos, para que sejam priorizados estudos mais específicos para tais locais, e reduzir os conflitos neles existentes (Paiva, 2009). 
Schoph (2006) destaca a ASV como ações proativas e menciona que a técnica é uma experiência internacional consolidada, que corrobora para os benefícios em relação aos aspectos da segurança viária. Também destaca que existem diversos manuais de ASV publicados nos países em que a ASV é utilizada. Nesses manuais constam modelos de lista de verificação de itens de segurança viária avaliados no processo de auditoria, os chamados checklist.

Para Rodrigues (2010), existe um número muito reduzido de trabalhos acadêmicos que versam sobre as Auditorias de Segurança Viária no Brasil, os quais são voltados para rodovias em operação. Diante disso, o autor elaborou um estudo que buscou desenvolver o tema por meio de aplicações práticas da técnica em segmentos rodoviários em operação, de forma a permitir uma discussão no meio acadêmico da ASV.

De acordo com Hildebrand e Wilson (1999), Castrillón e Candia (2003) e AUSTROADS (2009) e RTMC (2012) a ASV pode ser aplicada nas seguintes fases: Viabilidade (planejamento); Projeto preliminar; Projeto detalhado; Pré-abertura ao tráfego; Pós-abertura ao tráfego; Esquema de tráfego em rodovias e Rodovia existente. Identificou-se a consolidação da ASV em diferentes países e com uso em distintas fases de aplicação. Uma vez que a proposta desta dissertação é atuar na segurança viária com ações proativas, identificou-se a importância de desenvolver instrumento de ASV adaptado aos projetos rodoviários brasileiros para serem aplicados no estudo de viabilidade, projeto básico e projeto executivo.

Outra análise importante da aplicação de ASV é a relação custo/benefício, estudos realizados na Escócia, com base na experiência do uso de ASV, por exemplo, estimaram uma relação custo/benefício 1:15, enquanto a Nova Zelândia estimou a razão para em torno de 1:20 (TNZ, 1993, apud Hildebrand e Wilson, 1999).

Somado a isso, para o DNIT (2010), o grau de segurança de uma rodovia depende das medidas tomadas, desde a fase de planejamento até a sua abertura ao tráfego. A falta de atenção a problemas aparentemente pequenos, na fase de planejamento, pode revelar-se desastrosa quando a rodovia é aberta ao tráfego. A combinação desses problemas pode 
adquirir proporções que somente serão visíveis a posteriori, assim exigem-se correções que representam custos adicionais desnecessários.

Diante do exposto, observa-se a necessidade de estudos acadêmicos para o desenvolvimento de instrumento de ASV a fim de serem utilizados ainda nos proejtos rodoviários brasileiros. A consolidação desse instrumento poderá viabilizar a identificação de locais com pontencialidades de acidentes de trânsito, ainda nas fases de projetos antes da sua execução, e com isso proporcionar futuras rodovias mais seguras. A identificação desses locais, pode gerar correções antes da execução, reduzindo custos em medidas mitigadoras futuras e perdas de vidas.

\subsection{METODOLOGIA}

A pesquisa é desenvolvida com a utilização do método de abordagem qualitativa. Possui natureza aplicada e objetivo exploratório explicativo, a partir dos procedimentos da pesquisa bibliográfica e observação de técnicos do setor de infraestrutura de transportes.

O procedimento de elaboração desta dissertação está constituído em cinco etapas.

a) A primeira etapa consiste na contextualização de acidente de trânsito, segurança viária, projetos rodoviários, auditoria de segurança viária em projetos rodoviários nos âmbitos nacional e internacional.

b) A segunda etapa trata da revisão e análise de instrumentos lista de verificação existente nacional e internacionalmente para subsidiar a elaboração do instrumento de ASV proposto nesta dissertação.

c) Na terceira etapa foram elaborados os instrumentos de ASV adaptados aos projetos rodoviários brasileiros, para aplicação no estudo de viabilidade, projeto básico e projeto executivo.

d) A quarta etapa foi a avaliação do instrumento de ASV proposto pelos técnicos com experiência em planejamento, fiscalização, operação e segurança viária de projetos rodoviários. 
e) A quinta etapa foi a verificação das avaliações dos técnicos, para o aprimoramento do instrumento de ASV proposto nesta dissertação.

\subsection{LIMITAÇÃO DO TRABALHO}

A Auditoria de segurança viária é uma técnica que pode ser aplicada no estudo de viabilidade, projeto básico, projeto executivo, pré-abertura e pós-abertura ao tráfego, e rodovias em operação. No entanto, esta dissertação limitou-se em propor um instrumento de ASV a ser aplicado no estudo de viabilidade, projeto básico e projeto executivo.

\subsection{ESTRUTURA DA DISSERTAÇÃO}

A dissertação está organizada em seis capítulos, além das referências bibliográficas, apêndices e anexos.

O Capítulo 1 é composto pela introdução, abordagem do tema da dissertação, delimitação do problema, o objetivo geral e objetivos específicos, a justificativa, metodologia de pesquisa e a estrutura do trabalho.

O Capítulo 2 trata da revisão bibliográfica sobre acidentes de trânsito, segurança viária, projetos rodoviários referentes aos órgãos DNIT, ANTT e DER/SP.

O Capítulo 3 é composto pela revisão bibliográfica sobre ASV e as experiências de ASV internacional e nacional.

O Capítulo 4 contempla a estrutura metodológica da elaboração do instrumento de ASV.

O Capítulo 5 trata da avaliação realizada pelos técnicos em relação ao instrumento proposto, além do instrumento revisado e materializado.

Por fim, o Capítulo 6 é composto pelas conclusões e as sugestões para o desenvolvimento de trabalhos futuros relacionados à ASV. 


\section{CONTEXTUALIZAÇÕES: ACIDENTE DE TRÂNSITO, SEGURANÇA VIÁRA E PROJETOS RODOVIÁRIOS}

O objetivo deste capítulo é a contextualização das definições e considerações sobre acidente de trânsito, segurança viária e projetos rodoviários para construção da base conceitual da dissertação.

\subsection{ACIDENTE DE TRÂNSITO}

Ao considerar a circulação viária tanto urbana quanto rural é possível observar que algumas situações tornaram-se problemas graves para a sociedade, tais como: o acidente de trânsito, o congestionamento e a poluição ambiental. No entanto, entre esses problemas o acidente de trânsito é considerado o mais grave, pois representa grandes perdas humanas em termos de ferimentos e fatalidades, e também, representa perdas econômicas significativas para a sociedade como um todo (Panitz, 1999).

A Associação Brasileira de Normas Técnicas - ABNT apresenta um conceito abrangente sobre acidente de trânsito definindo-o: "como todo evento não premeditado que resulte dano em veículo ou na carga e/ou lesões em pessoas e/ou animais, em que pelo menos uma das partes está em movimento nas vias terrestres ou áreas abertas ao público (ABNT, 1989). ”.

O Departamento Nacional de Infraestrutura de Transporte - DNIT considera o acidente de trânsito como sendo a ocorrência resultante da perda de estabilidade de um veículo, colisão entre veículos, pedestres e/ou animais, com danos materiais, humanos e ao meio ambiente (BRASIL, 1997).

Chagas et al. (2012) ressaltam que os dados de acidentes de trânsito são a pedra fundamental para toda a atividade de segurança viária e são essenciais para o diagnóstico dos problemas motivadores dos acidentes. As informações sobre os acidentes ocorridos permitem reconhecer a dimensão e as características do problema a enfrentar, permitindo, também, que seja feita a avaliação da eficácia das ações implementadas para a redução de tais acidentes. 
O DNIT (2010) também cita que o grau de segurança de uma rodovia é normalmente indicado por estatísticas de acidentes de trânsito, que fornecem os números de mortos e feridos por veículos-quilômetros de viagens. Essas estatísticas indicam o risco relativo de viajar em uma determinada rodovia.

A ocorrência de um acidente de trânsito resulta da interação de fatores adversos presentes na via pública (sítio do acidente). Estes fatores adversos podem estar relacionados com a via propriamente dita, com o ambiente, com os veículos e também, ao próprio comportamento perigoso das pessoas, atuando como condutores ou como pedestres. Assim, uma situação de risco culminará em um acidente de trânsito se houver uma relação perversa de alguns desses fatores (Paula e Régio, 2008).

Em um acidente de trânsito, são elencados fatores que contribuíram para sua ocorrência, logo, para cada fator adverso que é percebido em um acidente existe a possibilidade de aplicação de medidas corretivas que impedirão ou dificultarão seu surgimento em situações futuras. Por isso, conhecer os fatores mais comuns nos acidentes que acontecem em determinado ponto crítico de segurança, ou em uma via perigosa, é condição necessária para se determinar as medidas preventivas adequadas, que poderão reduzir o número de sinistros nestes locais (Paula e Régio, 2008).

Nas revisões bibliográficas pesquisadas, encontraram-se três elementos principais que contribuem, individualmente ou em conjunto, para a ocorrência dos acidentes de trânsito, como citado por Castrillón e Candia (2003). Esses elementos denominam-se fatores contribuintes para os acidentes de trânsito, e classificam-se em três grupos: fator humano, fator via/meio ambiente e fator veicular.

\subsubsection{Fatores contribuintes para o acidente de trânsito}

Os fatores contribuintes para os acidentes de trânsito devem ser investigados para que sejam mapeados de maneira consistente os fatores mais relevantes. Geralmente, os fatores acontecem de maneira combinada em uma ocorrência, porém, é possível identificá-los.

a) Fatores Humanos 
Fatores humanos são ações arriscadas do indivíduo no trânsito, quer na condição de condutor de veículo que pode se envolver em um acidente, quer na de pedestre arriscando-se a ser atropelado. Estes comportamentos indevidos acabam, isolados ou juntamente com outros fatores, induzindo à ocorrência do acidente. Desrespeitar a indicação vermelha do semáforo, dirigir acima da velocidade regulamentada, não sinalizar intenção de manobra e dirigir alcoolizado são exemplos de fatores humanos que contribuem para que o acidente aconteça. Normalmente, são erros cometidos pelos usuários da via e, em sua maioria, constituem infrações de trânsito (Paula e Régio, 2008).

Cabe destacar que os fatores citados acima são bastante objetivos, não oferecendo dificuldades para serem identificados. No entanto, existem fatores humanos de outra ordem, mais subjetivos, aqui chamados de indiretos, que estão na raiz dos primeiros e que refletem aspectos ligados à formação precária do envolvido (imperícia, inabilitação, inexperiência etc.) ou às suas condições físicas / psicológicas desfavoráveis (cansaço, sonolência, estresse, agressividade, euforia, pressa, desatenção etc.) e que são mais difíceis de serem identificados, por necessitarem de entrevistas com os envolvidos (Paula e Régio, 2008).

Para Branco (1999) muitas vezes a falha humana é atribuída ao motorista por um erro que poderia ser evitado se a estrada fosse equipada com dispositivos de segurança. Se um veículo perde a direção porque o motorista teve sua visão ofuscada pelos faróis de outro veículo que vinha em sentido contrário, a causa do acidente será considerada como falha do motorista, mas o acidente poderia ser evitado se a estrada tivesse dispositivos anti-ofuscamento.

b) Fatores da via/meio ambiente

Fatores da via e/ou meio ambiente são características inseguras da via no momento do acidente que podem ter contribuído para a sua ocorrência. Os aspectos inseguros podem estar ligados às características geométricas da via (deficiências de projeto), à sinalização falha, estado dessa sinalização (problemas de manutenção, tal como, visibilidade), ao estado do pavimento, às condições climáticas, dentre outros (Paula e Régio, 2008).

\section{c) Fatores veiculares}

Fatores veiculares são aqueles decorrentes de falhas no desempenho dos veículos envolvidos no acidente, normalmente provocadas pelo seu mal estado de conservação. Farol desregulado provocando ofuscamento, estouro de pneu e deficiência no freio são exemplos 
de fatores contribuintes para o acidente de ordem veicular. Entre os fatores contribuintes, o fator veicular é o de mais rara caracterização, considerando a dificuldade de identificação de eventuais falhas do veículo danificado no acidente. Além disso, a atuação do órgão de trânsito em relação a esses fatores é bastante restrita (Paula e Régio, 2008).

Assim, pode-se observar que uma melhoria em qualquer destes fatores deverá se converter em aumento da segurança. No tocante às rodovias, o administrador deve se preocupar com a sua construção, manutenção adequada, fiscalização em todos os aspectos (condições dos veículos, etc.) e informação ao motorista, procurando reduzir a possibilidade de falha humana (Branco, 1999).

Nesta dissertação a abordagem está diretamente ligada ao fator via/meio ambiente, pois o foco da pesquisa foi construir um instrumento de auditoria de segurança viária a ser aplicada em projetos rodoviários que ainda serão executados, os quais refletem a via e o meio ambiente. Mas ressalta-se que os outros fatores contribuintes para os acidentes de trânsito, estão de forma indireta contemplados no instrumento.

\subsection{SEGURANÇA VIÁRIA}

Na interpretação mais ampla Sinay e Tamayo (2005) descrevem a segurança viária como sendo o conjunto de condições e fatores interligados que propiciam a circulação e interação dos diferentes elementos do tráfego na via sob níveis aceitáveis de risco e de forma suficientemente segura.

A segurança viária nos últimos anos tem sido objeto de diversas ações determinadas por órgãos relacionados ao trânsito, uma vez que as estatísticas são alarmantes, com elevado índice de acidentes de trânsito, tanto nas rodovias rurais quanto nas áreas urbanas. Tais ações podem ser reativas ou proativas.

Segundo Nodari (2003) existem muitas formas de tratar o problema de segurança no trânsito, destacando que uma das mais eficientes é um programa abrangente de gerenciamento da segurança viária. Nesse programa, a atuação na segurança viária pode ser classificada em duas ações: uma diz respeito a iniciativas reativas e outra, a iniciativas 
proativas. Um exemplo clássico de iniciativas reativas é a análise de pontos críticos, com relação às iniciativas proativas, a auditoria de segurança viária é um bom exemplo.

As medidas reativas objetivam resolver problemas revelados pela ocorrência excessiva de acidentes em determinados locais da rede viária, enquanto as medidas proativas pretendem identificar situações potenciais de risco presentes na malha viária, antes que os acidentes venham a ocorrer. Vale destacar que as abordagens reativas e proativas também diferem em seus custos (Nodari, 2003).

A busca das soluções para problemas de segurança viária requer estudos dos acidentes de forma detalhada, pois além da perda de vidas, da incapacitação permanente ou temporária dos envolvidos no acidente, dos ferimentos físicos e psicológicos e das consequências diretas na produção econômica nacional, os acidentes de trânsito também acarretam outro tipo de prejuízo, que diz respeito aos seus vultosos custos ao governo (LABTRANS, 2011).

\subsection{PROJETOS RODOVIÁRIOS}

São abordadas, nesta dissertação, definições de estudos e projetos rodoviários uma vez que o trabalho propõe a elaboração de um instrumento de auditoria de segurança viária para ser aplicado nas fases de projetos.

As definições foram obtidas a partir da revisão de estudos acadêmicos e revisão de documentos normativos e relatórios técnicos produzidos pelo Departamento Nacional de Infraestrutura de Transportes - DNIT, por ser responsável por boa parte da malha viária rural brasileira, pela Agência Nacional de Transportes Terrestres - ANTT, por ser responsável pela malha rodoviária federal concedida e pelo Departamento de Estradas de Rodagem do Estado de São Paulo - DER/SP, por ser responsável por malha estadual e por possuir representatividade na malha rodoviária brasileira.

A malha rodoviária brasileira é composta por Rodovias Federais, Estaduais e Municipais e possui distintas jurisdições, e cada jurisdição tem suas próprias políticas de planejamento, controle, análises e regulamentações. 
A seguir é apresentada a conceituação de Estudo de Viabilidade, Projeto Básico e Projeto Executivo, com destaque para as definições do Departamento Nacional de Infraestrutura (DNIT), Agência Nacional de Transportes Terrestres (ANTT) e Departamento de Estradas de Rodagem do Estado de São Paulo (DER/SP).

\subsubsection{Projeto de Estudo de Viabilidade}

Para o DNIT, estudo de viabilidade é denominado como Estudos de Viabilidade TécnicoEconômica-Ambiental (EVTEA) de Rodovias. Esses estudos devem demonstrar se a alternativa escolhida, sob o enfoque de traçado, características técnicas e operacionais, oferece maior benefício que outras, em termos de custo total de transporte. É imprescindível a realização de estudos relativos ao impacto da rodovia sobre o meio ambiente e a fixação de cronograma expedito para a execução das obras, de acordo com a disponibilidade dos recursos financeiros. Para fins de elaboração do estudo de viabilidade de implantação de rodovia, ou de melhoramentos em rodovia existente, haverá necessidade de estimar o tráfego, atual e futuro, nas condições "sem e com" a execução do empreendimento, estabelecer as características técnicas e operacionais, e fixar as possíveis diretrizes do eixo da rodovia (DNIT, 2006).

O DNIT (2006) menciona também que EVTEA de rodovias: "é o conjunto de estudos a serem desenvolvidos para a avaliação dos benefícios sociais e econômicos decorrentes dos investimentos, tanto em implantação de novas rodovias quanto em melhoramentos de rodovias existentes." O Quadro 2.1 mostra os estudos que contemplam o EVTEA do DNIT.

Quadro 2.1: Estudos do EVTEA - DNIT

\begin{tabular}{|l|l|}
\hline 0 & Tipo de Estudos \\
\cline { 2 - 3 } & Estudos de Ambientais \\
\hline & Estudos de Traçado \\
\hline & Estudos de Tráfego \\
\hline
\end{tabular}

Fonte: Adaptado DNIT, 2006 
Para Hildebrand e Wilson (1999), o estudo de viabilidade avalia o desempenho do potencial de segurança da proposta de projeto conceitual com relação à localização da rota, padrões de projeto de estrada e o escopo do projeto.

Para DER/SP (2005), as definições estão relacionadas, principalmente, aos elementos dos projetos geométricos. Assim, é importante mencionar a definição de Estudos Preliminares deste órgão, que nesta dissertação, está mencionado como estudo de viabilidade.

Entende-se por estudos preliminares (ou estudo de viabilidade): "No âmbito do projeto geométrico, o estudo que define as diretrizes técnicas da via e o estabelecimento de critérios a serem adotados e definição das alternativas de traçado. Cabe destacar que o projeto preliminar deve ser desenvolvido apenas para o caso de novas rodovias. Ainda, pode-se considerar no projeto preliminar elementos como: classificação funcional e técnica da via e velocidade de projeto; veículo de projeto; volume de tráfego; uso e ocupação do solo no entorno da via" (DER/SP, 2005).

O DER/SP considera: "a análise a partir desses elementos que resultarão em parâmetros como raios mínimos de curva horizontal, número e largura das faixas de rolamento, larguras do acostamento e dos canteiros, distâncias de visibilidade de parada e de ultrapassagem, superelevação máxima, gabaritos verticais e horizontais mínimos, rampas máximas, grau do controle de acesso à rodovia. Parâmetros esses que, caso não sejam dimensionados adequadamente, poderão provocar problemas relacionados à segurança do usuário da via" (DER/SP, 2005).

Assim, tanto o DNIT (2006), Hildebrand e Wilson (1999) quanto o DER/SP (2005) aludem que o estudo de viabilidade estabelece as características técnicas e operacionais, bem como os benefícios sociais e econômicos que podem gerados para uma determinada região. Também se faz necessário pensar na segurança viária que esse projeto deverá propor para o futuro usuário. Assim, a importância da utilização do instrumento de ASV para se auditar esse projeto na fase de Estudo de Viabilidade é de grande valia para prevenção de futuras intervenções que acarretarão em custos adicionais.

\subsubsection{Projeto Básico e Projeto Executivo}


Após a aprovação do estudo de viabilidade, em que são definidas as características técnicas e operacionais do traçado da nova rodovia, parte-se, então, para a elaboração do projeto básico e, sequencialmente, para o projeto executivo.

Sabe-se que os projetos rodoviários podem ser projetados, executados e fiscalizados por órgãos Federais, Estaduais e Municipais. Neste trabalho, serão abordadas as definições de projetos básico e executivo dos órgãos DNIT, ANTT e DER/SP.

a) DNIT - Segundo o Glossário de Termos Técnicos Rodoviários (DNER, 1997):

- PROJETO BÁSICO: “1) Projeto que reúne as descrições técnicas necessárias e suficientes à contratação da execução da obra. 2) Conjunto de elementos que define a obra ou serviço, ou o complexo das obras ou serviços, objeto da licitação e que possibilite a estimação do custo final e do prazo de execução".

- PROJETO EXECUTIVO: "Projeto que reúne os elementos necessários e suficientes e à execução completa da obra, detalhando o projeto básico".

Com a aprovação das conclusões e recomendações da Fase de Projeto Básico é iniciada a fase de projeto executivo, com a finalidade de detalhar a solução selecionada, fornecendo-se plantas, desenhos e notas de serviço que permitam a construção da rodovia. Devem ser fornecidos os seguintes elementos (DNIT, 2006):

$\checkmark$ informações que possibilitem o estudo e a dedução de métodos construtivos, instalações provisórias e condições organizacionais para a obra;

$\checkmark \quad$ subsídios para montagem do plano de licitação e gestão da obra;

$\checkmark$ orçamento detalhado do custo global da obra, fundamentado em quantitativos de serviços, fornecimentos dos materiais e transportes propriamente avaliados;

informações para a instrução dos processos desapropriatórios. 
b) ANTT - Segundo a Resolução 1187/2005 (ANTT, 2005), Capítulo 1 - Dos Conceitos e Definições, Art. $2^{\circ}$ Para os efeitos desta Resolução, pode-se destacar a definição de projeto básico e projeto executivo:

- PROJETO BÁSICO: “Conjunto de elementos necessários e suficientes, com grau de precisão adequado, para caracterizar a obra ou serviço, ou complexo de obras ou serviços, elaborados com base nas indicações dos estudos técnicos preliminares, que assegurem a viabilidade técnica e o adequado tratamento do impacto ambiental do empreendimento, e que possibilite a avaliação do custo da obra e a definição do prazo de execução".

- PROJETO EXECUTIVO: "Conjunto dos elementos necessários e suficientes à execução completa de obra, inclusive as peças, os diagramas e outros elementos elucidativos necessários à sua execução, de acordo com as normas pertinentes".

Cabe destacar o conjunto de projetos que compõem o projeto executivo da ANTT, que pode ser observado no Quadro 2.2, conforme a Resolução 1187/2005 (ANTT, 2005):

Quadro 2.2 - Conjunto do Projeto Executivo da ANTT

\begin{tabular}{ll|}
\multicolumn{1}{|c|}{ Tipo de projeto } \\
\cline { 2 - 2 } & Projeto de topografia \\
\hline projeto de terraplenagem \\
\hline
\end{tabular}

Fonte: Adaptado da ANTT (2005) e DNER (1997) 
Os projetos que compõem o projeto executivo da ANTT, que também em sua maior parte, constam nos projetos executivos do DNIT, fazem parte do conjunto de projetos que podem passar por ASV para proporcionar maior segurança aos usuários da via.

c) DER/SP - Segundo a Instrução de Projeto (DER, 2005):

- PROJETO EXECUTIVO: "Projeto que possui grau de detalhamento tendo como objetivo principal o desenvolvimento do projeto final de engenharia, que permite a determinação dos quantitativos e do orçamento da obra, e com todos os elementos para implantação da obra”.

Documentação que compõe o projeto executivo do DER/SP, os quais são apresentados no Quadro 2.3, conforme a Instrução de Projeto (DER, 2006):

Quadro 2.3: Conjunto do Projeto Executivo do DER/SP

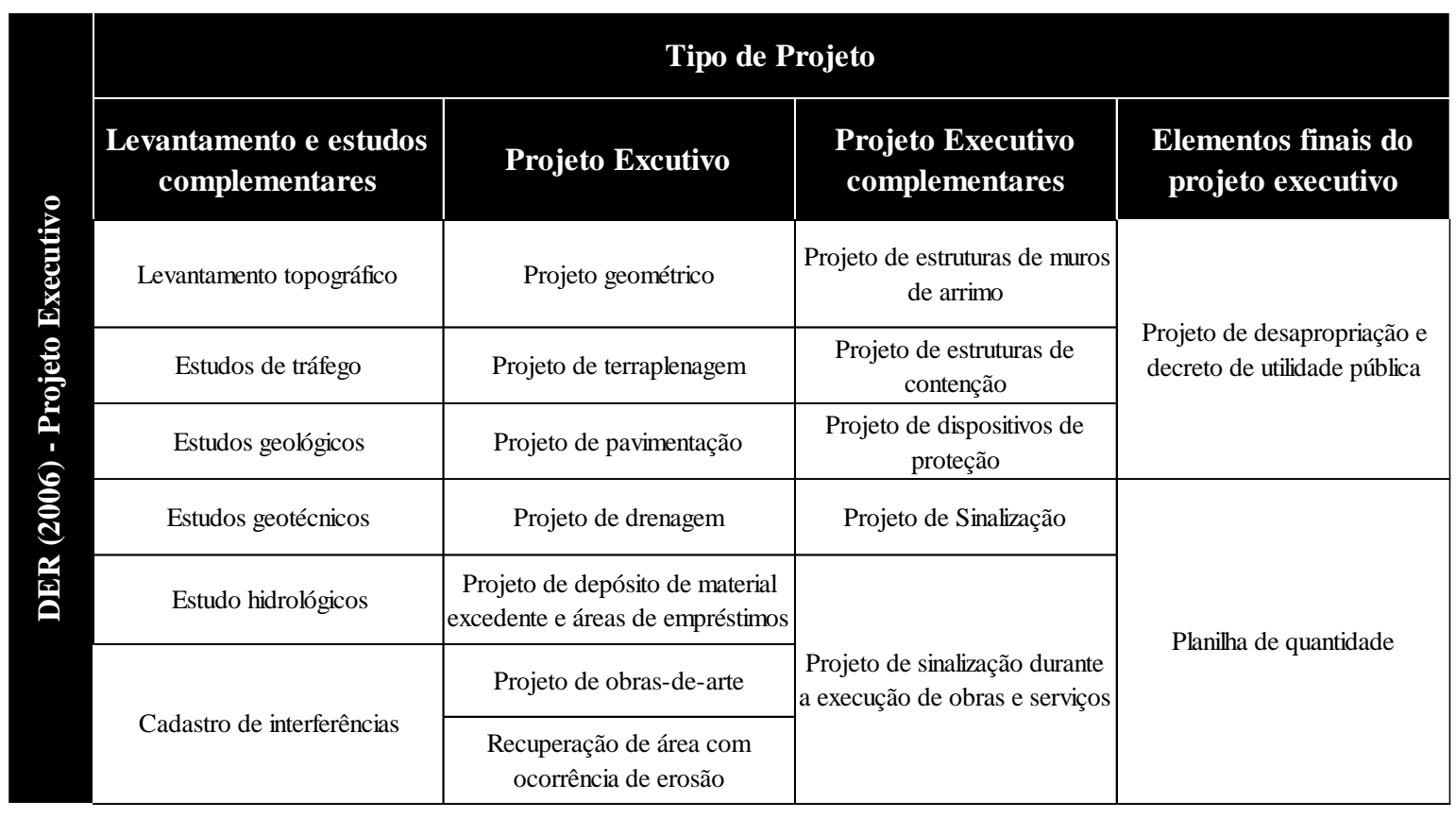

Fonte: Adaptado do DER/SP, 2005

\subsection{TÓPICOS CONCLUSIVOS}

Dentro do contexto da problemática de acidentes de trânsito e a segurança viária nas rodovias brasileiras, buscou-se mostrar neste capítulo a contextualização referente a acidentes de 
trânsito, segurança viária e fundamentalmente o que os órgãos DNIT, ANTT e DER-SP definem como projetos rodoviários e seus projetos complementares necessários para a implantação de uma rodovia, bem como obras de melhoramento para o entendimento de quais os elementos de projetos seriam abordados no instrumento de ASV proposto nesta dissertação.

Na revisão bibliográfica identificou-se que os projetos rodoviários são compostos por inúmeros subprojetos. O instrumento proposto desta dissertação tratará de elementos de projetos que compõem esses subprojetos.

O instrumento proposto de ASV é uma adaptação de instrumentos existentes à realidade brasileira, que para esta dissertação as principais adaptações adotadas foram os aspectos ligados ao clima brasileiro e aos termos técnicos usuais nos projetos rodoviários brasileiros.

Para segurança viária, um fator importante para a segurança é a antecipação de possíveis locais de acidentes de modo a poder investigar seus impactos. A cada ano são efetuadas correções de deficiências operacionais e de segurança, com intuito de promover maior segurança do usuário na rodovia.

E uma ação que pode ser aplicada nos projetos de estudo de viabilidade, projeto básico e projeto executivo brasileiros é a ASV que pode atuar como ação preventiva para que se possam tomar medidas ainda nesses projetos evitando futuras correções,

Assim, após a revisão bibliográfica apresentada na seção 2.3, identificou-se que os projetos que serão abordados no instrumento de ASV proposto nesta dissertação são o apresentado do Quadro 2.4. Ressalta-se que o Projeto de iluminação não é mencionado no conjunto de projetos da ANTT e DER, porém, é um projeto que faz partes das listas de verificação existentes. Assim foi incluído dentro dos projetos que foram abordados no instrumento proposto nesta dissertação. Além disso, o instrumento proposto é baseado em elementos viários que compõem esses projetos. Esses projetos que foram abordados no instrumento proposto são baseados nas categorias dos instrumentos existentes de ASV. 
Quadro 2.4; Resumo dos projetos abordados no instrumento de ASV proposto

\begin{tabular}{|c|c|}
\hline \multirow{16}{*}{ 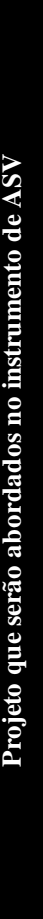 } & Estudo e Projeto \\
\hline & ANTT - DNIT - DER/SP \\
\hline & Estudo de Tráfego \\
\hline & Estudo de traçado \\
\hline & Estudos ambientais \\
\hline & Estudo geotécnicos \\
\hline & Estudo hidrológico \\
\hline & Projeto Geométrico \\
\hline & Projeto de interseções, retornos e acessos \\
\hline & Projeto de drenagem \\
\hline & Projeto de obra-de-arte (OAE) \\
\hline & Projeto de estruturass de conteção \\
\hline & Projeto de Sinalização e Segurança \\
\hline & Projeto de Paisagismo \\
\hline & Projeto de desapropriação \\
\hline & Projeto de iluminação** \\
\hline
\end{tabular}

Fonte: Elaborado pela autora, 2015 


\section{AUDITORIA DE SEGURANÇA VIÁRIA}

Historicamente, a ASV é atribuída ao britânico Malcoln Bulpitt, que, na década de 80, aplicou os conceitos de auditoria de segurança no setor ferroviário. Nessa época o governo britânico designou técnicos para inspecionar os aspectos relacionados com uma nova linha férrea antes da entrada em operação. Posteriormente, Bulpitt aplicou os conceitos de verificação independente para melhorar a segurança nos projetos rodoviários desenvolvidos pelo Departamento de Transportes e Rodovias do Município de Kent (Ferraz et al., 2012).

\subsection{DEFINIÇÕES DA AUDITORIA DE SEGURANÇA VIÁRIA}

A ASV, segundo Ferraz et al. (2012), é empregada para designar a análise formal, do ponto de vista da segurança no trânsito, de uma via, elemento viário ou esquema de circulação, existente ou projetado, por uma equipe de examinadores qualificados e independentes.

AUSTROADS (2009) define ASV como o exame formal de um projeto de uma rodovia nova ou de uma rodovia existente, no qual uma equipe independente e qualificada analisa e relata o potencial de acidentes e o desempenho de segurança do projeto.

O RTMC (2012) cita que a ASV é um exame formal de um projeto novo ou em melhoramentos, havendo a interação com os usuários da rodovia, em que uma equipe independente e qualificada identifica potenciais problemas de segurança viária e sugere medidas para atenuá-los.

Castrillón e Candia (2003) destacam o que é a ASV:

a) ASV é um processo formal baseado em considerações de segurança viária;

b) ASV é realizada por uma equipe de profissionais independentes que não possui nenhuma relação anterior com o projeto;

c) ASV é realizada por uma equipe multidisciplinar com formação e experiência pertinente;

d) ASV é uma metodologia que analisa a segurança viária de todos os usuários da via.

Cabe destacar, ainda, o que a:

a) ASV não é uma verificação de conformidades dos padrões de projetos; 
b) ASV não é uma investigação de acidentes;

c) ASV não se aplica apenas em projetos de alto custo ou com problemas de segurança viária;

d) ASV não é uma metodologia para comparar diferentes projetos ou escolher entre projetos concorrentes

Neste contexto, pode-se concluir que a ASV é uma técnica para aplicação de procedimentos para fins preventivos da segurança viária, de forma sistemática, para a verificação independente da necessidade de melhorias dos aspectos relacionados à segurança, a partir da perspectiva multidisciplinar, com vista à circulação segura dos usuários da rodovia.

\subsection{OBJETIVOS DE AUDITORIA DE SEGURANÇA VIÁRIA}

Entre os objetivos da ASV estudados, são descritos um objetivo, considerado principal, baseado em Hildebrand e Wilson (1999) e Ferraz, et al, (2012):

a) identificar as ausências de segurança para os usuários da via pública e considerar as medidas necessárias para eliminar ou reduzir os seus impactos. A avaliação deve considerar todos os usuários da via pública, não apenas os motoristas de automóveis uma vez que os usuários incluem pedestres, ciclistas, motociclistas, motoristas de transporte público, dentre outros e avaliar especificamente aspectos ligados às características físicas e operacionais da via e ao meio ambiente viário;

E considerando o processo em si da ASV, segue os objetivos, que podem vir a auxiliar os órgãos na tomada de decisão da instalação de um setor de ASV (RTMC, 2012):

a) reduzir a necessidade de medidas corretivas após a abertura de novas rodovias ao tráfego ;

b) reduzir os riscos da gravidade e risco de acidentes de trânsito que pode ser influenciado pela instalação da rodovia e áreas adjacentes;

c) reduzir o custo de um projeto de rodovia, com a redução do custo dos acidentes;

d) criar e manter uma consciência da prática de projeto seguro durante todas as fases do projeto da rodovia. 


\subsection{FASES DE APLICAÇÃO DA AUDITORIA DE SEGURANÇA VIÁRIA}

A partir da revisão conceitual das fases de aplicação da ASV é apresentada a adaptação para a terminologia brasileira conhecida pelos profissionais de empresas e órgãos responsáveis pelos projetos de rodovias no Brasil. Cabe destacar que nessa dissertação são abordadas as fases de estudo de viabilidade, projeto básico e projeto executivo.

Fases de aplicação de Auditoria de Segurança Viária:
a) Estudo de Viabilidade;
b) Projeto Básico;
c) Projeto Executivo;
d) Pré-abertura ou Pré-abertura ao tráfego;
e) Rodovia em operação.

A complexidade do uso da ASV em cada fase é diferenciada. Para explicar isso, segue breve descrição, adaptada de Hildebrand e Wilson (1999), do processo de ASV em cada fase do processo de concepção e implantação da rodovia:

a) Estudo de Viabilidade: avalia o desempenho do potencial de segurança da proposta de projeto conceitual com relação à localização da rota, padrões de projeto de estrada e o escopo do projeto. Os auditores devem se concentrar como a instalação do projeto irá afetar a continuidade da rede viária adjacente e identificar as necessidades de segurança de todos os usuários da rodovia (ou seja, pedestres, ciclistas, motoristas e outros). Auditoria pode ser muito eficaz nesta fase, podendo propor mudanças ou melhorias para o projeto, que serão muitas vezes altamente rentáveis devido ao custo de implementação ser baixo em relação ao custo de reparo.

b) Projeto básico: nesta fase deverá ser avaliada, principalmente, a segurança em relação ao layout de interseção, alinhamento vertical e horizontal, seção transversal, e distâncias de visibilidade. Destaca-se que a ASV nesta fase deve ser concluída antes da finalização da desapropriação da área para evitar complicações de futuras mudanças significativas de alinhamento. 
c) Projeto executivo: nesta fase a ASV verifica os detalhes do projeto, antes da preparação do caderno de encargos, incluindo o detalhamento do projeto geométrico, sinalização, iluminação, paisagismo, autorização de execução e entre outros projetos.

d) Pré-abertura ou pré-abertura ao tráfego: imediatamente antes da abertura, a equipe de ASV deve realizar uma inspeção no local para garantir as necessidades de segurança a todos os usuários da rodovia (pedestres, ciclistas, motoristas e outros). É essencial uma inspeção durante o dia e noturna para assegurar que a segurança será alcançada, especialmente em relação à sinalização. A ASV nesta fase tem o propósito de verificar a existência de riscos não detectada em auditorias realizadas nas fases anteriores.

Rodovia existente ou rodovia em operação: após a abertura da rodovia ao tráfego a auditoria pode ser realizada para verificar o comportamento operacional da rodovia, ou seja, avaliar se existe alguma deficiência na concepção do projeto ou na sua implantação. Medidas corretivas, embora muito mais caras nesta fase, ainda assim podem ser rentáveis por preservar vidas. A ASV pode ser realizada em qualquer seção da rodovia em operação para identificar potenciais locais de acidentes.

Ressalta-se que no instrumento proposto serão incluídos outros projetos não citados no resumo de etapas de ASV de Hildebrand e Wilson (1999).

O processo de ASV é caracterizado por identificar os potenciais locais de acidentes de trânsito antes que estes ocorram. Este é um procedimento muito mais amplo que o tratamento de pontos críticos de áreas problemáticas onde se concentram as ocorrências de acidentes de trânsito. Uma característica fundamental da ASV é que, geralmente, é rentável em qualquer etapa de aplicação de ASV (desde a fase de viabilidade até a etapa de operação). No entanto, sua maior eficácia é alcançada, quando o projeto ainda está no papel, isto é, entre a fase de viabilidade e projeto executivo. Ainda assim, a ascensão da ASV em alguns países está concentrada em vias existentes (Castrillón e Candia, 2003).

\subsection{EQUIPE DA AUDITORIA DE SEGURANÇA VIÁRIA}


Partindo da definição que a ASV deve ser realizada por uma equipe independente, com profissionais qualificados e que possuam conhecimentos multidisciplinares para identificar potenciais problemas de segurança viária, segue a descrição para a formação de equipes para o uso da ASV.

Schopf (2006) cita que a equipe de ASV precisa reunir um conjunto de habilidades que garanta que os aspectos de segurança mais relevantes de um projeto sejam abordados. Uma única pessoa pode deter vários conhecimentos necessários. Os conhecimentos requisitados envolvem, tipicamente, a engenharia de segurança viária, engenharia de tráfego e projeto geométrico. Se conhecimentos específicos forem necessários em determinada parte da auditoria, um especialista pode ser convidado a fazer parte da equipe de auditoria por tempo limitado, para resolver um pequeno número de questões.

Nas pesquisas realizadas nas revisões bibliográficas sobre a equipe de auditores, há a necessidade da experiência nos diversos elementos de projetos que envolvem o estudo de viabilidade, projeto básico e executivo, relacionados, principalmente, aos elementos de geometria, dispositivos de contenção (barreiras rígidas e flexíveis) e sinalização viária, o que pode caracterizar conhecimento em engenharia de tráfego e segurança viária.

Os autores Castrillón e Candia (2003), AUSTROADS (2009) e RTMC (2012) citam nos seus respectivos manuais que as auditorias atuam em diferentes fases dos projetos e que cada fase necessita de profissionais com diferentes habilidades. Observou-se que as principais habilidades estão relacionadas ao conhecimento no uso do solo, investigação de acidentes, gestão da segurança viária, projeto de estradas, conhecimento referente ao fator humano. Também é possível incorporar profissionais ligados à sinalização, semáforos, sistemas de transporte inteligentes, usuário da rodovia, vegetação, estruturas de contenção dentre outros.

\subsection{EXPERIÊNCIAS DA AUDITORIA DE SEGURANÇA VIÁRIA}

O emprego da ASV é cada vez mais comum nos países desenvolvidos, como Nova Zelândia, Austrália, Canadá, entre outros. Nos países em desenvolvimento o procedimento tem se restringido, em geral, aos grandes projetos rodoviários (Ferraz, et al, 2012). 
As experiências do uso da ASV em países como Austrália, Nova Zelândia, Canadá, Chile e África do Sul mostram que neles, já estão consolidadas e são aplicadas pelos seus respectivos departamentos de transportes desde o planejamento dos projetos a serem executados até a fase em que a rodovia está em operação. A partir das revisões dos manuais desses departamentos, e de alguns trabalhos elaborados por autores brasileiros que propuseram procedimentos a serem usados em rodovias brasileiras existentes foi possível obter o embasamento teórico e técnico para a elaboração do instrumento proposto nesta dissertação. Assim, foi elaborado o instrumento de ASV para ser aplicado nas fases de projetos. A adaptação do instrumento para realidade brasileira tem a expectativa de contribuir cientificamente para a sociedade, no aumento da segurança viária de novas rodovias brasileiras ou para rodovias remodeladas.

Ressalta-se que os instrumentos utilizados como referência para a elaboração do instrumento proposto desta dissertação encontram-se nos Apêndices e são citados no decorrer da dissertação.

\subsubsection{Auditoria de Segurança Viária na Nova Zelândia, Austrália, Canadá, Chile e África do Sul}

a) Nova Zelândia (TRANSFUND, 1998)

No Manual de Procedimentos de Auditoria de Segurança para Vias em operação elaborado por Transfund New Zealand estão contidas as listas de verificação para vias rurais e vias urbanas. As listas de verificação das vias rurais são de dois tipos: uma avalia as condições de manutenção e a outra, os padrões e problemas da via, sendo ambas sucintas. Este manual apresenta, ainda, uma lista de alertas gerais com itens que devem ser observados para avaliar cada característica das vias, sob o enfoque da segurança.

b) Austrália (AUSTROADS, 2009)

Desde 1994 tem-se conhecimento do uso de ASV na Austrália, o que ocorreu por meio do lançamento da publicação chamada de Road Safety Audit - Auditoria de Segurança Rodoviária, a qual estabeleceu um amplo conjunto de linhas de orientação para um programa nacional de auditoria de segurança viária, com objetivo de garantir projetos rodoviários mais 
seguros. Em 2002 e 2009 esse manual foi revisado, para melhoria dos procedimentos de ASV.

O processo de auditoria de segurança rodoviária diz respeito à segurança de todos os usuários da via pública. AUSTROADS (2009) relaciona os elementos essenciais da definição:

a) um processo formal e não uma verificação informal;

b) realizado por pessoas que são independentes do projeto ou da autoridade da estrada, ou de uma rodovia existente;

c) realizado por pessoas com experiência e formação adequada;

d) restrito a questões de segurança rodoviária.

AUSTROADS (2009) também cita que a ASV pode ser aplicada em vários estágios que incluem a fase de viabilidade, o projeto preliminar o projeto detalhado, e a pré-abertura, além de esquema de tráfego em rodovias novas e rodovias existentes, o que reforça o uso de ASV na fase de projetos. Isso tem o objetivo de introduzir alterações para a melhoria de características de segurança antes do início das operações da rodovia.

c) Canadá (Hildebrand e Wilson, 1999)

A elaboração dos Manuais de Auditoria de Segurança Rodoviária pelas agências de transporte na Austrália, Nova Zelândia e Reino Unido, refletia, muitas das vezes, os sistemas locais de rodovias, características, padrões e práticas de projetos do país em que o processo de auditoria foi implantado.

Em meados de 1999, a auditoria de segurança rodoviária era relativamente nova para o setor de transportes canadense. Incialmente, várias províncias introduziram o conceito de auditorias de segurança rodoviária, embora com diferentes finalidade e projeto. Não existia nenhum documento genérico que apresentasse formalmente uma sequência recomendada das técnicas e práticas mais eficazes para avaliar as estradas canadenses, as práticas de projeto e as condições de operação. A necessidade de um manual local resultou do fato de que as estradas canadenses são únicas em muitos aspectos, tais como: condições climáticas locais; tamanho do País; diversidade da frota; volume de tráfego e tipos e características de 
animais locais que podem acessar as rodovias canadenses trazendo riscos aos usuários da rodovia.

Assim, o desenvolvimento de um manual canadense foi um benefício para as agências de transporte, segurança para os profissionais e outras partes interessadas na realização de ASV para melhorar a segurança nas estradas canadenses.

d) Chile (Castrillón e Candia, 2003)

O objetivo do manual, desenvolvido por Castrillón e Candia (2003) é fornecer orientação para as agências realizar uma ASV. Esta metodologia baseia-se em documento desenvolvido por países que está há mais tempo trabalhando com este tema, como Inglaterra, Austrália, Nova Zelândia e Canadá. A ideia foi adaptar essas experiências para a realidade chilena, sem tentar fornecer uma receita única, mas apenas tomando as primeiras linhas desta técnica que ganhava cada vez mais espaço no mundo, fomentando a aspiração para reduzir os acidentes de trânsito e suas consequências.

O manual fornece uma visão prática e sugerem elementos para serem considerados na ASV, que pode ser realizada em qualquer fase de viabilidade, concepção, construção, operação e manutenção. Os procedimentos ASV continuam a evoluir e a viabilizar aplicações cada vez mais eficazes, de modo que deve ser entendido como um processo dinâmico que precisa ser conhecido e aprofundado por profissionais da área.

e) África do Sul (RTMC, 2012)

O Manual de Segurança Rodoviária da África do Sul (South African Road Safety Manual SARSM) foi publicado como um projeto de documento em 1999 pelo Departamento Nacional de Transporte, a fim de ser uma "ferramenta de boas práticas" para ajudar as autoridades rodoviárias com a avaliação das operações de tráfego e dos aspectos de segurança viária da sua rede rodoviária.

O RTMC (2012) cita que auditoria de segurança rodoviária (viária) pode ser utilizada de forma eficaz como medida de prevenção do impacto, durante as fases preliminares e projeto, 
de qualquer projeto de estrada ou de transporte. A auditoria permite a identificação de potenciais elementos rodoviários causadores de acidente que podem ser removidos antes da implementação. Também cita que pode atuar como uma ferramenta de redução de acidentes em instalações existentes por meio de relatórios sobre o potencial da instalação de desempenho de segurança e acidente, identificando deficiências de segurança em face de informações incompletas de acidente.

Antes da publicação do Manual de Segurança Rodoviária, os profissionais de segurança viária da África do Sul, realizaram algumas inspeções de segurança rodoviárias pontuais antes do ano de 2012. Porém, RTMC (2012) cita que a auditoria de segurança rodoviária, como descrito a seguir, é diferente, uma vez que é:

- Um processo formal;

- Um processo independente (ou seja, não é um empregado do cliente ou de um membro da equipe de projeto que verifica a concepção / instalação);

- Um processo que pode ser facilmente incorporado como uma fase / fases do ciclo de vida de um projeto de estrada;

- Um processo com foco na prevenção do impacto, em vez de remediar um problema existente de segurança rodoviária.

\subsubsection{Auditoria de Segurança Viária no Brasil}

A técnica da ASV no Brasil ainda não acontece de forma metódica, se considerados os aspectos que são obstáculos para a utilização da ASV nos projetos rodoviários. Podem-se citar os quatro principais (Ferraz, et al, 2012):

a) Ceticismo de alguns órgãos gestores do trânsito, que relutam em gastar recursos com ASV por falta de uma cultura de segurança no trânsito;

b) Dificuldade de alguns profissionais em aceitar que seus projetos sejam revisados por outros técnicos;

c) Dificuldade de conseguir que profissionais experientes sejam contratados, em vez daqueles considerados mais baratos e sem tanta prática ou conhecimento do assunto;

d) Restrições dos órgãos financiadores na liberação de recursos para aplicação em ASV. 
Observa-se que o uso da ASV no Brasil é restrito a auditorias compulsórias incluídas nos editais para a contratação de alguns projetos e obras. Também há iniciativas realizadas por concessionárias que operam rodovias brasileiras. Entretanto, diversos órgãos têm considerado a utilização da ASV como componente importante de programas de redução de acidentes. A ARTESP, Agência Reguladora das Concessões Rodoviárias no Estado de São Paulo, tem exigido das empresas contratadas a realização de serviços de ASV, embora a prática necessite de aperfeiçoamentos (CET, 2010).

Cabe destacar que conforme o mecanismo de concessão atual, as concessionárias recebem as rodovias existentes (em operação) e devem fazer melhorias, como implantação de interseções, duplicações, criação de faixas auxiliares, vias laterais, melhoramento na sinalização, entre outros.

As primeiras aplicações da ASV no Brasil ocorreram por iniciativa do Instituto Nacional de Segurança no Trânsito (INST). O Instituto documenta que desde 1996 foram desenvolvidas ASV no Brasil que resultaram em melhorias, tais como, a implantação dos semáforos inteligentes no Município de São Paulo. Atuou na fase de projeto básico das novas marginais dos Rios Pinheiros, na melhoria da fluidez e condições de segurança viária para duplicação da Rodovia Padre Manoel da Nóbrega - SP 55, entre outros (CET, 2010).

Dessa forma, as experiências brasileiras são ainda muito recentes e em número pequeno, não havendo uma análise referente à execução das recomendações resultantes e da sua eficácia na redução de acidentes de trânsito. Ressalta-se que as aplicações de ASV conduzidas no Brasil concentram-se em auditorias em vias em operação (CET, 2010).

\subsection{TÓPICOS CONCLUSIVOS}

No cenário em que o Brasil se encontra, referente ao número elevado de acidentes de trânsito, medidas são necessárias para que ocorra a redução e mitigação desses acidentes. Assim, a auditoria de segurança viária vem fortalecer as ações proativas a serem tomadas referentes aos projetos rodoviários.

A auditoria de segurança viária é um processo formal, que atua em projetos de forma sistemática e consistente. Para os departamentos de transportes de diferentes países é uma 
ferramenta que se consolidou devido a sua eficácia nas ações proativas com atuação nas fases de projetos, rodovias em operação, além de ser usada em rodovias rurais e vias urbanas.

Neste contexto, a ASV necessita de uma equipe de profissionais independentes e com experiências no âmbito de engenharia de tráfego e segurança viária. No que tange a uma equipe independente, entende-se que seja uma equipe separada dos projetistas responsáveis pela elaboração dos projetos e até mesmo dos executores.

No Brasil, os estudos acadêmicos encontrados no que tange ASV por meio de lista de verificação estão relacionados a instrumentos para a aplicação na etapa do processo de ASV em rodovias em operação. Assim, com base na revisão bibliográfica de listas de verificação existente, o instrumento proposto nesta dissertação trata da aplicação da ASV nos estudos de viabilidade, projeto básico e projeto executivo.

Para a elaboração de um instrumento de ASV, tipo lista de verificação, no Brasil, é importante a quebra de paradigmas, e fortalecer que a solução de projetos mal elaborados possa ser readequada com, simplesmente, o projeto de sinalização. É necessário incorporar nos órgãos setores de ASV. E no modelo de instrumento a ser aplicado no estudo de viabilidade, projeto básico e projeto executivo são relevantes inserir tópicos de todos os projetos que compõem o estudo de viabilidade, projeto básico e projeto executivo, pois na definição citada na seção 2.3 desta dissertação, pode observar que alguns projetos não foram abordados nas listas de verificação existente.

E na verificação das listas existentes, basicamente, o que foi observado que não pose ser usual no instrumento proposto nesta dissertação, trata de elementos referente ao clima e elementos viários de uma etapa de aplicação de ASV que não corresponde à definição de estudo de viabilidade, projeto básico e projeto executivo dos manuais brasileiros. 


\section{INSTRUMENTO DE AUDITORIA DE SEGURANÇA VIÁRIA PARA PROJETOS RODOVIÁRIOS BRASILEIROS}

Neste capítulo é apresentado o método proposto para a elaboração do instrumento de auditoria de segurança viária adaptado à realidade das rodovias brasileira para serem aplicado nos estudos de viabilidade, projetos básicos e projetos executivos. Durante a revisão bibliográfica, foi observado que há diferentes instrumentos de ASV com aplicação em distintas fases do projeto e em rodovia em operação (existente), com destaque para os instrumentos consolidados nos países Austrália, Nova Zelândia, Estados Unidos da América, Canadá, Chile e África do Sul. Além das diferentes fases desses instrumentos, considerouse, também, a forma de apresentação e conteúdo.

\subsection{ETAPAS METODOLÓGICAS}

A estrutura metodológica desta dissertação é apresentada na Figura 4.1 que mostra o procedimento adotado para a elaboração do instrumento de ASV proposto nesta dissertação. Essa estrutura foi criada, uma vez que os instrumentos de ASV existentes internacionalmente não corresponderem com a realidade das rodovias brasileiras.

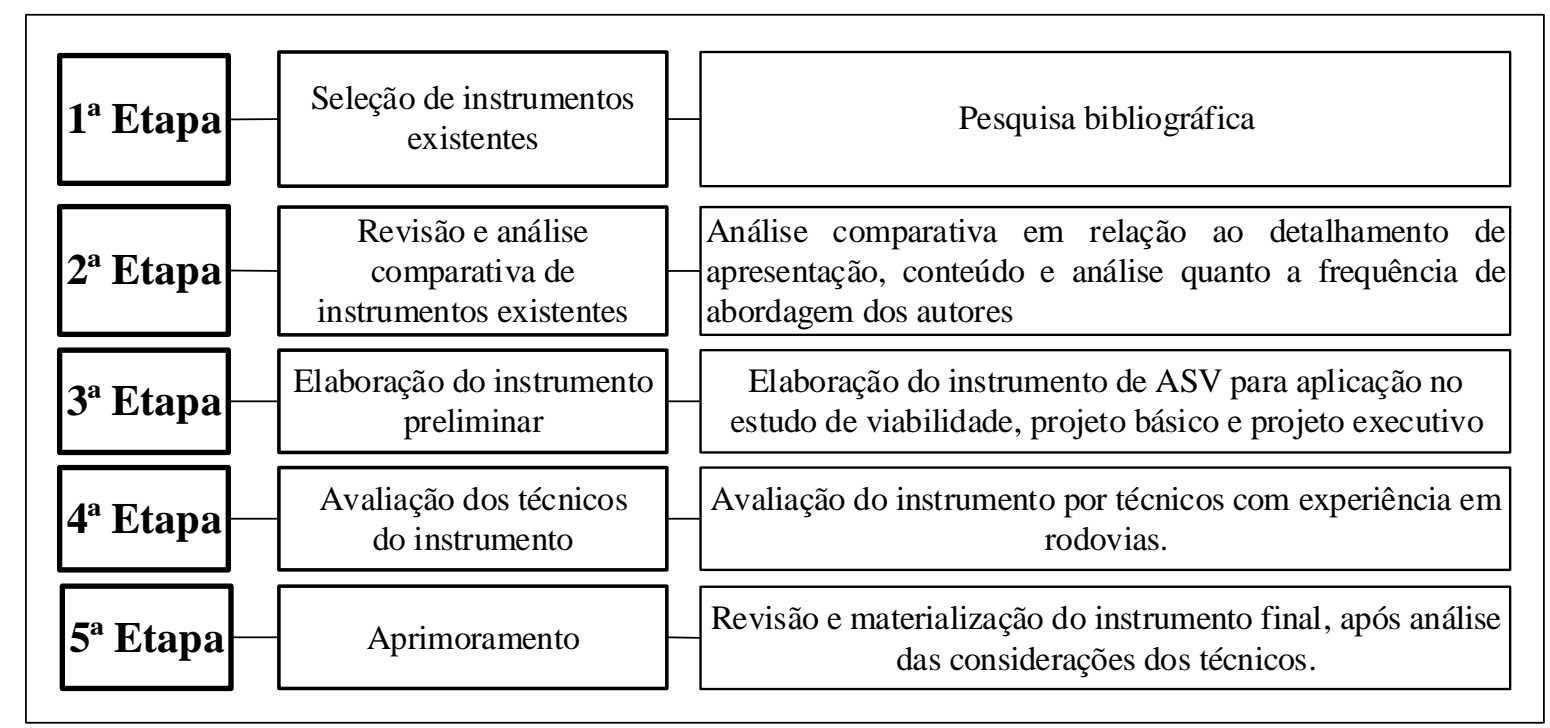

Figura 4.1: Estrutura Metodológica da elaboração do instrumento de ASV proposto

Fonte: Elaborado pela autora, 2015. 
Para a elaboração do instrumento foi necessário realizar a revisão dos principais instrumentos de ASV disponíveis na literatura nacional e internacional, bem como elencar os principais conteúdos e elementos referentes às diferentes fases do projeto rodoviário.

\subsection{ETAPA 1: SELEÇÃO DE INSTRUMENTOS EXISTENTES}

A etapa 1 consistiu na pesquisa bibliográfica para a seleção dos instrumentos de ASV baseados em lista de verificação disponível na literatura brasileira, bem como na literatura internacional para subsidiar a elaboração do instrumento de ASV proposto desta dissertação. O Quadro 4.1 refere-se ao panorama de pesquisas e trabalhos nacionais e internacionais que abrangem estudos voltados para ASV.

Quadro 4.1: Referências de pesquisa relacionadas à auditoria de segurança viária

\begin{tabular}{|c|c|c|c|c|}
\hline \multicolumn{2}{|l|}{ REFERENCIAL } & ELABORAÇÃOO & PAÍS & ANO \\
\hline $\begin{array}{l}\text { AUSTROADS } \quad \text { apud } \\
\text { Nodari, } 2003\end{array}$ & Manual & $\begin{array}{l}\text { Austroads - Associação de agências de } \\
\text { transporte rodoviário e de trânsito Austrália }\end{array}$ & Austrália & 1994 \\
\hline TRANSFUND & Manual & $\begin{array}{c}\text { Por Transfund New Zealand - TNZ - Agência de } \\
\text { Transportes da Nova Zelândia }\end{array}$ & Nova Zelândia & 1998 \\
\hline $\begin{array}{l}\text { HILDEBRAND e } \\
\text { WILSON }\end{array}$ & Manual & $\begin{array}{l}\text { Universidade de New Brunswick - pelo Grupo de } \\
\text { Transporte - Departamento de Engenharia Civil }\end{array}$ & Canadá & 1999 \\
\hline CASTRILLÓN e CANDIA & Manual & $\begin{array}{l}\text { Pelos Engenheiro Civil e Engenheiro Industrial } \\
\text { diplomados em Segurança no Trânsito }\end{array}$ & Chile & 2003 \\
\hline NODARI & Tese & Universidade Federal do Rio Grande do Sul & Brasil & 2003 \\
\hline SCHOPF & Dissertação & Universidade Federal do Rio Grande do Sul & Brasil & 2006 \\
\hline AUSTROADS & Manual & $\begin{array}{l}\text { Austroads - Associação de agências de } \\
\text { transporte rodoviário e de trânsito Austrália }\end{array}$ & Austrália & 2009 \\
\hline RODRIGUES & Dissertação & Universidade Estadual de Campinas & Brasil & 2010 \\
\hline DE SOUZA & Dissertação & Universidade de Brasília & Brasil & 2012 \\
\hline RTMC & Manual & Corporação de gestão de tráfego da rodovia & África do Sul & 2012 \\
\hline
\end{tabular}

Fonte: Elaborado pela autora, 2015.

Neste contexto, baseada nas referências citadas no Quadro 4.2 verificou-se que a aplicação de ASV internacionalmente encontra-se consolidada por meio de listas de verificação, as 
quais possuem as prerrogativas a ser utilizada na ASV em seus países de origem, como Nova Zelândia, Austrália, Chile, África do Sul e Brasil. Entretanto, a diferença entre o Brasil e os demais países é que no Brasil ainda são estudos incipientes. E nos demais países citados acima já existem manuais consolidados em seus departamentos de transportes.

Ainda baseada na revisão bibliográfica identificou-se a aplicação da ASV em diferentes etapas da aplicação de ASV. Assim, pode-se observa no Quadro 4.2 o resumo das fases e aplicação da ASV referente a cada autor, onde se pode identificar o panorama dos trabalhos de ASV relacionados ao ano de elaboração, autor, país e etapas de aplicação.

Quadro 4.2: Fases de aplicação de ASV nos estudos pesquisados

\begin{tabular}{|c|c|c|c|}
\hline 1994 & $\begin{array}{l}\text { AUSTROADS, } 1994 \\
\text { apud NODARI, } 2003\end{array}$ & Austrália & $\begin{array}{l}\text { Viabilidade de projeto; Anteprojeto; Projeto definitivo, Pré-abertura dos projetos novos ou período de } \\
\text { construção; Vias em operação e procedimentos de manuntenção de vias }\end{array}$ \\
\hline 1998 & TRANSFUND & $\begin{array}{l}\text { Nova } \\
\text { Zelândia }\end{array}$ & Rodovias em operação \\
\hline 1999 & $\begin{array}{l}\text { HILDEBRAND e } \\
\text { WILSON }\end{array}$ & Canadá & $\begin{array}{l}\text { Estudo de viabilidad; Projeto preliminar; Projeto detalhado; Pré-operação; Pós-operação; Rodovias em } \\
\text { operação. }\end{array}$ \\
\hline 2003 & NODARI & Brasil & Rodovias em operação \\
\hline 2006 & SCHOPF & Brasil & Rodovias em operação \\
\hline 2012 & DE SOUZA & Brasil & Projeto executivo \\
\hline 2012 & RTMC & África do Sul & $\begin{array}{l}\text { Viabilidade de projeto; Projeto Preliminar; Projeto detalhado; Pré-abertura; ASV na zona de gerenciamento } \\
\text { de tráfego; Rodovias em operação. }\end{array}$ \\
\hline
\end{tabular}

Fonte: Elaborado pela autora, 2015.

Consequentemente, com a revisão bibliográfica, definiram-se os instrumentos que foram usados na análise comparativa e os que não foram utilizados. Desta forma, foram desconsiderados os manuais elaborado por AUSTROADS (1994, apud Nodari, 2003), devido ter passado por revisão, adotando-se o da edição de 2009. Também foram retiradas as listas de verificação elaboradas por Transfund (1998), Schopf (2006) e Rodrigues (2010) por apresentarem instrumentos de ASV apenas para aplicação em rodovias em operação.

Também, após a análise das referências dos Quadros 4.1 e 4.2 identificou-se que o trabalho da autora Nodari (2003) é uma ASV assistida por meio do método de avaliação da segurança potencial de segmentos de rodovias rurais pavimentados de pista simples, menos qualitativo 
e mais quantitativo para aplicação em rodovias em operação. Dessa forma, não foi abordado como base para o instrumento de ASV desta dissertação, que é mais qualitativa devido à proposta de um instrumento tipo lista de verificação para projetos de estudo de viabilidade, projeto básico e projeto executivo.

Baseado nas referências foi retirado da base do instrumento desta dissertação o trabalho de De Souza (2012), apesar de tratar de uma ASV para aplicação em projetos executivos não foi abordado, uma vez que os modelos de ASV usados nesta dissertação é por meio de lista de verificação, um instrumento qualitativo, diferentemente do instrumento proposta pela referida autora.

Neste contexto, as listas de verificação selecionadas para serem analisadas como base desta dissertação foram dos autores: Hildebrand e Wilson (1999), Castrillón e Candia (2003), AUSTROADS (2009) e RTMC (2012), devido estes autores abordarem a ASV nos estudos de viabilidade, projeto básico e projeto executivo e modelo de lista de verificação. O Quadro 4.3 mostra as listas de verificação selecionadas, bem como o país de origem e ano elaboração ou atualização das listas de verificação de ASV.

Quadro 4.3: Listas de verificação selecionados para a análise comparativa

\begin{tabular}{|l|c|c|}
\hline \multicolumn{3}{|c|}{$\begin{array}{c}\text { LISTA DE VERIFICAÇÃO SELECIONADAS PARA A BASE } \\
\text { REFERENCIAL DESTA DISSERTAÇÃO }\end{array}$} \\
\hline \multicolumn{1}{|c|}{ AUTORES } & PAÍS & ANO \\
\hline HILDEBRAND e WILSON & Canadá & 1999 \\
\hline CASTRILLÓN e CANDIA & Chile & 2003 \\
\hline AUSTROADS & Austrália & 2009 \\
\hline RTMC & África do Sul & 2012 \\
\hline
\end{tabular}

Fonte: Elaborado pela autora, 2015.

Após seleção das listas de verificação foi iniciada a etapa 2 do procedimento metodológico desta dissertação. 


\subsection{ETAPA 2: REVISÃO E ANÁLISE COMPARATIVA DE INSTRUMENTOS EXISTENTES}

Para a execução da etapa 2 desta dissertação, foi realizada a tradução das 04 (quatro) listas de verificação selecionadas para análise comparativa, os quais foram disponibilizados nos Apêndices, conforme descrição abaixo:

- Anexo A - Lista de verificação de Hildenbrand e Wilson (1999);

- Anexo B - Lista de verificação dos autores Castrillón e Candia (2003);

- Anexo C - Lista de verificação de AUSTROADS (2009);

- Anexo D - Lista de verificação de RTMC (2012).

Para Schopf (2006) as listas de verificação selecionados apresentam basicamente dois níveis de detalhamento. Um dos níveis diz respeito às listas onde os itens de verificação não são detalhados, denominados de listas de alertas, onde Schopf denominou de nível geral. O outro nível identificado diz respeito às listas de verificação onde os itens são detalhados, denominadas listas de verificação detalhadas, e foi denominado de nível detalhado.

Nesta dissertação, após a ampla análise das 04 (quatro) listas de verificação, definiu-se analisar comparativamente os chamados detailed checklists que pode-se ser traduzido e interpretado como verificação detalhada (Schopf, 2006) ou lista de verificação detalhada.

E com base nas listas de verificação detalhada identificaram-se três categorias, e nesta dissertação foram definidos como três níveis de detalhamento, sendo o primeiro nível das macrocategorias, que são os elementos viários que fazem partes dos projetos, definidos pelos autores em suas listas de verificação, o segundo nível das mesocategorias, que são os sub elementos viários e o terceiro nível das microcategorias que sãos as questões relacionadas a cada sub elemento viário abordado nas mesocategorias. Esses níveis poder ser observado no Quadro 4.4, que mostra os níveis do instrumento proposto nesta dissertação. 
Quadro 4.4: Níveis do instrumento proposto nesta dissertação

\begin{tabular}{|l|l|l|}
\hline \multicolumn{2}{|c|}{ DIVISÃO DOS NÍVEIS } \\
\hline Nível 1 & Macrocategoria & Elementos viários dos projetos \\
\hline Nível 2 & Mesocategoria & Subdivisão dos elementos viários \\
\hline Nível 3 & Microcategoria & Questão a ser verificada relacionada à meso e a macrocategoria \\
\hline
\end{tabular}

Fonte: Elaborado pela autora, 2015.

Para a análise comparativa dos instrumentos existentes quanto à apresentação (item 4.3.1) e etapa da análise comparativa de instrumentos existentes quanto ao conteúdo (item 4.3.2) optou-se adotar a estrutura de análise comparativa, onde fez-se a adaptação de Schopf (2006).

A seguir é apresentada, resumidamente, a forma de apresentação das listas de verificação detalhadas selecionadas, para a base do instrumento desta dissertação, de cada autor citado no Quadro 4.3. Além disso, é possível observar os três níveis definidos nesta dissertação, ou seja, macrocategorias, mesocategorias e microcategorias.

\subsubsection{Análise comparativa de instrumentos existentes quanto à apresentação}

Cada lista de verificação apresenta-se de forma distinta. Como mencionado por Schopf (2006), eles se diferem quanto ao aspecto visual, aos campos que as compõem, ao formato, à facilidade de manuseio, entre outras características.

a) Hildebrand e Wilson

O modelo de lista de verificação de Hildebrand e Wilson (1999) apresenta todas as etapas do processo de ASV em uma única lista de verificação, como pode ser observado na Figura 4.2 , no item etapas.

Também podem ser observados na lista de verificação de Hildebrand e Wilson (1999) os níveis definidos nesta dissertação, observem os níveis:

- GERAL - macrocategoria;

- G1. Escopo - mesocategoria; 
- Verificar toda documentação pertinente do escopo do projeto, destacando os objetivos do projeto, características do usuário, veículos de projetos, projetos de acessos, características das áreas adjacentes, informações de redes existentes e projetos de futuras expansões - microcategoria.

\begin{tabular}{|c|c|c|}
\hline \multicolumn{3}{|c|}{$\begin{array}{l}\text { CHECKLIST DETALHADO } \\
\text { NOVAS INSTALAÇÕES / UPGRADES / EXISTENTE }\end{array}$} \\
\hline Item & Etapas* & $\begin{array}{c}\text { Potenciais problemas de segurança } \\
\text { (Nota: Nem todos os problemas pertencem a cada etapa de } \\
\text { Auditoria) } \\
\end{array}$ \\
\hline \multicolumn{3}{|l|}{ GERAL } \\
\hline G1. Escopo & 1 & $\begin{array}{l}\text { Verificar toda documentação pertinente do escopo do projeto, } \\
\text { destacando os objetivos do projeto, características do usuário, } \\
\text { veículos de projetos, projetos de acessos, características das áreas } \\
\text { adjacentes, informações de redes existentes e projetos de futuras } \\
\text { expansões. }\end{array}$ \\
\hline "G2 Etapas de Construção & $1,2,3$ & $\begin{array}{l}\text { Quais são os efeitos da realização da construção do projeto com um } \\
\text { único contrato ou dividindo-a em vários contratos? }\end{array}$ \\
\hline
\end{tabular}

Figura 4.1: Estrutura Metodológica da elaboração do instrumento de ASV propostoForma de apresentação da lista de verificação de Hildebrand e Wilson

Fonte: Adaptada de Hildebrand e Wilson, 1999

b) Castrillón e Candia

A lista de verificação de Castrillón e Candia (2003) é apresentada na Figura 4.3, onde observa-se a macrocategoria - Tópicos Gerais, e o item 1 - Aspectos gerais, função e composição do tráfego previsto é a mesocategorias, essa numeração é sequencial até o final da lista de verificação, ver Anexo B, diferenciado apenas pela macrocategoria em negrito, e em seguida os itens a ser verificado detalhadamente (chamados nesta dissertação de microcategoria). Também, há o espaço para os comentários dos auditores. Ressalta-se que a forma de apresentação é para as três etapas estudo de viabilidade, projeto básico e projeto executivo. 


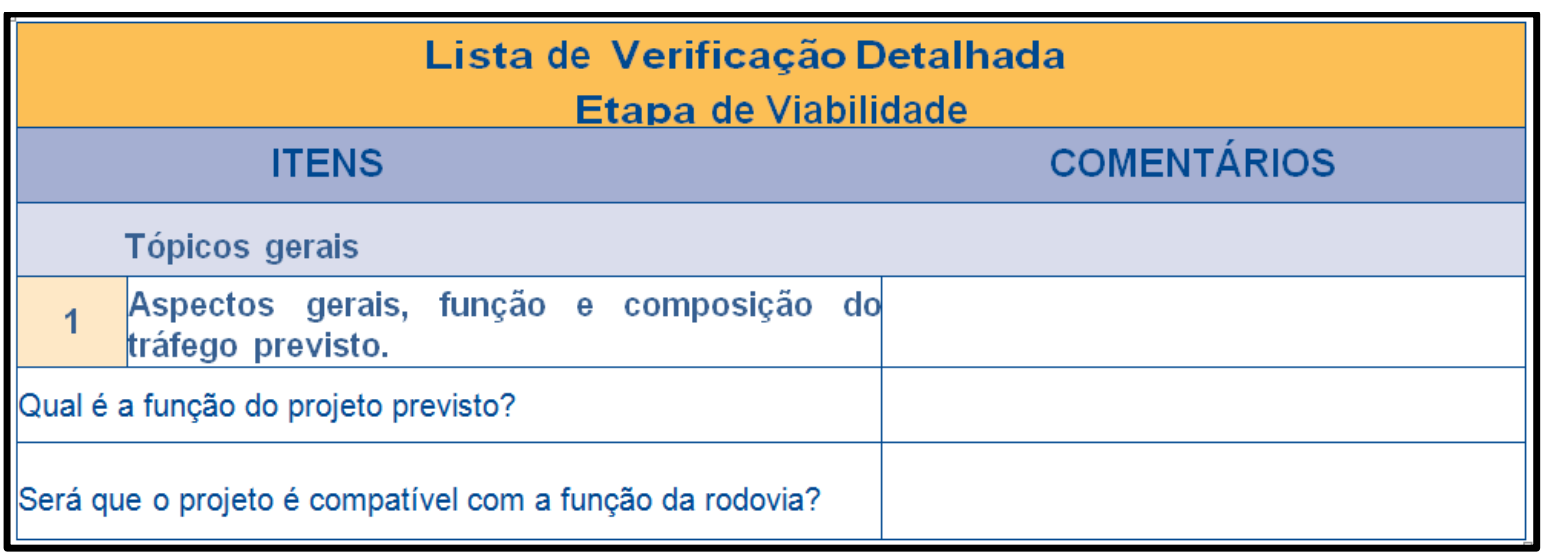

Figura 4.3: Forma de apresentação da lista de verificação de Castrillón e Candia Fonte: Adaptada de Castrillón e Candia, 2003.

\section{c) AUSTROADS}

Observou-se que para AUSTROADS, há listas de verificação para cada fase de projeto (ver Anexo C). Estas possuem a divisão em três níveis, com a subdivisão por elementos de projetos. Observa-se também que há locais para o auditor citar se os itens foram ou não contemplados no projeto analisado, além do espaço para comentários. A Figura 4.4 mostra de forma parcial a representação da lista de verificação de AUSTROADS (2009).

Sendo 1.1. Tópicos Gerais a macrocategoria, 1.1.1. Escopo do projeto; função; composição do tráfego a mesocategorias, e "Qual é a função prevista do projeto?" é a microcategoria.

11.2 Checklist detalhado
\begin{tabular}{l|l|l|l|}
\hline CHECKLIST 1: ESTÁGIO DE AUDITORIA VIABILIDADE \\
\hline Edição & Sim & Não & Comentários \\
\hline 1.1 Tópicos gerais & & & \\
1.1.1 Escopo do projeto; função; composição do tráfego. & & & \\
\hline Qual é a função prevista do projeto? & & & \\
\hline O projeto é compatível com a função da rodovia? & & & \\
\hline
\end{tabular}

Figura 4.4: Forma de apresentação da lista de verificação de AUSTROADS Fonte: Adaptada de AUSTROADS, 2009. 
d) RTMC

A apresentação da lista de verificação de RTMC, 2012 apresenta-se em tópicos apenas, e sem utilização de numeração, como pode ser observado na Figura 4.5. E o destaque está a macrocategoria, em seguida a mesocategorias e em seguida o questionamento a ser realizado pela equipe de ASV.

\begin{tabular}{ll}
\hline ANEXO D-1: Auditoria de Segurança Rodoviária Fase 1: Projeto Preliminar \\
\hline ITEM & POSSÍVEL PROBLEMA \\
\hline TÓPICOS GERAIS & \\
$\begin{array}{ll}\text { O escopo do projeto, função e composição do } & \\
\text { tráfego } & \text { Qual a função do projeto? } \\
& \text { O projeto é compatível com a função da rodovia? } \\
& \text { O projeto proposto enfatiza adequadamente for: } \\
& \text { - Pedestres } \\
& \text { - Veículos de passageiros } \\
& \text { - Ooículos pesados }\end{array}$ \\
\end{tabular}

Figura 4.5: Forma de apresentação da lista de verificação de RTMC (2012)

Fonte: Adaptado de RTMC, 2012.

As formas das listas de verificação apresentadas nas Figuras 4.2, 4.3, 4.4 e 4.5 foram extraídas das fases de estudo de viabilidade. Nos Anexos A, B, C e D são apresentadas as listas de verificação completas com todas as fases de aplicação da ASV abordada nesta dissertação.

\subsubsection{Análise comparativa de instrumentos existentes quanto ao conteúdo}

Entende-se que as listas de verificação selecionadas buscam representar a realidade de cada país de origem, bem como a representação dos principais tópicos relacionados à segurança viária. Para Schopf (2006) os conteúdos das listas de verificação refletem os problemas de segurança viária que os especialistas dos países, nos quais foram desenvolvidos, acreditam ser os mais frequentes e relevantes nas vias de seus países. 
Assim, para a elaboração do instrumento proposto nesta dissertação foi realizada uma primeira análise entre os elementos de projetos propostos nas listas de verificação selecionadas para a identificação de termos que não correspondem aos projetos rodoviários brasileiros e a segunda análise foi a verificação da frequência em que os itens da lista de verificação aparecem. Ressalta-se que essas análises seguiu a linha de análise comparativa de Schopf (2006).

A frequência foi distribuída conforme a Figura 4.6, que mostra a identificação da frequência, que varia entre $25 \%$ a $100 \%$, sendo que a frequência de $25 \%$ representa uma abordagem entre os autores, $50 \%$ quando há duas das quatro abordagens, $75 \%$ quando há três das quatro abordagens e $100 \%$ quando os quatro autores abordaram o mesmo item. É apresentada a análise comparativa completa da frequência nas listas de verificação selecionadas. Cabe ressaltar que a análise de frequência foi realizada nos níveis das macrocategorias, mesocategorias e microcategorias.

\begin{tabular}{|c|c|c|c|c|c|}
\hline $\begin{array}{c}\text { Frequência } \\
(\%)\end{array}$ & \multicolumn{5}{|c|}{ Abordagem por autor } \\
\hline $25 \%$ & $\mathrm{x}$ & & & & abordado por um autor \\
\hline $50 \%$ & $\mathrm{x}$ & $\mathrm{x}$ & & & abordado por dois autores \\
\hline $75 \%$ & $\mathrm{x}$ & $\mathrm{x}$ & $\mathrm{x}$ & & abordado por três autores \\
\hline $100 \%$ & $\mathrm{x}$ & $\mathrm{x}$ & $\mathrm{x}$ & $\mathrm{x}$ & abordado pelos quatro autores \\
\hline
\end{tabular}

Figura 4.6: Legenda de frequência adotada na comparação dos instrumentos existentes Fonte: Elaborado pela autora, 2015.

A análise de apresentação, conteúdo e frequência foram critérios baseados no trabalho de Schopf (2006) que também elaborou um instrumento de ASV, porém para rodovias em operação, que após ter definido o nível de detalhamento e a forma de apresentação, que incialmente na versão preliminar da lista de verificação proposta foi determinado que todos os itens que estavam com $50 \%$ de frequência fariam parte da lista preliminar. Caracterizando que se o item foi abordado pelo menos por dois autores, é porque o item é comum nos projetos e na relevância de ser analisado por uma ASV. 
Neste contexto, segue as observações para adequação de cada nível, ou seja, adequação das macrocategorias, mesocategorias e microcategorias das fases do estudo de viabilidade, projeto básico e projeto executivo propostas nesta dissertação.

A Figura 4.7 consta o resumo do processo da análise da frequência e os critérios para manter ou excluir um item na elaboração do instrumento proposto nesta dissertação.

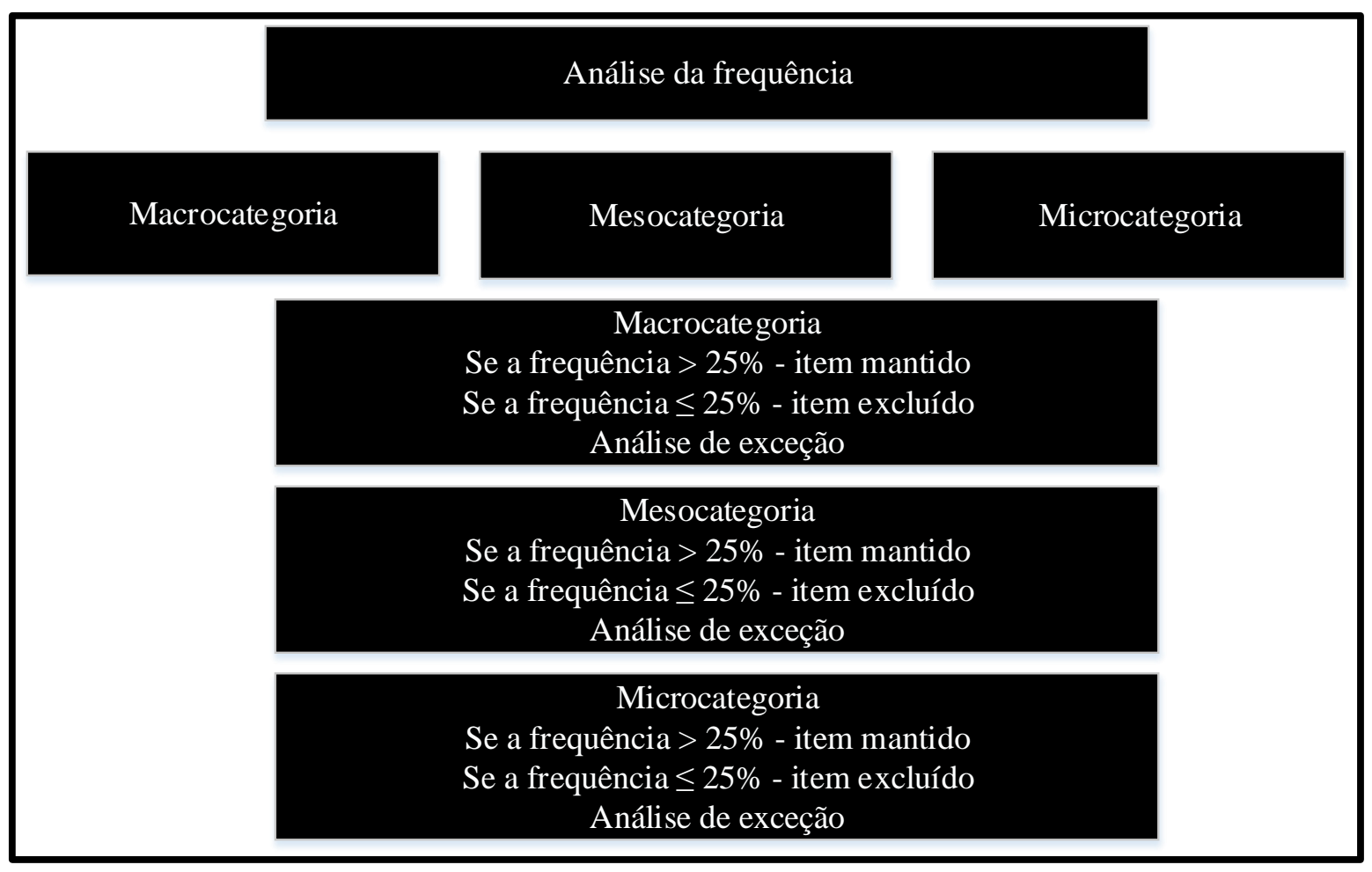

Figura 4.7: Processo da análise da frequência

As análises das frequências encontram-se no Apêndice A, conforme descrição abaixo:

- Apêndice A1- Análise da frequência da macrocategoria do estudo de viabilidade;

- Apêndice A2 - Análise da frequência da macrocategoria do projeto básico;

- Apêndice A3 - Análise da frequência da macrocategoria do projeto executivo.

4.3.2.1 Análise comparativa quanto ao conteúdo - Macrocategoria - do Instrumento de ASV do Estudo de viabilidade

Com o conhecimento inicialmente adquirido por meio da revisão bibliográfica, fez-se a análise comparativa e agrupamento por elementos de projetos e por níveis de categoria. $\mathrm{O}$ Quadro 4.5 mostra as macrocategorias do instrumento do estudo de viabilidade, divididas 
por autores e pelas categorias das listas de verificação selecionadas e as macrocategorias propostas e adaptadas para a linguagem técnica para a elaboração do instrumento de ASV desta dissertação. Ressalta-se que o quadro comparativo das frequências para a determinação das macrocategorias do estudo de viabilidade encontra-se no Apêndice A1.

Quadro 4.5: Macrocategorias do Estudo de Viabilidade

\begin{tabular}{|c|c|c|c|c|}
\hline $\begin{array}{l}\text { HILDEBRAND e } \\
\text { WILSON (1999) }\end{array}$ & $\begin{array}{l}\text { CASTRILLÓN e } \\
\text { CANDIA (2003) }\end{array}$ & $\begin{array}{l}\text { AUSTROADS } \\
\qquad(2009)\end{array}$ & RTMC (2012) & $\begin{array}{l}\text { MACROCATEGORIAS } \\
\text { PROPOSTA }\end{array}$ \\
\hline 1. Tópicos Gerais & 1. Tópicos Gerais & 1. Tópicos Gerais & 1. Tópicos Gerais & 1. Tópicos Gerais \\
\hline $\begin{array}{l}\text { 2. Alinhamento e Seções } \\
\text { Transversais }\end{array}$ & 2. Traçado & 2. Questões do traçado & 2. Traçado & 2. Geometria \\
\hline 3. Interseção & 3. Interseções & 3. Interseções & 3. Interseções & 3. Interseções \\
\hline 4. Interseção em desnível & 4. Restrições Ambientais & 4. Restrições Ambientais & 4. Questões Ambientais & 4. Obstáculos fixos \\
\hline 5. Objetos físicos & 5. Outras considerações & 5. Outras considerações & 5. Outras considerações & 5. Aspectos Ambientais \\
\hline 6. Considerações Ambientais & & & & 6. Outras considerações \\
\hline 7. Usuários da Rodovia & & & & \\
\hline $\begin{array}{l}\text { 8. Acessos e desenvolvimento } \\
\text { adjacentes }\end{array}$ & & & & \\
\hline
\end{tabular}

Fonte: Elaborado pela autora, 2015.

As macrocategorias Alinhamento e seções transversais, traçado e questões de traçado foram agrupados e adaptados para a macrocategoria geometria. Objetos físicos adaptados para obstáculos fixos, conforme NBR 15486 de 2007. Outro item agrupado e adaptado foi considerações ambientais, restrições ambientais e questões ambientais para a macrocategoria aspectos ambientais.

Para a consolidação das macrocategorias do estudo de viabilidade se fez necessário as seguintes compatibilizações:

a) Na revisão bibliográfica observou-se que a categoria "alinhamento e seções transversais" de Hildebrand e Wilson (1999), a categoria "traçado" de Castrillón e Candia (2003) e RTMC (2012) e a categoria "questões de traçado" de AUSTROADS (2009) tratam da mesma categoria a serem analisadas na macrocategoria. Assim, considerou-se que o total da frequência foi de $100 \%$, pois embora descritos por termos diferentes, se referiam aos 
mesmos elementos. Neste contexto, foram agrupadas na macrocategoria proposta desta dissertação - macrocategoria geometria.

b) Os autores Hildebrand e Wilson (1999) abordam na versão de seu instrumento a categoria "objetos físicos", que na análise obteve a frequência de $25 \%$. Entretanto, a categoria foi mantida como "obstáculos fixos" com base na NBR 15486/2007 - (ABNT, 2007) Segurança no tráfego - Dispositivo de contenção viária - Diretrizes. Os obstáculos fixos são elementos com grande potencial para causar graves acidentes de trânsito. Destaca-se que os obstáculos fixos são melhores observados em obras de melhoramentos, como exemplo, projetos de duplicação, que também é necessário ter estudo de viabilidade, projeto básico e executivo.

c) A categoria "considerações ambientais" de Hildebrand e Wilson (1999) e "restrições ambientais" de Castrillón e Candia (2003), AUSTROAS (2009) e RTMC (2012) foram agrupados na macrocategoria "aspectos ambientais".

d) Os itens "usuários da rodovia" e "acessos e desenvolvimentos adjacentes" de Hildebrand e Wilson (1999), também elementos importantes na caracterizam de acidentes, apresentaram a frequência de $25 \%$ na macrocategoria. Porém não foram abordados como macrocategoria do instrumento proposto de estudo de viabilidade. Pode-se observar que os demais autores abordaram os itens nas mesocategorias.

4.3.2.2 Análise comparativa quanto ao conteúdo - Macrocategoria - Instrumento do Projeto Básico

O Quadro 4.6 mostra as macrocategorias do instrumento do projeto básico segundo os autores selecionados para a análise comparativa e as macrocategorias do instrumento proposto desta dissertação, as quais abordam de forma geral as principais categorias que podem ser verificados nessa fase. Ressalta-se que o quadro comparativo das frequências para a determinação das macrocategorias do projeto básico encontra-se no Apêndice A2. 
Quadro 4.6: Macrocategorias da fase de Projeto Básico

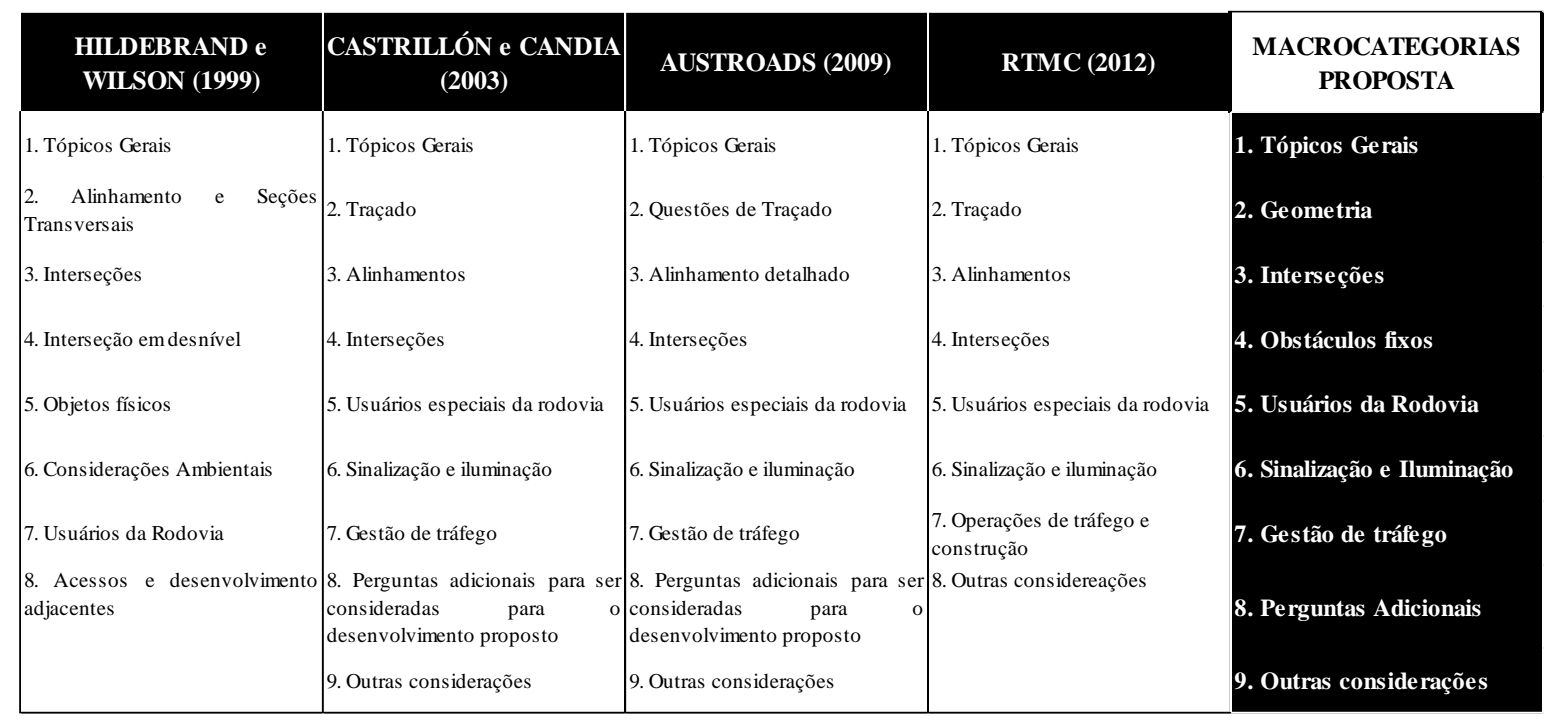

Fonte: Elaborado pela autora, 2015.

Assim, após a revisão bibliográfica fez-se as seguintes compatibilizações:

a) O item "alinhamento e seções transversais" abordado por Hildebrand e Wilson (1999) e "alinhamento" de Castrillón e Candia (2003) e RTMC (2012), e "alinhamento detalhado" de AUSTROADS (2009), após a revisão bibliográfica identificou-se que tratam da mesma categoria, embora com denominações diferentes. A frequência foi considerada o somatório tendo em vista que trata da mesma categoria. Assim, foram agrupados na macrocategoria “Geometria” proposta nesta dissertação.

b) As mesocategorias "traçado" de Castrillón e Candia (2003), e RTMC (2012), e "questões de traçado" de AUSTROADS (2009), foram agrupadas na macrocategoria "geometria" do instrumento proposto, por serem similares, bem como apresentaram microcategorias iguais entre si.

4.3.2.3 Análise comparativa quanto ao conteúdo - Macrocategoria - Instrumento do Projeto Executivo

O Quadro 4.7 mostra as macrocategorias do projeto executivo segundo os autores selecionados para a análise comparativa e as macrocategorias do instrumento proposto nesta dissertação, as quais abordam de forma macro as principais categorias que podem ser 
verificadas nessa fase. Ressalta-se que o quadro comparativo das frequências para a determinação das macrocategorias do projeto executivo encontra-se no Apêndice A3.

Quadro 4.7: Macrocategorias do Projeto Executivo

\begin{tabular}{|c|c|c|c|c|}
\hline $\begin{array}{l}\text { HILDEBRAND e } \\
\text { WILSON, } 1999\end{array}$ & $\begin{array}{l}\text { CASTRILLÓN e } \\
\text { CANDIA, } 2003\end{array}$ & AUSTROADS, 2009 & RTMC, 2012 & $\begin{array}{l}\text { MACROCATEGORIAS } \\
\text { PROPOSTA }\end{array}$ \\
\hline 1. Tópicos Gerais & 1. Tópicos Gerais & 1. Tópicos Gerais & 1. Tópicos Gerais & 1. Tópicos Gerais \\
\hline 2. Alinhamento e Seções Transver & 2. Traçado & 2. Questões de Traçado & 2. Traçado & 2. Geometria \\
\hline 3. Interseções & 3. Alinhamento detalhado & 3. Alinhamento detalhado & 3. Alinhamento & 3. Interseções \\
\hline 4. Interseção & 4. Interseções & 4. Interseções & 4. Interseções & 4. Obstáculos fixos \\
\hline 5. Recursos visuais & 5. Usuários Especiais da Rodovia & 5. Usuários especiais da Rodovia & 5. Usuários especiais da Rodovia & 5. Usuários da Rodovia \\
\hline 6. Objetos físicos & $\begin{array}{l}\text { 6. Sinalização vertical e } \\
\text { Iluminação }\end{array}$ & $\begin{array}{l}\text { 6. Sinalização vertical, sinalização } \\
\text { horizontal e Iluminação }\end{array}$ & $\begin{array}{l}\text { 6. Sinalização vertical, sinalização } \\
\text { horizontal e Iluminação }\end{array}$ & 6. Sinalização e iluminação \\
\hline $\begin{array}{l}\text { 9. Acessos e desenvolvimento } \\
\text { adjacentes }\end{array}$ & 9. Outras considerações & 9. Outras considerações & $\begin{array}{l}\text { 9. Acomodação do tráfego } \\
\text { 10. Outras considerações }\end{array}$ & \\
\hline
\end{tabular}

Fonte: Elaborado pela autora, 2015.

Para a consolidação das macrocategorias do projeto executivo foi necessário realizar as seguintes compatibilizações:

a) O item "alinhamento e seções transversais" de Hildebrand e Wilson (1999), "alinhamento detalhado" de Castrillón e Candia (2003) e AUSTROADS (2009) e "alinhamento" de RTMC (2012), após a revisão bibliográfica identificou-se que tratam da mesma categoria, embora com denominações diferentes. Para este caso a frequência foi considerada no somatório totalizando $100 \%$, tendo em vista que trata da mesma categoria. Assim, foram agrupados na macrocategoria "Geometria".

b) As categorias "traçado" de Castrillóm e Candia (2003) e RTMC (2012) e "questões de traçado" de AUSTROADS (2009), após revisão bibliográfica foram agrupadas na macrocategoria "geometria" do instrumento proposto.

d) Os autores Hildebrand e Wilson (1999) abordaram o item "Visual Aids" traduzido como "recursos visuais", e durante a revisão bibliográfica foi observado que este item tratava da 
categoria "sinalização", assim foi agrupado na macrocategoria "Sinalização e Iluminação" do instrumento proposto desta dissertação.

4.3.2.4 Análise comparativa quanto ao conteúdo - Mesocategorias - Instrumento do Estudo de Viabilidade

$\mathrm{Na}$ análise das mesocategorias identificaram-se particularidades com a necessidade de compatibilização e agrupamentos de itens das categorias do instrumento. Neste contexto, segue os comentários das mesocategorias correspondentes pelas suas macrocategorias:

a) Tópicos gerais

- A mesocategoria "finalidade" de Hildebrand e Wilson (1999) e "aspectos gerais, função e composição do tráfego previsto", abordado por Castrillón e Candia (2003), AUSTROADS (2009) e RTMC (2012) trata da mesma mesocategoria, embora com denominação diferente. Assim foram agrupados na mesocategoria "finalidade do projeto";

- A categoria "etapas de construção" foi agregada na mesocategoria "finalidade de projeto" proposta para o instrumento de ASV desta dissertação.

b) Geometria

- As categorias composição do projeto e fluxo de tráfego; traçado proposto; e impacto da continuidade com a rede rodoviária existente de Castrillón e Candia (2003), AUSTROADS (2009) e RTMC (2012) para o instrumento proposto foram agrupados na mesocategoria - traçado e alinhamento.

As análises das frequências das mesocategoriass encontram-se no Apêndice B, conforme descrição abaixo:

- Apêndice B1- Análise da frequência da memsocategoria do estudo de viabilidade;

- Apêndice B2 - Análise da frequência da mesocategoria do projeto básico;

- Apêndice B3 - Análise da frequência da mesocategoria do projeto executivo. 
No Quadro 4.8 são apresentadas resumidamente as mesocategorias do estudo de viabilidade. Ressalta-se que as definições também foram baseadas na frequência dos itens igual ou superior a 50\%. No Anexo B pode-se verificar o detalhamento da abordagem das mesocategorias.

Quadro 4.8: Mesocategorias do Estudo de Viabilidade

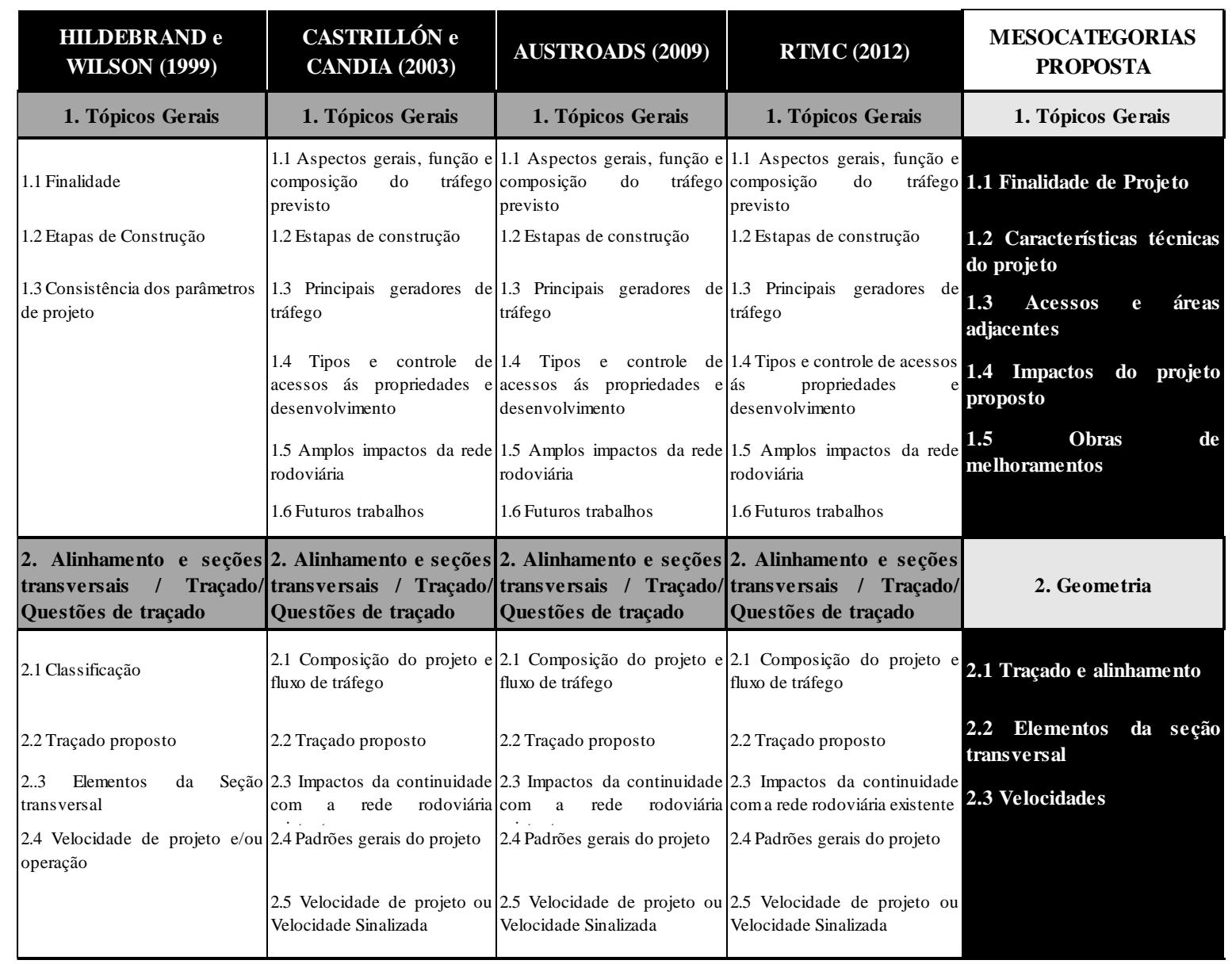


Quadro 4.8: Mesocategorias do Estudo de Viabilidade - continuação

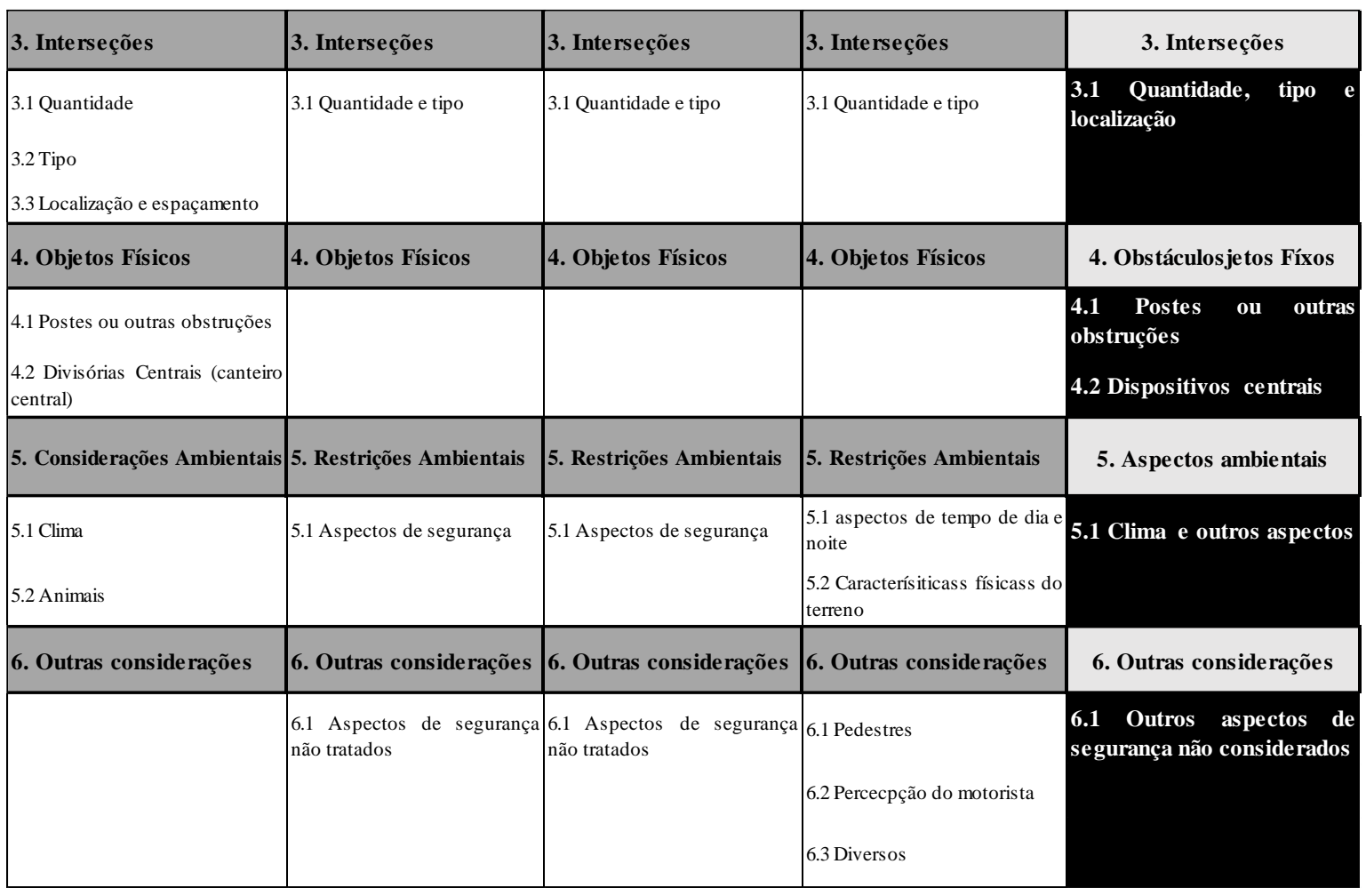

Fonte: Elaborado pela autora, 2015

4.3.2.5 Análise comparativa quanto ao conteúdo - Mesocategorias - Instrumento do Projeto Básico

$\mathrm{Na}$ análise das mesocategorias do projeto básico identificaram-se particularidades, que serão descritas abaixo, além da necessidade de ajustes para compatibilizar e unificar os itens das categorias do instrumento, julgando-se que ficariam mais claros para a compreensão dos auditores. Neste contexto, segue os comentários:

\section{a) Tópicos Gerais}

As categorias "ampliação e realinhamento futuro" de Castrillón e Candia (2003) e AUSTROADS (2009), e "planejamento futuro" de RTMC (2012) na revisão bibliográfica identificou que tratam dos mesmos itens, embora com nomes de mesocategoria diferentes. Assim, foram agrupados na mesocategoria "ampliação futura". 
b) Geometria

$\mathrm{Na}$ verificação da mesocategoria identificou-se que "traçado proposto" de Hildebrand e Candia (199), "disposição da rodovia" de Castrillón e Candia (2003) e "layout da rodovia" de AUSTROADS (2009) e RTMC (2012) tratam dos mesmos itens, embora com nomes distintos. Assim, foram agrupados na mesocategoria "traçado da rodovia".

Para o instrumento proposto os itens "elementos da seção transversal" de Hildebrand e Candia (1999), Castrillón e Candia (2003), AUSTROADS (2009) e RTMC (2012) e “efeitos da variação da seção transversal” de Castrillón e Candia (2003), AUSTROADS (2009) e RTMC (2012) foram agrupados na mesocategoria “elementos da seção transversal”.

$\mathrm{Na}$ análise da mesocategoria o item "drenagem" dos autores Hildebrand e Wilson (1999), foram abordados em "alinhamento e seção transversal", mas foram contabilizados na macrocategoria "tópicos gerais", para melhor análise da frequência.

c) Interseções

O item "localização e espaçamento" abordado por Hildebrand e Castrillón (1999) e distribuição, incluindo "adequação do tipo" abordado pelos autores Castrillón e Candia (2003) e AUSTROADS (2009) possuem a mesma concepção, diferindo apenas na denomição. Sendo assim, foram agrupados na mesocategoria "tipo e distribuição".

d) Obstáculos fixos

Devido ter definido na macrocategoria a inclusão deste elemento viário, foi necessária à análise da mesocategorias, considerando o grau de severidade que esse elemento pode proporcionar ao usuário da rodovia.

e) Usuários da rodovia

$\mathrm{Na}$ análise da frequência, foi desconsiderada a divisão que os autores Hildebrand e Wilson (1999) adotaram de "veículos motorizados" e "veículos não motorizados". No instrumento proposto foram considerados os veículos separadamente, sem a caracterização de 
motorizado e não motorizado. Ressalta-se que na análise final não houve prejuízo para a identificação da frequência.

$\mathrm{Na}$ lista de verificação de RTMC (2012) possuem a mesocategoria “ciclistas e motociclistas", sendo integrante da mesma mesocategoria, no entanto, para o instrumento proposto neste trabalho o item foi contabilizado separado, ou seja, mesocategoria "ciclistas" e mesocategoria "motociclistas".

No Quadro 4.9 contêm resumidamente as mesocategorias referentes ao projeto básico. Ressalta-se que as definições também foram baseadas na frequência dos itens com frequência igual ou superior a 50\%. No Apêndice B2, pode-se verificar o detalhamento da abordagem da frequência das mesocategorias.

Quadro 4.9: Mesocategorias do projeto básico

\begin{tabular}{|c|c|c|c|c|}
\hline $\begin{array}{l}\text { HILDEBRAND e } \\
\text { WILSON (1999) }\end{array}$ & $\begin{array}{c}\text { CASTRILLÓN e CANDIA } \\
(2003)\end{array}$ & AUSTROADS (2009) & RTMC (2012) & $\begin{array}{c}\text { MESOCATEGORIAS } \\
\text { PROPOSTA }\end{array}$ \\
\hline 1. Tópicos Gerais & 1. Tópicos Gerais & 1. Tópicos Gerais & 1. Tópicos Ge rais & 1. Tópicos Gerais \\
\hline $\begin{array}{l}\text { 1.1 As modificações feitas de } \\
\text { Auditoria anterior }\end{array}$ & $\begin{array}{l}\text { 1.1 As modificações feitas de } \\
\text { Auditoria anterior }\end{array}$ & $\begin{array}{l}1.1 \text { As modificações feitas de } \\
\text { Auditoria anterior }\end{array}$ & $\begin{array}{l}1.1 \text { As modificações feitas de } \\
\text { Auditoria anterior }\end{array}$ & 1.1 Auditorias anteriores \\
\hline 1.2 Etapas de Construção & 1.2 Estapas de construção & 1.2 Estapas de construção & 1.2 Estapas de construção & 1.2 Etapas da construcão \\
\hline $\begin{array}{lr}1.3 & \text { Consistência } \\
\text { parâmetros de projeto } & \text { dos }\end{array}$ & 1.3 Drenagem & 1.3 Drenagem & 1.3 Drenagem & 1.3 Drenagem \\
\hline $\begin{array}{l}\text { 1.4 Áreas de descanso ou } \\
\text { áreas de piquiniques }\end{array}$ & 1.4 Condições climáticas & 1.4 Condições climáticas & 1.4 Condições climáticas & 1.4 condições climáticas \\
\hline 1.5 Drenagem & 1.5 Paisagis mo & 1.5 Paisagismo & 1.5 Pais agis mo & 1.5 Paisagismo \\
\hline \multirow{7}{*}{$\begin{array}{l}\text { 1.6 Tipos e controle de acesso } \\
\text { às } \\
\text { desenvovilemento }\end{array}$} & 1.6 Serviço & 1.6 Serviço & 1.6 Serviço & 1.6 Serviços \\
\hline & $\begin{array}{l}1.7 \quad \text { Acesso e Veículos de } \\
\text { emergência }\end{array}$ & $\begin{array}{l}1.7 \quad \text { Acesso e Veículos de } \\
\text { emergência }\end{array}$ & $\begin{array}{l}1.7 \quad \text { Acesso e Veículos de } \\
\text { emergência }\end{array}$ & $\begin{array}{l}\text { 1.7 Acessos de veículos de } \\
\text { emergência }\end{array}$ \\
\hline & $\begin{array}{l}1.8 \text { Tipos e controle de acesso às } \\
\text { propriedade e desenvovilemento }\end{array}$ & $\begin{array}{l}1.8 \text { Tipos e controle de acesso às } \\
\text { propriedade e desenvovilemento }\end{array}$ & $\begin{array}{l}\text { 1.8 Tipos e controle de acesso às } \\
\text { propriedade e desenvovilemento }\end{array}$ & $\begin{array}{l}\text { 1.8 Acesso e áreas } \\
\text { adjacentes }\end{array}$ \\
\hline & $\begin{array}{l}\text { 1.9 Desenvolvimento urbanos } \\
\text { adjacentes }\end{array}$ & $\begin{array}{l}\text { 1.9 Desenvolvimento urbanos } \\
\text { adjacentes }\end{array}$ & $\begin{array}{l}\text { 1.9 Desenvolvimento urbanos } \\
\text { adjacentes }\end{array}$ & 1.9 ampliações futuras \\
\hline & $\begin{array}{l}\text { 1.10 Expansão e/ou realinhamento } \\
\text { futuro }\end{array}$ & $\begin{array}{l}\text { 1.10 Expansão e/ou realinhamento } \\
\text { futuro }\end{array}$ & $\begin{array}{l}1.10 \text { Expansão e/ou realinhamento } \\
\text { futuro }\end{array}$ & 1.10 Etapas do projeto \\
\hline & 1.11 Etapas de projetos & 1.11 Etapas de projetos & 1.11 Etapas de projetos & 1.11 Manutenção \\
\hline & 1.12 Manutenção & 1.12 Manutenção & 1.12 Manutenção & \\
\hline
\end{tabular}


Quadro 4.9: Mesocategorias do projeto básico - continuação

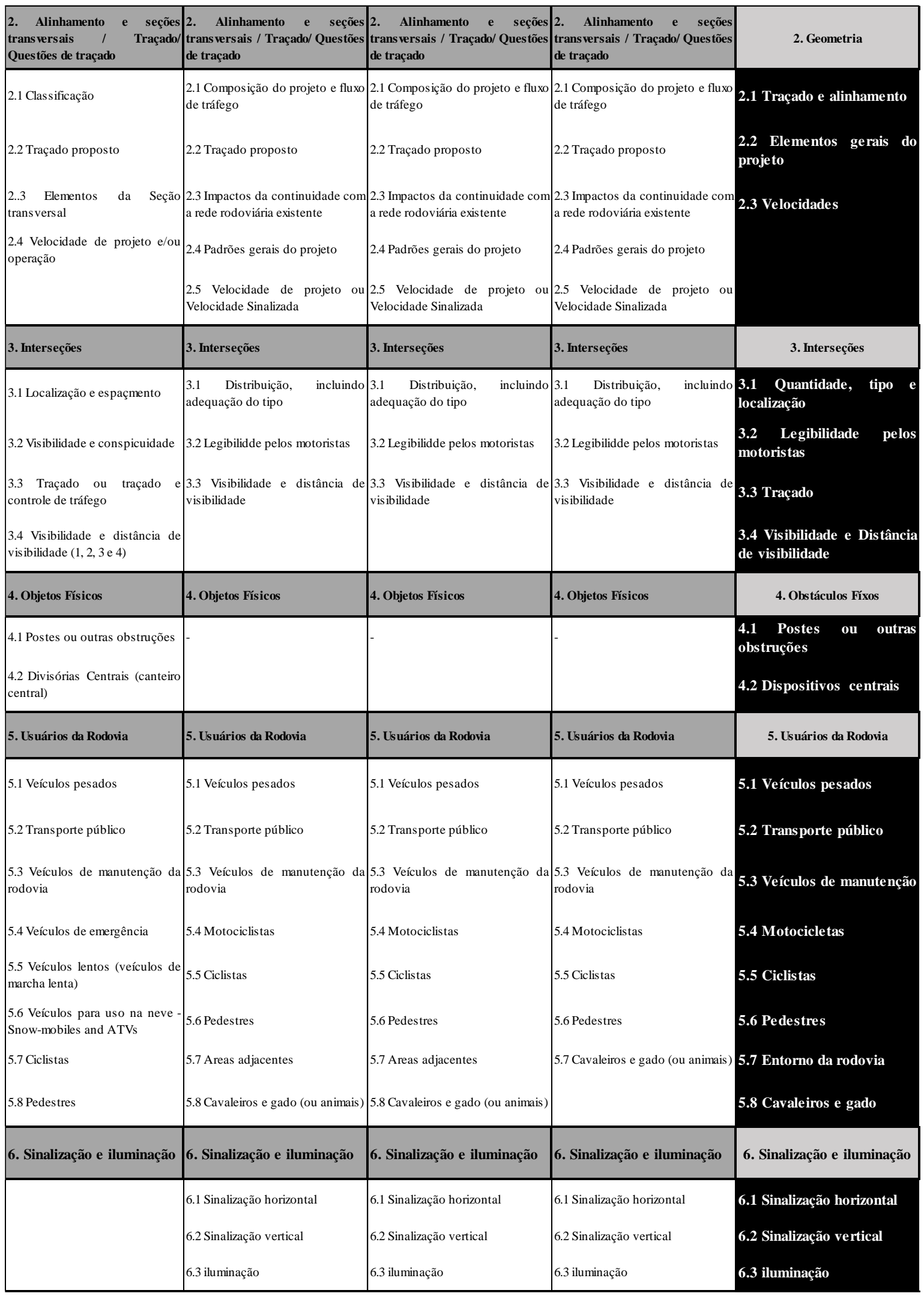


Quadro 4.9: Mesocategorias do projeto básico - continuação

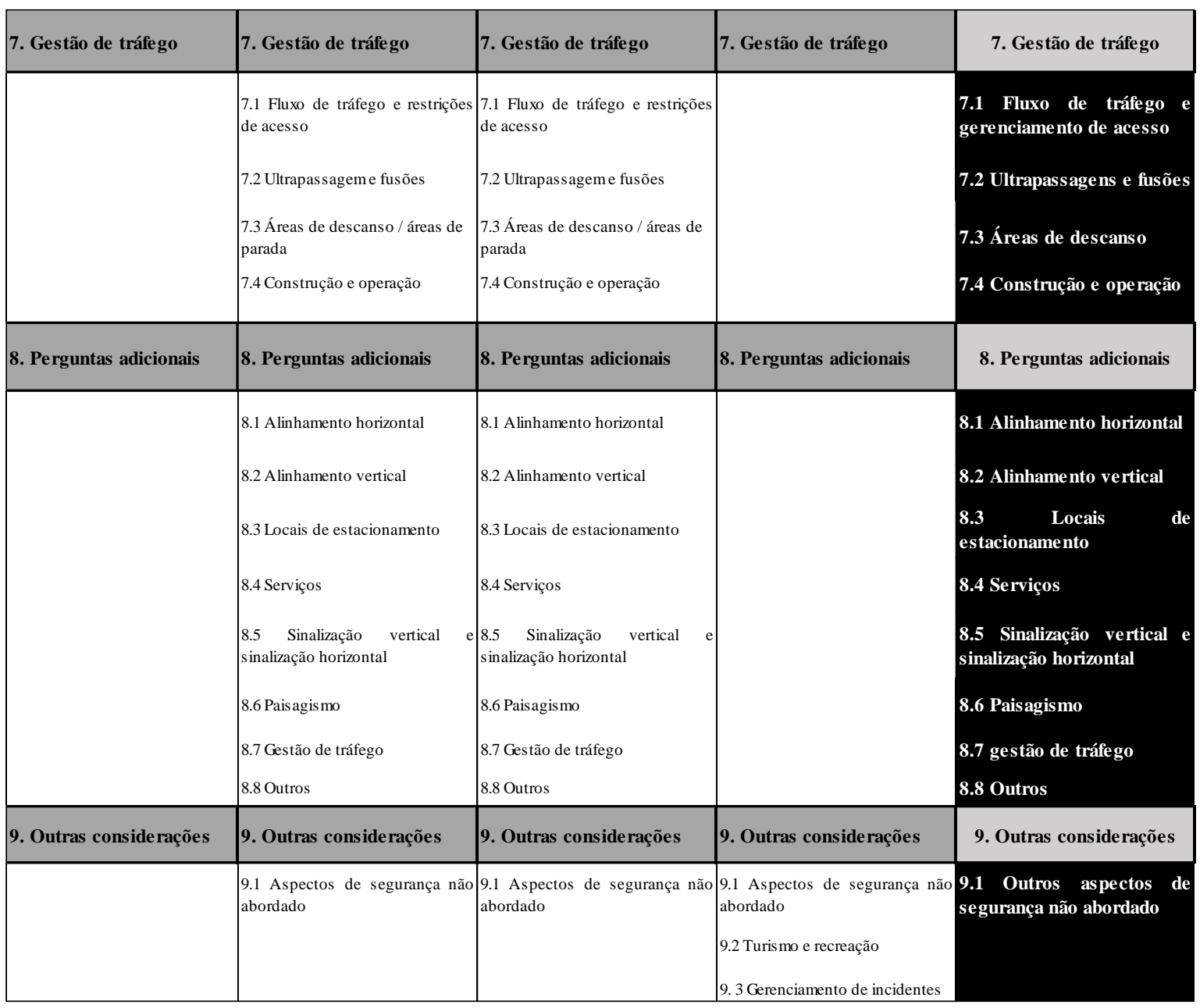

Fonte: Elaborado pela autora, 2015

\subsubsection{Análise comparativa quanto ao conteúdo - Mesocategorias - Instrumento do Projeto executivo}

$\mathrm{Na}$ análise das mesocategorias do projeto executivo identificaram-se algumas particularidades que serão descritas a seguir, além da necessidade de ajustes para compatibilizar e unificar os itens das categorias do instrumento, julgando-se que ficariam mais claros para a compreensão dos auditores. Neste contexto, segue os comentários:

a) Tópicos gerais 
A mesocategoria "acesso a propriedades e desenvolvimento" e "desenvolvimentos adjacentes" abordados por Castrillón e Candia (2003), AUSTROADS (2009) e RTMC (2012) foram agrupados na mesocategoria "acessos e áreas adjacentes".

A mesocategoria "aampliação e realinhamento futuro" de Castrillón e Candia (2003), AUSTROADS (2009) e "futuro planejamento" de RTMC (2012), tratam das mesmas concepções, apenas com denominações diferentes, foram agrupadas na mesocategoria "ampliação futura".

\section{b) Geometria}

Os autores Hildebrand e Wilson (1999) abordou na lista de verificação os itens drenagem, larguras de faixas, acostamentos, inclinação transversal / superelevação, largura do pavimento, como subitem da categoria "alinhamento e seção transversal". Porém, no instrumento proposto foram analisado por meio da frequência separadamente.

Na mesocategoria “alinhamento" dos autores Hildebrand e Wilson (1999) houve a sudivisão, com os itens alinhamento, alinhamento horizontal, alinhamento vertical e combinação do alinhamento vertical e horizontal. No entanto, para a análise de frequência esses itens foram analisados independente da subdivisão dos autores, tendo sido considerados mesocategorias separadas, com base nas demais listas de verificação que abordam dessa forma.

A categoria "elementos da seção transversal" de Hildebrand e Wilsom (1999), Castrillóm e Candia (2003), AUSTROADS (2003) e RTMC (2012) e "efeitos da variação da seção transversal” de Castrillóm e Candia (2003), AUSTROADS (2003) e RTMC (2012) foram agrupados na mesocategoria "elementos da seção transversal".

As categorias "disposição da rodovia" de Castrillón e Candia (2003) e "layout da rodovia" de AUSTROADS (2009) e RTMC (2012) foram agrupados na mesocategoria "detalhes de geometria", devido as microcategorias tratarem das mesmas questões, apenas, com nomes diferentes na mesocategoria. Ainda nesta mesocategoria foi agrupado o "detalhe do projeto geométrico" para melhor identificação dos elementos a serem auditados. 
Os austores Castrillón e Candia (2003), AUSTROADS (2009) e RTMC (2012) abordaram a mesocategoria "drenagem" dentro da macrocategoria "tópicos gerais, e os autores Hildebrand e Wilson (1999) abordaram na macrocategoria 'alinhamento e seções transversais", no entanto, após a análise da frequência das microcategorias, que identificouse que tratavam das mesmas microcategorias, apenas, em macrocategorias diferentes, no instrumento final a mesocategoria "drenagem" foi mantida na macrocategoria "tópicos gerais", com o agrupamento das microcategorias.

c) Interseções

Os autores Castrillón e Candia (2003) abordaram a mesocategora “distribuição", porém ao analisar as microcategorias dessa mesocategoria, identificou-se que tratava dos mesmos itens da mesocategoria "layout” abordada por Hildebrand e Wilson (1999) e RTMC (2012). Assim, foram agrupadas na mesocategoria "quantidade, tipo e localização" do instrumento proposto desta dissertação

Hildebrand e Wilson (1999) na mesocategoria "layout" subdividiram em "manobras e faixas auxiliares", na análise de frequência foram considerados independentes.

d) Usuários da rodovia

$\mathrm{Na}$ análise da frequência das mesocategorias da macrocategoria "Usuários da Rodovia" foi desconsiderada a separação que os autores Hildebrand e Candia (1999) adotaram de “veículos motorizados" e "veículos não motorizados". Ressalta-se que na análise final não houve nenhum prejuízo para a identificação da frequência.

Os autores Hildebrand e Wilson (1999), abordaram "ciclistas e pedestres" como uma única mesocategoria, porém, na análise de frequência foram considerados independentes. Assim, como RTMC (2012) na abordagem de "ciclistas e motociclistas", que foram tratados como mesocategorias independentes na proposta.

Os autores Castrillón e Candia (2003) e AUSTROADS (2009) adotaram como categoria “cavaleiros e gado", para RTMC (2012) adotou "animais", porém na análise da 
mesocategoria identificou que tratavam dos mesmos itens, assim foram agrupados na mesocategoria "travessia de animais na pista".

e) Perguntas adicionais

Os autores Castrillón e Candia (2003), abordoram como mesocategoria "entorno da via" e AUSTROADS (2009) abordou "paisagismo", porém tratam das mesmas microcategorias. Assim, seus elementos foram agrupados na mesocategoria "vegetação no entorno da via".

No Quadro 4.10 contêm as mesocategorias do instrumento preliminar proposto para ser aplicado no projeto executivo.

Quadro 4.10: Mesocategorias da fase do projeto executivo

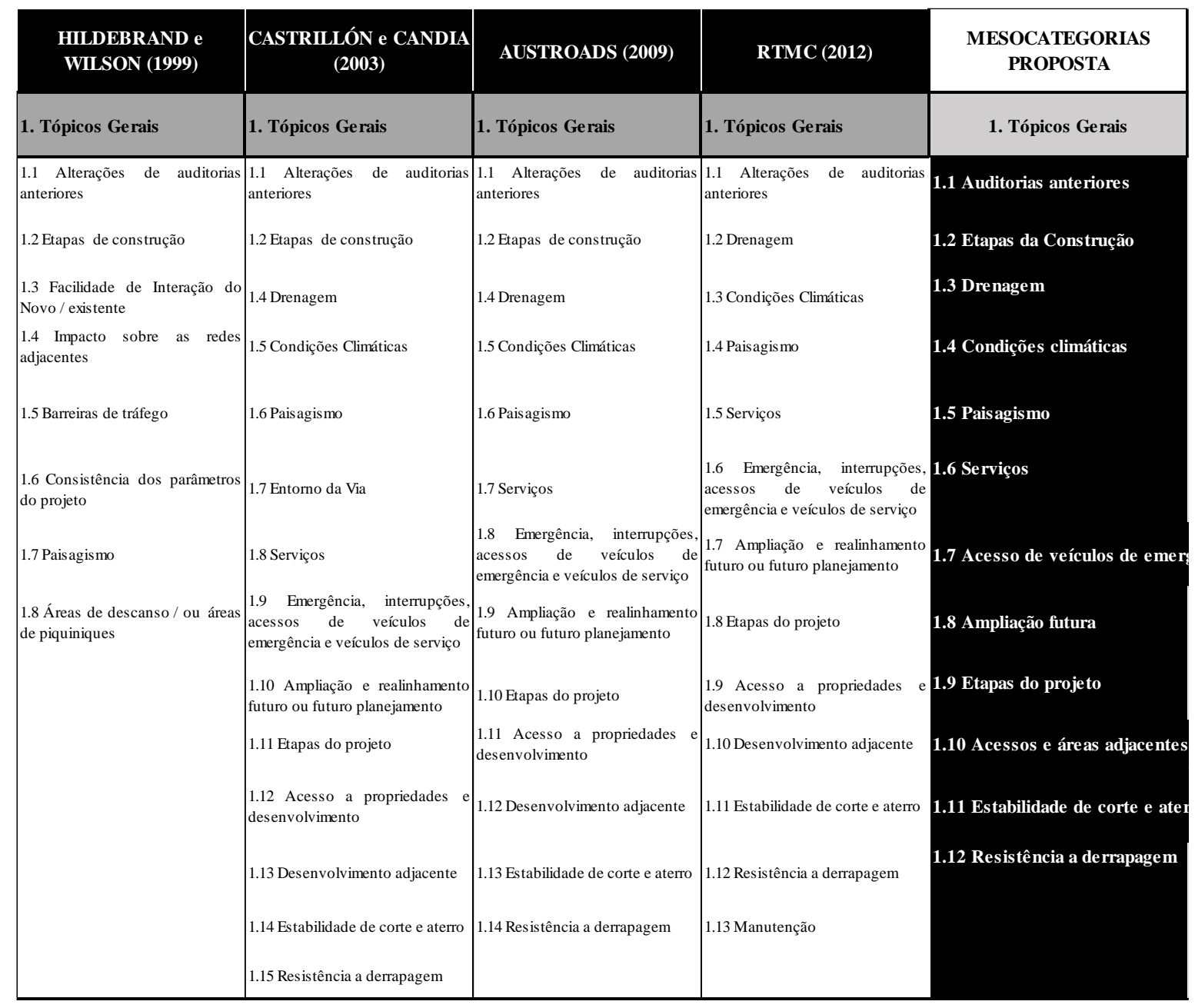


Quadro 4.109: Mesocategorias da fase do projeto executivo - continuação

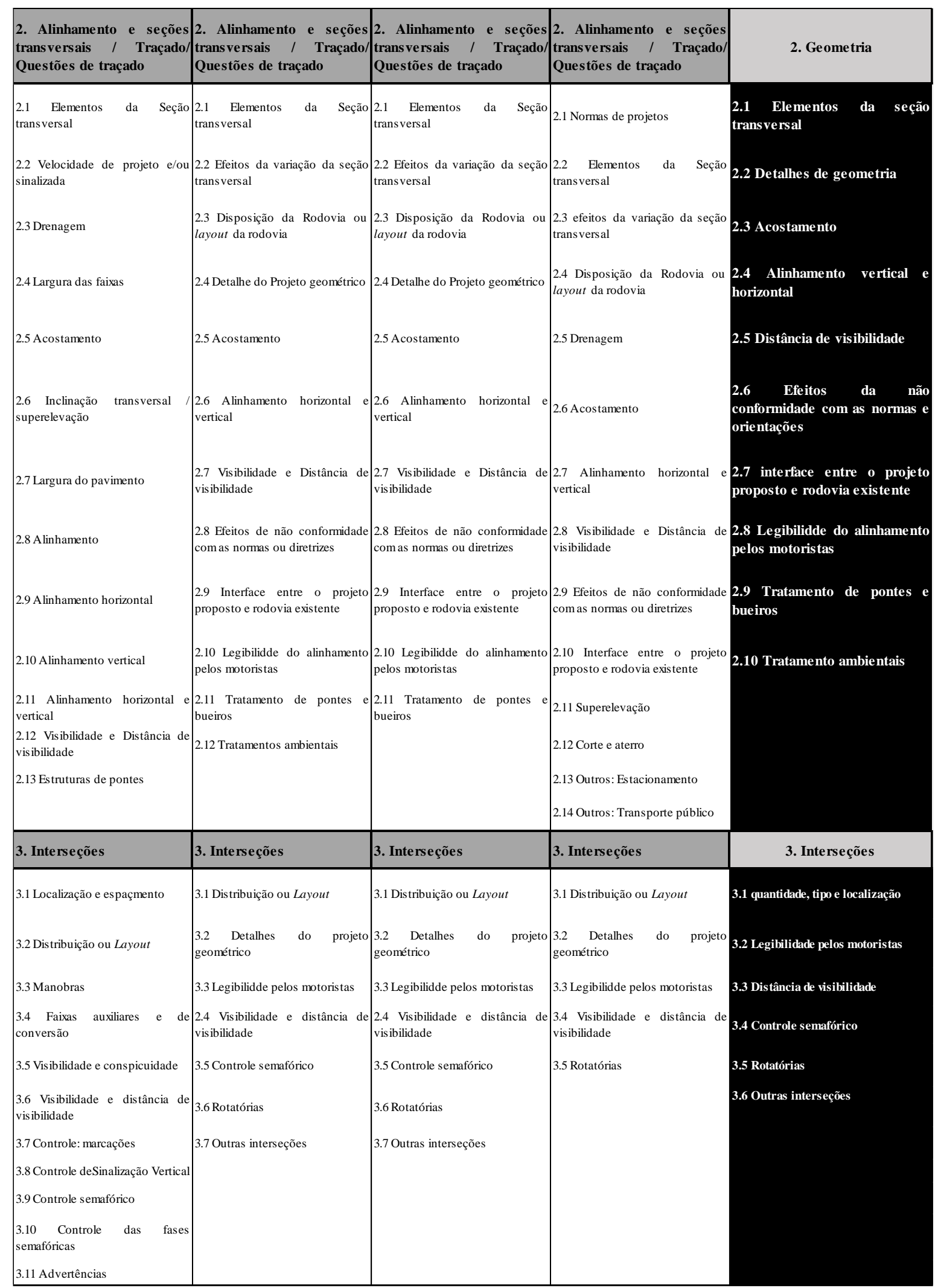


Quadro 4.10: Mesocategorias da fase do projeto executivo - continuação

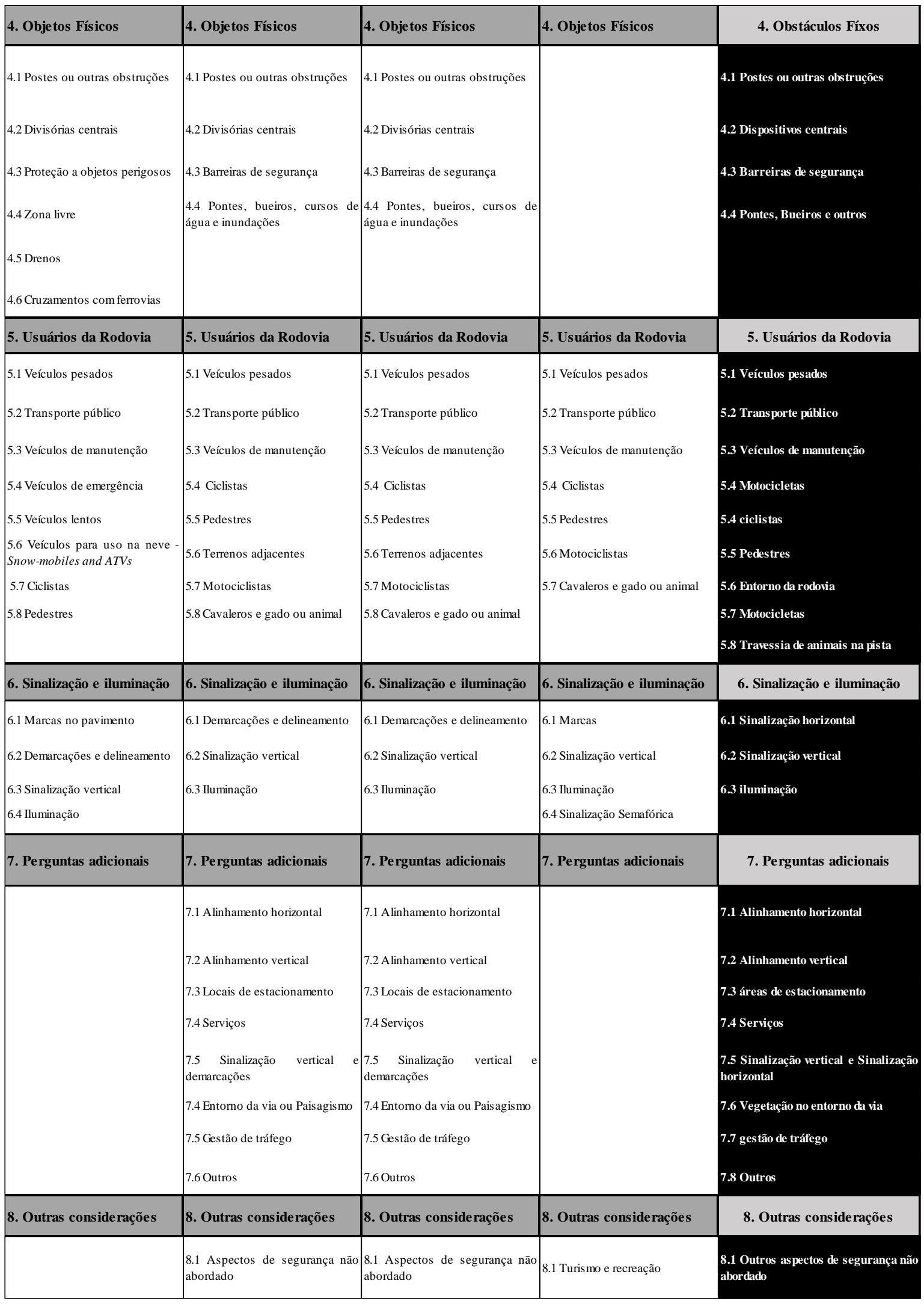

Fonte: Elaborado pela autora, 2015 
4.3.2.7 Análise comparativa quanto ao conteúdo - Microcategorias - Estudo de viabilidade

$\mathrm{Na}$ análise das microcategorias do estudo de viabilidade identificaram-se particularidades que serão descritas a seguir, além da necessidade de adequações para compatibilizar e agrupar os itens das categorias do instrumento, para melhor clareza e compreensão dos auditores.

A definição das microcategorias do instrumento proposto, as quais foram obtidas a partir da comparação da frequência dos elementos viários abordados nas quatro listas de verificação definidas como base desse estudo, foram definidas após a análise das macrocategorias e mesocategorias.

O Quadro 4.11 refere-se à amostra do processo que definiu as microcategorias do instrumento de estudo de viabilidade, em que "tópicos gerais" é macrocategoria, "finalidade do projeto" é mesocategorias do instrumento proposto, e "Qual a função do projeto previsto?" é a microcategoria dos autores pesquisados. Após a análise da macro e da mesocategorias, tem-se a análise da frequência das microcategorias. No Apêndice C1 encontra-se a análise das microcategorias completa.

Quadro 4.11: Representação comparativa da análise das microcategorias

\begin{tabular}{|c|c|c|c|c|c|c|c|}
\hline $\begin{array}{c}\text { Categorias - Macro } \\
\text { e mesocategorias }\end{array}$ & Microcategorias & $\begin{array}{l}\text { Hildebrand e } \\
\text { Wilson (1999) }\end{array}$ & $\begin{array}{c}\text { Castrillón e } \\
\text { Candia (2003) }\end{array}$ & $\begin{array}{l}\text { Austroads } \\
\text { (2009) }\end{array}$ & RTMC (2012) & Frequência & \begin{tabular}{|c|}
$\begin{array}{c}\text { Macrocategoria e } \\
\text { Mesocategoria } \\
\text { Proposta }\end{array}$ \\
\end{tabular} \\
\hline 1. Tópicos Gerais & 1. Tópicos Gerais & \multicolumn{4}{|c|}{ 1. Tópicos Gerais } & Frequência & 1. Tópicos gerais \\
\hline $\begin{array}{l}\text { Aspectos gerais, } \\
\text { funcão e composicão }\end{array}$ & $\begin{array}{l}\text { Qual é a função do } \\
\text { projeto previsto? }\end{array}$ & & $\mathbf{x}$ & $\mathbf{x}$ & $\mathbf{x}$ & $75 \%$ & 1.1 Finalidade \\
\hline
\end{tabular}

Fonte: Elaborado pela autora, 2015.

A definição das microcategorias da fase de estudo de viabilidade, também foi consolidada pela análise comparativa da frequência e adaptações com termos brasileiros.

Segue as particularidades na definição das microcategorias do instrumento de Estudo de Viabilidade: 
a) Tópicos gerais

A microcategoria "verificar toda documentação pertinente do escopo do projeto, destacando os objetivos do projeto, características do usuário, veículos de projetos, projetos de acessos, características das áreas adjacentes, informações de redes existentes e projetos de futuras expansões" de Hildebrand e Wilson (1999) foi agrupado na microcategoria "qual a função do projeto previsto" de Castrillón e Candia (2003), AUSTROADS (2009) e RTMC ((2012).

4.3.2.8 Análise comparativa quanto ao conteúdo - Microcategorias - Instrumento do Projeto básico

A definição das microcategorias da fase de projeto básico, também foi realizada pela análise comparativa da frequência e adaptações com termos de projetos brasileiros.

Segue as particularidades para a definição das microcategorias do projeto básico:

a) Etapas de construção:

A microcategoria “Quais são os efeitos da realização da construção do projeto com um único contrato ou dividindo-a em vários contratos?” de Hildbrand e Wilson (1999), a microcategoria "Se o projeto for ser construído ou implementado em diferentes fases: a) Foram detalhadas adequadamente para garantir a segurança? b) As fases de construção são seguras? c) Existem medidas para acomodar a gestão de tráfego temporário entra as diferentes fases?” e a microcategoria “Se a construção for realizada em vários contratos, eles serão realizados de forma segurança?” de RTMC (2012), foram agrupadas na microcategoria "Se o a construção for realizada em vários etapas (ou contratos), foram detalhadas para garantir a segurança?”.

b) drenagem

A microcategoria "Foi considerada a possibilidade de inundações?" de Hildebrand e Wilson (1999) foi agrupada no item "Foi considerada a possibilidade de inundações da superfície da rodovia, incluindo o transbordamento dos rios e bueiros?”. 
A microcategoria de RTMC (2012) "Há alguma vegetação ou outros efeitos ambientais que dificultam o funcionamento das entradas das drenagens (como por exemplo, cana-de-açúcar bloqueando as entradas)?" é mais apropriado para rodovias em operação. Em função disso foi retirado do instrumento proposto.

\subsubsection{Análise comparativa quanto ao conteúdo - Microcategorias - Projeto executivo}

A definição das microcategorias do instrumento proposto da fase de projeto executivo, também foram consolidadas a partir da análise comparativa da frequência e adaptações com termos de projetos brasileiros.

No Quadro 4.12 é apresentado os itens que não foram abordados devido a frequência ter sido de $25 \%$, conforme critérios definidos no item 4.3.2 desta dissertação. Neste quadro pode identificar as macro, meso e microcategorias não abordada no instrumento de ASV proposto nesta dissertação do estudo de viabilidade.

No Quadro 4.13 é apresentado os itens que não foram abordados no instrumento proposto do projeto Básico, pois apresentou frequência de $25 \%$, conforme critérios definidos no item 4.3.2 desta dissertação.

No Quadro 4.14 é apresentado os itens que não forma abordados no instrumento proposto do projeto executivo, pois apresentou frequência de $25 \%$, conforme os critérios definidos no item 4.3.2 desta dissertação. 
Quadro 4.12: Macro, meso e microcategorias não analisadas - Estudo de viabilidade

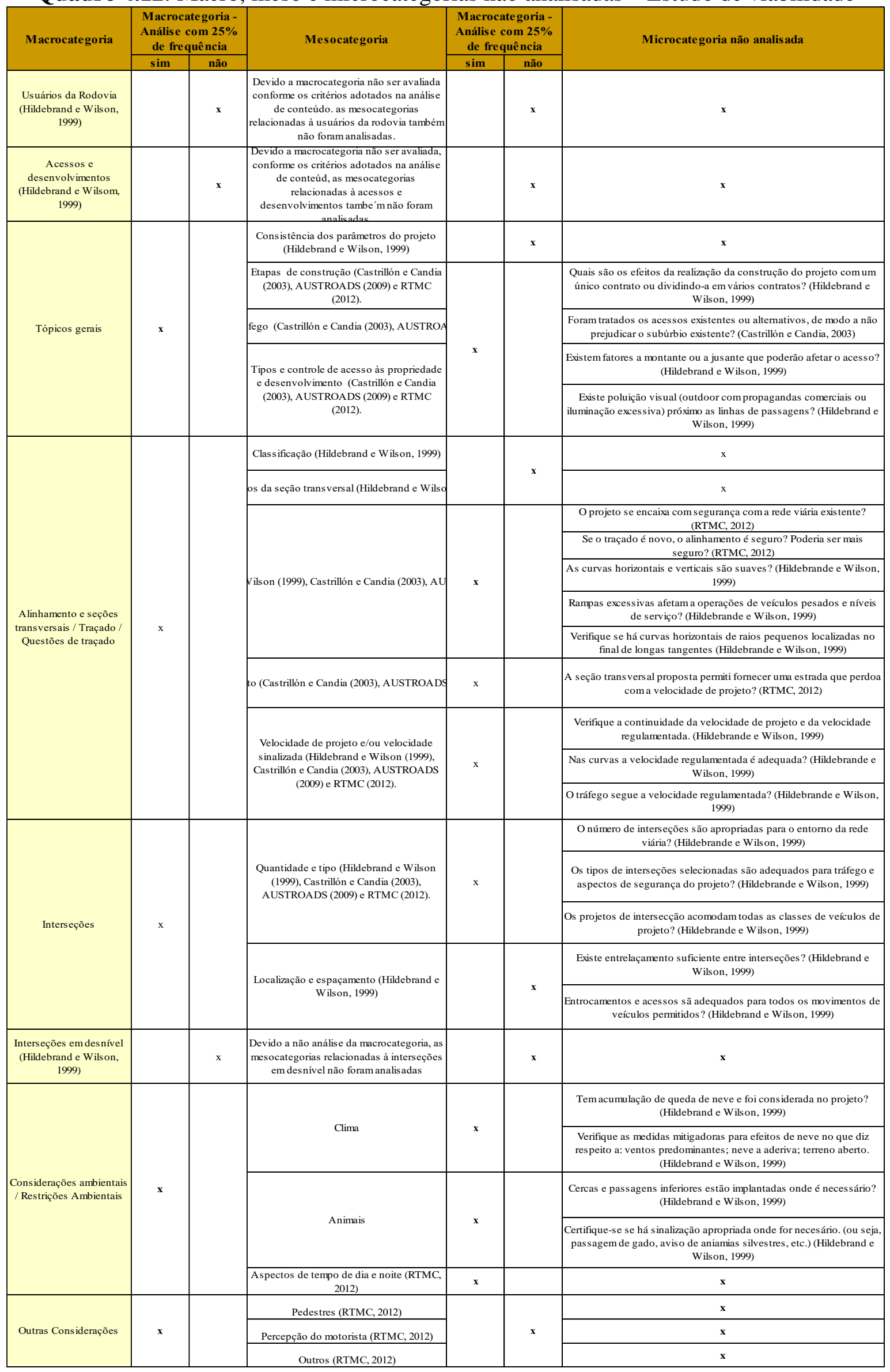


Quadro 4.13: Macro, meso e microcategorias não analisadas - Projeto Básico

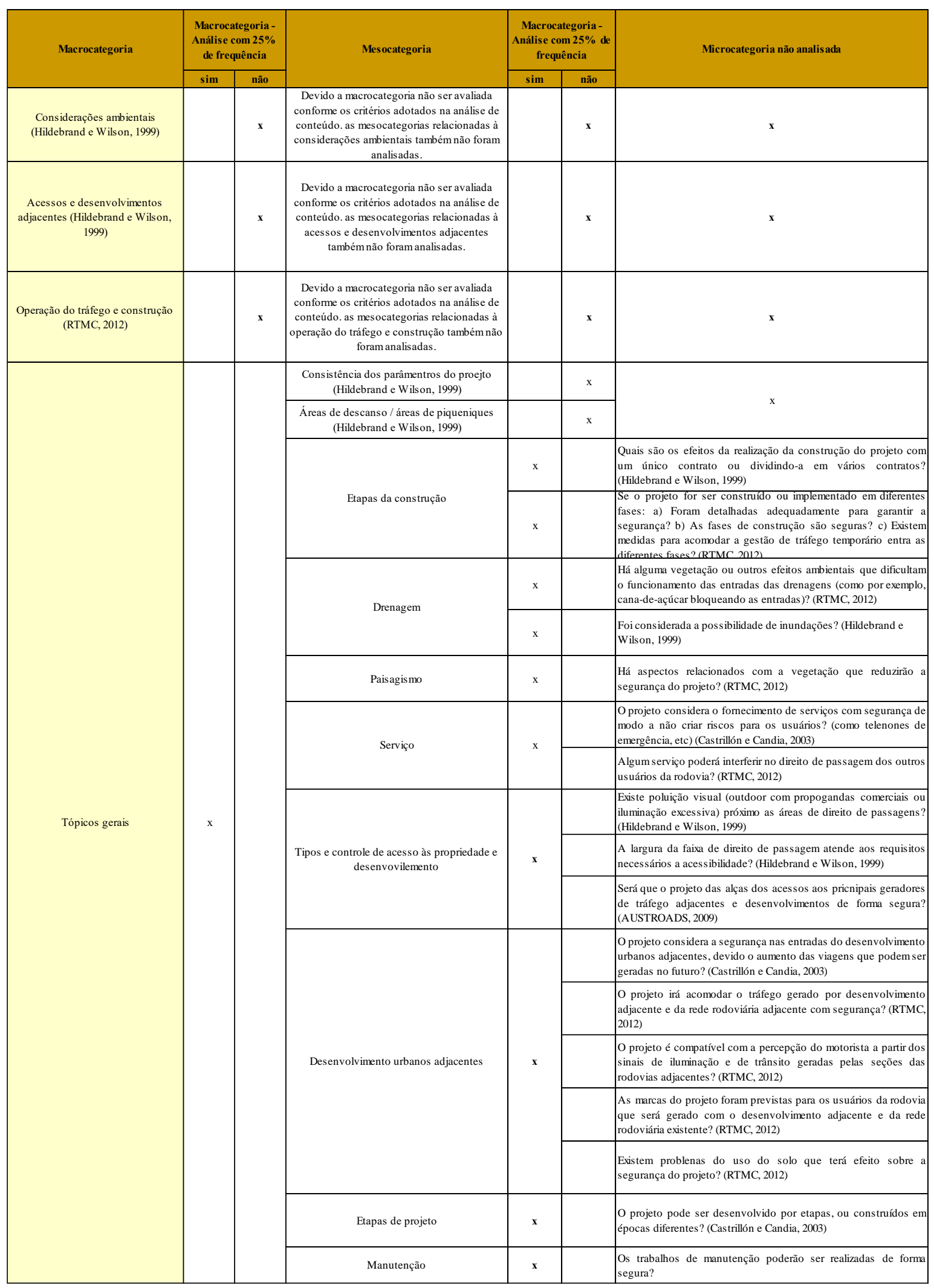


Quadro 4.13: Macro, meso e microcategorias não analisadas - Projeto Básico Continuação

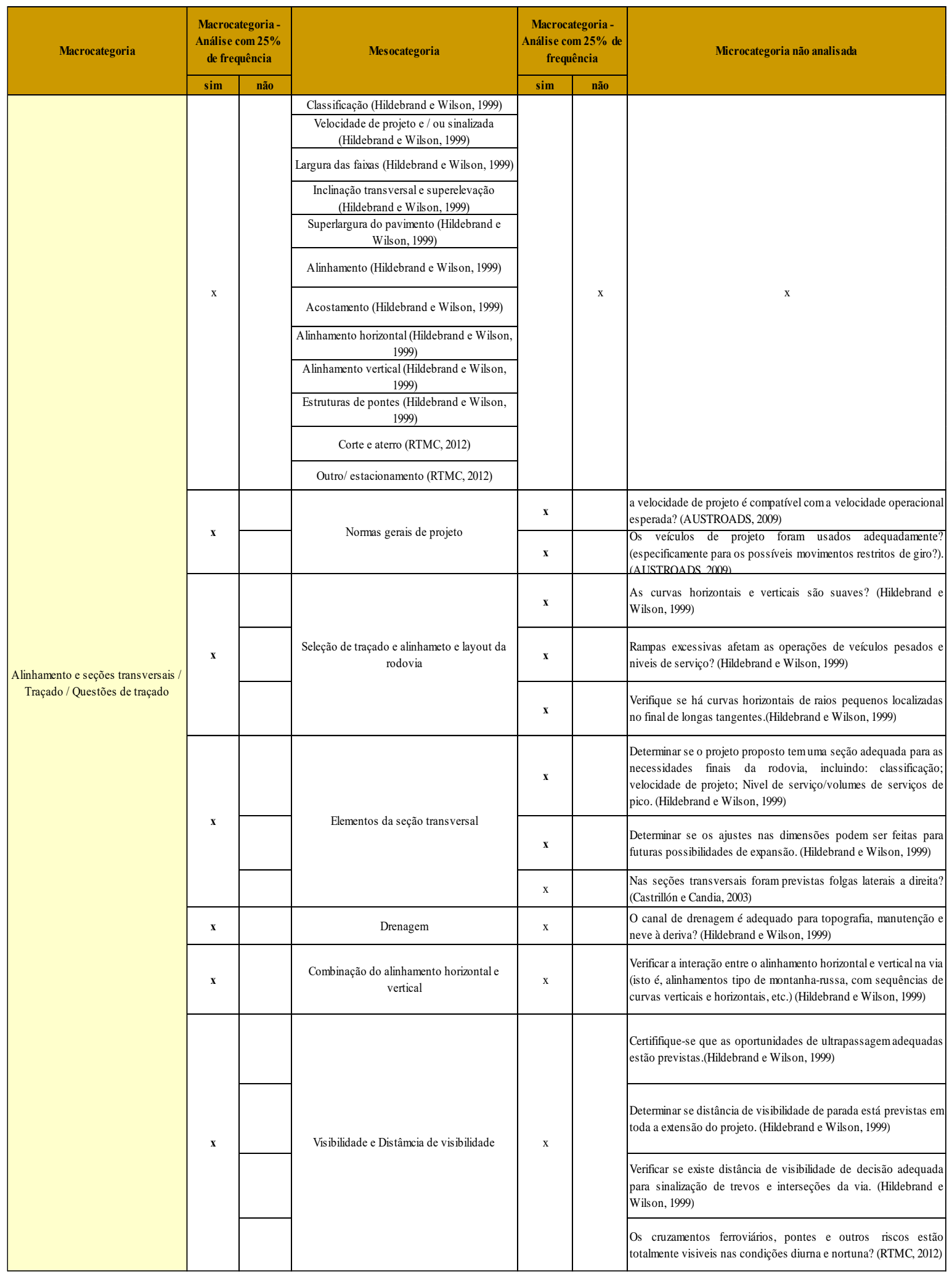


Quadro 4.13: Macro, meso e microcategorias não analisadas - Projeto Básico Continuação

\begin{tabular}{|c|c|c|c|c|c|c|}
\hline \multirow[t]{2}{*}{ Macrocategoria } & \multicolumn{2}{|c|}{$\begin{array}{l}\text { Macrocategoria - } \\
\text { Análise com } 25 \% \\
\text { de frequência }\end{array}$} & \multirow[t]{2}{*}{ Mesocategoria } & \multicolumn{2}{|c|}{$\begin{array}{c}\text { Macrocategoria- } \\
\text { Análise com } 25 \% \text { de } \\
\text { frequência }\end{array}$} & \multirow[t]{2}{*}{ Microcategoria não analisada } \\
\hline & $\operatorname{sim}$ & não & & $\operatorname{sim}$ & não & \\
\hline \multirow{14}{*}{ Interseções } & $\mathrm{x}$ & & $\begin{array}{l}\text { Visiblidade e conspicuidade (Hildebrand e } \\
\text { Wilson, 1999) }\end{array}$ & & $\mathrm{x}$ & $\mathrm{x}$ \\
\hline & $\mathrm{x}$ & & \multirow{3}{*}{ Distribuição, incluindo adequadamente o tipo } & $\mathrm{x}$ & & $\begin{array}{l}\text { O controle do tipo de interseção terá impacto negativo na } \\
\text { segurança dos usuários da rodovia, como: pedestres, usuários } \\
\text { vulneráveis da rodovia, ciclistas e veículos pesados? } \\
\text { 2012) }\end{array}$ \\
\hline & $\mathrm{x}$ & & & $\mathrm{x}$ & & $\begin{array}{l}\text { O controle do tipo de interseção afetará a segurança das } \\
\text { instalaçôs dos serviços de transporte público? (se previstos) } \\
\text { (RTMC, 2012) }\end{array}$ \\
\hline & $\mathrm{x}$ & & & $\mathrm{x}$ & & $\begin{array}{l}\text { O projeto prever o uso do tipo de veículo de projeto que irá usar a } \\
\text { interseç̃ô? (por exemplo, mudança de raios, larguras das faixas, } \\
\text { etc;) (RTMC, 2012) }\end{array}$ \\
\hline & $\mathrm{x}$ & & \multirow{5}{*}{ Legibilidade para os motoristas } & \multirow{5}{*}{$\mathrm{x}$} & & $\begin{array}{l}\text { Interseções sucessivas pode violar a expectativa do motoristas } \\
\text { por causas de inconsistências? (RTMC, 2012) }\end{array}$ \\
\hline & $\mathrm{x}$ & & & & & $\begin{array}{l}\text { O motorista tem tempo suficiente para perceber situaçōes futuras e } \\
\text { decidir por açōes necessárias de forma segura? (RTMC, 2012) }\end{array}$ \\
\hline & $\mathrm{x}$ & & & & & O projeto das interseções prevê decisões erradas? (RTMC, 2012) \\
\hline & $\mathrm{x}$ & & & & & $\begin{array}{l}\text { Será que a experiência do motorista lida com ofuscamento do a luz } \\
\text { dos veículos no sentido contrário ou iluminação rodoviária:? } \\
\text { (RTMC, 2012) }\end{array}$ \\
\hline & $\mathrm{x}$ & & & & & $\begin{array}{l}\text { Nas interseções o motorista poderá ser exposto na escuridão } \\
\text { repentina? (RTMC, 2012) }\end{array}$ \\
\hline & $\mathrm{x}$ & & Localização e espaçamento & & $\mathrm{x}$ & $\mathrm{x}$ \\
\hline & $\mathrm{x}$ & & Desenho (Layout) & $\mathrm{x}$ & & $\begin{array}{l}\text { A largura das faixas é adequada para todos as classes de } \\
\text { veículos? (Hildebrand e Wilson, 1999) } \\
\begin{array}{l}\text { Separação entre as faixas é necessária mas não provida? } \\
\text { (Hildebrand e Wilson, 1999) }\end{array} \\
\end{array}$ \\
\hline & \multirow{3}{*}{$\mathrm{x}$} & & \multirow{3}{*}{ Visibilidade e Distância de visibilidade } & \multirow{3}{*}{$\mathrm{x}$} & & $\begin{array}{l}\text { Todas as dist âncias de visibilidade estão adequadas para todos os } \\
\text { movimentos e usuários da rodovia? (Hildebrand e Wilson, 1999) }\end{array}$ \\
\hline & & & & & & $\begin{array}{l}\text { As linhas de visibilidade podem ser temporariamente obstruídas } \\
\text { por veículos estacionamentos, acúmulo de neve, vegetação } \\
\text { sazonal, etc? (Hildebrand e Wilson, 1999) }\end{array}$ \\
\hline & & & & & & $\begin{array}{l}\text { Greides nas interseções permitem uma distância de visibilidade } \\
\text { desejável? (Hildebrand e Wilson 1999). }\end{array}$ \\
\hline Interseções em desnível & & $\mathrm{x}$ & $\begin{array}{l}\text { Devido a macrocategoria não ser avaliada } \\
\text { conforme os critérios adotados na análise de } \\
\text { conteúdo. as mesocategorias relacionadas à } \\
\text { interseção e desnível também não foram } \\
\text { analisadas. }\end{array}$ & & $\mathrm{x}$ & $\mathrm{x}$ \\
\hline \multirow{20}{*}{ Usuários da rodovia } & $\mathrm{x}$ & & Veículos de emergência & & $\mathrm{x}$ & \multirow{3}{*}{$\mathrm{x}$} \\
\hline & $\mathrm{x}$ & & Veículos lentos (Hildebrand e Wilson, 1999) & & $\mathrm{x}$ & \\
\hline & $\mathrm{x}$ & & $\begin{array}{c}\text { Veículos para uso na neve - Snow- mobiles - } \\
\text { ATVs } \\
\end{array}$ & & $\mathrm{x}$ & \\
\hline & \multirow{7}{*}{$\mathrm{x}$} & & \multirow{7}{*}{ Veículos pesados e transporte público } & \multirow{7}{*}{$\mathrm{x}$} & \multirow{7}{*}{ 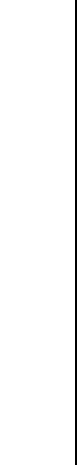 } & $\begin{array}{l}\text { Existe sinalização adequada para as atividades de veículos } \\
\text { pesados / transporte público? (Hildebrand e Wilson, 1999) }\end{array}$ \\
\hline & & & & & & $\begin{array}{l}\text { O projeto prever as limitaç̃oes de veículos pesados? (por exemplo, } \\
\text { nas distâncias de paradas, etc). (RTMC, 2012) }\end{array}$ \\
\hline & & & & & & $\begin{array}{l}\text { O projeto considera as seções transversais seguras para os } \\
\text { veículos pesados? (RTMC, 2012) }\end{array}$ \\
\hline & & & & & & \begin{tabular}{|l|} 
No terrenos montanhosos, as instalações de escape necessária no \\
projeto? São projetadas ou pode haver modificação no projeto \\
para eliminar se necessário? (RTMC, 2012)
\end{tabular} \\
\hline & & & & & & $\begin{array}{l}\text { Há áreas de descando projetadas? Se planejado, podem ser usadas } \\
\text { comseguranç? (RTMC, 2012) }\end{array}$ \\
\hline & & & & & & $\begin{array}{l}\text { São seguras as instalaçẽes de carregamento dos veículos pesados } \\
\text { com segurança? (RTMC, 2012) }\end{array}$ \\
\hline & & & & & & $\begin{array}{l}\text { Há previsão para as manobras seguras dos veículos pesados } \\
\text { quando necessárias? (RTMC, 2012) }\end{array}$ \\
\hline & $\mathrm{x}$ & & Transporte público & $\mathrm{x}$ & & \begin{tabular}{|l|} 
Há previsão para a circulacão segura dos pedestres, que usam os \\
serviços do transporte público? (por exemplo, espaços suficientes \\
para os passageiros que descem dos ônibus?) (RTMC, 2012)
\end{tabular} \\
\hline & $\mathrm{x}$ & & $\begin{array}{l}\text { Veículos de manutenção e veículos de } \\
\text { emergência }\end{array}$ & $\mathrm{x}$ & & $\begin{array}{l}\text { As divisórias centrais e cruzamentos estão visíveis e em locais } \\
\text { adequados para estes veículos? (Hildebrand e Wilson, 1999) }\end{array}$ \\
\hline & $\mathrm{x}$ & & Motociclista & $\mathrm{x}$ & & \begin{tabular}{|l} 
Foram levadas em consideração as necessidades dos \\
motociclistas? (RTMC, 2012)
\end{tabular} \\
\hline & \multirow{3}{*}{$\mathrm{x}$} & & \multirow{3}{*}{ Ciclista e pedestre } & \multirow{3}{*}{$\mathrm{x}$} & & $\begin{array}{l}\text { Os acostamentos possuem larguras suficientes para acomodar } \\
\text { ciclistas / pedestres onde são necessários? (Hildebrand e Wilson, } \\
\text { 1999) }\end{array}$ \\
\hline & & & & & & $\begin{array}{l}\text { acostamento / passeios estão previstos nas pontes? (Hildebrand e } \\
\text { Wilson, 1999) }\end{array}$ \\
\hline & & & & & & $\begin{array}{l}\text { o acumulo de neve prejudica o acesso ou a visibilidade dos } \\
\text { pedestres? (Hildebrand e Wilson, 1999) }\end{array}$ \\
\hline & \multirow{4}{*}{$\mathrm{x}$} & & & & & O projeto é seguro para os pedestres? (RTMC, 2012) \\
\hline & & & & & & $\begin{array}{l}\text { As travessias de pedestres foram consideradas ao longo das } \\
\text { linhas de desejo? (RTMC, 2012) }\end{array}$ \\
\hline & & & Pedestre & $\mathrm{x}$ & & $\begin{array}{l}\text { Onde houve alaargamento das faixas foi previsto o movimento dos } \\
\text { pedestres, e os pedestres poderá utilizar com segurança? (RTMC, } \\
\text { 2012) }\end{array}$ \\
\hline & & & & & & $\begin{array}{l}\text { A velocidade operacional esperada é apropriada para as } \\
\text { instalaçỗes fornecidas aos pedestres? (RTMC, 2012) }\end{array}$ \\
\hline
\end{tabular}




\section{Quadro 4.13: Macro, meso e microcategorias não analisadas - Projeto Básico - Continuação}

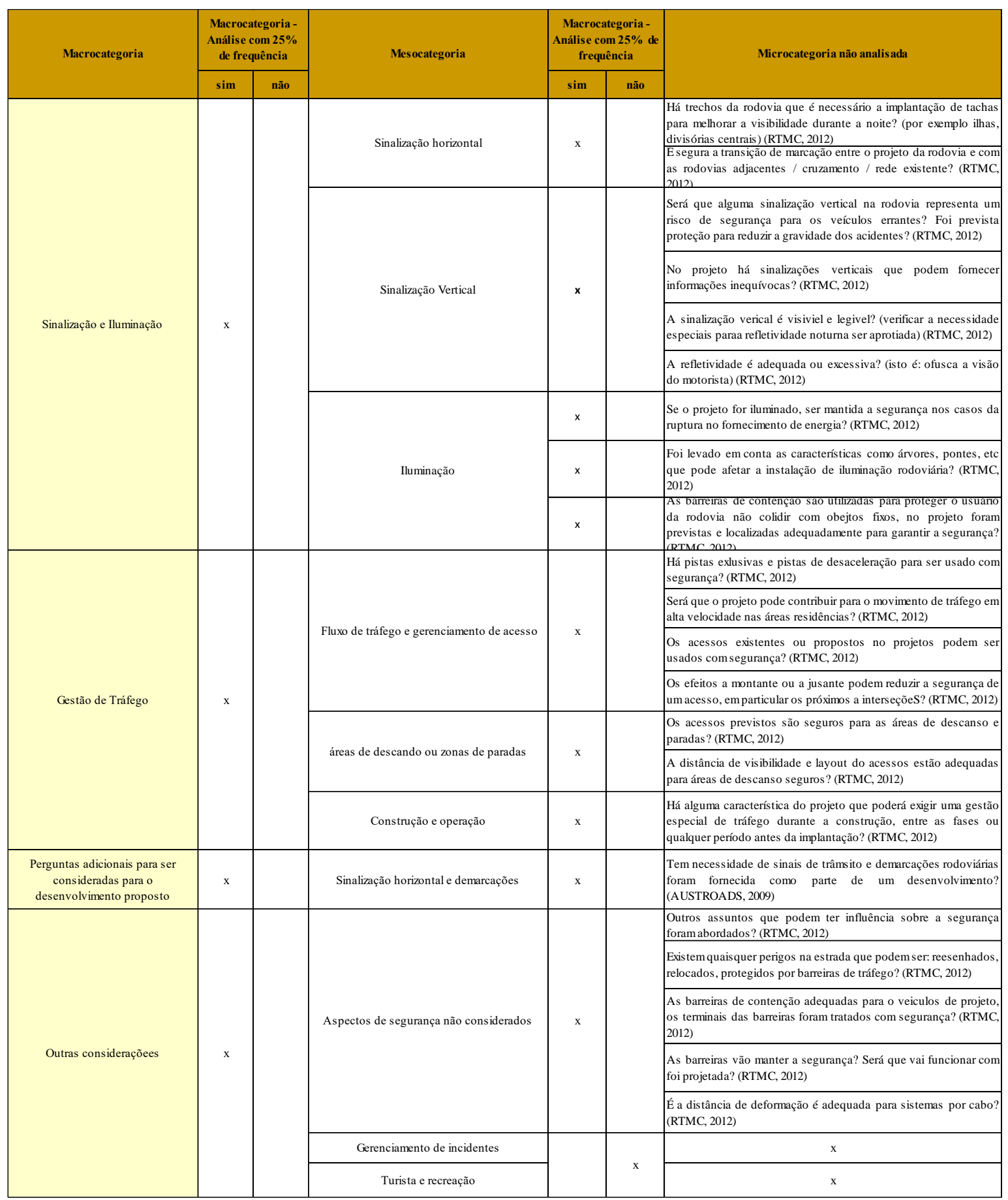


Quadro 4.14: Macro, meso e microcategorias não analisadas - Projeto Executivo

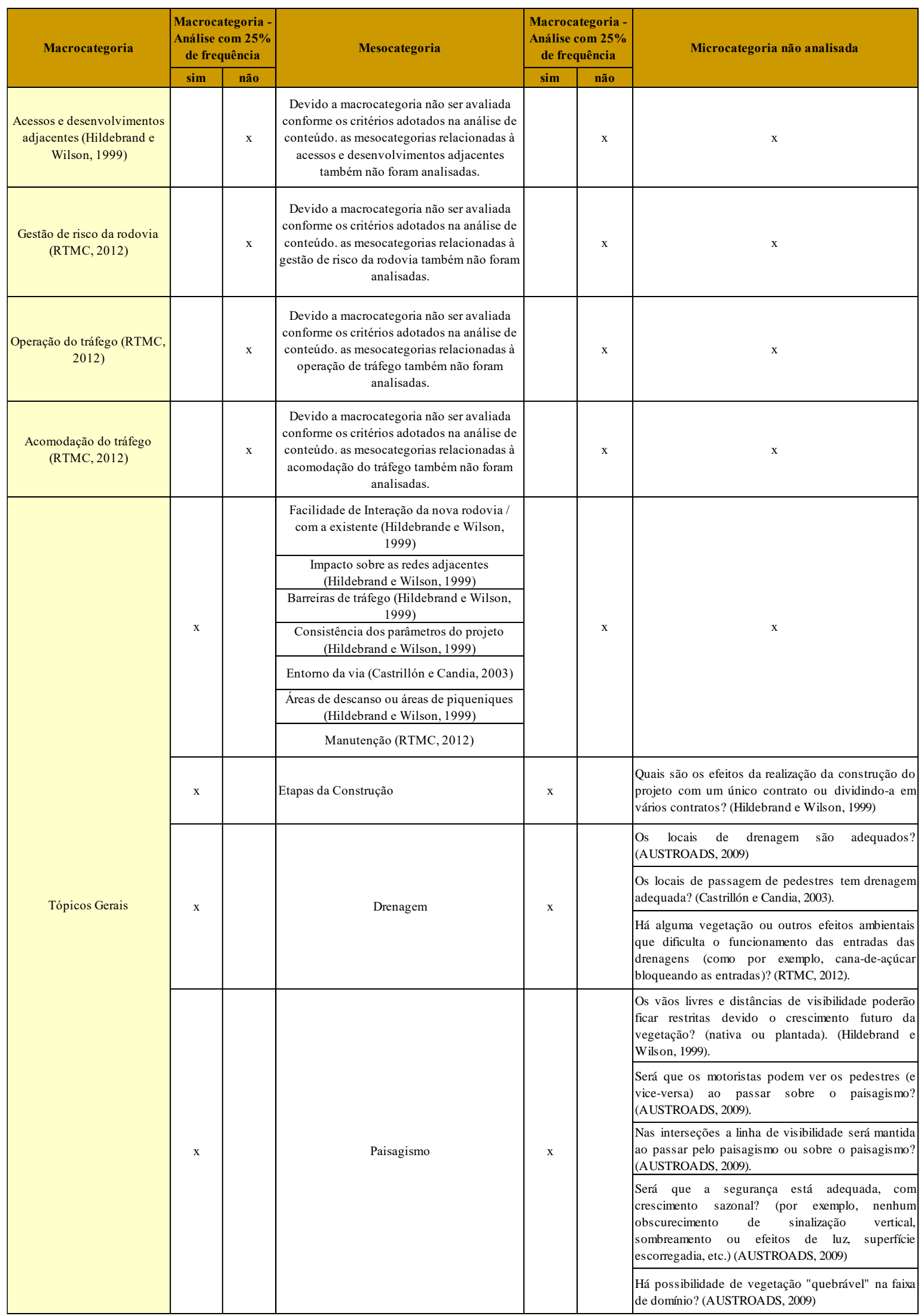




\section{Quadro 4.14: Macro, meso e microcategorias não analisadas - Projeto Executivo - continuação}

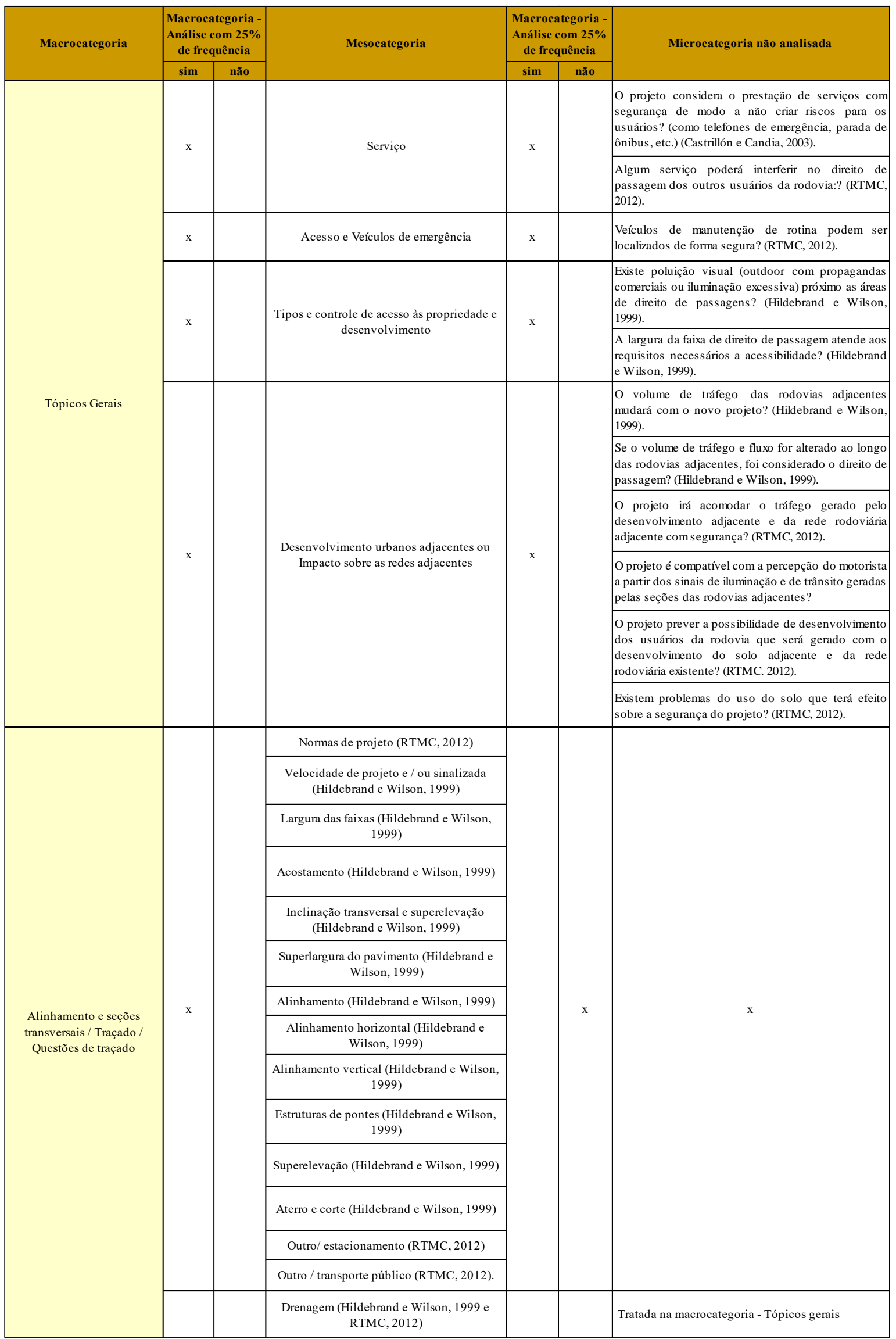




\section{Quadro 4.14: Macro, meso e microcategorias não analisadas - Projeto Executivo - continuação}

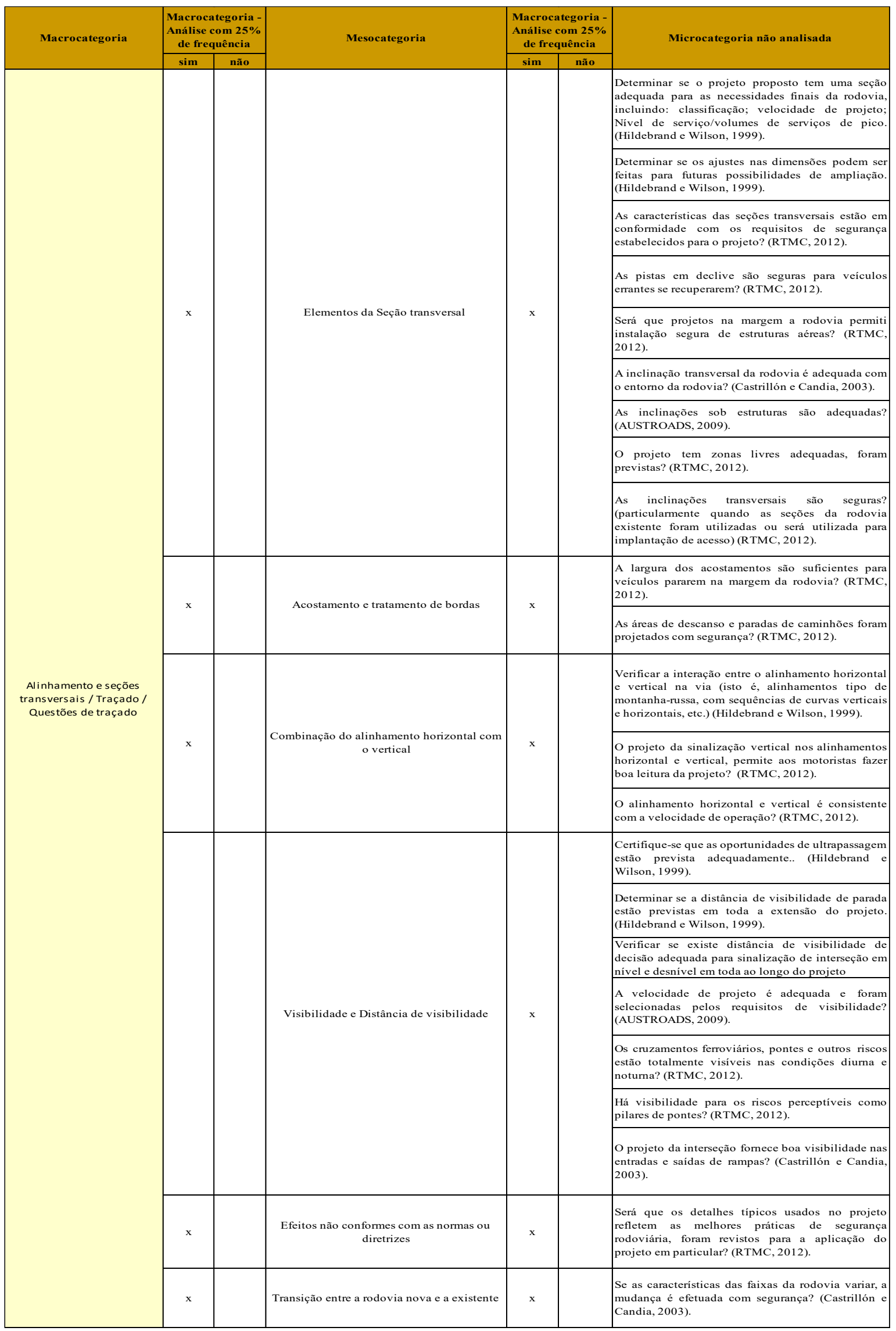




\section{Quadro 4.14: Macro, meso e microcategorias não analisadas - Projeto Executivo - continuação}

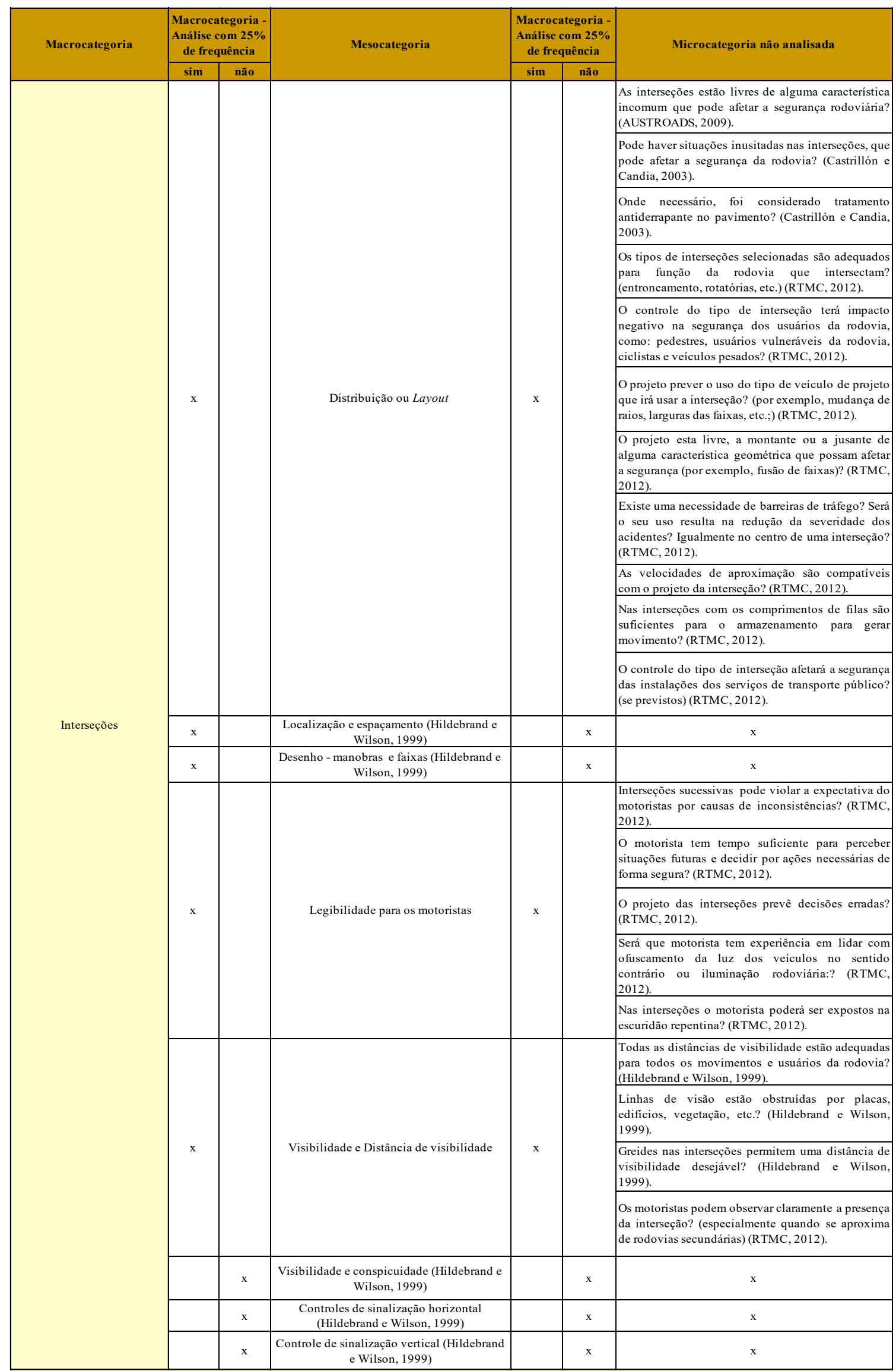




\section{Quadro 4.14: Macro, meso e microcategorias não analisadas - Projeto Executivo - continuação}

\begin{tabular}{|c|c|c|c|c|c|c|}
\hline \multirow[t]{2}{*}{ Macrocategoria } & \multicolumn{2}{|c|}{$\begin{array}{l}\text { Macrocategoria - } \\
\text { Análise com } 25 \% \\
\text { de frequência }\end{array}$} & \multirow[t]{2}{*}{ Mesocategoria } & \multicolumn{2}{|c|}{$\begin{array}{l}\text { Macrocategoria - } \\
\text { Análise com } 25 \% \\
\text { de frequência }\end{array}$} & \multirow[t]{2}{*}{ Microcategoria não analisada } \\
\hline & sim & não & & $\operatorname{sim}$ & não & \\
\hline \multirow{9}{*}{ Interseções } & \multirow{6}{*}{$\mathrm{x}$} & & \multirow{6}{*}{ Controle das fases semafóricas } & \multirow{6}{*}{$\mathrm{x}$} & & $\begin{array}{l}\text { Existem semáforos/painéis/protetores de alta } \\
\text { intensidade onde pode haver problemas com nascer } \\
\text { ou pôr-do-sol? (Hildebrand e Wilson, 1999). }\end{array}$ \\
\hline & & & & & & $\begin{array}{l}\text { Verificar a localização e o número de semáforos. } \\
\text { Eles estão visíveis? (Hildebrand e Wilson, 1999). }\end{array}$ \\
\hline & & & & & & $\begin{array}{l}\text { Verifique se os semáforos de vias adjacentes não } \\
\text { afetem a percepcão dos motoristas da via. } \\
\text { (Hildebrand e Wilson, 1999). }\end{array}$ \\
\hline & & & & & & $\begin{array}{l}\text { Os semáforos primários e secundários estão } \\
\text { instalados apropriadamente? (Hildebrand e Wilson, } \\
\text { 1999). }\end{array}$ \\
\hline & & & & & & 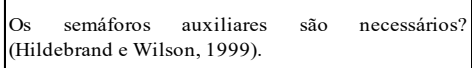 \\
\hline & & & & & & $\begin{array}{l}\text { São previstas mudanças de fases quando necessária? } \\
\text { (Castrillón e Candia, 2003). }\end{array}$ \\
\hline & & $\mathrm{x}$ & $\begin{array}{l}\text { Controles das fases dos semáforos } \\
\text { (Hildebrand e Wilson, 1999) }\end{array}$ & & $\mathrm{x}$ & $\mathrm{x}$ \\
\hline & & $\mathrm{x}$ & Advertências (Hildebrand e Wilson, 1999) & & $\mathrm{x}$ & $\mathrm{x}$ \\
\hline & $\mathrm{x}$ & & Rotatórias & $\mathrm{x}$ & & $\begin{array}{l}\text { Onde foi proposto rotatória, foram considerados os } \\
\text { movimentos dos ciclistas e os movimentos dos } \\
\text { pedestres, as faixas são suficientes? (RTMC, 2012). }\end{array}$ \\
\hline $\begin{array}{l}\text { Interseções em desnível } \\
\text { (Hildebrand e Wilson, 1999) }\end{array}$ & & $\mathrm{x}$ & \begin{tabular}{|c|} 
Devido a não análise da macrocategoria, as \\
mesocategorias relacionadas à interseções em \\
desnível não foram analisadas
\end{tabular} & & $\mathrm{x}$ & $\mathrm{x}$ \\
\hline \multirow{14}{*}{ Objetos Físicos } & \multirow[b]{2}{*}{$\mathrm{x}$} & & \multirow[b]{2}{*}{ Postes e outras obstruções } & \multirow[b]{2}{*}{$\mathrm{x}$} & & $\begin{array}{l}\text { As larguras dos canteiros centrais não protegidos são } \\
\text { apropriadas para os postes de iluminação? } \\
\text { (Hildebrand e Wilson, 1999). }\end{array}$ \\
\hline & & & & & & $\begin{array}{l}\text { Foi considerada localização de serviços e outras } \\
\text { utilidades em relação ao projeto (ou seja, enterrado } \\
\text { ou subterrâneo) como vão para cabos aéreos? } \\
\text { (Hildebrand e Wilson, 1999). }\end{array}$ \\
\hline & \multirow{8}{*}{$\mathrm{x}$} & & \multirow{8}{*}{ Divisórias centrais } & \multirow{8}{*}{$\mathrm{x}$} & & $\begin{array}{l}\text { O tipo de divisória central selecionado é apropriado } \\
\text { para a largura disponível? (Hildebrand e Wilson, } \\
\text { 1999). }\end{array}$ \\
\hline & & & & & & $\begin{array}{l}\text { As barreiras possuem configuração geométrica } \\
\text { adequada? (Hildebrand e Wilson, 1999). }\end{array}$ \\
\hline & & & & & & $\begin{array}{l}\text { As inclinações dos canteiros de grama estão } \\
\text { adequadas? (Hildebrand e Wilson, 1999). }\end{array}$ \\
\hline & & & & & & $\begin{array}{l}\text { As barreiras centrais estão suficientemente afastadas } \\
\text { da rodovia? (Hildebrand e Wilson, 1999). }\end{array}$ \\
\hline & & & & & & $\begin{array}{l}\text { O afastamento entre as barreiras centrais está dentro } \\
\text { dos limites corretos? (Hildebrand e Wilson, 1999). }\end{array}$ \\
\hline & & & & & & $\begin{array}{l}\text { As barreiras laterais e das pontes estão de acordo } \\
\text { com o nível de desempenho dos testes de impacto } \\
\text { para a classificação da rodovia? (Hildebrand e } \\
\text { Wilson, 1999). }\end{array}$ \\
\hline & & & & & & $\begin{array}{l}\text { Existe largura suficiente para pilares dos viadutos, } \\
\text { passagem subterrânea e iluminação? (Hildebrand e } \\
\text { Wilson, 1999). }\end{array}$ \\
\hline & & & & & & $\begin{array}{l}\text { Verificar o espaçamento apropriado entre travessias } \\
\text { de divisórias centrais? (Hildebrand e Wilson, 1999). }\end{array}$ \\
\hline & \multirow{4}{*}{$\mathrm{x}$} & & \begin{tabular}{|c|} 
Proteção de objetos perigosos (Hildebrand e \\
Wilson, 1999)
\end{tabular} & & \multirow{4}{*}{$\mathrm{x}$} & $\mathrm{x}$ \\
\hline & & & Zona livre (Hildebrand e Wilson, 1999) & & & $\mathrm{x}$ \\
\hline & & & Bueiros (Hildebrand e Wilson, 1999) & & & $\mathrm{x}$ \\
\hline & & & $\begin{array}{c}\text { Cruzamentos com ferrovias (Hildebrand e } \\
\text { Wilson, 1999) }\end{array}$ & & & $\mathrm{x}$ \\
\hline
\end{tabular}




\section{Quadro 4.14: Macro, meso e microcategorias não analisadas - Projeto Executivo - continuação}

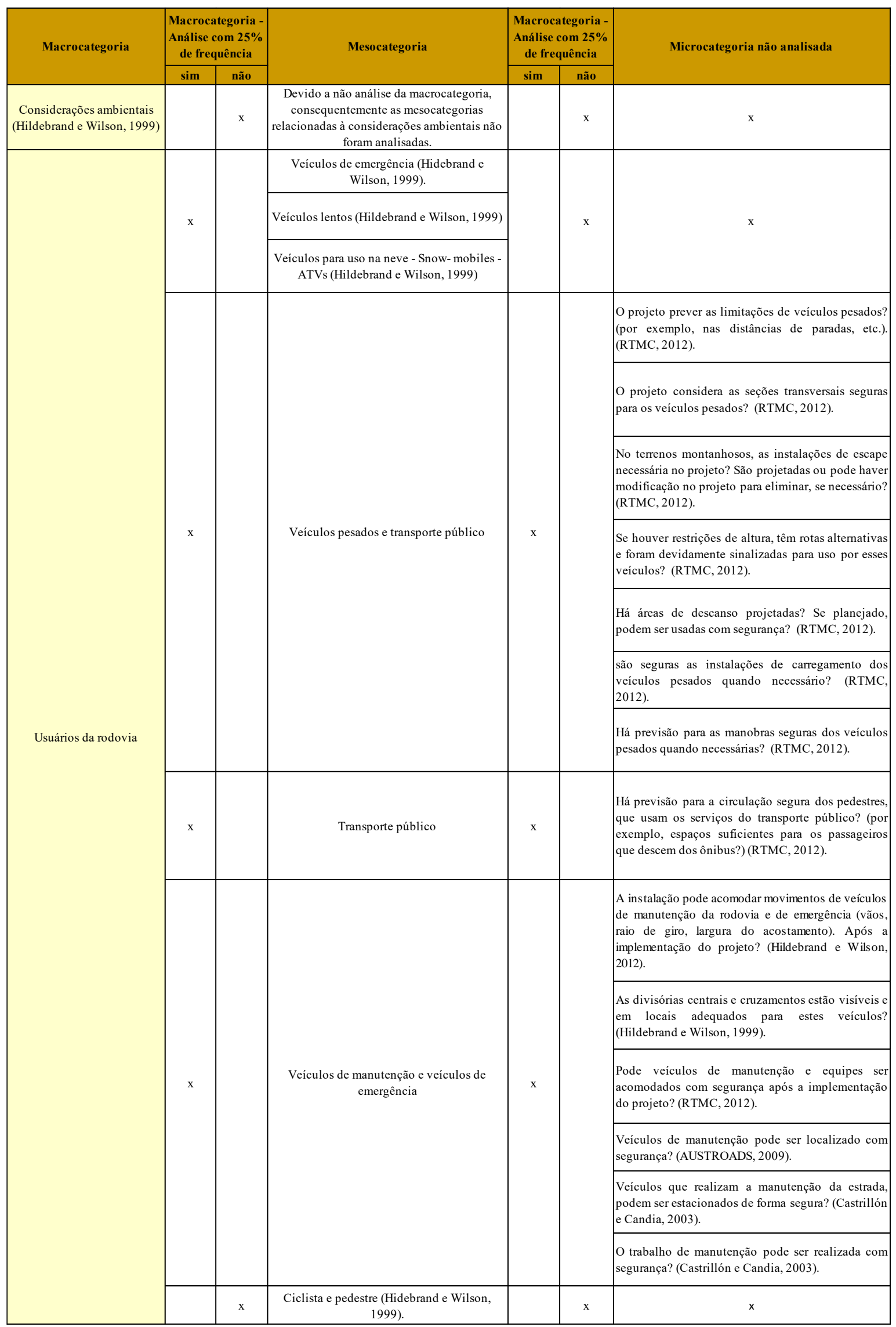




\section{Quadro 4.14: Macro, meso e microcategorias não analisadas - Projeto Executivo - continuação}

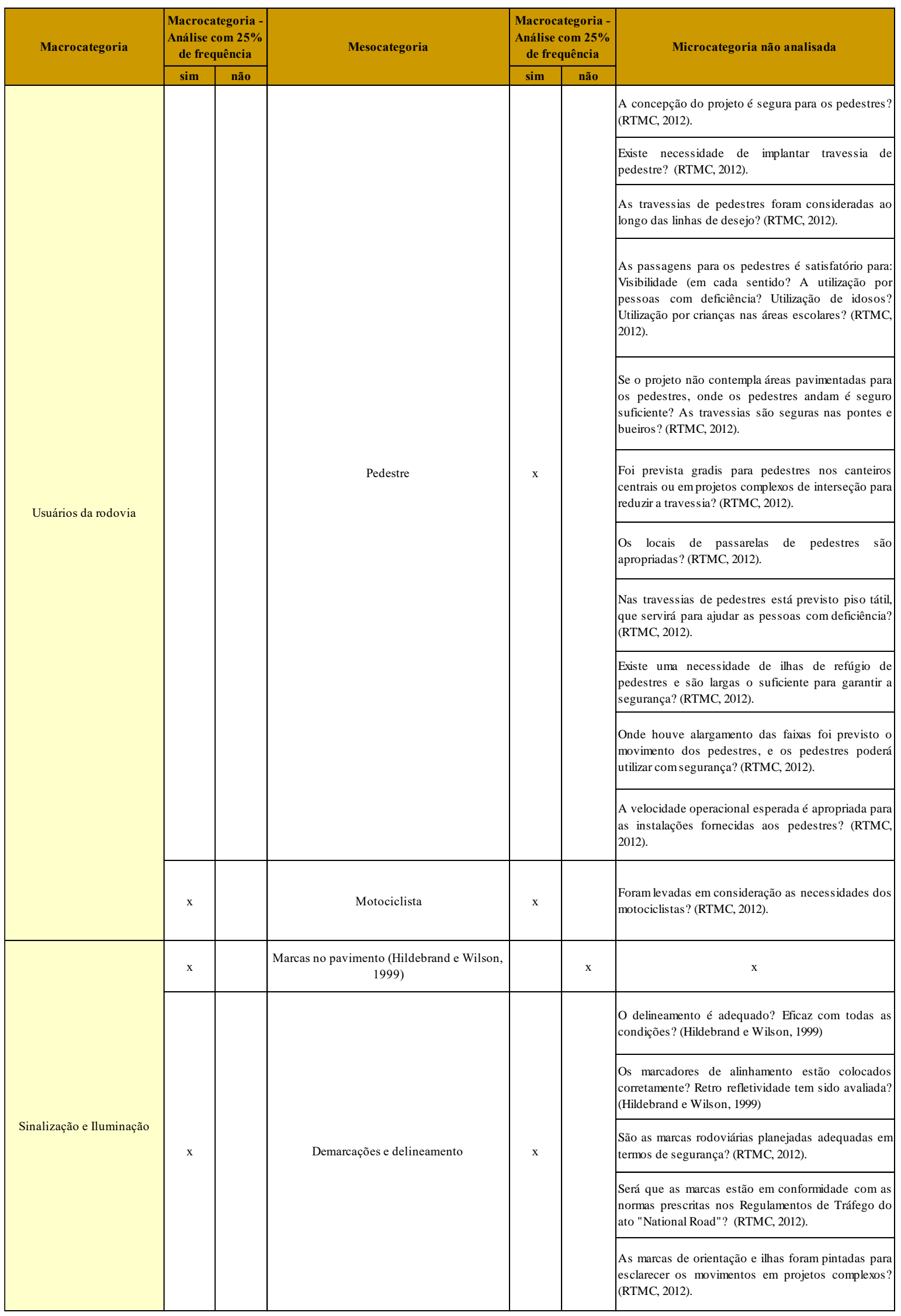




\section{Quadro 4.14: Macro, meso e microcategorias não analisadas - Projeto Executivo - continuação}

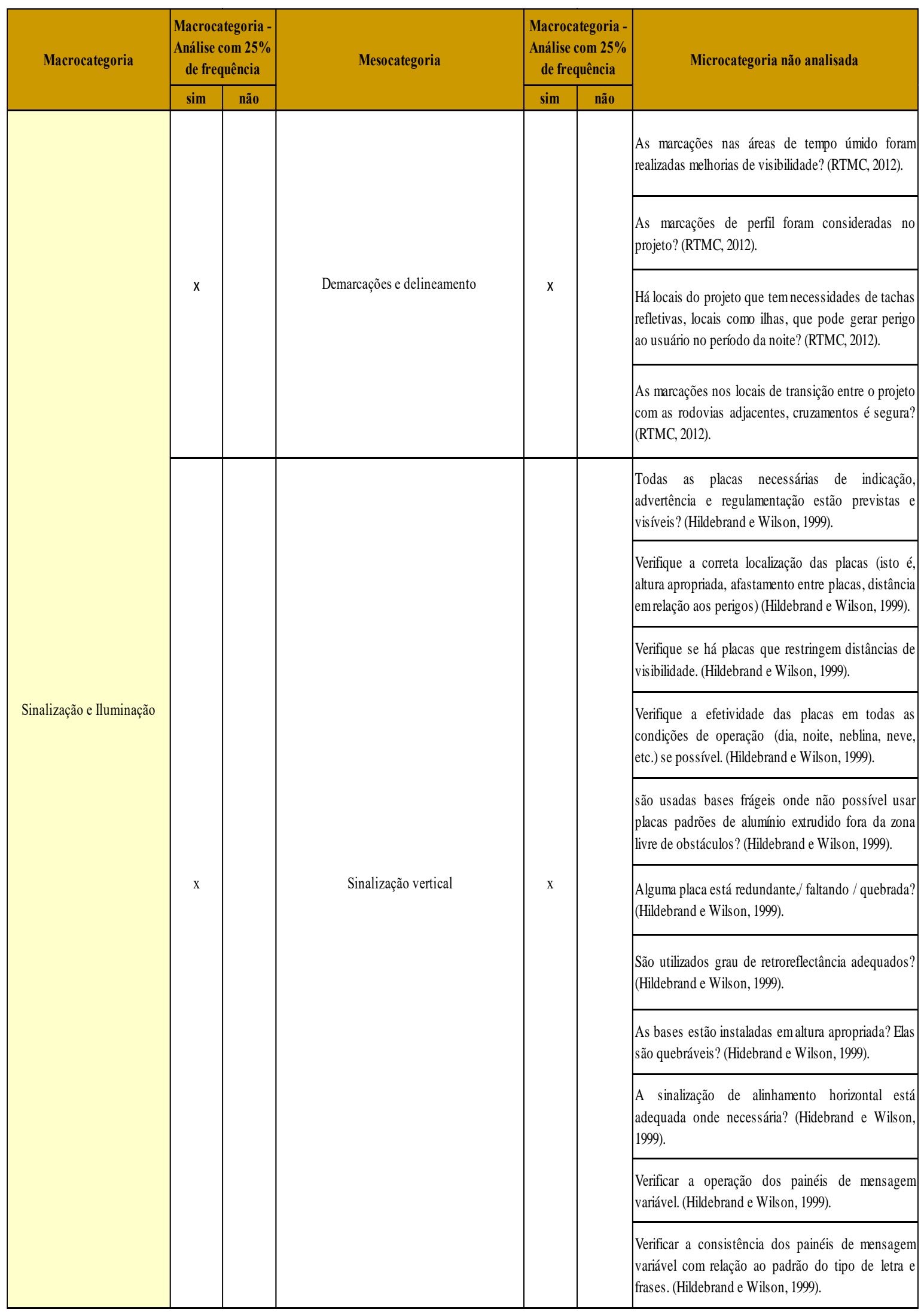


Quadro 4.14: Macro, meso e microcategorias não analisadas - Projeto Executivo continuação

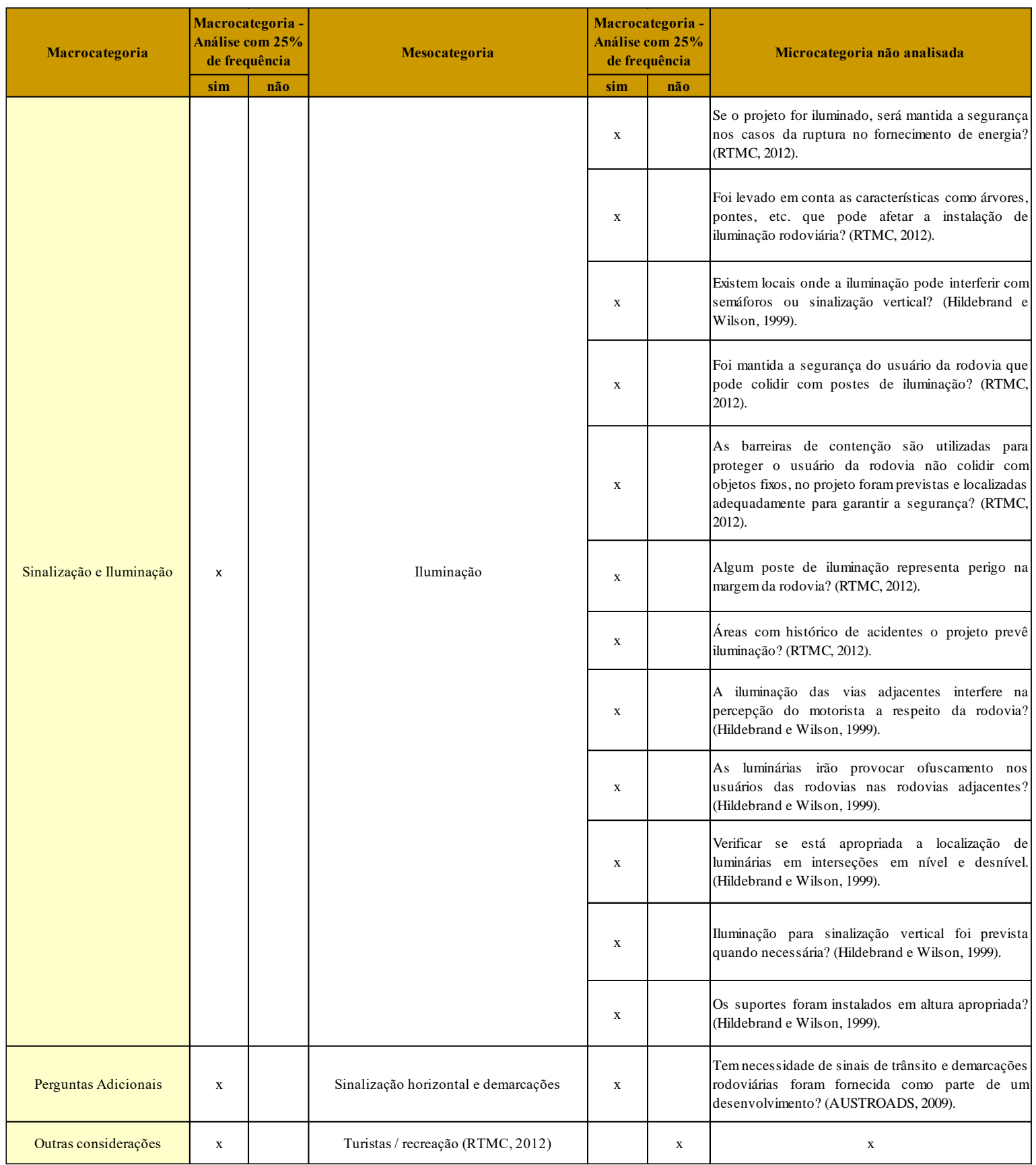

\subsection{ETAPA 3: MATERIALIZAÇÃO DO INSTRUMENTO PROPOSTO}

Após a ampla análise das quatro listas de verificação, base desta dissertação, elaborou-se o instrumento proposto por projeto de aplicação de ASV.

4.4.1 Materialização do instrumento proposto para aplicação no estudo de viabilidade, projeto básico e projeto executivo. 
Após as análises dos critérios estabelecidos para análise de conteúdo, houve a materialização do instrumento. Assim, o Quadro 4.15 mostra o resumo das quantidades de macrocategorias, mesocategorias e microcategorias que constituíram o instrumento encaminhado para avaliação dos técnicos.

Quadro 4.15 : Quantidade de itens abordados por categoria

\begin{tabular}{|l|c|c|c|}
\hline \multicolumn{4}{|c|}{ Instrumento Proposto } \\
\hline Categorias & $\begin{array}{c}\text { Estudo de } \\
\text { Viabilidade }\end{array}$ & $\begin{array}{c}\text { Projeto } \\
\text { Básico }\end{array}$ & $\begin{array}{c}\text { Projeto } \\
\text { Executivo }\end{array}$ \\
\hline Macrocategoria & 6 & 13 & 96 \\
\hline Mesocategoria & 9 & 51 & 172 \\
\hline Microcategoria & 8 & 52 & 243 \\
\hline
\end{tabular}

Fonte: Elaborado pela autora, 2015

Ressalta-se que o instrumento proposto para aplicação no estudo de viabilidade, projeto básico e projeto executivo, encontra-se no Apêndice D1, D2 e D3.

Após a elaboração do instrumento de ASV preliminar seguiu-se para a etapa de avaliação pelos técnicos, com o intuito do aprimoramento do instrumento de ASV para ser usados no estudos de viabilidade, projeto básico e projeto executivo.

\subsection{ETAPA 4: AVALIAÇÃO DO INSTRUMENTO PROPOSTO}

A elaboração inicial do instrumento proposto de ASV foi baseada na análise comparativa em relação à apresentação e quanto ao conteúdo por meio da análise da frequência.

Para a materialização final do instrumento proposto de ASV desta dissertação, submeteu-se o instrumento a avaliação de profissionais, que nesta dissertação foram chamados de técnicos, que possuem experiência com rodovias, segurança viária, operação de rodovias, entre outras, que será detalhada no Quadro 4.20.

A avaliação dos técnicos teve o objetivo do aprimoramento do instrumento proposto, realizada por meio da análise para identificar a correspondência das macrocategorias, 
mesocategorias e microcategorias com as fases de projetos do instrumento (estudo de viabilidade, projeto básico e projeto executivo) a correlação com a segurança viária e a clareza no entendimento dos itens das microcategorias.

Inicialmente o instrumento proposto seria submetido para avaliação, apenas, para os técnicos do DNIT, ANTT e DER/SP. Porém, verificou-se a necessidade e importância da participação de outros técnicos. Assim, o instrumento foi encaminhado também para os técnicos de Concessionárias de Rodovias e Consultores na área de segurança.

O instrumento de ASV proposto foi incialmente submetido a um técnico da Unidade Local da região Norte, e, houve a sugestão por parte desse técnico que além dele, os técnicos do setor de planejamento, segurança e operação, também, pudessem participar da pesquisa. Dessa forma, o instrumento proposto foi submetido, a um técnico de planejamento, um da unidade local e um da área de segurança e operação do DNIT.

Dessa forma, foi possível a participação de técnicos com formação e experiências distintas, que está de acordo com a característica da composição da equipe de ASV, ou seja, equipe multidisciplinar e com experiência em segurança viária.

A participação dos técnicos com experiências distintas, reflete nas características da composição da equipe de ASV, uma vez que deve ser uma equipe multidisciplinar e com experiência em segurança viária. O Quadro 4.16 mostra as diversas áreas de atuação e experiências dos técnicos, além de mostrar as regiões de atuações. 
Quadro 4.106 : Órgãos versus área de atuação dos técnicos

\begin{tabular}{|c|c|}
\hline Técnicos & Órgão \\
\hline 1 & DNIT \\
\hline 2 & DNIT \\
\hline 3 & DNIT \\
\hline 4 & ANTT \\
\hline 5 & ANTT \\
\hline 6 & ANTT \\
\hline 7 & CONSULTOR \\
\hline 8 & TÉCNICO PRÁTICO \\
\hline 9 & DER \\
\hline 10 & CONCESSIONÁRIA \\
\hline 11 & CONCESSIONÁRIA \\
\hline 12 & CONCESSIONÁRIA \\
\hline & \\
\hline
\end{tabular}

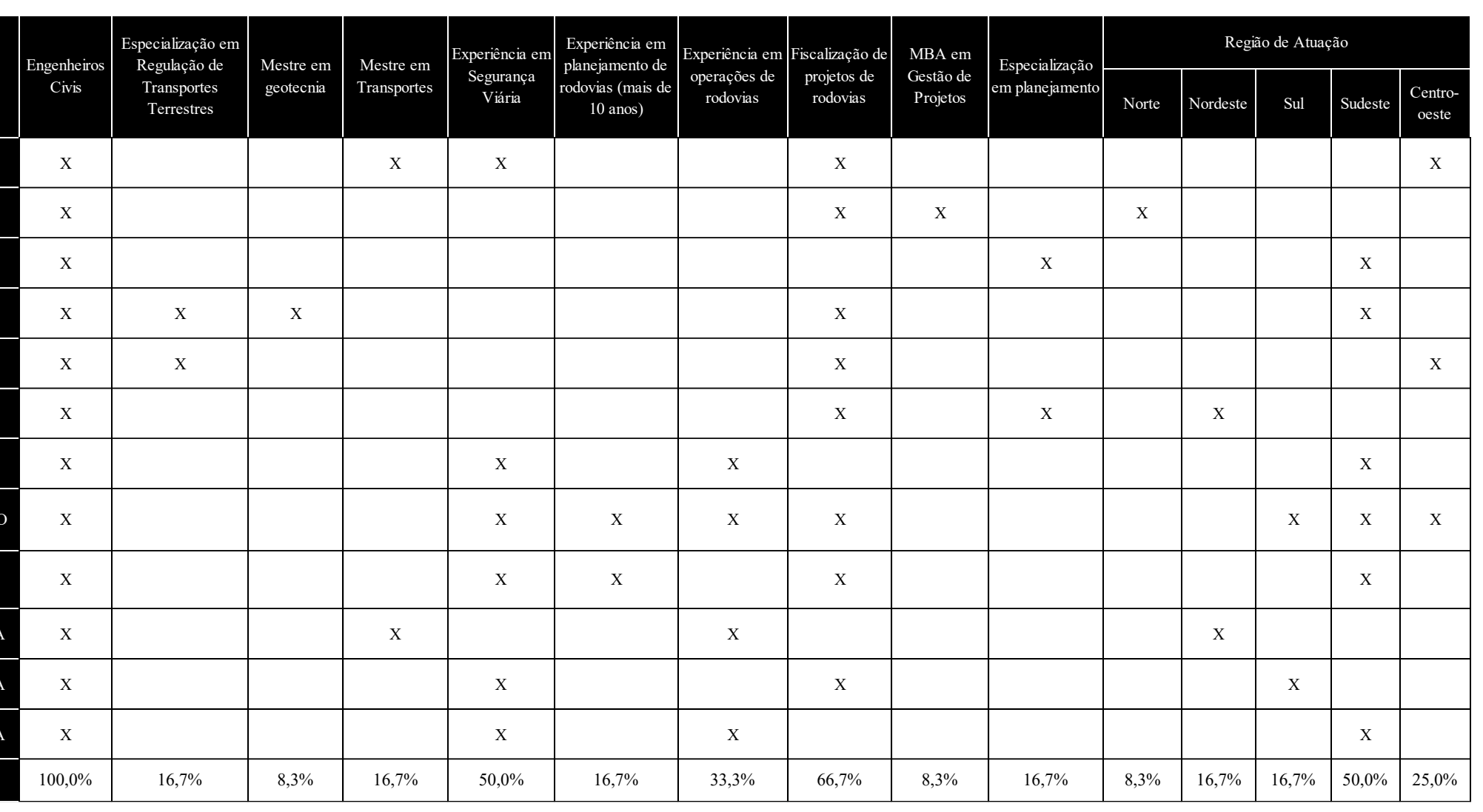

Fonte: Elaborado pela autora, 2015. 
O instrumento foi avaliado por 12 engenheiros civis, com experiência, principalmente, em fiscalização de projetos rodoviários, sendo $66,7 \%$ dos técnicos, $50 \%$ possuem experiências em segurança viária, e 33,3 experiências em operações de rodovias.

Ressalta-se que o percentual elevado dos técnicos que avaliaram o instrumento de ASV proposto nesta dissertação foram os com experiência em fiscalização de projetos, o que ratifica a importância desses técnicos na avaliação do instrumento, uma vez que, para auditar os projetos é essencial essa experiência. 


\section{APRIMORAMENTO DO INSTRUMENTO DE ASV}

Neste capítulo é descrita a revisão e análises do instrumento proposto a partir das observações dos técnicos que avaliaram o instrumento, e por fim o instrumento aprimorado que corresponde a Etapa 5 do procedimento metodológico desta dissertação.

\subsection{ETAPA 5: APRIMORAMENTO DO INSTRUMENTO DE ASV PROPOSTO}

Nesta etapa foi realizada a verificação das observações dos técnicos que avaliaram o instrumento proposto, e os critérios foram por meio da observação e seleção das sugestões realizadas por parte dos 12 técnicos. Esses critérios podem ser observados na Figura 5.1.

\section{Critérios de adequações}

Adequação de redação e clareza de entendimento

- Atendido quando 1(um) dos 12 (doze) técnicos realizaram a sugestão.
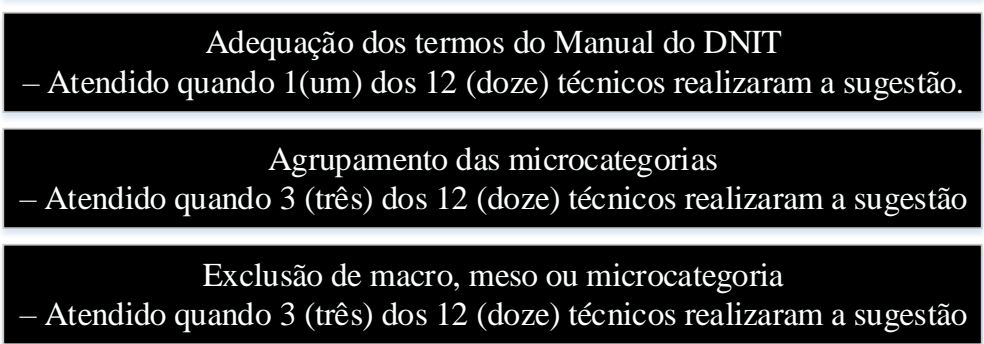

Inclusão de itens

Quando 1 (um) dos 12 (doze) técnicos realizaram a sugestão.

Figura 5.1: Lista de critérios para aceitação das sugestões dos técnicos

Fonte: Elaborado pela autora, 2015

É importante mencionar os comentários dos técnicos relativo ao instrumento proposto, destaca-se que foram realizados a parte pelos técnicos:

- Instrumento extenso e detalhado, e que pode ser usado por tipo de elemento de projeto, quando assim for necessário e de grande importância para a segurança viária;

- O instrumento proposto foi considerado de grande utilidade e importante pelos técnicos na mitigação de acidentes de trânsito, porém, entendem que a aplicação do 
instrumento pelos órgãos de transportes irá demandar a reformulação de equipes internas nesses órgãos.

- Dois técnicos recomendaram submeter o instrumento proposto nesta dissertação ao Instituto de Pesquisa Rodoviária - IPR do DNIT, para que possa ser avaliado e verificado a possibilidade de se tornar uma instrução de serviço.

\subsubsection{Aprimoramento do instrumento adaptado do estudo de viabilidade}

Nesta etapa são apresentados os itens do estudo de viabilidade que obtiveram sugestões conforme os critérios mostrado na Figura 5.1. As observações serão realizadas por nível das categorias, neste caso, por macrocategoria, mesocategoriaa microcategoria.

\subsubsection{Aprimoramento do instrumento do estudo de viabilidade}

Para melhor entendimento a descrição será identificada pela macrocategoria de cada instrumento proposto. Ressalta-se que as sugestões foram realizadas nas microcategorias. Além disso, os comentários apresentados referem-se, apenas, às recomendações de alterações realizadas pelos técnicos na avaliação do instrumento preliminar.

\section{a) Tópicos Gerais}

O Quadro 5.1 contemplam os comentários das avaliações realizadas pelos técnicos em relação à macrocategoria “tópicos gerais”, e suas respectivas microcategorias.

Quadro 5.1: Avaliações dos técnicos - Estudo de Viabilidade - macrocategoria "tópicos

$$
\text { gerais" }
$$

\begin{tabular}{|c|c|c|c|c|}
\hline \multicolumn{2}{|l|}{ Macrocategoria -Tópico Gerais } & \multirow{3}{*}{ Excluído } & & \multirow{3}{*}{ Incluído } \\
\hline \multicolumn{2}{|l|}{ Mesocategoria - Finalidade de projeto } & & 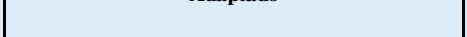 & \\
\hline Microcategoria preliminar & Considerações dos técnicos & & Microcategoria Final & \\
\hline $\begin{array}{l}\text { Verificar toda documentação pertinente do } \\
\text { escopo do projeto, destacando os objetivos } \\
\text { do projeto, características do usuário, } \\
\text { veículos de projetos, projetos de acessos, } \\
\text { características das áreas adjacentes, } \\
\text { informações de redes existentes e projetos de } \\
\text { futuras expansões. }\end{array}$ & $\begin{array}{l}\text { Adequação apenas no que se refere aos } \\
\text { "projetos de acessos". Na fase de Estudo de } \\
\text { viabilidade para rodovia em implantação, o } \\
\text { traçado pode ainda não estar completamente } \\
\text { definido. Neste caso, o projeto dos acessos seria } \\
\text { numa etapa posterior à definição do traçado. Se } \\
\text { tratar de uma pavimentação de rodovia já } \\
\text { implantada, mas em leito natural, pode-se } \\
\text { considerar possíveis projetos pré-existentes. } \\
\text { Logo, se tratar de um escopo geral, sugere-se } \\
\text { adequar para "Projetos pré-existentes de } \\
\text { acessos". }\end{array}$ & & $\begin{array}{l}\text { Verificar toda documentação pertinente do escopo } \\
\text { do projeto, destacando os objetivos do projeto, } \\
\text { características do usuário, veículos de projetos, } \\
\text { projetos novos ou pré-existentes de acessos, } \\
\text { características das áreas adjacentes, informações de } \\
\text { redes existentes e projetos de futuras expansões. }\end{array}$ & \\
\hline
\end{tabular}


Quadro 5.1: Avaliações dos técnicos - Estudo de Viabilidade - macrocategoria "tópicos gerais" - continuação

\begin{tabular}{|c|c|c|c|c|}
\hline \multicolumn{2}{|l|}{ Mesocategoria - Finalidade de projeto } & \multirow{2}{*}{ Excluído } & \multirow[b]{2}{*}{ Microcategoria Final } & \multirow{2}{*}{ Incluído } \\
\hline Microcategoria preliminar & Considerações dos técnicos & & & \\
\hline Qualé a função do projeto previsto? & $\begin{array}{l}\text { Adequação de termos para melhorar a clareza do } \\
\text { entendimento da microcategoria }\end{array}$ & & Qual a finalidade do projeto proposto? & \\
\hline $\begin{array}{l}\mathrm{O} \text { projeto é compatível com a função da } \\
\text { rodovia? }\end{array}$ & $\begin{array}{l}\text { Adequar com os termos usuais dos Manuais do } \\
\text { DNIT }\end{array}$ & & $\begin{array}{l}\text { O projeto proposto é compatível com a finalidade } \\
\text { da rodovia (conforme Classificação funcional e } \\
\text { técnica da rodovia)? }\end{array}$ & \\
\hline $\begin{array}{l}\text { O projeto proposto (ou reprojeto) enfatiza a } \\
\text { segurança adequadamente dos automóveis - } \\
\text { motociclistas - ciclistas - pedestres - veículos } \\
\text { pesados e ônibus? }\end{array}$ & $\begin{array}{l}\text { Adequação de termos para melhorar a clareza do } \\
\text { entendimento da microcategoria }\end{array}$ & & $\begin{array}{l}\text { O projeto proposto enfatiza adequadamente a } \\
\text { segurança dos veículos (carros, motos, ônibus e } \\
\text { caminhões), ciclistas e pedestres? }\end{array}$ & \\
\hline $\begin{array}{l}\text { Será que o projeto proposto está compatível } \\
\text { com as rodovias adjacentes, topografia e a } \\
\text { gestão de trânsito? }\end{array}$ & $\begin{array}{l}\text { Microcategoria apresentada na mesocategoria } \\
\text { tanto na "finalidade de projeto" e quanto nas } \\
\text { "características técnicas do projeto". Com os } \\
\text { comentários dos técnicos definiu-se apresentada } \\
\text { na mesocategoria características técnicas do } \\
\text { projeto. }\end{array}$ & & $\begin{array}{l}\text { Apresentada na mesocategoria "características } \\
\text { técnicas do projeto". }\end{array}$ & \\
\hline $\begin{array}{l}\text { O projeto será implementado em uma única } \\
\text { etapa de construção? }\end{array}$ & $\begin{array}{l}\text { Adequação de termos para melhorar a clareza do } \\
\text { entendimento da microcategoria }\end{array}$ & & $\begin{array}{l}\text { A execução do projeto da rodovia será executado } \\
\text { em uma única etapa? }\end{array}$ & \\
\hline $\begin{array}{l}\text { Se o projeto for implementado em mais de } \\
\text { uma etapa, foi dada a prioridade de } \\
\text { segurança: nas transições de etapas; e nas } \\
\text { transições com rodovias existentes. }\end{array}$ & $\begin{array}{l}\text { Adequação de termos para melhorar a clareza do } \\
\text { entendimento da microcategoria }\end{array}$ & & $\begin{array}{l}\text { Se execução do projeto da rodovia for realizada em } \\
\text { mais de uma etapa, houve prioridade da segurança na } \\
\text { transição dessas etapas e/ou nas transições com } \\
\text { rodovias existentes? }\end{array}$ & \\
\hline $\begin{array}{l}\text { O trabalho irá evitar problemas com as } \\
\text { normas de segurança durante a construção? }\end{array}$ & $\begin{array}{l}\text { Adequação de termos para melhorar a clareza do } \\
\text { entendimento da microcategoria }\end{array}$ & & $\begin{array}{l}\text { A execução da obra poderá ser realizada de acordo } \\
\text { com as normas de segurança? }\end{array}$ & \\
\hline \multicolumn{2}{|c|}{ Mesocategoria - Características técnicas do projeto } & Excluído & Adaptado & Incluído \\
\hline Microcategoria preliminar & Considerações dos técnicos & \multicolumn{3}{|c|}{ Microcategoria Final } \\
\hline $\begin{array}{l}\text { Os principais geradores de tráfego (incluindo } \\
\text { a habitação ou centros comerciais) estão } \\
\text { longe o suficiente para evitar influências de } \\
\text { insegurança sobre a forma do traçado? Se } \\
\text { sim, foram previstos ações mitigadoras? }\end{array}$ & $\begin{array}{l}\text { Adequar com os termos usuais dos Manuais do } \\
\text { DNIT }\end{array}$ & & $\begin{array}{l}\text { Há trechos da rodovia localizados na área de } \\
\text { influência de polos geradores de viagens? Se sim, } \\
\text { foram apresentadas medidas de gestão de segurança } \\
\text { para essas áreas? }\end{array}$ & \\
\hline $\begin{array}{l}\text { Está previsto acessos alternativos para } \\
\text { assegurar que subúrbios ou subáreas } \\
\text { existentes não ficaram isolados / devidos as } \\
\text { áreas não serem cortadas pelo } \\
\text { desenvolvimento do trabalho / obras? }\end{array}$ & $\begin{array}{l}\text { Adequação de termos para melhorar a clareza do } \\
\text { entendimento da microcategoria }\end{array}$ & & $\begin{array}{l}\text { Foram previstos acessos alternativos para assegurar } \\
\text { que subúrbios ou subáreas existentes não fiquem } \\
\text { isolados? }\end{array}$ & \\
\hline $\begin{array}{l}\text { Os acessos para os geradores de tráfego } \\
\text { estão significativamente longe das interseções } \\
\text { para fornecer a segurança? }\end{array}$ & $\begin{array}{l}\text { Adequação de termos para melhorar a clareza do } \\
\text { entendimento da microcategoria }\end{array}$ & & $\begin{array}{l}\text { Os acessos aos polos geradores de viagens estão } \\
\text { com distância adequada de interseções, pontes, túnel, } \\
\text { posto de pesagem e praças de pedágio para fornecer } \\
\text { segurança ao tráfego local e usuários da rodovia? }\end{array}$ & \\
\hline $\begin{array}{l}\text { A distância de visibilidade dos acessos para } \\
\text { os geradores de tráfego estão adequadas? }\end{array}$ & $\begin{array}{l}\text { Adequar com os termos usuais dos Manuais do } \\
\text { DNIT }\end{array}$ & & $\begin{array}{l}\text { A distância de visibilidade dos acessos para os polos } \\
\text { geradores de viagens estão adequadas? }\end{array}$ & \\
\hline $\begin{array}{l}\text { Será que o projeto proposto é coerente com } \\
\text { as estradas adjacentes, formas do relevo } \\
\text { (topografia) e gestão de tráfego? }\end{array}$ & $\begin{array}{l}\text { Adequação de termos para melhorar a clareza do } \\
\text { entendimento da microcategoria }\end{array}$ & & $\begin{array}{l}\text { O projeto proposto é coerente com as rodovias } \\
\text { adjacentes, no que tange a topografia? }\end{array}$ & \\
\hline \multicolumn{2}{|l|}{ Mesocategoria - Acesso e áreas adjacentes } & Excluído & Adaptado & Incluído \\
\hline Microcategoria preliminar & Considerações dos técnicos & & Microcategoria Final & \\
\hline $\begin{array}{l}\text { A velocidade de projeto (ou a velocidade de } \\
\text { operação dos veículos) é compatível com } \\
\text { número e o tipo de interseções / e acessos a } \\
\text { propriedades adjacentes? }\end{array}$ & $\begin{array}{l}\text { Adequação de termos para melhorar a clareza do } \\
\text { entendimento da microcategoria }\end{array}$ & & $\begin{array}{l}\text { A velocidade de projeto é compatível com número e } \\
\text { o tipo de interseções e/ou acessos a propriedades } \\
\text { adjacentes e marginais? }\end{array}$ & \\
\hline
\end{tabular}


Quadro 5.1:Avaliações dos técnicos - Estudo de Viabilidade - macrocategoria "tópicos gerais" - continuação

\begin{tabular}{|l|l|l|l|}
\hline \multicolumn{2}{|l|}{ Mesocategoria - Obras de Melhoramentos } & \multicolumn{2}{|l|}{ Microcategoria Final } \\
\hline Microcategoria preliminar & \multicolumn{1}{|c|}{ Considerações dos técnicos } & & \multicolumn{2}{|l|}{$\begin{array}{l}\text { O traçado não afetará o nível de segurança, se } \\
\text { houver futuros alargamentos, realinhamentos, adição } \\
\text { de novas faixas, alterações na geometria das } \\
\text { interseções ou nas extensões lineares do projeto? }\end{array}$} \\
$\begin{array}{l}\text { O traçado não afetará o nível de segurança, } \\
\text { se houver: futuro alargamento?; a adição de } \\
\text { um segunda faixa de sentido completo?; após } \\
\text { alinhamento?; principais alterações } \\
\text { geométricas nas interseções? E extensões } \\
\text { lineares do projeto? }\end{array}$ & $\begin{array}{l}\text { Adequação de termos para melhorar a clareza do } \\
\text { entendimento da microcategoria }\end{array}$ & \begin{tabular}{l} 
\\
\hline
\end{tabular}
\end{tabular}

Fonte: Elaborado pela autora, 2015

O Quadro 5.2 mostra os comentários realizados em relação à macrocategoria "geometria", e suas respectivas microcategorias, bem como as sugestões de adaptações realizadas pelos técnicos.

Quadro 5.2: Avaliações dos técnicos - Estudo de Viabilidade - macrocategoria "geometria"

\begin{tabular}{|c|c|c|c|c|}
\hline \multicolumn{2}{|l|}{ Macrocategoria - Geometria } & \multirow{2}{*}{ Excluído } & \multirow{2}{*}{ Adaptado } & \multirow{2}{*}{ Incluído } \\
\hline Mesocategoria - Traçado e alinhamento & & & & \\
\hline $\begin{array}{l}\text { Se o traçado é projetado sobre uma rota } \\
\text { existente, quais são os efeitos dele? }\end{array}$ & $\begin{array}{l}\text { Adequação de termos para melhorar a clareza do } \\
\text { entendimento da microcategoria }\end{array}$ & & $\begin{array}{l}\text { Nos casos em que um novo traçado é proposto } \\
\text { sobre um traçado existente, quais os efeitos desse } \\
\text { traçado referente a segurança viária? }\end{array}$ & \\
\hline $\begin{array}{l}\text { Se o traçado é em (corredor subdesenvolvido } \\
\text { ou sem construções) "áreas verdes", o } \\
\text { alinhamento é seguro? Poderia ser mais } \\
\text { seguro? }\end{array}$ & $\begin{array}{l}\text { Adequação de termos para melhorar a clareza do } \\
\text { entendimento da microcategoria }\end{array}$ & & $\begin{array}{l}\text { Verificar se o traçado proposto é seguro, e se } \\
\text { poderia ser mais seguro, principalmente, quando } \\
\text { tratar de traçado em áreas subdesenvolvidas ou em } \\
\text { áreas de vegetação densa. }\end{array}$ & \\
\hline $\begin{array}{l}\text { o projeto leva em conta as considerações da } \\
\text { rede principal (existente)? }\end{array}$ & $\begin{array}{l}\text { Adequação de termos para melhorar a clareza do } \\
\text { entendimento da microcategoria }\end{array}$ & & $\begin{array}{l}\text { O projeto proposto leva em conta as considerações } \\
\text { da rede principal existente e se encaixa com } \\
\text { segurança com essa rede? }\end{array}$ & \\
\hline $\begin{array}{l}\text { O projeto prevê acomodação segura com os } \\
\text { imprevistos com o aumento no volume do } \\
\text { tráfego? }\end{array}$ & \multirow{2}{*}{$\begin{array}{l}\text { Adequar e agrupar pois tratam do volume e } \\
\text { composição do tráfego }\end{array}$} & & \multirow{2}{*}{$\begin{array}{l}\text { O projeto prevê acomodação e contempla a } \\
\text { segurança com o aumento e mudança na composição } \\
\text { do volume de tráfego? }\end{array}$} & \\
\hline $\begin{array}{l}\text { O projeto prevê segurança com mudanças } \\
\text { imprevistas na composição do volume de } \\
\text { tráfego? }\end{array}$ & & & & \\
\hline- & Sugestão de inclusão & & $\begin{array}{l}\text { Há interferências transversal e/ou longitudinal do } \\
\text { projeto com os equipamentos de energia, } \\
\text { saneamento e telecomunicações (telefonia, fibras } \\
\text { ópticas, rede de água e esgoto, gasodutos, } \\
\text { oleodutos, etc...)? }\end{array}$ & $\mathbf{x}$ \\
\hline
\end{tabular}


Quaro 5.2:Avaliações dos técnicos - Estudo de Viabilidade - macrocategoria "geometria" - continuação

\begin{tabular}{|l|l|l|l|l|}
\hline Macrocategoria - Geometria & \multirow{2}{*}{ Excluído } & \multicolumn{2}{|c|}{ Adaptado } \\
\hline Mesocategoria - Elementos da seção transversal & \multicolumn{1}{|c|}{ Considerações dos técnicos } & \multicolumn{2}{|c|}{ Microcategoria Final } \\
\hline Microcategoria preliminar & $\begin{array}{l}\text { As normas de projeto foram utilizadas } \\
\text { apropriadamente, levando em conta as características } \\
\text { do projeto, composição do fluxo de tráfego e } \\
\text { usuários da rodovia? }\end{array}$ \\
$\begin{array}{l}\text { As normas de projeto foram utilizados } \\
\text { apropriadamente (levando em conta as } \\
\text { características do projeto e seu papel na } \\
\text { relação com a composição do fluxo de } \\
\text { tráfego, (os usuários da rodovia que utilizarão } \\
\text { / ser influenciado pelo projetos)? }\end{array}$ & $\begin{array}{l}\text { Adequação de termos para melhorar a clareza do } \\
\text { entendimento da microcategoria. E adaptá-la a a } \\
\text { mesocategoria Traçado e alinhamento. }\end{array}$ &
\end{tabular}

Fonte: Elaborado pela autora, 2015

O Quadro 5.3 mostra os comentários realizados em relação à macrocategoria "interseções" e suas respectivas microcategorias, bem como as sugestões e adaptações realizadas.

Quadro 5.3: Avaliações dos técnicos - Estudo de Viabilidade - macrocategoria "interseções"

\begin{tabular}{|c|c|c|c|c|}
\hline \multicolumn{2}{|l|}{ Macrocategoria - Interseções } & \multirow{2}{*}{ Excluído } & \multirow{2}{*}{ Adaptado } & \multirow{2}{*}{ Incluído } \\
\hline \multicolumn{2}{|l|}{ Mesocategoria - Quantidade, tipo e localização } & & & \\
\hline Microcategoria preliminar & Considerações dos técnicos & \multicolumn{3}{|c|}{ Microcategoria Final } \\
\hline $\begin{array}{l}\text { O número de interseções é apropriado (Não } \\
\text { é muito alta ou muito baixa): para garantir o } \\
\text { acesso seguro? para evitar impactos na rede } \\
\text { rodoviária adjacente? E para o acesso de } \\
\text { veículos de emergências? }\end{array}$ & $\begin{array}{l}\text { Adequação de termos para melhorar a clareza do } \\
\text { entendimento da microcategoria }\end{array}$ & & $\begin{array}{l}\text { O número de interseções proposto e gabarito vertical } \\
\text { atendem as necessidades de conexão entre o projeto } \\
\text { proposto e as rodovias adjacentes, assim como, } \\
\text { acesso seguro para os veículos de emergências? }\end{array}$ & \\
\hline $\begin{array}{l}\text { As restrições físicas, visibilidade ou gestão do } \\
\text { tráfego, que podem influenciar na escolha do } \\
\text { tipo ou o espaçamento das interseções } \\
\text { propostas foram consideradas? }\end{array}$ & $\begin{array}{l}\text { Adequação de termos para melhorar a clareza do } \\
\text { entendimento da microcategoria }\end{array}$ & & $\begin{array}{l}\text { Foram consideradas na escolha do tipo e } \\
\text { espaçamento das interseções propostas eventuais } \\
\text { restrições físicas, visibilidade ou a operação do } \\
\text { tráfego para garantir a segurança dos usuários da } \\
\text { rodovia? }\end{array}$ & \\
\hline $\begin{array}{l}\text { Todas as propostas de interseções são } \\
\text { necessárias ou essenciais? }\end{array}$ & $\begin{array}{l}\text { Adequação de termos para melhorar a clareza do } \\
\text { entendimento da microcategoria }\end{array}$ & & $\begin{array}{l}\text { Todas as interseções propostas são necessárias para } \\
\text { o projeto proposto? }\end{array}$ & \\
\hline $\begin{array}{l}\text { Algumas interseções que foram estimadas } \\
\text { desnecessárias podem ser removidas para } \\
\text { melhorar a segurança? E o acesso pode ser } \\
\text { conectado de forma segura por meio de } \\
\text { alterações da rede rodoviária adjacente? }\end{array}$ & $\begin{array}{l}\text { Adequação de termos para melhorar a clareza do } \\
\text { entendimento da microcategoria }\end{array}$ & & $\begin{array}{l}\text { Há interseções projetadas desnecessárias que podem } \\
\text { ser removidas para melhorar a segurança viária? E o } \\
\text { Acesso à rodovia pode ser de forma segura por meio } \\
\text { de eventuais mudanças na rede rodoviária adjacente? }\end{array}$ & \\
\hline $\begin{array}{l}\text { O ângulo das faixas da rodovia que cruzam o } \\
\text { projeto e linha de visibilidade são adequada } \\
\text { para a segurança de todos os usuários? }\end{array}$ & $\begin{array}{l}\text { Adequação de termos para melhorar a clareza do } \\
\text { entendimento da microcategoria }\end{array}$ & & $\begin{array}{l}\text { O ângulo de aproximação das faixas das rodovias } \\
\text { existentes que cruzam o alinhamento da rodovia } \\
\text { principal do projeto proposto, bem como a linha de } \\
\text { visibilidade estão adequadas para a segurança dos } \\
\text { usuários da rodovia? }\end{array}$ & \\
\hline $\begin{array}{l}\text { a circulação de veículos pesados é segura nas } \\
\text { interseções? }\end{array}$ & $\begin{array}{l}\text { Adequação de termos para melhorar a clareza do } \\
\text { entendimento da microcategoria }\end{array}$ & & $\begin{array}{l}\text { Os projetos propostos das interseções acomodam de } \\
\text { forma segura a circulação dos veículos de projeto, } \\
\text { inclusive os veículos pesados? }\end{array}$ & \\
\hline $\begin{array}{l}\text { Os alinhamentos verticais e/ou horizontais } \\
\text { foram considerados para determinar o tipo e } \\
\text { o espaçamento das intersecções? }\end{array}$ & $\begin{array}{l}\text { Adequação de termos para melhorar a clareza do } \\
\text { entendimento da microcategoria }\end{array}$ & & $\begin{array}{l}\text { O alinhamento horizontal e vertical do eixo principal } \\
\text { foram considerados para determinar o tipo e a } \\
\text { localização das interseções? }\end{array}$ & \\
\hline
\end{tabular}

Fonte: Elaborado pela autora, 2015 
O Quadro 5.4 mostra os comentários realizados em relação à macrocategoria “obstáculos fixos" e suas respectivas microcategorias, bem como as sugestões e adaptações realizadas.

Quadro 5.4: Avaliações dos técnicos - Estudo de Viabilidade - macrocategoria

\begin{tabular}{|c|c|c|c|c|}
\hline \multicolumn{2}{|l|}{ Macrocategoria - Obstáculos fixos } & \multirow{2}{*}{ Excluído } & \multirow{2}{*}{ Adaptado } & \multirow{2}{*}{ Incluído } \\
\hline Mesocategoria - Postes ou outras obstruçõ & & & & \\
\hline Microcategoria preliminar & Considerações dos técnicos & \multicolumn{3}{|c|}{ Microcategoria Final } \\
\hline $\begin{array}{l}\text { Os postes de semáforos e outros postes de } \\
\text { serviço estão posicionados adequadamente? }\end{array}$ & $\begin{array}{l}\text { Adequação de termos para melhorar a clareza do } \\
\text { entendimento da microcategoria }\end{array}$ & & $\begin{array}{l}\text { Os elementos de sustentação dos semáforos e } \\
\text { outros postes de serviço estão posicionados } \\
\text { adequadamente e com alturas adequadas para o } \\
\text { trânsito? }\end{array}$ & \\
\hline \multicolumn{2}{|l|}{ Macrocategoria - Obstáculos fixos } & \multirow{2}{*}{ Excluído } & \multirow{2}{*}{ Adaptado } & \multirow{2}{*}{ Incluído } \\
\hline \multicolumn{2}{|l|}{ Mesocategoria - Dispositivos centrais } & & & \\
\hline Microcategoria preliminar & Considerações dos técnicos & \multicolumn{3}{|c|}{ Microcategoria Final } \\
\hline $\begin{array}{l}\text { O tipo de divisória central escolhido é } \\
\text { apropriado para a largura disponível? }\end{array}$ & & & $\begin{array}{l}\text { O tipo de dispositivos de contenção viária escolhido } \\
\text { é apropriado para a largura dos canteiros centrais? }\end{array}$ & \\
\hline $\begin{array}{l}\text { Existe largura suficiente para pilares dos } \\
\text { viadutos, passagem subterrânea e iluminação? }\end{array}$ & $\begin{array}{l}\text { Adequação de termos para melhorar a clareza do } \\
\text { entendimento da microcategoria }\end{array}$ & & $\begin{array}{l}\text { Está prevista a distância mínima entre os dispositivos } \\
\text { de contenção e os pilares das obras de artes } \\
\text { especiais (OAE) e postes de iluminação? }\end{array}$ & \\
\hline $\begin{array}{l}\text { Verificar o espaçamento apropriado entre } \\
\text { travessias de divisórias centrais. }\end{array}$ & $\begin{array}{l}\text { Adequação de termos para melhorar a clareza do } \\
\text { entendimento da microcategoria }\end{array}$ & & $\begin{array}{l}\text { O espaçamento é apropriado entre as divisórias } \\
\text { centrais para a travessias de pedestres quando } \\
\text { necessário? }\end{array}$ & \\
\hline- & Sugestão de inclusão & & $\begin{array}{l}\text { As travessias de linhas de transmissão e/ou } \\
\text { telecomunicações estão com as alturas adequadas } \\
\text { para o trânsito da via? }\end{array}$ & $\mathbf{x}$ \\
\hline
\end{tabular}

Fonte: Elaborado pela autora, 2015

O Quadro 5.5 mostra os comentários realizados em relação à macrocategoria "Aspectos ambientais" e suas respectivas microcategorias, bem como as sugestões e adaptações realizadas. 
Quadro 5.5: Avaliações dos técnicos - Estudo de Viabilidade - macrocategoria “Aspectos Ambientais"

\begin{tabular}{|c|c|c|c|c|}
\hline \multicolumn{2}{|l|}{ Macrocategoria - Aspectos ambientais } & \multirow{2}{*}{ Excluído } & \multirow{2}{*}{ Adaptado } & \multirow{2}{*}{ Incluído } \\
\hline Mesocategoria - Clima e outros aspectos & & & & \\
\hline $\begin{array}{l}\text { A segurança foi considerada em lugares com } \\
\text { determinadas características ambientais? (por } \\
\text { exemplo, cercas de ruídos) }\end{array}$ & $\begin{array}{l}\text { Os técnicos citaram que a pergunta está muito } \\
\text { ampla e também, que é um item a ser verificado } \\
\text { no projeto básico. }\end{array}$ & $\mathbf{x}$ & & \\
\hline $\begin{array}{l}\text { Os declives, as curvas e projeto de acesso } \\
\text { em geral foram considerados as condições de } \\
\text { tempo ou condições ambientais do terreno? } \\
\text { (como por exemplo, áreas propensas a } \\
\text { nevoeiro) }\end{array}$ & $\begin{array}{l}\text { Na análise do aprimoramento, verificou-se que } \\
\text { não foi citada no instrumento de ASV } \\
\text { encaminhado aos técnicos. Porém, essa } \\
\text { microcategoria foi adaptada e inserida no } \\
\text { instrumento final. }\end{array}$ & & $\begin{array}{l}\text { Foram considerada as condições de tempo e } \\
\text { ambientais para os projeto dos declives (rampas) e } \\
\text { curvas? }\end{array}$ & $\mathbf{x}$ \\
\hline
\end{tabular}

Fonte: Elaborado pela autora, 2015

O Quadro 5.6 mostra os comentários realizados em relação à macrocategoria “outras considerações" e suas respectivas microcategorias, bem como as sugestões e adaptações realizadas.

Quadro 5.6: Avaliações dos técnicos - Estudo de Viabilidade - macrocategoria “Outros aspectos de segurança não considerados"

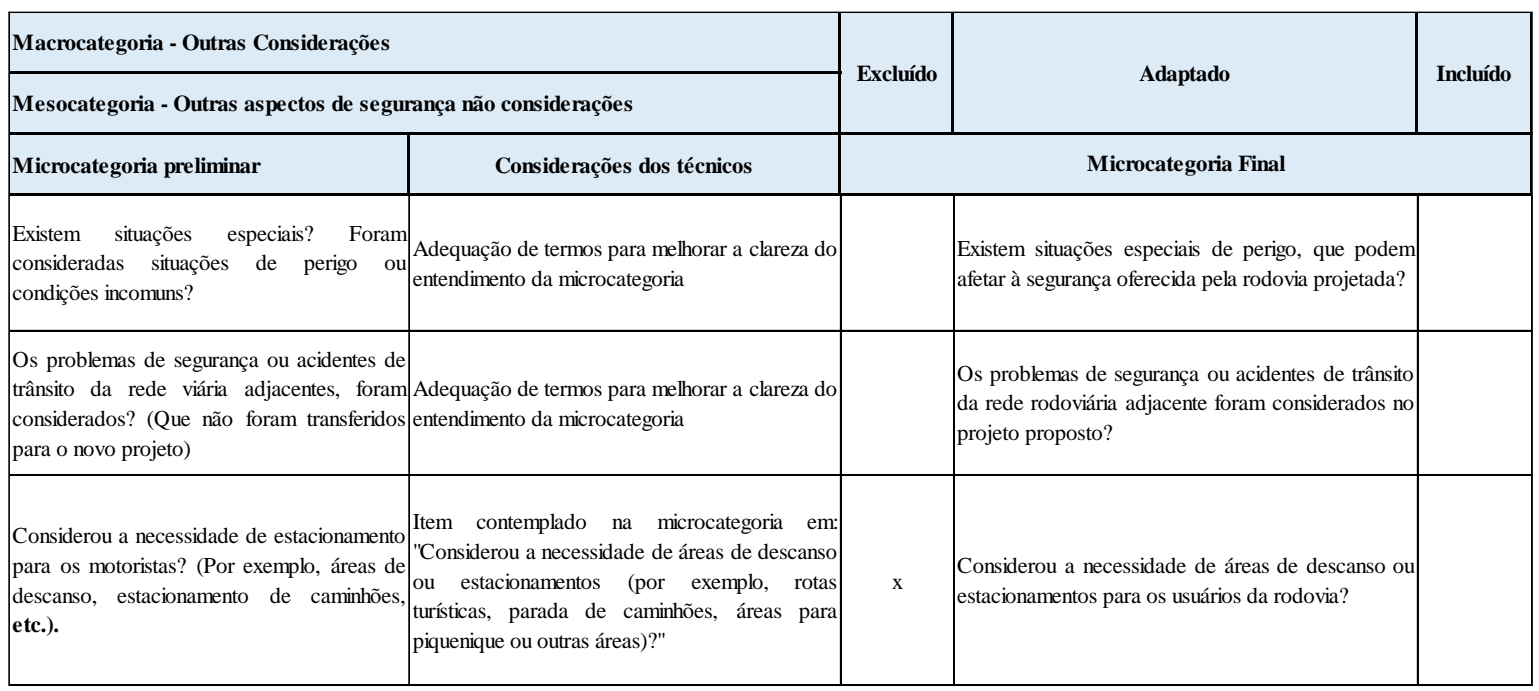

Fonte: Elaborado pela autora, 2015 


\subsubsection{Aprimoramento do instrumento do projeto básico}

$\mathrm{Na}$ análise da verificação das observações realizadas pelos técnicos, percebeu-se que os itens da macrocategoria “aspectos ambientais" foi encaminhado para avaliação. No entanto, havia sido verificado por meio dos critérios estabelecidos nesta dissertação que essa macrocategoria não fazia parte do instrumento preliminar a ser verificado pelos técnicos. Dessa forma, foi retirado e será alvo de indicação de avaliação para trabalhos futuros.

O Quadro 5.7 mostra os comentários realizados em relação à macrocategoria "tópicos gerais" do instrumento adaptado ao projeto básico, e suas microcategorias e suas respectivas avaliações.

Quadro 5.7: Avaliações dos técnicos - Projeto Básico - macrocategoria "tópicos gerais"

\begin{tabular}{|c|c|c|c|c|}
\hline \multicolumn{2}{|l|}{ Macrocategoria - Tópicos Gerais } & \multirow{2}{*}{ Excluído } & \multirow{2}{*}{ Adaptado } & \multirow{2}{*}{ Incluído } \\
\hline \multicolumn{2}{|l|}{ Mesocategoria - Drenagem } & & & \\
\hline Microcategoria preliminar & Considerações dos técnicos & \multicolumn{3}{|c|}{ Microcategoria Final } \\
\hline $\begin{array}{l}\text { O projeto de drenagem é adequado para a } \\
\text { função da rodovia proposta? }\end{array}$ & $\begin{array}{l}\text { Adequação de termos para melhorar a clareza } \\
\text { do entendimento da microcategoria pelo } \\
\text { auditor. }\end{array}$ & & $\mid \begin{array}{l}\mathrm{O} \text { projeto de drenagem (superficial e/profunda) } \\
\text { proposto é adequado para a finalidade da rodovia? }\end{array}$ & \\
\hline \multicolumn{2}{|l|}{ Mesocategoria - Serviços } & Excluído & Adaptado & Incluído \\
\hline Microcategoria preliminar & Considerações dos técnicos & \multicolumn{3}{|c|}{ Microcategoria Final } \\
\hline $\begin{array}{l}\text { A localização dos objetos fixos ou serviços } \\
\text { móveis foram verificados, incluindo a posição } \\
\text { dos postes? }\end{array}$ & $\begin{array}{l}\text { Microcategoria repetida na mesma } \\
\text { mesocategoria }\end{array}$ & $\mathbf{x}$ & & \\
\hline \multicolumn{2}{|l|}{ Macrocategoria - Tópicos Gerais } & \multirow{2}{*}{ Excluído } & \multirow{2}{*}{ Adaptado } & \multirow{2}{*}{ Incluído } \\
\hline \multicolumn{2}{|c|}{ Mesocategoria - Acessos de veículos de emergência } & & & \\
\hline Microcategoria preliminar & Considerações dos técnicos & \multicolumn{3}{|c|}{ Microcategoria Final } \\
\hline $\begin{array}{l}\text { A concepção e concepção do projeto de } \\
\text { barreiras centrais permite que veículos de } \\
\text { emergência possam parar e retornar por } \\
\text { caminhos sem interrupção do tráfego? }\end{array}$ & $\begin{array}{l}\text { Adequação de termos para melhorar a clareza } \\
\text { do entendimento } \\
\text { auditor. }\end{array}$ & & $\begin{array}{l}\text { Na concepção e execução do projeto de barreiras dos } \\
\text { canteiros centrais permitem a passagem e retorno dos } \\
\text { veículos de emergência sem interrupção do tráfego? }\end{array}$ & \\
\hline \multicolumn{2}{|l|}{ Macrocategoria - Tópicos Gerais } & Excluído & Adaptado & Incluído \\
\hline
\end{tabular}

Fonte: Elaborado pela autora, 2015 
O Quadro 5.8 mostra os comentários realizados em relação à macrocategoria "geometria" do instrumento adaptado ao projeto básico, suas microcategorias e suas respectivas avaliações.

\section{Quadro 5.8: Avaliações dos técnicos - Projeto Básico - macrocategoria "geometria"}

\begin{tabular}{|c|c|c|c|c|}
\hline \multicolumn{2}{|l|}{ Macrocategoria - Geometria } & \multirow{2}{*}{ Excluído } & \multirow{2}{*}{ Adaptado } & \multirow{2}{*}{ Incluído } \\
\hline \multicolumn{2}{|l|}{ 2.3 Elementos da seção transversal } & & & \\
\hline Microcategoria preliminar & Considerações dos técnicos & \multicolumn{3}{|c|}{ Microcategoria Final } \\
\hline $\begin{array}{l}\text { A largura das faixas das rodovias é adequada a } \\
\text { respeito do: alinhamentos? Fluxo de tráfego? } \\
\text { Dimensões dos veículos? Velocidade de } \\
\text { projeto? Combinações de veículos com o fluxo } \\
\text { de tráfego? }\end{array}$ & $\begin{array}{l}\text { Adequação de termos para melhorar a clareza } \\
\text { do entendimento da microcategoria pelo } \\
\text { auditor. }\end{array}$ & & $\begin{array}{l}\text { A largura das faixas das rodovias é adequada em } \\
\text { relação à(s) ou ao(s): alinhamentos? Fluxo de tráfego? } \\
\text { Dimensões dos veículos? Velocidade de projeto? } \\
\text { Combinações de veículos como fluxo de tráfego? }\end{array}$ & \\
\hline \multicolumn{2}{|l|}{ Macrocategoria - Geometria } & \multirow{2}{*}{ Excluído } & \multirow{2}{*}{ Adaptado } & \multirow{2}{*}{ Incluído } \\
\hline \multicolumn{2}{|l|}{ Mesocategoria - Alinhamentos } & & & \\
\hline Microcategoria preliminar & Considerações dos técnicos & \multicolumn{3}{|c|}{ Microcategoria Final } \\
\hline $\begin{array}{l}\text { O projeto do alinhamento horizontal e vertical } \\
\text { estão adequadamente alinhados? }\end{array}$ & $\begin{array}{l}\text { Adequação de termos para melhorar a clarezal } \\
\text { do entendimento da microcategoria pelo } \\
\text { auditor. }\end{array}$ & & $\begin{array}{l}\text { O projeto do alinhamento horizontal e alinhamento } \\
\text { vertical estão adequadamente compatibilizados? }\end{array}$ & \\
\hline $\begin{array}{l}\text { O projeto da sinalização vertical nos } \\
\text { alinhamentos horizontal e vertical, permite aos } \\
\text { motoristas fazer boa leitura da projeto? (por } \\
\text { exemplo, delimitações de vegetação, postes, } \\
\text { cercas, etc.) }\end{array}$ & $\begin{array}{l}\text { Adequação de termos para melhorar a clareza } \\
\text { do entendimento da microcategoria pelo } \\
\text { auditor. Além disso, esta microcategoria será } \\
\text { realocada na macrocategoria sinalização, por se } \\
\text { tratar de assunto relacionado à sinalização da } \\
\text { rodovia. }\end{array}$ & & $\begin{array}{l}\text { O projeto de sinalização vertical nos alinhamentos } \\
\text { horizontal e vertical, permitirá boa leitura pelos usuários } \\
\text { da rodovia? }\end{array}$ & \\
\hline $\begin{array}{l}\text { O alinhamento horizontal e vertical é consistente } \\
\text { com a velocidade? }\end{array}$ & $\begin{array}{l}\text { Adequação de termos para melhorar a clareza } \\
\text { do entendimento da microcategoria pelo } \\
\text { auditor. }\end{array}$ & & $\begin{array}{l}\text { O alinhamento horizontal e e oalinhamento vertical é } \\
\text { compatível com a velocidade diretriz?" }\end{array}$ & \\
\hline \multicolumn{2}{|l|}{ Macrocategoria - Geometria } & \multirow{2}{*}{ Excluído } & \multirow{2}{*}{ Adaptado } & \multirow{2}{*}{ Incluído } \\
\hline \multicolumn{2}{|l|}{ Mesocategoria - Distância de visibilidade } & & & \\
\hline Microcategoria preliminar & Considerações dos técnicos & \multicolumn{3}{|c|}{ Microcategoria Final } \\
\hline $\begin{array}{l}\text { Os alinhamentos verticais e horizontais fornecem } \\
\text { distância de } \\
\text { necessária? }\end{array}$ & $\begin{array}{l}\text { Adequação de termos para melhorar a clareza } \\
\text { do entendimento da microcategoria pelo } \\
\text { auditor. }\end{array}$ & & $\begin{array}{l}\text { Os alinhamentos verticais e horizontais fornecem } \\
\text { distância de visibilidade e visibilidade necessária para as } \\
\text { ultrapassagens? }\end{array}$ & \\
\hline \multicolumn{2}{|l|}{ Macrocategoria - Geometria } & \multirow{2}{*}{ Excluído } & \multirow{2}{*}{ Adaptado } & \multirow{2}{*}{ Incluído } \\
\hline \multicolumn{2}{|c|}{ Mesocategoria - Efeitos da não conformidade com as normas ou diretrizes } & & & \\
\hline Microcategoria preliminar & Considerações dos técnicos & \multicolumn{3}{|c|}{ Microcategoria Final } \\
\hline $\begin{array}{l}\text { Foi adotado algum aspecto particular no projeto } \\
\text { que não corresponde as normas? Porém a } \\
\text { segurança foi mantida? }\end{array}$ & \multirow{2}{*}{ Microcategorias agrupadas } & \multirow{2}{*}{ - } & \multirow{2}{*}{$\begin{array}{l}\text { Foi adotado algum aspecto particular no projeto que } \\
\text { não corresponde às normas, mas com justificativa } \\
\text { técnica aceitável? E a segurança foi mantida? }\end{array}$} & \\
\hline $\begin{array}{l}\text { Se for detectado algum projeto que não atende } \\
\text { as normas? Manteve a segurança? }\end{array}$ & & & & \\
\hline \multicolumn{2}{|l|}{ Macrocategoria - Geometria } & \multirow{2}{*}{ Excluído } & \multirow{2}{*}{ Adaptado } & \multirow{2}{*}{ Incluído } \\
\hline \multicolumn{2}{|c|}{ Mesocategoria - interface entre o projeto proposto e rodovia existente } & & & \\
\hline Microcategoria preliminar & Considerações dos técnicos & \multicolumn{3}{|c|}{ Microcategoria Final } \\
\hline $\begin{array}{l}\text { A ligação ocorre em zonas de perigo como } \\
\text { parte superior de curva vertical, eixo horizontal, } \\
\text { perigos na margem da rodovia ou áreas de } \\
\text { baixa visibilidade? }\end{array}$ & $\begin{array}{l}\text { Adequação de termos para melhorar a clareza } \\
\text { do entendimento da microcategoria pelo } \\
\text { auditor. }\end{array}$ & & $\begin{array}{l}\text { A ligação entre o projeto proposto e a rodovia } \\
\text { existente ocorre em zonas de perigo como parte } \\
\text { superior de curva vertical, em trecho de curva } \\
\text { horizontal, perigos na margem da rodovia ou áreas de } \\
\text { baixa visibilidade? }\end{array}$ & \\
\hline $\begin{array}{l}\text { Na transição da rodovia projetada com a } \\
\text { existente, considerou a necessidade de aviso } \\
\text { prévio? }\end{array}$ & $\begin{array}{l}\text { Adequação de termos para melhorar a clareza } \\
\text { do entendimento da microcategoria pelo } \\
\text { auditor. }\end{array}$ & & $\begin{array}{l}\text { Na ligação da rodovia projetada com a rodovia } \\
\text { existente, considerou a necessidade de pré sinalização? }\end{array}$ & \\
\hline
\end{tabular}

Fonte: Elaborado pela autora, 2015 
O Quadro 5.9 mostra as considerações realizadas pelos técnicos em relação às macrocategorias "obstáculos fixos", "usuários da rodovia" e "sinalização e iluminação" do instrumento adaptado ao projeto básico, suas microcategorias e suas respectivas avaliações.

Quadro 5.9: Avaliações dos técnicos - Projeto básico - macrocategoria - "obstáculos fixos", "usuários da rodovia", "sinalização e iluminação"

\begin{tabular}{|c|c|c|c|c|}
\hline \multicolumn{2}{|l|}{ Macrocategoria- Obstáculos fixos } & \multirow{2}{*}{ Excluído } & \multirow{2}{*}{ Adaptado } & \multirow{2}{*}{ Incluído } \\
\hline \multicolumn{2}{|l|}{ Mesocategoria -Dispositivos centrais } & & & \\
\hline Microcategoria preliminar & Considerações dos técnicos & \multicolumn{3}{|c|}{ Microcategoria Final } \\
\hline $\begin{array}{l}\text { As barreiras laterais e das pontes estão de } \\
\text { acordo com o nível de desempenho dos testes de } \\
\text { colisões para a classificação da rodovia? }\end{array}$ & $\begin{array}{l}\text { Adequação de termos para melhorar a clareza } \\
\text { do entendimento da microcategoria pelo auditor. }\end{array}$ & & $\begin{array}{l}\text { Os projetos de barreiras laterais ao longo da rodovia e } \\
\text { das obras de arte especiais estão de acordo com o nível } \\
\text { de desempenho dos testes dos impactos para a classe da } \\
\text { rodovia? }\end{array}$ & \\
\hline \multicolumn{2}{|l|}{ Macrocategoria - Usuários da rodovia } & \multirow{2}{*}{ Excluído } & \multirow{2}{*}{ Adaptado } & \multirow{2}{*}{ Incluído } \\
\hline \multicolumn{2}{|l|}{ Mesocategoria - Ciclistas } & & & \\
\hline Microcategoria preliminar & Considerações dos técnicos & \multicolumn{3}{|c|}{ Microcategoria Final } \\
\hline $\begin{array}{l}\text { O projeto das ciclovias estão de acordo com as } \\
\text { normas, ou adequadas? }\end{array}$ & $\begin{array}{l}\text { Adequação de termos para melhorar a clareza } \\
\text { do entendimento da microcategoria pelo } \\
\text { auditor. }\end{array}$ & & $\begin{array}{l}\text { O projeto das ciclovias está adequado e de acordo } \\
\text { com as normas? }\end{array}$ & \\
\hline \multicolumn{2}{|l|}{ Mesocategoria - Sinalização Horizontal } & Excluído & Adaptado & Incluído \\
\hline Microcategoria preliminar & Considerações dos técnicos & \multicolumn{3}{|c|}{ Microcategoria Final } \\
\hline $\begin{array}{l}\text { As demarcações anteriores e/ou adjacentes } \\
\text { podem ser melhoradas? Se não realizar as } \\
\text { melhorias e manutenções, a segurança poderá } \\
\text { ser mantida? }\end{array}$ & $\begin{array}{l}\text { Adequação de termos para melhorar a clareza } \\
\text { do entendimento da microcategoria } \\
\text { auditor. }\end{array}$ & & $\begin{array}{l}\text { As demarcações pré-existentes e/ou adjacentes podem } \\
\text { ser melhoradas? Se não realizar as melhorias e } \\
\text { manutenções, a segurança poderá ser mantida? }\end{array}$ & \\
\hline \multicolumn{2}{|l|}{ Macrocategoria - Sinalização e iluminação } & \multirow{2}{*}{ Excluído } & \multirow{2}{*}{ Adaptado } & \multirow{2}{*}{ Incluído } \\
\hline \multicolumn{2}{|l|}{ Mesocategoria - Sinalização Vertical } & & & \\
\hline
\end{tabular}

Fonte: Elaborado pela autora, 2015

O Quadro 5.10 mostra os comentários realizados pelos técnicos em relação à macrocategoria "gestão de tráfego" e "perguntas adicionais" do instrumento adaptado ao projeto básico, suas microcategorias e suas respectivas avaliações. 
Quadro 5.10: Avaliações dos técnicos - Projeto básico - macrocategorias - "gestão de tráfego e "perguntas adicionais"

\begin{tabular}{|c|c|c|c|c|}
\hline \multicolumn{2}{|l|}{ Macrocategoria - Gestão de tráfego } & Excluído & Adaptado & Incluído \\
\hline $\begin{array}{l}\text { As ultrapassagens, distância de visibilidade e de } \\
\text { parada são adequadas? }\end{array}$ & $\begin{array}{l}\text { Adequar texto e Inserir complementação para o } \\
\text { item ultrapassagem com uso de permissão e } \\
\text { proibição. }\end{array}$ & & $\begin{array}{l}\text { As permissões e proibições de ultrapassagens, distância } \\
\text { de visibilidade e de parada são adequadas? }\end{array}$ & \\
\hline \multicolumn{2}{|l|}{ Macrocategoria - Perguntas adicionais } & \multirow{2}{*}{ Excluído } & \multirow{2}{*}{ Adaptado } & \multirow{2}{*}{ Incluído } \\
\hline \multicolumn{2}{|l|}{ Mesocategoria - Gestão de tráfego } & & & \\
\hline Microcategoria preliminar & Considerações dos técnicos & \multicolumn{3}{|c|}{ Microcategoria Final } \\
\hline $\begin{array}{l}\text { O número e a localização dos acessos são } \\
\text { adequados? }\end{array}$ & $\begin{array}{l}\text { Adequação de termos para melhorar a clareza } \\
\text { do entendimento da microcategoria pelo } \\
\text { auditor. }\end{array}$ & & $\begin{array}{l}\text { O número e a localização dos acessos são adequados } \\
\text { para o projeto proposto? }\end{array}$ & \\
\hline
\end{tabular}

Fonte: Elaborado pela autora, 2015

\subsubsection{Aprimoramento do instrumento de projeto executivo}

$\mathrm{Na}$ análise da verificação das observações realizadas pelos técnicos, percebeu-se que os itens da macrocategoria “aspectos ambientais" foi encaminhado para avaliação. No entanto, havia sido verificado por meio dos critérios estabelecidos nesta dissertação que essa macrocategoria não fazia parte do instrumento preliminar a ser verificado pelos técnicos. Dessa forma, foi retirado do instrumento final, e será alvo de indicação de avaliação para trabalhos futuros.

Assim, o Quadro 5.11 contêm os comentários realizados pelos técnicos em relação à macrocategoria do projeto executivo "tópicos gerais", e suas respectivas microcategorias.

Quadro 5.11: Avaliação dos técnicos - Projeto executivo - macrocategoria - "Tópicos gerais"

\begin{tabular}{|c|c|c|c|c|}
\hline \multicolumn{2}{|l|}{ Mesocategoria - Drenagem } & Excluído & Adaptado & Incluído \\
\hline $\begin{array}{l}\text { O projeto proposto de drenagem da rodovia } \\
\text { está de forma adequado? }\end{array}$ & $\begin{array}{l}\text { Adequação de termos para melhorar a } \\
\text { clareza do entendimento da } \\
\text { microcategoria pelo auditor. }\end{array}$ & & $\begin{array}{l}\text { O projeto de drenagem proposto é adequado para a } \\
\text { finalidade da rodovia? }\end{array}$ & \\
\hline $\begin{array}{l}\text { Seções planas são evitadas ou adequadamente } \\
\text { distribuídas no início ou no final de uma } \\
\text { curvatura? }\end{array}$ & $\begin{array}{l}\text { Adequação de termos para melhorar a } \\
\text { clareza do entendimento da } \\
\text { microcategoria pelo auditor. }\end{array}$ & & $\begin{array}{l}\text { Nas seções em tangentes o projeto de drenagem } \\
\text { proposto está compatível com o projetos de início e final } \\
\text { das curvas? }\end{array}$ & \\
\hline
\end{tabular}


Quadro 5.121: Avaliação dos técnicos - Projeto executivo - macrocategoria - "Tópicos gerais" - continuação

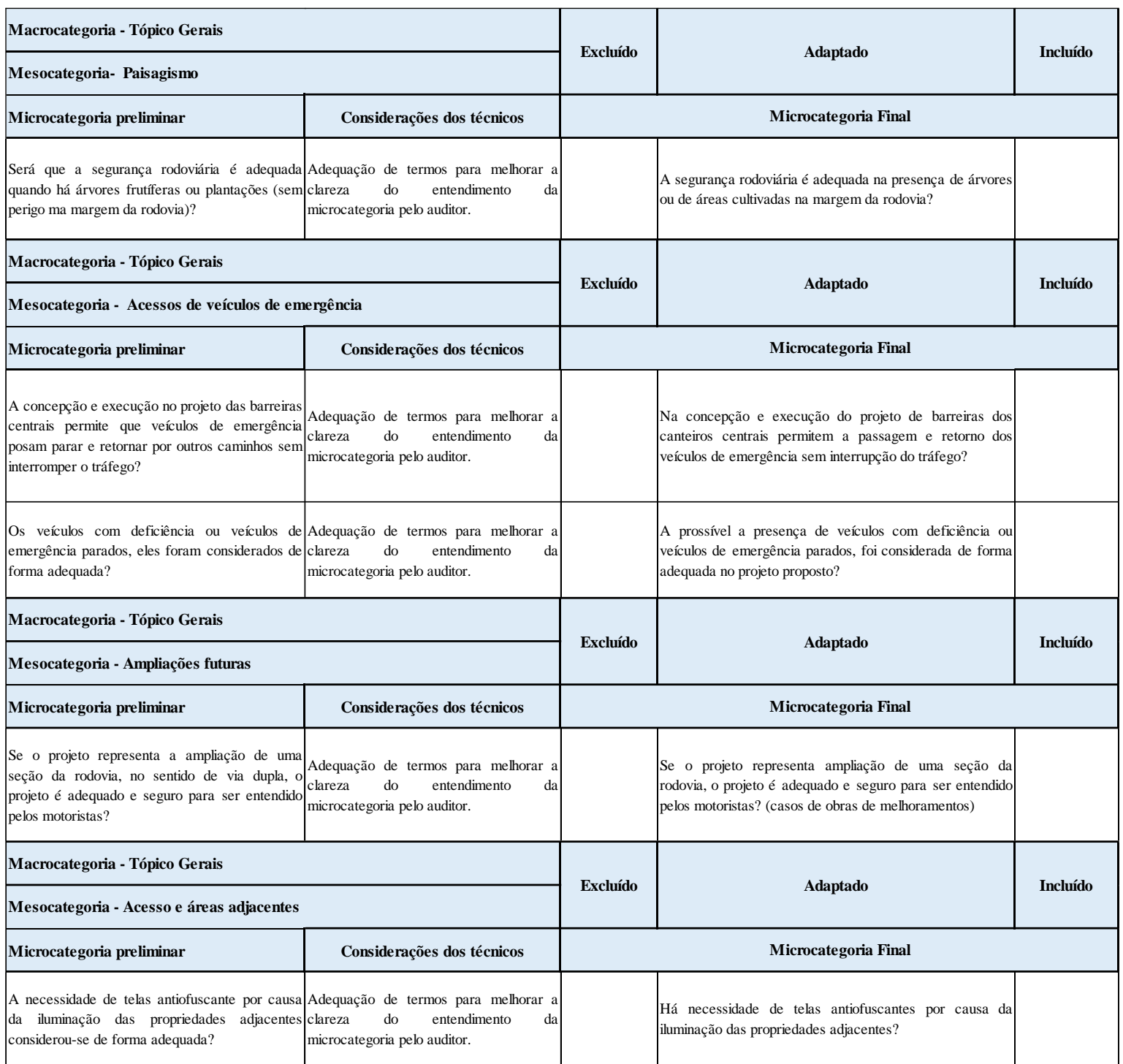

Fonte: Elaborado pela autora, 2015

O Quadro 5.12 mostra os comentários realizados pelos técnicos em relação à macrocategoria "geometria" do instrumento adaptado ao projeto executivo, suas microcategorias e suas respectivas avaliações. 
Quadro 5.12: Avaliações dos técnicos - Projeto executivo - macrocategoria "geometria"

\begin{tabular}{|c|c|c|c|c|}
\hline \multicolumn{2}{|l|}{ Mesocategoria - Elementos da seção transversal } & Excluído & Adaptado & Incluído \\
\hline $\begin{array}{l}\text { A superelevação é consistente com ambiente e } \\
\text { velocidade da rodovia? }\end{array}$ & $\begin{array}{l}\text { Adequação de termos para melhorar a } \\
\text { clareza do entendimento da } \\
\text { microcategoria pelo auditor. }\end{array}$ & & $\begin{array}{l}\text { A superelevação é compatível com a velocidade de projeto } \\
\text { da rodovia? }\end{array}$ & \\
\hline $\begin{array}{l}\text { As inclinações dos taludes é manobrável para } \\
\text { automóveis e caminhões? }\end{array}$ & 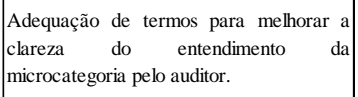 & & $\begin{array}{l}\text { Os veículos (como automóveis e caminhões) manobram de } \\
\text { forma segura devido às inclinações de taludes? }\end{array}$ & \\
\hline Existem instalações para os pedestres e ciclistas? & $\begin{array}{l}\text { Adequação de termos para melhorar a } \\
\text { clareza } \\
\text { microcategoria pelo auditor. }\end{array}$ & & $\begin{array}{l}\text { Existem instalações para circulação de pedestres e } \\
\text { ciclistas? }\end{array}$ & \\
\hline $\begin{array}{l}\text { As seções transversais são seguras } \\
\text { (especialmente onde as seções da rodovia } \\
\text { existentes foram utilizados ou serão utilizados } \\
\text { para gerar acesso a estreitamentos em pontes, } \\
\text { etc.) }\end{array}$ & $\begin{array}{ll}\text { Adequação de } & \\
\text { clareza } & \text { do entendimento para melhorar a } \\
\text { microcategoria pelo auditor. }\end{array}$ & & $\begin{array}{l}\text { As inclinações transversais são seguras? (particularmente } \\
\text { quando as seções da rodovia existente foram utilizadas ou } \\
\text { será utilizada para implantação de acesso nos casos de } \\
\text { melhoramento) }\end{array}$ & \\
\hline $\begin{array}{l}\text { A superelevação é adequada e suficiente em } \\
\text { todos os lugares onde é necessária? }\end{array}$ & $\begin{array}{l}\text { Adequação de termos para melhorar a } \\
\text { clareza do entendimento da } \\
\text { microcategoria pelo auditor. }\end{array}$ & & A superelevação é compatível em todo o projeto proposto? & \\
\hline $\begin{array}{l}\text { O projeto está livre de variações imprevistas em } \\
\text { relação a seção transversal? }\end{array}$ & 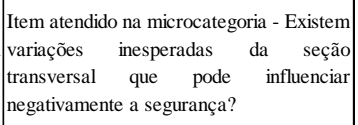 & $\mathbf{x}$ & $\begin{array}{l}\text { Existem variações inesperadas da seção transversal que } \\
\text { pode influenciar negativamente a segurança? }\end{array}$ & \\
\hline Microcategoria proposta & Considerações dos técnicos & \multicolumn{3}{|c|}{ Microcategoria Final } \\
\hline $\begin{array}{l}\text { Os recursos da gestão do tráfego estão } \\
\text { destinadas para evitar a criação de condições } \\
\text { inseguras e fornecer orientações adequadas? }\end{array}$ & $\begin{array}{l}\text { Retirar do item detalhe de geometria, pois } \\
\text { trata de microcategoria a ser verificado na } \\
\text { concepção e fiscalização do projeto e não } \\
\text { na ASV projetos rodoviários. }\end{array}$ & $\mathbf{x}$ & & \\
\hline $\begin{array}{l}\text { Os requisitos para ultrapassagem são } \\
\text { satisfatórios? }\end{array}$ & $\begin{array}{l}\text { item atendido na microcategoria - As } \\
\text { faixas de ultrapassagens onde necessárias } \\
\text { foram previstas e devidamente } \\
\text { sinalizadas? }\end{array}$ & $\mathbf{x}$ & & \\
\hline $\begin{array}{l}\text { As faixas de ultrapassagem são previstas com } \\
\text { segurança no início e ao término das manobras? } \\
\text { E estão devidamente sinalizadas? }\end{array}$ & $\begin{array}{l}\text { Adequação de termos para melhorar a } \\
\text { clareza do entendimento da } \\
\text { microcategoria pelo auditor. }\end{array}$ & & $\begin{array}{l}\text { As faixas de ultrapassagens, onde necessárias, foram } \\
\text { previstas e devidamente sinalizadas? }\end{array}$ & \\
\hline \multicolumn{2}{|l|}{ Macrocategoria - Geometria } & \multirow{2}{*}{ Excluído } & \multirow{2}{*}{ Adaptado } & \multirow{2}{*}{ Incluído } \\
\hline \multicolumn{2}{|l|}{ Mesocategoria - Alinhamento vertical e horizontal } & & & \\
\hline Microcategoria preliminar & Considerações dos técnicos & \multicolumn{3}{|c|}{ Microcategoria Final } \\
\hline $\begin{array}{l}\text { O projeto de alinhamento horizontal e vertical } \\
\text { estão alinhados corretamente? }\end{array}$ & $\begin{array}{l}\text { Adequação de termos para melhorar a } \\
\text { clareza do entendimento da } \\
\text { microcategoria pelo auditor. }\end{array}$ & & $\begin{array}{l}\text { O projeto do alinhamento horizontal e alinhamento vertical } \\
\text { estão adequadamente compatibilizados? }\end{array}$ & \\
\hline
\end{tabular}


Quadro 5.12: Avaliações dos técnicos - Projeto executivo - macrocategoria "geometria"

\begin{tabular}{|c|c|c|c|c|}
\hline \multicolumn{2}{|l|}{ Macrocategoria - Geometria } & \multirow{2}{*}{ Excluído } & \multirow{2}{*}{ Adaptado } & \multirow{2}{*}{ Incluído } \\
\hline \multicolumn{2}{|l|}{ Mesocategoria - Distância de visibilidade } & & & \\
\hline Microcategoria preliminar & Considerações dos técnicos & \multicolumn{3}{|c|}{ Microcategoria Final } \\
\hline $\begin{array}{l}\text { Os alinhamentos horizontal e vertical são } \\
\text { consistente com a visibilidade necessária? }\end{array}$ & $\begin{array}{l}\text { Item atendi na mesocategoria }- \text { Os } \\
\text { alinhamentos verticais } \\
\text { fornece distância de } \\
\text { visibilidade necessária? }\end{array}$ & $\mathbf{x}$ & $\begin{array}{l}\text { O alinhamentos verticais e horizontais possuem distância de } \\
\text { visibilidade adequada? }\end{array}$ & \\
\hline $\begin{array}{l}\text { A linha de visibilidade e redução da distância de } \\
\text { visibilidade do projeto obstruída por: defensas, } \\
\text { outdoors na margem da rodovia: cercas ou } \\
\text { divisórias; mobiliário na rodovia; } \\
\text { Estacionamentos, sinalização vertical, vegetação } \\
\text { e paisagismo, estrutura de pontes, veículos } \\
\text { estacionados na margem da rodovia, ou filas } \\
\text { formadas pelos veículos. }\end{array}$ & $\begin{array}{l}\text { Adequação de termos para melhorar a } \\
\text { clareza do entendimento da } \\
\text { microcategoria pelo auditor. }\end{array}$ & & $\begin{array}{l}\text { A linha de visibilidade ao longo do projeto está desobstruída } \\
\text { de elementos como: defensas, cercas ou divisórias; } \\
\text { estrutura de obras de arte; vegetação, etc. }\end{array}$ & \\
\hline $\begin{array}{l}\text { A rodovia pode ser usada por veículos de grande } \\
\text { altura, ou se não, foi considerado um desvio para } \\
\text { um rota alternativa quando necessário? }\end{array}$ & $\begin{array}{lll}\text { Adequação de termos para melhorar a } \\
\text { clareza do entendimento } & \text { da } \\
\text { microcategoria pelo auditor. }\end{array}$ & & $\begin{array}{l}\text { Antes de obra-de-arte-especiais com altura regulamentada, } \\
\text { está prevista e sinalização uma alternativa de saída para a } \\
\text { passagem de veículos com altura acima do padrão? }\end{array}$ & \\
\hline $\begin{array}{l}\text { Foi considerado a visão mínima do triângulo de } \\
\text { visibilidade: nas entradas e saídas de rampas? } \\
\text { áreas de minas? nas interseções? rotatórias? ou } \\
\text { outros pontos de conflitos? }\end{array}$ & $\begin{array}{l}\text { Adequação de termos para melhorar a } \\
\text { clareza do entendimento da } \\
\text { microcategoria pelo auditor. }\end{array}$ & & $\begin{array}{l}\text { Foi considerado o dimensionamento do triângulo de } \\
\text { visibilidade nas entradas e saídas de rampas e nas } \\
\text { interseções? }\end{array}$ & \\
\hline \multicolumn{2}{|l|}{ Macrocategoria - Geometria } & \multirow{2}{*}{ Excluído } & \multirow{2}{*}{ Adaptado } & \multirow{2}{*}{ Incluído } \\
\hline \multicolumn{2}{|c|}{ Mesocategoria - Efeitos da não conformidade com as normas ou diretrizes } & & & \\
\hline Microcategoria preliminar & Considerações dos técnicos & \multicolumn{3}{|c|}{ Microcategoria Final } \\
\hline $\begin{array}{l}\text { No caso de adoção de algum aspecto particular } \\
\text { no projeto não cumprir as normas? A segurançaa } \\
\text { foi mantida? }\end{array}$ & Sugestão de agrupar os itens. & & Foi adotado algum aspecto particular no projeto que não & \\
\hline $\begin{array}{l}\text { Se for detectado algum projeto que não atende as } \\
\text { normas: A segurança foi mantida? }\end{array}$ & & & aceitável? E a segurança foi mantida? & \\
\hline \multicolumn{2}{|l|}{ Macrocategoria - Geometria } & \multirow{2}{*}{ Excluído } & \multirow{2}{*}{ Adaptado } & \multirow{2}{*}{ Incluído } \\
\hline \multicolumn{2}{|c|}{ Mesocategoria - Interface entre o projeto proposto e rodovia existente } & & & \\
\hline Microcategoria preliminar & Considerações dos técnicos & \multicolumn{3}{|c|}{ Microcategoria Final } \\
\hline $\begin{array}{l}\text { É segura a transição, em áreas onde o ambiente } \\
\text { rodoviário muda (por exemplo, quando se desloca } \\
\text { da área urbana para rural, de um lugar restrito a } \\
\text { irrestrito, de uma via iluminada para uma sem } \\
\text { iluminação)? }\end{array}$ & $\begin{array}{lll}\text { Adequação de } & & \\
\text { clareza } & \text { do entendimento } & \text { da } \\
\text { microcategoria pelo auditor. }\end{array}$ & & $\begin{array}{l}\text { É segura a transição entre ambientes rodoviários como } \\
\text { áreas rurais e urbanas, ou entre lugares com e sem } \\
\text { iluminação? }\end{array}$ & \\
\hline $\begin{array}{l}\mathrm{Na} \text { transição da rodovia projetada com a } \\
\text { existente, considerou a necessidade de aviso } \\
\text { prévio? }\end{array}$ & $\begin{array}{ll}\text { Adequação de termos para melhorar a } \\
\text { clareza do entendimento da } \\
\text { microcategoria pelo auditor. }\end{array}$ & & $\begin{array}{l}\text { Na ligação da rodovia projetada com a existente, foi } \\
\text { considerada a necessidade de pré sinalização? }\end{array}$ & \\
\hline $\begin{array}{l}\text { A transição entre o projeto antigo e o novo } \\
\text { projeto é satisfatório? }\end{array}$ & Item inseridos em questões anteriores. & $\mathbf{x}$ & & \\
\hline $\begin{array}{l}\text { Se a rodovia existente possui padrão inferior ao } \\
\text { novo projeto, a advertência da redução é clara e } \\
\text { inequívoca? }\end{array}$ & Item inseridos em questões anteriores. & $\mathbf{x}$ & & \\
\hline $\begin{array}{l}\text { Se o padrão das faixas varia, a alteração é } \\
\text { realizada com segurança? }\end{array}$ & $\begin{array}{l}\text { Adequação de termos para melhorar a } \\
\text { clareza do entendimento da } \\
\text { microcategoria pelo auditor. }\end{array}$ & & $\begin{array}{l}\text { Se a rodovia existente possui padrão diferente do padrão da } \\
\text { rodovia projetada, a transição é realizada com segurança? }\end{array}$ & \\
\hline $\mid \begin{array}{l}\text { A transição ocorre quando a mudança de } \\
\text { ambiente é seguro? (Por exemplo, urbana para } \\
\text { rural, área com restrição ou sem restrições, uma } \\
\text { área iluminada, ou sem iluminação) }\end{array}$ & $\begin{array}{l}\text { Item atendido na mesocategoria - É } \\
\text { segura a transição entre ambientes } \\
\text { rodoviários como áreas rurais e urbanas, } \\
\text { ou entre lugares com e sem iluminação? }\end{array}$ & $\mathbf{x}$ & $\begin{array}{l}\text { É segura a transição entre ambientes rodoviários como } \\
\text { áreas rurais e urbanas, ou entre lugares com e sem } \\
\text { iluminaçãa? }\end{array}$ & \\
\hline
\end{tabular}

Fonte: Elaborado pela autora, 2015 
O Quadro 5.13 mostra os comentários realizados em relação à macrocategoria "interseções" do instrumento adaptado ao projeto executivo, suas microcategorias e suas respectivas avaliações.

\section{Quadro 5.133: Avaliações dos técnicos - Projeto executivo - macrocategoria "interseções"}

\begin{tabular}{|c|c|c|c|c|}
\hline \multicolumn{2}{|l|}{ Macrocategoria - Interseções } & \multirow{2}{*}{ Excluído } & \multirow{2}{*}{ Adaptado } & \multirow{2}{*}{ Incluído } \\
\hline \multicolumn{2}{|l|}{ Mesocategoria - Quantidade, tipo e localização } & & & \\
\hline Microcategoria preliminar & Considerações dos técnicos & \multicolumn{3}{|c|}{ Microcategoria Final } \\
\hline $\begin{array}{l}\text { Foram planejadas, onde necessário, os gradis de } \\
\text { pedestres? (Por exemplo, para orientar pedestres } \\
\text { ou para desencorajar estacionamento }\end{array}$ & $\begin{array}{l}\text { Adequação de } \\
\text { clareza do } \\
\text { microcategoria pelo auditor. }\end{array}$ & & $\begin{array}{l}\text { Em locais de travessia de pedestres foram previstos os } \\
\text { gradis de pedestres para orientar os pedestres? }\end{array}$ & \\
\hline $\begin{array}{l}\text { As ilhas e sinalizações verticais foram colocadas } \\
\text { quando necessário? }\end{array}$ & $\begin{array}{l}\text { Adequação de termos para melhorar a } \\
\text { clareza do entendimento da } \\
\text { microcategoria pelo auditor. }\end{array}$ & & $\begin{array}{l}\text { Nas interseções, ilhas e sinalização vertical foram } \\
\text { projetadas quando necessário? }\end{array}$ & \\
\hline \begin{tabular}{|l|} 
Os veículos podem estacionar perto da \\
intersecção: podem fazer com segurança, ou \\
requer que o estacionamento seja transferido? \\
Representam algum perigo e pode ser evitado?
\end{tabular} & $\begin{array}{l}\text { Adequação de termos para melhorar a } \\
\text { clareza do entendimento da } \\
\text { microcategoria pelo auditor. }\end{array}$ & & $\begin{array}{l}\text { Os veículos podem estacionar perto das interseções com } \\
\text { segurança? }\end{array}$ & \\
\hline $\begin{array}{l}\text { É adequado a altura vertical para infraestrutura? } \\
\text { (como por exemplo, linhas de energia elétrica?) }\end{array}$ & $\begin{array}{l}\text { Adequação de termos para melhorar a } \\
\text { clareza do entendimento da } \\
\text { microcategoria pelo auditor. }\end{array}$ & & $\begin{array}{l}\text { Nos casos de infraestrutura de linha de transmissão, a } \\
\text { altura dos vãos foi dimensionado adequadamente? }\end{array}$ & \\
\hline \multicolumn{2}{|l|}{ Macrocategoria - Interseções } & \multirow{2}{*}{ Excluído } & \multirow{2}{*}{ Adaptado } & \multirow{2}{*}{ Incluído } \\
\hline \multicolumn{2}{|l|}{ Mesocategoria - Controle semafórico } & & & \\
\hline Microcategoria preliminar & Considerações dos técnicos & \multicolumn{3}{|c|}{ Microcategoria Final } \\
\hline $\begin{array}{l}\text { As luzes dos semáforos são visíveis? (por } \\
\text { exemplo, elas não estão obstruídas por árvores, } \\
\text { postes, sinais de trânsito ou veículos de grande } \\
\text { porte). }\end{array}$ & $\begin{array}{l}\text { Sugestão de retirar, mais adequado para } \\
\text { as rodovias em operação. }\end{array}$ & $\mathrm{x}$ & & \\
\hline $\begin{array}{l}\text { As lâmpadas orientadas em outra direção de } \\
\text { atuação estão suficientemente protegidas de } \\
\text { modo a ser vistas apenas pelo tráfego que a } \\
\text { enfrenta? }\end{array}$ & $\begin{array}{l}\text { Sugestão de retirar, mais adequado para } \\
\text { as rodovias em operação. }\end{array}$ & $\mathrm{x}$ & & \\
\hline $\begin{array}{l}\text { Os condutores que se aproximam da interseção } \\
\text { ver claramente os pedestres? }\end{array}$ & $\begin{array}{l}\text { Sugestão de retirar, mais adequado para } \\
\text { as rodovias em operação. }\end{array}$ & $\mathrm{x}$ & & \\
\hline $\begin{array}{l}\text { É adequada as demarcações para o desvio do } \\
\text { tráfego? }\end{array}$ & $\begin{array}{l}\text { Sugestão de retirar pois não adequado } \\
\text { para interseções com controle de } \\
\text { semáforos. }\end{array}$ & $\mathrm{x}$ & & \\
\hline \multicolumn{2}{|l|}{ Macrocategoria - Interseções } & \multirow{2}{*}{ Excluído } & \multirow{2}{*}{ Adaptado } & \multirow{2}{*}{ Incluído } \\
\hline \multicolumn{2}{|l|}{ Mesocategoria - Rotatórias } & & & \\
\hline Microcategoria preliminar & Considerações dos técnicos & \multicolumn{3}{|c|}{ Microcategoria Final } \\
\hline $\begin{array}{l}\text { Os detalhes são adequados da ilha central? } \\
\text { (Como delimitação, elevação, visibilidade)? }\end{array}$ & $\begin{array}{l}\text { Sugestão de retirar, por estar contido no } \\
\text { item - Nas rotatórias a ilha central é alta e } \\
\text { visível? }\end{array}$ & $\mathrm{x}$ & & \\
\hline \multicolumn{2}{|l|}{ Macrocategoria - Interseções } & \multirow{2}{*}{ Excluído } & \multirow{2}{*}{ Adaptado } & \multirow{2}{*}{ Incluído } \\
\hline \multicolumn{2}{|l|}{ Mesocategoria - Outras interseções } & & & \\
\hline Microcategoria preliminar & Considerações dos técnicos & \multicolumn{3}{|c|}{ Microcategoria Final } \\
\hline $\begin{array}{l}\text { Considerou a necessidade de pintar as bordas das } \\
\text { ilhas e refúgios? }\end{array}$ & $\begin{array}{l}\text { Adequação de termos para melhorar a } \\
\text { clareza do entendimento da } \\
\text { microcategoria pelo auditor. }\end{array}$ & & $\begin{array}{l}\text { Nas bordas das ilhas e refúgios das interseções há } \\
\text { necessidade de pintura? }\end{array}$ & \\
\hline $\begin{array}{l}\text { As interseções tem comprimento adequado para } \\
\text { acomodar os veículos? As interseções tem } \\
\text { capacidade para acomodar veículos que efetuam } \\
\text { movimentos disponíveis? }\end{array}$ & 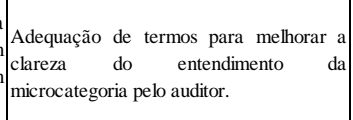 & & $\begin{array}{l}\text { Os ramos das interseções tem comprimento adequado para } \\
\text { acomodar os veículos? São projetdas, quando necesário, } \\
\text { faixas para armazenamento dos veículos que fazem } \\
\text { conversões? }\end{array}$ & \\
\hline
\end{tabular}


Fonte: Elaborado pela autora, 2015

O Quadro 5.14 mostra os comentários realizados em relação à macrocategoria “obstáculos fixos" do instrumento adaptado ao projeto executivo, suas microcategorias e suas respectivas avaliações.

Quadro 5.14: Avaliações dos técnicos - Projeto executivo - macrocategoria Obstáculos fixos

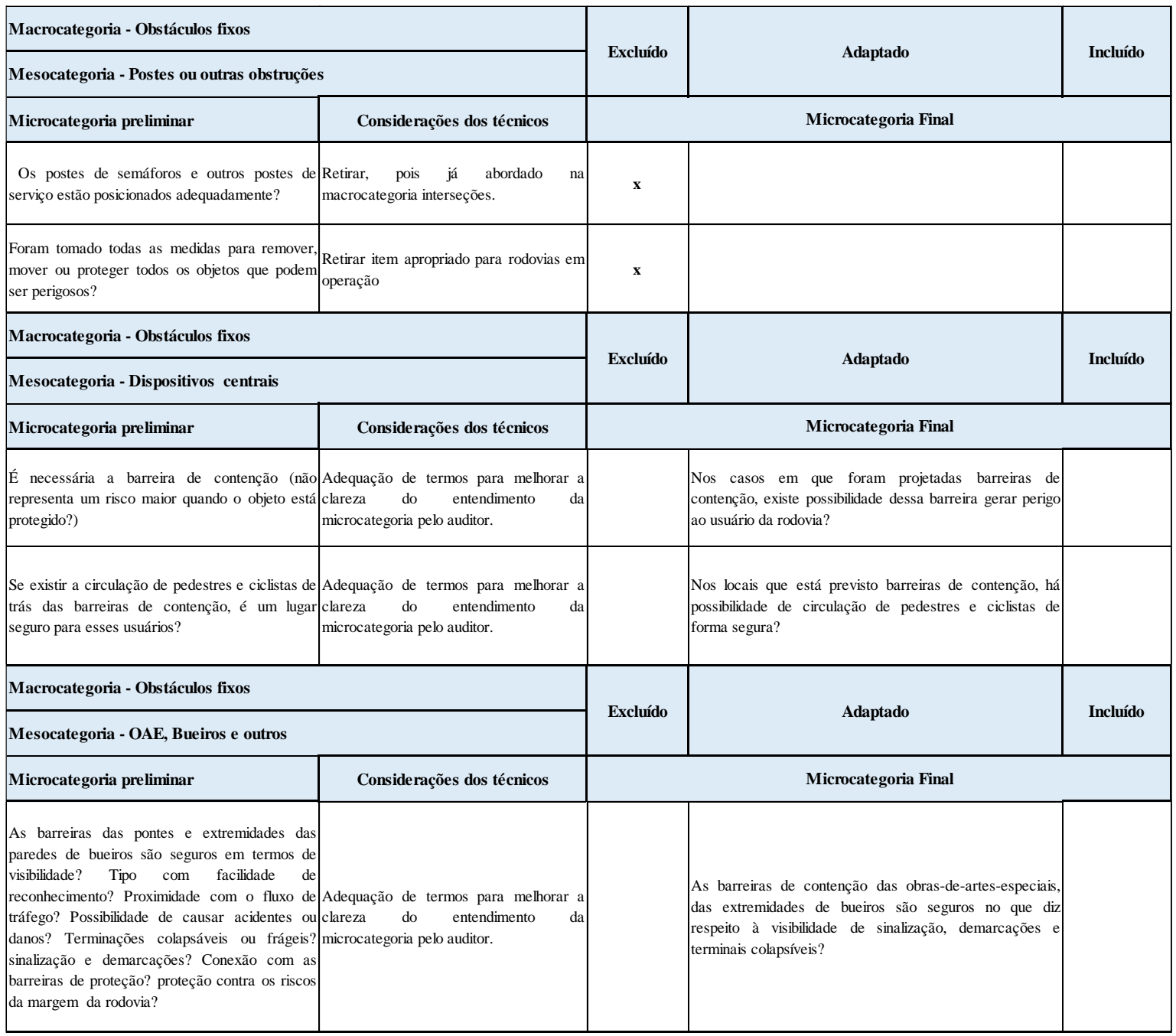

Fonte: Elaborado pela autora, 2015

O Quadro 5.15 mostra os comentários realizados em relação à macrocategoria "usuários da rodovia" do instrumento adaptado ao projeto executivo, suas microcategorias e suas respectivas avaliações. 
Quadro 5.15: Avaliações dos técnicos - Projeto executivo - macrocategoria "usuários da rodovia"

\begin{tabular}{|c|c|c|c|c|}
\hline \multicolumn{2}{|l|}{ Macrocategoria - Usuários da rodovia } & \multirow{2}{*}{ Excluído } & \multirow{2}{*}{ Adaptado } & \multirow{2}{*}{ Incluído } \\
\hline \multicolumn{2}{|l|}{ Mesocategoria - Veículos de manutenção } & & & \\
\hline Microcategoria preliminar & Considerações dos técnicos & \multicolumn{3}{|c|}{ Microcategoria Final } \\
\hline $\begin{array}{l}\text { Existe necessidade de considerar os veículos com } \\
\text { instalações e sinalização adequada? }\end{array}$ & complementar o tipo de veículo. & & $\begin{array}{l}\text { Existe necessidade de considerar instalações e sinalização } \\
\text { para os veículos de manutenção? }\end{array}$ & \\
\hline \multicolumn{2}{|l|}{ Macrocategoria - Usuários da rodovia } & \multirow{2}{*}{ Excluído } & \multirow{2}{*}{ Adaptado } & \multirow{2}{*}{ Incluído } \\
\hline \multicolumn{2}{|l|}{ Mesocategoria - Ciclistas } & & & \\
\hline Microcategoria proposta & Considerações dos técnicos & \multicolumn{3}{|c|}{ Microcategoria Final } \\
\hline $\begin{array}{l}\text { Onde existe a necessidade de compartilhar as } \\
\text { instalações para os uso dos pedestres e ciclistas, } \\
\text { foram tratadas de forma segura? (incluindo } \\
\text { metrô e ponte) }\end{array}$ & $\begin{array}{l}\text { Adequação de termos para melhorar a } \\
\text { clareza do entendimento da } \\
\text { microcategoria pelo auditor. }\end{array}$ & & $\begin{array}{l}\text { Nos casos de compartilhamento das instalações entre } \\
\text { pedestres e ciclistas o tratamento foi feito de forma } \\
\text { segura? }\end{array}$ & \\
\hline \multicolumn{2}{|l|}{ Macrocategoria - Usuários da rodovia } & \multirow{2}{*}{ Excluído } & \multirow{2}{*}{ Adaptado } & \multirow{2}{*}{ Incluído } \\
\hline \multicolumn{2}{|l|}{ Mesocategoria - Pedestre } & & & \\
\hline Microcategoria preliminar & Considerações dos técnicos & \multicolumn{3}{|c|}{ Microcategoria Final } \\
\hline $\begin{array}{l}\text { Os pedestres podem atravessar de forma segura } \\
\text { as interseções? Nas faixas de pedestres } \\
\text { marcadas? Refúgios? Extensões de calçadas? } \\
\text { Pontes e bueiros? Ou outras situações? }\end{array}$ & $\begin{array}{l}\text { Adequação de termos para melhorar a } \\
\text { clareza do entendimento da } \\
\text { microcategoria pelo auditor. }\end{array}$ & & $\begin{array}{l}\text { Nas interseções os pedestres podem atravessar de forma } \\
\text { segura? Há sinalização adequada? }\end{array}$ & \\
\hline $\begin{array}{l}\text { Cada cruzamento é satisfatória em termos de: } \\
\text { Visibilidade para ambas as direções? Utilização } \\
\text { por pessoas com deficiências? Por pessoa } \\
\text { idosas? E usado por crianças em idade escolar? }\end{array}$ & $\begin{array}{l}\text { Adequação de termos para melhorar a } \\
\text { clareza do entendimento da } \\
\text { microcategoria pelo auditor. }\end{array}$ & & $\begin{array}{l}\text { Nos cruzamentos é adequada a visibilidade em ambas as } \\
\text { direções, para o uso com segurança por pessoas com } \\
\text { deficiências, pessoas idosas ou uso por crianças em idade } \\
\text { escolar? }\end{array}$ & \\
\hline $\begin{array}{l}\text { Os gradis de pedestres estão instalados nos } \\
\text { cruzamentos quando necessário? (na margem da } \\
\text { rodovia e de canteiros centrais)? }\end{array}$ & $\begin{array}{l}\text { Adequação de termos para melhorar a } \\
\text { clareza do entendimento da } \\
\text { microcategoria pelo auditor. }\end{array}$ & & $\begin{array}{l}\text { Os gradis de pedestres estão instalados nos cruzamentos } \\
\text { quando necessário? }\end{array}$ & \\
\hline A iluminação é adequada para cada interseção? & $\begin{array}{l}\text { Adequação de termos para melhorar a } \\
\text { clareza do entendimento da } \\
\text { microcategoria pelo auditor. }\end{array}$ & & $\begin{array}{l}\text { Nas travessias de pedestres próximo a interseções, a } \\
\text { iluminação é adequada? }\end{array}$ & \\
\hline $\begin{array}{l}\text { Os cruzamentos estão localizados em lugares } \\
\text { onde se maximiza o seu uso? }\end{array}$ & $\begin{array}{l}\text { Sugestão de retirar, pois não está } \\
\text { relacionado com o mesocategoria } \\
\text { pedestre }\end{array}$ & $\mathbf{x}$ & & \\
\hline $\begin{array}{l}\text { é possível evitar o cruzamento? (por exemplo, } \\
\text { alternativa mais direta, porém menos seguro) }\end{array}$ & $\begin{array}{l}\text { Sugestão de retirar, pois não está } \\
\text { relacionado com o mesocategoria } \\
\text { pedestre }\end{array}$ & $\mathbf{x}$ & & \\
\hline \multicolumn{2}{|l|}{ Macrocategoria - Usuários da rodovia } & \multirow{2}{*}{ Excluído } & \multirow{2}{*}{ Adaptado } & \multirow{2}{*}{ Incluído } \\
\hline \multicolumn{2}{|l|}{ Mesocategoria - Motocicletas } & & & \\
\hline Microcategoria preliminar & Considerações dos técnicos & \multicolumn{3}{|c|}{ Microcategoria Final } \\
\hline $\begin{array}{l}\text { São todos os postes e dispositivos necessários? } \\
\text { Se assim for, existe opção para protegê-los? }\end{array}$ & $\begin{array}{l}\text { Sugestão de retirar, pois não está } \\
\text { relacionado com o mesocategoria } \\
\text { motociclistas }\end{array}$ & $\mathbf{x}$ & & \\
\hline $\begin{array}{l}\text { área de drenagem e bueiros podem ser } \\
\text { superados com satisfação pelos motociclistas? }\end{array}$ & $\begin{array}{l}\text { Adequação de termos para melhorar a } \\
\text { clareza do entendimento da } \\
\text { microcategoria pelo auditor. }\end{array}$ & & $\begin{array}{l}\text { Nas áreas de drenagem superficial os motociclistas } \\
\text { podem passar pelos dispositivos de forma segura? }\end{array}$ & \\
\hline
\end{tabular}

Fonte: Elaborado pela autora, 2015 
O Quadro 5.16 mostra os comentários realizados em relação à macrocategoria "sinalização e iluminação" da rodovia do instrumento adaptado ao projeto executivo, suas microcategorias e suas respectivas avaliações.

Quadro 5.14: Avaliações dos técnicos - Projeto executivo - macrocategoria "Sinalização e iluminação"

\begin{tabular}{|c|c|c|c|c|}
\hline \multicolumn{2}{|l|}{ Macrocategoria - Sinalização e iluminação } & \multirow{2}{*}{ Excluído } & \multirow{2}{*}{ Adaptado } & \multirow{2}{*}{ Incluído } \\
\hline \multicolumn{2}{|l|}{ Mesocategoria - Sinalização Horizontal } & & & \\
\hline $\begin{array}{l}\text { Foi identificado e tratado algum lugar de } \\
\text { demarcações que poderia ser confuso ou mal } \\
\text { interpretado, de modo a considerar as respostas } \\
\text { dos usuários? }\end{array}$ & $\begin{array}{l}\text { Sugestão de retirar, por ser mais } \\
\text { adequado em rodovias em operação }\end{array}$ & $\mathbf{x}$ & & \\
\hline \begin{tabular}{|l|} 
As demarcações do novo projeto estão \\
consistentes com as seções da rodovia de via \\
adjacente (ou as demarcações poderá ser \\
melhorada)?
\end{tabular} & $\begin{array}{l}\text { Adequação de termos para melhorar a } \\
\text { clareza do entendimento da } \\
\text { microcategoria pelo auditor. }\end{array}$ & & $\begin{array}{l}\text { A sinalização horizontal do projeto proposto está } \\
\text { dimensionada adequadamente ou compatível com a } \\
\text { sinalização horizontal das rodovias adjacentes? }\end{array}$ & \\
\hline $\begin{array}{l}\text { A demarcação diagonal ou de divisa é prevista } \\
\text { onde necessária? }\end{array}$ & $\begin{array}{l}\text { Sugestão de retirar do instrumento } \\
\text { proposto, não aplicável }\end{array}$ & $\mathbf{x}$ & & \\
\hline $\begin{array}{l}\text { Foram considerados as luzes baixas e altas dos } \\
\text { veículos? }\end{array}$ & $\mid \begin{array}{l}\text { Adequação de termos para melhorar a } \\
\text { clareza do entendimento da } \\
\text { microcategoria pelo auditor. }\end{array}$ & & $\begin{array}{l}\text { O material escollido para as sinalizações horizontais são } \\
\text { adequados no que tange a refletividade na presença de luz } \\
\text { baixa ou luz alta dos veículos? }\end{array}$ & \\
\hline \multicolumn{2}{|l|}{ Macrocategoria - Sinalização e iluminação } & \multirow{2}{*}{ Excluído } & \multirow{2}{*}{ Adaptado } & \multirow{2}{*}{ Incluído } \\
\hline \multicolumn{2}{|l|}{ Mesocategoria - Sinalização Vertical } & & & \\
\hline Microcategoria preliminar & Considerações dos técnicos & \multicolumn{3}{|c|}{ Microcategoria Final } \\
\hline $\begin{array}{l}\text { Onde a sinalização está instalado em zona livre, } \\
\text { os postes da sinalização são frágeis estão } \\
\text { suficientemente protegidos por uma barreira? }\end{array}$ & $\begin{array}{l}\text { Adequar texto, pois a segunda parte - } \\
\text { estão suficientemente protegidos por uma } \\
\text { barreira - está contradizendo a zona } \\
\text { livre. }\end{array}$ & & $\begin{array}{l}\text { Nos casos em que a sinalização vertical está instalada em } \\
\text { zona livre, os postes desta sinalização são colapsáveis, há } \\
\text { necessidade de proteção com dispositivos de contenção? }\end{array}$ & \\
\hline \multicolumn{2}{|l|}{ Macrocategoria - Sinalização e iluminação } & \multirow{2}{*}{ Excluído } & \multirow{2}{*}{ Adaptado } & \multirow{2}{*}{ Incluído } \\
\hline \multicolumn{2}{|l|}{ Mesocategoria - Sinalização Vertical } & & & \\
\hline Microcategoria preliminar & Considerações dos técnicos & \multicolumn{3}{|c|}{ Microcategoria Final } \\
\hline $\begin{array}{l}\text { O projeto é livre de iluminação em áreas } \\
\text { escuras? }\end{array}$ & $\begin{array}{l}\text { Sugestão retirar, pois não adequado } \\
\text { verificar no projeto executivo e sim no } \\
\text { projeto básico. }\end{array}$ & $\mathbf{x}$ & & \\
\hline
\end{tabular}

Fonte: Elaborado pela autora, 2015 
O Quadro 5:17 mostra os comentários realizados em relação à macrocategoria "sinalização e iluminação" da rodovia do instrumento adaptado ao projeto executivo, suas microcategorias e suas respectivas avaliações.

Quadro 5.17: Avaliações dos técnicos - Projeto executivo - macrocategoria "perguntas adicionais"

\begin{tabular}{|c|c|c|c|c|}
\hline \multicolumn{2}{|l|}{ Macrocategoria - Perguntas adicionais } & \multirow{2}{*}{ Excluído } & \multirow{2}{*}{ Adaptado } & \multirow{2}{*}{ Incluído } \\
\hline \multicolumn{2}{|l|}{ Mesocategoria - Alinhamento vertical } & & & \\
\hline Microcategoria preliminar & Considerações dos técnicos & \multicolumn{3}{|c|}{ Microcategoria Final } \\
\hline O alinhamento vertical é satisfatório? & $\left|\begin{array}{l}\text { Sugestão de retirar, microcategoria } \\
\text { ampla para a verificação do auditor. }\end{array}\right|$ & $\mathbf{x}$ & & \\
\hline \multicolumn{2}{|l|}{ Macrocategoria - Perguntas adicionais } & \multirow{2}{*}{ Excluído } & \multirow{2}{*}{ Adaptado } & \multirow{2}{*}{ Incluído } \\
\hline \multicolumn{2}{|l|}{ Mesocategoria - Gestão de tráfego } & & & \\
\hline Microcategoria preliminar & Considerações dos técnicos & \multicolumn{3}{|c|}{ Microcategoria Final } \\
\hline $\begin{array}{l}\text { O número e a localização dos acessos são } \\
\text { adequados? }\end{array}$ & $\begin{array}{l}\text { Inserir complementação - para o projeto } \\
\text { proposto }\end{array}$ & & $\begin{array}{l}\text { O número e a localização dos acessos são adequados } \\
\text { para o projeto proposto? }\end{array}$ & \\
\hline
\end{tabular}

Fonte: Elaborado pela autora, 2015

\subsubsection{Resumo da avaliação dos técnicos}

Assim, foram consolidadas as sugestões dos técnicos para o aprimoramento do instrumento de ASV adaptado para os projetos rodoviários brasileiros, composto pelo Estudo de viabilidade, Projeto Básico e Projeto executivo.

Após a revisão do instrumento proposto materializou-se no estudo de viabilidade 6 (seis) macrocategorias, 12 (doze) mesocategorias e 70 (setenta) microcategorias.

No instrumento final do projeto básico consolidou-se 09 (nove) macrocategoria, 49 (quarenta e nove) mesocategorias e 166 (cento e sessenta e seis) microcategorias.

E por fim, o instrumento final a ser aplicado no projeto executivo, consolidou-se com 8 (oito) macrocategorias, 52 (cinquenta e dois) mesocategorias e 214 (duzentos e quatorze) microcategorias.

Além disso, foi avaliado a percepção dos técnicos em relação ao instrumento de ASV para aplicação em projetos rodoviários brasileiros no modelo de lista de verificação, e pode 
observar que os técnicos do com experiência em sinalização viária, experiência em operações de rodovias e fiscalização de projetos, foram os que observaram as microcategorias com maior detalhamento, e com tendência para a macrocategoria geometria, sinalização e iluminação e usuários da rodovia. E que pode ser ratificado pelo percentual da experiência dos técnicos apresentando no Quadro 4.14. 


\section{CONCLUSÕES E SUGESTÕES DE TRABALHOS FUTUROS}

Neste capítulo serão abordadas as conclusões relacionadas aos objetivos propostos nesta dissertação, bem como sugestões para outros trabalhos na linha de auditoria de segurança viária nas fases de projetos.

Neste contexto, esta dissertação propôs a elaboração do instrumento adaptado à realidade brasileira de auditoria de segurança viária para serem utilizados nas fases do estudo de viabilidade, projeto básico e projeto executivo. Uma vez que o usuário ao trafegar pela rodovia espera, primordialmente, a segurança viária e conforto.

O instrumento de ASV proposto nesta dissertação foi idealizado com base em manuais de auditoria de segurança viária, desenvolvidos nos países Austrália, Canadá, Chile e África do Sul, que mostram por meio de aplicações nas fases propostas da ASV que tiveram sucessos no que tange à mitigação da severidade dos acidentes de trânsito, também na redução de futuras ocorrências, uma vez que puderam identificar possíveis locais com potenciais de acidentes de trânsito nos projetos.

\subsection{CONCLUSÕES}

Esta dissertação teve como objetivo geral a elaboração de um instrumento de ASV adaptado para projetos rodoviários brasileiros para ser aplicado no Estudo de Viabilidade, Projeto Básico e Projeto Executivo. O objetivo geral foi alcançado após as revisões bibliográficas e procedimento metodológico desenvolvido nesta dissertação, uma vez que consolidou-se o instrumento de ASV para projetos rodoviários brasileiros. Apêndice E1, E2 e E3.

Os objetivos específicos desta dissertação foram:

a) Identificar os instrumentos de auditoria de segurança viária do tipo lista de verificação estruturadas para projetos rodoviários - este objetivo foi alcançado por meio da revisão bibliográfica de instrumento internacionais e brasileiros na concepção de lista de verificação.

b) Definir metodologia de adaptação de instrumentos de auditoria de segurança viária do tipo lista de verificação para o uso em projetos rodoviários - este objetivo foi alcançado, ao 
desenvolver a metodologia de adaptação e aprimoramento dos instrumentos internacionais que foram a base para a elaboração do instrumento proposto nesta dissertação, uma vez que o modelo escolhido de listas de verificação eram espanhol e inglês, além de possuírem uma extensa lista.

c) Verificar a percepção dos técnicos brasileiros em relação ao instrumento de auditoria de segurança viária do tipo lista de verificação - este objetivo foi alcançando após a avaliação da experiência dos técnicos, bem como a avaliação das respostas dos técnicos, que mostraram a diversidade da experiência dos técnicos que avaliaram o instrumento proposto desta dissertação. Na revisão bibliográfica foram identificados instrumentos de ASV consolidados para o uso nas fases de projetos, nos países Canadá, Austrália, Colômbia, Chile, África do Sul, Nova Zelândia. Também, identificou que, além da aplicação em projetos de rodovias rurais, há instrumentos consolidados para uso em travessias urbanas.

- A pesquisa para a elaboração do instrumento proposto nesta dissertação permitiu solidificar o aprendizado relativo à auditoria de segurança viária, principalmente, os estudos avançados de aplicação de ASV em outros países. Além disso, viabilizou a construção de conhecimento necessário para realizar as análises e adequações que viabilizaram a consolidação do instrumento proposto nesta dissertação para projetos rodoviários brasileiros.

- O instrumento proposto foi considerado útil e importante pelos técnicos na mitigação de acidentes de trânsito. Os técnicos, porém, entendem que a aplicação do instrumento por meio de lista de verificação pelos órgãos de transportes demandará a reformulação de equipes nesses órgãos, pois é necessário a equipe independente.

- Os técnicos também recomendaram que o instrumento proposto seja submetido ao Instituto de Pesquisa Rodoviária - IPR do DNIT, para que seja avaliada a possibilidade de ser publicado como uma instrução de serviço deste órgão. Dessa forma, os técnicos ratificam a importância de órgãos de infraestrutura possam utilizar o instrumento de ASV para projetos rodoviários.

- Esta dissertação teve o intuito de propor um instrumento de ASV para projetos rodoviários adaptados à realidade brasileira. Assim, com o auxílio de técnicos foi 
consolidado o instrumento de ASV para projetos rodoviários brasileiros, que poderá auxiliar departamentos de transportes a identificarem locais propícios a acidentes de trânsito.

- A identificação, antes das ocorrências de acidentes, de locais potencialmente propícios a acidentes de trânsito tem grande impacto social e no planejamento, pois caso seja identificado esses locais, terão menos acidentes graves e/ou mortes no trânsito. No planejamento haverá redução de custos futuros devido a não necessidade de revisões de projetos ou correções nas rodovias já em operação.

Neste contexto, conclui-se que esta dissertação propôs um instrumento de ASV adaptado à realidade brasileira e que aparentemente, são questões simples de verificar em um projeto, que têm causas e consequências relevantes.

E por fim, é apresentado aqui o comentário realizado por um dos técnicos que avaliaram o instrumento, em relação a microcategoria "A localização dos objetos fixos ou serviços móveis foram verificados, incluindo a posição dos postes?": "microcategoria extremamente importante no que tange à segurança viária e que muitas vezes não tem a devida atenção que merece".

\subsection{SUGESTÕES DE TRABALHOS FUTUROS}

A segurança viária nas rodovias brasileiras é de fundamental importância, com a necessidade de haver esforços em prol de ações que viabilizem soluções que venham proporcionar grau de confiabilidade satisfatória para o usuário das rodovias. Neste contexto, seguem sugestões para trabalhos futuros, para que assim, mais pesquisas acadêmicas venham subsidiar a segurança viária.

- Desenvolver trabalho de pesquisa para a aplicação do instrumento proposto nesta dissertação para as fases de estudo de viabilidade, projeto básico e projeto executivo com intuito de verificar e testar o instrumento proposto em estudos de casos, identificando o quanto esse instrumento poderá auxiliar (estatisticamente) na mitigação dos acidentes de trânsito. 
- Desenvolver um instrumento de auditoria de segurança viária adaptada à realidade das rodovias brasileiras para ser aplicado nas fases de pré-abertura ou pós-abertura ao tráfego.

- Nesta dissertação a análise de conteúdo foi com base na frequência. Assim, ao analisar as macrocategorias, itens com $25 \%$ foram excluídos e outros com justificativa técnica foi mantido como macrocategoria, meso e microcategoria. Consequentemente, as mesocategorias e as microcategorias dessas macrocategorias foram excluídas e/ou mantidas. Dessa forma, sugere-se que esses itens sejam avaliados para verificar a possibilidade de serem inseridos e assim haver uma adequação do instrumento proposto nesta dissertação. Assim, nos Quadros 4.16, 4.17 e 4.18, podem ser conferidas as sugestões para avaliação de conteúdo.

- E por fim, sugere-se que seja realizada por meio de uma escala likert a avaliação dos itens das microcategorias do instrumento proposto nesta dissertação, para determinar quais itens são mais relevantes para sugestão de um instrumento menos extenso, mas que seja eficaz no que se propõe. 


\section{REFERÊNCIAS BIBLIOGRÁFICAS}

ABNT, (1989) Associação Brasileira de Normas Técnicas. Engenharia de Tráfego - Terminologia - NBR 7032.

Rio de Janeiro.

ANTT (2005) Agência Nacional de Transporte Terrestre. Resolução nº 1187, de 09 de novembro de 2005.

Dispõe sobre os procedimentos de execução de obras e serviços pelas concessionárias nas rodovias federais reguladas pela ANTT.

ABNT (2007) - Associação Brasileira de Normas Técnicas. Segurança no tráfego - Dispositivos de Contenção Viária - NBR 15486. Rio de Janeiro, RJ.

AUSTROADS (2009) Guide to Road Safety. Part 6: Road Safety Audit. Austroads Publication No. AGRS06/09. Sydney, Austrália.

BRANCO, A. M. (1999) Segurança Rodoviária. Câmara Brasileira do Livro, SP, Brasil.Editora Cl-A 1999..

BRASIL, (1997) Departamento Nacional de Estradas de Rodagem. Diretoria de Desenvolvimento Tecnológico. Divisão de Capacitação Tecnológica. Glossário de termos técnicos rodoviários, Rio de Janeiro/RJ. 296p.

CASTRILLÓN, A. D.; CANDIA, J. S. (2003) Guía para realizar una auditoria de seguridadvial. Chile: Comisión Nacional de Seguridad de Trânsito.

CHAGAS, R. M..NODARO, C.T, e LINDAU, L. A. (2012). Lista de fatores contribuintes de acidente de trânsito para pesquisa no Brasil. Artigo Científico. In: XXVI Congresso de Pesquisa e Ensino em Transportes - ANPET. Joivinlle/SC.

CET (2010) - Companhia de Engenharia de Tráfego, Auditoria de Segurança Viária - ASV. Nota Técnica 213, São Paulo.

DER-SP (2005) - Departamento de Estrada e Rodagem-SP, Instrução de Projeto - Instrução. Elaboração. Projeto Geométrico, São Paulo.

DER-SP (2006) - Departamento de Estrada e Rodagem-SP, Instrução de Projeto - Projeto de Engenharia para implantação de rodovias vicinais, São Paulo.

DENATRAN (2011) Departamento Nacional de Trânsito, Década de Ação pela Segurança no Trânsito 2011-2020.Disponível em http://www.denatran.gov.br/download/decada/Proposta\%20ANTPCEDATT-Instituto\%20de\%20Engenharia\%20SP.pdf. Acesso em 10/12/2013 e 10/01/2014.

DNER (1997) Departamento Nacional de Estradas de Rodagem. Diretoria de Desenvolvimento Tecnológico. Divisão de Capacitação Tecnológica. Glossário de termos técnicos rodoviários. Rio de Janeiro.

DE SOUZA, M. L. R. (2012). Procedimento para avaliação de projetos de rodovias rurais visando a segurança viária. Dissertação de Mestrado em Transportes, Publicação T.DM - 005/2012. Departamento de Engenharia Civil e Ambiental, Universidade de Brasília, Brasília, DF, 206 p.

DNIT (2006) Departamento Nacional de Infraestrutura de Transportes. Diretrizes Básicas para Estudos e Projetos Rodoviários: escopos básicos / Instrução de serviço. Anexo Al EB-101: Estudo de viabilidade técnico-econômica-ambiental de rodovias. Publicação 726. Instituto de Pesquisas Rodoviárias. 484p. Brasília.

DNIT (2010) Departamento Nacional de Infraestrutura de Transportes. Manual de Projeto e Práticas Operacionais para Segurança nas Rodovias. Publicação. Instituto de Pesquisas Rodoviárias. $280 f$. IPR-741. Rio de Janeiro. 
FERRAZ, C., RAIA JR., A., BEZERRA, B., BASTOS, T., RODRIGUES, K. (2012) Segurança Viária. São Carlos: Suprema Gráfica e Editora LTDA, 321 p.

HILDEBRAND, E.; WILSON, F. (1999) Road Safety Audit Guidelines. University of New Brunswick Transportation Group, Canada, 161p.

LABTRABS (2011). Caracterização dos acidentes de trânsito em rodovias de Santa Catarina. Laboratório de Transportes e Logística - LabTrans. Núcleo de Estudos sobre Acidentes de Tráfego em Rodovias NEA. UFSC. Disponível em : http://www.labtrans.ufsc.br/PSR/file.axd?file=2011\%2f6\%2fCaracteriza\%C3\%A7\%C3\%A3o+dos+ acidentes+de+tr\%C3\%A2nsito+em+rodovias+de+Santa+Catarina.pdf. Acessado em 18/03/2015.

PAIVA, T. R. (2009) Análise das condições de segurança viária para os pedestres em semáforos providos de equipamentos de fiscalização eletrônica - o caso da cidade Fortaleza - CE. 173 fl. Dissertação (mestrado) - Universidade Federal do Ceará, Centro de Tecnologia, Programa de Pós-Graduação em Engenharia de Transportes, Fortaleza/CE.

PAUlA, M. E. B., RÉGIO, M. (2008) Investigação de Acidentes de trânsito fatais. 68p. Companhia de Engenharia de Tráfego. Boletim Técnico da CET, 42. - São Paulo/SP.

PANITZ, M. A. (1999) A Segurança Viária e o Fator Humano. Verificação da presença de Álcool - Direção. No Sistema de Transporte Rodoviário do RGS. Dissertação (Mestre em Engenharia). Universidade Federal de Rio Grande do Sul. Porto Alegre/RS.

NODARI, C. (2003) Método de avaliação da segurança potencial de segmentos rodoviários rurais de pista simples. 215 p. Teses (Doutorado em Engenharia de Produção). Universidade Federal de Rio Grande do Sul.

ONU (2010) Década de Ação pela Segurança no Trânsito. Disponível em http://www.who.int/roadsafety/en/. Acesso em: 19/12/2013.

RODRIGUES, J. L. F. (2010). Aplicações da técnica de auditoria de segurança viária em segmentos viários no estado de São Paulo - avaliação crítica de reflexões. 119p. Dissertação (Mestrado). Faculdade de Engenharia Civil, Arquitetura e Urbanismo da Universidade Estadual de Campinas.

RTMC (2012) Road Traffic Management Corporation, South African Road Safety Audit Manual Second Edition: May 2012. South Africa.

SCHOPF, A. R. (2006) Proposição de uma lista de verificação para revisão de segurança viária de rodovias. Dissertação de Mestrado em Engenharia de Produção. Departamento de Engenharia de Produção. Universidade Federal do Rio Grande do Sul.

SINAY, M. C. F. e TAMAYO, A. S. (2005) Segurança Viária: Uma Visão Sistémica. In: Rio de Transportes III, Rio de Janeiro.

TRANSFUND (1998) Development of a safety performance index for safety audit of existing roads. TRANSFUND NEW ZEALAND. Report no. RA97/640, Review and Audit Division New Zealand.

VIAS SEGURAS (2014) Estatísticas Nacionais de Acidentes de Trânsito. Disponível em: http://www. viasseguras.com/layout/set/print/os_acidentes/estatisticas/estatisticas_nacionais. Acesso em: 10/01/2014. 


\section{ANEXO A \\ LISTA DE VERIFICAÇÃO DE HILDEBRAND E WILSON (1999)}

Checklist detalhado de Hidebrand e Wilson (1999) 
DETAILED CHECKLIST

NEW FACILITIES/UPGRADES/EXISTING

\begin{tabular}{|c|c|c|}
\hline Item & Stages* & $\begin{array}{c}\text { Potential Safety Issues } \\
\text { (Note: Not all Issues Pertain to Each Audit Stage }\end{array}$ \\
\hline \multicolumn{3}{|l|}{ GENERAL } \\
\hline G1. Scope & 1 & $\begin{array}{l}\text { Review all pertinent documentation to gain an understanding of the scope of the } \\
\text { project; including project objectives, user characteristics, design vehicles, access, } \\
\text { adjacent development, existing network information, and future network } \\
\text { expansion. }\end{array}$ \\
\hline $\begin{array}{l}\text { G2. Staging of } \\
\text { Construction }\end{array}$ & $1,1,2,3$ & $\begin{array}{l}\text { What are the effects of staging the construction of the project or dividing it into } \\
\text { several contracts? }\end{array}$ \\
\hline \multirow{4}{*}{$\begin{array}{l}\text { G3. New / Old } \\
\text { Facility } \\
\text { Interaction }\end{array}$} & \multirow[t]{4}{*}{$3,4,5$} & $\begin{array}{l}\text { Check that the horizontal and vertical alignments of the proposed } \\
\text { facility co-ordinate effectively with those of existing facilities }\end{array}$ \\
\hline & & Are road transition environments safe? Is advance warning required? \\
\hline & & $\begin{array}{l}\text { Is there a sudden change in speed regime, access or side friction } \\
\text { characteristics? }\end{array}$ \\
\hline & & Does the interface occur near hazards (i.e.,. crest, bend, etc.)? \\
\hline \multirow{2}{*}{$\begin{array}{l}\text { G4. Impact on } \\
\text { Adjacent } \\
\text { Networks }\end{array}$} & \multirow[t]{2}{*}{3} & $\begin{array}{l}\text { Will traffic volume on nearby roads change as a result of this } \\
\text { project? }\end{array}$ \\
\hline & & $\begin{array}{l}\text { If traffic volume and flow have altered along adjacent roads, has a } \\
\text { change in ROW been considered? }\end{array}$ \\
\hline \multirow{2}{*}{$\begin{array}{l}\text { G5. Changes Since } \\
\text { Previous Audi }\end{array}$} & \multirow[t]{2}{*}{$2,3,4$} & Check for changes in the scope of the project. \\
\hline & & $\begin{array}{l}\text { Check for changes in the conditions for which the project was } \\
\text { designed. }\end{array}$ \\
\hline \multirow{3}{*}{$\begin{array}{l}\text { G6. Traffic Barrier } \\
\text { Warrants }\end{array}$} & \multirow[t]{3}{*}{$3,4,5, \mathrm{E}$} & Presence of non-traversable or fixed object hazards within clear zone. \\
\hline & & $\begin{array}{l}\text { Does a potential risk exist for vehicles crossing over the median into } \\
\text { the path of an opposing vehicle? }\end{array}$ \\
\hline & & Accident history of area \\
\hline \multirow[t]{2}{*}{ G7. Landscaping } & \multirow[t]{2}{*}{$3,4,5, \mathrm{E}$} & Landscaping along road in accordance with guidelines? \\
\hline & & Required clearances and sight distances restricted due to future plant growth? \\
\hline \multirow{3}{*}{$\begin{array}{ll}\text { G8. } & \text { Construction } \\
& \text { Clean-up }\end{array}$} & \multirow[t]{3}{*}{ 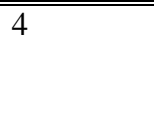 } & Interaction between construction clean-up area and traffic flow. \\
\hline & & Signage of clean-up area. \\
\hline & & Visibility of clean-up area from approaching traffic. \\
\hline \multirow[t]{4}{*}{ G9. Temporary Work } & \multirow[t]{4}{*}{ 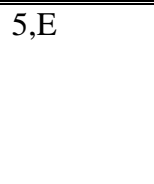 } & Interaction between temporary work and traffic flow. \\
\hline & & Is temporary work adequately signed? \\
\hline & & Does temporary work signage remain even though construction is complete? \\
\hline & & Visibility of temporary work area from approaching traffic. \\
\hline G10. Headlight Glare & 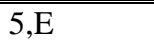 & Severity of head light glare during night time operations. \\
\hline \multirow[t]{3}{*}{ G11. Accident Reports } & \multirow[t]{3}{*}{ 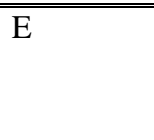 } & Accident reports available for specific facility? \\
\hline & & Frequency of accidents at facility. \\
\hline & & Common accident characteristics discussed in reports. \\
\hline $\begin{array}{l}\text { G12. Consistency of } \\
\text { Design } \\
\text { Parameters } \\
\end{array}$ & $\begin{array}{l}1,2,3,4,5 \\
\mathrm{E}\end{array}$ & $\begin{array}{l}\text { Ensure design parameters are consistent in alignment, cross section, interchanges, } \\
\text { and intersections. }\end{array}$ \\
\hline \multirow{5}{*}{$\begin{array}{r}\text { G13. Rest areas/ } \\
\text { Picnic sites }\end{array}$} & \multirow[t]{5}{*}{$2,3,4,5, \mathrm{E}$} & Are rest areas/picnic sites desirable? \\
\hline & & Is the number of rest areas/picnic sites within the project adequate? \\
\hline & & Do rest areas/picnic sites have safe access? \\
\hline & & Are rest areas/picnic sites placed appropriate locations? \\
\hline & & $\begin{array}{l}\text { Have appropriate signs been chosen and placed correctly to notify drivers of an } \\
\text { upcoming rest area/picnic sites? }\end{array}$ \\
\hline
\end{tabular}

* Stages: 1 = Feasibility, 2 = Preliminary, 3 = Detailed Design, 4 = Pre-Opening, 5 = Post-Opening, E = Existing

Detailed Checklist (continued) 


\begin{tabular}{|c|c|c|}
\hline Item & Stages* & $\begin{array}{c}\text { Potential Safety Issues } \\
\text { (Note: Not all Issues Pertain to Each Audit Stage) }\end{array}$ \\
\hline \multicolumn{3}{|c|}{ Alignment and Cross Sections } \\
\hline \multirow[t]{2}{*}{ A1. Classification } & \multirow[t]{2}{*}{$1,2, \mathrm{E}$} & $\begin{array}{l}\text { Check the appropriateness of the classification and design for the proposed } \\
\text { project's design volume and traffic composition. }\end{array}$ \\
\hline & & $\begin{array}{l}\text { Is the design of the proposed project flexible enough to accommodate unforeseen } \\
\text { increases in volume or changes in traffic characteristics? }\end{array}$ \\
\hline \multirow{4}{*}{$\begin{array}{l}\text { A2. Design Speed / Posted } \\
\text { Speed }\end{array}$} & \multirow[t]{4}{*}{$\begin{array}{l}1,2,3,4,5, \\
\mathrm{E}\end{array}$} & $\begin{array}{l}\text { Check the appropriateness of the design speed for horizontal and vertical } \\
\text { alignment, visibility, etc. }\end{array}$ \\
\hline & & Check the continuity of the design speed and the posted speed. \\
\hline & & Is the posted speed on each curve adequate? \\
\hline & & Is the traffic following the posted speed? \\
\hline \multirow{3}{*}{$\begin{array}{l}\text { A3. Route Selection / } \\
\text { Alignment }\end{array}$} & \multirow[t]{3}{*}{1,2} & Are horizontal and vertical curves minimized? \\
\hline & & Do excessive grades affect heavy vehicle operations and service levels? \\
\hline & & $\begin{array}{l}\text { Check for poor combinations of features (eg. small radius horizontal curve at end } \\
\text { of long tangent)? }\end{array}$ \\
\hline \multirow[t]{2}{*}{$\begin{array}{l}\text { A4. Cross Sectional } \\
\text { Elements }\end{array}$} & \multirow[t]{2}{*}{$\begin{array}{l}1,2,3,4,5, \\
\mathrm{E}\end{array}$} & $\begin{array}{l}\text { Determine if the proposed project has a suitable cross section for the ultimate } \\
\text { requirements of the road including: } \\
-\quad \text { classification } \\
-\quad \text { design speed } \\
-\quad \text { level of service/peak service volumes }\end{array}$ \\
\hline & & $\begin{array}{l}\text { Determine if adjustments in dimensions can be made for future expansion } \\
\text { possibilities. }\end{array}$ \\
\hline \multirow[t]{3}{*}{ A4.1 Drainage } & \multirow[t]{3}{*}{$2,3,4,5, \mathrm{E}$} & $\begin{array}{l}\text { Is the drainage channel appropriate for topography, maintenance and snow } \\
\text { drifting? }\end{array}$ \\
\hline & & $\begin{array}{l}\text { Is there possibility of surface flooding or overflow from surrounding or } \\
\text { intersecting drains and water courses? }\end{array}$ \\
\hline & & Does the proposed roadway have sufficient drainage? \\
\hline A4.2 Lane Width & $2,3,4,5, \mathrm{E}$ & Is the lane width sufficient for road design / classification? \\
\hline \multirow[t]{6}{*}{ A4.3 Shoulders } & \multirow[t]{6}{*}{$2,3,4,5, \mathrm{E}$} & Are shoulder widths adequate for all vehicles and road users? \\
\hline & & Is crossfall of shoulder adequate for drainage? \\
\hline & & Is treatment of embankments sufficient? \\
\hline & & Are there drop-offs? \\
\hline & & Is shoulder surfacing appropriate for road classification? \\
\hline & & Are rumble strips properly installed where warranted? \\
\hline \multirow[t]{2}{*}{$\begin{array}{l}\text { A4.4 Cross Slopes / } \\
\text { Superelevation }\end{array}$} & \multirow[t]{2}{*}{$2,3,4,5, \mathrm{E}$} & $\begin{array}{l}\text { Do crown and cross slope designs provide sufficient storm water drainage and } \\
\text { facilitate de-icing treatments? }\end{array}$ \\
\hline & & Do different rates of cross slope exist along adjacent traffic lanes? \\
\hline A 4.5 Pavement Widening & $2,2,3,4,5, \mathrm{E}$ & $\begin{array}{l}\text { Is sufficient pavement width provided along curves where offtracking } \\
\text { characteristics of vehicles are expected? }\end{array}$ \\
\hline A5. Alignment & $2,3,4,5, \mathrm{E}$ & Are there excessive curves that cause sliding in adverse weather conditions? \\
\hline \multirow[t]{2}{*}{ A5.1 Horizontal } & \multirow[t]{2}{*}{$2,3,4,5, \mathrm{E}$} & Check that a transition curve is required between a tangent and a circular curve. \\
\hline & & $\begin{array}{l}\text { Is the superelevation with transitions curves suitable in relation to affects of } \\
\text { drainage? }\end{array}$ \\
\hline \multirow[t]{5}{*}{ A5.2 Vertical } & \multirow[t]{5}{*}{$2,3,4,5, \mathrm{E}$} & Are there excessive grades which could be unsafe in adverse weather conditions? \\
\hline & & $\begin{array}{l}\text { Is a climbing lane provided where overtaking and passing manoeuvres are limited } \\
\text { due to terrain? }\end{array}$ \\
\hline & & $\begin{array}{l}\text { Is a climbing lane provided in areas where the design gradient exceeds the critical } \\
\text { length of the grade? }\end{array}$ \\
\hline & & $\begin{array}{l}\text { Verify that escape lanes are provided where necessary on steep down grades. If } \\
\text { not, are escape lanes feasible? }\end{array}$ \\
\hline & & Is there adequate provision of passing opportunities? \\
\hline
\end{tabular}


* Stages: 1 = Feasibility, 2 = Preliminary, 3 = Detailed Design, 4 = Pre-Opening, 5 = Post-Opening, E = Existing

Detailed Checklist (continued)

\begin{tabular}{|c|c|c|}
\hline Item & Stages* & $\begin{array}{c}\text { Potential Safety Issues } \\
\text { (Note: Not all Issues Pertain to Each Audit Stage) }\end{array}$ \\
\hline \multicolumn{3}{|c|}{ Alignment and Cross Sections (continued) } \\
\hline A5.2 Vertical (continued) & $2,3,4,5, \mathrm{E}$ & Is there sufficient spacing between passing zones? \\
\hline $\begin{array}{l}\text { A5.3 Combined Vertical } \\
\text { and Horizontal }\end{array}$ & $2,3,4,5, \mathrm{E}$ & $\begin{array}{l}\text { Check the interaction of horizontal and vertical alignments in the road (ie., roller } \\
\text { coaster alignment, sequencing of horizontal/vertical curves, etc.) }\end{array}$ \\
\hline \multirow{3}{*}{$\begin{array}{lr}\text { A6.Sight } & \text { Distance } \\
\text { (Stopping, } & \text { Decision, } \\
\text { Passing) } & \end{array}$} & $2,3,4,5, \mathrm{E}$ & Ensure that adequate passing opportunities are provided. \\
\hline & & $\begin{array}{l}\text { Determine if adequate stopping sight distance provided throughout the length of } \\
\text { the project. }\end{array}$ \\
\hline & & $\begin{array}{l}\text { Check that there is decision sight distance provided for interchange and } \\
\text { intersection signing throughout the project. }\end{array}$ \\
\hline $\begin{array}{l}\text { A7. Readability by } \\
\text { Drivers }\end{array}$ & $\overline{5, \mathrm{E}}$ & $\begin{array}{l}\text { Check for sections of roadway having potential for confusion } \\
\text {-alignment problems } \\
\text {-old pavement marking not properly removed } \\
\text {-streetlight/tree lines don't follow road alignment }\end{array}$ \\
\hline \multirow[t]{8}{*}{ A8. Bridge Structures } & \multirow[t]{8}{*}{$2,3,4,5, \mathrm{E}$} & $\begin{array}{l}\text { Check that the horizontal and vertical alignment conforms with the approach } \\
\text { roadways. }\end{array}$ \\
\hline & & Check for sufficient vertical clearance and proper signage of height restrictions. \\
\hline & & Is the horizontal clearance adequate from the roadway to the bridge rails/parapets? \\
\hline & & $\begin{array}{l}\text { Is stopping and passing sight distances obstructed by bridge abutment and } \\
\text { parapets? }\end{array}$ \\
\hline & & $\begin{array}{l}\text { Is signing required for delineation, weight restriction, or warning of deck } \\
\text { freezing? Is it properly installed? }\end{array}$ \\
\hline & & Are there drainage grates that interfere with cyclists? \\
\hline & & Are shoulder widths reduced across structure? Are warning signs required? \\
\hline & & $\begin{array}{l}\text { Is the proper clearance window provided at underpasses? Is the window providing } \\
\text { the minimum clearances for height and width? }\end{array}$ \\
\hline \multirow[t]{5}{*}{$\begin{array}{l}\text { A8. Bridge Structures } \\
\text { (continued) }\end{array}$} & \multirow[t]{5}{*}{$2,3,4,5, \mathrm{E}$} & $\begin{array}{l}\text { Are the proper curb heights used for sidewalks, parapets and safety curbs on } \\
\text { bridge structures? }\end{array}$ \\
\hline & & $\begin{array}{l}\text { Are the proper drainage features incorporated into the design of underpasses, } \\
\text { overpasses and bridge structures to prevent ponding? }\end{array}$ \\
\hline & & $\begin{array}{l}\text { Will there be a visual perception of narrowing or funneling at underpasses and } \\
\text { overpasses due to the location and type of abutment walls in relation to the } \\
\text { traveled roadway passing under the structure? }\end{array}$ \\
\hline & & $\begin{array}{l}\text { Are the toes of slope at abutments clear of the clear recovery zone for the } \\
\text { classification of highway/ }\end{array}$ \\
\hline & & $\begin{array}{l}\text { Do all the appropriate side clearances, median clearances and hazard clearances } \\
\text { for bridges meet classification standards? }\end{array}$ \\
\hline
\end{tabular}

* Stages: 1 = Feasibility, 2 = Preliminary, 3 = Detailed Design, 4 = Pre-Opening, 5 = Post-Opening, E = Existing

Detailed Checklist (continued)

\begin{tabular}{|c|c|c|}
\hline Item & Stages* & $\begin{array}{c}\text { Potential Safety Issues } \\
\text { (Note: Not all Issus Pertain to Each Audit Stage) }\end{array}$ \\
\hline \multicolumn{3}{|l|}{ Intersections } \\
\hline S1. Quantity & 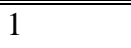 & Is the number of intersections appropriate given the surrounding network? \\
\hline \multirow[t]{2}{*}{ S2.Type } & \multirow[t]{2}{*}{1} & $\begin{array}{l}\text { Are types of intersections selected appropriate for traffic and safety aspects of the } \\
\text { project/ }\end{array}$ \\
\hline & & Can intersection designs accommodate all design vehicle classifications? \\
\hline \multirow[t]{2}{*}{ S3. Location/ Spacing } & & Is there sufficient spacing between intersections? \\
\hline & & Does horizontal/vertical alignment affect the location/spacing of the intersection? \\
\hline
\end{tabular}




\begin{tabular}{|c|c|c|}
\hline & $\begin{array}{l}1,2,3,4,5, \\
\mathrm{E}\end{array}$ & Junctions and access adequate for all permitted vehicle movements? \\
\hline \multirow{2}{*}{$\begin{array}{l}\text { S4. Visibility } \quad / \\
\text { Conspicuity }\end{array}$} & \multirow[t]{2}{*}{$2,3,4,5, \mathrm{E}$} & $\begin{array}{l}\text { Does the horizontal and vertical alignment provide adequate visibility of the } \\
\text { intersection? }\end{array}$ \\
\hline & & Are sight lines to the intersection obstructed? \\
\hline \multirow[t]{3}{*}{ S5. Layout } & \multirow[t]{3}{*}{$\overline{2,3,4,5, \mathrm{E}}$} & Are the lane widths adequate for all vehicle classes? \\
\hline & & $\begin{array}{l}\text { Are there any upstream and downstream features which may affect safety? (i.e., } \\
\text { "visual clutter", angle parking, high volume driveways) }\end{array}$ \\
\hline & & Are separate through lanes needed but not provided? \\
\hline \multirow[t]{2}{*}{ S5.1 Maneuvers } & \multirow[t]{2}{*}{$3,4,5, \mathrm{E}$} & Are vehicle maneuvers obvious to all users? \\
\hline & & Identify any potential conflicts in movements. \\
\hline \multirow{4}{*}{$\begin{array}{l}\text { S5.2 Auxiliary / Turning } \\
\text { Lanes }\end{array}$} & \multirow[t]{4}{*}{ 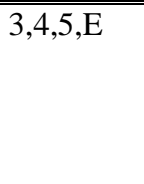 } & Are they of appropriate length? \\
\hline & & Is there advance warning of approaching auxiliary lanes? \\
\hline & & Is sight distance for entering/leaving vehicles adequate? \\
\hline & & Are tapers installed where needed? Are they correctly aligned? \\
\hline \multirow{4}{*}{$\begin{array}{ll}\text { S6. Sight } & \text { Distance } \\
\text { (Stopping, } & \text { Crossing, } \\
\text { Turning, Sight } & \text { Triangle) }\end{array}$} & \multirow[t]{4}{*}{$2,3,4,5, \mathrm{E}$} & Are all sight distances adequate for all movements and road users? \\
\hline & & Are sight lines obstructed by signs, bridge abutments, buildings, landscaping, etc.? \\
\hline & & $\begin{array}{l}\text { Could sight lines be temporarily obstructed by parked vehicles, snow, storage, } \\
\text { seasonal foliage, etc.? }\end{array}$ \\
\hline & & Do grades at intersecting roadway allow desirable sight distance? \\
\hline \multicolumn{3}{|l|}{ S7. Controls } \\
\hline \multirow[t]{2}{*}{ S7.1 Markings } & \multirow[t]{2}{*}{$\overline{3,4,5, \mathrm{E}}$} & Are pavement markings clearly visible in day and might time conditions? \\
\hline & & Check retroreflectivity of markings. \\
\hline \multirow[t]{4}{*}{ S7.2 Signs } & \multirow[t]{4}{*}{$3,4,5, \mathrm{E}$} & Check visibility and readability of signs to approaching users. \\
\hline & & Check location and number of signs \\
\hline & & Check for any missing/redundant/broken signs. \\
\hline & & Are stop/yield signs used where appropriate? \\
\hline \multirow[t]{5}{*}{ S7.3 Signals } & \multirow[t]{5}{*}{$3,4,5, \mathrm{E}$} & $\begin{array}{l}\text { Have high intensity signals/target boards/shields been provided where sunset and } \\
\text { sunrise may be a problem? }\end{array}$ \\
\hline & & Check location and number of signals. Are signals visible? \\
\hline & & $\begin{array}{l}\text { Ensure that traffic signals adjacent to roads do not affect driver perception of the } \\
\text { road. }\end{array}$ \\
\hline & & Are primary and secondary signal heads properly positioned? \\
\hline & & Are auxiliary heads necessary? \\
\hline \multirow{2}{*}{$\begin{array}{c}\text { S7.4 Signal Phasing } \\
\end{array}$} & \multirow[t]{2}{*}{$\overline{3,4,5, \mathrm{E}}$} & Are minimal green and clearance phases provided? \\
\hline & & Is the signal phasing plan consistent with adjacent intersections? \\
\hline \multirow[t]{3}{*}{ S8. Warnings } & \multirow[t]{3}{*}{$\overline{3,4,5, \mathrm{E}}$} & $\begin{array}{l}\text { Is adequate warning provided for signals not visible from an appropriate sight } \\
\text { distance? (i.e., signs, flashing light, etc.) }\end{array}$ \\
\hline & & Are lateral rumble strips required and properly positioned? \\
\hline & & Are pavement markings appropriate for the intersection? \\
\hline
\end{tabular}

* Stages: 1 = Feasibility, 2 = Preliminary, 3 = Detailed Design, 4 = Pre-Opening, 5 = Post-Opening, E = Existing

Detailed Checklist (continued)

\begin{tabular}{|l|l|l|}
\hline \multicolumn{1}{|c|}{ Item } & Stages* & \multicolumn{1}{c|}{\begin{tabular}{c}
\multicolumn{1}{c|}{ Potential Safety Issues } \\
(Note: Not all Issus Pertain to Each Audit Stage)
\end{tabular}} \\
\hline Interchanges & 1 & $\begin{array}{l}\text { Check the appropriateness of the interchange design with respect to topographical, } \\
\text { environmental and operational considerations. }\end{array}$ \\
\cline { 3 - 3 } & & $\begin{array}{l}\text { Is interchange layout consistent with other designs throughout the corridor or } \\
\text { network? }\end{array}$ \\
\hline \hline C2. Considerations & $\begin{array}{l}\text { Does the location of the interchange service the needs of the surrounding } \\
\text { community? }\end{array}$ \\
\hline
\end{tabular}




\begin{tabular}{|c|c|c|}
\hline & $\begin{array}{l}1,2,3,4,5, \\
\mathrm{E}\end{array}$ & Determine if spacing between interchanges in the network is sufficient. \\
\hline C3. Weaving Lanes & $2,3,4,5, \mathrm{E}$ & Ensure appropriate length and number of weaving lanes. \\
\hline \multirow[t]{3}{*}{ C4. Ramps } & \multirow[t]{3}{*}{$2,3,4,5, \mathrm{E}$} & $\begin{array}{l}\text { Is the design speed appropriate for site limitations, ramp configurations, and } \\
\text { vehicle mix? }\end{array}$ \\
\hline & & Adequate distance between successive entrance and exit noses? \\
\hline & & Is design of main lane adequate at exit/entrance terminals? \\
\hline \multirow[t]{3}{*}{ C4.1 Exit Terminals } & \multirow[t]{3}{*}{$2,3,4,5, \mathrm{E}$} & Is the length adequate for deceleration? \\
\hline & & Is adequate sight and decision sight distance provided? \\
\hline & & $\begin{array}{l}\text { Are spiral curves warranted? If so, do spirals begin and end at appropriate } \\
\text { locations? }\end{array}$ \\
\hline \multirow[t]{5}{*}{ C4.2 Entrance Terminals } & \multirow[t]{5}{*}{$2,3,4,5, \mathrm{E}$} & $\begin{array}{l}\text { Is the length appropriate for acceleration and safe and convenient merging with } \\
\text { through traffic? }\end{array}$ \\
\hline & & $\begin{array}{l}\text { Are spiral curves warranted? If so, do spirals begin and end at appropriate } \\
\text { locations? }\end{array}$ \\
\hline & & $\begin{array}{l}\text { Is the length of acceleration adequate for traffic composition (i.e. truck, buses, } \\
\text { etc.) }\end{array}$ \\
\hline & & Is there an adequate view of the speed change lane at the nose? \\
\hline & & Is visibility obscured by traffic barriers and other obstructions? \\
\hline \multirow[t]{3}{*}{ C5. Service Road Systems } & \multirow[t]{3}{*}{$3,4,5, \mathrm{E}$} & $\begin{array}{l}\text { Is there adequate distance between the highway and the service road to allow for } \\
\text { future development? }\end{array}$ \\
\hline & & Does service road traffic adversely affect traffic flow along the highway? \\
\hline & & Is there sufficient access to/from the service road? \\
\hline \multirow[t]{3}{*}{$\begin{array}{l}\text { C6. Lane Balance / Basic } \\
\text { Lanes / Lane Continuity }\end{array}$} & \multirow[t]{3}{*}{$\begin{array}{l}1,2,3,4,5, \\
\mathrm{E}\end{array}$} & $\begin{array}{l}\text { Is the number of lanes appropriate for safe operations and to accommodate } \\
\text { variations in traffic patterns? }\end{array}$ \\
\hline & & Is there coordination of lane balance and basic lanes? \\
\hline & & Is lane continuity maintained? \\
\hline \multirow{5}{*}{$\begin{array}{l}\text { C7. Auxiliary / Turning } \\
\text { Lanes }\end{array}$} & \multirow[t]{5}{*}{$3,4,5, \mathrm{E}$} & Are they of appropriate length? \\
\hline & & Is there advance warning of approaching auxiliary lanes? \\
\hline & & Is sight distance for entering/leaving vehicles appropriate? \\
\hline & & Are tapers installed where needed? Are they correctly aligned? \\
\hline & & Is the service road being used for its original intent/ \\
\hline
\end{tabular}

* Stages: 1 = Feasibility, 2 = Preliminary, 3 = Detailed Design, 4 = Pre-Opening, 5 = Post-Opening, E = Existing

Detailed Checklist (continued)

\begin{tabular}{|c|c|c|}
\hline Item & Stages* & $\begin{array}{c}\text { Potential Safety Issues } \\
\text { (Note: Not all Issus Pertain to Each Audit Stage) }\end{array}$ \\
\hline \multicolumn{3}{|l|}{ Road Surface } \\
\hline \multirow[t]{2}{*}{ R1. Skid Resistance } & \multirow[t]{2}{*}{$4,5, \mathrm{E}$} & $\begin{array}{l}\text { Does adequate skid resistance exist especially at curves, intersection approaches } \\
\text { and steep grades? }\end{array}$ \\
\hline & & Has skid resistance testing been carried out? \\
\hline \multirow[t]{2}{*}{ R2. Pavement Defects } & \multirow[t]{2}{*}{$\mathrm{E}$} & Check that pavement is free of defects. (i.e., potholes, rutting, etc.) \\
\hline & & $\begin{array}{l}\text { Check for segregations of mix. (i.e., pooling of bitumen, segregation of } \\
\text { aggregates) }\end{array}$ \\
\hline \multirow[t]{2}{*}{ R3. Surface Texture } & \multirow[t]{2}{*}{$\overline{\mathrm{E}}$} & Visibility in wet conditions. \\
\hline & & Check headlight glare/reflection during night time operations. \\
\hline R4. Pondir & $\mathrm{E}$ & areas where pondi \\
\hline
\end{tabular}

* Stages: 1 = Feasibility, 2 = Preliminary, 3 = Detailed Design, 4 = Pre-Opening, 5 = Post-Opening, E = Existing

Detailed Checklist (continued)

\begin{tabular}{|c|c|c|}
\hline Item & Stages* & $\begin{array}{c}\text { Potential Safety Issues } \\
\text { (Note: Not all Issus Pertain to Each Audit Stage) }\end{array}$ \\
\hline
\end{tabular}




\begin{tabular}{|c|c|c|}
\hline \multicolumn{3}{|l|}{ Visual Aids } \\
\hline \multirow[t]{5}{*}{ D1. Pavement Markings } & \multirow[t]{5}{*}{$3,4,5, \mathrm{E}$} & Are centre lines and edge lines clearly visible in day and night time conditions? \\
\hline & & Have old pavement markings been removed? \\
\hline & & Check retroreflectivity of existing markings. \\
\hline & & Estimate obliteration. \\
\hline & & Are raised profile markings necessary? \\
\hline \multirow[t]{2}{*}{ "D2. Delineation } & \multirow[t]{2}{*}{$3,4,5, \mathrm{E}$} & Is delineation adequate? Effective in all conditions? \\
\hline & & Are chevron markers placed correctly? Has retroreflectivity been measured? \\
\hline \multirow[t]{7}{*}{ D3. Lighting } & \multirow[t]{7}{*}{$3,4,5, \mathrm{E}$} & Have frangible or slip-base poles been used? \\
\hline & & Will luminares create glare for road users ono adjacent roads? \\
\hline & & Check appropriate location of luminares at interchanges, intersections, etc. \\
\hline & & Affect of adjacent road lighting on driver perception of roas? \\
\hline & & Do locations exist where lighting may interfere with traffic signals or signs? \\
\hline & & Has lighting for signs been provided where necessary? \\
\hline & & Have bases been installed at the proper height? \\
\hline \multirow[t]{3}{*}{ D4. Signs } & \multirow[t]{3}{*}{$3,4,5, \mathrm{E}$} & Are all necessary regulatory, warning and guide signs in place and visible? \\
\hline & & $\begin{array}{l}\text { Check correct location of signs. (i.e., proper height, offset, distance in advance of } \\
\text { hazard.) }\end{array}$ \\
\hline & & Check for signs which restrict sight distances. \\
\hline \multirow[t]{8}{*}{ D4. Signs (continued) } & \multirow[t]{8}{*}{$3,4,5, \mathrm{E}$} & $\begin{array}{l}\text { Check effectiveness of signs in all operating conditions (day, night, rain, fog, } \\
\text { snow, etc.) if possible. }\end{array}$ \\
\hline & & $\begin{array}{l}\text { Are frangible bases provided where its impossible to locate extruded aluminum } \\
\text { sign standards outside clear zone? }\end{array}$ \\
\hline & & Are any signs redundant/missing/broken? \\
\hline & & Are proper grades od retroreflective sheeting used? \\
\hline & & Have bases been installed at the proper height? Are they frangible? \\
\hline & & Is signage of horizontal alignment adequate where required? \\
\hline & & Check operations of variable message signs. \\
\hline & & $\begin{array}{l}\text { Check consistency of variable message signs with respect to standard fonts and } \\
\text { phrases. }\end{array}$ \\
\hline
\end{tabular}

* Stages: 1 = Feasibility, 2 = Preliminary, 3 = Detailed Design, 4 = Pre-Opening, 5 = Post-Opening, E = Existing

Detailed Checklist (continued)

\begin{tabular}{|c|c|c|}
\hline Item & Stages* & $\begin{array}{c}\text { Potential Safety Issues } \\
\text { (Note: Not all Issus Pertain to Each Audit Stage) }\end{array}$ \\
\hline \multicolumn{3}{|l|}{ Physical Objects } \\
\hline \multirow{3}{*}{$\begin{array}{l}\text { P1. Poles and Other } \\
\text { Obstructions }\end{array}$} & \multirow{3}{*}{$\begin{array}{l}1,2,3,4,5, \\
\mathrm{E}\end{array}$} & Unprotected median widths appropriate for lighting poles? \\
\hline & & Appropriate positioning of traffic signal and other service poles? \\
\hline & & $\begin{array}{l}\text { Consider the location of services and utilities with respect to the } \\
\text { project (i.e. buried and overhead) Clearance for overhead wires? }\end{array}$ \\
\hline \multirow[t]{8}{*}{ P2. Medians } & \multirow{8}{*}{$\begin{array}{l}1,2,3,4,5, \\
\mathrm{E}\end{array}$} & Is type of median chosen appropriate for width available? \\
\hline & & Do barriers possess the proper geometrical configuration? \\
\hline & & Are slopes of grass median adequate? \\
\hline & & Are median barriers sufficiently offset from roadway? \\
\hline & & Are median barrier offsets in the correct range of values? \\
\hline & & $\begin{array}{l}\text { Do roadside barriers and bridge barriers meet the appropriate crash } \\
\text { test performance level that is consistent with the roadway classification? }\end{array}$ \\
\hline & & Is there sufficient width for overpass/underpass piers and light standards? \\
\hline & & Check appropriate spacing between median crossovers. \\
\hline \multirow{4}{*}{$\begin{array}{l}\text { P3. Hazardous Object } \\
\text { Protection }\end{array}$} & \multirow[t]{4}{*}{$\begin{array}{l}3,4,5, \mathrm{E} \\
\end{array}$} & Is adequate protection provided where required? (i.e., barriers, energy attenuators) \\
\hline & & Is protection visible in all operating conditions? \\
\hline & & Are end treatments of guiderail properly treated? \\
\hline & & Are dimensions (i.e. length) of protection appropriate? \\
\hline
\end{tabular}




\begin{tabular}{|c|c|c|}
\hline & & Are barrier treatments consistent throughout? \\
\hline & & Is there appropriate transition from one barrier to another? \\
\hline & & Are reflectorized tabs used to delineate guiderail? \\
\hline P4. Clear Zone & 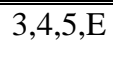 & $\begin{array}{l}\text { Ensure no unprotected objects (temporary or permanent) are within } \\
\text { the required clear zone. }\end{array}$ \\
\hline & & Check that clear zone is of adequate dimensions. \\
\hline P5. Culverts & 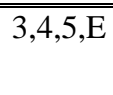 & $\begin{array}{l}\text { Check adequate protection of culverts at abutting driveways and } \\
\text { intersecting roads. }\end{array}$ \\
\hline P6. Railroad & 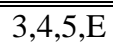 & Ensure proper active/passive signing and pavement markings. \\
\hline Crossings & & Check sight distances for signing and also approaching trains. \\
\hline
\end{tabular}

Stages: 1 = Feasibility, 2 = Preliminary, 3 = Detailed Design, 4 = Pre-Opening, 5 = Post-Opening, E = Existing

Detailed Checklist (continued)

\begin{tabular}{|c|c|c|}
\hline Item & Stages* & $\begin{array}{c}\text { Potential Safety Issues } \\
\text { (Note: Not all Issus Pertain to Each Audit Stage) }\end{array}$ \\
\hline \multicolumn{3}{|c|}{ Environmental Considerations } \\
\hline \multirow[t]{3}{*}{ E1. Weather } & \multirow[t]{3}{*}{$\begin{array}{l}1,2,3,4,5, \\
\mathrm{E}\end{array}$} & $\begin{array}{l}\text { Check the effects of rain, fog, snow, ice, wind on design features of } \\
\text { the project. }\end{array}$ \\
\hline & & $\begin{array}{l}\text { Has snow fall accumulation been considered in the design? (i.e.,. } \\
\text { storage, sight distance around snowbanks, etc.) }\end{array}$ \\
\hline & & $\begin{array}{l}\text { Check the mitigating measures for effects of snow with respect to: } \\
\text { - prevailing winds } \\
\text { - snow drifting } \\
\text { - open terrain }\end{array}$ \\
\hline \multirow[t]{3}{*}{ E2. Animals } & \multirow[t]{3}{*}{$\begin{array}{l}1,2,3,4,5 \\
\mathrm{E}\end{array}$} & $\begin{array}{l}\text { Are there any known animal travel/migration routes in surrounding } \\
\text { areas which could affect design? }\end{array}$ \\
\hline & & Are fencing and underpasses installed where required? \\
\hline & & $\begin{array}{l}\text { Ensure appropriate signing (i.e cattle crossing, deer warning, etc) } \\
\text { where required. }\end{array}$ \\
\hline
\end{tabular}

Stages: 1 = Feasibility, 2 = Preliminary, 3 = Detailed Design, 4 = Pre-Opening, 5 = Post-Opening, E = Existing

Detailed Checklist (continued)

\begin{tabular}{|c|c|c|}
\hline Item & Stages* & $\begin{array}{c}\text { Potential Safety Issues } \\
\text { (Note: Not all Issus Pertain to Each Audit Stage) }\end{array}$ \\
\hline \multicolumn{3}{|l|}{ Road Users } \\
\hline \multicolumn{3}{|l|}{ U1. Motorized Traffic } \\
\hline \multirow[t]{2}{*}{$\begin{array}{l}\text { U1.1 Heavy } \\
\text { Vehicles } \\
\text { U1.2 Public } \\
\text { Transport }\end{array}$} & \multirow[t]{2}{*}{$\begin{array}{l}1,2,3,4,5, \\
\mathrm{E}\end{array}$} & $\begin{array}{l}\text { Can facility accommodate movements of heavy/public transport } \\
\text { vehicles where required? (clearances, turning radii, shoulder widths, operational } \\
\text { capacity?) }\end{array}$ \\
\hline & & Is there adequate signage of heavy vehicle/public transport activity? \\
\hline \multirow{2}{*}{$\begin{array}{l}\text { U1.3 Road } \\
\text { Maintenance } \\
\text { U1.4 Emergency } \\
\text { Vehicles }\end{array}$} & \multirow[t]{2}{*}{$\begin{array}{l}1,2,3,4,5, \\
\mathrm{E}\end{array}$} & $\begin{array}{l}\text { Can facility accommodate movements of road maintenance and } \\
\text { emergency vehicles (clearances, turning radii, shoulder widths) }\end{array}$ \\
\hline & & $\begin{array}{l}\text { Are medians and cross overs visible and in adequate locations for } \\
\text { these vehicles? }\end{array}$ \\
\hline \multirow[t]{2}{*}{$\begin{array}{l}\text { U1.5 Slow } \\
\text { Moving } \\
\text { Vehicles }\end{array}$} & \multirow[t]{2}{*}{$\begin{array}{l}1,2,3,4,5 \\
\mathrm{E}\end{array}$} & $\begin{array}{l}\text { Can shoulders accommodate slow-moving vehicles where required? } \\
\text {-width } \\
\text {-structural capacity } \\
\text {-continuity }\end{array}$ \\
\hline & & Is there appropriate signing of slow-moving vehicles as necessary? \\
\hline \multirow{4}{*}{$\begin{array}{l}\text { U1.6 Snow-mobiles } \\
\text { and ATVs }\end{array}$} & \multirow{4}{*}{$\begin{array}{l}1,2,3,4,5, \\
\mathrm{E}\end{array}$} & Check visibility of adjacent trail signage. Could it cause confusion to road users? \\
\hline & & Check signage and visibility of points where trails cross the highway \\
\hline & & $\begin{array}{l}\text { Has adequate stopping sight distance been considered where trails } \\
\text { cross the highway? }\end{array}$ \\
\hline & & Could headlight of oncoming snowmobile/ATV confuse motorist? \\
\hline Non-Motorized & $1,2,3,4,5$, & Are shoulders wide enough to accommodate cyclists/pedestrians \\
\hline
\end{tabular}




\begin{tabular}{|l|l|l|}
\hline \hline Traffic & E & where required? \\
$\begin{array}{l}\text { U2.1 Cyclists } \\
\text { U2.2 Pedestrians }\end{array}$ & & Are shoulders/sidewalks provided on bridges? \\
\cline { 3 - 3 } & & Will snow storage disrupt pedestrian access or visibility? \\
\hline
\end{tabular}

Stages: 1 = Feasibility, 2 = Preliminary, 3 = Detailed Design, 4 = Pre-Opening, 5 = Post-Opening, E = Existing

Detailed Checklist (continued)

\begin{tabular}{|c|c|c|}
\hline Item & Stages* & $\begin{array}{c}\text { Potential Safety Issues } \\
\text { (Note: Not all Issus Pertain to Each Audit Stage) }\end{array}$ \\
\hline \multicolumn{3}{|c|}{ Access and Adjacent Development } \\
\hline \multirow{3}{*}{$\begin{array}{l}\text { AA1. Right-of-way } \\
\text { (ROW) }\end{array}$} & \multirow[t]{3}{*}{$\overline{11,2,3, \mathrm{E}}$} & Check width of ROW as affected by access requirements. \\
\hline & & Are there any upstream or downstream factors which may effect access? \\
\hline & & $\begin{array}{l}\text { Will there be "visual clutter" (excessive commercial signing or } \\
\text { lighting) beyond ROW? }\end{array}$ \\
\hline $\begin{array}{l}\text { AA2. Proposed } \\
\text { Development }\end{array}$ & $4,5, \mathrm{E}$ & Check effects on traffic patterns. \\
\hline \multirow[t]{3}{*}{ AA3. Driveways } & \multirow[t]{3}{*}{ 4,5,E } & $\begin{array}{l}\text { Check interaction between driveway and road. Is driveway } \\
\text { adequately designed for land use? }\end{array}$ \\
\hline & & Check for adequate space between driveways on same side of street. \\
\hline & & Check effects on traffic patterns. \\
\hline $\begin{array}{l}\text { AA4. Roadside } \\
\text { Development }\end{array}$ & $\overline{\mathrm{E}}$ & Check effects on traffic patterns \\
\hline $\begin{array}{l}\text { AA5. Building } \\
\text { Setbacks }\end{array}$ & $\bar{E}$ & Ensure adequate distance from edge of ROW. \\
\hline
\end{tabular}

Stages: 1 = Feasibility, 2 = Preliminary, 3 = Detailed Design, 4 = Pre-Opening, 5 = Post-Opening, E = Existing

Fonte: Hildebrand e Wilson (1999). 


\section{ANEXO B \\ LISTA DE VERIFICAÇÃO DE CASTRILLÓN E CANDIA (2003)}

Checklist detalhado de Castrillón e Candia (2003) - Estudo de Viabilidade 


\begin{tabular}{|c|c|c|}
\hline & $\begin{array}{c}\text { Lista de Chequeo Detallada } \\
\text { Etapa de Factibilidad }\end{array}$ & \\
\hline ÍTE & & COMENTARIOS \\
\hline & Alcances Generales & \\
\hline 1 & Aspectos generales, función y composición del tránsito previsto & \\
\hline & ál es la función prevista del proyecto? & \\
\hline ¿El & seño es compatible con la función de la vía? & \\
\hline & $\begin{array}{l}\text { oyecto propuesto (o rediseño) permite que operen adecuadamente: } \\
\text { tomóviles? } \\
\text { otociclistas? } \\
\text { clistas? } \\
\text { eatones? } \\
\text { éculos Pesados? }\end{array}$ & \\
\hline & ha considerado efectivamente la composición del tránsito esperado? & \\
\hline & $\begin{array}{l}\text { oroyecto propuesto será compatible con el uso del suelo y la gestión de tránsito de la red } \\
\text { adyacente? }\end{array}$ & \\
\hline 2 & Tipos y control de accesos a propiedades y desarrollos & \\
\hline & control de los accesos es compatible con la función de la vía y con secciones de la vía? & \\
\hline & $\begin{array}{l}\text { istancia de visibilidad será satisfactoria: } \\
\text { En intersecciones? } \\
\text { En accesos a la propiedad adyacente? }\end{array}$ & \\
\hline $\begin{array}{l}\text { ¿Es } \\
\text { con }\end{array}$ & $\begin{array}{l}\text { velocidad de diseño (o las probables velocidades de operación de los vehículos) compatible } \\
\text { número y el tipo de intersecciones/ accesos a la propiedad adyacente? }\end{array}$ & \\
\hline & ancho de la pista que cede prioridad satisface los requerimientos del acceso? & \\
\hline 3 & Principales generadores de viajes & \\
\hline & $\begin{array}{l}\text { tán los centros generadores y/o atractores de viajes (incluyendo vivienda y centros } \\
\text { erciales) lo suficientemente lejos para evitar influencias inseguras sobre el diseño vial? Si } \\
\text { s así, ¿Se han mitigado sus efectos? }\end{array}$ & \\
\hline & $\begin{array}{l}\text { han tratado los accesos existentes o alternativos, de modo de evitar que el suburbio } \\
\text { tente afecte? }\end{array}$ & \\
\hline & $\begin{array}{l}\text { han provisto accesos alternativos para asegurar que los suburbios existentes no sean } \\
\text { ido con el desarrollo del proyecto (por los trabajos)? }\end{array}$ & \\
\hline & $\begin{array}{l}\text { accesos a centros generadores de viajes están bien diseñados y lo suficientemente } \\
\text { idos de las intersecciones? }\end{array}$ & \\
\hline & $\begin{array}{l}\text { stancia de visibilidad, desde y hacia los accesos a centros generadores de viajes, es } \\
\text { ada? }\end{array}$ & \\
\hline
\end{tabular}




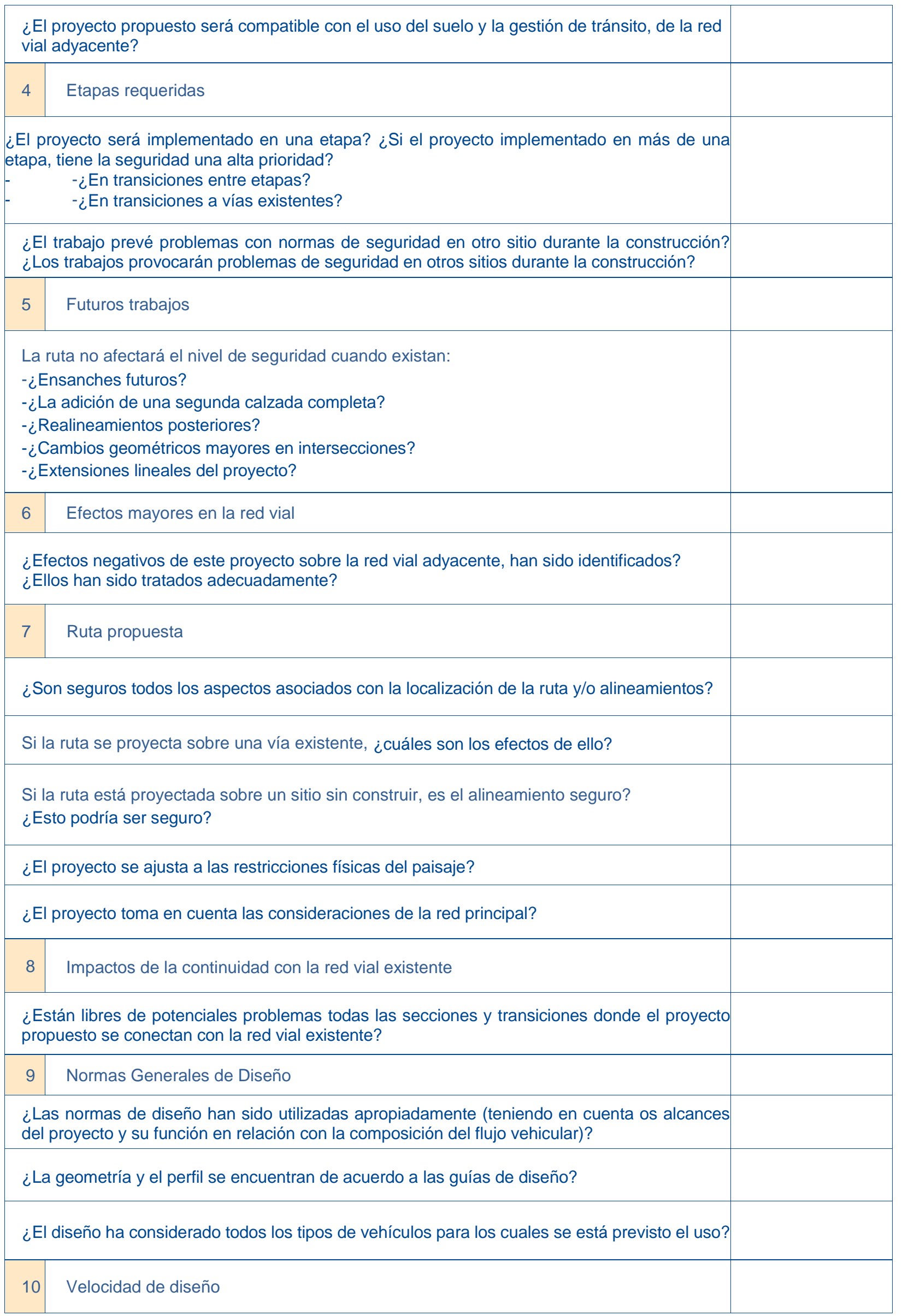


La velocidad de diseño apropiada ha sido seleccionada de acuerdo a:

- ¿Alineamiento vertical y horizontal?

- ¿Visibilidad?

-¿Accesos?

- ¿Entre-cruzamientos?

-¿Deceleración y aceleración del flujo vehicular en intersecciones?

-¿Composición del tránsito previsto?

Es la distancia de visibilidad generalmente satisfactoria:

- ¿En intersecciones?

- ¿En la entrada o salida de pendientes?

- ¿En entradas a propiedades adyacentes?

- ¿En puntos de accesos de vehículos de emergencia?

¿Puede algún cambio en el régimen o límite de velocidad ser fijado en forma segura?

¿Es adecuado el límite de velocidad fijado para la vía, o parte de ella?

¿Es el límite de velocidad pretendido, o fijado, consistente con la velocidad de diseño?

11 Diseño de la composición y del flujo vehicular

¿Es el diseño apropiado con respecto a la composición y flujo vehicular (incluyendo los efectos de la inusual proporción entre vehículos pesados, ciclistas y peatones o efectos de la fricción lateral)?

¿El proyecto solucionará aumentos imprevistos, o grandes incrementos, en el flujo vehicular?

¿El proyecto solucionará cambios imprevistos en la composición del flujo vehicular?

Intersecciones

12 Número y tipos de intersecciones

Son todos los aspectos de las intersecciones (por ejemplo, el espaciado, el tipo, la disposición, etc.) apropiados en lo que concierne a:

- ¿la idea general del proyecto?

- ¿la función de la vía y las que la cruzan?

- ¿la composición del flujo vehicular de la vía y de las que la cruzan?

- ¿los tipos de intersecciones son consistentes para el proyecto y compa-tibles con las secciones adyacentes?

Es la frecuencia de las intersecciones apropiada (ni muy alta, ni muy baja):

- ¿Para accesos seguros?

- ¿Para evitar impactos en la red vial adyacente?

- ¿Para el acceso de vehículos de emergencia?

¿Las restricciones físicas, de visibilidad o de gestión de tránsito, que influencia pueden tener sobre el espaciado de las intersecciones propuesto?

¿Los alineamientos verticales y/u horizontales han sido considerados para determinar el tipo o espaciado de las intersecciones?

¿Son todas as intersecciones propuestas necesarias o esenciales?

¿Algunas intersecciones que se estiman innecesarias pueden ser eliminadas o puede el acceso ser conectado en forma más segura mediante cambios sobre la red vial adyacente (un enlace por ejemplo)? 
¿El ángulo de las vías que cruzan el proyecto y la línea de visibilidad, es adecuado para la seguridad de todos los usuarios?

¿El movimiento de los vehículos pesados es seguro en todas las intersecciones?

¿El movimiento de los vehículos pesados es seguro en todas las intersecciones?

\section{Restricciones ambientales}

13 Aspectos de seguridad

¿El terreno del entorno de la vía está libre de objetos físicos o vegetación que pueda afectar la seguridad del proyecto? (por ejemplo grandes cultivos, terrenos boscosos, cortes profundos (barrancos), cortes elevados, o zonas rocosas que pueden restringir el diseño)

¿Se han considerado en forma adecuada los efectos del viento, la niebla, la neblina, el hielo, los ángulos del sol al amanecer y atardecer?

¿Las pendientes, las curvas y el diseño de accesos en general ha considerado las probables condiciones meteorológicas o ambientales del terreno?

(Por ejemplo, áreas propensas niebla)

¿La seguridad ha sido considerada en lugares con ciertas características ambientales? (por ejemplo, cercas antiruidos)

¿El proyecto considera la posible irrupción de animales hacia la vía? (bovinos, caballos, etc.)

¿El proyecto funcionará en forma segura en condiciones ambientales adversas como por ejemplo de noche, con niebla o la calzada mojada?

¿Existen distracciones visuales (por ejemplo, paisaje pintoresco) tratados adecuadamente (por ejemplo proveyendo de áreas para que las personas estacionen sus vehículos en forma segura?

¿Han sido considerados aspectos inusuales? (por ejemplo hundimientos del terreno por actividad minera)

\section{Algunas otras materias}

14

Aspectos de seguridad no tratados

¿Se ha considerado la posibilidad de inundaciones?

¿Los cruces ferroviarios han sido identificados y tratados adecuadamente?

¿Se han considerado otras distracciones visuales (por ejemplo, publicidad, etc.)?

¿Se ha considerado la necesidad de áreas de descanso o estacionamientos (por ejemplo, rutas turísticas, descanso para camioneros, zonas de picnic u otras áreas)?

¿Se han considerado potenciales puntos de atracción al borde de la vía (por ejemplo, vendedores)?

¿Existirán situaciones especiales? Han sido consideradas situaciones inusuales o de peligro?

¿Todos los peatones que puedan verse seriamente afectados con el proyecto, han sido considerados? (por ejemplo escolares, ancianos)

¿Los problemas de seguridad o de accidentes de tránsito de la red vial adyacente, han sido considerados? (que no sean transferidos al nuevo proyecto)

¿El suministro de energía para la iluminación de la vía (alumbrado) ha sido considerado en el diseño?

¿Se ha considerado la necesidad de estacionamiento de los conductores? (por ejemplos, áreas de descanso, estacionamiento de camiones)

¿Existe alguna otro aspecto que pueda afectar a seguridad de la vía? 
Checklist detalhado de Castrillón e Candia (2003) - Projeto Básico

\begin{tabular}{|c|c|c|}
\hline \multicolumn{3}{|c|}{$\begin{array}{l}\text { Lista de Chequeo Detallada } \\
\text { Etapa de Diseno Preliminar }\end{array}$} \\
\hline \multicolumn{3}{|c|}{$\begin{array}{l}\text { ITTEMS } \\
\text { COMENTARIOS }\end{array}$} \\
\hline \multicolumn{3}{|c|}{ Alcances Generales } \\
\hline 1 & Cambios desde la ASV previa & \\
\hline \multicolumn{2}{|r|}{$\begin{array}{l}\text { ¿Las condiciones del proyecto originalmente disenado todavía se aplican? (por ejemplo, } \\
\text { no existen cambios en la red vial adyacente, área de actividades o composición del flujo } \\
\text { vehicular) }\end{array}$} & \\
\hline \multicolumn{2}{|r|}{$\begin{array}{l}\text { ¿La forma general del diseno del proyecto se mantiene sin alteraciones desde la ASV } \\
\text { anterior? }\end{array}$} & \\
\hline 2 & Drenaje & \\
\hline \multicolumn{3}{|c|}{ ¿El proyecto tiene un escurrimiento adecuado de las aguas? } \\
\hline \multicolumn{2}{|r|}{$\begin{array}{l}\text { ¿La posibilidad de que la superficie de rodado se inundada ha sido considerada, } \\
\text { incluyendo desbordes de cursos de agua o alcantarillados? }\end{array}$} & \\
\hline 3 & Condiciones Climáticas & \\
\hline \multicolumn{2}{|r|}{$\begin{array}{l}\text { ¿Han sido considerados los registros meteoro lógicos o la experiencia local que pueda } \\
\text { indicar algún problema particular? (por ejemplo nieve, hielo, viento, niebla) }\end{array}$} & \\
\hline 4 & Paisajismo & \\
\hline \multicolumn{2}{|r|}{$\begin{array}{l}\text { ¿Si las propuestas de diseno están disponibles, ellas son compatibles con las exigencias } \\
\text { de seguridad? (por ejemplo, línea de visibilidad, peligros en zonas despejadas) }\end{array}$} & \\
\hline 5 & Servicios & \\
\hline \multicolumn{2}{|r|}{$\begin{array}{l}\text { ¿El diseno considera la provisión de servicios en forma segura de modo de no generar } \\
\text { riesgos sobre los usuarios? (Teléfonos de Emergencia, paraderos, etc.) }\end{array}$} & \\
\hline \multicolumn{2}{|r|}{$\begin{array}{l}\text { La localización o fijación de objetos o mobiliarios asociados con servicios ha sido revisada, } \\
\text { incluyendo la posición de postes? }\end{array}$} & \\
\hline 6 & $\begin{array}{l}\text { Accesos a propriedades } \\
\text { y desarrollos inmobiliarios }\end{array}$ & \\
\hline \multicolumn{2}{|r|}{$\begin{array}{l}\text { ¿Todos los accesos pueden ser usados seguramente? (Entrada y salida I } \\
\text { combinaciones.) } \\
\text { ¿Tanto aguas abajo, como aguas arriba, desde los puntos de acceso el proyecto provoca } \\
\text { algún problema, en particular, cerca de una intersección? } \\
\text { ¿En las áreas de descanso y de estacionamiento de camiones, los accesos presenta }\end{array}$} & \\
\hline 7 & Desarrollos urbanos adyacentes & \\
\hline
\end{tabular}




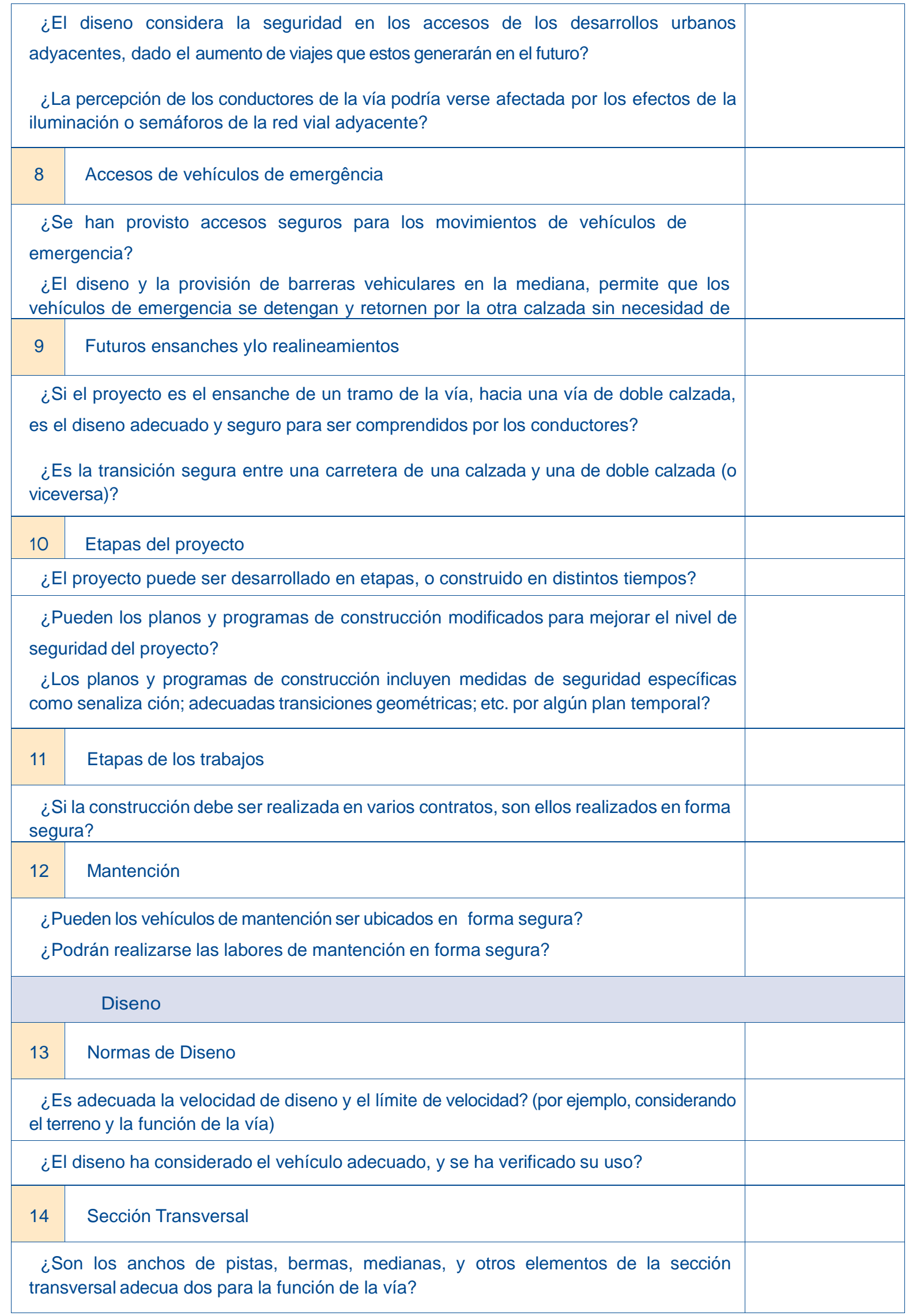




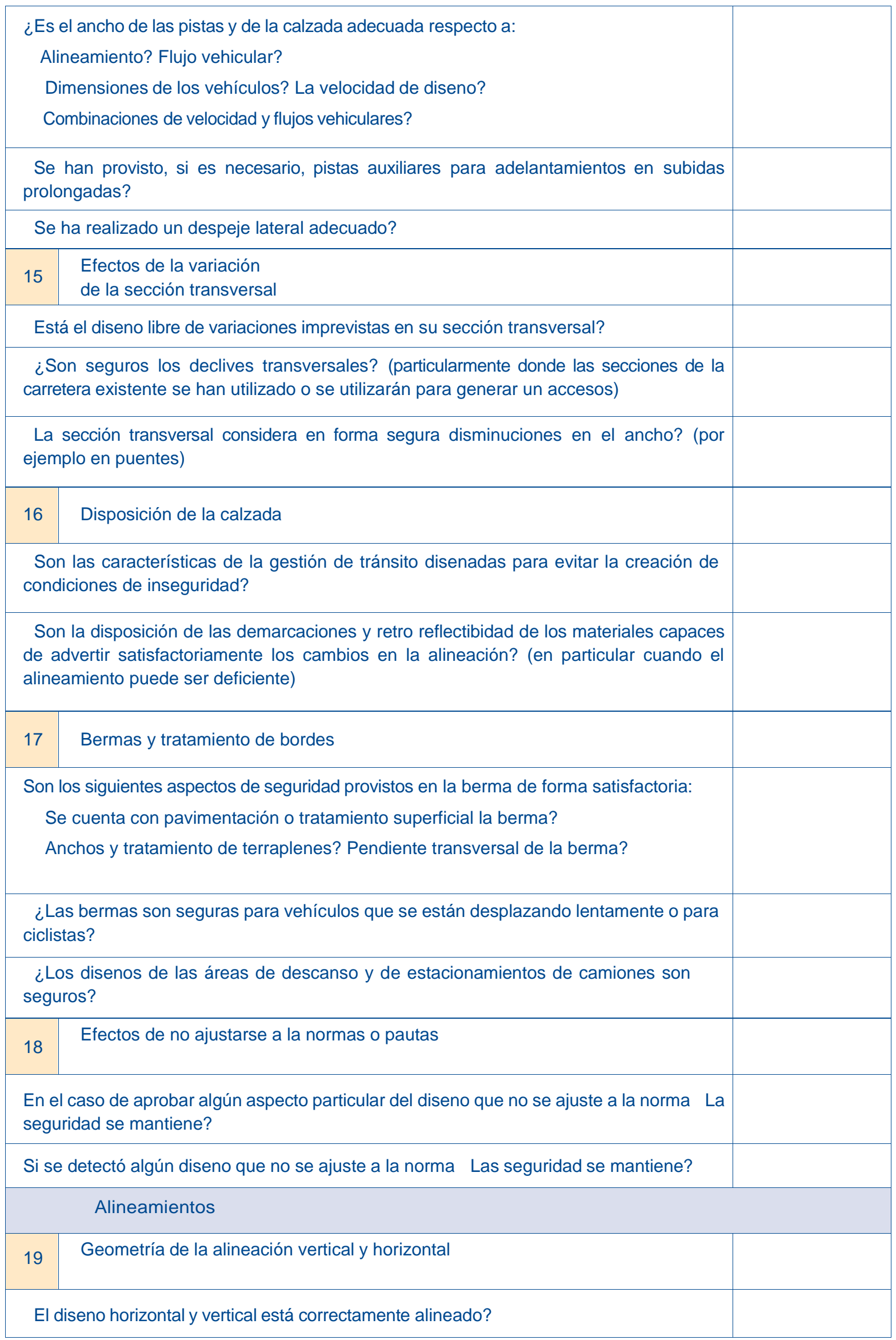




\begin{tabular}{|c|c|c|}
\hline \multicolumn{2}{|r|}{$\begin{array}{l}\text { El diseno sin las senales verticales, permite que el conductor haga una buena lectura del } \\
\text { trazado? (por ejemplo, ilusiones ópticas, delineaciones subli minales con la línea de árboles, } \\
\text { postes, cercos,etc.) }\end{array}$} & \\
\hline \multicolumn{3}{|c|}{ El alineamiento es consistente con la velocidad? } \\
\hline 20 & Visibilidad y distancia de visibilidad & \\
\hline \multicolumn{3}{|c|}{ Son los alineamientos horizontales y verticales consistentes con la visibilidad } \\
\hline \multicolumn{2}{|r|}{$\begin{array}{l}\text { El diseno permitirá que la línea de visibilidad esté libre de obstrucciones producto de } \\
\text { defensas ca mineras o vallas: } \\
\text { Vallas o cercos divisores? Mobiliario vial? Estacionamientos? } \\
\text { Sena lización Vertical? Vegetación, paisaje? Estructura } \\
\text { depuentes? Vehículos estacionados al borde de la vía? Colas } \\
\text { formadas por vehículos? }\end{array}$} & \\
\hline \multicolumn{3}{|c|}{ Los cruces ferroviarios, puentes y otros peligros son totalmente visibles? } \\
\hline \multicolumn{2}{|r|}{ Está el diseno libre de otras características del lugar que puedan afectar la visibilidad? } & \\
\hline 21 & Enlaces entre vías nuevas y existentes & \\
\hline \multicolumn{2}{|r|}{$\begin{array}{l}\text { El enlace ocurre lejos de alguna zona de riesgo de la vía (por ejemplo, la parte alta de } \\
\text { una curva vertical, de una curva horizontal, de algún peligro al borde de la calzada, o en } \\
\text { zonas de baja visibilidad o de distracciones)? }\end{array}$} & \\
\hline \multicolumn{3}{|c|}{ ¿Si el estándar de de la calzada varia, tiene algún efecto sobre la seguridad? } \\
\hline \multicolumn{2}{|r|}{$\begin{array}{l}\text { ¿Es la transición segura, en zonas donde el entorno de la vía cambia (por ejemplo, al pasar } \\
\text { de una zona urbana a rural, de un lugar con restricción a sin restricción, de una vía } \\
\text { iluminada a una sin iluminación)? }\end{array}$} & \\
\hline \multicolumn{2}{|r|}{ ¿Se ha considerado la necesidad de advertencias anticipadas? } & \\
\hline 22 & Legibilidad del alineamiento para los conductores & \\
\hline \multicolumn{2}{|r|}{$\begin{array}{l}\text { ¿El trazado general, la función y las características generales de la vía serán reconocidos } \\
\text { por los conductores con suficiente anticipación? }\end{array}$} & \\
\hline \multicolumn{3}{|c|}{$\begin{array}{l}\text { Las velocidades de aproximación serán convenientes y los conductores podrán se } \\
\text { guiados correctamente por la vía? }\end{array}$} \\
\hline \multicolumn{3}{|c|}{ Intersecciones } \\
\hline 23 & Visibilidad en y visibilidad de las intersecciones & \\
\hline \multicolumn{3}{|c|}{$\begin{array}{l}\text { ¿Son los alineamientos horizontales y verticales en las intersecciones, o en las } \\
\text { proximidades de la intersección, consistentes con la visibilidad requerida? }\end{array}$} \\
\hline \multicolumn{3}{|c|}{$\begin{array}{l}\text { ¿Los conductores podrán advertir claramente la presencia de la intersección? } \\
\text { (especialmente al acercarse a vías menores) }\end{array}$} \\
\hline \multicolumn{2}{|r|}{$\begin{array}{l}\text { ¿El diseno considera la línea de visibilidad libre de obstrucciones, producto de: } \\
\text { Barreras de seguridad o vallas? Cercas o vallas divisoras? Mobiliario } \\
\text { vial? Estacionamientos? } \\
\text { Senalización vertical? Vegetación y paisaje? Estructura de } \\
\text { puentes? }\end{array}$} & \\
\hline ¿s & $\begin{array}{l}\text { n los cruces ferroviarios, puentes y otros peligros cercanos a las intersecciones } \\
\text { ente visibles? }\end{array}$ & \\
\hline
\end{tabular}




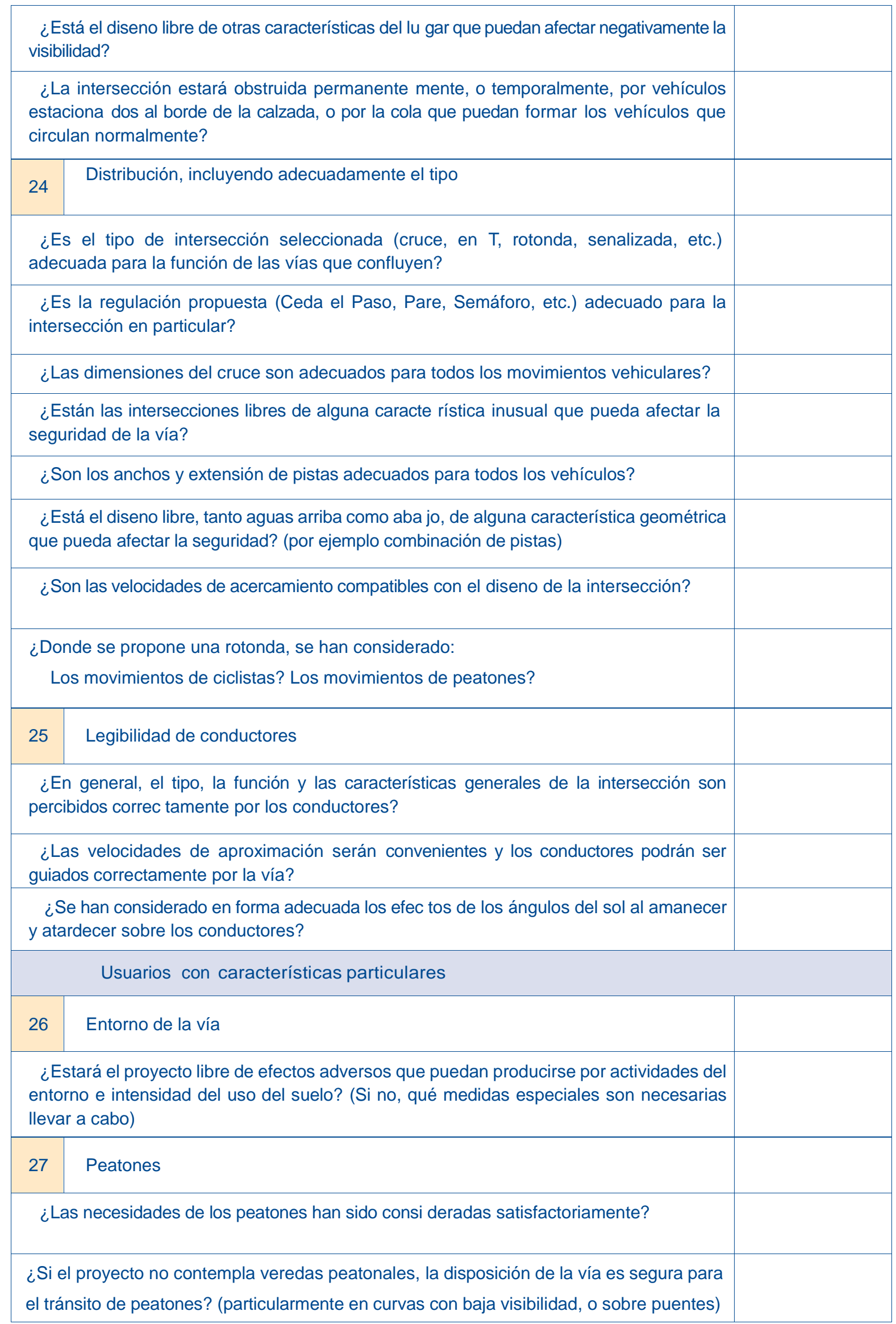




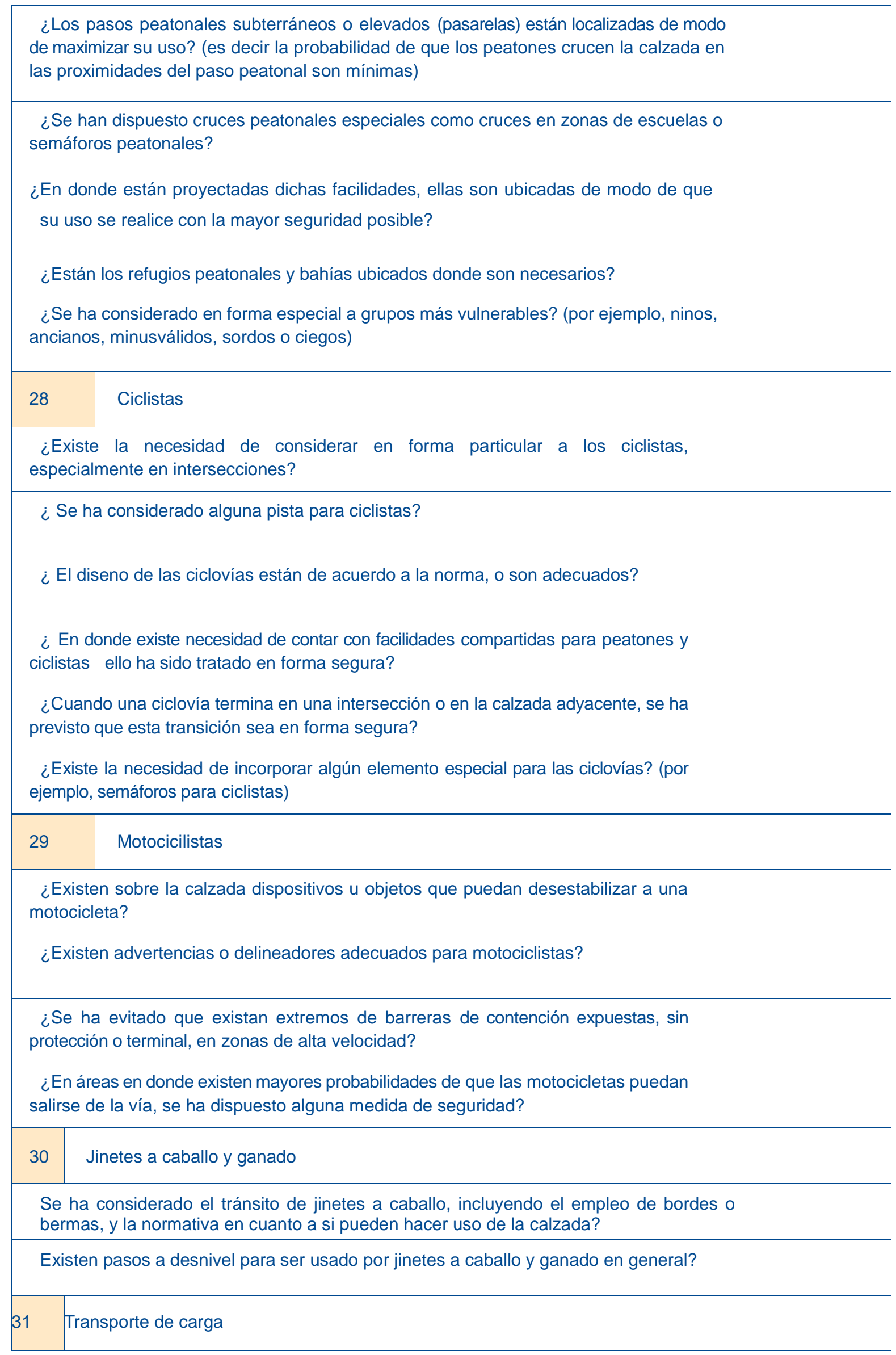




\begin{tabular}{|c|c|c|}
\hline \multicolumn{2}{|r|}{$\begin{array}{l}\text { Se han considerado las maniobras de camiones, incluyendo amplios radios de giro } \\
\text { y anchos de pistas? }\end{array}$} & \\
\hline 32 & Transporte de público & \\
\hline \multicolumn{3}{|c|}{ Circularán servicios de transporte público? } \\
\hline \multicolumn{3}{|c|}{ Han sido consideradas las necesidades de los usuarios del transporte público? } \\
\hline \multicolumn{3}{|c|}{ Se han considerado las maniobras del transporte público? } \\
\hline \multicolumn{2}{|r|}{ Las paradas de buses están localizadas de forma segura? } & \\
\hline 33 & Vehículos de mantención de la vía & \\
\hline \multicolumn{3}{|c|}{$\begin{array}{l}\text { Se ha dispuesto que los vehículos de manteni miento realicen en forma segura su } \\
\text { trabajo en el lugar? }\end{array}$} \\
\hline \multicolumn{3}{|c|}{ Senalización e iluminación } \\
\hline 34 & lluminación & \\
\hline \multicolumn{3}{|c|}{$\begin{array}{l}\text { El proyecto debe contar con iluminación? Si el proyecto no cuenta con iluminación } \\
\text { existirán pro blemas de seguridad? }\end{array}$} \\
\hline \multicolumn{2}{|r|}{$\begin{array}{l}\text { El diseno contará con secciones que tendrán pro blemas de iluminación (por ejemplo, } \\
\text { sombra de ár boles o sobre puentes) }\end{array}$} & \\
\hline \multicolumn{2}{|r|}{$\begin{array}{l}\text { La localización de los postes de iluminación se ha considerado como parte del concepto } \\
\text { general del proyecto? }\end{array}$} & \\
\hline \multicolumn{2}{|r|}{$\begin{array}{l}\text { Los postes a utilizar serán frágiles (quebradizos) } \\
\text { o de base colapsable? }\end{array}$} & \\
\hline \multirow{2}{*}{\multicolumn{2}{|c|}{$\begin{array}{l}\text { Se crean necesidades especiales por la ilumina ción ambiental? La seguridad será } \\
\text { mantenida si las medidas especiales no se llevan a cabo? } \\
\text { Las consecuencias de seguridad de los vehículos que puedan chocar con los postes de } \\
\text { iluminación se han considerado? }\end{array}$}} & \\
\hline & & \\
\hline 35 & Senalización vertical & \\
\hline \multicolumn{2}{|r|}{ Están bien localizadas las senales? } & \\
\hline \multicolumn{2}{|r|}{ Están localizadas de modo que puedan ser vistas y leídas con la anticipación suficiente? } & \\
\hline \multicolumn{2}{|r|}{ Las senales son fácilmente entendidas? } & \\
\hline \multicolumn{2}{|r|}{$\begin{array}{l}\text { Están instaladas de modo que la visibilidad desde y hacia accesos e intersecciones sea } \\
\text { mantenida? }\end{array}$} & \\
\hline \multicolumn{2}{|r|}{$\begin{array}{l}\text { Están instaladas de modo que la visibilidad desde y hacia accesos e intersecciones sea } \\
\text { mantenida? }\end{array}$} & \\
\hline \multicolumn{2}{|r|}{$\begin{array}{l}\text { Son las senales adecuadas para las necesidades del conductor? (por ejemplo, senales que } \\
\text { informan destinos, velocidad máxima, etc.) }\end{array}$} & \\
\hline & $\begin{array}{l}\text { postes de senales verticales tienen conse cuencias de seguridad para los vehículos } \\
\text { caso de choques? }\end{array}$ & \\
\hline
\end{tabular}




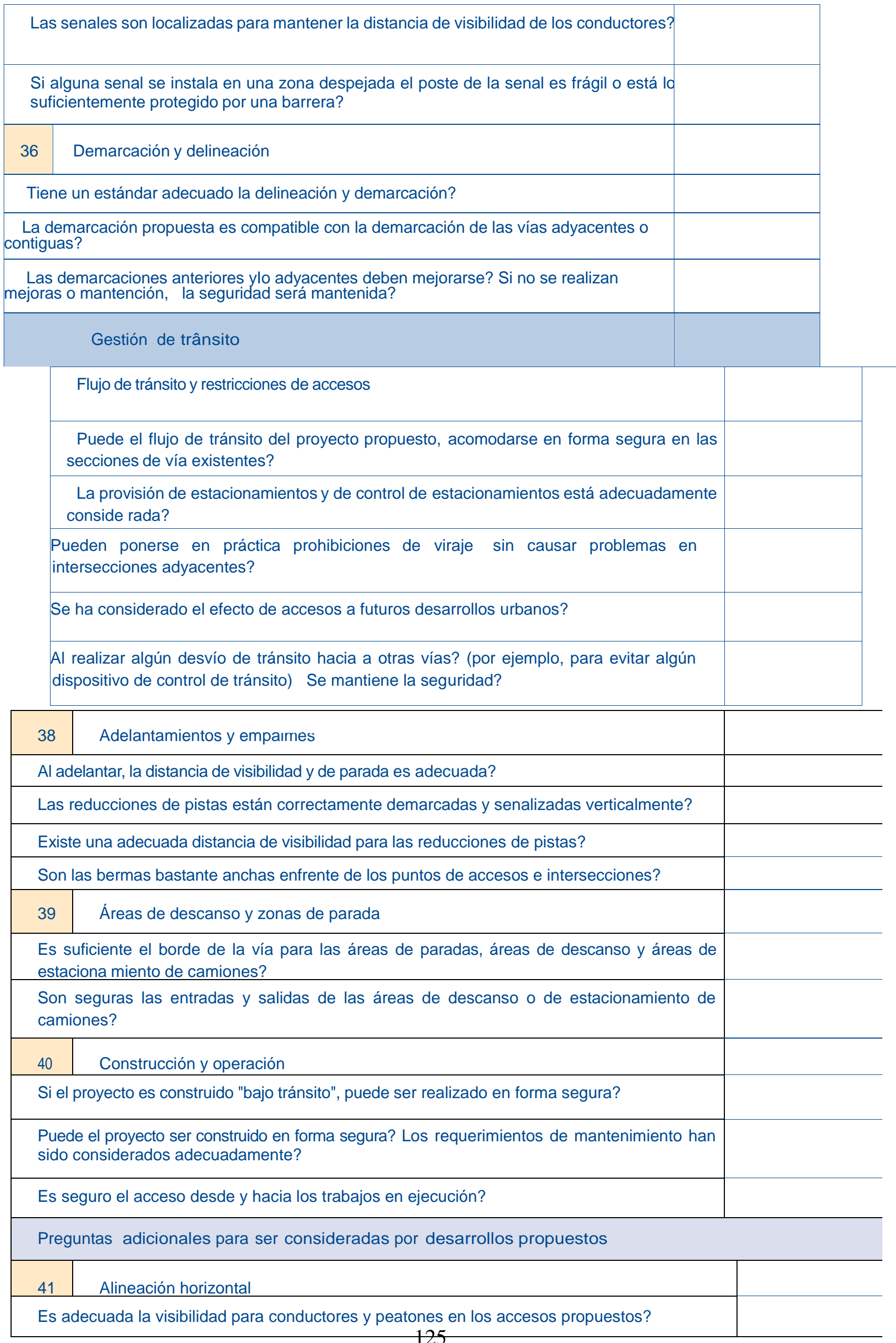


Es adecuado el espacio provisto para el viraje del flujo y velocidad del tránsito?

Tienen los radios de curva una visibilidad adecuada?

Las distancias de visibilidad y parada son adecuadas?

$41 \quad$ Alineación vertical

Son las pendientes satisfactorias?

Las distancias de visibilidad y parada son adecuadas?

$42 \quad$ Provisión de estacionamientos

El estacionamiento local es adecuado para evitar que los vehículos se estacionen sobre la calzada con el riesgo asociado a ello?

Los estacionamientos son localizados en áreas seguras?

Es adecuado el espacio proporcionado en las áreas de estacionamiento para la circulación y la distancia de visibilidad de la intersección?

\section{$43 \quad$ Servicios}

Son adecuadas las áreas de carga I descarga de la vía?

Los virajes de vehículos grandes son previstos en lugares seguros?

Los accesos para vehículos de emergencia son adecuados?

\section{$44 \quad$ Senalización vertical y demarcaciones}

Está la prioridad claramente definida en todas las intersecciones, dentro de estacionamientos y rutas de accesos?

Las senales verticales y demarcaciones serán visibles en todas las condiciones? (Incluyendo día y noche, la lluvia, la niebla, etc.)

\section{$45 \quad$ Paisaje}

El paisaje mantiene la visibilidad en intersecciones, curvas, accesos y localización de peatones?

Han sido evitada la plantación de árboles en lugares donde los vehículos pueden salirse de la vía?

$46 \quad$ Gestión de tránsito

Se han considerado efectos adversos del proyecto en alguna área?

El diseno mantendrá las velocidades vehiculares en forma segura?

Son el número y la localización de los accesos adecuados?

Existen facilidades para servicios de transporte público?

Existen facilidades para ciclistas?

Están ubicadas en forma segura con respecto a los movimientos vehicular?

Existen facilidades peatonales?

Están localizadas en lugares seguros y justifi cados?

\begin{tabular}{l|l}
\hline 47 & Otros \\
\hline \multicolumn{2}{|c|}{ En la vía se ha provisto de iluminación? Es adecuada? }
\end{tabular}

Existen peligro al borde de la vía? Han sido tratados en forma correcta?

Los peatones pueden acceder en forma segura a los desarrollos urbanos propuestos?

Otras materias a considerar

$48 \quad$ Aspectos de seguridad no cubiertos

Existirán situaciones especiales? Han sido consideradas situaciones inusuales o de peligro?

La vía es capaz de admitir la circulación de vehículos de sobretamano, o vehículos grandes como camiones, autobuses, vehículos de emergencia, vehículos de mantenimiento vial?

Si se requiere, la vía puede ser cerrada para eventos especiales de una manera segura?

Si corresponde, los requerimientos especiales del paisaje y rutas turísticas son satisfechos? 


\section{Lista de verificação detalhada de Castrillón e Candia (2003) - Projeto Executivo}

\begin{tabular}{|c|c|c|}
\hline \multicolumn{3}{|c|}{$\begin{array}{l}\text { Lista de Chequeo Detallada } \\
\text { Etapa de Diseno en Detalle }\end{array}$} \\
\hline \multicolumn{3}{|c|}{ COMENTARIOS } \\
\hline \multicolumn{3}{|c|}{ Alcances Generales } \\
\hline 1 & Cambios desde la ASV previa & \\
\hline \multicolumn{2}{|r|}{$\begin{array}{l}\text { Las condiciones del proyecto originalmente disenado todavía se aplican? (por ejemplo, no } \\
\text { existen cambios en la red vial adyacente, área de actividades o composición del flujo vehicular) }\end{array}$} & \\
\hline \multicolumn{2}{|r|}{ El diseno del proyecto se mantiene sin alteraciones desde la ASV anterior? } & \\
\hline 2 & Drenaje & \\
\hline \multicolumn{3}{|c|}{ La nueva vía tendrá un escurrimiento adecuado de las aguas? } \\
\hline \multicolumn{2}{|r|}{ Es la pendiente longitudinal y transversal correcta para un drenaje satisfactorio? } & \\
\hline \multicolumn{2}{|r|}{ Son los tramos planos evitados o adecuadamente repartidos al comienzo o final de un peralte? } & \\
\hline \multicolumn{2}{|r|}{$\begin{array}{l}\text { La posibilidad de inundación de la superficie de rodado ha sido adecuadamente tratada, } \\
\text { incluyendo desbordamientos desde áreas vecinas o en intersecciones de alcantarillas y cursos } \\
\text { de agua? }\end{array}$} & \\
\hline \multicolumn{2}{|r|}{ La profundidad del canal es adecuado para limitar inundaciones? } & \\
\hline \multicolumn{2}{|r|}{ Es la rejilla de sumidero disenada en forma segura para ciclistas? } & \\
\hline \multicolumn{2}{|c|}{ Las sendas peatonales, tienen un adecuado drenaje? } & \\
\hline 3 & Condiciones climáticas & \\
\hline \multicolumn{2}{|r|}{$\begin{array}{l}\text { El diseno toma en cuenta los registros meteorológicos o la experiencia local que pueda } \\
\text { indicar algún problema particular? (por ejemplo nieve, hielo, viento, niebla) }\end{array}$} & \\
\hline 4 & Entorno de la vía & \\
\hline \multicolumn{2}{|r|}{$\begin{array}{l}\text { Los conductores serán capaces de ver a peatones (y viceversa) más allá del paisaje (cerros, } \\
\text { valles, ríos, vegetación, etc.)? }\end{array}$} & \\
\hline \multicolumn{2}{|r|}{ La línea de visibilidad en una intersección será mantenida más allá o sobre el paisaje? } & \\
\hline \multicolumn{2}{|r|}{$\begin{array}{l}\text { La seguridad será adecuada con los cambios estacionales (por ejemplo, que no se oscurezcan } \\
\text { senales de tránsito, protección del sol o efectos de la luz, de la superficie resbaladiza por hielo, } \\
\text { etc.)? }\end{array}$} & \\
\hline \multicolumn{2}{|r|}{ Se mantendrá la seguridad al borde de la vía cuando los árboles crezcan, florezcan? } & \\
\hline
\end{tabular}




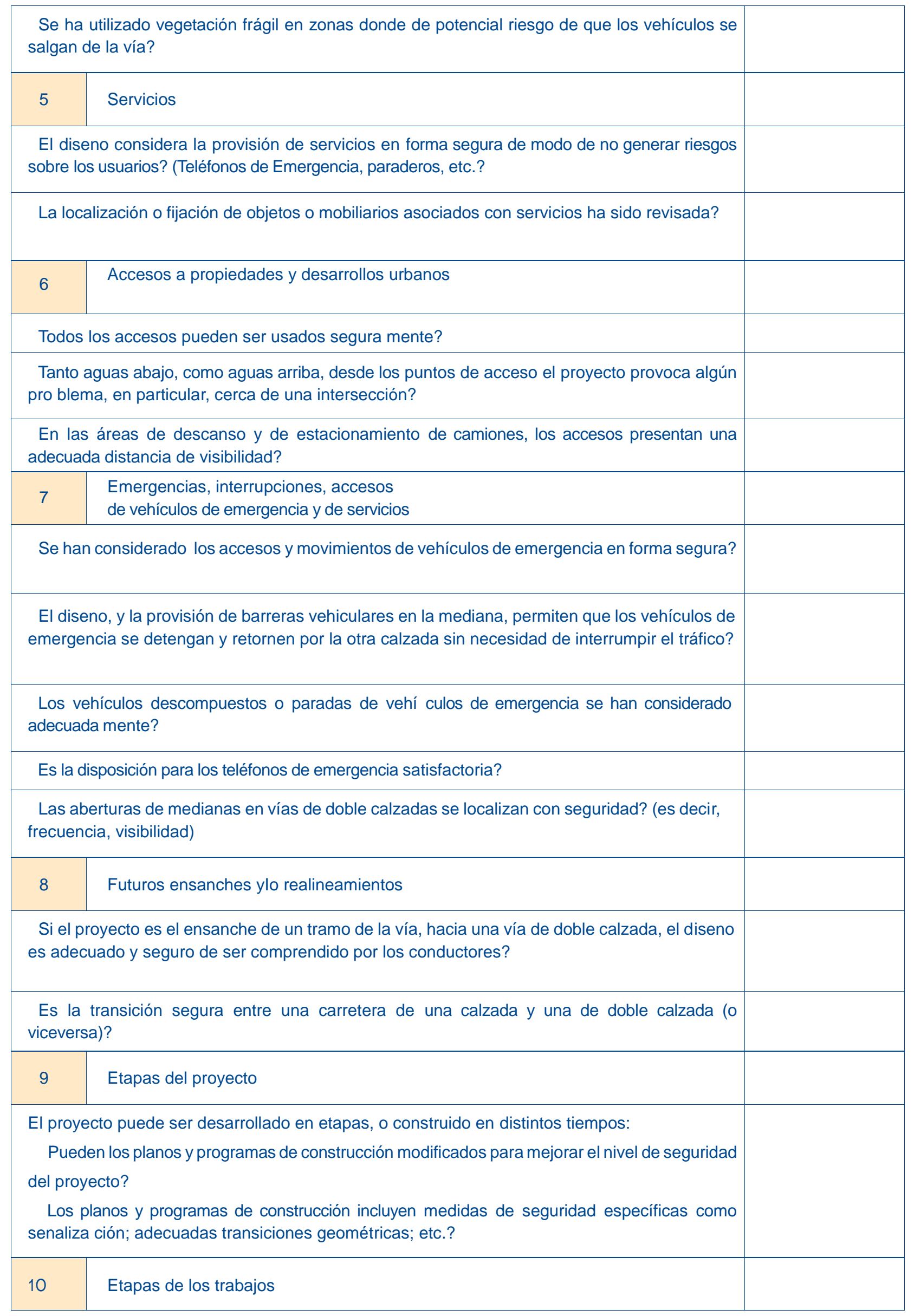




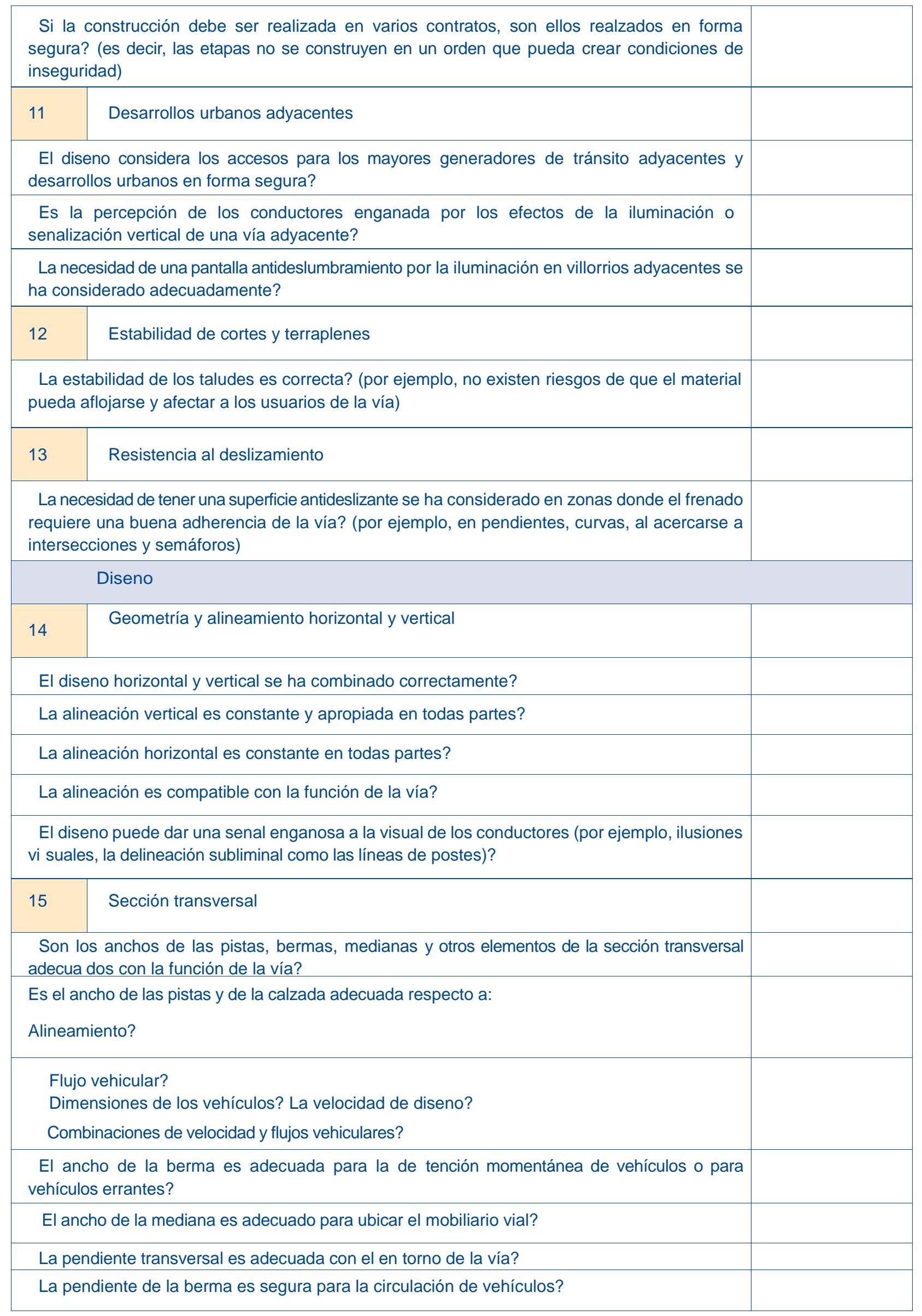




\begin{tabular}{|c|c|c|}
\hline \multicolumn{2}{|c|}{ El talud de la pendiente es maniobrable para automóviles y camiones? } & \\
\hline \multicolumn{2}{|c|}{ Se han provisto facilidades para peatones y ciclistas? } & \\
\hline 16 & $\begin{array}{l}\text { Efectos de la variación } \\
\text { de la sección transversal }\end{array}$ & \\
\hline \multicolumn{3}{|c|}{ Está el diseno libre de variaciones imprevistas en su sección transversal? } \\
\hline \multicolumn{2}{|c|}{$\begin{array}{l}\text { Son seguras las pendientes transversales (particu larmente donde las secciones de la carretera } \\
\text { exis tente se han utilizado o se utilizarán para generar un acceso, en angostamientos en } \\
\text { puentes, etc.) }\end{array}$} & \\
\hline \multicolumn{3}{|c|}{ Si alguna curva tiene un contraperalte, se encuentra este dentro de los límites apropiados? } \\
\hline \multicolumn{2}{|r|}{ El peralte es adecuado y suficiente en todos los lugares donde es requerido? } & \\
\hline 17 & Disposición de la calzada & \\
\hline \multicolumn{3}{|c|}{$\begin{array}{l}\text { Son las características de la gestión de tránsito disenadas para evitar la creación de } \\
\text { condiciones de inseguridad? }\end{array}$} \\
\hline \multicolumn{2}{|c|}{$\begin{array}{l}\text { Son la disposición de las demarcaciones y retro reflectibidad de los materiales capaces de } \\
\text { advertir satisfactoriamente los cambios en la alineación? (en particular cuando el alineamiento } \\
\text { puede ser deficiente) }\end{array}$} & \\
\hline \multicolumn{3}{|c|}{ Están contemplados adecuadamente los adelantamientos? } \\
\hline \multicolumn{2}{|r|}{$\begin{array}{l}\text { Las pistas de adelantamientos son provistas en forma segura, desde que comienza hasta que } \\
\text { termina la maniobra? }\end{array}$} & \\
\hline \multicolumn{3}{|c|}{ Los requerimientos para adelantamientos son satisfactorios? } \\
\hline \multicolumn{2}{|r|}{$\begin{array}{l}\text { El diseno puede generar algún problema de visibilidad para el conductor producto del sol } \\
\text { al amanecer ylo atardecer? }\end{array}$} & \\
\hline \multicolumn{2}{|r|}{ Los requerimientos de transporte público están satisfechos adecuadamente? } & \\
\hline 18 & Bermas y tratamiento de bordes & \\
\hline \multirow{3}{*}{\multicolumn{3}{|c|}{$\begin{array}{l}\text { Son los siguientes aspectos de seguridad provistos en la berma de forma satisfactoria: } \\
\text { Se cuenta con pavimentación o tratamiento superficial la berma? } \\
\text { Anchos y tratamiento sobre terraplenes? Pendiente transversal de la berma? }\end{array}$}} \\
\hline & & \\
\hline & & \\
\hline \multicolumn{2}{|c|}{$\begin{array}{l}\text { Las bermas son seguras sin para vehículos que se están desplazando lentamente o para } \\
\text { ciclista? }\end{array}$} & \\
\hline 19 & Efectos de no ajustarse a normas o pautas & \\
\hline \multicolumn{2}{|r|}{ En el caso de aprobar algún diseno que no se ajuste a la norma La seguridad se mantiene? } & \\
\hline \multicolumn{2}{|r|}{ Si se detectó algún diseno que no se ajuste a la norma: La seguridad se mantiene? } & \\
\hline 20 & Visibilidad y distancia de visibilidad & \\
\hline \multicolumn{3}{|c|}{ Son los alineamientos horizontales y verticales consistentes con la visibilidad requerida? } \\
\hline & idad de diseno seleccionada es coherente con la visibilidad requerida? & \\
\hline
\end{tabular}




\begin{tabular}{|c|c|c|}
\hline 21 & Tratamientos ambientales & \\
\hline \multicolumn{3}{|c|}{$\begin{array}{l}\text { La seguridad vial ha sido considerada en la mitigación de impactos ambientales? (por ejemplo, } \\
\text { panel antiruido) }\end{array}$} \\
\hline \multicolumn{3}{|c|}{ Detalles del alineamiento } \\
\hline 22 & Visibilidad; distancia de visibilidad & \\
\hline \multicolumn{3}{|c|}{ Son los alineamientos horizontales y verticales consistentes con la visibilidad requerida? } \\
\hline \multicolumn{3}{|c|}{$\begin{array}{l}\text { El diseno permitirá que la línea de visibilidad esté libre de obstrucciones producto de defensas } \\
\text { camineras o vallas: }\end{array}$} \\
\hline \multicolumn{3}{|c|}{ Vallas o cercos divisores? Mobiliario vial? Estacionamientos? } \\
\hline \multicolumn{3}{|c|}{ Senalización Vertical Vegetación, paisaje Estructura de puentes } \\
\hline \multicolumn{3}{|c|}{$\begin{array}{l}\text { Vehículos estacionados al borde de la vía } \\
\text { Colas formadas por vehículos }\end{array}$} \\
\hline \multicolumn{3}{|c|}{ Son los cruces ferroviarios, puentes y otros peligros totalmente visibles? } \\
\hline \multicolumn{3}{|c|}{ Está el diseno libre de otras características del lugar que puedan afectar la visibilidad? } \\
\hline \multicolumn{3}{|c|}{$\begin{array}{l}\text { Existen obstrucciones elevadas (por ejemplo, pasos sobre nivel o ferroviarios, pórticos de } \\
\text { senalización, follaje de árboles ) que puedan limitar la distancia de visibilidad especialmente en la } \\
\text { parte baja de una curva vertical? }\end{array}$} \\
\hline \multicolumn{3}{|c|}{$\begin{array}{l}\text { La vía puede ser utilizada por vehículos de gran altura, o si no, se ha considerado un desvío } \\
\text { hacia una ruta alternativa donde sea necesario? }\end{array}$} \\
\hline \multicolumn{3}{|c|}{$\begin{array}{l}\text { Es la visibilidad adecuada para: } \\
\text { Cualquier peatón, bicicleta o cruces de ganado? Accesos a vías, vías de acceso, sobre y de } \\
\text { accesos a desnivel, etc.? }\end{array}$} \\
\hline \multicolumn{3}{|c|}{$\begin{array}{l}\text { Se ha proporcionado una buena visibilidad a: Entradas y salidas de rampas? } \\
\text { Intersecciones? Rotondas? otros puntos de conflicto? }\end{array}$} \\
\hline 23 & Enlaces entre vías nuevas y existentes & \\
\hline \multicolumn{3}{|c|}{ Se han considerado implicaciones de seguridad en la transición? } \\
\hline \multicolumn{3}{|c|}{ La transición desde la vía antigua hacia el nuevo proyecto es satisfactoria? } \\
\hline \multicolumn{3}{|c|}{$\begin{array}{l}\text { Si la vía existente tiene un estándar inferior al del nuevo proyecto, es clara la advertencia e } \\
\text { inequívoca la reducción del estándar? }\end{array}$} \\
\hline \multicolumn{3}{|c|}{$\begin{array}{l}\text { Se han tomado las medidas apropiadas de seguridad en dónde se requieran cambios } \\
\text { repentinos de velocidad? }\end{array}$} \\
\hline \multicolumn{3}{|c|}{ El acceso o la fricción lateral son manejados seguramente? } \\
\hline $\begin{array}{l}\text { El e } \\
\text { curv }\end{array}$ & $\begin{array}{l}\text { ocurre lejos de algún riesgo? (por ejemplo, de la parte alta de una curva vertical, de una } \\
\text { izontal, donde existen peligros de visibilidad o distracciones al borde de la vía) }\end{array}$ & \\
\hline
\end{tabular}


Si el estándar de la calzada varía, el cambio es efectuado en forma segura?

La transición ocurre donde el cambio del entorno es seguro? (por ejemplo, de urbano a rural, de zona restricción a sin restricción, de zona iluminada a una sin iluminación)

Se ha considerado la necesidad de realizar advertencias con anticipación?

24 Legibilidad del alineamiento para los conductores

El trazado general, la función y las características generales de la vía serán reconocidos por los conductores con suficiente anticipación

Las velocidades de aproximación serán conve nientes y los conductores podrán se guiados co rrectamente por la vía?

\begin{tabular}{|c|c|}
\hline 25 & Detalles del diseno geométrico \\
\hline \multicolumn{2}{|r|}{ Son las normas de diseno apropiadas por todas las exigencias del proyecto? } \\
\hline \multicolumn{2}{|r|}{$\begin{array}{l}\text { El ancho de las pistas y la pendiente transversal son consistentes con las normas y pautas } \\
\text { generales de diseno? }\end{array}$} \\
\hline 26 & Tratamiento de puentes y alcantarillas \\
\hline \multicolumn{2}{|r|}{$\begin{array}{l}\text { La transición geométrica de la sección transversal al entrar a un puente se puede realizar en } \\
\text { forma segura? }\end{array}$} \\
\hline \multicolumn{2}{|r|}{ Intersecciones } \\
\hline 27 & Visibilidad de y visibilidad en intersecciones \\
\hline \multicolumn{2}{|r|}{$\begin{array}{l}\text { Los alineamientos horizontales y verticales en las intersecciones, o en las proximidades de la } \\
\text { intersec ción, son consistentes con la visibilidad requerida? }\end{array}$} \\
\hline \multicolumn{2}{|r|}{$\begin{array}{l}\text { El estándar adoptado permite una buena visibilidad para la velocidad del tránsito y para una } \\
\text { composición del tránsito inusual? }\end{array}$} \\
\hline \multirow{2}{*}{\multicolumn{2}{|c|}{$\begin{array}{l}\text { El diseno considera que la línea de visibilidad estará libre de obstrucciones, producto de: } \\
\text { Barreras de seguridad o vallas? Cercas o vallas divisoras? Mobiliario vial? } \\
\text { Estacionamientos? } \\
\text { Senalización vertical? Vegetación y paisaje? Estructura de puentes? }\end{array}$}} \\
\hline & \\
\hline \multicolumn{2}{|r|}{$\begin{array}{l}\text { Los cruces ferroviarios, puentes y otros peligros cercanos a las intersecciones, son totalmente } \\
\text { visibles? }\end{array}$} \\
\hline \multicolumn{2}{|c|}{$\begin{array}{l}\text { El diseno está libre de alguna otra característica del lugar que pueda afectar negativamente } \\
\text { la visibilidad? }\end{array}$} \\
\hline 28 & Distribución \\
\hline \multicolumn{2}{|r|}{ Las intersecciones y accesos son adecuados para todos los movimientos vehiculares? } \\
\hline
\end{tabular}




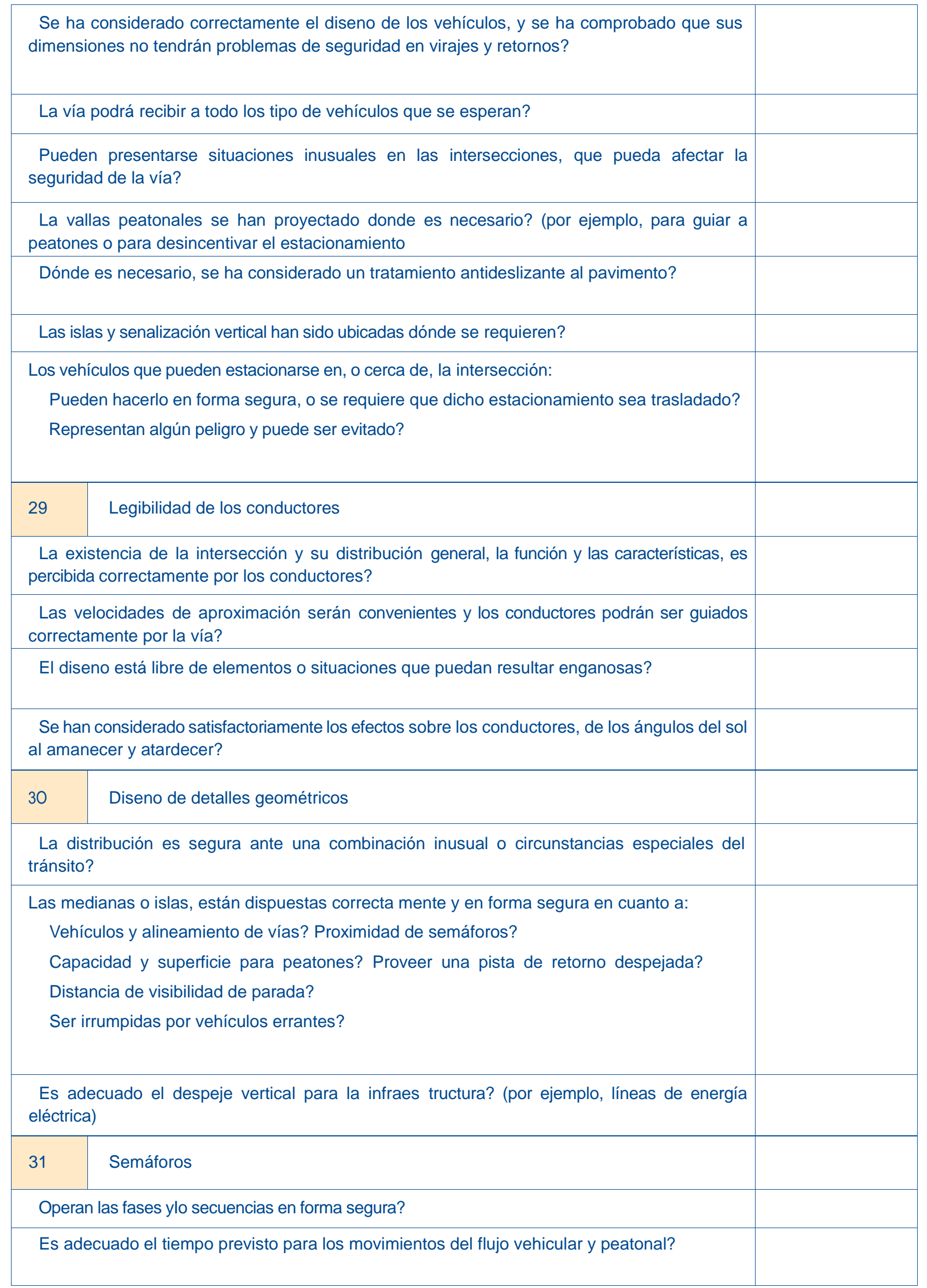




\begin{tabular}{|c|c|c|}
\hline \multicolumn{2}{|r|}{$\begin{array}{l}\text { Las lámparas del semáforo son visibles? (por ejemplo, que no estén obstruidas por árboles, } \\
\text { postes, senales de tránsito o grandes vehículos) }\end{array}$} & \\
\hline \multicolumn{3}{|c|}{$\begin{array}{l}\text { Las lámparas orientadas en otras direcciones de acercamiento están suficientemente } \\
\text { protegidas de modo de ser vistas sólo por el tránsito que las enfrenta? }\end{array}$} \\
\hline \multicolumn{3}{|c|}{$\begin{array}{l}\text { Las lámparas tienen una intensidad de luz suficiente, de modo de, si corresponde, no ser } \\
\text { afectadas por la salida o puesta de sol? }\end{array}$} \\
\hline \multicolumn{2}{|r|}{$\begin{array}{l}\text { La alineación vertical proporciona una adecuada distancia de visibilidad de parada hacia la } \\
\text { intersección o detrás de la cola vehicular? }\end{array}$} & \\
\hline \multicolumn{3}{|c|}{ Dónde se requiere, se han provisto facilidades para peatones? } \\
\hline \multicolumn{3}{|c|}{ Los conductores que se aproximan a la intersección podrán ver claramente a los peatones? } \\
\hline \multicolumn{3}{|c|}{ Son provistas fases de viraje requeridas? } \\
\hline \multicolumn{3}{|c|}{ Son controladas parcial o totalmente las fases de viraje? } \\
\hline \multicolumn{3}{|c|}{ Los postes de los semáforos son localizados en lugares donde no generen un riesgo? } \\
\hline \multicolumn{3}{|c|}{ Es adecuada la demarcación para el tránsito que vira? } \\
\hline \multicolumn{2}{|c|}{ Existe una fase exclusiva para peatones? Es adecuada? } & \\
\hline 32 & Rotondas & \\
\hline \multicolumn{3}{|c|}{ Es adecuada la desviación o curva proyectada para reducir las velocidades de acercamiento. } \\
\hline \multicolumn{2}{|c|}{$\begin{array}{l}\text { Si son necesarias las islas encauzadoras, ellas tienen una buena distancia de visibilidad, } \\
\text { longitud y capacidad para almacenar peatones? }\end{array}$} & \\
\hline \multicolumn{3}{|c|}{ La isla central es elevada y visible? } \\
\hline \multicolumn{2}{|r|}{ Se ha comprobado que el diseno es adecuado para todo tipo de vehículos? } & \\
\hline \multicolumn{2}{|r|}{ Son adecuados los detalles de la isla central? (como: delineación, elevación, visibilidad)? } & \\
\hline \multicolumn{2}{|r|}{ Los conductores pueden ver a los peatones con el tiempo suficiente? } & \\
\hline \multicolumn{2}{|c|}{$\begin{array}{l}\text { Pueden los peatones advertir cuando los vehículos comienzan a virar? (no existen obstrucciones } \\
\text { de la línea de visibilidad) }\end{array}$} & \\
\hline \multicolumn{2}{|c|}{ Se requiere que las pistas de aproximación estén demarcadas? } & \\
\hline \multicolumn{2}{|c|}{ La iluminación es adecuada? } & \\
\hline 33 & Otras intersecciones & \\
\hline \multicolumn{3}{|c|}{ Se ha considerado la necesidad de pintar los bordes de las islas y los refugios? } \\
\hline \multicolumn{3}{|c|}{$\begin{array}{l}\text { Las intersecciones tienen la longitud de cola vehicular adecuada? } \\
\text { Las intersecciones tienen capacidad para albergar a los vehículos que efectúan movimientos de } \\
\text { viraje? }\end{array}$} \\
\hline \multicolumn{3}{|c|}{ Usuarios Especiales } \\
\hline 34 & Terrenos adyacentes & \\
\hline
\end{tabular}




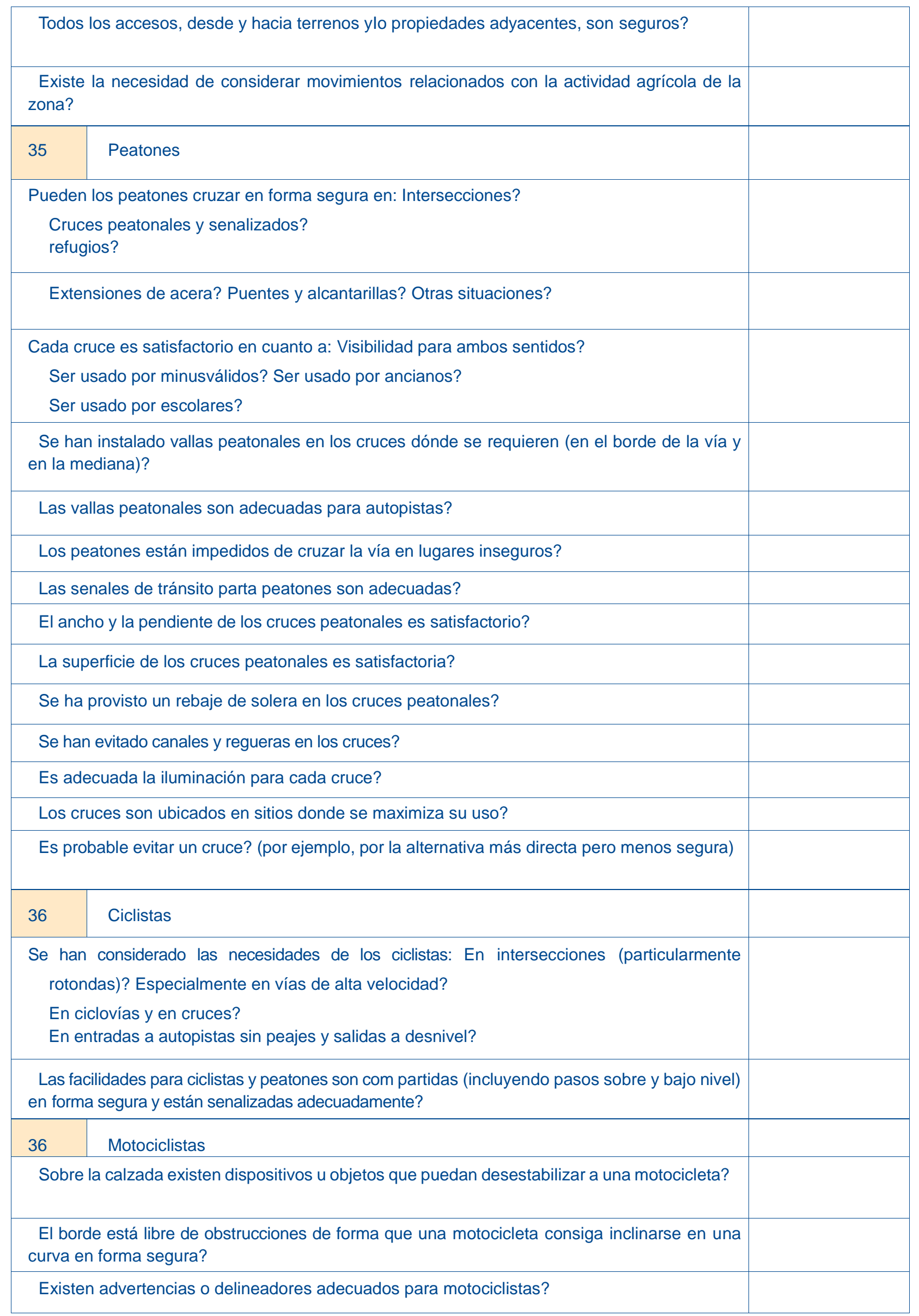


Se ha evitado que existan extremos de barreras de contención expuestas, sin protección o terminales, en zonas de alta velocidad?

En áreas en donde existen mayores probabilidades de que las motocicletas puedan salirse de la vía, se ha dispuesto alguna medida de seguridad?

Son todos los postes y dispositivos necesarios? Si es así, Existe la opción de protegerlos?

Los estanques de drenajes y alcantarillas pueden ser superados satisfactoriamente por los motociclistas?

37

Jinetes a caballo y tránsito de ganado

Se ha considerado el tránsito de jinetes a caballo, incluyendo el empleo de bordes o bermas y la normativa en cuanto a, si pueden hacer uso de la calzada?

Existen pasos a desnivel que puedan ser usados por jinetes a caballo y ganado en general?

\begin{tabular}{l|l}
\hline 38 & Transporte de carga
\end{tabular}

Se han considerado las maniobras de camiones, incluyendo radios de giro y anchos de pistas amplios?

Se han considerado las necesidades de transporte de carga, adecuadamente senalizadas?

39

Transporte público

Las necesidades del transporte público han sido consideradas, con facilidades y senalización adecuada?

Se han considerado las necesidades de los usuarios del transporte público?

Se han considerado las maniobras del transporte público?

Las paradas de buses son ubicadas en forma segura?

\begin{tabular}{|l|l}
40 & Vehículos que realizan mantención de la vía
\end{tabular}

Existe la necesidad de considerar a los vehículos con facilidades y senalización adecuada?

Los vehículos que realizan la mantención de la vía, pueden ser estacionados en forma segura?

Pueden realizarse las labores de mantención en forma segura?

Senalización Vertical e iluminación

$41 \quad$ lluminación

Se requiere iluminación? es proporcionada adecuadamente?

El diseno está libre de aspectos que puedan interrumpir una correcta iluminación? (por ejemplo árboles o sobre puentes)

Algún poste de iluminación representa un peligro al borde de la vía?

Los postes a utilizar serán frágiles (quebradizos)

o de base colapsable? 


\begin{tabular}{|c|c|c|}
\hline \multicolumn{2}{|r|}{$\begin{array}{l}\text { El proyecto de iluminación confundirá o provocará efectos enganosos sobre la senalización o } \\
\text { semáforos? }\end{array}$} & \\
\hline \multicolumn{3}{|c|}{ La iluminación permitirá iluminar adecuadamente los cruces, las vías cercanas, refugios, etc.? } \\
\hline \multicolumn{3}{|c|}{ Son todos los empalmes de áreas adecuada mente iluminados? } \\
\hline \multicolumn{3}{|c|}{ Existen zonas muy oscuras en el proyecto? } \\
\hline \multicolumn{2}{|r|}{$\begin{array}{l}\text { Si existen lugares con problemas de accidentes, puede ser favorable tratarlos mejorando la } \\
\text { iluminación, o instalando iluminación? }\end{array}$} & \\
\hline 42 & Senalización de tránsito vertical & \\
\hline \multicolumn{3}{|c|}{ La localización de la senalización vertical será la apropiada? } \\
\hline \multicolumn{2}{|r|}{$\begin{array}{l}\text { La senalización de tránsito estará ubicada en un lugar donde puedan ser vistas y leídas con la } \\
\text { debida anticipación? }\end{array}$} & \\
\hline \multicolumn{3}{|c|}{ Todas las senales verticales serán fácilmente entendidas? } \\
\hline \multicolumn{2}{|r|}{$\begin{array}{l}\text { Las senales son apropiadas para las necesidades del conductor? (por ejemplo, senales de } \\
\text { dirección, de velocidad, informativas, de advertencia, etc.) }\end{array}$} & \\
\hline \multicolumn{2}{|r|}{$\begin{array}{l}\text { La senalización está instalada de modo que la distancia de visibilidad de los conductores } \\
\text { sea mantenida? }\end{array}$} & \\
\hline \multicolumn{3}{|c|}{$\begin{array}{l}\text { La senalización está instalada de modo que la visibilidad de los conductores sea mantenida? } \\
\text { Desde y hacia intersecciones? Desde y hacia los peatones? } \\
\text { Desde y hacia características importantes de la vía? }\end{array}$} \\
\hline \multicolumn{2}{|r|}{$\begin{array}{l}\text { Se han considerado las posibles consecuencias de los vehículos que pudiesen impactar a los } \\
\text { postes de senalización? }\end{array}$} & \\
\hline \multicolumn{2}{|r|}{$\begin{array}{l}\text { Están los postes de la senalización fuera de las zonas despejadas? } \\
\text { Si no, son ellos: Frágiles? } \\
\text { Protegidos con barreras? (por ejemplo defensas camineras, amortiguador de impacto) }\end{array}$} & \\
\hline \multicolumn{2}{|r|}{$\begin{array}{l}\text { Se ha evitado una sobre dependencia de la senalización? (en lugar de un diseno geométrico } \\
\text { adecuado) }\end{array}$} & \\
\hline \multicolumn{2}{|r|}{$\begin{array}{l}\text { La nueva senalización es compatible con la de la red vial adyacente? (o la senalización antigua } \\
\text { tendrá que ser mejorada) }\end{array}$} & \\
\hline 43 & Demarcación y delineación & \\
\hline \multicolumn{3}{|c|}{ Las formas y símbolos de la demarcación son consistentes con el manual de senalización? } \\
\hline \multicolumn{2}{|r|}{$\begin{array}{l}\text { Se ha identificado y tratado algún lugar donde la demarcación puede ser confusa o mal } \\
\text { interpretada, de modo de considerar las respuestas probables del usuario? }\end{array}$} & \\
\hline \multicolumn{2}{|r|}{ Están las líneas continuas (de no adelantamiento) provistas donde se requieren? } & \\
\hline \multicolumn{2}{|c|}{ Las tachas son retroreflectivas y provistas donde son necesarias? } & \\
\hline \multicolumn{2}{|r|}{$\begin{array}{l}\text { Las senales de advertencia de peligro de la curva, de velocidad o chevrones alineadores están } \\
\text { provistas donde son requeridas? }\end{array}$} & \\
\hline & $\begin{array}{l}\text { Ircación del nuevo proyecto es consistente con las secciones de vías de la vía contigua } \\
\text { arcación tendrá que ser mejorada)? }\end{array}$ & \\
\hline
\end{tabular}




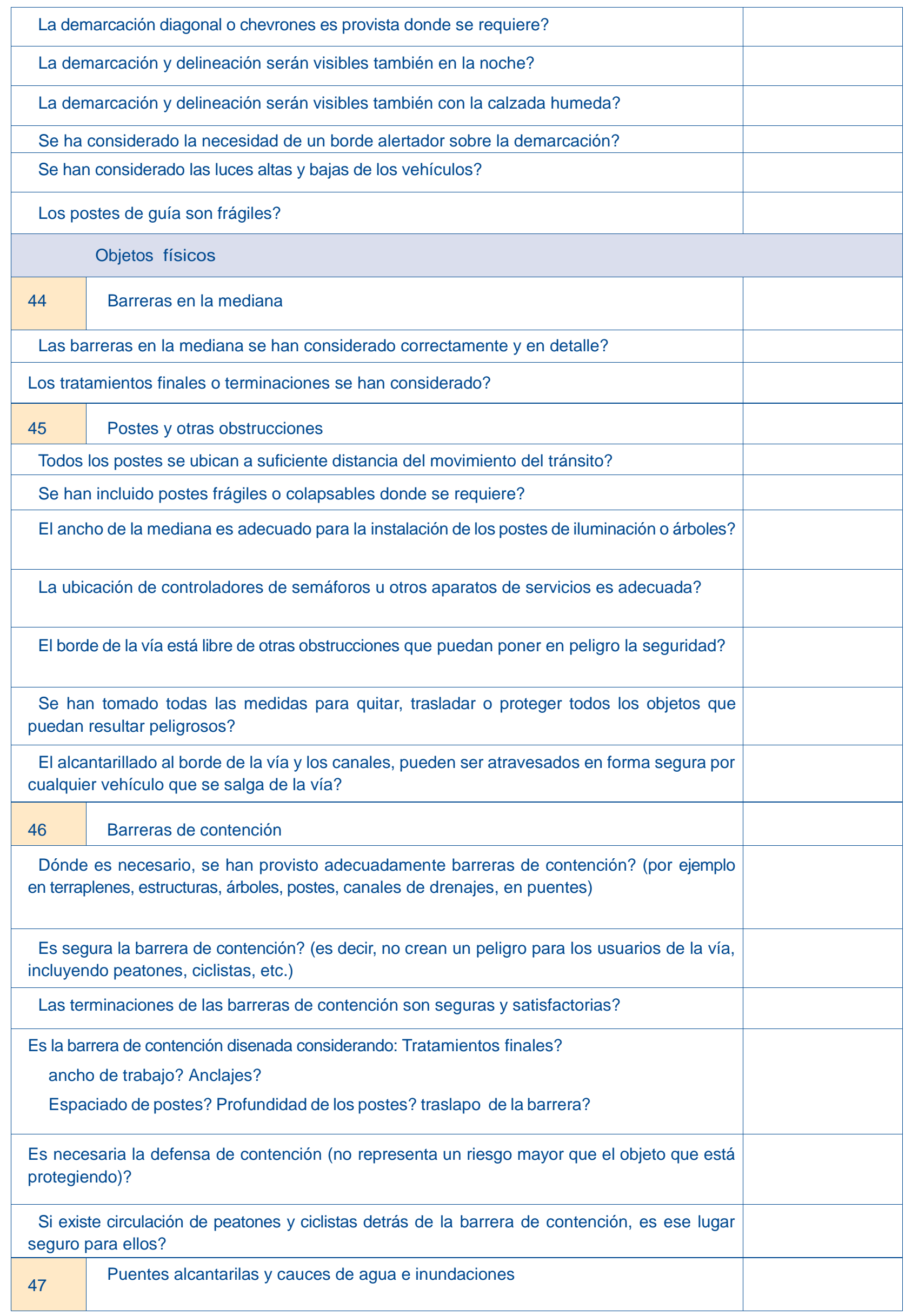


Las barreras de los puentes y la pared final de las alcantarillas son seguras en cuanto a:

Visibilidad?

facilidad de reconocimiento? Proximidad al movimiento del tránsito?

La posibilidad de causar heridas o danos? terminaciones colapsables o frágiles? senalización y demarcación?

Conexión con las barreras de protección? Protección de riesgos al borde de la carretera?

El pasamanos del puente está a un nivel correcto y bastante firme?

El ancho de la berma sobre el puente es igual al resto de la vía?

Es segura el espacio para el tránsito no vehicular sobre el puente? (por ejemplo, peatones, bicicletas, caballos, etc.)

Las salidas de las alcantarillas representan algún riesgo para los conductores que se puedan salir de la vía?

Las vías con causes de agua propensas a inundaciones cuentan con una correcta senalización y una adecuada distancia de visibilidad?

Preguntas adicionales a ser consideradas para desarrollos propuestas

\begin{tabular}{|l|l|}
\hline 48 & Alineamiento horizontal
\end{tabular}

Es adecuada la visibilidad para conductores y peatones en los accesos propuestos?

Es adecuado el espacio provisto para el viraje del flujo y velocidad del tránsito?

Tienen los radios de curva una visibilidad adecuada?

Las distancias de visibilidad y parada son adecuadas?

\begin{tabular}{|l|l|}
\hline 49 & Alineamiento vertical \\
\hline Las pendientes son satisfactorias y seguras? \\
\hline \multicolumn{2}{|c|}{ Las distancias de visibilidad y parada son adecuadas? } \\
\hline 50 & Provisión de estacionamientos \\
\hline $\begin{array}{l}\text { El estacionamiento local es adecuado para evitar que los vehículos se estacionen sobre la } \\
\text { calzada con el riesgo asociado a ello? }\end{array}$
\end{tabular}

Los estacionamientos son localizados en áreas seguras?

Es adecuado el espacio proporcionado en las áreas de estacionamiento para la circulación y la distancia de visibilidad de la intersección?

\section{$51 \quad$ Servicios}

Son adecuadas las áreas de carga ylo descarga de la vía?

Los virajes de vehículos grandes son previstos en lugares seguros?

Los accesos para vehículos de emergencia son adecuados? 


\begin{tabular}{|c|c|}
\hline 52 & Senalización vertical y demarcaciones \\
\hline \multicolumn{2}{|r|}{$\begin{array}{l}\text { La prioridad está claramente definida en todos los puntos de intersección, dentro de } \\
\text { estaciona mientos y rutas de accesos? }\end{array}$} \\
\hline \multicolumn{2}{|r|}{$\begin{array}{l}\text { Las senales verticales y demarcaciones serán visibles en todas las condiciones? (Incluyendo } \\
\text { día y noche, la lluvia, la niebla, etc.) }\end{array}$} \\
\hline 53 & Entorno de la vía \\
\hline \multicolumn{2}{|r|}{ El paisaje mantiene la visibilidad en intersecciones, curvas, accesos y localización de peatones? } \\
\hline \multicolumn{2}{|r|}{$\begin{array}{l}\text { La plantación de árboles en lugares donde los vehículos pueden salirse de la vía se ha } \\
\text { evitado? }\end{array}$} \\
\hline 54 & Gestión de trânsito \\
\hline \multicolumn{2}{|r|}{ El diseno mantendrá las velocidades vehiculares en forma segura? } \\
\hline \multicolumn{2}{|c|}{ Son el número y la localización de los accesos adecuados? } \\
\hline \multicolumn{2}{|r|}{$\begin{array}{l}\text { Existen facilidades para servicios de transporte público? Están localizadas en lugares } \\
\text { seguros y justificados? }\end{array}$} \\
\hline \multicolumn{2}{|r|}{$\begin{array}{l}\text { Existen facilidades para ciclistas? Están ubicadas en forma segura con respecto a los } \\
\text { movimientos vehiculares? }\end{array}$} \\
\hline \multicolumn{2}{|r|}{ Existen facilidades peatonales? Están localizadas en lugares seguros y justificados? } \\
\hline 55 & Otros \\
\hline \multicolumn{2}{|r|}{ En la vía se ha provisto de iluminación? Es adecuada? } \\
\hline \multicolumn{2}{|r|}{ Existen peligros al borde de la vía? Han sido tratados en forma correcta? } \\
\hline \multicolumn{2}{|r|}{ Los peatones pueden acceder en forma segura a los desarrollos urbanos adyacentes? } \\
\hline \multicolumn{2}{|r|}{ Otras materias a considerar } \\
\hline 56 & Aspectos de seguridad no cubiertos \\
\hline \multicolumn{2}{|r|}{ Existirán situaciones especiales? Han sido consideradas situaciones inusuales o de peligro? } \\
\hline \multicolumn{2}{|r|}{$\begin{array}{l}\text { La vía es capaz de admitir la circulación de vehículos de sobretamano, o vehículos grandes } \\
\text { como camiones, autobuses, vehículos de emergencia, vehículos de mantenimiento vial? }\end{array}$} \\
\hline \multicolumn{2}{|r|}{ Si se requiere, la vía puede ser cerrada para eventos especiales de una manera segura? } \\
\hline Si c & sponde, los requerimientos especiales del paisaje y rutas turísticas son satisfechas? \\
\hline
\end{tabular}


ANEXO C

LISTA DE VERIFICAÇÃO DE AUSTROADS (2009) 


\subsection{Detailed Checklists}

\section{CHECKLIST 1: FEASIBILITY STAGE AUDIT}

\begin{tabular}{|c|c|c|c|}
\hline Issue & Yes & No & Comment \\
\hline \multicolumn{4}{|l|}{ 1.1 General topics } \\
\hline 1.1.1 Scope of project; function; traffic mix & & & \\
\hline \multicolumn{4}{|l|}{ What is the intended function of the scheme? } \\
\hline \multicolumn{4}{|l|}{ Is the design consistent with the function of the road? } \\
\hline \multicolumn{4}{|l|}{$\begin{array}{l}\text { Will the proposed scheme/redesign safely cater for: } \\
\text { - cars? } \\
\text { - motorcyclists? } \\
\text { - } \text { Cyclists } \\
\text { - hedestrians? } \\
\text { - heavy vehicles? }\end{array}$} \\
\hline \multicolumn{4}{|l|}{ Is the expected mix of traffic adequately catered for? } \\
\hline \multicolumn{4}{|l|}{$\begin{array}{l}\text { Will the proposed scheme be consistent with adjacent roads, land forms } \\
\text { and traffic management? }\end{array}$} \\
\hline \multicolumn{4}{|l|}{ 1.1.2 Type and degree of access to property and developments } \\
\hline \multicolumn{4}{|l|}{$\begin{array}{l}\text { Is the degree of access control consistent with the road's function and with } \\
\text { other sections of the road? }\end{array}$} \\
\hline \multicolumn{4}{|l|}{$\begin{array}{l}\text { Will sight distances be satisfactory: } \\
\text { - at intersections? } \\
\text { - at property accesses? }\end{array}$} \\
\hline \multicolumn{4}{|l|}{$\begin{array}{l}\text { Is the design speed (or the likely vehicle speeds) compatible with the } \\
\text { number and type of intersections/property accesses present? }\end{array}$} \\
\hline \multicolumn{4}{|l|}{ Does the width of the right of way satisfy access needs? } \\
\hline \multicolumn{4}{|l|}{ 1.1.3 Major generators of traffic } \\
\hline \multicolumn{4}{|l|}{$\begin{array}{l}\text { Are all major generators of traffic (including housing or shopping centres) } \\
\text { far enough away to avoid unsafe influences on the form of the design? }\end{array}$} \\
\hline \multicolumn{4}{|l|}{$\begin{array}{l}\text { Have existing or alternative accesses been arranged to ensure existing } \\
\text { suburbs/areas are not cut off by the development of the scheme/works? }\end{array}$} \\
\hline \multicolumn{4}{|l|}{$\begin{array}{l}\text { Are the accesses for significant traffic generators far enough away from } \\
\text { intersections for safety? }\end{array}$} \\
\hline $\begin{array}{l}\text { Is sight distance to and from accesses to significant traffic generators } \\
\text { adequate? }\end{array}$ & & & \\
\hline
\end{tabular}


Will the proposed scheme be consistent with adjacent roads, land forms and traffic management?

\subsubsection{Staging requirements}

Will this design be implemented in one stage only?

If the design is to be implemented in more than one stage, has safety been given a high priority

Will the work avoid problems with safety standards elsewhere during construction?

\subsubsection{Future works}

Will the route be free of compromises in safety if there is to be:

- future widening?

- $\quad$ the addition of a complete second carriageway?

- $\quad$ after realignments?

- major geometric changes at intersections?

- linear extensions of the scheme?

\subsubsection{Wider network effects}

Have all harmful safety effects of this scheme upon the surrounding road network been identified? Have they been adequately dealt with?

\subsection{Design issues (general)}

Are all aspects associated with the location of the route and/or its alignment safe?

If the route follows existing roads what are the effects of this? (comment)

If the route is in 'green fields' (undeveloped corridor), is the alignment safe? Could it be safer? (comment)

Does the scheme fit in with the physical constraints of the landscape?

Does the scheme take account of major network considerations?

\subsubsection{Impact of continuity with the existing network}

Are all sections/transitions where the proposed road scheme connects with the existing network free of potential problems?

\subsubsection{Broad design standards}

Have the appropriate design standards been used? (having regard to the scope of the project and its function in relation to the traffic mix)

Does the geometric plan and profile meet design guidelines?

Have the appropriate design vehicle and check vehicle been used?

\subsubsection{Design speed}




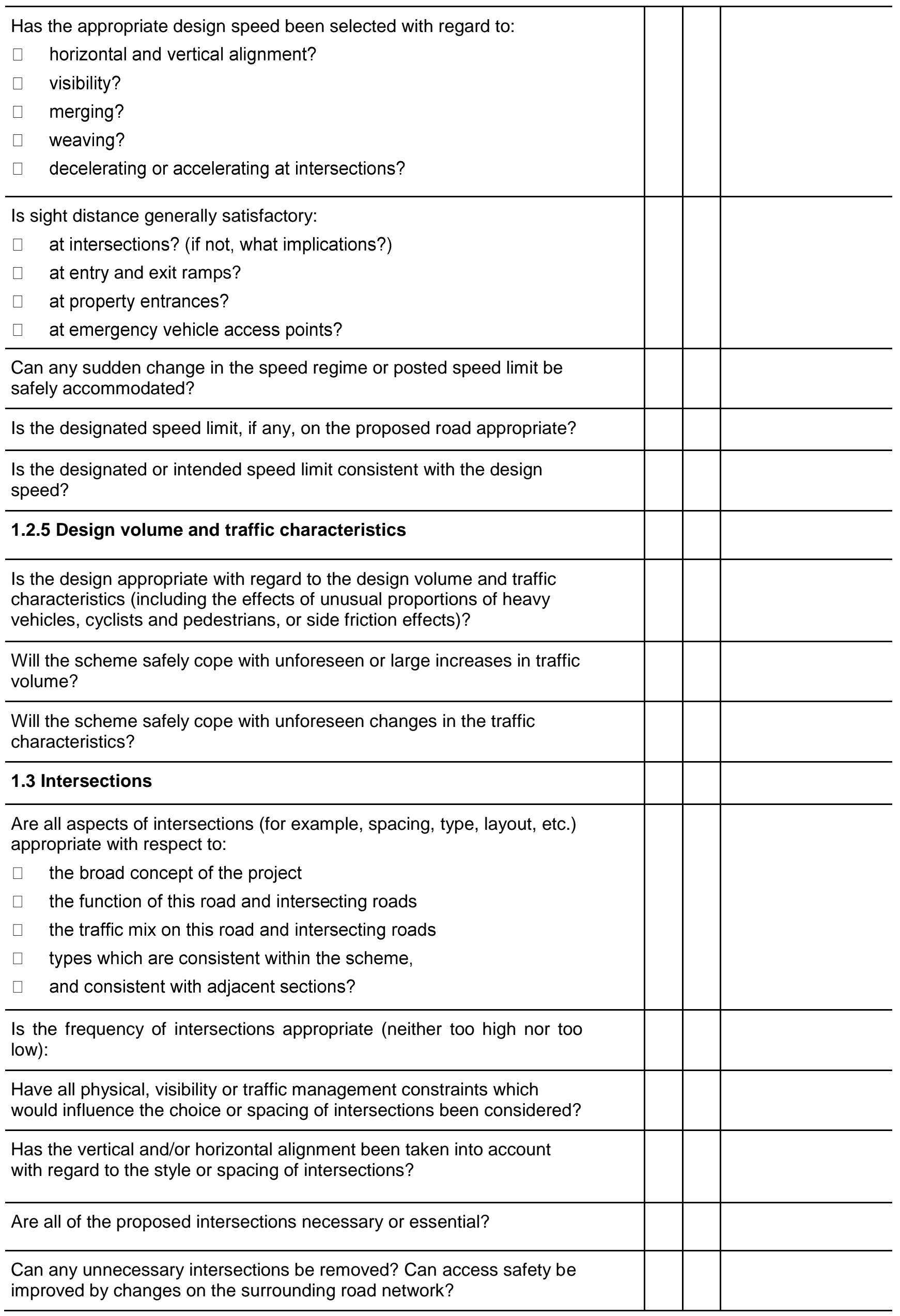


Will the angle of the intersecting roads and the sight lines be adequate for the safety of all road users?

\subsection{Environmental constraints}

Is the surrounding terrain free of physical or vegetation defects which could affect the safety of the scheme? (for example, heavy planting, forestry, deep cuttings, steep or rocky bluffs which constrain the design)

Do the gradients, curves and general design approaches fit in with the likely weather or environmental aspects of the terrain? (for example, fog-prone areas)

Has safety been considered in the location of environmental features? (for example, noise fences)

Does the scheme deal adequately with potential animal conflicts? (for example, kangaroos, wombats, cattle, etc.)

Will the scheme perform safely at night when it is wet, or there is fog?

Has the issue of unstable country been considered? (for example, mine subsidence)

\subsection{Any other matters}

Has the possibility of flooding been adequately dealt with?

Have any railway level crossings been identified and are they treated adequately?

Have other distractions (for example, low-flying aircraft, advertising, etc.) been adequately dealt with?

Has the need for laybys or parking (for example, for tourist routes, trucks, picnic or rest areas) been considered?

Has the potential of the location to attract roadside stalls been considered?

Have all unusual or hazardous conditions associated with special events been considered?

Have all classes of pedestrians that could be seriously affected by the proposal been catered for? (for example, school children, elderly, etc.)

Have any safety or accident problems on the existing network been addressed? (not carried over to the new scheme)

Has the issue of providing lighting for the design been considered?

Has the need for drivers to stop been considered? (for example, generally, rest areas, truck parking, enforcement)

Have all other matters which may have a bearing on safety been addressed? 


\subsection{General topics}

\subsubsection{Changes since previous audit}

Do the conditions for which the scheme was originally designed still apply? (for example, no changes to the surrounding network, area activities or traffic mix)

Has the general form of the project design remained unchanged since previous audit (if any)?

2.1.2 Drainage
Will the scheme drain adequately?
Has the possibility of surface flooding been adequately addressed,
including overflow from surrounding or intersecting drains and water
courses?

\subsubsection{Climatic conditions}

Has consideration been given to weather records or local experience that may indicate a particular problem? (for example, snow, ice, wind, fog)

\subsubsection{Landscaping}

If any landscaping proposals are available, are they compatible with safety requirements? (for example, sight lines and hazards in clear zones)

\subsubsection{Services}

Does the design adequately deal with buried and overhead services? (especially in regard to overhead clearances, etc)

Has the location of fixed objects or furniture associated with services been checked, including the position of poles?

\subsubsection{Access to property and developments}

Can all accesses be used safely? (entry and exit/merging)

Is the design free of any downstream or upstream effects from points of access, particularly near intersections?

Have rest areas and truck parking accesses been checked for adequate sight distance, etc.?

\subsubsection{Adjacent developments}

Does the design handle accesses to major adjacent generators of traffic and developments safely?

Is the driver's perception of the road ahead free of misleading effects of any lighting or traffic signals on an adjacent road?

\subsubsection{Emergency vehicles and access}


Has provision been made for safe access and movements by emergency vehicles?

Does the design and positioning of medians and vehicle barriers allow emergency vehicles to stop and turn without unnecessarily disrupting traffic?

\subsubsection{Future widening and/or realignments}

If the scheme is only a stage towards a wider or dual carriageway is the design adequate to impart this message to drivers? (is the reliance on signs minimal/appropriate, rather than excessive?)

Is the transition between single and dual carriageway (either way) handled safely?

\subsubsection{Staging of the scheme}

If the scheme is to be staged or constructed at different times:

- are the construction plans and program arranged to ensure maximum safety?

- do the construction plans and program include specific safety measures, signing; adequate transitional geometry, etc. for any temporary arrangements?

\subsubsection{Staging of the works}

If the construction is to be split into several contracts, are they arranged safely?

\subsubsection{Maintenance}

Can maintenance vehicles be safely located?

\subsection{Design issues (general)}

\subsubsection{Design standards}

Is the design speed and speed limit appropriate? (for example, consider the terrain, function of the road)

Has the appropriate design vehicle and check vehicle been used?

\subsubsection{Typical cross-sections}

Are lane widths, shoulders, medians and other cross- section features adequate for the function of the road?

Is the width of traffic lanes and carriageway suitable in relation to:

- alignment?

- traffic volume?

- vehicle dimensions?

- the speed environment?

- combinations of speed and traffic volume?

Are overtaking/climbing lanes provided if needed?

Have adequate clear zones been achieved?

\subsubsection{The effect of cross-sectional variation}


Is the design free of undesirable variations in cross-section design?

Are crossfalls safe? (particularly where sections of existing highway have been used or there have been compromises to accommodate accesses, etc.)

Does the cross-section avoid unsafe compromises such as narrowings at bridge approaches or past physical features?

\subsubsection{Roadway layout}

Are all traffic management features designed to avoid creating unsafe conditions?

Is the layout of road markings and reflective materials able to deal satisfactorily with changes in alignment? (particularly where the alignment may be substandard)

\subsubsection{Shoulders and edge treatment}

Are the following safety aspects of shoulder provision satisfactory:

- provision of sealed or unsealed shoulders

- width and treatment on embankments

- crossfalls all of shoulders

Are the shoulders likely to be safe if used by slow moving vehicles or cyclists?

Are any rest areas and truck parking areas safely designed?

\subsubsection{Effect of departures from standards or guidelines}

Any approved departures from standards or guidelines:

is safety maintained?

Any hitherto undetected departures from standards:

is safety maintained?

\subsection{Alignment details}

\subsubsection{Geometry of horizontal and vertical alignment}

Do the horizontal and vertical design fit together correctly?

Is the design free of visual cues that would cause a driver to misread the road characteristics? (for example, visual illusions, subliminal delineation such as lines of trees, poles, etc.)

Does the alignment provide for speed consistency?

\subsubsection{Visibility; sight distance}

Are horizontal and vertical alignments consistent with the visibility requirements? 
Will the design be free of sight line obstructions due to safety fences or barriers?

- boundary fences?

- street furniture?

- parking facilities?

- signs?

- landscaping?

- bridge abutments?

- parked vehicles in laybys or at the kerb?

- queued traffic?

Are railway crossings, bridges and other hazards all conspicuous?

Is the design free of any other local features which may affect visibility?

\subsubsection{New/existing road interface}

Does the interface occur well away from any hazard? (for example, a crest, a bend, a roadside hazard or where poor visibility/distractions may occur)

If carriageway standards differ, is the change effected safely?

Is the transition where the road environment changes (for example, urban to rural; restricted to unrestricted; lit to unlit) done safely?

Has the need for advance warning been considered?

\subsubsection{Readability of the alignment by drivers}

Will the general layout, function and broad features be recognised by drivers in sufficient time?

Will approach speeds be suitable and can drivers correctly track through the scheme?

\subsection{Intersections}

\subsubsection{Visibility to and at intersections}

Are horizontal and vertical alignments at the intersection or on the approaches to the intersection consistent with the visibility requirements?

Will drivers be aware of the presence of the intersection? (especially on the minor road approach)

Will the design be free of sight line obstructions due to:

- safety fences or barriers?

- boundary fences?

- street furniture?

- parking facilities?

- signs?

- landscaping?

- bridge abutments?

Are railway crossings, bridges and other hazards near intersections conspicuous? 
Will the design be free of any local features which adversely affect visibility?

Will intersection sight lines be obstructed by permanent or temporary features such as parked vehicles in laybys, or by parked or queued traffic generally?

\subsubsection{Layout, includes its appropriateness}

Is the type of intersection selected (cross roads, T, roundabout, signalised, etc.) appropriate for the function of the two roads?

Are the proposed controls (Give Way, Stop signals, etc.) appropriate for the particular intersection?

Are junction sizes appropriate for all vehicle movements?

Are the intersections free of any unusual features which could affect road safety?

Are the lane widths and swept paths adequate for all vehicles?

Is the design free of any upstream or downstream geometric features that could affect safety? (for example, merging of lanes)

Are the approach speeds consistent with the intersection design?

Where a roundabout is proposed:

- have pedal cycle movements been considered?

- have pedestrian movements been considered?

- are details regarding the circulating carriageway sufficient?

\subsubsection{Readability by drivers}

Will the general type, function and broad features be perceived correctly by drivers?

Are the approach speeds and likely positions of vehicles as they track through the scheme safe?

Is the design free of sunrise or sunset problems that may create a hazard for motorists?

\subsection{Special road users}

\subsubsection{Adjacent land}

Will the scheme be free of adverse effects from adjacent activity and intensity of land use? (if not, what special measures are needed?)

\subsubsection{Pedestrians}

Have pedestrian needs been satisfactorily considered?

If footpaths are not specifically provided, is the road layout safe for use by pedestrians? (particularly at blind corners or on bridges)

Are pedestrian subways or footbridges sited to provide maximum use? (i.e. Is the possibility of pedestrians crossing at grade in their vicinity minimised?) 
Has specific provision been made for pedestrian crossings, school crossings or pedestrian signals?

Where present, are these facilities sited to provide maximum use with safety?

Are pedestrian refuges/kerb extensions provided where needed?

Has specific consideration been given to provision required for special groups? (for example, young, elderly, disabled, deaf or blind)

\subsubsection{Cyclists}

Have the needs of cyclists been satisfactorily considered, especially at intersections?

Have cycle lanes been considered?

Are all cycleways of standard or adequate design?

Where a need for shared pedestrian/cycle facilities exists, have they been safely treated?

Where cycleways terminate at intersections or adjacent to the carriageway, has the transition treatment been handled safely?

Have any needs for special cycle facilities been satisfactorily considered? (for example, cycle signals)

\subsubsection{Motorcyclists}

Has the location of devices or objects that might destabilise a motorcycle been avoided on the road surface?

Will warning or delineation be adequate for motorcyclists?

Has barrier kerb been avoided in high-speed areas?

In areas more likely to have motorcycles run off the road is the roadside forgiving or safely shielded?

\subsubsection{Equestrians and stock}

Have the needs of equestrians been considered, including the use of verges or shoulders and rules regarding the use of the carriageway?

Can underpass facilities be used by equestrians/stock?

\subsubsection{Freight}

Have the needs of truck drivers been considered, including turning radii and lane widths?

\subsubsection{Public transport}

Has public transport been catered for?

Have the needs of public transport users been considered? 
Have the manoeuvring needs of public transport vehicles been considered?

Are bus stops well positioned for safety?

\subsubsection{Road maintenance vehicles}

Has provision been made for road maintenance vehicles to be used safely at the site?

\subsection{Signs and lighting}

\subsubsection{Lighting}

Is this project to be lit? Will safety be maintained if the project is not lit?

Is the design free of features that make illuminating sections of the road difficult? (for example, shadow from trees or over bridges)

Has the question of sighting of lighting poles been considered as part of the general concept of the scheme?

Are frangible or slip-base poles to be provided?

Are any special needs created by ambient lighting? Will safety be maintained if special treatments are not provided?

Have the safety consequences of vehicles striking lighting poles (of any type) been considered?

\subsubsection{Signs}

Are signs appropriate for their location?

Are signs located where they can be seen and read in adequate time?

Will signs be readily understood?

Are signs located so that visibility to and from accesses and intersecting roads is maintained?

Are signs appropriate to the driver's needs? (for example, destination signs, advisory speed signs, etc.)

Have the safety consequences of vehicles striking sign posts been considered?

Are signs located so that drivers' sight distance is maintained?

Where signs are to be located in the clear zone, are they frangible or adequately shielded by a crash barrier?

\subsubsection{Marking and delineation}

Has the appropriate standard of delineation and marking been adopted?

Are the proposed markings consistent with the works in the adjoining section of the route? 
Are the previous/adjacent markings to be upgraded? If not, will safety be maintained?

\subsection{Traffic management}

\subsubsection{Traffic flow and access restrictions}

Can traffic volumes from the proposed scheme be safely accommodated on existing sections of road?

Have parking provision and parking control been adequately considered?

Can any turn bans be implemented without causing problems at adjacent intersections?

Has the effect of access to future developments been considered?

Is safety maintained for any traffic diverting to other roads? (for example, to avoid a traffic control device)

\subsubsection{Overtaking and merges}

Are overtaking sight distance and stopping distance adequate?

Have suitable shoulder widths been provided at lane drop merges?

Have standard signs and markings been provided for any lane drop?

Has adequate sight distance been provided to any lane drop?

Are shoulders wide enough opposite access points and intersections?

\subsubsection{Rest areas and stopping zones}

Are there sufficient roadside stopping areas, rest areas and truck parking areas?

Are any entries and exits to rest areas or truck parking areas safe?

Issue
2.7.4 Construction and operation

If the scheme is to be constructed 'under traffic', can this be done so safely?

Can the scheme be safely constructed?

Have the maintenance requirements been adequately considered?

Is safe access to and from the works available? 


\subsection{Additional questions to be considered for development proposals}

\subsubsection{Horizontal alignment}

Is visibility adequate for drivers and pedestrians at proposed accesses?

Is adequate turning space provided for the volume and speed of traffic?

Are curve radii and forward visibility satisfactory?

Are sight and stopping distances adequate?

\subsubsection{Vertical alignment}

Are gradients satisfactory?

Are sight and stopping distances adequate?

\subsubsection{Parking provision}

Is on-site parking adequate to avoid on-street parking and associated risks?

Are parking areas conveniently located?

Is adequate space provided in parking areas for circulation and intersection sight distance?

\subsubsection{Servicing facilities}

Are off-street loading/unloading areas adequate?

Are turning facilities for large vehicles provided in safe locations?

Is emergency vehicle access adequate?

\subsubsection{Signs and markings}

Have necessary traffic signs and road markings been provided as part of a development?

\begin{tabular}{|c|c|c|c|}
\hline Issue & Yes & No & Comment \\
\hline \multicolumn{4}{|c|}{$\begin{array}{l}\text { Is priority clearly defined at all the intersection points within the car park and } \\
\text { access routes? }\end{array}$} \\
\hline \multicolumn{4}{|c|}{$\begin{array}{l}\text { Will the signs and markings be clear in all conditions, including } \\
\text { day/night, rain, fog, etc.? }\end{array}$} \\
\hline \multicolumn{4}{|l|}{ 2.8.6 Landscaping } \\
\hline \multicolumn{4}{|c|}{$\begin{array}{l}\text { Does landscaping maintain visibility at intersections, bends, accesses and } \\
\text { pedestrian locations? }\end{array}$} \\
\hline \multicolumn{4}{|c|}{ Has tree planting been avoided where vehicles are likely to run off the road? } \\
\hline \multicolumn{4}{|l|}{ 2.8.7 Traffic management } \\
\hline Have any adverse area-wide effects been addressed? & & & \\
\hline
\end{tabular}




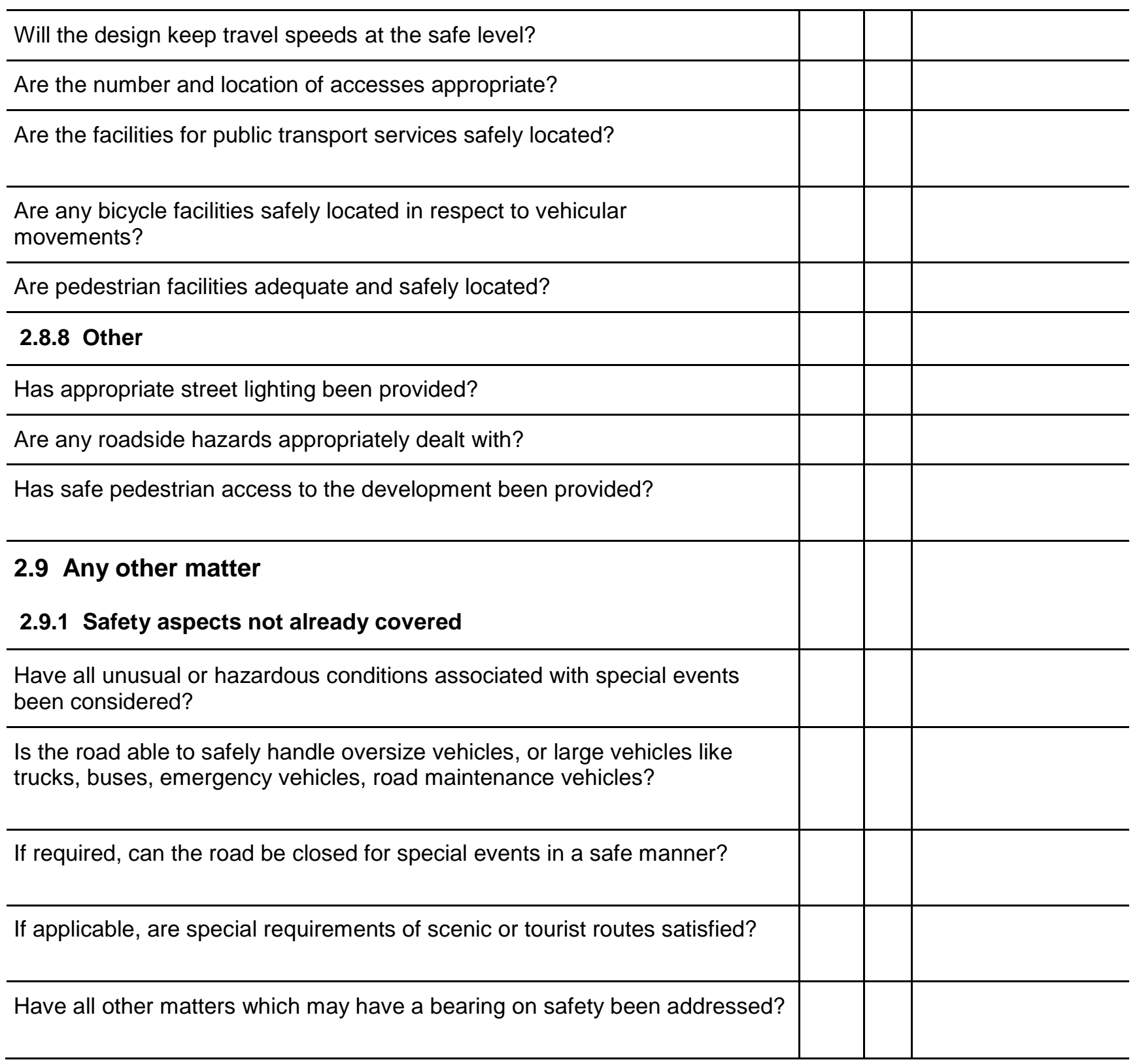




\section{Issue \\ 3.1 General topics \\ 3.1.1 Changes since previous audit}

Do the conditions for which the scheme was originally designed still apply? (i.e. no significant changes to the surrounding network or area to be served, or traffic mix)

Has the design of the project remained unchanged since previous audit (if any)?

\subsubsection{Drainage}

Will the new road drain adequately?

Are the road grades and crossfalls adequate for satisfactory drainage?

Are flat spots avoided or adequately dealt with at start/end of superelevation?

Has the possibility of surface flooding been adequately addressed, including overflow from surrounding or intersecting drains and water courses?

Is gully pit spacing adequate to limit flooding?

Is pit grate design safe for pedal cycles? (i.e. gaps not parallel with wheel tracks)

Will footpaths drain adequately?

\subsubsection{Climatic conditions}

Has the design taken into account weather records or local experience which may indicate a particular problem? (for example, snow, ice, wind, fog)

\subsubsection{Landscaping}

Will drivers be able to see pedestrians (and vice versa) past or over the landscaping?

Will intersection sight lines be maintained past or over the landscaping?

Will safety be adequate with seasonal growth? (for example, no obscuring of signs, shading or light effects, slippery surface, etc.)

Will roadside safety be adequate when trees or plantings mature (no roadside hazard)?

Has 'frangible' vegetation been used in possible run-off road areas? 


\subsubsection{Services}

Does the design adequately deal with buried and overhead services? (especially in regard to overhead clearances, etc.)

Has the location of fixed objects/furniture associated with services been checked? (including any loss of visibility, position of poles, and clearance to overhead wires)

\subsubsection{Access to property and developments}

Can all accesses be used safely?

Is the design free of any downstream or upstream effects from accesses, particularly near intersections?

Do rest areas and truck parking area have adequate sight distance at access points?

\subsubsection{Emergencies, breakdowns, emergency and service vehicle access}

Has provision been made for safe access and movements by emergency vehicles?

Does the design and positioning of medians and vehicle barriers allow emergency vehicles to stop and turn without unnecessarily disrupting traffic?

Have broken-down vehicles or stopped emergency vehicles been adequately considered?

Is provision for emergency telephones satisfactory?

Are median breaks on divided carriageways safely located? (i.e. frequency, visibility)

\subsubsection{Future widening and/or realignments}

If the scheme is only a stage towards a wider or dual carriageway is the design adequate to impart this message to drivers? (is the reliance on signs minimal/appropriate, rather than excessive?)

Is the transition between single and dual carriageway (either way) handled safely?

\subsubsection{Staging of the scheme}

If the scheme is to be staged or constructed at different times:

- are the construction plans and program arranged to ensure maximum safety?

- do the construction plans and program include specific safety measures, signing; adequate transitional geometry; etc. for any temporary arrangements?

\subsubsection{Staging of the work}

If the construction is to be split into several subprojects, is the order safe? (i.e. the stages are not constructed in an order that creates unsafe conditions) 


\subsubsection{Adjacent developments}

Does the design handle accesses to major adjacent generators of traffic and developments safely?

Is drivers' perception of the road ahead free of misleading effects of any lighting or traffic signals on an adjacent road?

Has the need for screening against glare from lighting of adjacent property been adequately considered?

\subsubsection{Stability of cut and fill}

Is the stability of batters satisfactory? (for example, no potential for loose material to affect road users)

\subsubsection{Skid resistance}

Has the need for anti-skid surfacing been considered where braking or good road adhesion is most essential? (for example, on gradients, curves, approaches to intersections and signals)

\subsection{Design issues (general)}

\subsubsection{Geometry of horizontal and vertical alignment}

Does the horizontal and vertical design fit together correctly?

Is the vertical alignment consistent and appropriate throughout?

Is the horizontal alignment consistent throughout?

Is the alignment consistent with the function of the road?

Is the design free of misleading visual cues? (for example, visual illusions, subliminal delineation like lines of poles)

\subsubsection{Typical cross-sections}

Are lane widths, shoulders, medians and other cross- section features adequate for the function of the road?

Are the shoulder widths adequate for stationary vehicles and errant vehicles?

Are median widths adequate for road furniture?

Is superelevation consistent with the road environment?

Is the width of traffic lanes and carriageways suitable in relation to:

alignment?

traffic volume?

vehicle dimensions?

the speed environment?

$\square \quad$ combinations of speed and traffic volume?

Are the shoulder crossfalls safe for vehicles to traverse? 


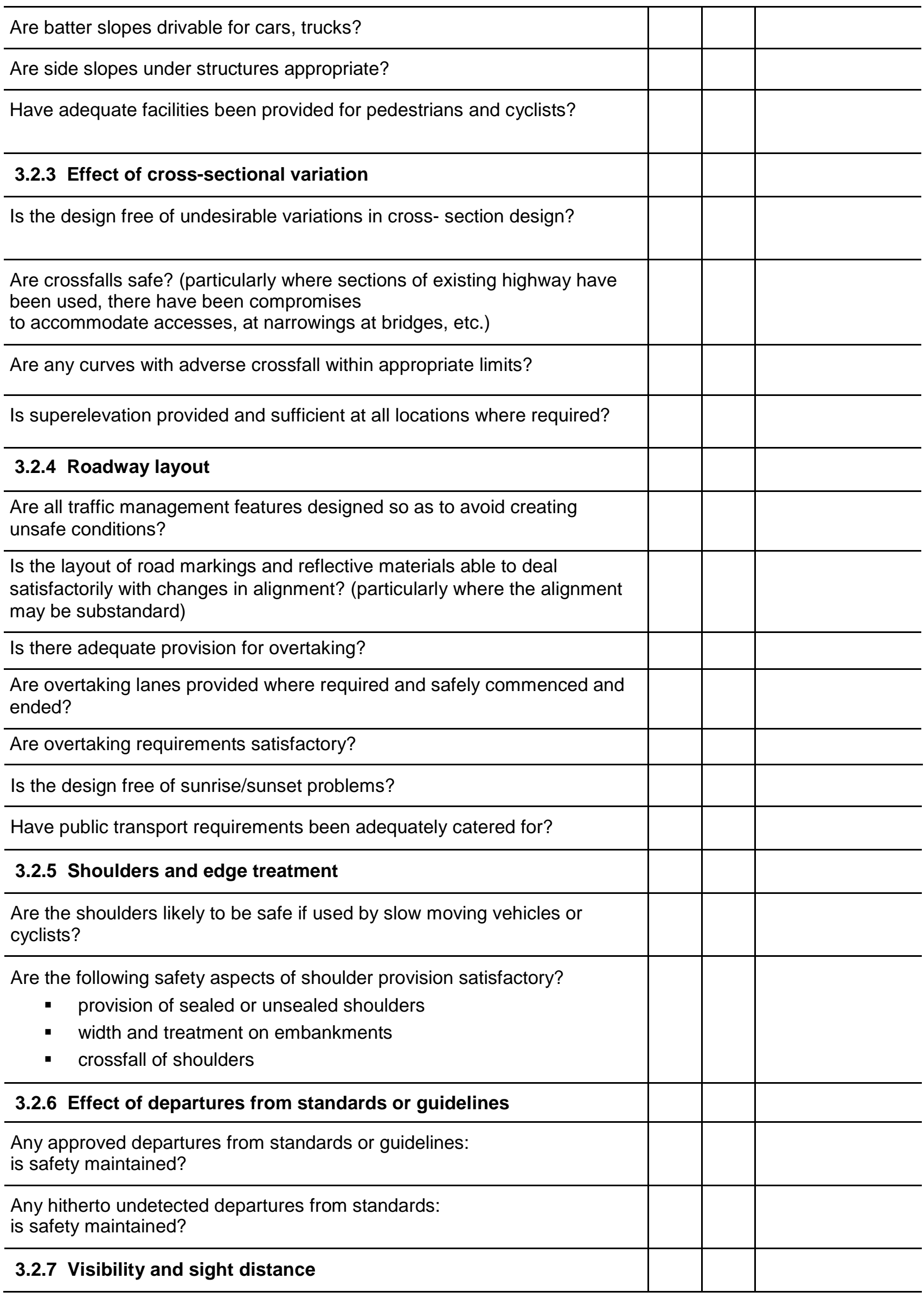


Are horizontal and vertical alignments consistent with visibility requirements?

Has an appropriate design speed been selected for visibility requirements?

\subsubsection{Environmental treatments}

Has safety been considered in the location of environmental features? (for example, noise fences)

\subsection{Alignment details}

\subsubsection{Visibility; sight distance}

Are horizontal and vertical alignments consistent with the visibility requirements?

Is the design free of sight line obstructions due to safety fences or barriers?

- boundary fences?

- street furniture?

- parking facilities?

- signs?

- landscaping?

- bridge abutments?

- parked vehicles in laybys or at the kerb?

- queued traffic?

Are railway crossings, bridges and other hazards all conspicuous?

Is the design free of any other local features which may affect visibility?

Is the design free of overhead obstructions (for example, road or rail overpasses, sign gantries, overhanging trees) which may limit sight distance at sag curves?

Has a clear headroom or a high vehicle detour been provided where necessary?

Is visibility adequate at:

- any pedestrian, bicycle or cattle crossings?

- access roads, driveways, on and off ramps, etc.?

Has the minimum sight triangle been provided at:

- entry and exit ramps?

- gore areas?

- intersections?

- roundabouts?

- other conflict points?

\subsubsection{New/existing road interface}

Have implications for safety at the interface been considered? 
Is the transition from old road to the new scheme satisfactory?

If the existing road is of a lower standard than the new scheme, is there clear and unambiguous warning of the reduction in standard?

Have the appropriate provisions for safety been made where sudden changes in speed are required?

Is access or side friction handled safely?

Does the interface occur well away from any hazard? (for example, a crest, a bend, a roadside hazard or where poor visibility/distractions may occur)

If carriageway standards differ, is the change effected safely?

Is the transition where the road environment changes (for example, urban to rural; restricted to unrestricted; lit to unlit) done safely?

Has the need for advance warning been considered?

\subsubsection{Readability of the alignment by drivers}

Will the general layout, function and broad features be recognised by drivers in sufficient time?

Will approach speeds be suitable and will drivers correctly track through the scheme?

\subsubsection{Detail of geometric design}

Are the design standards appropriate for all the requirements of the scheme?

Is consistency of general standards and guidelines, such as lane widths and crossfalls, maintained?

\subsubsection{Treatment at bridges and culverts}

Is the geometric transition from the standard cross-section to that on the bridge handled safely?

\subsection{Intersections}

\subsubsection{Visibility to and at intersections}

Are horizontal and vertical alignments at the intersection or on the approaches to the intersection consistent with the visibility requirements?

Is the standard adopted for provision of visibility appropriate for the speed of traffic and for any unusual traffic mix? 
Will the design be free of sight line obstructions due to safety fences or barriers

- boundary fences?

- street furniture?

- parking facilities?

- signs?

- landscaping?

- bridge abutments?

- parked vehicles in laybys and at the kerb?

- queued traffic?

Are railway crossings, bridges and other hazards all conspicuous?

Is the design free of any other local features which may affect visibility?

\subsubsection{Layout}

Are intersections and accesses adequate for all vehicular movements?

Have the appropriate design vehicle and check vehicle been used for turning dimensions?

Are swept paths accommodated for all likely vehicle types? (has the appropriate design vehicle been used?)

Are intersections free of any unusual features which could affect road safety?

Are pedestrian fences provided where needed? (for example, to guide pedestrians or discourage parking)

Has pavement anti-skid treatment been provided where needed?

Have islands and signs been provided where required?

Vehicles which may park at or close to the intersection: can they do this safely or does this activity need to be relocated?

Are safety hazards due to parked vehicles avoided?

\subsubsection{Readability by drivers}

Will the existence of the intersection and its general layout, function and broad features be perceived correctly and in adequate time?

Are the approach speeds and likely positions of vehicles tracking through the intersection safe?

Is the design free of misleading elements?

Is the design free of sunise or sunset problems which may create a hazard for motorists?

\subsubsection{Detailed geometric design}


Does any median or any island safely account for:

- vehicle alignments and paths?

- future traffic signals?

- pedestrian storage space and surface?

- turning path clearance?

- stopping sight distance to the nose?

- mountability by errant vehicles?

Is adequate vertical clearance to structures provided? (for example, powerlines, shop awnings)

\subsubsection{Traffic signals}

Is the signal phasing/sequence safe?

Is adequate time provided for traffic movements and pedestrian movements?

Will the signal lanterns be visible? (for example, not obstructed by trees, poles, signs or large vehicles)

Are lanterns for other approach directions adequately shielded from view?

Are high-intensity signals and/or target boards provided if likely to be affected by sunrise/sunset?

Does the alignment (vertical and horizontal) provide satisfactory stopping sight distance to the intersection or back of queue?

Are pedestrian facilities provided where they are required?

Will approaching drivers be able to see pedestrians?

Are partially or fully controlled turning phases provided where required?

Are signal posts located where they are not an undue hazard?

Are road markings for turning traffic satisfactory?

Have adequate pedestrian phases been provided?

\subsubsection{Roundabouts}

Is adequate deflection provided to reduce approach speeds?

If splitter islands are needed, are they adequate for sight distance, length, pedestrian storage, etc.?

Is the central island prominent?

Can the appropriate design vehicle and check vehicle be accommodated? 


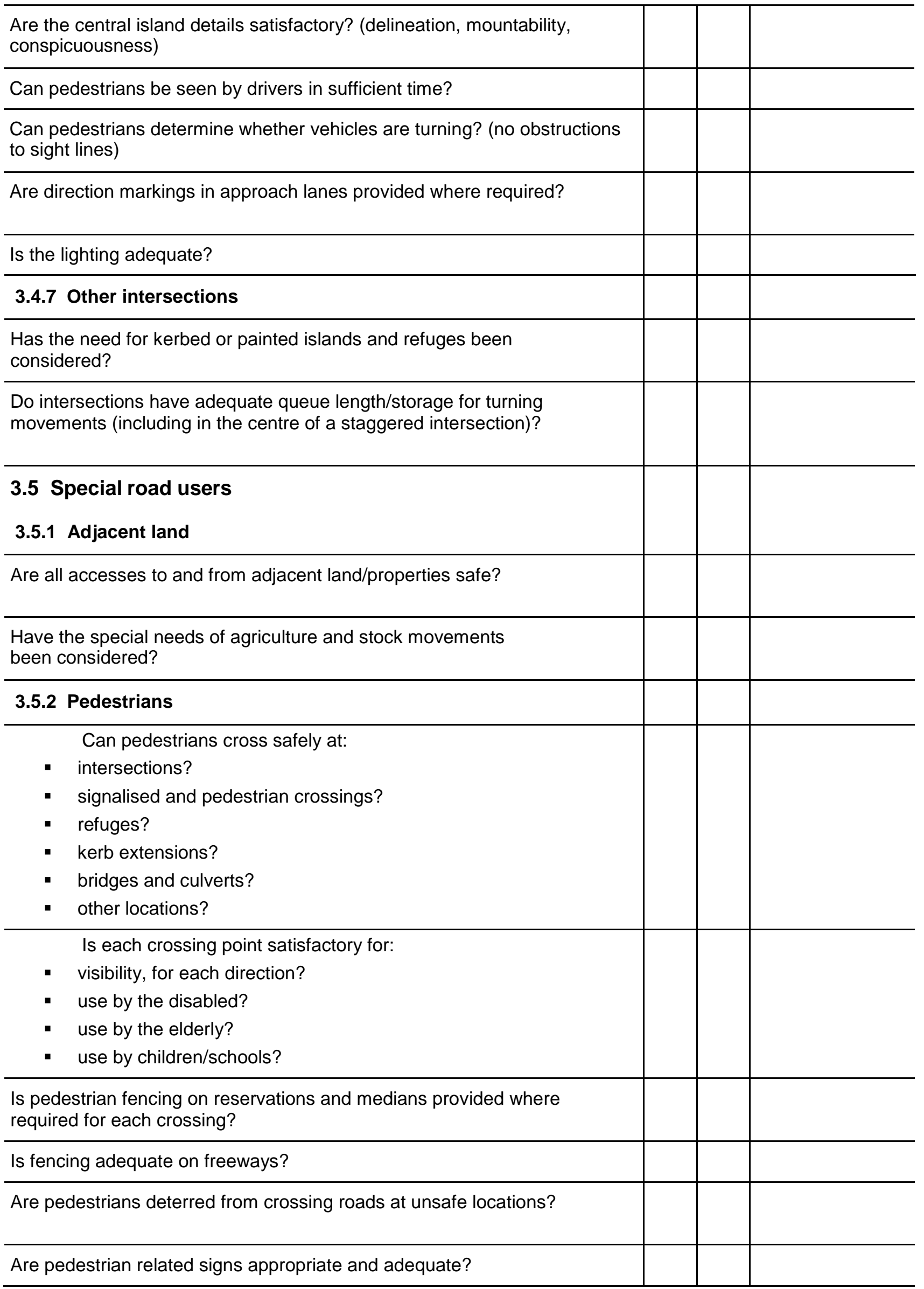


Is width and gradient of pedestrian paths, crossings, etc. satisfactory?

Is surfacing of pedestrian paths, crossings, etc. satisfactory?

Have dropped kerbs been provided for each crossing?

Have channels and gullies been avoided at each crossing?

Is lighting satisfactory for each crossing?

Are crossings sited to provide maximum use?

Is avoidance of a crossing unlikely? (for example, by more direct but less safe alternative)

\subsubsection{Cyclists}

Have the needs of cyclists been considered:

- at intersections (particularly roundabouts)?

- especially on higher speed roads?

- on cycle routes and crossings?

- at freeway entry and exit ramps?

Are shared cycleway/footway facilities (including subways and bridges) safe and adequately signed?

\subsubsection{Motorcyclists}

Has the location of devices or objects that might destabilise a motorcycle been avoided on the road surface?

Is the roadside clear of obstructions where motorcyclists may lean into curves?

Will warning or delineation be adequate for motorcyclists?

Has barrier kerb been avoided in high-speed areas?

In areas more likely to have motorcycles run off the road is the roadside forgiving or safely yielded?

Are all unnecessary poles, posts and devices removed or appropriately shielded?

Are drainage pits and culverts traversable by motorcycle?

\subsubsection{Equestrians and stock}

Have the needs of equestrians been considered, including the use of verges or shoulders and rules regarding the use of the carriageway?

Can underpass facilities be used by equestrians/stock?

\subsubsection{Freight}


Have the needs of truck drivers been considered, including turning radii and lane widths?

Have the needs of freight transport been considered, adequately signed and catered for?

\subsubsection{Public transport}

Have the needs for public transport been considered, adequately signed and catered for?

Have the needs of public transport users been considered?

Have the manoeuvring needs of public transport vehicles been considered?

Are bus stops well positioned for safety?

\subsubsection{Road maintenance vehicles}

Have the needs of road maintenance vehicles been considered, adequately signed and catered for?

Can maintenance vehicles be safely located?

\subsection{Lighting, signs and delineation}

\subsubsection{Lighting}

Has lighting been adequately provided where required?

Is the design free of features which interrupt illumination? (for example, trees or overbridges)

Is the design free of lighting poles that would present a fixed roadside hazard?

Are frangible or slip-base poles to be provided?

Ambient lighting: if it creates special lighting needs, have these been satisfied?

Is the lighting scheme free of confusing or misleading effects on signals or signs?

Does the lighting adequately illuminate crossings, nearby paths, refuges, etc.?

Are all gore areas adequately illuminated?

Are all merge areas adequately illuminated?

Is the scheme free of any lighting black patches?

If there are locations with accident problems that are known to be amenable to treatment with improved lighting, has this lighting been provided?

\subsubsection{Signs}

Are signs appropriate for their location? 


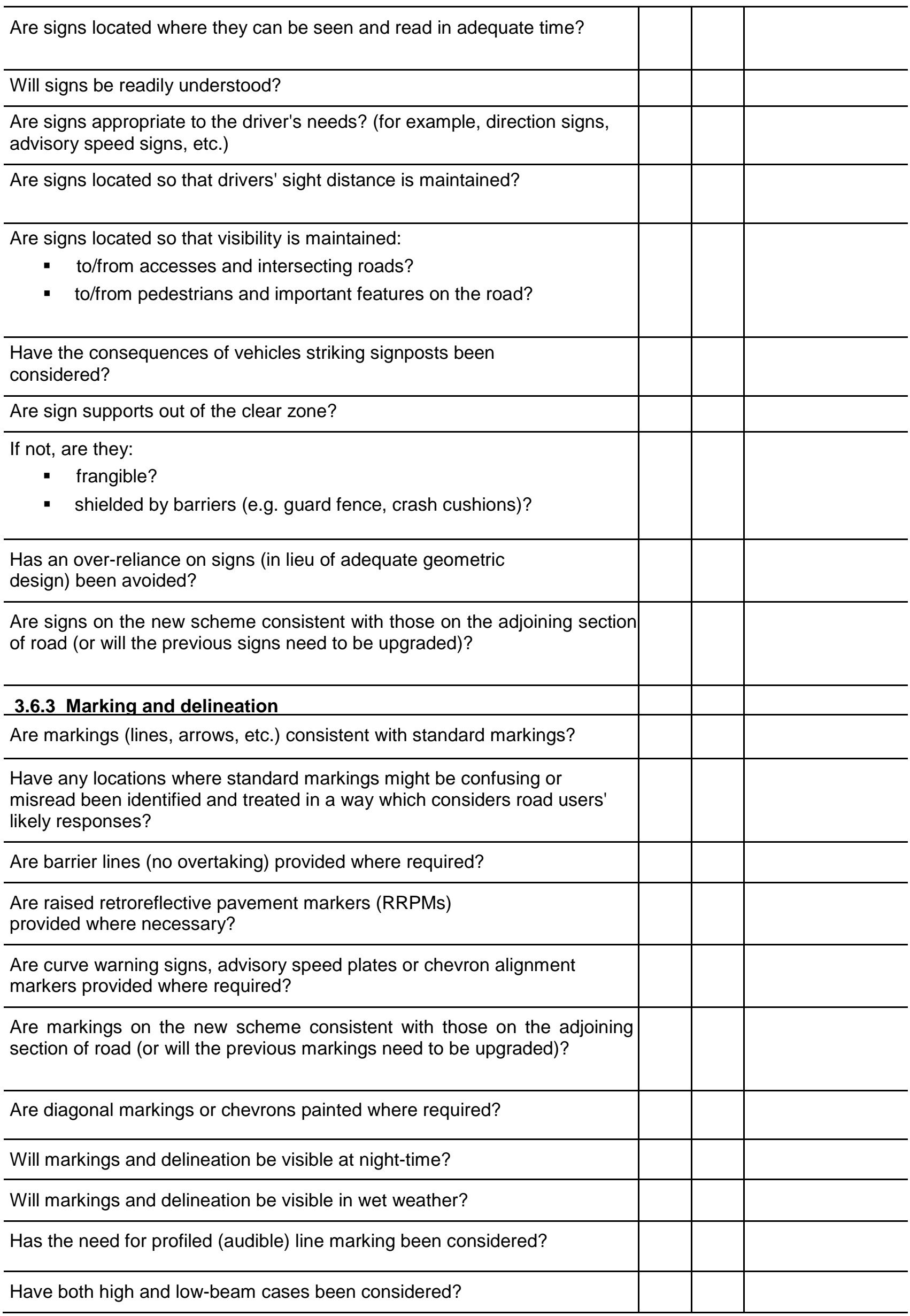


Are guide posts of the frangible type?

\subsection{Physical objects}

\subsubsection{Median barriers}

Have median barriers been considered and properly detailed?

Have all design features that require special attention (for example, end treatments) been considered?

\subsubsection{Poles and other obstructions}

Are all poles located well away from moving traffic?

Have frangible or breakaway poles been included where required?

Are median widths adequate to accommodate lighting poles or trees?

Is the position of traffic signal controllers and other service apparatus satisfactory?

Is the roadside clear of any other obstructions that may create a safety hazard?

Have all necessary measures been taken to remove, relocate or shield all hazards?

Can roadside drains and channels be safely traversed by any vehicle that runs off the road?

\subsubsection{Crash barriers}

Are crash barriers provided where necessary and properly detailed? (for example, at embankments, structures, trees, poles, drainage channels, bridge piers, gore areas)

Is the crash barrier safe? (i.e. unlikely to create a danger for road users including pedestrians, cyclists, motorcyclists, etc.)

Are the end conditions of the crash barrier safe and satisfactory?

Is the guard fence designed according to standards for:

- end treatments?

- anchorages?

- post spacing?

- block outs?

- post depth?

- rail overlap?

- $\quad$ stiffening at rigid obstacles?

Is all guard fence necessary? (i.e. what it shields is a greater hazard than the fence)

Where pedestrians and cyclists travel behind guard fence, is the rear of the fence safe for them?

\subsubsection{Bridges, culverts and causeways/floodways}


Are bridge barriers and culvert end walls safe regarding:

- visibility?

- ease of recognition?

- proximity to moving traffic?

- the possibility of causing injury or damage?

- collapsible or frangible ends?

- signs and markings?

- connection of crash barriers?

- roadside hazard protection?

Is the bridge railing at the correct level and strong enough?

Is the shoulder width on the bridge the same as on the adjacent road lengths?

Is safe provision made for non-vehicular traffic over structures? (for example, pedestrians, pedal cycles, horses/stock, etc)

Are all culvert end walls (including driveway culverts) drivable or outside the clear zone?

Have causeways/floodways etc. been given correct signing and adequate sight distance?

\subsection{Additional questions to be considered for development proposals}

\subsubsection{Horizontal alignment}

Is visibility adequate for drivers and pedestrians at proposed accesses?

Is adequate turning space provided for the volume and speed of traffic?

Are curve radii and forward visibility satisfactory?

Are sight and stopping distances adequate?

\subsubsection{Vertical alignment}

Are gradients satisfactory?

Are sight and stopping distances adequate?

\subsubsection{Parking provision}

Is on-site parking adequate to avoid on-street parking and associated risks?

Are parking areas conveniently located?

Is adequate space provided in parking areas for circulation and intersection sight distance?

\subsubsection{Servicing facilities}

Are off-street loading/unloading areas adequate?

Are turning facilities for large vehicles provided in safe locations? 
Is emergency vehicle access adequate?

\subsubsection{Signs and markings}

Have necessary traffic signs and road markings been provided as part of a development?

Is priority clearly defined at all the intersection points within the car park and access routes?

Will the signs and markings be clear in all conditions, including day/night, rain, fog, etc.?

\subsubsection{Landscaping}

Does landscaping maintain visibility at intersections, bends, accesses and pedestrian locations?

Has tree planting been avoided where vehicles are likely to run off the road?

\subsubsection{Traffic management}

Have any adverse area-wide effects been addressed?

Will the design keep travel speeds at a safe level?

Are the number and location of accesses appropriate?

Are the facilities for public transport services safely located?

Are any bicycle facilities safely located in respect of vehicular movements?

Are pedestrian facilities adequate and safely located?

\subsubsection{Other}

Has appropriate street lighting been provided?

Are all roadside hazards appropriately dealt with?

Has safe pedestrian access to the development been provided?

\subsection{Any other matter}

\section{Safety aspects not already covered}

Is the road able to safely handle oversize vehicles, or large vehicles like trucks, buses, emergency vehicles, road maintenance vehicles?

If required, can the road be closed for special events in a safe manner?

If applicable, are special requirements of scenic or tourist routes satisfied?

Have all unusual or hazardous conditions associated with special events been considered?

Have all other matters which may have a bearing on safety been addressed? 
ANEXO D

LISTA DE VERIFICAÇÃO DE RTMC (2012) 


\section{APPENDIX D-1: Stage 1 Road Safety Audit: Preliminary Design ITEM POSSIBLE ISSUE}

\section{GENERAL TOPICS}

Project scope, function and mix of traffic

Type and degree of access to Property and developments

Major traffic generators

Staging requirements

Future works

Wider network effects
What is the function of the scheme?

Is the design consistent with the function of the road?

Does the project make adequate provision for:

- Pedestrians

- Passenger vehicles

- Heavy vehicles

- Buses

- Other road users that will make use of the facility?

Does the Project make adequate provision for the expected traffic mix?

Is the proposed project consistent with adjacent roads, land forms and traffic management?

Is the degree of access control consistent with the function of the road and with other sections of the road?

Will sight distances be satisfactory at intersections and property accesses?

Is the design speed (or the anticipated vehicle speeds) compatible with the number and type of intersections or property accesses?

Does the width of the road satisfy access needs?

Are all major traffic generators far enough away from the project or from intersections to avoid unsafe influences on the form of the design?

Have existing or alternative accesses been arranged to ensure that existing subareas are not cut off by the Project?

Will the proposed scheme be consistent with adjacent roads, land forms and traffic management?

Will this design be implemented is one stage only?

If the design is to be implemented in more than one stage, has safety been given a high priority?

- in the transitions between stages?

- in transitions to existing roads?

Will the work avoid problems with safety standards elsewhere during construction?

Will the route be free of compromises in safety if there is to be:

- future widening?

- the addition of a complete second carriageway?

- after realignments?

- major geometric changes at intersections?

- linear extensions of the scheme?

Have all harmful safety effects of this scheme upon the surrounding road network been identified? Have they been adequately dealt with? 


\section{DESIGN}

Route choice

Consistency/ continuity with the Existing road section/ network

General design standards

Design speed

Design traffic characteristics
Are all aspects regarding the location of the route and the alignment thereof safe?

Does the project safely tie in with the existing road network?

If the route is new, is the alignment safe? Could it be safer?

Does the Project safely fit in with the physical constraints of the landscape?

Does the project design safely take account of the existing road network?

Does the project pose any safety problems where it ties in with the adjacent road network/sections?

Were the appropriate design standards used with specific reference to:

- the project scope?

- road users that will utilize/be influenced by the project?

- the traffic mix utilizing the project?

Does the geometric plan and profile meet design guidelines?

Does the design meet the needs of the appropriate design vehicles?

Does the proposed cross-section allow for providing a forgiving road at the design speed?

Is the appropriate design speed appropriate for:

Vertical and horizontal alignment

Sight distances and visibility

- Merging

- Weaving

- Deceleration/ aceleration of traffic at controlled intersections/ accesses

Are there any changes in the speed/ posted speed limit?

Are the design speed and speed limit appropriate?

Is the sight distance safe enough at:

- Intersections?

- Interchange on and off ramps?

- Accesses to properties?

- Accesses for emergency vehicles?

Is the design speed and posted speed limit reconcilable with each other?

Is the design appropriate for the:

- Design volume

- Design traffic characteristics (e.g. vulnerable road users and heavy vehicle)

Does the design provide for the safe accommodation of

- An increase in traffic volume if expected?

- Changes in traffic characteristics? 


\section{INTERSECTIONS}

Type and number

\section{ENVIRONMENATAL ISSUES}

Physical characteristics of the terrain

Day-night time aspects
Are all aspects of the intersections (e.g. spacing, type, layout, etc.) appropriate with respect to:

- The broad concept of the project

- The function of the road and intersecting roads

- The traffic mix on the roads and intersecting roads

- Road users to use the project

- Land-use adjacent to the project

- Consistent with adjacent sections

Is the frequency of intersections appropriate:

- For safe access?

- To avoid impacts on the surrounding network?

- For emergency vehicle access?

Have all physical, visibility or traffic management constraints which would influence the choice and spacing of intersections been considered?

Has the vertical and horizontal alignment of the intersections road sections been taken into account in the design, layout and spacing of intersections?

Are all the intersections essential or necessary?

Can the number of intersections be reduced to improve safety?

Can access safety be improved by changes on the surrounding road network?

Is the angle of the intersections road sections and sight lines safe for all road users?

Is there adequate provision for the movement of vulnerable road users?

Is there adequate provision for the movement of heavy vehicles?

Is the surrounding terrain free from physical or vegetation characteristics which could affect the safety of the project? (For example deep cuttings, steep or rocky bluffs, heavy planting or forestry that constrain the design)

Do the gradients, curves and general design approaches fit in with the likely weather or environmental aspects of the terrain? (For example, fog-prone areas)

Are there any vegetation-related aspects that will reduce the safety of the project?

Does the project deal safety with possible animal conflicts? (e.g. stray cattle \& game).

Has safety been considered in the location of environmental features like noise fences?

Are visual distractions like scenic vistas safety dealt with?

Has the issue of unstable countryside been considered? (e.g. mining subsidence)

Has the effect of the angles of the sun at sunrise and sunset been considered?

Will the safety of the project be satisfactory at night-time, when it is wet or there is fog? 


\section{ITEM}

OTHER

Pedestrians

been

Driver perception

Miscellaneous

\section{POSSIBLE ISSUES}

Are there any pedestrian desire lines crossing the project? Has provision

made for pedestrian movement along these lines?

Will the project cause the division of existing communities or cause separations of communities from basic commodities like water, firewood or retail facilities?

Can the proposed project be properly signed to allow the driver sufficient reactions and manoueuvre time to respond without information overload?

Has possible constrains on information transfer to the driver been considered that may limit his safe and timeous response from the driving tasks?

Will the driver ever be exposed to sudden darkness?

Has the possibility of flooding been dealt with?

Have all railway level crossings been identified and treated adequately?

Have other possible distractions like advertising or low-flying aircraft been identified and adequately dealt with?

Has the need for facilities such as laybys, parking or rest areas or safe facilities for informal trading been considered and provide where required?

Have all unusual or hazardous conditions associated with especial events been

considered?

Has the risk implications of the transport or hazardous materials

been

considered?

Has any safety or crash problems on the existing network been considered to ensure that they will not be transferred to the new facility?

Has the need for provide lighting on the design been considered?

Has the absence electricity that will limit the use of lighting, warning signs or flashing signals been considered?

Has the need for drivers to stoop been considered? (e.g. rest areas, truck parking, overload control, enforcement,

etc.) 


\section{APPENDIX D-2: Stage 2 Road Safety Audit: Draft Design}

\section{ITEM}

\section{GENERAL}

Changes since previous audit

Drainage

Climate

Landscaping

Services

Access to property and developments

Adjacent land-use

Emergency vehicles and access

\section{POSSIBLE ISSUE}

Do the conditions for which the original planning had been done, still apply? (e.g. no changes to the surrounding network, area activities or traffic mix).

Has the general form of the project design remained unchanged since the previous audit, (if any)?

Will the project drain adequately?

Has the probability of surface flooding or overflowing of drainage from adjacent drainage features from adjacent road, intersecting drains or water courses considered?

$=$ Are there any environmental/ vegetation/ other effects that will hamper the functioning of drainage inlets (e.g. sugar cane blocking inlets)?

Has consideration been given to weather records or local experience that may indicate problems related to adverse weather conditions such as snow, fog, etc. typical in the area?

If landscaping proposals are available, how will they affect the safety of the project? (e.g. inter-visibility of drivers and pedestrians, sight lines, shade/ sun interplay on the road and hazards in the clear zones).

Does the design adequately deal with buried and overhead services, especially overhead clearances on roads in superelevation, etc.?

Has the location of fixed objects of furniture associated with services been checked, including the location of specific poles.

Do any of the services intrude in the right of way of other road users? (e.g. poles located on the sidewalks, etc.)

Can all accesses be used safely?

Is the design free from any downstream or upstream effects from points of access, particularly near intersections?

Have truck parking and rest area accesses been checked for adequate sight distance, etc.?

Will the project accommodate the traffic generated by adjacent developments and the adjacent road network safely?

Is the design reconcilable with driver expectancy from the lighting and traffic signals provided on the adjacent road section/ intersection/ network?

Does the design make provision for special road users that are generated by adjacent land-uses and the existing road network?

d) Are there any land-use issues that will have an effect on the safety of the project?

Has provision been made for safe access and movement by emergency vehicles? (e.g. fire brigade trucks.) 
Does the design and position of medians and vehicle barriers allow emergency vehicle to stop and turn without unnecessary disrupting traffic or being exposed to danger? 
Future planning

Project phasing

\section{Maintenance}

\section{DESIGN}

Design standards (General)

Typical cross-sections

Variations in cross-sections

Layout of roadway
If widening is planned:

- Are drivers adequately guided by the design?

- Are drivers adequately informed by signage?

Is the possible transition between a single and dual carriageway (both directions) being handled safely?

If the project is to be constructed/ implemented in different phases:

- Are the phases details adequate to ensure safety?

- Is the phase programming safe?

- Are there measures to accommodate temporary traffic management between the different phases?

Is the construction is to be split into different contracts, are they arranged safely?

Can routine maintenance vehicles be safely located?

Is the design speed and proposed posted speed limits appropriate for the terrain and function of the road? Are they appropriate for the design vehicles and the road users?

Is the design speed reconcilable with the expected operational speed?

Has the appropriate design vehicles/ been used? (specifically also for possible constraining turning movements)

Are the cross-sections features such as widths of lanes and shoulders, medians, etc. adequate for the function of the project?

Do the cross-sections features conform to the requirements set for design for safety?

Are lane and shoulder widths appropriate for:

- The alignment?

- Road users?

- The vehicles that will utilize the project?

- The operating speeds?

- The combinations of speed and volume?

Are overtaking/ climbing/ crawler lanes provided if needed?

- Have adequate clear zones been provided?

Are there any variations in cross-section that will influence safety negatively?

Are the cross-falls safe? (particularly where sections of existing roadways are used or accesses accommodated)

Are the any unsafe compromises such as sudden narrowing at existing bridges.

Do the traffic management features:

- Create unsafe conditions?

- Provide adequate warning or guidance?

Do the road signs and marking provide adequate warning and guidance at 7 locations where the alignment is substandard or changing? (also under nighttime or low visibility conditions). 
Shoulders and edge treatment

Cut-and-fill

Deviations from and changes to standard design guidelines and standards

\section{ALIGNMENT}

Vertical and horizontal alignment

Visibility and sight distance

Transition between project and existing adjacent road section/ intersection/ network
Are the following safety aspects of shoulder provision satisfactory:

- Provision of surfaced or unsurfaced shoulders?

- Width and treatment on embankments?

- Crossfalls of shoulders?

Are the shoulders likely to be safe when used by slow moving vehicles or cyclists?

Are any rest areas or truck parking areas designed safely?

Are there any geological characteristics of the cut-and fill of the project that will endanger road users?

Do any of the deviations from accepted design guidelines or standards reduce the safety performance of the project?

Does the horizontal and vertical alignment fit together appropriately?

Does the vertical and horizontal alignment guide a driver accurately - is it free of visual clues that would cause the driver to misread the road characteristics?

Is the vertical and horizontal alignment conducive to consistent operating speed?

Does the vertical and horizontal alignment provide the required sight distance and visibility?

Are there any of the following objects or structures present that will obstruct sight lines or reduce sight distance that will have an adverse effect on safety:

- Fencing?

- Traffic barriers?

- Street furniture (including trash bins)?

- Services?

- Parking facilities?

- Signs?

- Landscaping/ vegetation?

- Bridge abutments?

Are all hazards such as bridge abutments noticeable?

Is there any local feature that will obstruct sight lines?

Are railways crossings, bridges, intersections and other hazards clearly visible under daytime and nighttime driving?

Does the transition from existing to new (and opposite) occur well away from any hazardous condition like the following:

- Speed differences?

- Differences in accesses provision?

- Geometry (e.g. is it on a curve or a crest where the visibility is poor/ where the driver is likely to be distracted?)

- Differences in design standards?

- Differences in the physical features of the environment? (e.g. for example from lit to until, rural or urban) 
Other:

Parking

\section{INTERSECTIONS}

Visibility of intersection

Layout and traffic control
- Differences in the posted speed limit?

Is adequate advance warning provided where required"

Is on-site parking planned to minimize on-street parking?

An on-street parking be provided safely?

If not, are measures provided to prevent it?

Do the horizontal and vertical alignment at the intersections or on the approach to the intersection allow safe forward visibility to the intersection and intervisibility between the main road and the intersecting road/s?

Will drivers be aware of the presence of the intersection and the control thereof? (Especially approaching on the minor road) and will they be able to react safely to it?

Are there any of the following temporary features present that will obstruct sight lines:

- Parked vehicles?

- Public transport facilities/ lay-bys?

- Queuing vehicles?

- Heavy vehicles loading zones?

Are the following appropriate for the function of the two intersecting roads:

- Layout? (e.g. crossroad, T-junction, roundabout, interchange)

- Traffic control type? (e.g. signalization, Stop or Yield control)

Will the layout or traffic control have a negative safety impact on special road users such as:

- Pedestrians?

- Vulnerable road users?

- Cyclists?

- Heavy vehicles?

Does the layout make provision for all design vehicles that will utilize the intersection? (e.g. turning radii, swept paths of vehicles, lane widths, etc.)

Where a roundabout is proposed:

- Have cyclist movements been considered?

- Have pedestrian movements been considered?

- Are the details pertaining to the circulating roadway sufficient?

Will the layout or traffic control affect the safety of public transport facilities (if planned)?

- Is the design free from any upstream or downstream geometric features that could affect safety? (e.g. lane merges)

Are the approach speeds on the intersecting road sections safe? 
Readability by drivers

\section{SPECIAL ROAD USERS}

Pedestrians

Cyclists and motorcyclists

Animals

Heavy vehicles
Will the general type, function and broad features be perceived correctly by the drivers?

Are the approach speeds and likely positions of vehicles as they track through the intersection safe?

Do successive intersections violate driver expectancy because of inconsistencies?

Does the driver get sufficient time to perceive the upcoming situation, decide upon a course of actions, prepare for and execute the necessary actions safely?

Does the design provide for erroneous decisions?

Is the design free from possible sunrise and sunset problems that may create a hazard?

Will the driver experience glare from oncoming vehicles or from road lighting?

Is the driver ever exposed to sudden darkness?"

Is the design safe for pedestrians?

Is there a need for the provision of pedestrian crossings?

Are pedestrian crossings provided along desire lines?

Is there a need for paved footpaths? If not planned, where will the pedestrians walk and will it be safe enough?

Is the carriageway widened to provide for pedestrian movement and can pedestrians utilize this safely?

Is there a need for pedestrian refuge islands and are they wide enough to ensure safety?

Is the expected operational speed appropriate for the pedestrian facilities that are provided?

Is there a need for the special provision of facilities for vulnerable road users such a children and the elderly?

Is consideration being given to the needs of cyclists and motorcyclists?

Are bicycle lanes needed or can shared pedestrian-cycle facilities be implemented?

Is the roadside forgiving in areas more prone to run off the road crashes by motorcyclists?

Is there a need to make provision for stock or equestrians?

Does the design make provision for the limitations of heavy vehicles? (e.g longer stopping distance, etc.)

Does the design consider safe gradients for heavy vehicles?

If in mountainous terrain, are any arrestor bed facilities required for the design? Are they provided or can a modification of the design eliminate the need?

Should rest areas be provided? If planned, can they be used safely?

Are safe heavy vehicle loading facilities provided where required?

Is provision made for the safe manoeuvring of heavy vehicles where necessary? 
Public transport

Maintenance vehicles and crews
Is safe provision made for public transport facilities where needed?

Is provision made for the safe movement of pedestrians to, at and from the public transport facilities? (e.g. Are sufficient space available for passengers alighting from buses?)

Can maintenance vehicles and crews be safely accommodated after implementation of the project?

\section{ROAD TRAFFIC SIGNS AND LIGHTNING}

Road signs

Road marking

Road lighting
Can the project be provided with direction signs in an unambiguous manner?

Are the road signs adequate to provide for driver needs (guidance, control and warning)

Will the road signs be visible and readable? (review special needs for appropriate night-time reflectivity)

Is the amount of reflectivity adequate/ excessive, i.e. blinding the driver?

Will any of the road signing limit the visibility or sight lines at accesses or intersections?

Will any of the road signing pose a safety hazard to errant vehicles? Was provision made to reduce the severity of such crashes?

Were road signs placed with due cognizance of road safety?

Are the planned road markings adequate in terms of safety?

Are there many road elements that will require the provision of road studs for visibility at night-time? (e.g. raised median islands etc.)

Is the transition of road marking between the project and the existing adjacent road section/ intersection/ network safe?

Should road lighting be provided for this project?

If lit, will safety be maintained in the case of a break in power supply?

Are there any special needs created by ambient lighting and will safety be maintained if such special features are not provided?

Was due cognizance taken of features such as trees, over-bridges, etc. that will affect the installation of road lighting?

Does the road user adequately protected from colliding with lighting poles?

Is the road user adequately protected from colliding with lighting poles?

If traffic barriers are used for this purpose, are they properly located or installed to ensure improved safety and will they function as intended?

\section{TRAFFIC OPERATIONS AND CONSTRUCTION}

Traffic flow

Will the traffic flow of the project have a negative influence on the safety of adjacent road network/ developments?

Was adequate consideration given to parking control features?

Can exclusive turning lanes and deceleration lanes be used safely?

Will the project cause or contribute to the movement of traffic at high speeds through residential areas (rat-running)? 
Access management

Merging and overtaking

Rest areas and stopping facilities

Construction

\section{OTHER ISSUES}

Roadside hazard management

Incident management

Tourism/ recreation
Was adequate consideration given to the possible provision of accesses of future developments in or adjacent to the project?

Are the existing and proposed accesses in the road project safe to use?

Will any up-or downstream effects reduce the safety of an access, particularly those located close to intersections?

Are adequate shoulder widths provided during and after lane merges?

Is adequate overtaking sight distance and stopping distance provided?

Is advance warning provided for lane merging?

Is proper sight distance provided for lane merging?

Are sufficient stopping and rest areas provided?

Are safe access provided to rest areas and stopping facilities?

Is the sight distance and access design for accesses for rest areas safe?

Is the project is to be constructed "under traffic", can this be done safely as far as the construction is concerned as well as the extent to which the general travelling public will be affected?

Are there any elements of the project that will hamper the safe construction of the project? (e.g. construction vehicle routes and interaction with general public traffic)

Can safe access be provided for construction vehicles?"

Are there any features of the project that will require special traffic management during construction, phasing or any period before implementation?

Are there any roadside hazards that can be:

- Redesigned

- Relocated

- Protected by traffic barriers?

- Made breakaway?

Are traffic barriers adequate for the design vehicles of the project?

Are safe end-treatments provided?

Can traffic barriers be safely maintained?

Will they function as was intended?

Is adequate deflection distance provided for guardrail and cable systems?

Can traffic be safely accommodated during an incident?

Is safe access possible for emergency vehicles?

In the case of fixed medians, does the project provide for the safe stopping and turning of emergency vehicles?

Are there any safety requirements for the accommodation of tourism or recreation facilities?

Have all unusual or potentially hazardous conditions associated with special events been considered? If required, can the road be closed in a safe manner? 


\section{APPENDIX D-3: Stage 3 Road Safety Audit: Detail Design}

\begin{tabular}{|c|c|}
\hline ITEM & POSSIBLE ISSUE \\
\hline \multicolumn{2}{|l|}{ GENERAL } \\
\hline \multirow[t]{2}{*}{ Changes since previous audit } & $\begin{array}{l}\text { Do the conditions for which the draft design had bee done, still apply? (e.g. no } \\
\text { changes to the surrounding network, area activities or traffic mix) }\end{array}$ \\
\hline & $\begin{array}{l}\text { Has the general form of the project design remained unchanged since the } \\
\text { previous audit, (if any)? }\end{array}$ \\
\hline \multirow[t]{3}{*}{ Drainage } & Will the project drain adequately? \\
\hline & $\begin{array}{l}\text { Has the probability of surface flooding or overflowing of drainage from adjacent } \\
\text { drainage features from adjacent roads, intersecting drains or water courses } \\
\text { been considered? }\end{array}$ \\
\hline & $\begin{array}{l}\text { Are there any environmental/ vegetation/ other effects that will hamper the } \\
\text { functioning of drainage inlets (e.g. sugar cane blocking inlets). }\end{array}$ \\
\hline Climate & $\begin{array}{l}\text { Has consideration been given to weather records or local experience that may } \\
\text { indicate problems related to adverse weather conditions such as snow, fog, etc. } \\
\text { typical in the area? }\end{array}$ \\
\hline \multirow[t]{2}{*}{ Landscaping } & $\begin{array}{l}\text { If landscaping proposals are available, how will they affect the safety of the } \\
\text { project? (e.g. inter-visibility of drivers and pedestrians, sight lines, shade/ sun } \\
\text { interplay on the road and hazards in the clear zones). }\end{array}$ \\
\hline & $\begin{array}{l}\text { Will the landscaping proposals introduce roadside hazards when the vegetation } \\
\text { matures? }\end{array}$ \\
\hline \multirow[t]{3}{*}{ Services } & $\begin{array}{l}\text { Does the design adequately deal with buried and overhead services, especially } \\
\text { overhead clearances on roads in superelevation, etc.? }\end{array}$ \\
\hline & $\begin{array}{l}\text { Has the location of fixed objects of furniture associated with services been } \\
\text { checked, including the location of specific poles. }\end{array}$ \\
\hline & $\begin{array}{l}\text { Do any of the services intrude in the right of way of other road users? (e.g. poles } \\
\text { located on the sidewalks, etc.) }\end{array}$ \\
\hline \multirow{3}{*}{$\begin{array}{l}\text { Access to property and } \\
\text { developments }\end{array}$} & Can all accesses be used safely? \\
\hline & $\begin{array}{l}\text { Is the design free from any downstream or upstream effects from points of } \\
\text { access, particularly near intersections? }\end{array}$ \\
\hline & $\begin{array}{l}\text { Have truck parking and rest area accesses been checked for adequate sight } \\
\text { distance, etc.? }\end{array}$ \\
\hline \multirow[t]{4}{*}{ Adjacent land-use } & $\begin{array}{l}\text { Will the project accommodate the traffic generated by adjacent developments } \\
\text { and the adjacent road network safely? }\end{array}$ \\
\hline & $\begin{array}{l}\text { Is the design reconcilable with driver expectancy from the lighting and traffic } \\
\text { signals provided on the adjacent road section/ intersection/ network? }\end{array}$ \\
\hline & $\begin{array}{l}\text { Does the design make provision for special road users that are generated by } \\
\text { adjacent land-uses and the existing road network? }\end{array}$ \\
\hline & $\begin{array}{l}\text { Are there any land-use issues that will have an effect on the safety of the } \\
\text { project? }\end{array}$ \\
\hline
\end{tabular}


Emergency vehicles and access

Future planning

Project phasing

Maintenance

Skid resistance

\section{DESIGN}

Design standards (General)
Has provision been made for safe access and movement by emergency vehicles? (e.g. fire brigade trucks.)

Does the design and position of medians and vehicle barriers allow emergency vehicle to stop and turn without unnecessary disrupting traffic or being exposed to danger?

Will broken-down vehicles or stopped emergency vehicles safe from passing traffic?

Have median breaks been safely provided on dual carriageway roads? (e.g. frequency, visibility, usage constraints, signage)

If widening is planned:

- Are drivers adequately guided by the design?

- Are drivers adequately informed by signage?

Is the possible transition between a single and dual carriageway (both directions) being handled safely?

If the project is to be constructed/ implemented in different phases:

- Are the phases details adequate to ensure safety?

- Is the phase programming safe?

- Are there measures to accommodate temporary traffic management between the different phases?

Is the construction is to be split into different contracts, are they arranged safely?

Do the construction plans and program for staged construction include specific safety measures for temporary arrangements?

Can routine maintenance vehicles be safely located?

Has the need for anti-skid surfacing been considered and provided for in areas where improved braking or road adhesion is essential?

Is the design speed and proposed posted speed limits appropriate for the terrain and function of the road? Are they appropriate for the design vehicles and the road users?

Is the design speed reconcilable with the expected operational speed?

Has the appropriate design vehicles/ been used? (specifically also for possible constraining turning movements).

Does the cross section provide for safe drainage parallel and perpendicular to the road? (e.g. Are the side slopes of concrete drains such that errant vehicles can recover after entering?)

If concrete side drains pose a risk of trapping vehicles, has provision been made for guard rails?

Are concrete head walls perpendicular to the main road sloped to reduce the impact upon an errant vehicle?

Is the design of grid inlets such that it does not pose a danger to cyclists?

Are kerb inlets set back from the face of guard rails? 
Typical cross-section

Superelevation

Variations in cross-sections

Layout of roadway

Shoulders and edge treatment
Are the cross-section features such as widths of lanes and shoulders, medians, etc. adequate for the function of the project?

Do the cross-section features conform to the requirements set for design for safety?

Are lane and shoulder widths appropriate for:

- The alignment?

- Road users?

- The vehicles that will utilize the project?

- The operating speeds?

- The combinations of speed and volume?

Have adequate clear zones been provided?

Are the batter slopes safe for errant vehicles to recover?

Does the median width allow street furniture to be located safely?

Does the verge design allow the safe installation of ground-mounted or overhead structures?

Has provision been made for sidewalks and the safe handling of pedestrians and cyclists? (Including full width dropped kerbs at pedestrian crossings.)

Is the superelevation consistent with the design speed and the type of road?

Will changes in superelevation at operating speeds result in the possible shifting of freight on heavy vehicles?

Are there any curves with adverse cross-fall?

Are there any variations in cross-section that will influence safety negatively?

Are the cross-falls safe? (particularly where sections of existing roadways are used or accesses accommodated)

Are the any unsafe compromises such as sudden narrowing at existing bridges.

Do the traffic management features:

- Create unsafe conditions?

- Provide adequate warning or guidance?

Do the road signs and marking provide adequate warning and guidance at locations where the alignment is substandard or changing? (also under nighttime or low visibility conditions).

Are overtaking/ climbing/ crawler lanes provided if needed? Are they properly signed and marked at the start and the end of these lanes?

Are the following safety aspects of shoulder provision satisfactory:

- Provision of surfaced or unsurfaced shoulders?

- Width and treatment on embankments?

- Crossfalls of shoulders? (to allow safe use of shoulder as recovery area Are the shoulders likely to be safe when used by slow moving vehicles or cyclists?

Are shoulder widths sufficient for stationary vehicles?

Are any rest areas or truck parking areas designed safely? 
Cut-and-fill

Deviations from and changes to standard design guidelines and standards

\section{ALIGNMENT}

Vertical and horizontal alignment

Visibility and sight distance
Are there any geological characteristics of the cut-and fill of the project that will endanger road users?

Is the stability of slopes safe to ensure that debris or loose material does not collect on the road or that an embankment remains stable?

Do the typical details used on the project reflect road safety best practices and have they been reviewed for applicability to this particular project?

Do any of the deviations from accepted design guidelines or standards reduce the safety performance of the project?

Does the horizontal and vertical alignment fit together appropriately?

Does the vertical and horizontal alignment guide a driver accurately - is it free of visual clues that would cause the driver to misread the road characteristics?

Is the vertical and horizontal alignment conducive to consistent operating speed?

Is the design free from any misleading visual clues?

Does the vertical and horizontal alignment provide the required sight distance and visibility?

Are there any of the following objects or structures present that will obstruct sight lines or reduce sight distance that will have an adverse effect on safety:

- Fencing?

- Traffic barriers/ guard rails?

- Street furniture (including trash bins)?

- Services?

- Parking facilities?

- Signs?

- Landscaping/ vegetation?

- Bridge abutments?

Are all hazards such as bridge abutments noticeable?

Is there any local feature that will obstruct sight lines?

Are railways crossings, bridges, intersections and other hazards clearly visible under daytime and nighttime driving?

Is the design free from overhead obstructions that may restrict sight distance in sag curves or forward sight distance towards overhead mounted road traffic signs?

Has minimum sight triangles been provided at:

- Entry and exit ramps?

- Gore areas?

- Intersections?

- Roundabouts?

- Other possible conflict points? 
Transition between project and existing adjacent road section/ intersection/ network

Public transport

\section{INTERSECTIONS}

Readability by drivers

Visibility of intersection

Other:

Parking
Does the transition from existing to new (and opposite) occur well away from any hazardous condition like the following:

- Speed differences?

- Differences in accesses provision?

- Geometry (e.g. is it on a curve or a crest where the visibility is poor/ where the driver is likely to be distracted?)

- Differences in design standards?

- Differences in the physical features of the environment? (e.g. for example from lit to until, rural to urban)

- Differences in the posted speed limit?

Is adequate advance warning provided where required?

Is on-site parking planned to minimize on-street parking?

Can on-street parking be provided safely?

If not, are measures provided to prevent it?

Has the need for public transport facilities considered and implemented in a manner that would allow safe ingress and egress to possible bus stops?

Will the general type, function and broad features be perceived correctly by drivers?

Are the approach speeds and likely positions of vehicles as they track through the intersection safe?

Do successive intersections violate driver expectancy because of inconsistencies?

Does the driver get sufficient time to perceive the upcoming situation, decide upon a course of actions, prepare for and execute the necessary actions safely?

Does the design provide for erroneous decisions?

Is the design free from possible sunrise and sunset problems that may create a hazard?

Will the driver experience glare from oncoming vehicles or from road lighting?

Is the driver ever exposed to sudden darkness?

Do the horizontal and vertical alignment at the intersections or on the approach to the intersection allow safe forward visibility to the intersection and intervisibility between the main road and the intersecting road/s?

Will drivers be aware of the presence of the intersection and the control thereof? (Especially approaching on the minor road) and will they be able to react safely to it?

Are there any of the following temporary features present that will obstruct sight lines:

- Parked vehicles?

- Public transport facilities/ lay-bys?

- Queuing vehicles?

- Heavy vehicles loading zones? 
Layout and traffic control

Roundabout

Geometric design details
Are the following appropriate for the function of the two intersecting roads:

- Layouts? (e.g. crossroad, T-junction, roundabout, interchange)

- Traffic control type? (e.g. signalization, Stop or Yield control)

Will the layout or traffic control have a negative safety impact on special road users such as:

- Pedestrians?

- Vulnerable road users?

- Cyclists?

- Heavy vehicles?

Does the layout make provision for all design vehicles that will utilize the intersection? (e.g. turning radii, swept paths of vehicles, lane widths, etc.)

Is the design free form an upstream or downstream geometric features that could affect safety? (e.g. lane merges)

Is there a need for traffic barriers? Will their use result in the reduction of the severity of injuries?

Have islands been provided to clarify specific movements and to provide refuge for pedestrians?

Are the approach speeds on the intersecting road sections safe?

Are sufficient queue lengths/ storage for turning movements available? (also in the centre of a staggered intersection)

Will the layout or traffic control affect the safety of public transport facilities (if planned)?

Where a roundabout is proposed:

- Have cyclist movements been considered?

- Have pedestrian movements been considered?

- Are the details pertaining to the circulating roadway sufficient?

Is adequate deflection provided to reduce approach speeds?

If splitter islands are required, are they adequate for sight distance, length, pedestrian storage, etc.?

Is the central island prominent and does it limit see-through?

Can pedestrians be seen early enough by drivers?

Can pedestrians determine if vehicles would be turning in conflicting movements?

Are direction markings provided in approach lanes where needed?

Is the lighting at the roundabout adequate and columns in safe locations?

Can the layout safely handle unusual traffic mixes or circumstances?

Does any median or islands safely provide for:

- Vehicle alignments and paths?

- Future traffic signals?

- Pedestrian storage and surface?

- Turning path clearance?

- Stopping sight distance to the nose?

- Mountability by errant vehicles? 
SPECIAL ROAD USERS

Pedestrians

Cyclists and motorcyclists

Heavy vehicles
Is the design safe for pedestrians?

Is there a need for the provision of pedestrian crossings?

Are pedestrian crossings provided along desire lines?

Is each pedestrian crossing satisfactory for:

- Visibility (in each direction)?

- Use by the disabled?

- Use by the elderly?

- Use by children/ schools?

Is there a need for paved footpaths? If not planned, where will the pedestrians walk and will it be safe enough? Are pedestrians safely provided for at bridges and culverts?

Is the carriageway widened to provide for pedestrian movement and can pedestrians utilize this safely?

Is there a need for pedestrian refuge islands and are they wide enough to ensure safety?

Is the expected operational speed appropriate for the pedestrian facilities that are provided?

Has pedestrian fencing been provided on medians or complex intersection layouts to reduce jay-walking?

Is the surfacing of pedestrian walkways appropriate?

Has tactile edging been provided at pedestrian crossing to assist the disabled?

Is consideration being given to the needs of cyclists and motorcyclists?

Are bicycle lanes needed or can shared pedestrian-cycle facilities be implemented?

Has the location of devices or objects that could destabilize a motorcyclist avoided on the road surface?

Is the roadside clear of obstruction where the motorcyclist may lean into curves?

Is the roadside forgiving in areas more prone to run off the road crashes by motorcyclists?

Are drainage grids, culverts and bridge expansion joints traversable by motorcycle?

Does the design make provision for the limitations of heavy vehicles? (e.g. longer stopping distance, etc.)

Does the design consider safe gradients for heavy vehicles?

If in mountainous terrain, are any arrestor bed facilities required for the design? Are they provided or can a modification of the design eliminate the need?

If there are height restrictions, have alternative routes been provided and properly signed for use by such vehicles?

Should rest areas be provided? If planned, can they be used safely?

Are safe heavy vehicle loading facilities provided where required?

Is provision made for the safe manoeuvring of heavy vehicles where necessary? 
Public transport

Maintenance vehicles and crews

Animals

\section{ROAD TRAFFIC SIGNS, SIGNALS AND LIGHTNING}

Road signs

Road markings underpasses) reflectivity) intersections? the road?
Is safe provision made for public transport facilities where needed?

Is provision made for the safe movement of pedestrians to, at and from the public transport facilities? (e.g. Are sufficient space available for passengers alighting from buses?)

Can maintenance vehicles and crews be safely accommodated after implementation of the project?

Is there a need to make provision for stock or equestrians? (e.g. animal

Can the project be provided with direction signs in an unambiguous manner?

Do the signs comply with the standards prescribed in the Act and National Road Traffic Regulations?

Are the road signs adequate to provide for driver needs (guidance, control and warning)? Have the necessary advance warning signs been provided, including advisory speeds for hazardous conditions as well as hazard marker plates?

Does the design overly rely on signs to be effective? (in lieu of appropriate geometric design)

Are all physical obstructions property signed to identify them as hazardous?

Will the road signs be visible and readable with sufficient time for the driver to read, consider options, prepare to manoeuvre and act on the information in a timely and safe manner? (review special needs for appropriate night-time

Is the amount of reflectivity adequate/ excessive, i.e. blinding the driver?

Will any of the road signing limit the visibility or sight lines at accesses or

Will any of the road signing pose a safety hazard to errant vehicles? Was provision made to reduce the severity of such crashes?

K\&'\&"'+-:";) 81;".7-H\&:"O)*C" :5\&"H+81);-1H\&"+,"'+-:";-,\&\$\$p"

Are the signs on the project consistent with those on the adjacent sections of

Are the planned road markings adequate in terms of safety?

Do the markings comply with the standards prescribed in the Act and National Road Traffic Regulations?

Have no-overtaking line markings been provided where required?

Have guideline markings and painted island been provided to clarify movements in complex layouts?

Has attention been given to the improvement of wet weather visibility of markings in critical locations?

Has the need for profiled marking been considered and implemented in the design?

Are there many road elements that will require the provision of road studs for visibility at night-time? (e.g. raised median islands etc.)

Is the transition of road marking between the project and the existing adjacent road section/ intersection/ network safe? 
Are the traffic signal reads visible, i.e. are there any features such as trees, lighting, signage, etc. that may prevent drivers approaching the intersection from seeing the signals?

Are there any signal aspects visible near or within the intersection that may confuse drivers?

Will the intersection be affected by sunrise/ sunset problems? Is provision made for this in the form of backboards, louvres or high intensity signals?

Does the vertical alignment on the approaches allow for sufficient stopping distances?

Is the signal phasing clear to the driver?

Does the phasing conform to the safety requirements set for the amber and allred periods?

Are pedestrians considered in the planned signal phasing?

If islands are located in the path of the pedestrians, is the size of these sufficient to act as a refuge island?

Will drivers be able to see pedestrians crossing?

Is the signal phasing appropriate for:

- The expected traffic movements?

- The accommodation of all design vehicles?

- The geometry of the intersection?

- The geometry of the approaches?

Road lighting

Should road lighting be provided for this project?

If lit, will safety be maintained in the case of a break in power supply?

Are all gore areas and lane merge conditions adequately lit?

Are there any special needs created by ambient lighting and will safety be maintained if such special features are not provided?

Was due cognizance taken of features such as trees, over-bridges, etc. that will affect the installation of road lighting?

Does the road lighting pose a roadside hazard?

Is the road user adequately protected from colliding with lighting poles?

If traffic barriers are used for this purpose, are they properly located or installed to ensure improved safety and will they function as intended?

Has lighting been provided at locations with known crash history?

\section{ROADSIDE HAZARD MANAGEMENT}

Roadside hazards

Traffic barriers/ crash barriers
Are there any fixed objects within the clear zone that should be relocated, redesigned, protected by traffic barriers or be made breakaway?

Are traffic barriers provided where necessary and properly detailed for use at structures, embankments, trees, poles/ posts, drainage channels, bridge piers and gore areas of off-ramps? 
Traffic barriers/ crash barriers (including wire rope systems)

Bridges and drainage structures

Median barriers
Are proper deflection distances provided between the traffic barrier and the roadside hazard if flexible traffic barrier systems are used?

Are all end treatments safe if hit by a vehicle?

Will the traffic barrier pose a danger to any of the road users (also pedestrians and motorcyclists)?

Was the movement of pedestrians considered in the location and placement detail of the traffic barrier systems?

If guardrail barrier systems are provided, are the design and details safe in terms of:

- End-treatment?

- Anchorage?

- Post spacing?

- Block outs?

- Post depth?

- Soil stability?

- Rail overlap?

Is all traffic barriers necessary? (e.g. is what it shield a greater hazard than the barrier?)

Are bridges and culvert end walks visible and easily recognized?

Is horizontal clearance to moving traffic adequate?

Are sight lines through bridge railing sufficient for safety purposes?

Are end treatments safe?

Are Road traffic signs and markings installed to warn of possible hazards?

Are the transitions between different traffic barrier system types safe? (approach traffic barrier to bridge parapet)

Are the differences in the shoulder widths of the approaches and on the bridge?

Is provision made for the movement of non-vehicular traffic such as pedestrians, horses/ stock over the bridge?

Does the bridge railing conform to the requirements set for safe traffic barriers in terms of rail height, containment and the fixing detail to the bridge?

Do traffic barriers adequately protect dangerous culvert structures?

Are there any headwalls present within the clear zone? Are they adequately protected or can the culverts be extended to place the end walls outside the clear zone?

Is adequate warning signage and sight distance provided at floodway/ causeways?

Was the need for median barriers considered and adequately provided for?

Is the design and median barrier type adequate for the particular application? (e.g. design vehicle, median within, maintenance requirements, etc.)

Are the details for the location and installation of traffic barriers correct?

Are the end-treatments safe? 


\section{TRAFFIC OPERATIONS}

Traffic flow

Access management

Merging and overtaking

Rest areas and stopping facilities
Will the traffic flow of the project have a negative influence on the safety of adjacent road network/ developments?

Was adequate consideration given to parking control features?

Can exclusive turning lanes and deceleration lanes be used safely?

Will the project cause or contribute to the movement of traffic at high speeds through residential areas (rat-running)?

Was adequate consideration given to the possible provision of accesses of future developments in or adjacent to the project?

Are the existing and proposed accesses in the road project safe to use?

Will any up-or downstream effects reduce the safety of an access, particularly those located close to intersections?

Are adequate shoulder widths provided during and after lane merges?

Is adequate overtaking sight distance and stopping distance provided?

Is advance warning provided for lane merging?

Is proper sight distance provided for lane merging?

Are sufficient stopping and rest areas provided?

Are safe access provided to rest areas and stopping facilities?

Is the sight distance and access design for accesses for rest areas safe?

\section{ACCOMMODATION OF TRAFFIC}

Construction

Construction program
Is the project is to be constructed "under traffic", can this be done safely as far as the construction is concerned as well as the extent to which the general travelling public will be affected?

Have innovate or accelerated construction techniques been considered to reduce the exposure of the public to restrictive construction conditions?

Have different phasing options been considered? Are there any features of the project that will require special traffic management during construction phases or any period before implementation?

Are there any elements of the project that will hamper the safe construction of the project? (e.g. construction vehicle routes and interaction with general public traffic).

Have all applicable work zone types been adequately considered to establish the safest construction program?

- Work outside of roadway

- Full roadway closure

- Permanent lane/ shoulder/ ramp closures

- Crossovers/ contra-flow

- Detour

- Intermittent road closures (i.e.15-minutes, weekend)

- Reduced lane widths

- Reduced shoulder widths

- Lane shifts

- Daily lane/ shoulder closures 
Construction program

Temporary traffic management planning

Project timing

Protective devices
- Use of shoulder or median

- One-lane, two-way operation or Reversible lanes

- Use of temporary structures

- Use of temporary pavement

- Widening

- Nightwork

- Weekend work

Are bypasses or temporary widening needed?

Does pedestrian/bicycle traffic access need to be maintained?

Are minimum allowable lane widths achievable?

Is the reduced work zone speed limit realistic and appropriate?

Should certain types of vehicles be prohibited from entering the work zone (over-height, weight restrictions)? Will oversized load permits be affected?

Will the work zone be adequate in terms of:

- Traffic control devices?

- Rail crossings and controls?

- Geometrics (turning radii, ramp merge/diverge areas, etc.)?

- Bridge restrictions and other structures?

Can the contractor restrict the roadway during:

- Peak hours?

- One direction?

- Both directions?

- Overnight?

- Holidays or weekends?

- Sporting projects in the immediate area?

- Other projects in the immediate area?

Are temporary barriers and impact attenuators required?

Has extra protection be provided for:

- Pedestrian/Bicyclists?

- School areas and crossing?

- Playgrounds and parks?

Have areas been designated for the contractor to safely store (where necessary):

- Equipment?

- Construction materials?

- Waste materials? 
Detours or deviations

Work zone analysis

Mobility impacts

Temporary traffic control
Does the detour planning show that the detours are adequate in terms of:

- Weight restrictions?

- Height-width constrains and accommodation of abnormal vehicles?

- Capacity?

- Adequate traffic control devices?

- Railway crossing and controls (if needed)?

- Geometrics (turning radii, etc.)?

- Bridge restrictions and other structures?

Is there other construction along the detour that might influence traffic?

Will all fronting businesses have acceptable ingress and egress?

Are alternate routes available to local motorists?

Is a public information meeting required?

Has the work zone traffic analysis been conducted to identify work zone and ramp capacities?

Have required number of maintained lanes and allowable lane closure hours been identified?

Does the project comply with the guidelines set in the SADC Road Traffic Signs Manual and SARTSM Volume 2 Chapter 13?

Has the work zone traffic analysis identified impacts on any of the following and are measures included to minimize such impact?

- Ability to maintain all accesses (business, community, etc.)

- Pedestrian, and bicycle facilities

- Public safety (workers and travelling public)

- Emergency vehicle access

- Construction equipment access \& movement through the work zone

- Specific user groups (businesses, communities)

- Over-height, over-weight vehicles

- Public transport services and bus stops

- Traffic operations in and around the work zone (freeway queues, network operations, effect on local roads and detour routes)

- Ramp capacity

- Intersection traffic control (signal timing, adequate signage, etc.)

- Existing special traffic operations (HOV lanes, etc.)

- User Costs (delay)

Are the temporary traffic control signs and markings shown on the drawings or referenced to typical details?

Will sign message modifications be required on permanent signs? Have the modifications been shown?

Are temporary signals required or will existing signals need to be kept operational?

Will the removal of marking be required and has the work zone been set up to minimize removal?

Will Portable Changeable Message Signs be required? 
Work zone safety management strategies

Incident management
Have the following work zone safety management strategies been considered?

- Speed limit reduction/ variable aped limits with portable changeable message signs displaying speed?

- Temporary traffic barriers and movable traffic barrier systems?

- Temporary transverse rumble strips?

- Warning lights?

- Temporary roadway lighting?

- etc.

Is provision made for Standby towing service, Emergency lay-byes and Planned detour routes in case of an incident?

Have Work Zone ITS strategies like CCTV monitoring been considered for traffic monitoring/ management?

Are there any safety requirements for the accommodation of tourism or recreation facilities?

Have all unusual or potentially hazardous conditions associated with special events been considered? If required, can the road be closed in a safe manner? 


\section{APÊNDICE A1 - MACROCATEGORIA - ESTUDO DE VIABILIDADE -ANÁLISE DE FREQUÊNCIA}

\begin{tabular}{|c|c|c|c|c|c|c|}
\hline Categorias - Macro categorias & $\begin{array}{l}\text { Hildebrand e } \\
\text { Wilson,(1999) } \\
\text { (1) }\end{array}$ & $\begin{array}{c}\text { Castrillón e } \\
\text { Candia (2003) } \\
\text { (2) }\end{array}$ & $\begin{array}{l}\text { AUTROADS } \\
\text { (2009) (3) }\end{array}$ & $\begin{array}{c}\text { RTMC (2012) } \\
\text { (4) }\end{array}$ & Frequência & $\begin{array}{l}\text { Macrocategorias } \\
\text { propostas }\end{array}$ \\
\hline Tópicos Gerais (1, 2, 3 e 4) & $\mathbf{x}$ & $\mathbf{x}$ & $\mathbf{x}$ & $\mathbf{x}$ & $100 \%$ & 1. Tópicos gerais \\
\hline $\begin{array}{l}\text { Alinhamento e seções transversais } \\
\text { (1) - Traçado - Questões de projeto } \\
(2 \text { e 4) }\end{array}$ & $\mathbf{x}$ & $\mathbf{x}$ & $\mathbf{x}$ & $\mathbf{x}$ & $100 \%$ & 2. Geometria \\
\hline $\begin{array}{l}\text { Interseções ou interseção em } \\
\text { desnivel }(1,2,3 \text { e } 4)\end{array}$ & $\mathbf{x}$ & $\mathbf{x}$ & $\mathbf{x}$ & $\mathbf{x}$ & $100 \%$ & 3. Interseções \\
\hline Objetos Físicos (1) & $\mathbf{x}$ & & & & $25 \%$ & 4. Obstáculos fixos \\
\hline $\begin{array}{l}\text { Considerações ambientais (1) } \\
\text { Restrições ambientais }(2,3 \text { e } 4)\end{array}$ & $\mathbf{x}$ & $\mathbf{x}$ & $\mathbf{x}$ & $\mathbf{x}$ & $100 \%$ & 5. Aspesctos Ambientais \\
\hline Usuários da Rodovia (1) & $\mathbf{x}$ & & & & $25 \%$ & $\begin{array}{l}\text { Não abordado como } \\
\text { macrocategoria }\end{array}$ \\
\hline $\begin{array}{lrr}\text { Acessos } & \mathrm{e} & \text { desenvolvimentos } \\
\text { adjacentes (1) } & \end{array}$ & $\mathbf{x}$ & & & & $25 \%$ & $\begin{array}{l}\text { Não abordado como } \\
\text { macrocategoria }\end{array}$ \\
\hline Outras considerações $(2,3$ e 4$)$ & & $\mathbf{x}$ & $\mathbf{x}$ & $\mathbf{x}$ & $75 \%$ & 6. Outras considerações \\
\hline
\end{tabular}




\section{APÊNDICE A2 - MACROCATEGORIA - PROJETO BÁSICO -ANÁLISE DE FREQUÊNCIA}

\begin{tabular}{|c|c|c|c|c|c|c|}
\hline Categorias - Macrocategorias & $\begin{array}{c}\text { Hildebrand e } \\
\text { Wilson (1999) } \\
\text { (1) }\end{array}$ & $\begin{array}{c}\text { Castrillón e } \\
\text { Candia (2003) } \\
\text { (2) }\end{array}$ & $\begin{array}{l}\text { AUSTROAD } \\
\text { S (2009) (3) }\end{array}$ & $\begin{array}{c}\text { RTMC (2012) } \\
\text { (4) }\end{array}$ & Frequência & $\begin{array}{c}\text { Macrocategorias } \\
\text { propostas }\end{array}$ \\
\hline Tópicos Gerais $(1,2,3$ e 4$)$ & $\mathbf{x}$ & $\mathbf{x}$ & $\mathbf{x}$ & $\mathbf{x}$ & $100 \%$ & 1. Tópicos gerais \\
\hline $\begin{array}{l}\text { Alinhamento e seções transversais } \\
\text { (1) - Alinhamento (3) - } \\
\text { Alinhamento detalhado (2 e 4) }\end{array}$ & $\mathbf{x}$ & $\mathbf{x}$ & $\mathbf{x}$ & $\mathbf{x}$ & $100 \%$ & \multirow{2}{*}{ 2. Geometria } \\
\hline $\begin{array}{l}\text { Traçado (2 e 4) - Questões de } \\
\text { traçao (3) }\end{array}$ & & $\mathbf{x}$ & $\mathbf{x}$ & $\mathbf{x}$ & $75 \%$ & \\
\hline $\begin{array}{l}\text { Interseções e interseções em } \\
\text { desnível }(1,2,3 \text { e } 4))\end{array}$ & $\mathbf{x}$ & $\mathbf{x}$ & $\mathbf{x}$ & $\mathbf{x}$ & $100 \%$ & 3. Interseções \\
\hline Objetos Físicos (1) & $\mathbf{x}$ & & & & $25 \%$ & 4. Obstáculos fixos \\
\hline Considerações ambientais (1) & $\mathrm{x}$ & & & & $25 \%$ & $\begin{array}{c}\text { Não abordado como } \\
\text { macrocategoria }\end{array}$ \\
\hline $\begin{array}{l}\text { Usuários especiais da Rodovia (1, } \\
2,3 \text { e } 4)\end{array}$ & $\mathbf{x}$ & $\mathbf{x}$ & $\mathbf{x}$ & $\mathbf{x}$ & $100 \%$ & 5. Usários da Rodovia \\
\hline Sinalização e iluminação $(2,3$ e 4$)$ & & $\mathbf{x}$ & $\mathbf{x}$ & $\mathbf{x}$ & $75 \%$ & $\begin{array}{l}\text { 6. Sinalização e } \\
\text { iluminação }\end{array}$ \\
\hline $\begin{array}{l}\text { Acessos e desenvolvimentos } \\
\text { adjacentes (1) }\end{array}$ & $\mathbf{x}$ & & & & $25 \%$ & $\begin{array}{l}\text { Não abordado como } \\
\text { macrocategoria }\end{array}$ \\
\hline Gestão de Tráfego (2 e 3) & & $\mathbf{x}$ & $\mathbf{x}$ & & $\mathbf{5 0 \%}$ & 7. Gestão de Tráfego \\
\hline $\begin{array}{l}\text { Perguntas adicionais para ser } \\
\text { consideradas para } \\
\text { desenvolvimento proposto }(2 \text { e } 3)\end{array}$ & & $\mathbf{x}$ & $\mathbf{x}$ & & $\mathbf{5 0 \%}$ & 8. Perguntas Adicionais \\
\hline $\begin{array}{l}\text { Operação do tráfego e } \\
\text { construção }\end{array}$ & & & & $\mathbf{x}$ & $25 \%$ & $\begin{array}{l}\text { Não abordado como } \\
\text { macrocategoria }\end{array}$ \\
\hline Outras considerações $(2,3$ e 4$)$ & & $\mathbf{x}$ & $\mathbf{x}$ & $\mathbf{x}$ & $75 \%$ & 9. Outras considerações \\
\hline
\end{tabular}




\section{APÊNDICE A3 - MACROCATEGORIA - PROJETO EXECUTIVO -ANÁLISE DE FREQUENNCIA}

\begin{tabular}{|c|c|c|c|c|c|c|}
\hline $\begin{array}{c}\text { Categorias - Macro } \\
\text { categoria }\end{array}$ & $\begin{array}{c}\text { Hildebrand e } \\
\text { Wilson } \\
(1999)(1)\end{array}$ & \begin{tabular}{|c} 
Castrillón e \\
Candia (2003) \\
(2)
\end{tabular} & $\begin{array}{r}\text { Austroads } \\
(2009)(3)\end{array}$ & $\begin{array}{c}\text { RTMC } \\
(\mathbf{2 0 1 2})(4)\end{array}$ & Frequência & $\begin{array}{c}\text { Macrocategorias } \\
\text { propostas }\end{array}$ \\
\hline Tópicos Gerais (1, 2, 3 e 4) & $\mathbf{x}$ & $\mathbf{x}$ & $\mathbf{x}$ & $\mathbf{x}$ & $100 \%$ & 1. Tópicos gerais \\
\hline $\begin{array}{l}\text { Alinhamento e seções transversais } \\
\text { (1) }\end{array}$ & $\mathbf{x}$ & $\mathbf{x}$ & $\mathbf{x}$ & $\mathbf{x}$ & $25 \%$ & \\
\hline $\begin{array}{l}\text { Traçado (2 e 3) - Questões de } \\
\text { traçado (4) }\end{array}$ & & $\mathbf{x}$ & $\mathbf{x}$ & $\mathbf{x}$ & $75 \%$ & \\
\hline $\begin{array}{l}\text { Interseções e interseções em } \\
\text { desnível }(1,2,3 \text { e } 4)\end{array}$ & $\mathbf{x}$ & $\mathbf{x}$ & $\mathbf{x}$ & $\mathbf{x}$ & $100 \%$ & 3. Interseções \\
\hline Objetos Físicos $(1,2,3)$ & $\mathbf{x}$ & $\mathbf{x}$ & $\mathbf{x}$ & & $75 \%$ & 4. Obstáculos fixos \\
\hline Considerações ambientais (1) & $\mathbf{x}$ & & & & $25 \%$ & $\begin{array}{l}\text { Não abordado como } \\
\text { macrocategoria }\end{array}$ \\
\hline $\begin{array}{l}\text { Usuários Especiais da Rodovia (1, } \\
2 \text { e } 3 \text { e } 4 \text { ) }\end{array}$ & $\mathbf{x}$ & $\mathbf{x}$ & $\mathbf{x}$ & $\mathbf{x}$ & $100 \%$ & 5. Usários da Rodovia \\
\hline $\begin{array}{l}\text { Recursos visuais (1) - Sinalização } \\
\text { vertical, sinalização horizontal e } \\
\text { iluminação }(2,3 \text { e } 4)\end{array}$ & $\mathbf{x}$ & $\mathbf{x}$ & $\mathbf{x}$ & $\mathbf{x}$ & $100 \%$ & $\begin{array}{l}\text { 6. Sinalização } \\
\text { iluminação }\end{array}$ \\
\hline $\begin{array}{l}\text { Acessos e desenvolvimentos } \\
\text { adjacentes (1) }\end{array}$ & $\mathbf{x}$ & & & & $25 \%$ & $\begin{array}{l}\text { Não abordado como } \\
\text { macrocategoria }\end{array}$ \\
\hline $\left.\mid \begin{array}{llr}\text { Perguntas adicionais para } & \text { ser } \\
\text { consideradas } & \text { para } & \\
\text { desenvolvimento proposto } & (2 \mathrm{e} & 3\end{array}\right)$ & & $\mathbf{x}$ & $\mathbf{x}$ & & $\mathbf{5 0 \%}$ & 7. Perguntas adicionais \\
\hline Outras considerações $(2,3$ e 4$)$ & & $\mathbf{x}$ & $\mathbf{x}$ & $\mathbf{x}$ & $75 \%$ & 8. Outras considerações \\
\hline Gestão de risco da rodovia (4) & & & & $\mathrm{x}$ & $25 \%$ & $\begin{array}{l}\text { Não abordado como } \\
\text { macrocategoria }\end{array}$ \\
\hline Operação de tráfego (4) & & & & $\mathrm{x}$ & $25 \%$ & $\begin{array}{l}\text { Não abordado como } \\
\text { macrocategoria }\end{array}$ \\
\hline Acomodação do tráfego (4) & & & & $\mathbf{x}$ & $25 \%$ & $\begin{array}{l}\text { Não abordado como } \\
\text { macrocategoria }\end{array}$ \\
\hline
\end{tabular}




\section{APÊNDICE B1 - MESOCATEGORIA - ESTUDO DE VIABILIDADE - ANÁLISE DE FREQUÊNCIA}

\section{Mesocategorias dos Tópicos Gerais e Geometria}

\begin{tabular}{|c|c|c|c|c|c|c|}
\hline Mesocategorias & \begin{tabular}{|c|} 
Hildebrand e \\
Wilson (1999) \\
(1)
\end{tabular} & $\begin{array}{c}\text { Castrillón e } \\
\text { Candia (2003) } \\
\text { (2) }\end{array}$ & $\begin{array}{l}\text { AUSTROADS } \\
\text { (2009)(3) }\end{array}$ & $\begin{array}{c}\text { RTMC (2012) } \\
\text { (4) }\end{array}$ & \multirow[t]{2}{*}{ Frequência } & Mesocategorias propostas \\
\hline 1. Tópicos gerais & \multicolumn{4}{|c|}{ 1. Tópicos gerais } & & 1. Tópicos Gerais \\
\hline $\begin{array}{l}\text { Finalidade (1) - Aspectos gerais, } \\
\text { função e composição do tráfego } \\
\text { previsto. }(2,3 \text { e } 4)\end{array}$ & $\mathbf{x}$ & $\mathbf{x}$ & $\mathbf{x}$ & $\mathbf{x}$ & $100 \%$ & 1.1 Finalidade do proieto \\
\hline Etapas de construção $(1,2,3$ e 4$)$ & $\mathbf{x}$ & $\mathbf{x}$ & $\mathbf{x}$ & $\mathbf{x}$ & $100 \%$ & \\
\hline $\begin{array}{l}\text { Principais geradores de tráfego }(2,3 \\
\text { e 4) }\end{array}$ & & $\mathbf{x}$ & $\mathbf{x}$ & $\mathbf{x}$ & $75 \%$ & $\begin{array}{l}\text { 1.2 Características técnicas do } \\
\text { projeto }\end{array}$ \\
\hline $\begin{array}{l}\text { Consistência dos parâmetros do } \\
\text { projeto (1) }\end{array}$ & $\mathbf{x}$ & & & & $25 \%$ & $\begin{array}{l}\text { Não abordado como } \\
\text { macrocategoria }\end{array}$ \\
\hline $\begin{array}{l}\text { Tipos e controle de acesso às } \\
\text { propriedade e desenvovilemento }(2, \\
3 \text { e } 4)\end{array}$ & & $\mathbf{x}$ & $\mathbf{x}$ & $\mathbf{x}$ & $75 \%$ & 1.3 Acessos e áreas adjacentes \\
\hline $\begin{array}{l}\text { Amplos impactos da rede } \\
\text { rodoviária }(2,3 \text { e } 4)\end{array}$ & & $\mathbf{x}$ & $\mathbf{x}$ & $\mathbf{x}$ & $75 \%$ & $\begin{array}{l}1.4 \text { Impactos do projeto } \\
\text { proposto }\end{array}$ \\
\hline Futuros Trabalhos $(2,3$ e 4$)$ & & $\mathbf{x}$ & $\mathbf{x}$ & $\mathbf{x}$ & $75 \%$ & 1.5 Obras de Melhoramentos \\
\hline $\begin{array}{l}\text { 2. Alinhamento e seções } \\
\text { transversais / Traçado / } \\
\text { Questões de traçado }\end{array}$ & $\begin{array}{l}\text { 2. Alinhamento } \\
\text { traçado }\end{array}$ & e seções trans & versais / Traçad & / Questões de & Frequência & 2. Geometria \\
\hline Classificação (1) & $\mathbf{x}$ & & & & $25 \%$ & $\begin{array}{l}\text { Não abordado como } \\
\text { macrocategoria }\end{array}$ \\
\hline $\begin{array}{l}\text { Composição do projeto e fluxo de } \\
\text { tráfego }(2,3 \text { e } 4)\end{array}$ & & $\mathbf{x}$ & $\mathbf{x}$ & $\mathbf{x}$ & $75 \%$ & \\
\hline Traçado proposto $(1,2,3$ e 4$)$ & $\mathbf{x}$ & $\mathbf{x}$ & $\mathbf{x}$ & $\mathbf{x}$ & $100 \%$ & 2.1 Traçado e alinhamento \\
\hline $\begin{array}{l}\text { Impactos da continuidade com a } \\
\text { rede rodoviária existente }(2,3 \mathrm{e} 4)\end{array}$ & & $\mathbf{x}$ & $\mathbf{x}$ & $\mathbf{x}$ & $75 \%$ & \\
\hline Padrões gerais do projeto $(2,3$ e 4$)$ & & $\mathbf{x}$ & $\mathbf{x}$ & $\mathbf{x}$ & $75 \%$ & $\begin{array}{l}\text { 2.2 Elementos gerais do } \\
\text { projeto }\end{array}$ \\
\hline Elementos da Seção transversal (1) & $\mathbf{x}$ & & & & $25 \%$ & $\begin{array}{l}\text { Não abordado como } \\
\text { macrocategoria }\end{array}$ \\
\hline $\begin{array}{l}\text { Velocidade de projeto e velocidade } \\
\text { sinalizada }(1,2,3 \text { e } 4)\end{array}$ & $\mathbf{x}$ & $\mathbf{x}$ & $\mathbf{x}$ & $\mathbf{x}$ & $100 \%$ & 2.3 Velocidades \\
\hline
\end{tabular}




\section{Mesocategorias dos Interseções, Obstáculos Fixos, Aspectos ambientais e Outras}

considrações

\begin{tabular}{|c|c|c|c|c|c|c|}
\hline Mesocategorias & $\begin{array}{c}\text { Hildebrand e } \\
\text { Wilson (1999) } \\
\text { (1) }\end{array}$ & $\begin{array}{c}\text { Castrillón e } \\
\text { Candia (2003) } \\
\text { (2) }\end{array}$ & $\begin{array}{l}\text { AUSTROADS } \\
\text { (2009) (3) }\end{array}$ & $\begin{array}{c}\text { RTMC (2012) } \\
\text { (4) }\end{array}$ & Frequência & Mesocategorias propostas \\
\hline 3. Interseções & 3. Interseções & & & & Frequência & 3. Interseções \\
\hline Tipo e Quantidade $(1,2,3$ e 4$)$ & $\mathbf{x}$ & $\mathbf{x}$ & $\mathbf{x}$ & $\mathbf{x}$ & $100 \%$ & $\begin{array}{l}\text { 3.1 Quantidade, tipo e } \\
\text { localização }\end{array}$ \\
\hline Localização e espaçmento (1) & $\mathbf{x}$ & & & & $25 \%$ & $\begin{array}{c}\text { Não abordado como } \\
\text { macrocategoria }\end{array}$ \\
\hline 4. Objetos Físicos & 4. Objetos Físic & & & & Frequência & 4. Obstáculos fixos \\
\hline Postes ou outras obstruções (1) & $\mathbf{x}$ & & & & $25 \%$ & $\begin{array}{l}\text { 4.1 Postes ou outras } \\
\text { obstruções }\end{array}$ \\
\hline Divisórias Centrais (1) & $\mathbf{x}$ & & & & $25 \%$ & 4.2 Dispositivos centrais \\
\hline $\begin{array}{l}\text { 5. Considerações ambientais / } \\
\text { Restrições Ambientais }\end{array}$ & 5. Consideraçõ & s ambientais / & estrições Ambie & htais & Frequência & 5. Aspectos Ambientais \\
\hline Clima (1) & $\mathbf{x}$ & & & & $25 \%$ & $\begin{array}{l}\text { Não abordado como } \\
\text { macrocategoria }\end{array}$ \\
\hline Animais (1) & $\mathbf{x}$ & & & & $25 \%$ & $\begin{array}{l}\text { Não abordado como } \\
\text { macrocategoria }\end{array}$ \\
\hline Aspectos de segurança ( 2 e 3 ) & & $\mathbf{x}$ & $\mathbf{x}$ & & $50 \%$ & 5.1 Clima e outros aspectos \\
\hline $\begin{array}{l}\text { Características físicas do terreno } \\
\text { (4) }\end{array}$ & & & & $\mathbf{x}$ & $25 \%$ & $\begin{array}{l}\text { Não abordado como } \\
\text { macrocategoria }\end{array}$ \\
\hline $\begin{array}{l}\text { Aspectos de tempo de dia e noite } \\
\text { (4) }\end{array}$ & & & & $\mathbf{x}$ & $50 \%$ & $\begin{array}{l}\text { Não abordado como } \\
\text { macrocategoria }\end{array}$ \\
\hline 6. Outras considerações & 6. Outras consi & derações & & & Frequência & 6. Outras considerações \\
\hline Aspectos de segurança não tratados & & $\mathbf{x}$ & $\mathbf{x}$ & & $50 \%$ & 6.1 Outras considerações \\
\hline Pedestres & & & & $\mathbf{x}$ & $25 \%$ & \\
\hline Percecpção do motorista & & & & $\mathbf{x}$ & $25 \%$ & \\
\hline Diversos & & & & $\mathbf{x}$ & $25 \%$ & \\
\hline
\end{tabular}




\section{APÊNDICE B2 - MESOCATEGORIA - PROJETO BÁSICO - ANÁLISE DA FREQUÊNCIA}

1. Mesocategorias dos tópicos gerais

\begin{tabular}{|c|c|c|c|c|c|c|}
\hline Categorias - Mesocategorias & $\begin{array}{c}\text { Hildebrand e } \\
\text { Wilson (1999) } \\
\text { (1) }\end{array}$ & $\begin{array}{c}\text { Castrillón e } \\
\text { Candia (2003) } \\
\text { (2) }\end{array}$ & $\begin{array}{l}\text { AUSTROAD } \\
\text { S (2009) (3) }\end{array}$ & $\begin{array}{c}\text { RTMC (2012) } \\
(4)\end{array}$ & \multirow[t]{2}{*}{ Frequência } & $\begin{array}{c}\text { Mesocategorias } \\
\text { propostas }\end{array}$ \\
\hline 1, Tópicos Gerais & \multicolumn{4}{|c|}{ 1. Tópicos Gerais } & & 1. Tópicos gerais \\
\hline $\begin{array}{l}\text { Alterações desde auditorias anteriores (1, } \\
2,3 \text { e } 4 \text { ) }\end{array}$ & $\mathbf{x}$ & $\mathbf{x}$ & $\mathbf{x}$ & $\mathbf{x}$ & $100 \%$ & 1.1 Auditorias anteriores \\
\hline Etapas de construção (1, 2 e 3$)$ & $\mathbf{x}$ & $\mathbf{x}$ & $\mathbf{x}$ & & $75 \%$ & 1.2 Etapas da construção \\
\hline $\begin{array}{l}\text { Consistência dos parâmetros do projeto } \\
\text { (1) }\end{array}$ & $\mathbf{x}$ & & & & $25 \%$ & $\begin{array}{l}\text { Não abordado como } \\
\text { macrocategoria }\end{array}$ \\
\hline $\begin{array}{l}\text { Áreas de descanso / áreas de piquiniques } \\
\text { (1) }\end{array}$ & $\mathbf{x}$ & & & & $25 \%$ & $\begin{array}{l}\text { Não abordado como } \\
\text { macrocategoria }\end{array}$ \\
\hline Drenagem $(2,3$ e 4$)$ & & $\mathrm{x}$ & $\mathrm{x}$ & $\mathrm{x}$ & $75 \%$ & 1.3 Drenagem \\
\hline Condições Climáticas (2, 3 e 4) & & $\mathrm{x}$ & $\mathrm{x}$ & $\mathrm{x}$ & $75 \%$ & 1.4 Condições climáticas \\
\hline Paisagismo (2, 3 e 4$)$ & & $\mathrm{x}$ & $\mathrm{X}$ & $\mathrm{X}$ & $75 \%$ & 1.5 Paisagismo \\
\hline Serviços $(2,3$ e 4$)$ & & $\mathrm{x}$ & $\mathrm{x}$ & $\mathrm{x}$ & $75 \%$ & 1.6 Serviços \\
\hline $\begin{array}{l}\text { acesso e veiculos de emergências (2, } 3 \text { e } \\
\text { 4) }\end{array}$ & & $\mathrm{x}$ & $\mathrm{x}$ & $\mathrm{x}$ & $75 \%$ & $\begin{array}{l}1.7 \text { Acessos de veículos } \\
\text { de emergência }\end{array}$ \\
\hline $\begin{array}{l}\text { Acesso } \quad \text { a } \quad \text { propriedades } \\
\text { empreendimentos imobiliários }(2,3 \mathrm{e} 4)\end{array}$ & & $\mathrm{x}$ & $\mathrm{x}$ & $\mathrm{x}$ & $75 \%$ & \\
\hline Desenvolvimento adjacente $(2,3$ e 4$)$ & & $\mathrm{x}$ & $\mathrm{x}$ & $\mathrm{x}$ & $75 \%$ & \\
\hline $\begin{array}{l}\text { Ampliação e realinhamento futuro ou } \\
\text { planejamento futuro }(2,3 \mathrm{e} 4)\end{array}$ & & $\mathrm{x}$ & $\mathrm{x}$ & $\mathrm{x}$ & $75 \%$ & 1.9 Ampliação futura \\
\hline Etapas dos projeto $(2,3$ e 4$)$ & & $\mathrm{x}$ & $\mathrm{x}$ & $\mathrm{x}$ & $75 \%$ & 1.10 Etapas do projeto \\
\hline Manutenção (2, 3 e 4) & & $\mathrm{x}$ & $\mathrm{x}$ & $\mathrm{x}$ & $75 \%$ & 1.11 Manutenção \\
\hline
\end{tabular}




\section{Mesocategorias dos geometria}

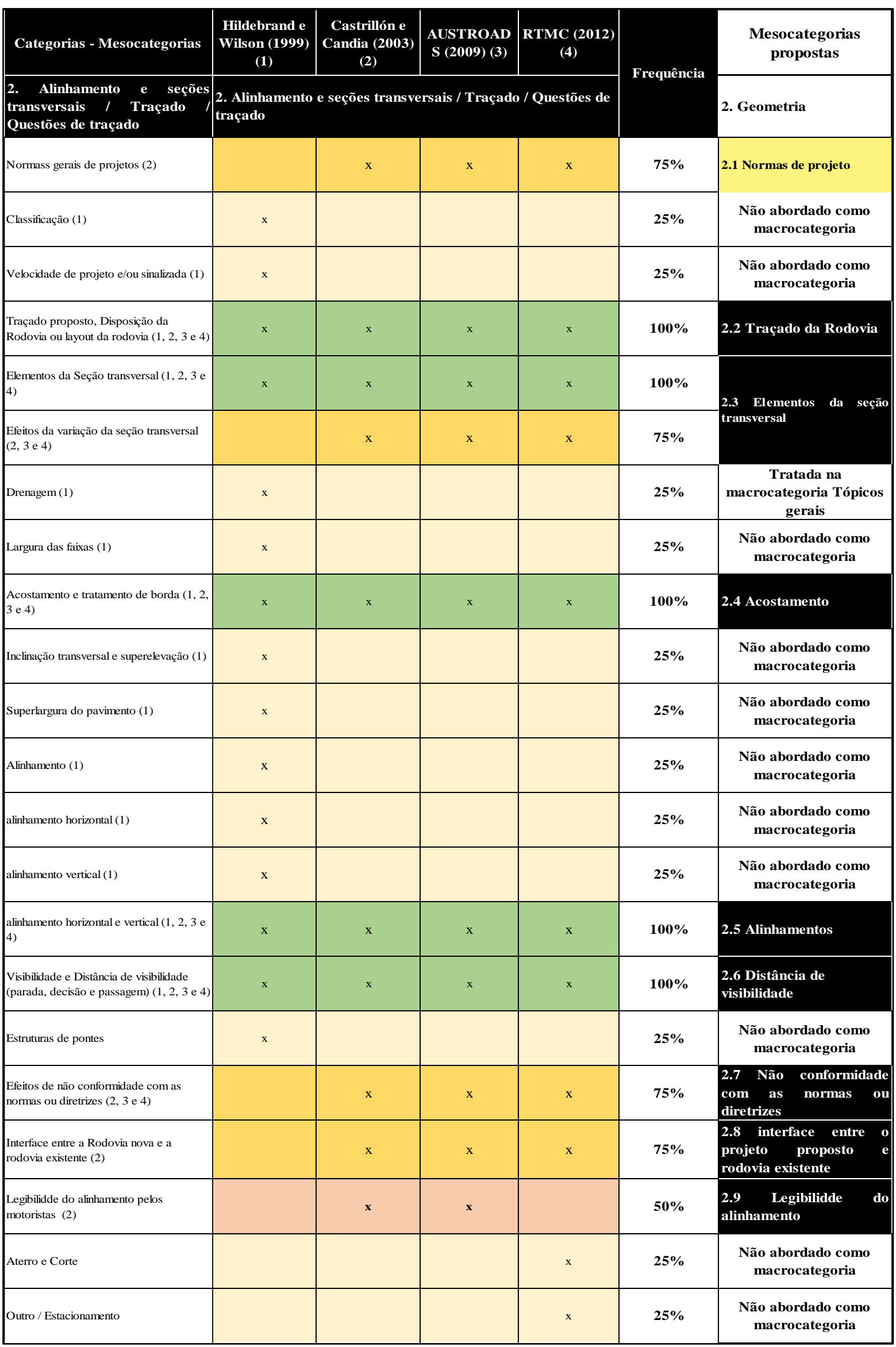




\section{Mesocategorias das interseções, obstáculos fixos, usuários da rodovia}

\begin{tabular}{|c|c|c|c|c|c|c|}
\hline Categorias - Mesocategorias & $\begin{array}{c}\text { Hildebrand e } \\
\text { Wilson (1999) }\end{array}$ & $\begin{array}{c}\text { Castrillón e } \\
\text { Candia (2003) }\end{array}$ & $\begin{array}{l}\text { Austroads } \\
\text { (2009) }\end{array}$ & $\begin{array}{l}\text { RTMC (2012) } \\
\text { - Africa }\end{array}$ & Frequência & $\begin{array}{l}\text { Mesocategorias } \\
\text { propostas }\end{array}$ \\
\hline 3. Interseções & \multicolumn{4}{|l|}{ 3. Interseções } & Frequência & 3. Interseções \\
\hline $\begin{array}{l}\text { Localização e Espaçamento (1) } \\
\text { Distribuição, incluindo adequação } \\
\text { do tipo }(2 \text { e } 3)\end{array}$ & $\mathrm{x}$ & $\mathrm{x}$ & $\mathrm{x}$ & & $75 \%$ & $\begin{array}{l}\text { 3.1 Quantidade, tipo e } \\
\text { localização }\end{array}$ \\
\hline $\begin{array}{l}\text { Legibilidde pelos motoristas (2, } 3 \\
\text { e 4) }\end{array}$ & & $\mathrm{x}$ & $\mathrm{x}$ & $\mathrm{x}$ & $75 \%$ & $\begin{array}{l}\text { 3.2 Legibilidade pelos } \\
\text { motoristas }\end{array}$ \\
\hline Visibilidade e conspicuidade (1) & $\mathrm{x}$ & & & & $25 \%$ & $\begin{array}{l}\text { Não abordado como } \\
\text { macrocategoria }\end{array}$ \\
\hline $\begin{array}{l}\text { Traçado ou traçado e controle de } \\
\text { tráfego (1 e } 4)\end{array}$ & $\mathbf{x}$ & & & $\mathbf{x}$ & $\mathbf{5 0 \%}$ & 3.3 Traçado \\
\hline $\begin{array}{l}\text { Visibilidade e distância de } \\
\text { visibilidade }(1,2,3 \text { e } 4)\end{array}$ & $\mathrm{x}$ & $\mathrm{x}$ & $\mathrm{x}$ & $\mathrm{x}$ & $100 \%$ & $\begin{array}{l}\text { 3.4 Distância de } \\
\text { visibilidade }\end{array}$ \\
\hline 4. Objetos Físicos & 4. Objetos Físi & & & & Frequência & 4. Obstáculos fixos \\
\hline Postes ou outras obstruções (1) & $\mathrm{x}$ & & & & $25 \%$ & $\begin{array}{l}\text { 4.1 Postes ou outras } \\
\text { obstruções }\end{array}$ \\
\hline Divisórias centrais (1) & $\mathrm{x}$ & & & & $25 \%$ & 4.2 Dispositivos centrais \\
\hline 5. Usuários da Rodovia & 5. Usuários da & Rodovia & & & Frequência & 5. Usuários da Rodovia \\
\hline Veículos pesados $(1,2,3$ e 4$)$ & $\mathrm{x}$ & $\mathrm{x}$ & $\mathrm{x}$ & $\mathrm{x}$ & $100 \%$ & 5.1 Veículos pesados \\
\hline Transporte público $(1,2,3$ e 4$)$ & $\mathrm{x}$ & $\mathrm{x}$ & $\mathrm{x}$ & $\mathrm{x}$ & $100 \%$ & 5.2 Transporte público \\
\hline $\begin{array}{l}\text { Veículos de manutenção da } \\
\text { rodovia }(1,2,3 \text { e } 4)\end{array}$ & $\mathrm{x}$ & $\mathrm{x}$ & $\mathrm{x}$ & $\mathrm{x}$ & $100 \%$ & $\begin{array}{l}5.3 \quad \text { Veículos de } \\
\text { manutenção }\end{array}$ \\
\hline Veículos de emergência (1) & $\mathrm{x}$ & & & & $25 \%$ & $\begin{array}{l}\text { Não abordado como } \\
\text { macrocategoria }\end{array}$ \\
\hline Motociclistas (2, 3 e 4) & & $\mathrm{x}$ & $\mathrm{x}$ & $\mathrm{x}$ & $75 \%$ & 5.4 Motocicletas \\
\hline $\begin{array}{l}\text { Veículos lentos (veículos de } \\
\text { marcha lenta) (1) }\end{array}$ & $\mathrm{x}$ & & & & $25 \%$ & $\begin{array}{l}\text { Não abordado como } \\
\text { macrocategoria }\end{array}$ \\
\hline $\begin{array}{l}\text { Veículos para uso na neve - } \\
\text { Snow-mobiles and ATVs (1) }\end{array}$ & $\mathrm{x}$ & & & & $25 \%$ & $\begin{array}{l}\text { Não abordado como } \\
\text { macrocategoria }\end{array}$ \\
\hline \multicolumn{7}{|l|}{ * Veículos Não motorizados (1) } \\
\hline Ciclistas $(1,2,3$ e 4$)$ & $\mathrm{x}$ & $\mathrm{x}$ & $\mathrm{x}$ & $\mathrm{x}$ & $100 \%$ & 5.5 Ciclistas \\
\hline Pedestres $(1,2,34)$ & $\mathrm{x}$ & $\mathrm{x}$ & $\mathrm{x}$ & $\mathrm{x}$ & $100 \%$ & 5.6 Pedestres \\
\hline Areas adjacentes $(2,3)$ & & $\mathbf{x}$ & $\mathbf{x}$ & & $50 \%$ & 5.7 Entorno da rodovia \\
\hline $\begin{array}{l}\text { Cavaleiros e gado (ou animais) (2, } \\
3 \text { e } 4 \text { ) }\end{array}$ & & $\mathrm{x}$ & $\mathrm{x}$ & $\mathrm{x}$ & $75 \%$ & 5.8 Cavaleiros e gado \\
\hline
\end{tabular}


4. Mesocategorias das sinalição e iluminação, gestão de tráfego, perguntas adicionais e outras considerações

\begin{tabular}{|c|c|c|c|c|c|c|}
\hline Categorias - Mesocategorias & \begin{tabular}{|c} 
Hildebrand e \\
Wilson (1999)
\end{tabular} & $\begin{array}{c}\text { Castrillón e } \\
\text { Candia (2003) }\end{array}$ & $\begin{array}{l}\text { Austroads } \\
\text { (2009) }\end{array}$ & $\begin{array}{c}\text { RTMC (2012) } \\
\text { - Africa }\end{array}$ & Frequência & $\begin{array}{l}\text { Mesocategorias } \\
\text { propostas }\end{array}$ \\
\hline 6.Sinalização e Iluminação & \multicolumn{4}{|c|}{ 6.Sinalização e Iluminação } & Frequência & $\begin{array}{l}\text { 6. Sinalização e } \\
\text { Iluminação }\end{array}$ \\
\hline Sinalização Horizontal (2, 3 e 4) & & $\mathbf{x}$ & $\mathbf{x}$ & $\mathbf{x}$ & $75 \%$ & 6.1 Sinalização horizontal \\
\hline Sinalização vertical (2, 3 e 4$)$ & & $\mathrm{x}$ & $\mathrm{x}$ & $\mathrm{x}$ & $75 \%$ & 6.2 Sinalização vertical \\
\hline Iluminação (2, 3 e 4) & & $\mathrm{x}$ & $\mathrm{x}$ & $\mathrm{x}$ & $75 \%$ & 6.3 iluminação \\
\hline 7. Gestão de tráfego & \multicolumn{4}{|c|}{ 7. Gestão de tráfego } & Frequência & 7. Gestão de tráfego \\
\hline $\begin{array}{l}\text { fluxo de tráfego e restrições de acesso (2 } \\
\text { e 3) }\end{array}$ & & $\mathrm{x}$ & $\mathrm{x}$ & & $50 \%$ & $\begin{array}{l}\text { 7.1 Fluxo de tráfego e } \\
\text { gerenciamento de acesso }\end{array}$ \\
\hline ultrapassagem e fusões (2 e 3) & & $\mathrm{x}$ & $\mathrm{x}$ & & $50 \%$ & $\begin{array}{l}7.2 \text { ultrapassagens e } \\
\text { fusões }\end{array}$ \\
\hline $\begin{array}{l}\text { areas de descanso / áreas de parada ( } 2 \mathrm{e} \\
\text { 3) }\end{array}$ & & $\mathbf{x}$ & $\mathbf{x}$ & & $50 \%$ & 7.3 áreas de descanso \\
\hline Construção e operação (2 e 3) & & $\mathrm{x}$ & $\mathrm{x}$ & & $\mathbf{5 0} \%$ & $\begin{array}{l}7.4 \text { construção e } \\
\text { operação }\end{array}$ \\
\hline 8. Perguntas adicionais & \multicolumn{4}{|c|}{ 8. Perguntas adicionais } & Frequência & 8. Perguntas adicionais \\
\hline Alinhamento horizontal $(2,3)$ & & $\mathrm{x}$ & $\mathrm{x}$ & & $50 \%$ & $\begin{array}{l}8.1 \\
\text { horizontal }\end{array}$ \\
\hline Alinhamento vertical (2 e 3 ) & & $\mathbf{x}$ & $\mathbf{x}$ & & $\mathbf{5 0 \%}$ & 8.2 Alinhamento vertical \\
\hline Locais de estacionamento ( 2 e 3 ) & & $\mathbf{x}$ & $\mathrm{x}$ & & $\mathbf{5 0} \%$ & $\begin{array}{l}8.3 \quad \text { áreas de } \\
\text { estacionamento }\end{array}$ \\
\hline serviços (2 e 3) & & $\mathbf{x}$ & $\mathbf{x}$ & & $50 \%$ & 8.4 Serviços \\
\hline sinalização vertical e demarcações ( 2 e 3 ) & & $\mathbf{x}$ & $x$ & & $50 \%$ & $\begin{array}{l}\text { 8.5 Sinalização vertical e } \\
\text { sinalização horizontal }\end{array}$ \\
\hline Paisagismo (2 e 3) & & $\mathbf{x}$ & $\mathbf{x}$ & & $50 \%$ & 8.6 Paisagismo \\
\hline Gestão de tráfego (2 e 3) & & $\mathbf{x}$ & $\mathbf{x}$ & & $\mathbf{5 0 \%}$ & 8.7 gestão de tráfego \\
\hline Outros (2 e 3 ) & & $\mathbf{x}$ & $\mathbf{x}$ & & $50 \%$ & 8.8 Outros \\
\hline 9. Outras considerações & 9. Outras consi & derações & & & Frequência & 9. Outras considerações \\
\hline $\begin{array}{l}\text { Aspectos de segurança não } \\
\text { considerado }(2,3 \text { e } 4)\end{array}$ & & $\mathbf{x}$ & $\mathbf{x}$ & $\mathbf{x}$ & $75 \%$ & $\begin{array}{l}9.1 \text { Outros aspectos de } \\
\text { segurança } \\
\text { considerado }\end{array}$ \\
\hline turismo e recreação (1) & & & & $\mathrm{x}$ & $25 \%$ & $\begin{array}{l}\text { Não abordado como } \\
\text { macrocategoria }\end{array}$ \\
\hline gerenciamento de incidentes (1) & & & & $\mathrm{x}$ & $25 \%$ & $\begin{array}{l}\text { Não abordado como } \\
\text { macrocategoria }\end{array}$ \\
\hline
\end{tabular}




\section{ANEXO B3 - MESOCATEGORIA - PROJETO EXECUTIVO - ANÁLISE DA FREQUÊNCIA}

\section{Mesocategorias dos tópicos gerais}

\begin{tabular}{|c|c|c|c|c|c|c|}
\hline Categorias - mesocategorias & $\begin{array}{c}\text { Hildebrand e } \\
\text { Wilson } \\
\text { (1999) (1) }\end{array}$ & $\begin{array}{c}\text { Castrillón e } \\
\text { Candia (2003) } \\
\text { (2) }\end{array}$ & $\begin{array}{c}\text { AUSTROADS } \\
\text { (2009) (3) }\end{array}$ & $\begin{array}{c}\text { RTMC } \\
(2012)(4)\end{array}$ & \multirow[t]{2}{*}{ Frequência } & Mesocategorias propostas \\
\hline 1. Tópicos Gerais & \multicolumn{4}{|c|}{ 1. Tópicos Gerais } & & 1. Tópicos gerais \\
\hline $\begin{array}{l}\text { Alterações de auditorias anteriores ( } 1 \text {, } \\
2,3 \text { e } 4 \text { ) }\end{array}$ & $\mathbf{x}$ & $\mathbf{x}$ & $\mathbf{x}$ & $\mathbf{x}$ & $100 \%$ & 1.1 Auditorias anteriores \\
\hline Etapas de construção $(1,2$, e 3$)$ & $\mathbf{x}$ & $\mathbf{x}$ & $\mathbf{x}$ & & $75 \%$ & 1.2 Etapas da Construção \\
\hline $\begin{array}{l}\text { Facilidade de Interação da nova } \\
\text { rodovia / com a existente (1) }\end{array}$ & $\mathrm{x}$ & & & & $25 \%$ & $\begin{array}{l}\text { Não abordado como } \\
\text { macrocategoria }\end{array}$ \\
\hline Impacto sobre as redes adjacentes (1) & $\mathrm{x}$ & & & & $25 \%$ & $\begin{array}{l}\text { Não abordado como } \\
\text { macrocategoria }\end{array}$ \\
\hline Barreiras de tráfego (1) & $\mathrm{x}$ & & & & $25 \%$ & $\begin{array}{l}\text { Não abordado como } \\
\text { macrocategoria }\end{array}$ \\
\hline $\begin{array}{l}\text { Consistência dos parâmetros do } \\
\text { projeto (1) }\end{array}$ & $\mathrm{x}$ & & & & $25 \%$ & $\begin{array}{l}\text { Não abordado como } \\
\text { macrocategoria }\end{array}$ \\
\hline Drenagem $(2,3$ e 4$)$ & & $\mathbf{x}$ & $\mathbf{x}$ & $\mathbf{x}$ & $75 \%$ & 1.3 Drenagem \\
\hline Condições Climáticas (2, 3 e 4) & & $\mathbf{x}$ & $\mathbf{x}$ & $\mathbf{x}$ & $75 \%$ & 1.4 Condições climáticas \\
\hline Paisagismo (1, 2,3 e 4$)$ & $\mathbf{x}$ & $\mathbf{x}$ & $\mathbf{x}$ & $\mathbf{x}$ & $100 \%$ & 1.5 Paisagismo \\
\hline Entorno da Via (2) & & $\mathbf{x}$ & & & $25 \%$ & $\begin{array}{l}\text { Não abordado como } \\
\text { macrocategoria }\end{array}$ \\
\hline Serviços $(2,3$ e 4$)$ & & $\mathbf{x}$ & $\mathbf{x}$ & $\mathbf{x}$ & $75 \%$ & 1.6 Serviços \\
\hline $\begin{array}{l}\text { emergência, interrupções, acessos de } \\
\text { veículos de emergência e veículos de } \\
\text { serviço }(2,3 \text { e } 4)\end{array}$ & & $\mathbf{x}$ & $\mathbf{x}$ & $\mathbf{x}$ & $75 \%$ & $\begin{array}{l}1.7 \text { Acesso de veículos de } \\
\text { emergência }\end{array}$ \\
\hline $\begin{array}{l}\text { Ampliação e realinhamento futuro ou } \\
\text { futuro planejamento }(2,3 \mathrm{e} 4)\end{array}$ & & $\mathbf{x}$ & $\mathbf{x}$ & $\mathbf{x}$ & $75 \%$ & 1.8 Ampliação futura \\
\hline Etapas do projeto $(2,3 \mathrm{e} 4)$ & & $\mathbf{x}$ & $\mathbf{x}$ & $\mathbf{x}$ & $75 \%$ & 1.9 Etapas do projeto \\
\hline $\begin{array}{l}\text { Acesso a propriedades } \\
\text { desenvolvimento }(2,3 \mathrm{e} 4)\end{array}$ & & $\mathbf{x}$ & $\mathbf{x}$ & $\mathbf{x}$ & $75 \%$ & \\
\hline Desenvolvimento adjacente $(2,3$ e 4$)$ & & $\mathbf{x}$ & $\mathbf{x}$ & $\mathbf{x}$ & $75 \%$ & \\
\hline Estabilidade de corte e aterro ( 2 e 3 ) & & $\mathbf{x}$ & $\mathbf{x}$ & & $50 \%$ & $\begin{array}{l}1.11 \text { Estabilidade de corte } \\
\text { e aterro }\end{array}$ \\
\hline Resistência a derrapagem $(2,3$ e 4$)$ & & $\mathbf{x}$ & $\mathbf{x}$ & $\mathbf{x}$ & $75 \%$ & $\begin{array}{l}1.12 \text { Resistência a } \\
\text { derrapagem }\end{array}$ \\
\hline $\begin{array}{l}\text { Áreas de descanso ou áreas de } \\
\text { piquiniques (1) }\end{array}$ & $\mathrm{x}$ & & & & $25 \%$ & $\begin{array}{l}\text { Não abordado como } \\
\text { macrocategoria }\end{array}$ \\
\hline Manutenção (4) & & & & $\mathrm{x}$ & $25 \%$ & $\begin{array}{l}\text { Não abordado como } \\
\text { macrocategoria }\end{array}$ \\
\hline
\end{tabular}




\section{Mesocategorias de geometria}

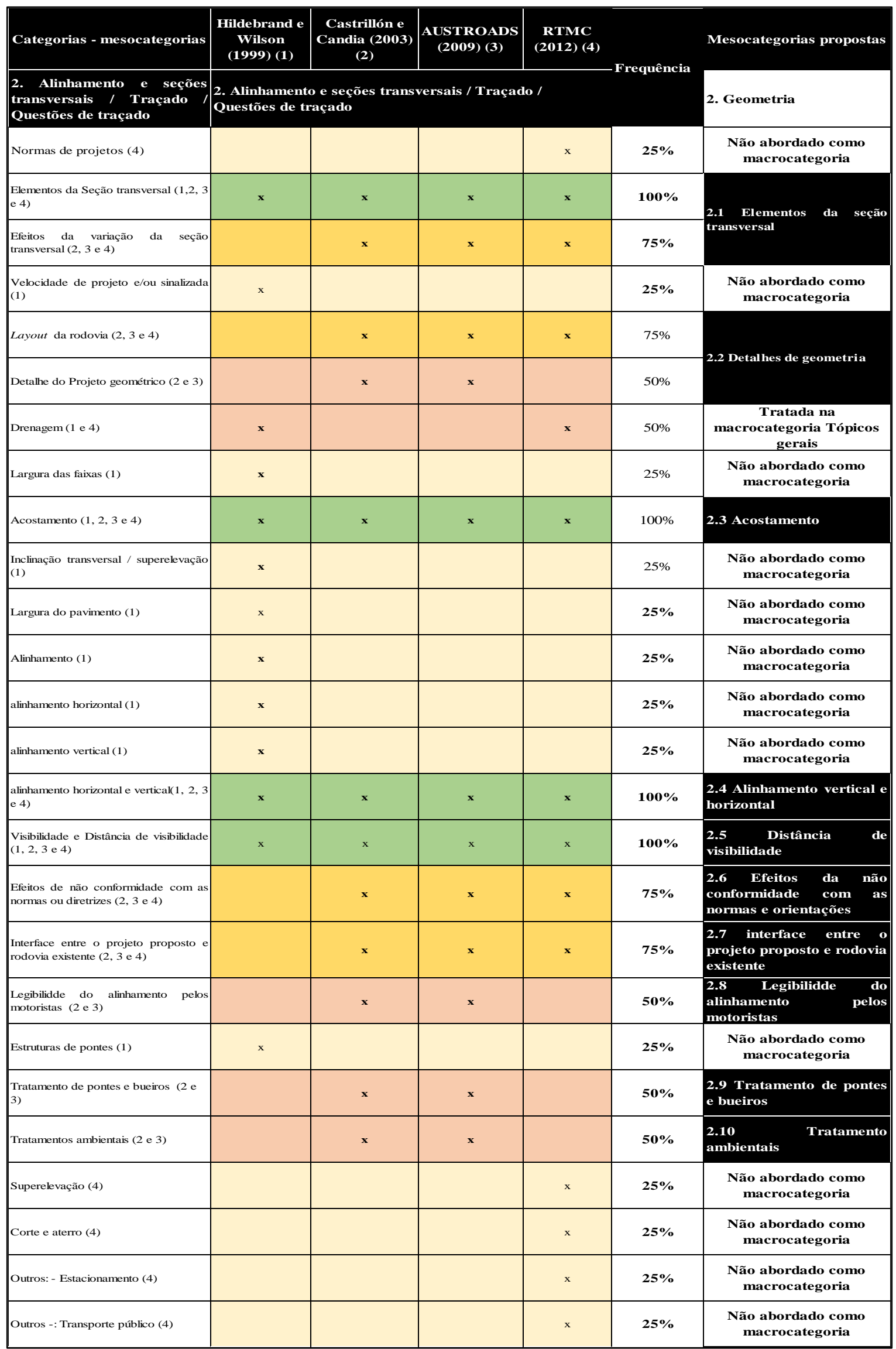




\section{Mesocategorias das interseções}

\begin{tabular}{|c|c|c|c|c|c|c|}
\hline Categorias - mesocategorias & \begin{tabular}{|c|} 
Hildebrand e \\
Wilson \\
$(1999)(1)$
\end{tabular} & $\begin{array}{c}\text { Castrillón e } \\
\text { Candia (2003) } \\
\text { (2) }\end{array}$ & $\begin{array}{c}\text { AUSTROADS } \\
\text { (2009) (3) }\end{array}$ & $\begin{array}{c}\text { RTMC } \\
(2012)(4)\end{array}$ & \multirow[t]{2}{*}{ Frequência } & Mesocategorias propostas \\
\hline 3. Interseções & \multicolumn{4}{|l|}{ 3. Interseções } & & 3. Interseções \\
\hline Localização e espaçmento (1) & $\mathrm{x}$ & & & & $25 \%$ & $\begin{array}{c}\text { Não abordado como } \\
\text { macrocategoria }\end{array}$ \\
\hline Distribuição ou Layout (1, 2, 3 e 4) & $\mathbf{x}$ & $\mathbf{x}$ & $\mathbf{x}$ & $\mathbf{x}$ & $100 \%$ & \\
\hline $\begin{array}{l}\text { Detalhes do projeto geométrico }(2,3 \mathrm{e} \\
\text { 4) }\end{array}$ & & $\mathbf{x}$ & $\mathbf{x}$ & $\mathbf{x}$ & $75 \%$ & localização \\
\hline Manobras (1) & $\mathbf{x}$ & & & & $25 \%$ & $\begin{array}{c}\text { Não abordado como } \\
\text { macrocategoria }\end{array}$ \\
\hline Faixas auxiliares e de conversão (1) & $\mathbf{x}$ & & & & $125 \%$ & $\begin{array}{c}\text { Não abordado como } \\
\text { macrocategoria }\end{array}$ \\
\hline Legibilidde pelos motoristas $(2,3$ e 4$)$ & & $\mathbf{x}$ & $\mathbf{x}$ & $\mathbf{x}$ & $75 \%$ & $\begin{array}{l}\text { 3.2 Legibilidade pelos } \\
\text { motoristas }\end{array}$ \\
\hline Visibilidade e conspicuidade (1) & $\mathrm{x}$ & & & & $25 \%$ & $\begin{array}{c}\text { Não abordado como } \\
\text { macrocategoria }\end{array}$ \\
\hline $\begin{array}{l}\text { Visibilidade e distância de visibilidade } \\
(1,2,3 \text { e } 4)\end{array}$ & $\mathrm{x}$ & $\mathrm{x}$ & $\mathrm{x}$ & $\mathrm{x}$ & $100 \%$ & $\begin{array}{l}\text { 3.3 Distância de } \\
\text { visibilidade }\end{array}$ \\
\hline Controle: de marcações (1) & $\mathrm{x}$ & & & & $25 \%$ & $\begin{array}{l}\text { Não abordado como } \\
\text { macrocategoria }\end{array}$ \\
\hline Controle de Sinalização Vertical (1) & $\mathrm{x}$ & & & & $25 \%$ & $\begin{array}{c}\text { Não abordado como } \\
\text { macrocategoria }\end{array}$ \\
\hline Controle semafórico (1, 2 e 3$)$ & $\mathbf{x}$ & $\mathbf{x}$ & $\mathbf{x}$ & & $75 \%$ & 3.4 Controle semafórico \\
\hline Controle das fases semafóricas (1) & $\mathrm{x}$ & & & & $25 \%$ & $\begin{array}{l}\text { Não abordado como } \\
\text { macrocategoria }\end{array}$ \\
\hline Advertências (1) & $\mathrm{x}$ & & & & $25 \%$ & $\begin{array}{l}\text { Não abordado como } \\
\text { macrocategoria }\end{array}$ \\
\hline Rotatórias (2, 3 e 4) & & $\mathbf{x}$ & $\mathbf{x}$ & $\mathbf{x}$ & $75 \%$ & 3.5 Rotatórias \\
\hline Outras interseções (2 e 3) & & $\mathbf{x}$ & $\mathbf{x}$ & & $\mathbf{5 0 \%}$ & 3.6 Outras interseções \\
\hline
\end{tabular}




\section{Mesocategorias das obstáculos fixos, usuários da rodovia}

\begin{tabular}{|c|c|c|c|c|c|c|}
\hline Categorias - mesocategorias & $\begin{array}{l}\text { Hildebrand e } \\
\text { Wilson } \\
\text { (1999) (1) }\end{array}$ & $\begin{array}{c}\text { Castrillón e } \\
\text { Candia (2003) } \\
\text { (2) }\end{array}$ & $\begin{array}{l}\text { AUSTROADS } \\
(2009)(3)\end{array}$ & $\begin{array}{c}\text { RTMC } \\
(2012)(4)\end{array}$ & \multirow[t]{2}{*}{ Frequência } & Mesocategorias propostas \\
\hline 4. Objetos Físicos & \multicolumn{4}{|c|}{ 4. Objetos Físicos } & & 4. Obstáculos Fixos \\
\hline Postes ou outras obstruções $(1,2,3)$ & $\mathbf{x}$ & $\mathbf{x}$ & $\mathbf{x}$ & & $75 \%$ & $\begin{array}{l}\text { 4.1 Postes ou outras } \\
\text { obstruções }\end{array}$ \\
\hline Divisórias centrais $(1,2,3)$ & $\mathbf{x}$ & $\mathbf{x}$ & $\mathbf{x}$ & & $75 \%$ & 4.2 Dispositivos centrais \\
\hline Proteção de objetos perigosos (1) & $\mathrm{x}$ & & & & $25 \%$ & $\begin{array}{l}\text { Não abordado como } \\
\text { macrocategoria }\end{array}$ \\
\hline Zona livre (1) & $\mathrm{x}$ & & & & $25 \%$ & $\begin{array}{l}\text { Não abordado como } \\
\text { macrocategoria }\end{array}$ \\
\hline Drenos (1) & $\mathrm{x}$ & & & & $25 \%$ & $\begin{array}{l}\text { Não abordado como } \\
\text { macrocategoria }\end{array}$ \\
\hline Cruzamentos com ferrovias (1) & $\mathrm{x}$ & & & & $25 \%$ & $\begin{array}{l}\text { Não abordado como } \\
\text { macrocategoria }\end{array}$ \\
\hline Barreiras de segurança $(2,3)$ & & $\mathbf{x}$ & $\mathbf{x}$ & & $50 \%$ & $\begin{array}{l}\text { 4.3 Barreiras de } \\
\text { segurança }\end{array}$ \\
\hline $\begin{array}{l}\text { Pontes, bueiros, cursos de água e } \\
\text { inundações }(2 \text { e } 3 \text { ) }\end{array}$ & & $\mathbf{x}$ & $\mathbf{x}$ & & $50 \%$ & $\begin{array}{l}4.4 \text { Pontes, Bueiros e } \\
\text { outros }\end{array}$ \\
\hline 5. Usuários da Rodovia & 5. Usuários da & Rodovia & & & Frequência & 5. Usuários da Rodovia \\
\hline Veículos pesados (1, 2, 3 e 4)) & $\mathrm{x}$ & $\mathrm{x}$ & $\mathrm{x}$ & $\mathrm{x}$ & $100 \%$ & 5.1 Veículos pesados \\
\hline Transporte público (1,2, 3 e 4) & $\mathrm{x}$ & $\mathrm{x}$ & $\mathrm{x}$ & $\mathrm{x}$ & $100 \%$ & 5.2 Transporte público \\
\hline Veículos de manutenção $(1,2,3$ e 4$)$ & $\mathrm{x}$ & $\mathrm{x}$ & $\mathrm{x}$ & $\mathrm{x}$ & $100 \%$ & $\begin{array}{l}5.3 \quad \text { Veículos } \\
\text { manutenção }\end{array}$ \\
\hline Veículos de emergência (1) & $\mathrm{x}$ & & & & $25 \%$ & $\begin{array}{l}\text { Não abordado como } \\
\text { macrocategoria }\end{array}$ \\
\hline Veículos lentos (1) & $\mathrm{x}$ & & & & $25 \%$ & $\begin{array}{l}\text { Não abordado como } \\
\text { macrocategoria }\end{array}$ \\
\hline $\begin{array}{l}\text { Veículos para uso na neve - Snow- } \\
\text { mobiles and ATVs (1) }\end{array}$ & $\mathrm{x}$ & & & & $25 \%$ & $\begin{array}{l}\text { Não abordado como } \\
\text { macrocategoria }\end{array}$ \\
\hline ciclistas $(1,2,3$ e 4$)$ & $\mathrm{x}$ & $\mathrm{x}$ & $\mathrm{x}$ & $\mathrm{x}$ & $100 \%$ & 5.4 ciclistas \\
\hline Pedestres (1, 2, 3 e 4$)$ & $\mathrm{x}$ & $\mathrm{x}$ & $\mathrm{x}$ & $\mathrm{x}$ & $100 \%$ & 5.5 Pedestres \\
\hline Terrenos adjacentes $(2,3)$ & & $\mathbf{x}$ & $\mathbf{x}$ & & $\mathbf{5 0 \%}$ & 5.6 Entorno da rodovia \\
\hline Motociclistas (2, 3 e 4$)$ & & $\mathrm{x}$ & $\mathrm{x}$ & $\mathrm{x}$ & $75 \%$ & 5.7 Motocicletas \\
\hline Cavaleros e gado ou animal (2,3 e 4$)$ & & $\mathrm{x}$ & $\mathrm{x}$ & $\mathrm{x}$ & $75 \%$ & $\begin{array}{l}5.8 \text { Travessia de animais } \\
\text { na pista }\end{array}$ \\
\hline
\end{tabular}




\section{Mesocategorias da sinalização e iluminação, perguntas adicionais e outras}

\section{considerações}

\begin{tabular}{|c|c|c|c|c|c|c|}
\hline Categorias - mesocategorias & $\begin{array}{l}\text { Hildebrand e } \\
\text { Wilson } \\
\text { (1999) (1) }\end{array}$ & $\begin{array}{c}\text { Castrillón e } \\
\text { Candia (2003) } \\
\text { (2) }\end{array}$ & $\begin{array}{c}\text { AUSTROADS } \\
(2009)(3)\end{array}$ & $\begin{array}{c}\text { RTMC } \\
(2012)(4)\end{array}$ & \multirow{2}{*}{ Frequência } & Mesocategorias propostas \\
\hline $\begin{array}{l}\text { 6.Sinalização e Iluminação / } \\
\text { recursos visuais }\end{array}$ & \multicolumn{4}{|c|}{ 6.Sinalização e Iluminação / recursos visuais } & & $\begin{array}{l}\text { 6. Sinalização e } \\
\text { Iluminação }\end{array}$ \\
\hline Marcas no pavimento (1 e 4) & $\mathrm{x}$ & & & $\mathrm{x}$ & $50 \%$ & \\
\hline $\begin{array}{l}\text { Demarcações e delineamento }(1,2 \text { e } \\
\text { 3) }\end{array}$ & $\mathbf{x}$ & $\mathbf{x}$ & $\mathbf{x}$ & & $75 \%$ & \\
\hline Sinalização vertical $(1,2,3$ e 4$)$ & $\mathrm{x}$ & $\mathrm{x}$ & $\mathrm{x}$ & $\mathrm{x}$ & $100 \%$ & 6.2 Sinalização vertical \\
\hline Iluminação (1, 2, 3 e 4$)$ & $\mathrm{x}$ & $\mathrm{x}$ & $\mathrm{x}$ & $\mathrm{x}$ & $100 \%$ & 6.3 iluminação \\
\hline Sinalização Semafórica (4) & & & & $\mathrm{x}$ & $25 \%$ & $\begin{array}{l}\text { Não abordado como } \\
\text { macrocategoria }\end{array}$ \\
\hline $\begin{array}{l}\text { 7. Perguntas adicionais para } \\
\text { ser consideradas para o } \\
\text { desenvolvimento proposto }\end{array}$ & $\begin{array}{l}\text { 7. Perguntas } \\
\text { desenvolvimen }\end{array}$ & $\begin{array}{l}\text { adicionais par: } \\
\text { to proposto }\end{array}$ & a ser consider & idas para o & Frequência & 7. Perguntas adicionais \\
\hline Alinhamento horizontal $(2,3)$ & & $\mathbf{x}$ & $\mathbf{x}$ & & $50 \%$ & $\begin{array}{l}7.1 \quad \text { Alinhamento } \\
\text { horizontal }\end{array}$ \\
\hline Alinhamento vertical (2 e 3) & & $\mathbf{x}$ & $\mathbf{x}$ & & $\mathbf{5 0 \%}$ & 7.2 Alinhamento vertical \\
\hline Locais de estacionamento ( 2 e 3 ) & & $\mathbf{x}$ & $\mathbf{x}$ & & $50 \%$ & $\begin{array}{l}7.3 \quad \text { áreas de } \\
\text { estacionamento }\end{array}$ \\
\hline serviços (2 e 3$)$ & & $\mathbf{x}$ & $\mathbf{x}$ & & $\mathbf{5 0 \%}$ & 7.4 Serviços \\
\hline $\begin{array}{l}\text { sinalização vertical e demarcações (2 e } \\
\text { 3) }\end{array}$ & & $\mathbf{x}$ & $\mathbf{x}$ & & $50 \%$ & $\begin{array}{l}7.5 \text { Sinalização vertical e } \\
\text { Sinalização horizontal }\end{array}$ \\
\hline Entorno da via ou Paisagismo(2 e 3 ) & & $\mathbf{x}$ & $\mathbf{x}$ & & $\mathbf{5 0 \%}$ & $\begin{array}{l}\text { 7.6 Vegetação no entorno } \\
\text { da via }\end{array}$ \\
\hline Gestão de tráfego (2 e 3) & & $\mathbf{x}$ & $\mathbf{x}$ & & $\mathbf{5 0 \%}$ & 7.7 gestão de tráfego \\
\hline Outras (2 e 3) & & $\mathbf{x}$ & $\mathbf{x}$ & & $\mathbf{5 0 \%}$ & 7.8 Outros \\
\hline 8. Outras considerações & 8. Outras con & siderações & & & Frequência & 8. Outras considerações \\
\hline $\begin{array}{l}\text { Aspectos de segurança não abordado } \\
(2 \text { e 3) }\end{array}$ & & $\mathbf{x}$ & $\mathbf{x}$ & & $\mathbf{5 0} \%$ & $\begin{array}{l}\text { 8.1 Outros aspectos de } \\
\text { segurança não abordado }\end{array}$ \\
\hline Turismo e recreação & & & & $\mathrm{x}$ & $25 \%$ & \\
\hline
\end{tabular}


APÊNDICE C1 - ANÁLISE DA FREQUÊNCIA - MICROCATEGORIA - ESTUDO DE VIABILIDADE

\begin{tabular}{|c|c|c|c|c|c|c|c|}
\hline $\begin{array}{c}\text { Macro e } \\
\text { mesocategorias }\end{array}$ & Microcategorias & \begin{tabular}{|c|}
$\begin{array}{c}\text { Hildebran } \\
\text { d e Wilson } \\
(1999)-1\end{array}$ \\
\end{tabular} & \begin{tabular}{|c|} 
Castrillón e \\
Candia (2003) \\
-2 \\
\end{tabular} & $\begin{array}{l}\text { Austroads } \\
(2009)-3\end{array}$ & $\begin{array}{c}\text { RTMC } \\
(2012)-4\end{array}$ & Frequência & $\begin{array}{c}\text { Macro e } \\
\text { Mesocategoria } \\
\text { Proposta } \\
\end{array}$ \\
\hline 1. Tópicos Gerais & 1. Tópicos Gerais & \multicolumn{4}{|c|}{ 1. Tópicos Gerais } & Frequência & 1. Tópicos gerais \\
\hline \multirow{6}{*}{$\begin{array}{l}\text { Finalidade (1) } \\
\text { Aspectos gerais, } \\
\text { função e composição } \\
\text { do tráfego previsto } \\
\quad(2,3 \text { e } 4)\end{array}$} & $\begin{array}{l}\text { Verificar toda documentação pertinente do escopo do projeto, } \\
\text { destacando os objetivos do projeto, características do usuário, } \\
\text { veículos de projetos, projetos de acessos, características das áreas } \\
\text { adjacentes, informações de redes existentes e projetos de futuras } \\
\text { expansões. }\end{array}$ & $\mathbf{x}$ & & & & $25 \%$ & \multirow{10}{*}{$\begin{array}{l}\text { 1.1 Finalidade do } \\
\text { projeto }\end{array}$} \\
\hline & Qual é a função do projeto previsto? & & $\mathbf{x}$ & $\mathbf{x}$ & $\mathbf{x}$ & $75 \%$ & \\
\hline & O projeto é compatível com a função da rodovia? & & $\mathbf{x}$ & $\mathbf{x}$ & $\mathbf{x}$ & $75 \%$ & \\
\hline & $\begin{array}{l}\text { O projeto proposto (ou reprojeto) enfatiza a segurança } \\
\text { adequadamente dos automóveis - motociclistas - ciclistas - } \\
\text { pedestres - veículos pesados e ônibus? }\end{array}$ & & $\mathbf{x}$ & $\mathbf{x}$ & $\mathbf{x}$ & $75 \%$ & \\
\hline & $\begin{array}{l}\text { Foram considerados adequadamente a composição do tráfego } \\
\text { esperado? }\end{array}$ & & $\mathbf{x}$ & $\mathbf{x}$ & $\mathbf{x}$ & $75 \%$ & \\
\hline & $\begin{array}{l}\text { Será que o projeto proposto está compatível com as rodovias } \\
\text { adjacentes, topografia e a gestão de trânsito? }\end{array}$ & & $\mathbf{x}$ & $\mathbf{x}$ & $\mathbf{x}$ & $75 \%$ & \\
\hline \multirow{4}{*}{$\begin{array}{c}\text { Etapas de } \\
\text { construção }(1,2,3 \mathrm{e} \\
\text { 4) }\end{array}$} & $\begin{array}{l}\text { Quais são os efeitos da realização da construção do projeto com um } \\
\text { único contrato ou dividindo-a em vários contratos? }\end{array}$ & $\mathbf{x}$ & & & & $25 \%$ & \\
\hline & O projeto será implementado em uma única etapa de construção? & & $\mathbf{x}$ & $\mathbf{x}$ & $\mathbf{x}$ & $75 \%$ & \\
\hline & $\begin{array}{l}\text { Se o projeto for implementado em mais de uma etapa, foi dada a } \\
\text { prioridade de segurança: nas transições de etapas; e nas transições } \\
\text { com rodovias existentes. }\end{array}$ & & $\mathbf{x}$ & $\mathbf{x}$ & $\mathbf{x}$ & $75 \%$ & \\
\hline & $\begin{array}{l}\text { O trabalho irá evitar problemas com as normas de segurança durante } \\
\text { a construção? }\end{array}$ & & $\mathbf{x}$ & $\mathbf{x}$ & $\mathbf{x}$ & $75 \%$ & \\
\hline
\end{tabular}




\begin{tabular}{|c|c|c|c|c|c|c|c|}
\hline \multirow{6}{*}{$\begin{array}{l}\text { Principais geradores } \\
\text { de tráfego }(2,3 \text { e } 4)\end{array}$} & $\begin{array}{l}\text { Os principais geradores de tráfego (incluindo a habitação ou } \\
\text { centros comerciais) estão longe o suficiente para evitar influências } \\
\text { de insegurança sobre a forma do traçado? Se sim, foram previstos } \\
\text { ações mitigadoras? }\end{array}$ & & $\mathbf{x}$ & $\mathbf{x}$ & $\mathbf{x}$ & $75 \%$ & \multirow{6}{*}{$\begin{array}{c}1.2 \\
\text { Características } \\
\text { técnicas do } \\
\text { projeto }\end{array}$} \\
\hline & $\begin{array}{l}\text { Foram tratados os acessos existentes ou alternativos, de modo a não } \\
\text { prejudicar o subúrbio existente? }\end{array}$ & & $\mathbf{x}$ & & & $25 \%$ & \\
\hline & $\begin{array}{l}\text { Está previsto acessos alternativos para assegurar que subúrbios ou } \\
\text { subáreas existentes não ficaram isolados / devidos as áreas não } \\
\text { serem cortadas pelo desenvolvimento do trabalho / obras? }\end{array}$ & & $\mathbf{x}$ & $\mathbf{x}$ & $\mathbf{x}$ & $75 \%$ & \\
\hline & $\begin{array}{l}\text { Os acessos para os geradores de tráfego estão significativamente } \\
\text { longe das interseções para fornecer a segurança? }\end{array}$ & & $\mathbf{x}$ & $\mathbf{x}$ & & $50 \%$ & \\
\hline & $\begin{array}{l}\text { A distância de visibilidade dos acessos para os geradores de tráfego } \\
\text { estão adequadas? }\end{array}$ & & $\mathbf{x}$ & $\mathbf{x}$ & & $50 \%$ & \\
\hline & $\begin{array}{l}\text { Será que o projeto proposto é coerente com as estradas adjacentes, } \\
\text { formas do relevo (topografia) e gestão de tráfego? }\end{array}$ & & $\mathbf{x}$ & $\mathbf{x}$ & $\mathbf{x}$ & $75 \%$ & \\
\hline \multirow{6}{*}{$\begin{array}{l}\text { Tipos e controle de } \\
\text { acesso às propriedade } \\
\text { e desenvolvimento }(1, \\
2,3 \text { e 4) }\end{array}$} & $\begin{array}{l}\text { Existem fatores a montante ou a jusante que poderão afetar o } \\
\text { acesso? }\end{array}$ & $\mathbf{x}$ & & & & $25 \%$ & \multirow{6}{*}{$\begin{array}{l}1.3 \text { Acessos e } \\
\text { áreas adjacentes }\end{array}$} \\
\hline & $\begin{array}{l}\text { Existe poluição visual (outdoor com propagandas comerciais ou } \\
\text { iluminação excessiva) próximo as linhas de passagens? }\end{array}$ & $\mathbf{x}$ & & & & $25 \%$ & \\
\hline & $\begin{array}{l}\text { O controle dos acessos é compatível com a função e com outras } \\
\text { seções da rodovia? }\end{array}$ & & $\mathrm{X}$ & $\mathrm{x}$ & $\mathrm{x}$ & $75 \%$ & \\
\hline & $\begin{array}{l}\text { A distância de visibilidade é satisfatória: nas interseções e acesso ás } \\
\text { propriedades? }\end{array}$ & & $\mathrm{x}$ & $\mathrm{x}$ & $\mathrm{x}$ & $75 \%$ & \\
\hline & $\begin{array}{l}\text { A velocidade de projeto (ou a velocidade de operação dos veículos) } \\
\text { é compatível com número e o tipo de interseções / e acessos a } \\
\text { propriedades adjacentes? }\end{array}$ & & $\mathrm{x}$ & $\mathrm{x}$ & $\mathrm{x}$ & $75 \%$ & \\
\hline & $\begin{array}{l}\text { A largura da faixa de direito de passagem atende aos requisitos } \\
\text { necessários a acessibilidade? }\end{array}$ & $\mathrm{x}$ & $\mathrm{x}$ & $\mathrm{x}$ & $\mathrm{x}$ & $100 \%$ & \\
\hline $\begin{array}{l}\text { Amplos impactos da } \\
\text { rede rodoviária }(2,3 \\
\text { e 4) }\end{array}$ & $\begin{array}{l}\text { Efeitos negativos do projeto sobre as vias adjacentes, foram } \\
\text { identificados? E foram tratados adequadamente? }\end{array}$ & & $\mathrm{X}$ & $\mathrm{x}$ & $\mathrm{x}$ & $75 \%$ & $\begin{array}{l}1.4 \text { Impactos do } \\
\text { projeto proposto }\end{array}$ \\
\hline $\begin{array}{l}\text { Futuros Trabalhos } \\
(2,3 \text { e } 4)\end{array}$ & $\begin{array}{l}\text { O traçado não afetará o nível de segurança, se houver: futuro } \\
\text { alargamento?; a adição de um segunda faixa de sentido completo?; } \\
\text { após alinhamento?; principais alterações geométricas nas } \\
\text { interseções? E extensões lineares do projeto?. }\end{array}$ & & $\mathrm{x}$ & $\mathrm{x}$ & $\mathrm{x}$ & $75 \%$ & $\begin{array}{l}1.5 \text { Obras de } \\
\text { Melhoramentos }\end{array}$ \\
\hline
\end{tabular}




\begin{tabular}{|c|c|c|c|c|c|c|c|}
\hline $\begin{array}{l}\text { 2. Alinhamento e } \\
\text { seções transversais / } \\
\text { Traçado / Questões }\end{array}$ & $\begin{array}{l}\text { 2. Alinhamento e seções transversais / Traçado / Questões de } \\
\text { traçado }\end{array}$ & 2. A & ues & ers & do $/$ & Frequência & 2. Geometria \\
\hline \multirow{10}{*}{$\begin{array}{l}\text { Traçado proposto }(1, \\
2,3 \text { e 4) }\end{array}$} & $\begin{array}{l}\text { São seguras todos os aspectos relacionados com a localização do } \\
\text { traçado e/ou alinhamento? }\end{array}$ & & $\mathrm{x}$ & $\mathrm{x}$ & $\mathrm{x}$ & $75 \%$ & \multirow{14}{*}{$\begin{array}{l}\text { 2.1 Traçado e } \\
\text { alinhamento }\end{array}$} \\
\hline & $\begin{array}{l}\text { Se o traçado é projetado sobre uma rota existente, quais são os } \\
\text { efeitos dele? }\end{array}$ & & $\mathrm{x}$ & $\mathrm{x}$ & & $50 \%$ & \\
\hline & $\begin{array}{l}\text { Se o traçado é em (corredor subdesenvolvido ou sem construções) } \\
\text { "áreas verdes", o alinhamento é seguro? Poderia ser mais seguro? }\end{array}$ & & $\mathrm{x}$ & $\mathrm{x}$ & & $50 \%$ & \\
\hline & o projeto está de acordo com as limitações físicas da paisagem? & & $\mathrm{x}$ & $\mathrm{x}$ & $\mathrm{x}$ & $75 \%$ & \\
\hline & $\begin{array}{l}\text { o projeto leva em conta as considerações da rede principal } \\
\text { (existente)? }\end{array}$ & & $\mathrm{x}$ & $\mathrm{x}$ & $\mathrm{x}$ & $75 \%$ & \\
\hline & O projeto se encaixa com segurança com a rede viária existente? & & & & $\mathrm{x}$ & $25 \%$ & \\
\hline & $\begin{array}{l}\text { Se o traçado é novo, o alinhamento é seguro? Poderia ser mais } \\
\text { seguro? }\end{array}$ & & & & $\mathrm{x}$ & $25 \%$ & \\
\hline & As curvas horizontais e verticais são suaves? & $\mathrm{x}$ & & & & $25 \%$ & \\
\hline & $\begin{array}{l}\text { Rampas excessivas afetam a operações de veículos pesados e níveis } \\
\text { de serviço? }\end{array}$ & $\mathrm{x}$ & & & & $25 \%$ & \\
\hline & $\begin{array}{l}\text { Verifique se há curvas horizontais de raios pequenos localizadas no } \\
\text { final de longas tangentes. }\end{array}$ & $\mathrm{x}$ & & & & $25 \%$ & \\
\hline \multirow{3}{*}{$\begin{array}{c}\text { Composição do } \\
\text { tráfego e volume de } \\
\text { tráfego }(2,3 \text { e 4) }\end{array}$} & $\begin{array}{l}\text { O projeto é adequado no que diz respeito à composição e fluxo de } \\
\text { tráfego (incluindo os efeitos da relação incomum de veículos } \\
\text { pesados, bicicletas e pedestres ou efeitos de atrito lateral)? }\end{array}$ & & $\mathrm{x}$ & $\mathrm{x}$ & $\mathrm{x}$ & $75 \%$ & \\
\hline & $\begin{array}{l}\text { O projeto prevê acomodação segura com os imprevistos com o } \\
\text { aumento no volume do tráfego? }\end{array}$ & & $\mathrm{x}$ & $\mathrm{x}$ & $\mathrm{x}$ & $75 \%$ & \\
\hline & $\begin{array}{l}\text { O projeto prevê segurança com mudanças imprevistas na } \\
\text { composição do volume de tráfego? }\end{array}$ & & $\mathrm{x}$ & $\mathrm{x}$ & $\mathrm{x}$ & $75 \%$ & \\
\hline $\begin{array}{c}\text { Impactos da } \\
\text { continuidade com a } \\
\text { rede rodoviária } \\
\text { existente }(2,3 \text { e } 4)\end{array}$ & $\begin{array}{l}\text { As seções e transições do traçado proposto estão livres de potenciais } \\
\text { problemas na conexão com a rede viária existente? }\end{array}$ & & $\mathrm{x}$ & $\mathrm{x}$ & $\mathrm{x}$ & $75 \%$ & \\
\hline
\end{tabular}




\begin{tabular}{|c|c|c|c|c|c|c|c|}
\hline \multirow{4}{*}{$\begin{array}{l}\text { Padrões gerais do } \\
\text { projeto }(2,3 \text { e } 4)\end{array}$} & $\begin{array}{l}\text { As normas de projeto foram utilizadas apropriadamente (levando } \\
\text { em conta as características do projeto e seu papel na relação com a } \\
\text { composição do fluxo de tráfego, (os usuários da rodovia que } \\
\text { utilizarão / ser influenciado pelo projetos)? }\end{array}$ & & $\mathrm{x}$ & $\mathrm{x}$ & $\mathrm{x}$ & $75 \%$ & \multirow{4}{*}{$\begin{array}{l}\text { 2.2 Elementos } \\
\text { gerais de projeto }\end{array}$} \\
\hline & $\begin{array}{l}\text { O perfil e a geometria estão em conformidade com as diretrizes do } \\
\text { projeto? }\end{array}$ & & $\mathrm{x}$ & $\mathrm{x}$ & $\mathrm{x}$ & $75 \%$ & \\
\hline & $\begin{array}{l}\text { O projeto considerou os tipos de veículos para os quais está previsto } \\
\text { o seu uso? }\end{array}$ & & $\mathrm{x}$ & $\mathrm{x}$ & $\mathrm{x}$ & $75 \%$ & \\
\hline & $\begin{array}{l}\text { A seção transversal proposta permiti fornecer uma estrada que } \\
\text { perdoa com a velocidade de projeto? }\end{array}$ & & & & $\mathrm{x}$ & $25 \%$ & \\
\hline \multirow{8}{*}{$\begin{array}{c}\text { Velocidade de } \\
\text { projeto e/ou } \\
\text { velocidade sinalizada } \\
(1,2,3 \text { e 4) }\end{array}$} & $\begin{array}{l}\text { A velocidade de projeto está adequada com: Alinhamento vertical, } \\
\text { horizontal, visibilidade, acessos, entre cruzamentos, aceleração e } \\
\text { desaceleração do fluxo de veículos nos cruzamento, composição do } \\
\text { tráfego previsto? }\end{array}$ & $\mathrm{x}$ & $\mathrm{x}$ & $\mathrm{x}$ & $\mathrm{x}$ & $100 \%$ & \multirow{8}{*}{2.3 Velocidades } \\
\hline & $\begin{array}{l}\text { A distância de visibilidade é satisfatória para: interseções? Entrada } \\
\text { e saída das rampas? Entradas de propriedades adjacentes? Em } \\
\text { entradas de acesso de veículos de emergência? }\end{array}$ & & $\mathrm{x}$ & $\mathrm{x}$ & $\mathrm{x}$ & $75 \%$ & \\
\hline & $\begin{array}{l}\text { Pode haver qualquer mudança no limite de velocidade com } \\
\text { segurança? }\end{array}$ & & $\mathrm{x}$ & $\mathrm{x}$ & $\mathrm{x}$ & $75 \%$ & \\
\hline & $\begin{array}{l}\text { A velocidade de projeto e o limite de velocidade são adequadas para } \\
\text { a rodovia ou parte dela? }\end{array}$ & & $\mathrm{x}$ & $\mathrm{x}$ & $\mathrm{x}$ & $75 \%$ & \\
\hline & $\begin{array}{l}\text { O limite de velocidade projeto, está de acordo com a velocidade de } \\
\text { sinalizada? }\end{array}$ & & $\mathrm{x}$ & $\mathrm{x}$ & $\mathrm{x}$ & $75 \%$ & \\
\hline & $\begin{array}{l}\text { Verifique a continuidade da velocidade de projeto e da velocidade } \\
\text { regulamentada. }\end{array}$ & $\mathrm{x}$ & & & & $25 \%$ & \\
\hline & Nas curvas a velocidade regulamentada é adequada? & $\mathrm{x}$ & & & & $25 \%$ & \\
\hline & O tráfego segue a velocidade regulamentada? & $\mathrm{x}$ & & & & $25 \%$ & \\
\hline 3. Interseções & 3. Interseções & \multicolumn{4}{|c|}{ 3. Interseções } & Frequência & 3. Interseções \\
\hline \multirow{2}{*}{ Quantidade e tipo (1) } & $\begin{array}{l}\text { O número de interseções são apropriadas para o entorno da rede } \\
\text { viária? }\end{array}$ & $\mathrm{x}$ & & & & $25 \%$ & \multirow{2}{*}{$\begin{array}{l}\text { 3.1 Quantidade, } \\
\text { tipo e localização }\end{array}$} \\
\hline & $\begin{array}{l}\text { Os tipos de interseções selecionadas são adequados para tráfego e } \\
\text { aspectos de segurança do projeto? }\end{array}$ & $\mathrm{x}$ & & & & $25 \%$ & \\
\hline
\end{tabular}




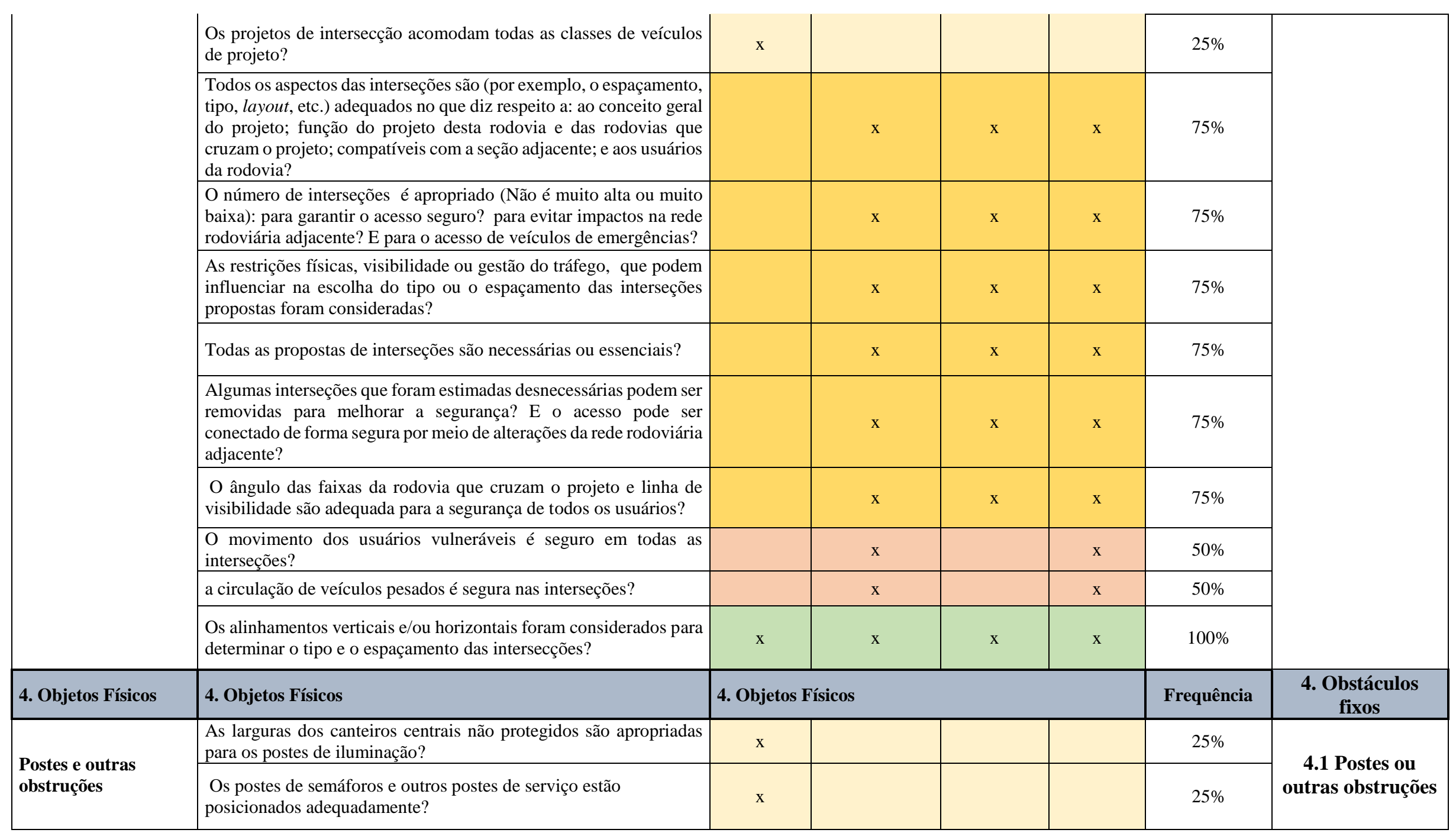




\begin{tabular}{|c|c|c|c|c|c|c|c|}
\hline & $\begin{array}{l}\text { Foi considerada localização de serviços e outras utilidades em } \\
\text { relação ao projeto (ou seja, enterrado ou subterrâneo) com vão para } \\
\text { cabos aéreos? }\end{array}$ & $\mathrm{x}$ & & & & $25 \%$ & \\
\hline \multirow{8}{*}{ Divisórias centrais } & $\begin{array}{l}\text { O tipo de divisória central escolhido é apropriado para a largura } \\
\text { disponível? }\end{array}$ & $\mathrm{x}$ & & & & $25 \%$ & \multirow{8}{*}{$\begin{array}{l}\text { 4.2 Dispositivos } \\
\text { centrais }\end{array}$} \\
\hline & As barreiras possuem configuração geométrica adequada? & $\mathrm{x}$ & & & & $25 \%$ & \\
\hline & As inclinações dos canteiros de grama estão adequadas? & $\mathrm{x}$ & & & & $25 \%$ & \\
\hline & As barreiras centrais estão suficientemente afastadas da rodovia? & $\mathrm{x}$ & & & & $25 \%$ & \\
\hline & $\begin{array}{l}\text { O afastamento entre as barreiras centrais está dentro dos limites } \\
\text { corretos? }\end{array}$ & $\mathrm{x}$ & & & & $25 \%$ & \\
\hline & $\begin{array}{l}\text { As barreiras laterais e das pontes estão de acordo com o nível de } \\
\text { desempenho dos testes de colisões para a classificação da rodovia? }\end{array}$ & $\mathrm{x}$ & & & & $25 \%$ & \\
\hline & $\begin{array}{l}\text { Existe largura suficiente para pilares dos viadutos, passagem } \\
\text { subterrânea e iluminação? }\end{array}$ & $\mathrm{x}$ & & & & $25 \%$ & \\
\hline & $\begin{array}{l}\text { Verificar o espaçamento apropriado entre travessias de divisórias } \\
\text { centrais? }\end{array}$ & $\mathrm{x}$ & & & & $25 \%$ & \\
\hline \begin{tabular}{|c|} 
5. Considerações \\
ambientais / Restrições \\
Ambientais
\end{tabular} & 5. Considerações ambientais / Restrições Ambientais & \multicolumn{4}{|c|}{ 5. Considerações ambientais / Restrições Ambientais } & Frequência & $\begin{array}{l}\text { 5. Aspectos } \\
\text { ambientais }\end{array}$ \\
\hline \multirow{6}{*}{$\begin{array}{c}\text { Clima(1), Animal (1) } \\
\text { Aspectos de } \\
\text { segurança ou } \\
\text { características físicas } \\
\text { do terrenos }(2,3 \text { e } 4)\end{array}$} & $\begin{array}{l}\text { Verifique os efeitos da chuva, neblina, neve, gelo, vento sobre } \\
\text { características na concepção do projeto. }\end{array}$ & $\mathrm{x}$ & $\mathrm{x}$ & & & $50 \%$ & \\
\hline & $\begin{array}{l}\text { Existem animais nas rotas de viagens / ou migração conhecidas em } \\
\text { áreas que poderiam afetar o entorno com o projeto? }\end{array}$ & & $\mathrm{x}$ & $\mathrm{x}$ & $\mathrm{x}$ & $75 \%$ & \\
\hline & $\begin{array}{l}\text { O terreno do entorno da rodovia está livre de objetos físicos ou vegetação } \\
\text { que poderiam afetar a segurança do projeto? ( por exemplo, grandes cultivos, } \\
\text { florestas, cortes profundos (barrancos) cortes elevados, ou áreas rochosas } \\
\text { que podem restringir o projeto. }\end{array}$ & & $\mathrm{x}$ & $\mathrm{x}$ & $\mathrm{x}$ & $75 \%$ & \\
\hline & $\begin{array}{l}\text { Os declives, as curvas e projeto de acesso em geral foram } \\
\text { considerados as condições de tempo ou condições ambientais do } \\
\text { terreno? (como por exemplo, áreas propensas a nevoeiro) }\end{array}$ & & $\mathrm{x}$ & $\mathrm{x}$ & $\mathrm{x}$ & $75 \%$ & \\
\hline & $\begin{array}{l}\text { A segurança foi considerada em lugares com determinadas } \\
\text { características ambientais? (por exemplo, cercas de ruídos) }\end{array}$ & & $\mathrm{x}$ & $\mathrm{x}$ & $\mathrm{x}$ & $75 \%$ & \\
\hline & $\begin{array}{l}\text { Projeto irá operar com segurança em condições ambientais } \\
\text { adversas, como a noite, com neblina ou estrada molhada? }\end{array}$ & & $\mathrm{x}$ & $\mathrm{x}$ & $\mathrm{x}$ & $75 \%$ & \\
\hline
\end{tabular}




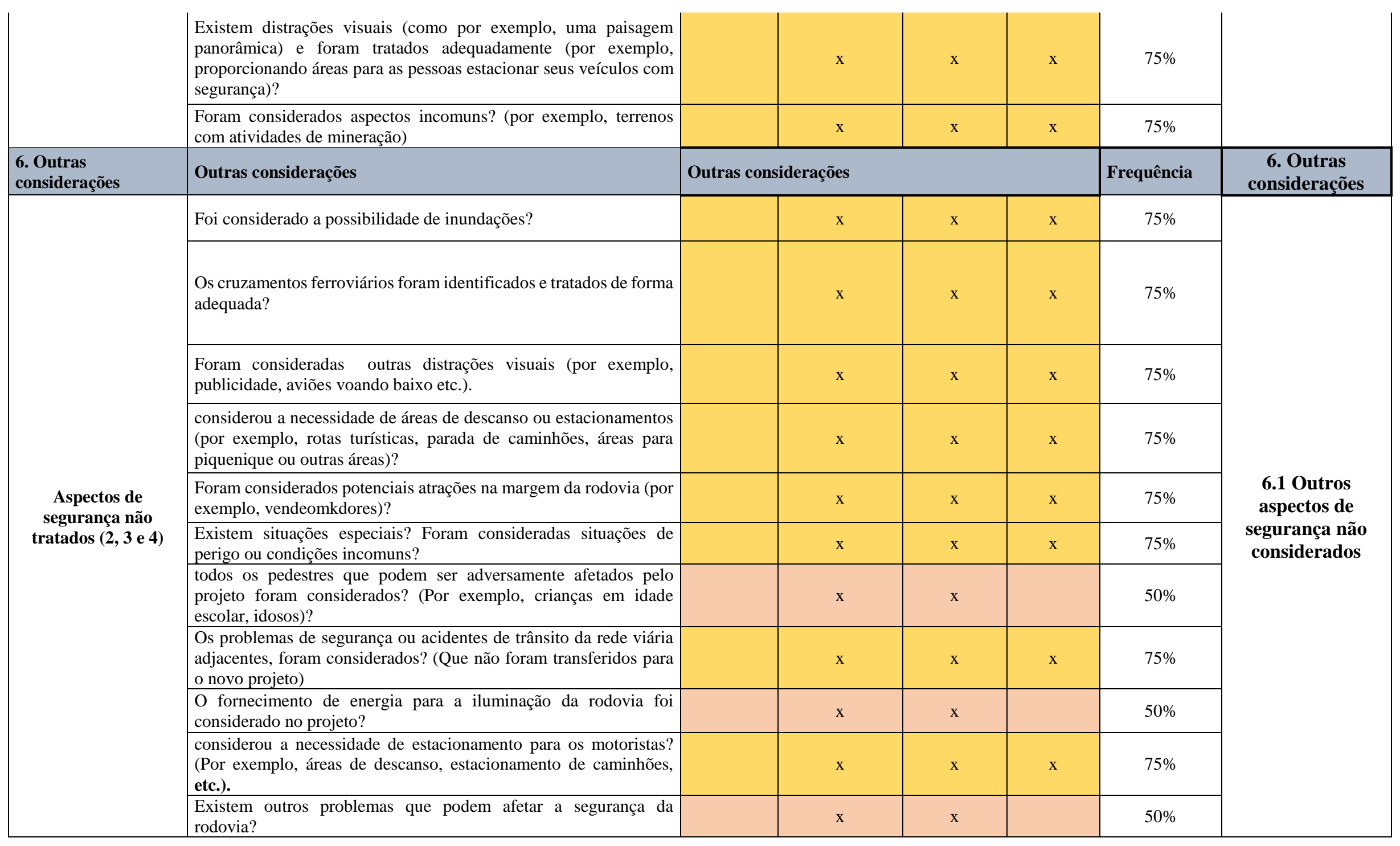




\section{APÊNDICE C2- MICROCATEGORIA - PROJETO BÁSICO - ANÁLISE DE FREQUÊNCIA}

\begin{tabular}{|c|c|c|c|c|c|c|}
\hline Macro e mesocategorias & Microcategorias & $\begin{array}{l}\text { Hildebrand e } \\
\text { Wilson (1999) }\end{array}$ & $\begin{array}{l}\text { Castrillón e } \\
\text { Candia (2003) }\end{array}$ & Austroads (2009) & $\begin{array}{c}\text { RTMC } \\
(\mathbf{2 0 1 2})\end{array}$ & Frequência \\
\hline 1. Tópicos Gerais & 1. Tópicos Gerais & \multicolumn{4}{|c|}{ 1. Tópicos Gerais } & Frequência \\
\hline \multirow{2}{*}{$\begin{array}{l}\text { As modificações feitas de } \\
\text { Auditoria anterior }(1,2 \text {, } \\
\text { 3 e 4) }\end{array}$} & Verifique se houve alterações nas condições para que o projeto foi planejado inicialmente. & $\mathbf{x}$ & $\mathbf{x}$ & $\mathbf{x}$ & $\mathbf{x}$ & $100 \%$ \\
\hline & Em caso que houve auditoria anterior, verificar se houve alterações no escopo do projeto. & $\mathbf{x}$ & $\mathbf{x}$ & $\mathbf{x}$ & $\mathbf{x}$ & $100 \%$ \\
\hline \multirow{3}{*}{$\begin{array}{l}\text { Etapas de construção } \\
\qquad(1,2,3 \text { e } 4)\end{array}$} & $\begin{array}{l}\text { Quais são os efeitos da realização da construção do projeto com um único contrato ou } \\
\text { dividindo-a em vários contratos? }\end{array}$ & $\mathbf{x}$ & & & & $25 \%$ \\
\hline & $\begin{array}{l}\text { Se o projeto for ser construído ou implementado em diferentes fases: a) Foram detalhadas } \\
\text { adequadamente para garantir a segurança? b) As fases de construção são seguras? c) } \\
\text { Existem medidas para acomodar a gestão de tráfego temporário entra as diferentes fases? }\end{array}$ & & & & $\mathbf{x}$ & $25 \%$ \\
\hline & $\begin{array}{l}\text { Se a construção for realizada em várias contratos, eles serão realizados de forma } \\
\text { segurança? }\end{array}$ & & $\mathbf{x}$ & $\mathbf{x}$ & $\mathbf{x}$ & $75 \%$ \\
\hline $\begin{array}{l}\text { Consistência dos } \\
\text { parâmetros do projeto } \\
\text { (1) }\end{array}$ & $\begin{array}{l}\text { Os parâmetros do projeto são consistentes em relação aos alinhamentos, seção transversal, } \\
\text { interseções em nível e desníveis? }\end{array}$ & $\mathrm{x}$ & & & & $25 \%$ \\
\hline \multirow{5}{*}{$\begin{array}{l}\text { Áreas de descanso ou } \\
\text { áreas de piquiniques (1) }\end{array}$} & As áreas de piquinique e descanso são desejáveis? & $\mathrm{x}$ & & & & $25 \%$ \\
\hline & O número de áreas de descando / piquinique está adequado para o projeto? & $\mathrm{x}$ & & & & $25 \%$ \\
\hline & Os acessos as áreas de descanso e piquinique são seguros? & $\mathrm{x}$ & & & & $25 \%$ \\
\hline & Áreas de descanso / piquiniques estão de localizadas em locais apropriadaos? & $\mathrm{x}$ & & & & $25 \%$ \\
\hline & $\begin{array}{l}\text { Existe sinalização adequada e posicionada corretamente informando aos usuários sobre a } \\
\text { aproximação de áreas de piquinique e descanso? }\end{array}$ & $\mathrm{x}$ & & & & $25 \%$ \\
\hline
\end{tabular}




\begin{tabular}{|c|c|c|c|c|c|c|}
\hline & O projeto de dreangem está de forma adequado? & $\mathbf{x}$ & $\mathbf{x}$ & $\mathbf{x}$ & $\mathbf{x}$ & $100 \%$ \\
\hline & $\begin{array}{l}\text { Foi considerada a possibilidade de inundações da superficie da rodovia, incluindo o } \\
\text { transbordamento dos rios e bueiros? }\end{array}$ & $\mathbf{x}$ & $\mathbf{x}$ & $\mathbf{x}$ & $\mathbf{x}$ & $100 \%$ \\
\hline ( & $\begin{array}{l}\text { Há alguma vegetação ou outros efeitos ambientais que dificultam o funcionamento das } \\
\text { entradas das drenagens (como por exemplo, cana-de-açúcar bloqueando as entradas)? }\end{array}$ & & & & $\mathrm{x}$ & $25 \%$ \\
\hline & Foi considerada a possibilidade de inundações? & $\mathrm{x}$ & & & & $25 \%$ \\
\hline $\begin{array}{l}\text { Condições climáticas ( } 2 \text {, } \\
3 \text { e 4) }\end{array}$ & $\begin{array}{l}\text { Foi considerado regitros meteorológios ou experiência local que pudesse indicar algum } \\
\text { problema particular das condições climáticas? (por exemplo, neve, gelo vento nevoeiro). }\end{array}$ & & $\mathbf{x}$ & $\mathbf{x}$ & $\mathbf{x}$ & $75 \%$ \\
\hline & Há aspectos relacionados com a vegetação que reduzirão a segurança do projeto? & & & & $\mathrm{x}$ & $25 \%$ \\
\hline Paisagismo $(2,3$ e 4$)$ & $\begin{array}{l}\text { O paisagismo está em conformidade com as orientações das normas de segurança? (como } \\
\text { por exemplo, vãos livres, distância de visibilidade, etc.) }\end{array}$ & & $\mathbf{x}$ & $\mathbf{x}$ & $\mathbf{x}$ & $75 \%$ \\
\hline & $\begin{array}{l}\text { O projeto considera o fornecimento de serviços com segurança de modo a não criar riscos } \\
\text { para os usuários? (como telenones de emergência, etc) }\end{array}$ & & $\mathrm{x}$ & & & $25 \%$ \\
\hline Serviço $(2,3$ e 4$)$ & $\begin{array}{l}\text { A localização ds objetos fixos ou serviços móveis foram verificados, incluindo a posição } \\
\text { dos postes? }\end{array}$ & & $\mathbf{x}$ & $\mathbf{x}$ & $\mathbf{x}$ & $75 \%$ \\
\hline & O projeto lida adequadamente com os serviços aéreos e subterrâneos? & & & $\mathbf{x}$ & $\mathbf{x}$ & $50 \%$ \\
\hline & Algum serviço poderá interferir no direito de passagem dos outros usuários da rodovia? & & & & $\mathbf{x}$ & $25 \%$ \\
\hline Acesso e Veículos de & $\begin{array}{l}\text { o projeto prevê o acesso seguro e circulação de veículos de emergência? (como por } \\
\text { exemplo, caminhão dos bombeiros?). }\end{array}$ & & $\mathbf{x}$ & $\mathbf{x}$ & $\mathbf{x}$ & $75 \%$ \\
\hline emergência $(2,3$ e 4$)$ & $\begin{array}{l}\text { A concepção e execução no projeto de barreiras centrais que permite que veiculos de } \\
\text { emergência possa parar e retornar por outros caminhos sem interromper o tráfego? }\end{array}$ & & $\mathbf{x}$ & $\mathbf{x}$ & $\mathbf{x}$ & $75 \%$ \\
\hline $\begin{array}{l}\text { Tipos e controle de } \\
\text { acesso às propriedade e }\end{array}$ & $\begin{array}{l}\text { Existem fatores a montante ou a jusante que poderão afetar os pontos de acesso? (perto de } \\
\text { interseções) }\end{array}$ & $\mathbf{x}$ & $\mathbf{x}$ & $\mathbf{x}$ & $\mathbf{x}$ & $100 \%$ \\
\hline $\begin{array}{l}\text { desenvovilemento }(1,2,3 \\
\text { e 4) }\end{array}$ & $\begin{array}{l}\text { Existe poluição visual (outdoor com propogandas comerciais ou iluminação excessiva) } \\
\text { próximo as áreas de direito de passagens? }\end{array}$ & $\mathbf{x}$ & & & & $25 \%$ \\
\hline
\end{tabular}




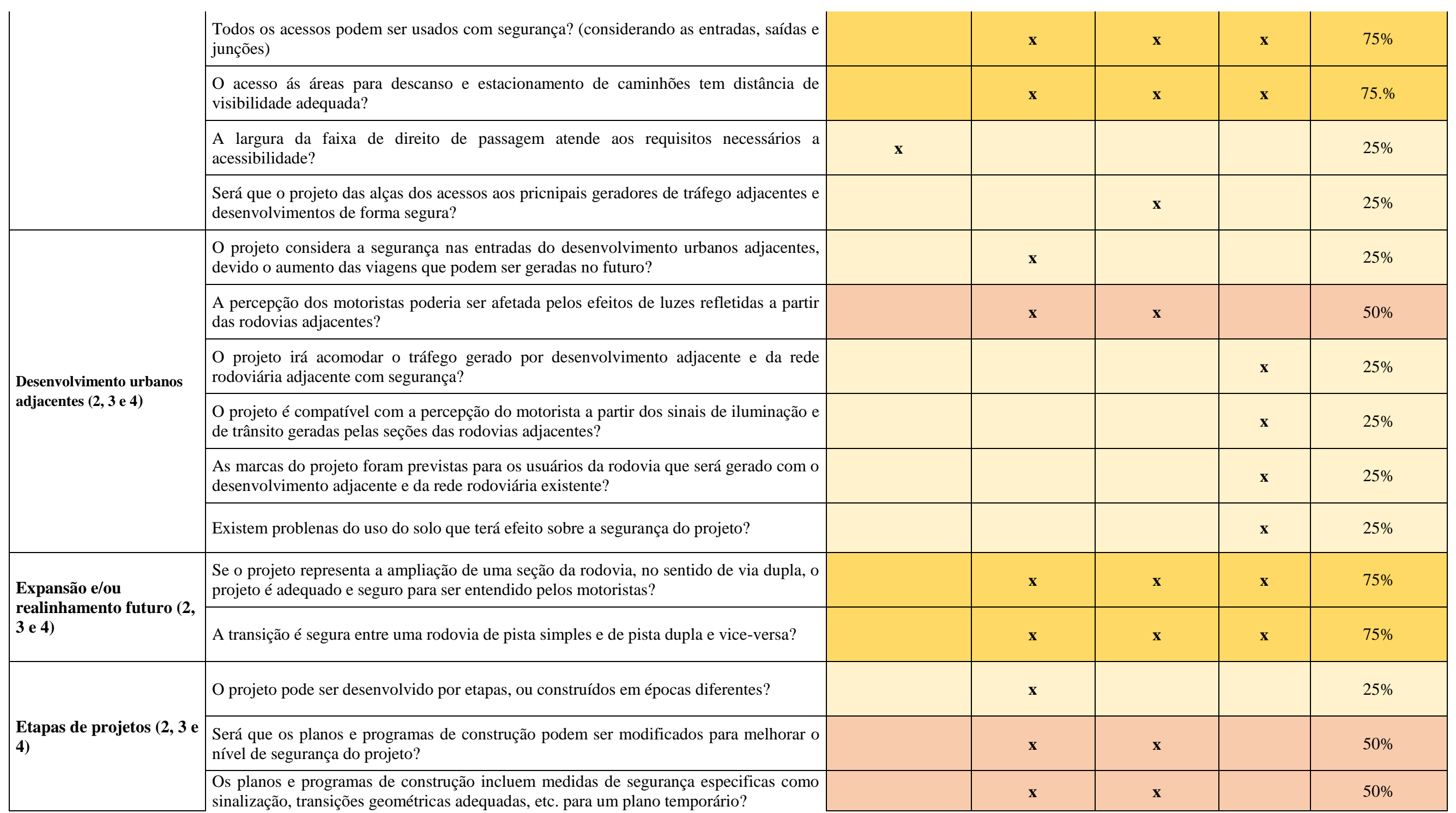




\begin{tabular}{|c|c|c|c|c|c|c|}
\hline \multirow{2}{*}{ Manutenção ( 2, 3 e 4) } & Os veículos de manutenção podem ser localizados de forma segura? & & $\mathbf{x}$ & $\mathbf{x}$ & $\mathbf{x}$ & $75 \%$ \\
\hline & Os trabalhos de manutenção poderão ser realizadas de forma segura? & & $\mathbf{x}$ & & & $25 \%$ \\
\hline \multicolumn{2}{|c|}{ 2. Alinhamento e Seções Transversais, alinhamento, alinhamento detalhado ou traçado (desenho) } & \multicolumn{4}{|c|}{$\begin{array}{l}\text { 2. Alinhamento e Seções Transversais, alinhamento, alinhamento } \\
\text { detalhado ou traçado (desenho) }\end{array}$} & Frequência \\
\hline \multirow{2}{*}{ Classificação (1) } & $\begin{array}{l}\text { Verificar a adequação da classificação e traçado do projeto para o volume e composição } \\
\text { do tráfego do projeto proposto. }\end{array}$ & $\mathrm{x}$ & & & & $25 \%$ \\
\hline & $\begin{array}{l}\text { A concepção do projeto é flexível para acomodar os imprevistos no aumento do tráfego } \\
\text { ou alterações nas características do tráfego? }\end{array}$ & $\mathrm{x}$ & & & & $25 \%$ \\
\hline \multirow{4}{*}{$\begin{array}{l}\text { Normas gerais do } \\
\text { projeto }(2,3 \text { e } 4)\end{array}$} & a velocidade de projeto é compatível com a velocidade operacional esperada? & & & $\mathrm{x}$ & & $25 \%$ \\
\hline & $\begin{array}{l}\text { Os veículos de projeto foram usados adequadamente? (especificamente para os possíveis } \\
\text { movimentos restritos de giro?). }\end{array}$ & & & $\mathrm{x}$ & & $25 \%$ \\
\hline & $\begin{array}{l}\text { A velocidade de projeto e o limite de velocidade são adequados para a função da rodovia } \\
\text { ou parte dela? }\end{array}$ & & $\mathrm{x}$ & $\mathrm{x}$ & $\mathrm{x}$ & $75 \%$ \\
\hline & O projeto considerou os tipos de veículos para os quais está previsto o seu uso? & & $\mathrm{x}$ & & $\mathrm{x}$ & $50 \%$ \\
\hline \multirow{6}{*}{$\begin{array}{l}\text { Seleção de traçado e } \\
\text { alinhameto (1) e layout } \\
\text { da rodovia }(2,3 \text { e } 4)\end{array}$} & As curvas horizontais e verticais são suaves? & $\mathrm{x}$ & & & & $25 \%$ \\
\hline & Rampas excessivas afetam as operações de veículos pesados e niveis de serviço? & $\mathrm{x}$ & & & & $25 \%$ \\
\hline & $\begin{array}{l}\text { Verifique se há curvas horizontais de raios pequenos localizadas no final de longas } \\
\text { tangentes. }\end{array}$ & $\mathrm{x}$ & & & & $25 \%$ \\
\hline & O veículo de projeto é apropriado e verifique se foi usado no projeto? & & & $\mathrm{x}$ & $\mathrm{x}$ & $50 \%$ \\
\hline & $\begin{array}{l}\text { As características da gestão do tráfego estão destinadas para evitar a criação de condições } \\
\text { inseguras e fornecer orientações adequadas? }\end{array}$ & & $\mathrm{x}$ & $\mathrm{x}$ & $\mathrm{x}$ & $75 \%$ \\
\hline & $\begin{array}{l}\text { O layout das demarcações e materiais refletivos da rodovia são capazes de advertir de } \\
\text { forma satisfatória as mudanças de alinhamento? (principalmente quando alinhamento for } \\
\text { deficiente) }\end{array}$ & & $\mathrm{x}$ & $\mathrm{x}$ & $\mathrm{x}$ & $75 \%$ \\
\hline 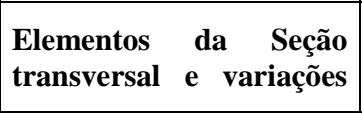 & $\begin{array}{l}\text { Determinar se o projeto proposto tem uma seção adequada para as necessidades finais da } \\
\text { rodovia, incluindo: classificação; velocidade de projeto; Nivel de serviço/volumes de } \\
\text { serviços de pico. }\end{array}$ & $\mathrm{x}$ & & & & $25 \%$ \\
\hline
\end{tabular}




\begin{tabular}{|c|c|c|c|c|c|c|}
\hline \multirow[t]{9}{*}{$\begin{array}{l}\text { da seção transversal }(1,2 \\
3 \text { e 4) }\end{array}$} & $\begin{array}{l}\text { Determinar se os ajustes nas dimensões podem ser feitas para futuras possibilidades de } \\
\text { expansão. }\end{array}$ & $\mathrm{x}$ & & & & $25 \%$ \\
\hline & $\begin{array}{l}\text { As larguras das faixas, acostamentos, canteiro central e outros elementos da seção } \\
\text { transversal são adequados para a função da rodovia? (seção típica) }\end{array}$ & $\mathrm{x}$ & & $\mathrm{x}$ & $\mathrm{x}$ & $75 \%$ \\
\hline & $\begin{array}{l}\text { A largura das faixas das rodovias é adequada a respesito de: alinhamentos? Fluxo de } \\
\text { tráfego? Dimensões dos veículos? Velocidade de projeto? Combinações de veículos com } \\
\text { o fluxo de tráfego? }\end{array}$ & & $\mathrm{x}$ & $\mathrm{x}$ & $\mathrm{x}$ & $75 \%$ \\
\hline & Há previsão, se necessário, de faixas auxiliares para ultrapassagens em longas subidas? & & $\mathrm{x}$ & $\mathrm{x}$ & $\mathrm{x}$ & $75 \%$ \\
\hline & O projeto tem zonas livres adequadas, ou foram previstas? & & & $\mathrm{x}$ & $\mathrm{x}$ & $50 \%$ \\
\hline & Nas seções transversais foram previstas folgas laterais a direita? & & $\mathrm{x}$ & & & $25 \%$ \\
\hline & $\begin{array}{l}\text { Existem variações inesperadas da seção transversal que pode influenciar negativamente a } \\
\text { segurança? }\end{array}$ & & $x$ & $\mathrm{x}$ & $\mathrm{x}$ & $75 \%$ \\
\hline & $\begin{array}{l}\text { As inclinações transversais são seguras? (particularmente quando as seções da rodovia } \\
\text { existente foram utilizadas ou será utilizada para implantação de acesso) }\end{array}$ & & $\mathrm{x}$ & $\mathrm{x}$ & $\mathrm{x}$ & $75 \%$ \\
\hline & A largura da seção transversal são seguras nos casos de estreitamento em pontes? & & $\mathrm{x}$ & $\mathrm{x}$ & $\mathrm{x}$ & $75 \%$ \\
\hline Drenagem (1) & O canal de drenagem é adequado para topografia, manutenção e neve à deriva? & $\mathbf{x}$ & & & & $25 \%$ \\
\hline Largura das faixas (1) & A largura da faixa é adequada para o projeto viário / classificação? & $\mathbf{x}$ & & & & $25 \%$ \\
\hline \multirow{2}{*}{ Acostamento (1) } & Existem desníveis? & $\mathrm{x}$ & & & & $25 \%$ \\
\hline & Faixas sonoras estão instaladas adequadamente onde necessárias? & $\mathrm{x}$ & & & & $25 \%$ \\
\hline \multirow{3}{*}{$\begin{array}{l}\text { acostamento e } \\
\text { tratamento de bordas }\end{array}$} & $\begin{array}{l}\text { Os aspectos de segurança são previstos nos acostamentos de forma satisfatória nos } \\
\text { seguintes aspectos: previsão de revestimento/ Largura e tratamentos de aterros? Inclinação } \\
\text { transversal do acostamento? }\end{array}$ & $\mathrm{x}$ & $\mathrm{x}$ & $\mathrm{x}$ & $\mathrm{x}$ & $100 \%$ \\
\hline & Os acostamentos são seguros para os veículos em movimento lento ou bicicletas? & & $\mathrm{x}$ & $\mathrm{x}$ & $\mathrm{x}$ & $75 \%$ \\
\hline & As áreas de descanso e paradas de caminhões foram projetados com segurança? & & $\mathrm{x}$ & $\mathrm{x}$ & $\mathrm{x}$ & $75 \%$ \\
\hline
\end{tabular}




\begin{tabular}{|c|c|c|c|c|c|c|}
\hline \multirow{2}{*}{$\begin{array}{l}\text { Inclinação transversal e } \\
\text { superelevação (1) }\end{array}$} & $\begin{array}{l}\text { A inclinação da rodovia é suficiente para drenar a água durante temporais e degelos de } \\
\text { neve? }\end{array}$ & $\mathrm{x}$ & & & & $25 \%$ \\
\hline & Existem diferentes taxas de inclinação transversal ao longo das faixas de tráfego? & $\mathrm{x}$ & & & & $25 \%$ \\
\hline $\begin{array}{l}\text { Superlargura do } \\
\text { pavimento }(1)\end{array}$ & $\begin{array}{l}\text { A largura do pavimento prevista é suficiente ao longo das curvas onde são esperadas } \\
\text { saídas dos veículos? }\end{array}$ & $\mathbf{x}$ & & & & $25 \%$ \\
\hline alinhamento (1) & $\begin{array}{l}\text { Existem curvas muitos acentuadas que possam causar derrapagens em condições de } \\
\text { climáticas adversas? }\end{array}$ & $\mathbf{x}$ & & & & $25 \%$ \\
\hline \multirow{2}{*}{$\begin{array}{l}\text { alinhamento horizontal } \\
\text { (1) }\end{array}$} & Verificar se curvas de transição são necessárias entre tangentes e curvas circulares & $\mathrm{x}$ & & & & $25 \%$ \\
\hline & $\begin{array}{l}\text { É adequada a combinação da superelevação com curvas de transição em relação aos } \\
\text { efeitos de drenagem? }\end{array}$ & $\mathrm{x}$ & & & & $25 \%$ \\
\hline \multirow{6}{*}{ Alinhamento vertical (1) } & $\begin{array}{l}\text { Existem rampas com inclinação excessivas que podem ser inseguras em condições do } \\
\text { tempo adversas? }\end{array}$ & $\mathrm{x}$ & & & & $25 \%$ \\
\hline & $\begin{array}{l}\text { Está prevista faixa de ultrapassagem em áreas onde a ultrapassagem e as manobras de } \\
\text { ultrapassagem são limitadas devido ao terreno? }\end{array}$ & $\mathrm{x}$ & & & & $25 \%$ \\
\hline & $\begin{array}{l}\text { Está prevista faixa de ultrapassagem em áreas onde a inclinação excede o comprimento } \\
\text { crítico do greide? }\end{array}$ & $\mathrm{x}$ & & & & $24 \%$ \\
\hline & $\begin{array}{l}\text { Verificar se áreas de escape são previstas onde necessárias em declives acentuados. Se } \\
\text { não, áreas de escape são viáveis }\end{array}$ & $\mathrm{x}$ & & & & $25 \%$ \\
\hline & Existem provisões de oportunidades de ultrapassagens adequadas? & $\mathrm{x}$ & & & & $25 \%$ \\
\hline & Existe espaçamento suficiente entre as zonas de ultrapassagens? & $\mathrm{x}$ & & & & $25 \%$ \\
\hline \multirow{3}{*}{$\begin{array}{l}\text { Combinação do } \\
\text { alinhamento horizontal e } \\
\text { vertical }(1,2,3 \text { e } 4)\end{array}$} & $\begin{array}{l}\text { Verificar a interação entre o alinhamento horizontal e vertical na via (isto é, alinhamentos } \\
\text { tipo de montanha-russa, com sequências de curvas verticais e horizontais, etc.) }\end{array}$ & $\mathrm{x}$ & & & & $25 \%$ \\
\hline & O projeto de alinhamento horizontal e vertical está alinhado corretamente? & & $\mathrm{x}$ & $\mathrm{x}$ & $\mathrm{x}$ & $75 \%$ \\
\hline & $\begin{array}{l}\text { O projeto da sinalização vertical nos alinhamentos horizontal e vertical, permite aos } \\
\text { motoristas fazer boa leitura da projeto? (por exemplo, ilusões de óticas, delimitações de } \\
\text { árvores, postes, cercas, etc.) }\end{array}$ & & $\mathrm{x}$ & $\mathrm{x}$ & $\mathrm{x}$ & $75 \%$ \\
\hline
\end{tabular}




\begin{tabular}{|c|c|c|c|c|c|c|}
\hline & O alinhamento horizontal e vertical é consistente com a velocidade? & & $\mathrm{x}$ & $\mathrm{x}$ & $\mathrm{x}$ & $75 \%$ \\
\hline \multirow{8}{*}{$\begin{array}{l}\text { Visibilidade e Distâmcia } \\
\text { de visibilidade }(1,2,3 \text { e } \\
\text { 4) }\end{array}$} & Certififique-se que as oportunidades de ultrapassagem adequadas estão previstas. & $\mathrm{x}$ & & & & $25 \%$ \\
\hline & $\begin{array}{l}\text { Determinar se distância de visibilidade de parada está previstas em toda a extensão do } \\
\text { projeto. }\end{array}$ & $\mathrm{x}$ & & & & $25 \%$ \\
\hline & $\begin{array}{l}\text { Verificar se existe distância de visibilidade de decisão adequada para sinalização de trevos } \\
\text { e interseções da via }\end{array}$ & $\mathrm{x}$ & & & & $25 \%$ \\
\hline & $\begin{array}{l}\text { Os alinhamentos verticais e horizontais fornecem distância de visibilidade e visibilidade } \\
\text { necessária? }\end{array}$ & & $\mathrm{x}$ & $\mathrm{x}$ & $\mathrm{x}$ & $75 \%$ \\
\hline & $\begin{array}{l}\text { A linha de visibilidade do projeto está desobstruída de defensas, outdoors na margem da } \\
\text { rodovia: cercas ou divisórias; mobiliário na rodovia; Estacionamentos, sinalização } \\
\text { vertical, vegetação e paisagismo, estrutura de pontes, veiculos estacionados na margem } \\
\text { da rodovia, ou filas formadas pelos veículos. }\end{array}$ & & $\mathrm{x}$ & $\mathrm{x}$ & $\mathrm{x}$ & $75 \%$ \\
\hline & Os cruzamentos ferroviários, pontes e outros riscos estão totalmente visiveis? & & $\mathrm{x}$ & $\mathrm{x}$ & $\mathrm{x}$ & $75 \%$ \\
\hline & $\begin{array}{l}\text { Os cruzamentos ferroviários, pontes e outros riscos estão totalmente visiveis nas } \\
\text { condiçôes diurna e nortuna? }\end{array}$ & & & & $\mathrm{x}$ & $25 \%$ \\
\hline & No projeto existe alguma outra característica local que possam afetar a visibilidade? & & $\mathrm{x}$ & $\mathrm{x}$ & $\mathrm{x}$ & $75 \%$ \\
\hline \multirow{6}{*}{ Estruturas de pontes (1) } & $\begin{array}{l}\text { Verificar se o alinhamento vertical e horizontal está em conformidade com as rodovias } \\
\text { que interceptam? }\end{array}$ & $\mathrm{x}$ & & & & $25 \%$ \\
\hline & Verificar se o vão vertical é suficiente e a sinalização de restrição de altura é apropriada & $\mathrm{x}$ & & & & $25 \%$ \\
\hline & O vão horizontal entre a rodovia e a mureta/guarda-corpo está adequado? & $\mathrm{x}$ & & & & $25 \%$ \\
\hline & $\begin{array}{l}\text { As distâncias de visibilidade de parada e ultrapassagem são obstruídas pelos pilares da } \\
\text { ponte e guarda-corpos? }\end{array}$ & $\mathrm{x}$ & & & & $25 \%$ \\
\hline & $\begin{array}{l}\text { É necessária sinalização para delineamento, restrição de peso, ou advertência de } \\
\text { congelamento da plataforma? Ela está instalada adequadamente? }\end{array}$ & $\mathrm{x}$ & & & & $25 \%$ \\
\hline & Existem grades de drenos que atrapalhem os ciclistas? & $\mathrm{x}$ & & & & $25 \%$ \\
\hline
\end{tabular}




\begin{tabular}{|c|c|c|c|c|c|c|}
\hline & $\begin{array}{l}\text { Existe redução da largura do acostamento na estrutura? Existem placas advertindo essa } \\
\text { redução? }\end{array}$ & $\mathrm{x}$ & & & & $25 \%$ \\
\hline & $\begin{array}{l}\text { O vão livre é adequado nas passagens subterrâneas? O vão prevendo as alturas e larguras } \\
\text { mininas? }\end{array}$ & $\mathrm{x}$ & & & & $25 \%$ \\
\hline & $\begin{array}{l}\text { São utilizados meio-fios de altura apropriados nos passeios, guarda-corpos e nas guias de } \\
\text { segurança (guarda-rodas) das pontes? }\end{array}$ & $\mathrm{x}$ & & & & $25 \%$ \\
\hline & $\begin{array}{l}\text { As características de drenagem são adequadas e estão incorporadas no projeto de } \\
\text { passagem inferior, viadutos e estruturas das pontes para evitar alagamentos? }\end{array}$ & $\mathrm{x}$ & & & & $25 \%$ \\
\hline & $\begin{array}{l}\text { Haverá percepçãp visual do afunilamento ou estreitamento nos túneis, viadutos devido a } \\
\text { localização dos pilares em relação à rodovia que passa sob a estrutura? }\end{array}$ & $\mathrm{x}$ & & & & $25 \%$ \\
\hline & $\begin{array}{l}\text { a base dos pilares das pontes está suficientemente afastada da zona livre de obstáculos } \\
\text { para classificação da rodovia? }\end{array}$ & $\mathrm{x}$ & & & & $25 \%$ \\
\hline & $\begin{array}{l}\text { Os espaços laterais, os espaços dos canteiros centrais e a zona livre de perigos das pontes } \\
\text { odedecem aos padrões das classes da rodovia? }\end{array}$ & $\mathrm{x}$ & & & & $25 \%$ \\
\hline \multirow{2}{*}{$\begin{array}{l}\text { Efeitos não conformes } \\
\text { com as normas ou } \\
\text { diretrizes }(2,3 \text { e } 4)\end{array}$} & $\begin{array}{l}\text { No caso de adoção de algum aspecto particular no projeto não cumprir as normas? A } \\
\text { segurança foi mantida? }\end{array}$ & & $\mathrm{x}$ & $\mathrm{x}$ & $\mathrm{x}$ & $75 \%$ \\
\hline & Se for detecatado algum projeto que não atende as normas: A segurança foi mantida? & & $\mathrm{x}$ & $\mathrm{x}$ & & $50 \%$ \\
\hline \multirow{4}{*}{$\begin{array}{l}\text { Velocidade de projeto } \\
\text { e/ou velocidade } \\
\text { sinalizada (1) }\end{array}$} & \begin{tabular}{|l|l|} 
A velocidade de projeto está adequada com: Alinhamento vertical, horizontal, \\
visibilidade, acessos, entre cruzamentos, aceleração e desaceleração do fluxo de veículos \\
nos cruzamento, composição do tráfego previsto?
\end{tabular} & $\mathrm{x}$ & & & & $25 \%$ \\
\hline & Verifique a continuidade da velocidade de projeto e da velocidade regulamentada. & $\mathrm{x}$ & & & & $25 \%$ \\
\hline & Nas curvas a velocidade regulamentanda é adequada? & $\mathrm{x}$ & & & & $25 \%$ \\
\hline & O tráfego segue a velocidade regulamentada? & $\mathrm{x}$ & & & & $25 \%$ \\
\hline \multirow{2}{*}{$\begin{array}{l}\text { Ligação entra a rodovia } \\
\text { nova e a existente (2,3 e } \\
\text { 4) }\end{array}$} & $\begin{array}{l}\text { A ligação ocorre distante da zona de perigo da rodovia (por exemplo, na parte superior de } \\
\text { uma curva vertical, eixo horizontal, perigos na margem da rodovia, ou em áreas de baixa } \\
\text { visibilidade ou distrações). }\end{array}$ & & $\mathrm{x}$ & $\mathrm{x}$ & & $50 \%$ \\
\hline & Se a característica das faixas da rodovia varia, a mundaça é efetuada com segurança? & & $\mathrm{x}$ & $\mathrm{x}$ & & $50 \%$ \\
\hline
\end{tabular}




\begin{tabular}{|c|c|c|c|c|c|c|}
\hline & $\begin{array}{l}\text { É segura a transição, em áreas onde o ambiente rodoviário muda (por exemplo, quando se } \\
\text { desloca da área urbana para rural, de um lugar restrito a irrestrito, de uma via iluminada } \\
\text { para uma sem iluminação)? }\end{array}$ & & $\mathrm{x}$ & $\mathrm{x}$ & $\mathrm{x}$ & $75 \%$ \\
\hline & $\begin{array}{l}\text { Na ligação da rodovia projetada com a existente, considerou a necessidade de aviso } \\
\text { prévio? }\end{array}$ & & $\mathrm{x}$ & $\mathrm{x}$ & $\mathrm{x}$ & $75 \%$ \\
\hline \multirow{2}{*}{$\begin{array}{l}\text { Legibilidade para os } \\
\text { motoristas ( } 2 \text { e } 3)\end{array}$} & $\begin{array}{l}\text { O traçado geral, função e características gerais da rodovia serão reconhecidos pelos } \\
\text { motoristas com antecedência? }\end{array}$ & & $\mathrm{x}$ & $\mathrm{x}$ & & $50 \%$ \\
\hline & $\begin{array}{l}\text { As velocidades de aproximação são adequadas e os motoristas podem ser guiados } \\
\text { corretamente pela rodovia? }\end{array}$ & & $\mathrm{x}$ & $\mathrm{x}$ & & $50 \%$ \\
\hline Corte e aterro (1) & $\begin{array}{l}\text { Existem características geológicas de corte e aterro no projeto que poderá pôr em perigo } \\
\text { os usuários da rodovia? }\end{array}$ & & & & $\mathrm{x}$ & $25 \%$ \\
\hline 3. Interseções & 3. Interseções & \multicolumn{4}{|l|}{ 3. Interseções } & Frequência \\
\hline \multirow{8}{*}{$\begin{array}{l}\text { Distribuição, incluindo } \\
\text { adequadamente o tipo } \\
(2,3 \text { e 4) }\end{array}$} & $\begin{array}{l}\text { Os tipos de interseções selecionadas são adequados para função da rodovia que } \\
\text { convergem? (entrocamento, rotatórias, sinalizada, etc) }\end{array}$ & & $\mathrm{x}$ & $\mathrm{x}$ & $\mathrm{x}$ & $75 \%$ \\
\hline & $\begin{array}{l}\text { O controle do tipo de interseção terá impacto negativo na segurança dos usuários da } \\
\text { rodovia, como: pedestres, usuários vulneráveis da rodovia, ciclistas e veículos pesados? }\end{array}$ & & & & $\mathrm{x}$ & $25 \%$ \\
\hline & $\begin{array}{l}\text { O controle do tipo de interseção afetará a segurança das instalações dos serviços de } \\
\text { transporte público? (se previstos) }\end{array}$ & & & & $\mathrm{x}$ & $25 \%$ \\
\hline & $\begin{array}{l}\text { O projeto prever o uso do tipo de veículo de projeto que irá usar a interseção? (por } \\
\text { exemplo, mudança de raios, larguras das faixas, etc;) }\end{array}$ & & & & $\mathrm{x}$ & $25 \%$ \\
\hline & $\begin{array}{l}\text { A proposta de controles da interseção (Dê a preferência, sinal de Pare) é adequada para o } \\
\text { tipo de interseção particular? }\end{array}$ & & $\mathrm{x}$ & $\mathrm{x}$ & & $50 \%$ \\
\hline & As dimensões das junções são adequadas para todos os movimentos dos veiculos? & & $\mathrm{x}$ & $\mathrm{x}$ & & $50 \%$ \\
\hline & $\begin{array}{l}\text { As interseções estão livres de alguma característica incomum que pode afetar a segurança } \\
\text { rodoviária? }\end{array}$ & & $\mathrm{x}$ & $\mathrm{x}$ & & $50 \%$ \\
\hline & $\begin{array}{l}\text { Nas interseções as larguras e extensões das faixas estão adequadas para todos os tipos de } \\
\text { veículos? }\end{array}$ & & $\mathrm{x}$ & $\mathrm{x}$ & & $50 \%$ \\
\hline
\end{tabular}




\begin{tabular}{|c|c|c|c|c|c|c|}
\hline & $\begin{array}{l}\text { O projeto esta livre, a montante ou a jusante de alguma característica geométrica que } \\
\text { possam afetar a segurança (por exemplo, combinação de faixas)? }\end{array}$ & & $\mathrm{x}$ & $\mathrm{x}$ & $\mathrm{x}$ & $75 \%$ \\
\hline & As velocidades de aproximação são compatíveis com o projeto da interseção? & & $\mathrm{x}$ & $\mathrm{x}$ & $\mathrm{x}$ & $75 \%$ \\
\hline & $\begin{array}{l}\text { Onde foi proposto uam rotatória, foram considerados os movimentos dos ciclistas e os } \\
\text { movimentos dos pedestres e as faixas são suficientes? }\end{array}$ & & $\mathrm{x}$ & $\mathrm{x}$ & $\mathrm{x}$ & $75 \%$ \\
\hline \multirow{8}{*}{$\begin{array}{l}\text { Legibilidade para os } \\
\text { motoristas }(2,3 \text { e } 4)\end{array}$} & $\begin{array}{l}\text { Em geral, o tipo, função e características gerais da interseção ser percebidos pelos } \\
\text { motoristas corretamente? }\end{array}$ & & $\mathrm{x}$ & $\mathrm{x}$ & $\mathrm{x}$ & $75 \%$ \\
\hline & $\begin{array}{l}\text { As velocidades de aproximação das interseções são adequadas e os motoristas podem ser } \\
\text { guiados corretamente pela rodovia? }\end{array}$ & & $\mathrm{x}$ & $\mathrm{x}$ & $\mathrm{x}$ & $75 \%$ \\
\hline & $\begin{array}{l}\text { Interseções sucessivas pode violar a expectativa do motoristas por causas de } \\
\text { inconsistências? }\end{array}$ & & & & $\mathrm{x}$ & $25 \%$ \\
\hline & $\begin{array}{l}\text { O motorista tem tempo suficiente para perceber situações futuras e decidir por ações } \\
\text { necessárias de forma segura? }\end{array}$ & & & & $\mathrm{x}$ & $25 \%$ \\
\hline & O projeto das interseções prevê decisões erradas? & & & & $\mathrm{x}$ & $25 \%$ \\
\hline & $\begin{array}{l}\text { Foram considerados de forma adequada os efeitos dos ângulos do nascer do sol e pôr do } \\
\text { sol que poderia acarretar riscos para os motoristas? }\end{array}$ & & $\mathrm{x}$ & $\mathrm{x}$ & $\mathrm{x}$ & $75 \%$ \\
\hline & $\begin{array}{l}\text { Será que a experiência do motorista lida com ofuscamento do a luz dos veículos no sentido } \\
\text { contrário ou iluminação rodoviária:? }\end{array}$ & & & & $\mathrm{x}$ & $25 \%$ \\
\hline & Nas interseções o motorista poderá ser exposto na escuridão repentina? & & & & $\mathrm{x}$ & $25 \%$ \\
\hline \multirow{3}{*}{$\begin{array}{l}\text { Localização e } \\
\text { espaçamento (1) }\end{array}$} & Existe espaçamemnto suficiente entre interseções? & $\mathrm{x}$ & & & & $25 \%$ \\
\hline & $\begin{array}{l}\text { Os alinhamentos verticais e/ou horizontais afetam o tipo/ localização e o espaçamento das } \\
\text { intersecções? }\end{array}$ & $\mathrm{x}$ & & & & $100 \%$ \\
\hline & $\begin{array}{l}\text { Entrocamentos e acessos são adequados para todos os movimentos permitidos para } \\
\text { veículos? }\end{array}$ & $\mathrm{x}$ & & & & $25 \%$ \\
\hline $\begin{array}{l}\text { Visibilidade / } \\
\text { conspicuidade (1) }\end{array}$ & Alinhamento vertical / horizontal permite visibilidade adequada da interseção? & $\mathrm{x}$ & & & & $25 \%$ \\
\hline
\end{tabular}




\begin{tabular}{|c|c|c|c|c|c|c|}
\hline & As linhas de visão das interseções estão obstruídas? & $\mathrm{x}$ & & & & $25 \%$ \\
\hline \multirow{3}{*}{ Desenho (layout) (1 e 2) } & A largura das faixas é adequada para todos as classes de veículos? & $\mathrm{x}$ & & & & $25 \%$ \\
\hline & $\begin{array}{l}\text { Existem características a montante ou a jusante que possam afetar a segurança (obstruções } \\
\text { visuais, estacionamentos oblíquos, alto volume de entrada de automóveis)? }\end{array}$ & $\mathrm{x}$ & $\mathrm{x}$ & & & $50 \%$ \\
\hline & Separação entre as faixas é necessária mas não provida? & $\mathrm{x}$ & & & & $25 \%$ \\
\hline \multirow{10}{*}{$\begin{array}{l}\text { Visibilidade e Distância } \\
\text { de visibilidade (1, 2, } 3 \text { e } \\
\text { 4) }\end{array}$} & $\begin{array}{l}\text { Todas as distâncias de visibilidade estão adequadas para todos os movimentos e usuários } \\
\text { da rodovia? }\end{array}$ & $\mathrm{x}$ & & & & $25 \%$ \\
\hline & Linhas de visibilidade estão obstruídas por placas, edíficios, vegetação, etc? & $\mathrm{x}$ & $\mathrm{x}$ & & & $50 \%$ \\
\hline & $\begin{array}{l}\text { As linhas de visibilidade podem ser temporariamente obstruídas por veículos } \\
\text { estacionamentos, acúmulo de neve, vegetação sazonal, etc? }\end{array}$ & $\mathrm{x}$ & & & & $25 \%$ \\
\hline & Greides nas interseções permitem uma distância de visibilidade desejável? & $\mathrm{x}$ & & & & $25 \%$ \\
\hline & $\begin{array}{l}\text { Os alinhamentos horizontais e verticais nas interseções ou nas proximidades dsa } \\
\text { interseções, está de acordo com as condições necessárias de visibilidade? }\end{array}$ & & $\mathrm{x}$ & $\mathrm{x}$ & $\mathrm{x}$ & $75 \%$ \\
\hline & $\begin{array}{l}\text { Os motoristas podem observar claramente a presença da interseção? (especialmente } \\
\text { quando se aproxima de rodovias secundárias) }\end{array}$ & & $\mathrm{x}$ & $\mathrm{x}$ & $\mathrm{x}$ & $75 \%$ \\
\hline & $\begin{array}{l}\text { A linha de visibilidade do projeto está desobstruída de: Barreiras de segurança e cercas, } \\
\text { divisórias; mobiliário na rodovia; Estacionamentos, sinalização vertical, vegetação e } \\
\text { paisagismo, estrutura de pontes. }\end{array}$ & & $\mathrm{x}$ & $\mathrm{x}$ & & $50 \%$ \\
\hline & $\begin{array}{l}\text { Os cruzamentos ferroviários, pontes e outros riscos próximos das interseções estão } \\
\text { totalmente visiveis? }\end{array}$ & & $\mathrm{x}$ & $\mathrm{x}$ & & $50 \%$ \\
\hline & $\begin{array}{l}\text { O projeto está livre de outras características locaisl que podem afetar negativamente a } \\
\text { visibilidade? }\end{array}$ & & $\mathrm{x}$ & $\mathrm{x}$ & & $50 \%$ \\
\hline & $\begin{array}{l}\text { será que a interseção estará obstruída permanentemente ou temporariamente por veículos } \\
\text { estacionados na margem da rodovia ou por filas formadas por veículos que circulam } \\
\text { normalmente? }\end{array}$ & & $\mathrm{x}$ & $\mathrm{x}$ & $\mathrm{x}$ & $75 \%$ \\
\hline
\end{tabular}




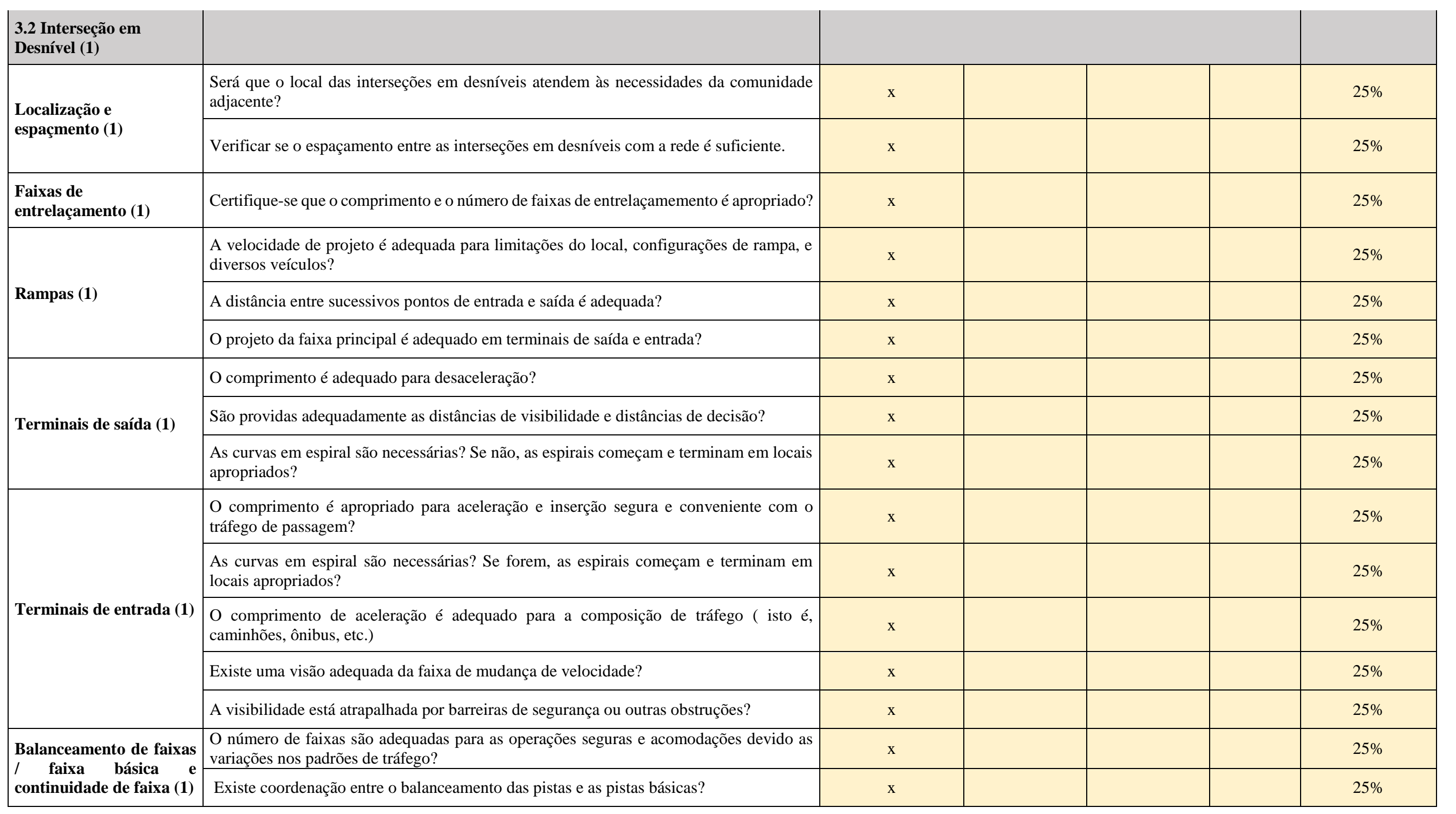




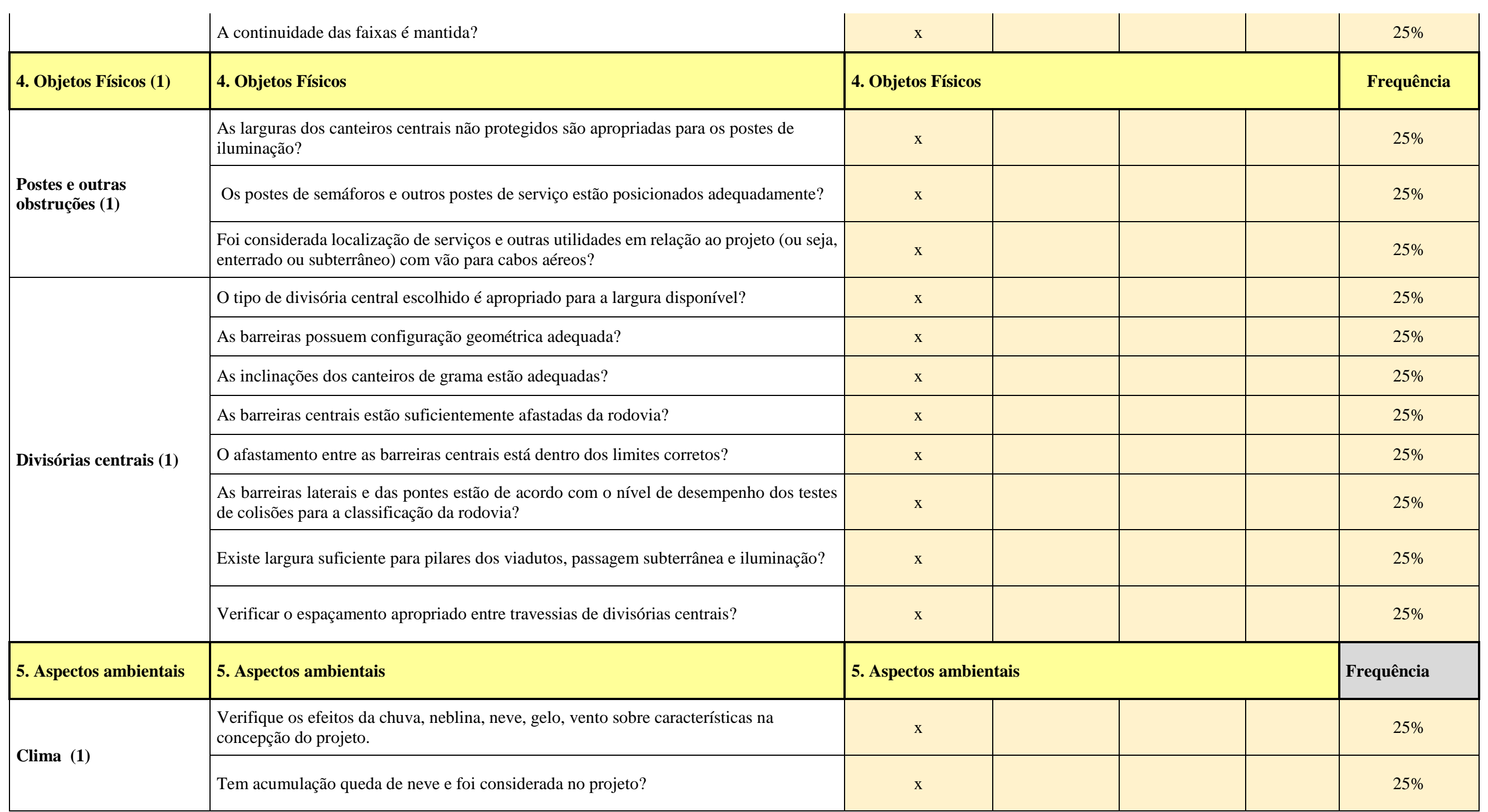




\begin{tabular}{|c|c|c|c|c|c|c|}
\hline & $\begin{array}{l}\text { Verifique as medidas mitigadoras para efeitos de neve no que diz respeito a: ventos } \\
\text { predominantes; neve a aderiva; terreno aberto; }\end{array}$ & $\mathrm{x}$ & & & & $25 \%$ \\
\hline \multirow{3}{*}{ Animais (1) } & $\begin{array}{l}\text { Existem animais nas rotas de viagens / ou migração conhecidas em áreas que poderiam } \\
\text { afetar o entorno com o projeto? }\end{array}$ & $\mathrm{x}$ & & & & $25 \%$ \\
\hline & Cercas e passagens inferiores estão implantadas onde é necessário? & $\mathrm{x}$ & & & & $25 \%$ \\
\hline & $\begin{array}{l}\text { Certifique-se se há sinalização apropriada onde for necessário. (ou seja, passagem de } \\
\text { gado, aviso de animais silvestres (veados), etc) }\end{array}$ & $\mathrm{x}$ & & & & $25 \%$ \\
\hline 6. Usuários da rodovia & 6. Usuários da rodovia & \multicolumn{4}{|c|}{ 6. Usuários da Rodovia } & Frequência \\
\hline motorizados & & & & & & \\
\hline \multirow{7}{*}{$\begin{array}{l}\text { Veículos pesados e } \\
\text { transporte público }(1,2 \mathrm{e} \\
\text { 4) }\end{array}$} & $\begin{array}{l}\text { A instalação pode acomodar movimentos de veículos pesados/transporte público quando } \\
\text { necessário? (vãos, raios de giro, largura do acostamento, capacidade operacional)? }\end{array}$ & $\mathrm{x}$ & $\mathrm{x}$ & & & $50 \%$ \\
\hline & $\begin{array}{l}\text { O projeto prever as limitações de veículos pesados? (por exemplo, nas distâncias de } \\
\text { paradas, etc). }\end{array}$ & & & & $\mathrm{x}$ & $25 \%$ \\
\hline & O projet considera as seções transversais seguras para os veículos pesados? & & & & $\mathrm{x}$ & $25 \%$ \\
\hline & $\begin{array}{l}\text { No terrenos montanhosos, as instalações de escape necessária no projeto? São projetadas } \\
\text { ou pode haver modificação no projeto para eliminar se necessário? }\end{array}$ & & & & $\mathrm{x}$ & $25 \%$ \\
\hline & Há áreas de descando projetadas? Se planejado, podem ser usadas com segurança? & & & & $\mathrm{x}$ & $25 \%$ \\
\hline & são seguras as instalações de carregamento dos veículos pesados com segurança? & & & & $\mathrm{x}$ & $25 \%$ \\
\hline & Há previsão para as manobras seguras dos veículos pesados quando necessárias? & & & & $\mathrm{x}$ & $25 \%$ \\
\hline \multirow[t]{2}{*}{$\begin{array}{l}\text { Transporte de carga ( } 2 \text { e } \\
\text { 3) }\end{array}$} & $\begin{array}{l}\text { Foram considerados os movimentos dos caminhões incluindo os grandes raios de giro e } \\
\text { larguras das faixas? }\end{array}$ & & $\mathrm{x}$ & $\mathrm{x}$ & & $50 \%$ \\
\hline & Foram atendidos os serviços de transporte público? & & $\mathrm{x}$ & $\mathrm{x}$ & $\mathrm{x}$ & $75 \%$ \\
\hline
\end{tabular}


Há previsão para a circulação segura dos pedestres, que usam os serviços do transporte público? (por exemplo, espaços suficientes para os passageiros que descem dos ônibus?)

Transporte público $(2,3$ Foram consideradas as necessidades dos usuários de transporte público?

e 4)

Foram considerados os movimentos dos transportes públicos?

As paradas de ônibus estão localizadas de forma segura?

A instalação pode acomodar movimentos de veículos de manutenção da rodovia e de

Veículos de manutenção

e veículos de emergência

$(1,2$ e 3)

Amergência (vãos, raio de giro, largura do acostamento). Após a implementação do

projeto?

As divisórias centrais e cruzamentos estão visíveis e em locais adequados para este veículos?

Veículos de manutenção Está previsto que os veiculos de manutenção realizem de forma segura o seu trabalho em

(2 e 3) qualquer lugar?

Veículos lentos (1)

Os acostamentos podem acomodar veículos lentos quando necessário? Em temos de largura, capacidade estrutural, continuidade.

Verculos lentos (1)

Existe sinalização apropriada a respeito de veículos lentos quando necessários?

Verificar a visibilidade da sinalização de trilhas adjacentes. Ela poderia causar confusão para os usuários da rodovia?

veículos de neve (1)

verificar a sinalização e a visibilidade de pontos onde as trilhas atravessam a rodovia

distância de visibilidade de parada foi considerada onde trilhas atravessam a rodovia?

o farol dianteiro do carro para neve / ATV pod ofuscar o motorista?

Foram levadas em consideração as necessidades dos motociclistas?

Motociclistas (1, 2, 3 e 4)

Existem dispositivos na rodovia ou objetos que podem desestabilizar uma motocicleta?

Existem advertências ou delineadores adequados para os motociclistas?

\begin{tabular}{|c|c|c|c|c|}
\hline & & & $\mathrm{x}$ & $25 \%$ \\
\hline & $\mathrm{x}$ & $\mathrm{x}$ & & $50 \%$ \\
\hline & $\mathrm{x}$ & $\mathrm{x}$ & & $50 \%$ \\
\hline & $\mathrm{x}$ & $\mathrm{x}$ & & $50 \%$ \\
\hline$x$ & $\mathrm{x}$ & $x$ & & $75 \%$ \\
\hline \multirow[t]{2}{*}{$\mathrm{x}$} & & & & $25 \%$ \\
\hline & $\mathrm{x}$ & $\mathrm{x}$ & & $50 \%$ \\
\hline $\mathrm{x}$ & & & & $25 \%$ \\
\hline$x$ & & & & $25 \%$ \\
\hline$x$ & & & & $25 \%$ \\
\hline$x$ & & & & $25 \%$ \\
\hline$x$ & & & & $25 \%$ \\
\hline \multirow[t]{4}{*}{$\mathrm{x}$} & & & & $25 \%$ \\
\hline & & & $\mathrm{x}$ & $25 \%$ \\
\hline & $\mathrm{x}$ & $\mathrm{x}$ & & $50 \%$ \\
\hline & $\mathrm{x}$ & $\mathrm{x}$ & & $50 \%$ \\
\hline
\end{tabular}




\begin{tabular}{|c|c|c|c|c|c|c|}
\hline & $\begin{array}{l}\text { Existe extremidades de barreiras de contenção expostas, desprotegidas ou terminal em } \\
\text { áreas de alta velocidade? }\end{array}$ & & $\mathrm{x}$ & $\mathrm{x}$ & & $50 \%$ \\
\hline & $\begin{array}{l}\text { Onde as áreas que existem maiores probabilidades das motocicletas sairem da rodovia, há } \\
\text { alguma medida de segurança? }\end{array}$ & & $\mathrm{x}$ & $\mathrm{x}$ & $\mathrm{x}$ & $75 \%$ \\
\hline \multicolumn{7}{|l|}{ Não motorizados } \\
\hline \multirow{3}{*}{ Ciclista e pedestre (1) } & $\begin{array}{l}\text { Os acostamentos possuem larguras suficientes para acomodar ciclistas / pedestres onde } \\
\text { são necessários? }\end{array}$ & $\mathrm{x}$ & & & & $25 \%$ \\
\hline & acostamento / passeios estão previstos nas pontes? & $\mathrm{x}$ & & & & $25 \%$ \\
\hline & o acumulo de neve prejudica o acesso ou a visibilidade dos pedestres? & $\mathrm{x}$ & & & & $25 \%$ \\
\hline \multirow{6}{*}{ Ciclistas (2) } & $\begin{array}{l}\text { As necessidade dos ciclistas foram consideradas de forma satisfatória, especialmente nas } \\
\text { interseções? }\end{array}$ & & $\mathrm{x}$ & $\mathrm{x}$ & $\mathrm{x}$ & $75 \%$ \\
\hline & Foi considerado alguma faixa para os ciclistas? & & $\mathrm{x}$ & $\mathrm{x}$ & & $50 \%$ \\
\hline & O projeto das ciclovias estão de acordo com as normas, ou adequadas? & & $\mathrm{x}$ & $\mathrm{x}$ & & $50 \%$ \\
\hline & $\begin{array}{l}\text { Onde existe a necessidade de compartilhar as instalações para os uso dos pedestres e } \\
\text { ciclistas, foram tratadas de forma segura? }\end{array}$ & & $\mathrm{x}$ & $\mathrm{x}$ & $\mathrm{x}$ & $75 \%$ \\
\hline & $\begin{array}{l}\text { Quando uma ciclovia termina em interseção ou rodovia adjacente, foi prevista uma } \\
\text { transição com segurança? }\end{array}$ & & $\mathrm{x}$ & $\mathrm{x}$ & & $50 \%$ \\
\hline & $\begin{array}{l}\text { Existe a necessidade de incorporar algum elemento especial nas ciclovias? (por exemplo, } \\
\text { semáforos para ciclistas) }\end{array}$ & & $\mathrm{x}$ & $\mathrm{x}$ & & $50 \%$ \\
\hline \multirow{5}{*}{ Pedestre $(2,3$ e 4) } & O projeto é seguro para os pedestres? & & & & $\mathrm{x}$ & $25 \%$ \\
\hline & As necessidades dos pedestres foram consideradas satisfatoriamente? & & $\mathrm{x}$ & $\mathrm{x}$ & $\mathrm{x}$ & $75 \%$ \\
\hline & As travessias de pedestres foram consideradas ao longo das linhas de desejo? & & & & $\mathrm{x}$ & \\
\hline & $\begin{array}{l}\text { Se o projeto não contempla calçadas de pedestres, a disposição da rodovia é segura para } \\
\text { o tráfego dos pedestres? (particularmente em curvas com baixa visibilidade e em pontes). }\end{array}$ & & $\mathrm{x}$ & $\mathrm{x}$ & $\mathrm{x}$ & $75 \%$ \\
\hline & $\begin{array}{l}\text { As passagens subterrâneas ou elevadas (passarelas) para os pedestres estão localizadas de } \\
\text { forma a maximizar o seu uso? ( ou seja, a probabilidade dos pedestres atravessarem a } \\
\text { rodovia perto dos cruzamentos) }\end{array}$ & & $\mathrm{x}$ & $\mathrm{x}$ & & $50 \%$ \\
\hline
\end{tabular}




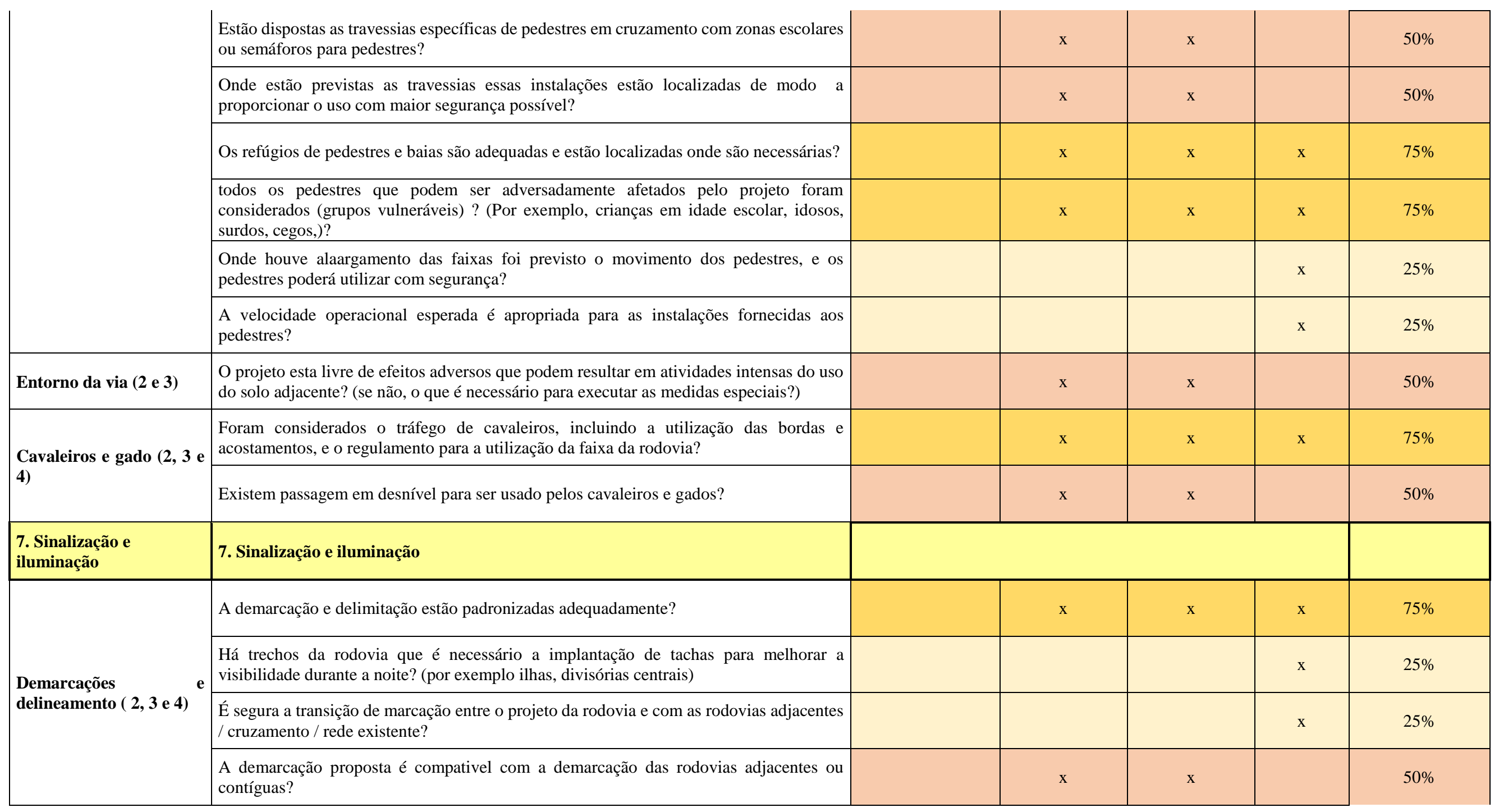




\begin{tabular}{|c|c|c|c|c|c|}
\hline & $\begin{array}{l}\text { As demarcações anteriores e/ou adjacentes podem ser melhoradas? Se não realizar as } \\
\text { melhorias e manutenções, a segurança poderá ser mantida? }\end{array}$ & $\mathrm{x}$ & $\mathrm{x}$ & & $50 \%$ \\
\hline \multirow{12}{*}{$\begin{array}{l}\text { sinalização vertical }(2,3 \mathrm{e} \\
\text { 4) }\end{array}$} & As sinalizações verticais estão bem localizadas? & $\mathrm{x}$ & $\mathrm{x}$ & & $50 \%$ \\
\hline & Estão localizadas de modo que podem ser observadas e lidas em tempo adequado? & $\mathrm{x}$ & $\mathrm{x}$ & & $50 \%$ \\
\hline & As sinalizações verticais são facilmente entendidas? & $\mathrm{x}$ & $\mathrm{x}$ & & $50 \%$ \\
\hline & $\begin{array}{l}\text { As sinalizações verticais estão instaladas de modo que a visibilidade dos acessos para as } \\
\text { interseções esteja mantida? }\end{array}$ & $\mathrm{x}$ & $\mathrm{x}$ & $\mathrm{x}$ & $75 \%$ \\
\hline & $\begin{array}{l}\text { As sinalizações verticais são adequadas para as necessidades do condutor? (por exemplo, } \\
\text { sinalização de destino, velocidade máxima, etc) }\end{array}$ & $\mathrm{x}$ & $\mathrm{x}$ & $\mathrm{x}$ & $75 \%$ \\
\hline & $\begin{array}{l}\text { Os postes da sinalização vertical têm consequências de segurança para os veículos em } \\
\text { caso de colisões? }\end{array}$ & $\mathrm{x}$ & $\mathrm{x}$ & & $50 \%$ \\
\hline & $\begin{array}{l}\text { Será que alguma sinalização vertical na rodovia representa um risco de segurança para os } \\
\text { veículos errantes? Foi prevista proteção para reduzir a gravidade dos acidentes? }\end{array}$ & & & $\mathrm{x}$ & $25 \%$ \\
\hline & $\begin{array}{l}\text { As localizações das sinalizações veriticais mantêm a distância de visibilidade dos } \\
\text { condutores? }\end{array}$ & $\mathrm{x}$ & $\mathrm{x}$ & & $50 \%$ \\
\hline & $\begin{array}{l}\text { Onde a sinalização está instalado em zona livre, os postes da sinalização são frágeis estão } \\
\text { suficientemente protegidos por uma barreira? }\end{array}$ & $\mathrm{x}$ & $\mathrm{x}$ & & $50 \%$ \\
\hline & No projeto há sinalizações verticais que podem fornecer informações inequívocas? & & & $\mathrm{x}$ & $25 \%$ \\
\hline & $\begin{array}{l}\text { A sinalização verical é visiviel e legivel? (verificar a necessidade especiais paraa } \\
\text { refletividade noturna ser aprotiada) }\end{array}$ & & & $\mathrm{x}$ & $25 \%$ \\
\hline & A refletividade é adequada ou excessiva? (isto é: ofusca a visão do motorista) & & & $\mathrm{x}$ & $25 \%$ \\
\hline \multirow{2}{*}{ Iluminação $(2,3$ e 4$)$} & $\begin{array}{l}\text { Há projeto de iluminação? Caso não tenha o projeto de iluminação, haverá problemas de } \\
\text { segurança? }\end{array}$ & $\mathrm{x}$ & $\mathrm{x}$ & $\mathrm{x}$ & $75 \%$ \\
\hline & $\begin{array}{l}\text { Se o projeto for iluminado, ser mantida a segurança nos casos da ruptura no fornecimento } \\
\text { de energia? }\end{array}$ & & & $\mathrm{x}$ & $25 \%$ \\
\hline
\end{tabular}




\begin{tabular}{|c|c|c|c|c|c|}
\hline & $\begin{array}{l}\text { Foi levado em conta as características como árvores, pontes, etc que pode afetar a } \\
\text { instalação de iluminação rodoviária? }\end{array}$ & & & $\mathrm{x}$ & $25 \%$ \\
\hline & $\begin{array}{l}\text { O projeto terá seções com problemas de iluminação? (por exemplo, sombras de árvores } \\
\text { ou pontes). }\end{array}$ & $\mathrm{x}$ & $\mathrm{x}$ & & $50 \%$ \\
\hline & $\begin{array}{l}\text { A localização dos postes de iluminação foram considerados como parte do conceito geral } \\
\text { do projeto? }\end{array}$ & $\mathrm{x}$ & $\mathrm{x}$ & & $50 \%$ \\
\hline & Os postes a serem utilizados são frágeis (quebradiços) ou dobrável na base? & $\mathrm{x}$ & $\mathrm{x}$ & & $50 \%$ \\
\hline & $\begin{array}{l}\text { Há necessidade de requisitos especiais para iluminação ambiente? A segurança será } \\
\text { mantida casos as medidas especiais não forem realizadas? }\end{array}$ & $\mathrm{x}$ & $\mathrm{x}$ & $\mathrm{x}$ & $75 \%$ \\
\hline & $\begin{array}{l}\text { foi mantida a segurança do veículo que pode colidir com postes de iluminação, foram } \\
\text { considerados? }\end{array}$ & $\mathrm{x}$ & $\mathrm{x}$ & $\mathrm{x}$ & $75 \%$ \\
\hline & $\begin{array}{l}\text { As barreiras de contenção são utilizadas para proteger o usuário da rodovia não colidir } \\
\text { com obejtos fixos, no projeto foram previstas e localizadas adequadamente para garantir } \\
\text { a segurança? }\end{array}$ & & & $\mathrm{x}$ & $25 \%$ \\
\hline 8. Gestão de tráfego & Gestão de tráfego & \multicolumn{3}{|l|}{ 8. Gestão de tráfego } & Frequência \\
\hline \multirow{6}{*}{$\begin{array}{l}\text { Fluxo de tráfego e } \\
\text { gerenciamento de acessos } \\
(2,3 \text { e 4) }\end{array}$} & $\begin{array}{l}\text { Pode o fluxo de tráfego do projeto proposto, ser acomodado com segurança em seções } \\
\text { existentes da rodovia? }\end{array}$ & $\mathrm{x}$ & $\mathrm{x}$ & $\mathrm{x}$ & $75 \%$ \\
\hline & $\begin{array}{l}\text { A disposição de estacionamentos e controle de estacionamentos foi considerado } \\
\text { corretamente? }\end{array}$ & $\mathrm{x}$ & $\mathrm{x}$ & $\mathrm{x}$ & $75 \%$ \\
\hline & Há pistas exlusivas e pistas de desaceleração para ser usado com segurança? & & & $\mathrm{x}$ & $25 \%$ \\
\hline & $\begin{array}{l}\text { Será que o projeto pode contribuir para o movimento de tráfego em alta velocidade nas } \\
\text { áreas residências? }\end{array}$ & & & $\mathrm{x}$ & $25 \%$ \\
\hline & $\begin{array}{l}\text { Podem ser implementadas proibições de deslocamento sem causar problemas nas } \\
\text { interseções adjacentes? }\end{array}$ & $\mathrm{x}$ & $\mathrm{x}$ & & $50 \%$ \\
\hline & Foi considerado os efeitos de acessos a furutos desenvolvimento? & $\mathrm{x}$ & $\mathrm{x}$ & $\mathrm{x}$ & $75 \%$ \\
\hline
\end{tabular}




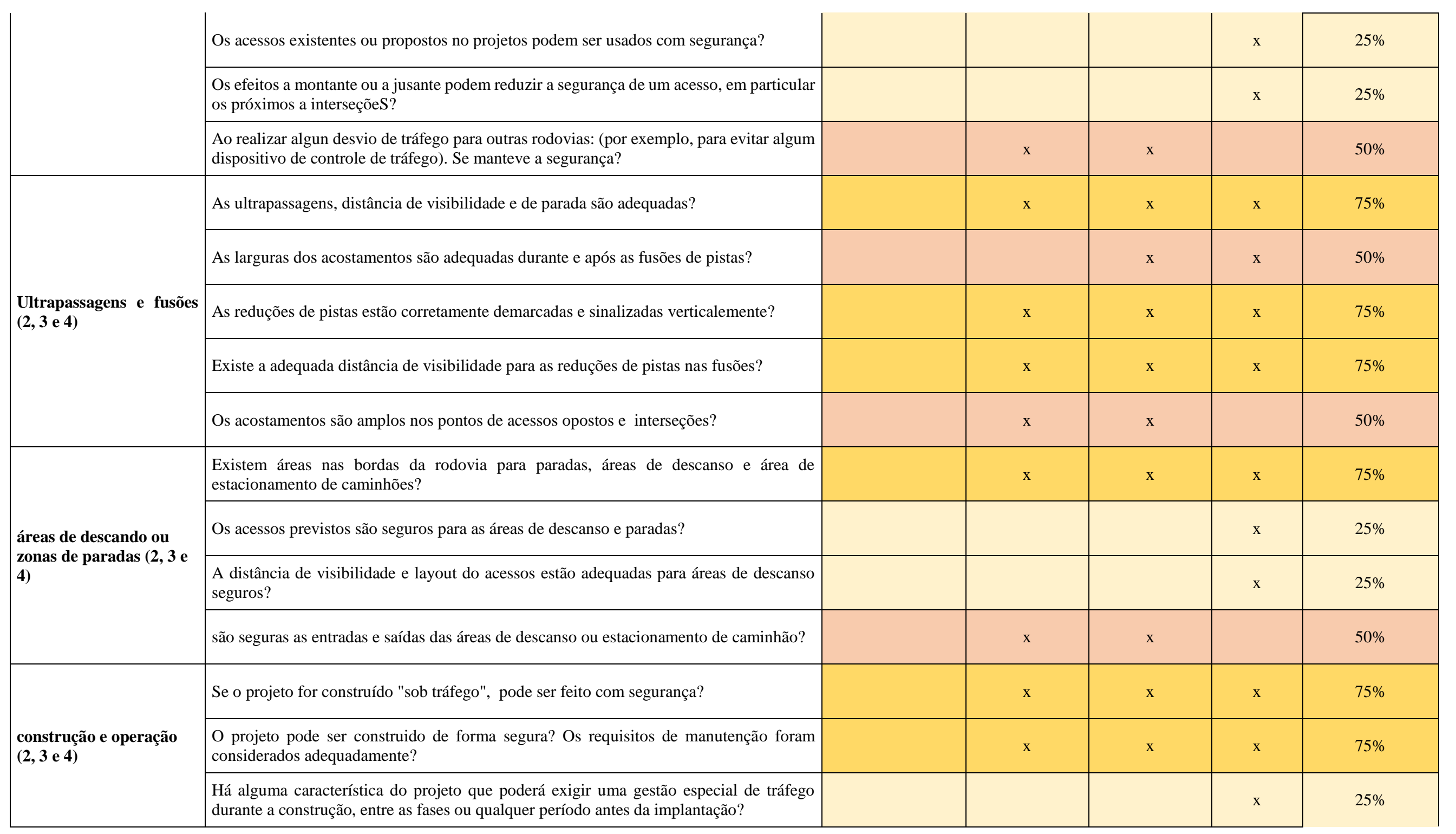


É seguro o acesso de veículos para executar os trabalhos (obras)?

9. Perguntas adicionais para ser consideradas para o desenvolvimento proposto

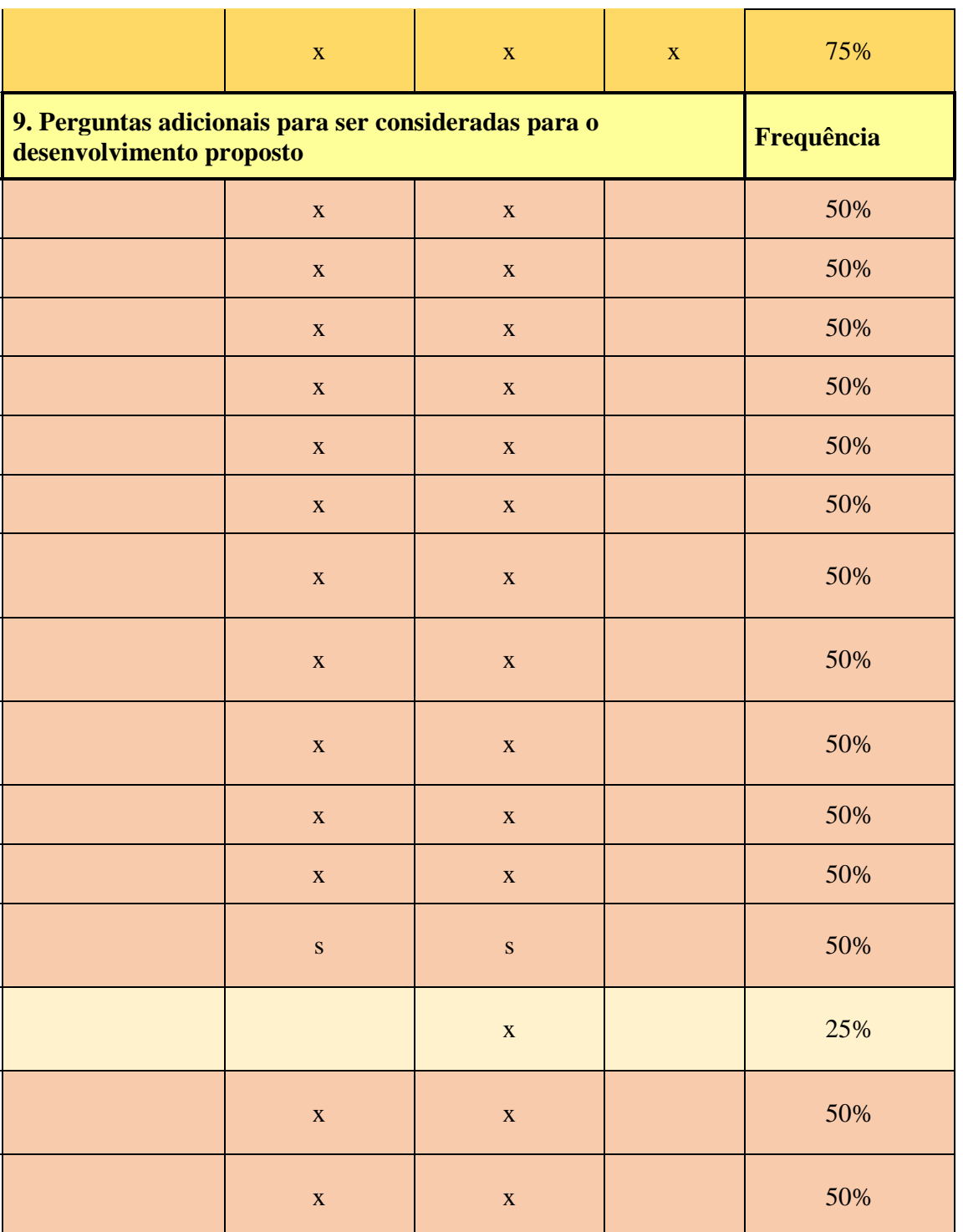




\begin{tabular}{|c|c|c|c|c|c|}
\hline \multirow{2}{*}{ Paisagismo } & $\begin{array}{l}\text { A paisagem mantém a visibilidade nas interseções, curvas, acessos e localizações de } \\
\text { pedestres? }\end{array}$ & $\mathrm{x}$ & $\mathrm{x}$ & x & $50 \%$ \\
\hline & foi evitado a plantação de vegetação em lugares onde os veículos podem sair da rodovia? & $\mathrm{x}$ & $\mathrm{x}$ & x & $50 \%$ \\
\hline \multirow{6}{*}{ Gestão de tráfego (2) } & Foi considerado efeitos adversos em alguma área do projeto? & $\mathrm{x}$ & $\mathrm{x}$ & x & $50 \%$ \\
\hline & O projeto vai manter a velocidade de projeto de forma segura? & $\mathrm{x}$ & $\mathrm{x}$ & $x$ & $50 \%$ \\
\hline & O número e a localização dos aceassos são adequados? & $\mathrm{x}$ & $\mathrm{x}$ & $x$ & $50 \%$ \\
\hline & $\begin{array}{l}\text { Há instalações para os serviços de transporte públicos? E estão localizados em lugares } \\
\text { seguros e justificados? }\end{array}$ & $\mathrm{x}$ & $\mathrm{x}$ & $\mathrm{x}$ & $50 \%$ \\
\hline & $\begin{array}{l}\text { Existem instalações para os ciclistas? Estão localizados de forma segura a respeito dos } \\
\text { movimentos dos veiculos? }\end{array}$ & $\mathrm{x}$ & $\mathrm{x}$ & $\mathrm{x}$ & $50 \%$ \\
\hline & Existem instalações para os pedestres? Estão localizadas em lugares seguros e adequados? & $\mathrm{x}$ & $\mathrm{x}$ & x & $50 \%$ \\
\hline \multirow{3}{*}{ Outros } & No projeto está prevista iluminação pública? É adequada? & $\mathrm{x}$ & $\mathrm{x}$ & x & $50 \%$ \\
\hline & Há riscos na margem da rodovia? Foram tratados corretamente? & $\mathrm{x}$ & $\mathrm{x}$ & x & $50 \%$ \\
\hline & Os pedestres podem acessar de forma segura o desenvolvimento urbano proposto? & $\mathrm{x}$ & $\mathrm{x}$ & $x$ & $50 \%$ \\
\hline 10. Outras considerações & 10. Outras considerações & \multicolumn{3}{|l|}{ 10. Outras considerações } & Frequência \\
\hline \multirow{6}{*}{$\begin{array}{l}\text { Aspectos de segurança } \\
\text { não considerados }(2,3 \mathrm{e} 4)\end{array}$} & há situações especiais? Foram consideradas situações incomuns ou de perigo? & $\mathrm{x}$ & $\mathrm{x}$ & $\mathrm{x}$ & $50 \%$ \\
\hline & $\begin{array}{l}\text { A rodovia é capaz de suportar com segurança a circulação de veículos de grande porte, } \\
\text { caminhões, ônibus, veiculos de emergência, veículos de manutenção da rodovia? }\end{array}$ & $\mathrm{x}$ & $\mathrm{x}$ & $\mathrm{x}$ & $50 \%$ \\
\hline & Se necessário, a rodovia pode ser fechada para eventos especiais de forma segura? & $\mathrm{x}$ & $\mathrm{x}$ & $x$ & $50 \%$ \\
\hline & Se for o caso, os requisitos especiais de paisagem e rotas turisticas são satisfeitos? & $\mathrm{x}$ & $\mathrm{x}$ & $\mathrm{x}$ & $50 \%$ \\
\hline & Outros assuntos que podem ter influência sobre a segurança foram abordados? & & $\mathrm{x}$ & x & $25 \%$ \\
\hline & $\begin{array}{l}\text { Existem quaisquer perigos na estrada que podem ser: reesenhados, relocados, protegidos } \\
\text { por barreiras de tráfego? }\end{array}$ & & & $\mathrm{x}$ & $25 \%$ \\
\hline
\end{tabular}




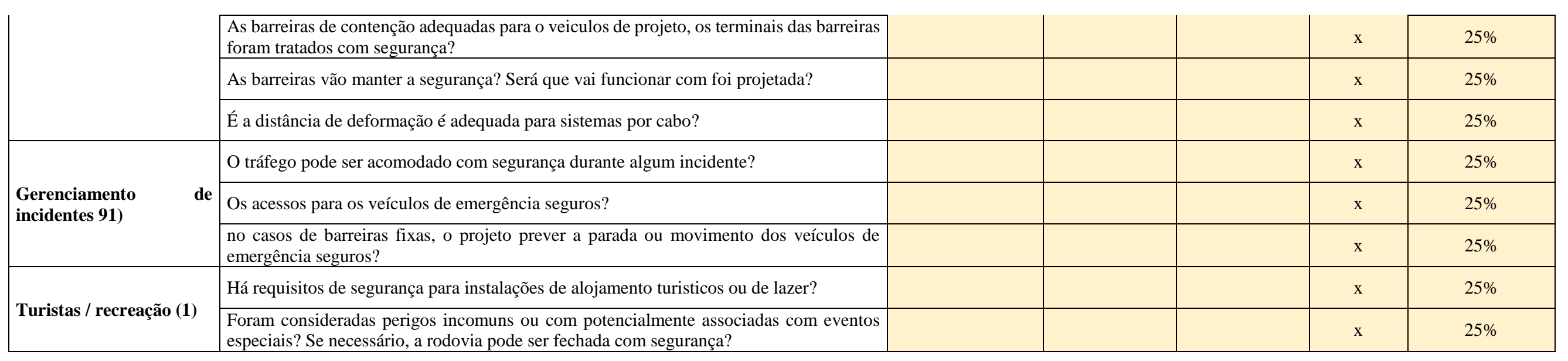


APÊNDICE C3 - MICROCATEGORIA - PROJETO EXECUTIVO - ANÁLISE DE FREQUÊNCIA

\begin{tabular}{|c|c|c|c|c|c|c|}
\hline Macro e mesocategorias & Microcategorias & $\begin{array}{l}\text { Hildebrand e Wilson } \\
\text { (1999) }\end{array}$ & $\begin{array}{l}\text { Castrillón e Candia } \\
\quad(2003)\end{array}$ & $\begin{array}{l}\text { Austroads } \\
(2009)\end{array}$ & RTMC (2012) & Frequência \\
\hline 1. Tópicos Gerais & 1. Tópicos Gerais & 1. Tópicos Gerais & & & & Frequência \\
\hline \multirow{2}{*}{$\begin{array}{l}\text { Transição do existente como } \\
\text { o novo projeto (1) }\end{array}$} & $\begin{array}{l}\text { Existe alguma mudança súbita nas características do limite de velocidade, acesso ou } \\
\text { atrito lateral? }\end{array}$ & $\mathrm{x}$ & & & & $25 \%$ \\
\hline & $\begin{array}{l}\text { Será que a interface ocorre perto riscos (ou seja, próximo a crista de curvas verticais, } \\
\text { etc.)? }\end{array}$ & $\mathrm{x}$ & & & & $25 \%$ \\
\hline \multirow{3}{*}{$\begin{array}{l}\text { Etapas de construção }(1,2 \text {, } \\
3 \text { e 4) }\end{array}$} & $\begin{array}{l}\text { Quais são os efeitos da realização da construção do projeto com um único contrato } \\
\text { ou dividindo-a em vários contratos? }\end{array}$ & $\mathrm{x}$ & & & & $25 \%$ \\
\hline & $\begin{array}{l}\text { Se o projeto for ser construído ou implementado em diferentes fases: a) Foram } \\
\text { detalha adequadamente para garantir a segurança? b) As fases de construção é } \\
\text { segura? c) Existem medidas para acomodar a gestão de tráfego temporário entra as } \\
\text { diferentes fases? }\end{array}$ & & & $\mathbf{x}$ & $\mathbf{x}$ & $50 \%$ \\
\hline & $\begin{array}{l}\text { Se a construção for realizada em vários contratos, eles serão realizados de forma } \\
\text { segurança? }\end{array}$ & & $\mathbf{x}$ & & $\mathbf{x}$ & $50 \%$ \\
\hline \multirow{2}{*}{$\begin{array}{l}\text { As modificações feitas de } \\
\text { Auditoria anterior }\end{array}$} & $\begin{array}{l}\text { Verifique se houve alterações nas condições para que o projeto foi planejado } \\
\text { inicialmente. }\end{array}$ & $\mathbf{x}$ & $\mathbf{x}$ & $\mathbf{x}$ & $\mathbf{x}$ & $100 \%$ \\
\hline & Em caso que houve auditoria anterior, houve alterações no escopo do projeto? & $\mathbf{x}$ & $\mathbf{x}$ & $\mathbf{x}$ & $\mathbf{x}$ & $100 \%$ \\
\hline \multirow{3}{*}{ Barreiras de tráfego } & $\begin{array}{l}\text { Há presença de obejtos intransponíveis ou objetos fixos perigosos dentro da zona } \\
\text { livre? }\end{array}$ & $\mathrm{x}$ & & & & $25 \%$ \\
\hline & $\begin{array}{l}\text { Existe risco em potencial de veículos atravesarem o canteiro central e irem para a } \\
\text { pista de sentido contrário? }\end{array}$ & $\mathrm{x}$ & & & & $25 \%$ \\
\hline & Existe histórico de acidentes da área? & $\mathrm{x}$ & & & & $25 \%$ \\
\hline \multirow{6}{*}{ Drenagem (2) } & O projeto proposto de dreangem da rodovia está de forma adequado? & $\mathbf{x}$ & $\mathbf{x}$ & $\mathbf{x}$ & $\mathbf{x}$ & $100 \%$ \\
\hline & A inclinação longitudinal e transversal está adequada para drenagem satisfatória? & $\mathbf{x}$ & & $\mathbf{x}$ & & $50 \%$ \\
\hline & $\begin{array}{l}\text { Seções planas são evitadas ou adequadamente distribuídas no início ou no final de } \\
\text { uma curvatura? }\end{array}$ & $\mathbf{x}$ & & $\mathbf{x}$ & & $50 \%$ \\
\hline & $\begin{array}{l}\text { Foi considerado a possibilidade de inundações da superficie da rodovia, incluindo o } \\
\text { transbordamento dos rios e bueiros? }\end{array}$ & $\mathbf{x}$ & $\mathbf{x}$ & $\mathbf{x}$ & $\mathbf{x}$ & $100 \%$ \\
\hline & A profundidade do canal é adequado para limitar as enchentes? & & $\mathbf{x}$ & $\mathbf{x}$ & & $50 \%$ \\
\hline & As grelhas dos bueiro foram projetadas de forma segurança para os motociclistas? & & $\mathbf{x}$ & $\mathbf{x}$ & & $50 \%$ \\
\hline
\end{tabular}




\begin{tabular}{|c|c|c|c|c|c|c|}
\hline & Os locais de drenagem são adequados? & & & $\mathbf{x}$ & & $50 \%$ \\
\hline & Os locais de passagem de pedestres tem drenagem adequada? & & $\mathbf{x}$ & & & $25 \%$ \\
\hline & $\begin{array}{l}\text { Há alguma vegetação ou outros efeitos ambientais que dificulta o funcionamento das } \\
\text { entradas das drenagem (como por exemplo, cana-de-açúcar bloqueando as entradas)? }\end{array}$ & & & & $\mathbf{x}$ & $25 \%$ \\
\hline Condições climáticas (2) & $\begin{array}{l}\text { Foi considerado regitros meteorológios ou experiência local que pudesse indicar } \\
\text { algum problema particular das condições climáticas? (por exemplo, neve, gelo vento } \\
\text { nevoeiro). }\end{array}$ & & $\mathbf{x}$ & $\mathbf{x}$ & $\mathbf{x}$ & $75 \%$ \\
\hline \multirow{8}{*}{ Paisagismo } & $\begin{array}{l}\text { O paisagismo está em conformidade com as orientações das normas? (como por } \\
\text { exemplo, vãos livres, distância de visibilidade, etc.) }\end{array}$ & $\mathbf{x}$ & & & & $25 \%$ \\
\hline & $\begin{array}{l}\begin{array}{l}\text { Os vãos livres e distâncias de visibilidade poderão ficar restritas devido o } \\
\text { crescimento futuro da vegetação? (nativa ou plantada) }\end{array} \\
\end{array}$ & $\mathbf{x}$ & & & & $25 \%$ \\
\hline & $\begin{array}{l}\text { Será que os motoristas possam ver os pedestres (e vice-versa) ao passar sobre o } \\
\text { paisagismo? }\end{array}$ & & & $\mathbf{x}$ & & $25 \%$ \\
\hline & $\begin{array}{l}\text { Nas interseções a linha de visibilidade será mantida ao passar pelo paisagismo ou } \\
\text { sobre o paisagismo? }\end{array}$ & & & $\mathbf{x}$ & & $25 \%$ \\
\hline & $\begin{array}{l}\text { Será que a segurança está adequada, com crescimento sazonal? (por exemplo, } \\
\text { nenhum obscurecimento de sinalização vertical, sombreamento ou efeitos de luz, } \\
\text { superfície escorregadia, etc.) }\end{array}$ & & & $\mathbf{x}$ & & $25 \%$ \\
\hline & $\begin{array}{l}\text { Será que a segurança rodoviária ser adequada quando as árvores frutíferas ou } \\
\text { plantações (sem perigo ma margem da rodovia)? }\end{array}$ & & & $\mathbf{x}$ & $\mathbf{x}$ & $50 \%$ \\
\hline & Há possibilidade de vegetação "quebrável" na faixa de domínio? & & & $\mathbf{x}$ & & $25 \%$ \\
\hline & $\begin{array}{l}\begin{array}{l}\text { O paisagismo está em conformidade com as orientações das normas de segurança? } \\
\text { (como por exemplo, vãos livres, distância de visibilidade, etc.) }\end{array} \\
\end{array}$ & & & & $\mathbf{x}$ & $25 \%$ \\
\hline $\begin{array}{l}\text { Consistência dos parâmetros } \\
\text { do projeto (1) }\end{array}$ & $\begin{array}{l}\text { Os parâmetros do projeto são consistentes em relação ao alinhamento, seção } \\
\text { transversal, interseções em nível e desníveis? }\end{array}$ & $\mathbf{x}$ & & & & $25 \%$ \\
\hline \multirow{4}{*}{ Serviço (2) } & $\begin{array}{l}\text { O projeto considera o prestação de serviços com segurança de modo a não criar riscos } \\
\text { para os usuários? (como telenones de emergência, parada de ônibus, etc) }\end{array}$ & & $\mathbf{x}$ & & & $25 \%$ \\
\hline & $\begin{array}{l}\text { A localização de objetos fixos ou serviços móveis foram verificados, incluindo a } \\
\text { posição dos postes? }\end{array}$ & & $\mathbf{x}$ & $\mathbf{x}$ & $\mathbf{x}$ & $75 \%$ \\
\hline & O projeto lidar adequadamente com os serviços aéreos e subterrâneos? & & & $\mathbf{x}$ & $\mathbf{x}$ & $50 \%$ \\
\hline & $\begin{array}{l}\text { Algum serviço poderá interferir no direito de passagem dos outros usuários da } \\
\text { rodovia:? }\end{array}$ & & & & $\mathbf{x}$ & $25 \%$ \\
\hline \multirow{3}{*}{$\begin{array}{l}\text { Áreas de descanso ou áreas } \\
\text { de piquiniques }\end{array}$} & As áreas de piquinique e descando são desejáveis? & $\mathbf{x}$ & & & & $25 \%$ \\
\hline & O número de áreas de descando / piquinique estão adequadas para o projeto? & $\mathbf{x}$ & & & & $25 \%$ \\
\hline & Os acessos as áreas de descanso e piquinique são seguros? & $\mathbf{x}$ & & & & $25 \%$ \\
\hline
\end{tabular}




\begin{tabular}{|c|c|c|c|c|c|c|}
\hline & Áreas de descanso / piquiniques estão localizadas em locais apropriadaos? & $\mathbf{x}$ & & & & $25 \%$ \\
\hline & $\begin{array}{l}\text { Existe sinalização adequada e posicionada corretamente informando aos usuários } \\
\text { sobre a aaproximação de áreas de piquinique e descanso? }\end{array}$ & $\mathbf{x}$ & & & & $25 \%$ \\
\hline \multirow{6}{*}{$\begin{array}{l}\text { Acesso e Veículos de } \\
\text { emergência }\end{array}$} & $\begin{array}{l}\text { o projeto prever o acesso seguro e circulação de veículos de emergência? (como por } \\
\text { exemplo, caminhão dos bombeiros) }\end{array}$ & & $\mathbf{x}$ & $\mathbf{x}$ & $\mathbf{x}$ & $75 \%$ \\
\hline & $\begin{array}{l}\text { A concepção e execução no projeto das barreiras centrais que permite que veiculos } \\
\text { de emergência posam parar e retornar por outros caminhos sem interromper o } \\
\text { tráfego? }\end{array}$ & & $\mathbf{x}$ & $\mathbf{x}$ & $\mathbf{x}$ & $75 \%$ \\
\hline & $\begin{array}{l}\text { Os veículos com deficiência ou veículos de emergência parados, eles foram } \\
\text { considerados de forma adequada? }\end{array}$ & & $\mathbf{x}$ & $\mathbf{x}$ & $\mathbf{x}$ & $75 \%$ \\
\hline & A disposição dos telefones de emergência é satisfatória? & & $\mathbf{x}$ & $\mathbf{x}$ & & $50 \%$ \\
\hline & $\begin{array}{l}\text { As aberturas nas divisórias dos canteiros centrais de vias duplicadas estão localizadas } \\
\text { em locais seguros? (isto é frequência, visibilidade) }\end{array}$ & & $\mathbf{x}$ & $\mathbf{x}$ & $\mathbf{x}$ & $75 \%$ \\
\hline & Veículos de manutenção de rotina podem ser localizados de forma segura? & & & & $\mathbf{x}$ & $25 \%$ \\
\hline \multirow{2}{*}{$\begin{array}{l}\text { Expansão e/ou } \\
\text { realinhamento futuro }\end{array}$} & $\begin{array}{l}\text { Se o projeto representa a ampliação de uma seção da rodovia, no sentido de via dupla, } \\
\text { o projeto é adequado e seguro para ser entendido pelos motoristas? }\end{array}$ & & $\mathbf{x}$ & $\mathbf{x}$ & $\mathbf{x}$ & $75 \%$ \\
\hline & A transição é segura entre uma rodovia de pista simples e de pista dupla e vice-versa? & & $\mathbf{x}$ & $\mathbf{x}$ & $\mathbf{x}$ & $75 \%$ \\
\hline \multirow[t]{2}{*}{ Etapas de projetos } & $\begin{array}{l}\text { O projeto pode ser desenvolvido por etapas, ou construídos em épocas diferentes: } \\
\text { será que os planos e programas de cosntrução podem ser modificados para melhorar } \\
\text { o nível de segurança do projeto? }\end{array}$ & & $\mathbf{x}$ & $\mathbf{x}$ & & $50 \%$ \\
\hline & $\begin{array}{l}\text { Os planos e programas de construção incluem medidas de segurança especifícas } \\
\text { como sinalização, transições geométricas adequadas, etc. para um plano temporário? }\end{array}$ & & $\mathbf{x}$ & & $\mathbf{x}$ & $50 \%$ \\
\hline \multirow{5}{*}{$\begin{array}{l}\text { Tipos e controle de acesso às } \\
\text { propriedade } \\
\text { desenvovilemento }(1,2,3 \text { e } 4)\end{array}$} & $\begin{array}{l}\text { Exitem fatores a montante ou a jusante que poderão afetar o pontos de acesso? (perto } \\
\text { de interseções) }\end{array}$ & $\mathbf{x}$ & $\mathbf{x}$ & $\mathbf{x}$ & $\mathbf{x}$ & $100 \%$ \\
\hline & $\begin{array}{l}\text { Existe poluição visual (outdoor com propogandas comerciais ou iluminação } \\
\text { excessiva) próximo as áreas de direito de passagens? }\end{array}$ & $\mathbf{x}$ & & & & $25 \%$ \\
\hline & $\begin{array}{l}\text { Todos os acessos podem ser usados com segurança? (considerando as entradas, } \\
\text { saídas e junções) }\end{array}$ & & $\mathbf{x}$ & $\mathbf{x}$ & $\mathbf{x}$ & $75 \%$ \\
\hline & $\begin{array}{l}\text { O acesso as áreas para descando e estacionamento de caminhões tem distância de } \\
\text { visibilidade adequada? }\end{array}$ & & $\mathbf{x}$ & $\mathbf{x}$ & $\mathbf{x}$ & $75 . \%$ \\
\hline & $\begin{array}{l}\text { A largura da faixa de direito de passagem atende aos requisitos necessários a } \\
\text { acessibilidade? }\end{array}$ & $\mathbf{x}$ & & & & $25 \%$ \\
\hline \multirow{3}{*}{$\begin{array}{l}\text { Desenvolvimento urbanos } \\
\text { adjacentes (2) ou Impacto } \\
\text { sobre as redes adjacentes (1) }\end{array}$} & O volume de tráfego das rodovias adjacentes mudará com o novo projeto? & $\mathbf{x}$ & & & & $25 \%$ \\
\hline & $\begin{array}{l}\text { Se o volume de tráfego e fluxo for alterado ao longo das rodovias adjacentes, foi } \\
\text { considerado o direito de passagem? }\end{array}$ & $\mathbf{x}$ & & & & $25 \%$ \\
\hline & $\begin{array}{l}\text { O projeto considera o acesso aos maiores geradores de tráfego e de desenvolvimento } \\
\text { urbano adjacente com segurança? }\end{array}$ & & $\mathbf{x}$ & $\mathbf{x}$ & & $50 \%$ \\
\hline
\end{tabular}




\begin{tabular}{|c|c|c|c|c|c|c|}
\hline & $\begin{array}{l}\text { A percepção dos motoristas poderiam ser afetada pelos efeitos de luzes refletidas ou } \\
\text { de trânsito a partir das rodovias adjacentes? }\end{array}$ & & $\mathbf{x}$ & $\mathbf{x}$ & & $50 \%$ \\
\hline & $\begin{array}{l}\text { A necesidade de telas antiofuscante por causa da iluminação das propriedades } \\
\text { adjacentes considerou-se de forma adequada? }\end{array}$ & & $\mathbf{x}$ & $\mathbf{x}$ & & $50 \%$ \\
\hline & $\begin{array}{l}\text { O projeto irá acomodar o tráfego gerado por desenvolvimento adjacente e da rede } \\
\text { rodoviária adjacente com segurança? }\end{array}$ & & & & $\mathbf{x}$ & $25 \%$ \\
\hline & $\begin{array}{l}\text { O projeto é compatível com a percepção do motorista a partir dos sinais de } \\
\text { iluminação e de trânsito geradas pelas seções das rodovias adjacentes? }\end{array}$ & & & & $\mathbf{x}$ & $25 \%$ \\
\hline & $\begin{array}{l}\text { O projeto prever a possibilidade de desenvolvimento dos usuários da rodovia que } \\
\text { será gerado com o desenvolvimento do solo aadjacente e da rede rodoviária } \\
\text { existente? }\end{array}$ & & & & $\mathbf{x}$ & $25 \%$ \\
\hline & Existem problenas do uso do solo que terá efeito sobre a segurança do projeto? & & & & $\mathbf{x}$ & $25 \%$ \\
\hline \multirow{5}{*}{ Entorno da via } & $\begin{array}{l}\text { Os motoristas serão capazes de ver os pedestres (e vice-versa) além da paisagem } \\
\text { (montanhas, vales, rios, vegetação, etc.)? }\end{array}$ & & $\mathbf{x}$ & & & $25 \%$ \\
\hline & A linha de visibilidade em um cruzamento será mantido além ou na paisagem? & & $\mathbf{x}$ & & & $25 \%$ \\
\hline & $\begin{array}{l}\text { A segurança será adequada às mudanças sazonais (por exemplo, nenhum sinal de } \\
\text { trânsito, proteção do sol ou efeitos de luz, a superfície de gelo escorregadio, } \\
\text { escurecendo etc.)? }\end{array}$ & & $\mathbf{x}$ & & & $25 \%$ \\
\hline & $\begin{array}{l}\text { Asegurança na borda da pista permanecerá quando as árvores crescerem, } \\
\text { florescerem? }\end{array}$ & & $\mathbf{x}$ & & & $25 \%$ \\
\hline & $\begin{array}{l}\text { foram utilizado vegetação frágil em áreas onde o potencial de risco de veículos } \\
\text { sairem do percurso? }\end{array}$ & & $\mathbf{x}$ & & & $25 \%$ \\
\hline $\begin{array}{l}\text { Estabilidade de corte e } \\
\text { aterro }\end{array}$ & $\begin{array}{l}\text { A estabilidade das encostas é adequada? (Por exemplo, sem o risco de material solto } \\
\text { para afetar os usuários da rodovia) }\end{array}$ & & $\mathbf{x}$ & $\mathbf{x}$ & & $50 \%$ \\
\hline Resistência ao deslizamento & $\begin{array}{l}\text { foi considerada a necessidade de um revestimento antiderrapante em áreas onde a } \\
\text { frenagem exige boa aderência da rodovia? (por exemplo, inclinações, curvas, e } \\
\text { quando se aproxima de cruzamentos e semáforos). }\end{array}$ & & $\mathbf{x}$ & $\mathbf{x}$ & $\mathbf{x}$ & $75 \%$ \\
\hline $\begin{array}{l}\text { 2. Alinhamento e Seções } \\
\text { Transversais e projeto }\end{array}$ & 2. Alinhamento e Secções Transversais & \multicolumn{4}{|c|}{ 2. Alinhamento e Seções Transversais } & Frequência \\
\hline \multirow{3}{*}{$\begin{array}{l}\text { Padrões gerais do projeto }(2, \\
3 \text { e 4) }\end{array}$} & a velocidade de projeto é compatível com a velocidade operacional esperada? & & & & $\mathrm{x}$ & $25 \%$ \\
\hline & $\begin{array}{l}\text { Os veículos de projeto foram usados adequadamente? (especificamente para os } \\
\text { possíveis movimentos restritos de giro? }\end{array}$ & & & & $\mathrm{x}$ & $25 \%$ \\
\hline & $\begin{array}{l}\text { A velocidade de projeto e limites de velocidade propostas estão apropriadas para a } \\
\text { topografia e função da rodovia? São apropriados para os veículos de projeto e } \\
\text { usuários da rodovia? }\end{array}$ & & & & $\mathrm{x}$ & $25 \%$ \\
\hline \multirow[b]{2}{*}{ Drenagem } & O canal de drenagem é adequado para topografia, manutenção e neve à deriva? & $\mathrm{x}$ & & & & $25 \%$ \\
\hline & $\begin{array}{l}\text { A seção transversal fornece com segurança drenagem paralela ou perpendicular à } \\
\text { estrada? (como por ecemplo, as inclinações laterais são de drenos de concretos, onde } \\
\text { os veículos errantes podem recuperar depois de enttrar? }\end{array}$ & & & & $\mathrm{x}$ & $25 \%$ \\
\hline
\end{tabular}




\begin{tabular}{|c|c|c|c|c|c|c|}
\hline & $\begin{array}{l}\text { Se os bueiros de concreto representam risco de interceptação de veículos, tem } \\
\text { previsão de canalização para guiar esses veiculos? }\end{array}$ & & & & $\mathrm{x}$ & $25 \%$ \\
\hline & $\begin{array}{l}\text { Existem muros de concreto (barreiras) perpendiculares a rodovia principal inclinados } \\
\text { para reduzir o impacto em cima de veículos errantes? }\end{array}$ & & & & $\mathrm{x}$ & $25 \%$ \\
\hline & $\begin{array}{l}\text { O layout dos drenos da rodovia estão de tal forma disponibilizados que não } \\
\text { representaa perigo para os ciclistas? ão entradas de freio afastado da face do guarda- } \\
\text { corpos? }\end{array}$ & & & & $\mathrm{x}$ & $25 \%$ \\
\hline Largura das faixas & A largura da faixa é adequada para o projeto viário / classificação? & $\mathrm{x}$ & & & & $25 \%$ \\
\hline \multirow{6}{*}{ Acostamento } & $\begin{array}{l}\text { A largura dos acostamentos são adequados para todos os veículos e os usuários da } \\
\text { rodovia? }\end{array}$ & $\mathrm{x}$ & & & & $25 \%$ \\
\hline & A inclinação transversal do acostamento é adequada para a drenagem? & $\mathrm{x}$ & & & & $25 \%$ \\
\hline & O tratamento dos aterros são adequados? & $\mathrm{x}$ & & & & $25 \%$ \\
\hline & Existem desníveis? & $\mathrm{x}$ & & & & $25 \%$ \\
\hline & O revestimento do acostamento é adequado para a classificação da rodovia? & $\mathrm{x}$ & & & & $25 \%$ \\
\hline & Faixas sonoras estão instaladas adequadamente onde necessárias? & $\mathrm{x}$ & & & & $25 \%$ \\
\hline \multirow{4}{*}{$\begin{array}{l}\text { Inclinação transversal } \\
\text { (taludes?)/ superelevação }\end{array}$} & $\begin{array}{l}\text { A inclinação transversal do projeto da rodovia é suficiente para dreangen de águas } \\
\text { pluviais e facillita o tratamento de degelos? }\end{array}$ & $\mathrm{x}$ & & & & $25 \%$ \\
\hline & $\begin{array}{l}\text { Existem diferentes taxas de inclinação transversal ao longo das faixas de tráfego } \\
\text { adjacentes? }\end{array}$ & $\mathrm{x}$ & & & & $25 \%$ \\
\hline & $\begin{array}{l}\text { As mudanças da superelevação com as velocidades de operação pode resuktar em } \\
\text { eventual transferência do transporte de mercadorias em veículos pesados? }\end{array}$ & & & & $\mathrm{x}$ & $25 \%$ \\
\hline & todas as curvas com inclinação transversal adversa? & & & & $\mathrm{x}$ & $25 \%$ \\
\hline \multirow{4}{*}{$\begin{array}{lrr}\text { Elementos } & \text { da } & \text { Seção } \\
\text { transversal } & \text { e } & \text { Efeitos da } \\
\text { variações } & \text { da } & \text { seção } \\
\text { transversal (1) } & & \end{array}$} & $\begin{array}{l}\text { Determinar se o projeto proposto tem uma seção adequada para as necessidades } \\
\text { finais da rodovia, incluindo: classificação; velocidade de projeto; Nivel de } \\
\text { serviço/volumes de serviços de pico. }\end{array}$ & $\mathrm{x}$ & & & & $25 \%$ \\
\hline & $\begin{array}{l}\text { Determinar se os ajustes nas dimensões podem ser feitas para futuras possibilidades } \\
\text { de ampliação. }\end{array}$ & $\mathrm{x}$ & & & & $25 \%$ \\
\hline & $\begin{array}{l}\text { As larguras das faixas, acostamentos, canteiro central e outros elementos da seção } \\
\text { transversal são adequados para a função da rodovia? (seção típica) }\end{array}$ & & $\mathrm{x}$ & $\mathrm{x}$ & $\mathrm{x}$ & $75 \%$ \\
\hline & $\begin{array}{l}\text { A largura das faixas das rodovias e dos acostamentos é adequada a respesito de: } \\
\text { alinhamentos? Fluxo de tráfego? Dimensões dos veículos? Velocidade de projeto? } \\
\text { Combinações de veículos com o fluxo de tráfego? }\end{array}$ & & $\mathrm{x}$ & $\mathrm{x}$ & $\mathrm{x}$ & $75 \%$ \\
\hline
\end{tabular}




\begin{tabular}{|c|c|c|c|c|c|c|}
\hline & $\begin{array}{l}\text { As características das seções transversais estão em conformidade com os requisitos } \\
\text { de segurança estabelecidos para o projeto? }\end{array}$ & & & & $\mathrm{x}$ & $25 \%$ \\
\hline & As pistas em declive são seguras para veículos errantes se recuperarem? & & & & $\mathrm{x}$ & $25 \%$ \\
\hline & $\begin{array}{l}\text { A largura dos acostamentos estão adequados para acomodar veículos quebrados ou } \\
\text { de emergência? }\end{array}$ & & $x$ & $\mathrm{x}$ & & $50 \%$ \\
\hline & A largura do canteiro central é adequado para localizar os mobiliarios da rodovia? & & $\mathrm{x}$ & $\mathrm{x}$ & $\mathrm{x}$ & $75 \%$ \\
\hline & $\begin{array}{l}\text { Será que projetos na margem a rodovia permiti instalação segura de estruturas } \\
\text { aéreas? }\end{array}$ & & & & $\mathrm{x}$ & $25 \%$ \\
\hline & A superelevação é consistente com ambiente e velocidade da rodovia? & & & $\mathrm{x}$ & $\mathrm{x}$ & $50 \%$ \\
\hline & A inclinação transversal da rodovia é adequada com o entorno da rodovia? & & $\mathrm{x}$ & & & $25 \%$ \\
\hline & A inclinação dos acostamentos é segura para a circulação dos veículos? & & $\mathrm{x}$ & $\mathrm{x}$ & & $50 \%$ \\
\hline & As inclinações dos taludes é manobrável para automóveis e caminhões? & & $\mathrm{x}$ & $\mathrm{x}$ & & $50 \%$ \\
\hline & Existem instalações para os pedestres e ciclistas? & & $\mathrm{x}$ & $\mathrm{x}$ & $\mathrm{x}$ & $75 \%$ \\
\hline & As inclinações sob estruturas são adequadas? & & & $\mathrm{x}$ & & $25 \%$ \\
\hline & O projeto está livre de variações imprevistas em relação a seção transversal? & & $\mathrm{x}$ & $\mathrm{x}$ & & $50 \%$ \\
\hline & $\begin{array}{l}\text { As seções transversais são seguros (especialmente onde ass seções da rodovia } \\
\text { existentes foram utilizados ou serão utilizados para gerar acesso a estreitamentos em } \\
\text { pontes, etc.) }\end{array}$ & & $\mathrm{x}$ & $\mathrm{x}$ & & $50 \%$ \\
\hline & $\begin{array}{l}\text { todas as curvas com inclinação transversal adversa, estão dentro dos limites } \\
\text { adequados? }\end{array}$ & & $x$ & $\mathrm{x}$ & & $50 \%$ \\
\hline & A superelevação é adequada e suficiente em todos os lugares onde é necessária? & & $\mathrm{x}$ & $\mathrm{x}$ & & $50 \%$ \\
\hline & O projeto tem zonas livres adequadas, foram previstas? & & & & $\mathrm{x}$ & $25 \%$ \\
\hline & $\begin{array}{l}\text { Existem variações inesperadas da seção transversal que pode influenciar } \\
\text { negativamente a segurança? }\end{array}$ & $\mathrm{x}$ & $\mathrm{x}$ & & $\mathrm{x}$ & $75 \%$ \\
\hline & $\begin{array}{l}\text { As inclinações transversais são seguras? (particularmente quando as seções da } \\
\text { rodovia existente foram utilizadas ou será utilizada para implantação de acesso) }\end{array}$ & & & & $\mathrm{x}$ & $25 \%$ \\
\hline & A largura da seção transversal são seguras nos casos de estreitamento em pontes? & & $\mathrm{x}$ & & $\mathrm{x}$ & $50 \%$ \\
\hline \begin{tabular}{|l|} 
desenho ou detalhe da \\
geometria
\end{tabular} & $\begin{array}{l}\text { Os recursos da gestão do tráfego estão destinadas para evitar a criação de condições } \\
\text { inseguras e fornecer orientações adequadas? }\end{array}$ & & $\mathrm{x}$ & $\mathrm{x}$ & $\mathrm{x}$ & $75 \%$ \\
\hline
\end{tabular}




\begin{tabular}{|c|c|c|c|c|c|c|}
\hline & $\begin{array}{l}\text { O layout das demarcações e materiais reflexivos da rodovia são capazes de advertir } \\
\text { de forma satisfatória as mudanças de alinhamento? (principalmente quando } \\
\text { alinhamento for deficiente). }\end{array}$ & & $\mathrm{x}$ & $\mathrm{x}$ & $\mathrm{x}$ & $75 \%$ \\
\hline & As faixas de ultrapassagem foram contempladas adequadamente? & & $\mathrm{x}$ & $\mathrm{x}$ & & $50 \%$ \\
\hline & $\begin{array}{l}\text { As faixas de ultrapassagem são previstas com segurança no início e ao término das } \\
\text { manobras? E estão devidamentes sinalizadas? }\end{array}$ & & $x$ & $\mathrm{x}$ & $\mathrm{x}$ & $75 \%$ \\
\hline & Os requisitos para ultrapassagem são satisfátórios? & & $\mathrm{x}$ & $\mathrm{x}$ & & $50 \%$ \\
\hline & $\begin{array}{l}\text { O projeto pode criar problema de visibilidade para o motorista produzido pelo nascer } \\
\text { do sol ou pôr do sol? }\end{array}$ & & $\mathrm{x}$ & $\mathrm{x}$ & & $50 \%$ \\
\hline & Os requisitos de transporte público foram devidamente atendidos? & & $\mathrm{x}$ & $\mathrm{x}$ & & $50 \%$ \\
\hline & As normas de projeto são apropriadas para todos os requisitos do projeto? & & $\mathrm{x}$ & $\mathrm{x}$ & & $50 \%$ \\
\hline & $\begin{array}{l}\text { A largura das faixas e inclinação transversal são consistentes com as normas e } \\
\text { orientações gerais do projeto? }\end{array}$ & & $\mathrm{x}$ & $\mathrm{x}$ & & $50 \%$ \\
\hline Superlargura do pavimento & $\begin{array}{l}\text { A largura do pavimento prevista é suficiente ao longo das curvas onde são esperadas } \\
\text { saídas dos veículos? }\end{array}$ & $x$ & & & & $25 \%$ \\
\hline \multirow{4}{*}{$\begin{array}{l}\text { acostamento e tratamento de } \\
\text { bordas }\end{array}$} & $\begin{array}{l}\text { Os seguintes aspectos de segurança são previstos nos acostamentos de forma } \\
\text { satisfatória: previsão de revestimento/ Largura e tratamentos de aterros? Inclinação } \\
\text { transversal do acostamento? }\end{array}$ & & $\mathrm{x}$ & $\mathrm{x}$ & $\mathrm{x}$ & $75 \%$ \\
\hline & Os acostamentos são seguros para os veículos em movmento lento ou bicicletas? & & $\mathrm{x}$ & $\mathrm{x}$ & $\mathrm{x}$ & $75 \%$ \\
\hline & $\begin{array}{l}\text { A larrgura dos acostamentos são suficientes para veículos pararem na margem da } \\
\text { rodovia? }\end{array}$ & & & & $\mathrm{x}$ & $25 \%$ \\
\hline & As áreas de descanso e paradas de caminhões foram projetados com segurança? & & & & $\mathrm{x}$ & $25 \%$ \\
\hline alinhamento & $\begin{array}{l}\text { Existem curvas muitos acentuadas que possam causar derrapagens em condições de } \\
\text { climáticas adversas? }\end{array}$ & $\mathrm{x}$ & & & & $25 \%$ \\
\hline \multirow{2}{*}{ alinhamento horizontal } & Verificar se curvas de transição são necessárias entre tangentes e curvas circulares & $\mathrm{x}$ & & & & $25 \%$ \\
\hline & $\begin{array}{l}\text { É adequada a combinação da superelevação e curvas de transição em relação aos } \\
\text { efeitos de drenagem? }\end{array}$ & $\mathrm{x}$ & & & & $25 \%$ \\
\hline \multirow{4}{*}{ alinhamento vertical } & $\begin{array}{l}\text { Existem rampas com inclinação excessivas que podem ser inseguras em condições } \\
\text { climáticas adversas? }\end{array}$ & $\mathrm{x}$ & & & & $25 \%$ \\
\hline & $\begin{array}{l}\text { Está prevista faixa de ultrapassagem em áreas onde a ultrapassagem e as manobras } \\
\text { de ultrapassagem são limitadas devido ao terreno? }\end{array}$ & $\mathrm{x}$ & & & & $25 \%$ \\
\hline & $\begin{array}{l}\text { Está prevista faixa de ultrapassagem em áreas onde a inclinação excede o } \\
\text { comprimento crítico do greide? }\end{array}$ & $\mathrm{x}$ & & & & $25 \%$ \\
\hline & $\begin{array}{l}\text { Verificar se áreas de escape são previstas onde necessárias em declives acentuados. } \\
\text { Se não, áreas de escape são viáveis }\end{array}$ & $\mathrm{x}$ & & & & $25 \%$ \\
\hline
\end{tabular}




\begin{tabular}{|c|c|c|c|c|c|c|}
\hline & Existem provisões de oportunidades de ultrapassagens adequadas? & $\mathrm{x}$ & & & & $25 \%$ \\
\hline & Existe espaçamento suficiente entre as zonas de ultrapassagens? & $\mathrm{x}$ & & & & $25 \%$ \\
\hline \multirow{8}{*}{$\begin{array}{l}\text { Combinação do alinhamento } \\
\text { horizontal e vertical }\end{array}$} & $\begin{array}{l}\text { Verificar a interação entre o alinhamento horizontal e vertical na via (isto é, } \\
\text { alinhamentos tipo de montanha-russa, com sequências de curvas verticais e } \\
\text { horizontais, etc.) }\end{array}$ & $\mathrm{x}$ & & & & $25 \%$ \\
\hline & O projeto de alinhamento horizontal e vertical estão alinhados corretamente? & & $\mathrm{x}$ & $\mathrm{x}$ & $\mathrm{x}$ & $75 \%$ \\
\hline & alinhamento vertical é constante e adequado em todos os lugares? & & $\mathrm{x}$ & $\mathrm{x}$ & & $50 \%$ \\
\hline & O alinhamento horizontal é constante em todos os lugares? & & $\mathrm{x}$ & $\mathrm{x}$ & & $50 \%$ \\
\hline & O alinhamento é compatível com a função da estrada? & & $\mathrm{x}$ & $\mathrm{x}$ & & $50 \%$ \\
\hline & $\begin{array}{l}\text { O projeto pode causar sugestões visuais enganosas para os motoristas (por exemplo, } \\
\text { ilusões visuais, com delimitação de linhas subliminar como dos postes? }\end{array}$ & & $\mathrm{x}$ & $\mathrm{x}$ & $\mathrm{x}$ & $75 \%$ \\
\hline & $\begin{array}{l}\text { O projeto da sinalização vertical nos alinhamentos horizontal e vertical, permite aos } \\
\text { motoristas fazer boa leitura da projeto? }\end{array}$ & & & & $\mathrm{x}$ & $25 \%$ \\
\hline & O alinhamento horizontal e vertical é consistente com a velocidade de operação? & & & & $\mathrm{x}$ & $25 \%$ \\
\hline \multirow{9}{*}{$\begin{array}{l}\text { Visibilidade e Distâmcia de } \\
\text { visibilidade }\end{array}$} & \begin{tabular}{|lrcrrr}
$\begin{array}{l}\text { Certififique-se que as oportunidades de } \\
\text { adequadamente. }\end{array}$ & ultrapassagem estão prevista \\
\end{tabular} & $\mathrm{x}$ & & & & $25 \%$ \\
\hline & $\begin{array}{l}\text { Determinar se a distância de visibilidade de parada estão previstas em toda a extensão } \\
\text { do projeto. }\end{array}$ & $\mathrm{x}$ & & & & $25 \%$ \\
\hline & $\begin{array}{l}\text { Verificar se existe distância de visibilidade de decisão adequada para sinalização de } \\
\text { interseção em nível e denivel em toda ao longo do projeto } \\
\end{array}$ & $\mathrm{x}$ & & & & $25 \%$ \\
\hline & $\begin{array}{l}\text { Os alinhamentos verticais e horizontais fornece distância de visibilidade e } \\
\text { visibilidade necessária? }\end{array}$ & & $\mathrm{x}$ & $\mathrm{x}$ & $\mathrm{x}$ & $75 \%$ \\
\hline & Os alinhamentos horizontal e vertical são consistente com a visibilidade necessária? & & $\mathrm{x}$ & $\mathrm{x}$ & & $50 \%$ \\
\hline & $\begin{array}{l}\text { A velocidade de projeto é adequada e foram selecionadas pelos requisitos de } \\
\text { visibilidade? }\end{array}$ & & & $\mathrm{x}$ & & $25 \%$ \\
\hline & $\begin{array}{l}\text { A linha de visibilidade e redução da disttância de visibilidade do projeto obstruída } \\
\text { por: defensas, outdoors na margem da rodovia: cercas ou divisórias; mobiliário na } \\
\text { rodovia; Estacionamentos, sinalização vertical, vegetação e paisagismo, estrutura de } \\
\text { pontes, veiculos estacionados na margem da rodovia, ou filas formadas pelos } \\
\text { veículos. }\end{array}$ & & $\mathrm{x}$ & $\mathrm{x}$ & $\mathrm{x}$ & $75 \%$ \\
\hline & Os cruzamentos ferroviários, pontes e outros riscos estão totalmente visiveis? & & $\mathrm{x}$ & $\mathrm{x}$ & & $50 \%$ \\
\hline & $\begin{array}{l}\text { Os cruzamentos ferroviários, pontes e outros riscos estão totalmente visiveis nas } \\
\text { condições diurna e nortuna? }\end{array}$ & & & & $\mathrm{x}$ & $25 \%$ \\
\hline
\end{tabular}




\begin{tabular}{|c|c|c|c|c|c|c|}
\hline & $\begin{array}{l}\text { Existem obstruções elevadas (tais como passagens superiores ou ferroviário, pórticos } \\
\text { de sinalização, galhos das árvores), que pode limitar a distância de visibilidade, } \\
\text { especialmente na parte inferior de uma curva vertical? }\end{array}$ & & $\mathrm{x}$ & $\mathrm{x}$ & $\mathrm{x}$ & $75 \%$ \\
\hline & Todos os riscos perceptíveis como pilares de pontes? & & & & $\mathrm{x}$ & $25 \%$ \\
\hline & $\begin{array}{l}\text { A rodovia pode ser usada por veículos de grande altura, ou se não, foi considerado } \\
\text { um desvio para uma rota alternativa quando necessário? }\end{array}$ & & $\mathrm{x}$ & $\mathrm{x}$ & & $50 \%$ \\
\hline & $\begin{array}{l}\text { A visibilidade está adequada para: pedestre, bicicletas ou travessia de animais,? } \\
\text { Acesso a rodovia, vias de acesso e no acesso a desníveis }\end{array}$ & & $\mathrm{x}$ & $\mathrm{x}$ & & $50 \%$ \\
\hline & $\begin{array}{l}\text { O projeto está livre de alguma outra característica do local que possam afetar a } \\
\text { visibilidade? }\end{array}$ & & $\mathrm{x}$ & $\mathrm{x}$ & $\mathrm{x}$ & $75 \%$ \\
\hline & $\begin{array}{l}\text { Foi considerado a visão minima do triângulo de visibilidade: nas entradas e saídas } \\
\text { de rampas? áreas de minas? nas interseções? rotatórias? ou outros pontos de } \\
\text { conflitos? }\end{array}$ & & & $\mathrm{x}$ & $\mathrm{x}$ & $50 \%$ \\
\hline & O projeto da interseção fornece boa visibilidade nas entradas e saídas de rampas? & & $\mathrm{x}$ & & & $25 \%$ \\
\hline & $\begin{array}{l}\text { Verifique se o alinhamneto horizontal e vertical está em conformidade com as } \\
\text { rodovias que se aproximam }\end{array}$ & $x$ & & & & $25 \%$ \\
\hline & $\begin{array}{l}\text { Verificar se o vão vertical é suficiente e a sinalização de restrição de altura é } \\
\text { apropriada }\end{array}$ & $\mathrm{x}$ & & & & $25 \%$ \\
\hline & O vão horizontal entre a rodovia e a mureta/guarda-corpo está adequado? & $\mathrm{x}$ & & & & $25 \%$ \\
\hline & $\begin{array}{l}\text { As distâncias de visibilidade de parada e ultrapassagem estão obstruídas pelos pilares } \\
\text { da ponte e guarda-corpos? }\end{array}$ & $x$ & & & & $25 \%$ \\
\hline & $\begin{array}{l}\text { É necessária sinalização para delineamento, restrição de peso, ou advertência de } \\
\text { congelamento da plataforma? Ela está instalada adequadamente? }\end{array}$ & $\mathrm{x}$ & & & & $25 \%$ \\
\hline & Existem grades de drenos que atrapalham os ciclistas? & $\mathrm{x}$ & & & & $25 \%$ \\
\hline Estruturas de pontes & $\begin{array}{l}\text { Existe redução da largura do acostamento na estrutura? Existem placas advertindo } \\
\text { essa redução? }\end{array}$ & $\mathrm{x}$ & & & & $25 \%$ \\
\hline & $\begin{array}{l}\text { O vão livre é adequado nas passagens subterrâneas ? O vão livre prever as alturas e } \\
\text { larguras mininas? }\end{array}$ & $x$ & & & & $25 \%$ \\
\hline & $\begin{array}{l}\text { São utilizados meio-fios de altura apropriados nos passeios, guarda-corpos e nas } \\
\text { guias de segurança (guarda-rodas) dnas estruturas das pontes? }\end{array}$ & $x$ & & & & $25 \%$ \\
\hline & $\begin{array}{l}\text { As características de drenagem são adequadas e estão incorporadas no projeto de } \\
\text { passagem inferior, viadutos e estruturas das pontes para evitar alagamentos? }\end{array}$ & $\mathrm{x}$ & & & & $25 \%$ \\
\hline & $\begin{array}{l}\text { Haverá percepçãp visual do afunilamento ou estreitamento nos túneis, viadutos } \\
\text { devido a localização dos pilares em relação à rodovia que passa sob a estrutura? }\end{array}$ & $\mathrm{x}$ & & & & $25 \%$ \\
\hline & $\begin{array}{l}\text { a base dos pilares das pontes está suficientemente afastada da zona livre de } \\
\text { obstáculos para classificação da rodovia? }\end{array}$ & $\mathrm{x}$ & & & & $25 \%$ \\
\hline & $\begin{array}{l}\text { Os espaços laterais, os espaços dos canteiros centrais e a zona livre de perigos das } \\
\text { pontes odedecem aos padrôes das classes da rodovia? }\end{array}$ & $x$ & & & & $25 \%$ \\
\hline
\end{tabular}




\begin{tabular}{|c|c|c|c|c|c|c|}
\hline \multirow{3}{*}{$\begin{array}{l}\text { Efeitos não conformes com } \\
\text { as normas ou diretrizes (2) }\end{array}$} & $\begin{array}{l}\text { No caso de adoção de algum aspecto particular no projeto não cumprir as normas? } \\
\text { A segurança foi mantida? }\end{array}$ & & $\mathrm{x}$ & $\mathrm{x}$ & & $50 \%$ \\
\hline & $\begin{array}{l}\text { Será que os detalhes típicos usados no projeto refletem as mehores práticas de } \\
\text { segurança rodoviária, foram revistos para a aplicação do projeto em particular? }\end{array}$ & & & & $\mathrm{x}$ & $25 \%$ \\
\hline & Se for detecatado algum projeto que não atende as normas: A segurança foi mantida? & & $\mathrm{x}$ & $\mathrm{x}$ & $\mathrm{x}$ & $75 \%$ \\
\hline \multirow{4}{*}{$\begin{array}{l}\text { Velocidade de projeto e/ou } \\
\text { velocidade sinalizada }(1,2,3 \\
\text { e 4) }\end{array}$} & $\begin{array}{l}\text { A velocidade de projeto está adequada com: Alinhamento vertical, horizontal, } \\
\text { visibilidade, acessos, entre cruzamentos, aceleração e desaceleração do fluxo de } \\
\text { veículos nos cruzamento, composição do tráfego previsto? }\end{array}$ & $\mathrm{x}$ & & & & $25 \%$ \\
\hline & Verifique a continuidade da velocidade de projeto e da velocidade regulamentada. & $\mathrm{x}$ & & & & $25 \%$ \\
\hline & Nas curvas a velocidade regulamentanda é adequada? & $\mathrm{x}$ & & & & $25 \%$ \\
\hline & O tráfego segue a velocidade regulamentada? & $\mathrm{x}$ & & & & $25 \%$ \\
\hline \multirow{11}{*}{$\begin{array}{l}\text { Transição entre a rodovia } \\
\text { nova e a existente }\end{array}$} & $\begin{array}{l}\text { A ligação ocorre distante da zona de perigo da rodovia (por exemplo, no topo da } \\
\text { curva vertical, eixo horizontal, perigos na margem da rodovia, ou em áreas de baixa } \\
\text { visibilidade ou distrações). }\end{array}$ & $\mathrm{x}$ & $\mathrm{x}$ & & & $50 \%$ \\
\hline & $\begin{array}{l}\text { Se as características das faixas da rodovia variar, a mundaça é efetuada com } \\
\text { segurança? }\end{array}$ & & $\mathrm{x}$ & & & $25 \%$ \\
\hline & $\begin{array}{l}\text { É segura a transição, em áreas onde o ambiente rodoviário muda (por exemplo, } \\
\text { quando se desloca da área urbana para rural, de um lugar restrito a irrestrito, de uma } \\
\text { via iluminada para uma sem iluminação)? }\end{array}$ & & $\mathrm{x}$ & & $\mathrm{x}$ & $50 \%$ \\
\hline & $\begin{array}{l}\text { Na transição da rodovia projetada com a existente, considerou a necessidade de aviso } \\
\text { prévio? }\end{array}$ & $\mathrm{x}$ & $\mathrm{x}$ & $\mathrm{x}$ & $\mathrm{x}$ & $100 \%$ \\
\hline & Foi considerado as implicações de segurança nas transições? & & $\mathrm{x}$ & $\mathrm{x}$ & & $50 \%$ \\
\hline & A transição entre o projeto antigo e o novo projeto é satisfatório? & & $\mathrm{x}$ & $\mathrm{x}$ & & $50 \%$ \\
\hline & $\begin{array}{l}\text { Se a rodovia existente possui padrão inferior ao novo projeto, a advertência da } \\
\text { redução é clara e inequívoca? }\end{array}$ & & $\mathrm{x}$ & $\mathrm{x}$ & & $50 \%$ \\
\hline & $\begin{array}{l}\text { Foram tomados medidas de segurança adequadas quando necessárias mudança súbita } \\
\text { de velocidade? }\end{array}$ & & $\mathrm{x}$ & $\mathrm{x}$ & & $50 \%$ \\
\hline & Acesso ou atrito lateral são tratados de forma segura? & & $\mathrm{x}$ & $\mathrm{x}$ & & $50 \%$ \\
\hline & Se o padrão das faixas varia, a alteração é realizada com segurança? & & $\mathrm{x}$ & $\mathrm{x}$ & & $50 \%$ \\
\hline & $\begin{array}{l}\text { A transição ocorre quando a mudança de ambiente é seguro? (Por exemplo, urbana } \\
\text { para rural, área com restrição ou sem restrições, uma área iluminada, ou sem } \\
\text { iluminação) }\end{array}$ & & $\mathrm{x}$ & $\mathrm{x}$ & & $50 \%$ \\
\hline $\begin{array}{l}\text { Legibilidade para os } \\
\text { motoristas }\end{array}$ & $\begin{array}{l}\text { O traçado geral, função e características gerais da rodovia será reconhecido pelos } \\
\text { motoristas com antecedência? }\end{array}$ & & $\mathrm{x}$ & $\mathrm{x}$ & & $50 \%$ \\
\hline
\end{tabular}




\begin{tabular}{|c|c|c|c|c|c|c|}
\hline & $\begin{array}{l}\text { As velocidades de aproximação são adequadas e os motoristas podem ser guiados } \\
\text { corretamente pela rodovia? }\end{array}$ & & $\mathrm{x}$ & $\mathrm{x}$ & & $50 \%$ \\
\hline $\begin{array}{l}\text { Tratamento de pontes e } \\
\text { bueiros }\end{array}$ & $\begin{array}{l}\text { A transição geométrica da seção transversal ao entrar na ponte pode ser realiazada } \\
\text { com segurança? }\end{array}$ & & $\mathrm{x}$ & $\mathrm{x}$ & & $50 \%$ \\
\hline Tratamento ambiental & $\begin{array}{l}\text { A segurança rodoviária foi considerada em lugares com determinadas características } \\
\text { ambientais? (por exemplo, painel anti-ruído) }\end{array}$ & & $\mathrm{x}$ & $\mathrm{x}$ & & $25 \%$ \\
\hline \multirow{2}{*}{ corte e aterro } & $\begin{array}{l}\text { Existem características geológicas de corte e aterro no projeto que poderá pôr em } \\
\text { perigo os usuários da rodovia? }\end{array}$ & & & & $\mathrm{x}$ & $25 \%$ \\
\hline & $\begin{array}{l}\begin{array}{l}\text { A estabilidade das encostas é adequada? (Por exemplo, sem o risco de material solto } \\
\text { para afetar os usuários da rodovia) }\end{array} \\
\end{array}$ & & & & $\mathrm{x}$ & $25 \%$ \\
\hline 3. Interseções & 3. Interseções & \multicolumn{4}{|l|}{ 3. Interseções } & Frequência \\
\hline & $\begin{array}{l}\text { As interseções estão livres de alguma característica incomum que pode afetar a } \\
\text { segurança rodoviária? }\end{array}$ & & & $\mathrm{x}$ & & $25 \%$ \\
\hline & $\begin{array}{l}\text { Considera-se corretamente à concepção dos veículos de projeto, e verificou que suas } \\
\text { dimensões não terá problemas de segurança em giros e retornos? }\end{array}$ & & $\mathrm{x}$ & $\mathrm{x}$ & & $50 \%$ \\
\hline & A rodovia poderá receber todos os tipos de veículos que são esperados? & & $\mathrm{x}$ & $\mathrm{x}$ & & $50 \%$ \\
\hline & $\begin{array}{l}\text { Pode haver situações inusitadas nas interseções, que pode afetar a segurança da } \\
\text { rodovia? }\end{array}$ & & $\mathrm{x}$ & & & $25 \%$ \\
\hline & $\begin{array}{l}\begin{array}{l}\text { Foram planejadas, onde necessário, os gradis de pedestres? (Por exemplo, para } \\
\text { orientar pedestres ou para desencorajar estacionamento }\end{array} \\
\end{array}$ & & $\mathrm{x}$ & $\mathrm{x}$ & & $50 \%$ \\
\hline & Onde necessário, foi considerado tratamento antiderrapante no pavimento? & & $\mathrm{x}$ & & & $25 \%$ \\
\hline & As ilhas e sinalizações verticais foram colocadas quando necessário? & & $\mathrm{x}$ & $\mathrm{x}$ & $\mathrm{x}$ & $50 \%$ \\
\hline & $\begin{array}{l}\text { Os veículos podem estacionar perto na intersecção: podem fazer com segurança, ou } \\
\text { requer que o estacionamento seja transferido? Representam algum perigo e pode ser } \\
\text { evitado? (3) }\end{array}$ & & $\mathrm{x}$ & $\mathrm{x}$ & & $50 \%$ \\
\hline & $\begin{array}{l}\text { Os tipos de interseções selecionadas são adequados para função da rodovia que } \\
\text { intesectam? (entrocamento, rotatórias, sinalizaa, etc) }\end{array}$ & & & & $\mathrm{x}$ & $25 \%$ \\
\hline & $\begin{array}{l}\text { O controle do tipo de interseção terá impacto negativo na segurança dos usuários da } \\
\text { rodovia, como: pedestres, usuários vulneráveis da rodovia, ciclistas e veículos } \\
\text { pesados? }\end{array}$ & & & & $\mathrm{x}$ & $25 \%$ \\
\hline & $\begin{array}{l}\text { O projeto prever o uso do tipo de veículo de projeto que irá usar a interseção? (por } \\
\text { exemplo, mudança de raios, larguras das faixas, etc;) }\end{array}$ & & & & $\mathrm{x}$ & $25 \%$ \\
\hline & $\begin{array}{l}\text { O projeto esta livre, a montante ou a jusante de alguma característica geométrica que } \\
\text { possam afetar a segurança (por exemplo, fusão de faixas)? }\end{array}$ & & & & $\mathrm{x}$ & $25 \%$ \\
\hline & \begin{tabular}{|l} 
Existe uma necessidade de barreiras de tráfego? Será o seu uso resulta na redução da \\
severidade dos acidnetes? Igualamente no centro de uma interseção?
\end{tabular} & & & & $\mathrm{x}$ & $25 \%$ \\
\hline & As velocidades de aproximação são compatíveis com o projeto da interseção? & & & & $\mathrm{x}$ & $25 \%$ \\
\hline
\end{tabular}




\begin{tabular}{|c|c|c|c|c|c|c|}
\hline & $\begin{array}{l}\text { Nas interseções com os comprimentos de filas são suficientes para o armazenamento } \\
\text { para gerar movimento? }\end{array}$ & & & & $\mathrm{x}$ & $25 \%$ \\
\hline & $\begin{array}{l}\text { O controle do tipo de interseção afetará a segurança das instalações dos serviços de } \\
\text { transporte público? (se previstos) }\end{array}$ & & & & $\mathrm{x}$ & $25 \%$ \\
\hline \multirow{3}{*}{ Localização e espaçamento } & Existe espaçamemnto suficiente entre interseções? & $\mathrm{x}$ & & & & $25 \%$ \\
\hline & $\begin{array}{l}\text { Os alinhamentos verticais e/ou horizontais afetam o tipo/ localização e o } \\
\text { espaçamento das intersecções? }\end{array}$ & $\mathrm{x}$ & & & & $25 \%$ \\
\hline & $\begin{array}{l}\text { Entrocamentos e acessos são adequados para todos os movimentos permitidos dos } \\
\text { veículos? }(2 \text { e } 3)\end{array}$ & $\mathrm{x}$ & $\mathrm{x}$ & $\mathrm{x}$ & & $75 \%$ \\
\hline \multirow{3}{*}{$\begin{array}{l}\text { Desenho do detalhe } \\
\text { geométrico }\end{array}$} & $\begin{array}{l}\text { o layout é seguro para uma combinação incomum ou circunstâncias especiais de } \\
\text { tráfego? }\end{array}$ & & $\mathrm{x}$ & $\mathrm{x}$ & $\mathrm{x}$ & $75 \%$ \\
\hline & $\begin{array}{l}\text { Os canteiros centrais ou ilhas, estão dispostas de forma adequada e com segurança a } \\
\text { respeito: veículos e alinhamnetos da rodovia? Proximidade de semáforos? } \\
\text { Capacidade e áreas para pedestres? Previsto faixa de retorno desejada? Distância de } \\
\text { visibilidade de parada? Ser interrupidas por veículos errantes? }\end{array}$ & & $\mathrm{x}$ & $\mathrm{x}$ & $\mathrm{x}$ & $75 \%$ \\
\hline & $\begin{array}{l}\text { É adequado a altura vertical para infraestrutura? (como por exemplo, linhas de } \\
\text { energia elétrica?) }\end{array}$ & & $\mathrm{x}$ & $\mathrm{x}$ & & $50 \%$ \\
\hline \multirow{9}{*}{$\begin{array}{l}\text { Desenho - manobras e } \\
\text { faixas }\end{array}$} & A largura das faixas é adequada para todos as classes de veículos? & $\mathrm{x}$ & & & & $25 \%$ \\
\hline & $\begin{array}{l}\text { Existem características a montante ou a jusante que possam afetar a segurança } \\
\text { (obstruções visuais, estacionamentos oblíquos, alto volume de entrada de } \\
\text { automóveis)? }\end{array}$ & $\mathrm{x}$ & & & & $25 \%$ \\
\hline & Separação entre as faixas é necessária mas não provida? & $\mathrm{x}$ & & & & $25 \%$ \\
\hline & As manobras dos veículos são óbvias para todos os usuários? & $\mathrm{x}$ & & & & $25 \%$ \\
\hline & Identificar qualquer conflito potencial nos movimentos & $\mathrm{x}$ & & & & $25 \%$ \\
\hline & Elas possuem comprimento adequado? & $\mathrm{x}$ & & & & $25 \%$ \\
\hline & Existe advertência quanto à aproximação das faixas auxiliares? & $\mathrm{x}$ & & & & $25 \%$ \\
\hline & A distância de visibilidade de entrada e saída de veículos está adequada? & $\mathrm{x}$ & & & & $25 \%$ \\
\hline & Estreitamentos estão instalados onde necessário? Eles estão corretamente alinhados? & $\mathrm{x}$ & & & & $25 \%$ \\
\hline
\end{tabular}




\begin{tabular}{|c|c|c|c|c|c|c|}
\hline \multirow{9}{*}{$\begin{array}{l}\text { Legibilidade para os } \\
\text { motoristas }\end{array}$} & $\begin{array}{l}\text { O tipo geral, função e características gerais da interseção ser percebidos pelos } \\
\text { motoristas corretamente? }\end{array}$ & & $\mathrm{x}$ & $\mathrm{x}$ & $\mathrm{x}$ & $75 \%$ \\
\hline & $\begin{array}{l}\text { As velocidades de aproximação das interseções são adequadas e os motoristas podem } \\
\text { ser guiados corretamente pela rodovia? }\end{array}$ & & $\mathrm{x}$ & $\mathrm{x}$ & $\mathrm{x}$ & $75 \%$ \\
\hline & O traçado está livre de elementos ou situações que podem ser enganosas? & & $\mathrm{x}$ & $\mathrm{x}$ & & $50 \%$ \\
\hline & $\begin{array}{l}\text { Interseções sucessivas pode violar a expectativa do motoristas por causas de } \\
\text { inconsistências? }\end{array}$ & & & & $\mathrm{x}$ & $25 \%$ \\
\hline & $\begin{array}{l}\text { O motorista tem tempo suficiente para perceber situações futuras e decidir por ações } \\
\text { necessárias de forma segura? }\end{array}$ & & & & $\mathrm{x}$ & $25 \%$ \\
\hline & O projeto das interseções prevê decisões erradas? & & & & $\mathrm{x}$ & $25 \%$ \\
\hline & $\begin{array}{l}\text { Foram considerados de forma adequada os efeitos dos ângulos do nascer do sol e por } \\
\text { do sol que poderia acarretar riscos para os motoristas? }\end{array}$ & & $\mathrm{x}$ & $\mathrm{x}$ & $\mathrm{x}$ & $75 \%$ \\
\hline & $\begin{array}{l}\text { Será que motorista tem experiência em lidar com ofuscamento da luz dos veículos } \\
\text { no sentido contrário ou iluminação rodoviária:? }\end{array}$ & & & & $\mathrm{x}$ & $25 \%$ \\
\hline & Nas interseções o motorista poderá ser expostos na escuridão repentina? & & & & $\mathrm{x}$ & $25 \%$ \\
\hline \multirow{10}{*}{$\begin{array}{l}\text { Visibilidade e Distância de } \\
\text { visibilidade }\end{array}$} & $\begin{array}{l}\text { todas as distâncias de visibilidade estão adequadas para todos os movimentos e } \\
\text { usuários da rodovia? }\end{array}$ & $\mathrm{x}$ & & & & $25 \%$ \\
\hline & Linhas de visão estão obstruídas por placas, edíficios, vegetação, etc? & $\mathrm{x}$ & & & & $25 \%$ \\
\hline & $\begin{array}{l}\text { As linhas de visão podem ser temporariamente obstruídas por veículos } \\
\text { estacionamentos, acúmulo de neve, vegetação sazonal, meio de transporte público, } \\
\text { enfileiramento de veículos, etc? }\end{array}$ & $\mathrm{x}$ & & & $\mathrm{x}$ & $50 \%$ \\
\hline & Greides nas interseções permitem uma distância de visibilidade desejável? & $\mathrm{x}$ & & & & $25 \%$ \\
\hline & $\begin{array}{l}\text { Os alinhamentos horizontais e verticais nas interseções ou nas proximidades dsa } \\
\text { interseções, está de acordo com as condições necessárias de visibilidade? }\end{array}$ & & $\mathrm{x}$ & $\mathrm{x}$ & $\mathrm{x}$ & $75 \%$ \\
\hline & $\begin{array}{l}\text { Os motoristas podem observar claramente a presença da interseção? (especialmente } \\
\text { quando se aproxima de rodovias secundárias) }\end{array}$ & & & & $\mathrm{x}$ & $25 \%$ \\
\hline & $\begin{array}{l}\text { A linha de visibilidade do projeto está desobstruída de: Barreiras de segurança e } \\
\text { cercas, divisórias; mobiliário na rodovia; Estacionamentos, sinalização vertical, } \\
\text { vegetação e paisagismo, estrutura de pontes. }\end{array}$ & & $\mathrm{x}$ & $\mathrm{x}$ & & $50 \%$ \\
\hline & $\begin{array}{l}\text { Os cruzamentos ferroviários, pontes e outros riscos próximos das interseções estão } \\
\text { totalmente visiveis? }\end{array}$ & & $\mathrm{x}$ & $\mathrm{x}$ & & $50 \%$ \\
\hline & $\begin{array}{l}\text { O projeto está livre de outras características locais que podem afetar negativamente } \\
\text { a visibilidade? }\end{array}$ & & $\mathrm{x}$ & $\mathrm{x}$ & & $50 \%$ \\
\hline & $\begin{array}{l}\text { As normas adotadass permite uma boa visibilidade para velocidade de tráfego e } \\
\text { composição do tráfego incomum? }\end{array}$ & & $\mathrm{x}$ & $\mathrm{x}$ & & $50 \%$ \\
\hline Visibilidade / conspicuidade & Alinhamento vertical / horizontal permite visibilidade adequada da interseção? & $\mathrm{x}$ & & & & $25 \%$ \\
\hline
\end{tabular}




\begin{tabular}{|c|c|c|c|c|c|}
\hline & As linhas de visão das interseções estão obstruídas? & $\mathrm{x}$ & & & $25 \%$ \\
\hline \multirow{2}{*}{$\begin{array}{l}\text { Controles de sinalização } \\
\text { horizontal }\end{array}$} & As marcas do pavimento são claramente visíveis em condições diurnas e nortunas? & $\mathrm{x}$ & & & $25 \%$ \\
\hline & Verificar a retrorefletividade da sinalização horizontal & $\mathrm{x}$ & & & $25 \%$ \\
\hline \multirow{4}{*}{$\begin{array}{l}\text { Controles de sinalização } \\
\text { vertical }\end{array}$} & Verifique a visibilidade e legibilidade das placas para os usuários que se aproximam & $\mathrm{x}$ & & & $25 \%$ \\
\hline & Verifique a localização e o número de placas & $\mathrm{x}$ & & & $25 \%$ \\
\hline & Vefirifique se há alguma placa faltando / redundante / quebrada & $\mathrm{x}$ & & & $25 \%$ \\
\hline & Plascas de PARE/DÊ A PREFERÊNCIA são usadas onde necessárias? & $\mathrm{x}$ & & & $25 \%$ \\
\hline \multirow{13}{*}{ Controles Semafórico } & $\begin{array}{l}\text { Existem semáforos/painéis/protetores de alta intensidade onde pode haver problemas } \\
\text { com nascer ou pôr-do-sol? }\end{array}$ & $\mathrm{x}$ & & & $25 \%$ \\
\hline & Verificar a localização e o número de semáforos. Eles estão visiveís? & $\mathrm{x}$ & & & $25 \%$ \\
\hline & $\begin{array}{l}\text { Verifique que os semáforos de vias adjacentes não afetem a percepção dos motoristas } \\
\text { da via }\end{array}$ & $\mathrm{x}$ & & & $25 \%$ \\
\hline & Os semáforos primários e secundários estão instalados apropriadamente? & $\mathrm{x}$ & & & $25 \%$ \\
\hline & Os semáforos auxiliares são necessários? & $\mathrm{x}$ & & & $25 \%$ \\
\hline & Os semáforos estão operando em fases e/ou sequências com segurança? & & $\mathrm{x}$ & $\mathrm{x}$ & $50 \%$ \\
\hline & O tempo é suficiente para o movimento do fluxo de veículos e pedestres? & & $\mathrm{x}$ & $\mathrm{x}$ & $50 \%$ \\
\hline & $\begin{array}{l}\text { As luzes dos semáforos são visiveis? (por exemplo, elas não estão obstruídas por } \\
\text { árvores, postes, sinais de trânsito ou veículos de grande porte). }\end{array}$ & & $\mathrm{x}$ & $\mathrm{x}$ & $50 \%$ \\
\hline & $\begin{array}{l}\text { As lâmpadas orientadas em outra direção de atuação estão suficientemente } \\
\text { protegidas de modo a ser vistas apenas pelo tráfego que a enfrenta? }\end{array}$ & & $\mathrm{x}$ & $\mathrm{x}$ & $50 \%$ \\
\hline & $\begin{array}{l}\text { As lâmpadas tem uma intensidade de luz suficiente, de modo de, se for o caso, não } \\
\text { ser afetadas pelo nascer do sol ou pôr do sol? }\end{array}$ & & $\mathrm{x}$ & $\mathrm{x}$ & $50 \%$ \\
\hline & $\begin{array}{l}\text { O alinhamento vertical proporciona uma adequada distância de visibilidade de } \\
\text { parada para a interseção ou filas atrás do veículo? }\end{array}$ & & $\mathrm{x}$ & $\mathrm{x}$ & $50 \%$ \\
\hline & Quando necessária são proporcionada instalações para o pedestre? & & $\mathrm{x}$ & $\mathrm{x}$ & $50 \%$ \\
\hline & Os condutores que se aproxiam da interseção ver claramente os pedestres? & & $\mathrm{x}$ & $\mathrm{x}$ & $50 \%$ \\
\hline
\end{tabular}




\begin{tabular}{|c|c|c|c|c|c|c|}
\hline & São previstas mudanças de fases quando necessária? & & $\mathrm{x}$ & & & $25 \%$ \\
\hline & As fases do semáforo são controladas parcial ou totalmente? & & $\mathrm{x}$ & $\mathrm{x}$ & & $50 \%$ \\
\hline & Os postes dos semáforos estão localizados em lugares que não geram risco? & & $\mathrm{x}$ & $\mathrm{x}$ & & $50 \%$ \\
\hline & É adequada as demarcações para o desvio do tráfego? & & $\mathrm{x}$ & $\mathrm{x}$ & & $50 \%$ \\
\hline & Existe una fase exclusiva para pedestres? É conveniente? & & $\mathrm{x}$ & $\mathrm{x}$ & & $50 \%$ \\
\hline \multirow{2}{*}{$\begin{array}{l}\text { Controles das fases dos } \\
\text { semáforos }\end{array}$} & São providos verde mínimo e vermelho geral? & $\mathrm{x}$ & & & & $255 \%$ \\
\hline & O plano de fases do semáforo é consistente com as interseções? & $\mathrm{x}$ & & & & $25 \%$ \\
\hline \multirow{3}{*}{ Advertências } & $\begin{array}{l}\text { A advertência prevista é adequada para semáforos não visiveis de uma distância de } \\
\text { visibilidade apropriada? (isto é, sinais, luz intermitente, etc.) }\end{array}$ & $\mathrm{x}$ & & & & $25 \%$ \\
\hline & são necessárias e apropriadamente posicionadas faixas sonoras laterais? & $\mathrm{x}$ & & & & $25 \%$ \\
\hline & sinalização horizontal está adequada para a interseçção? & $\mathrm{x}$ & & & & $25 \%$ \\
\hline \multirow{10}{*}{ Rotatórias } & $\begin{array}{l}\text { Onde foi proposto rotatória, foram considerados os movimentos dos ciclistas e os } \\
\text { movimentos dos pedestres, as faixas são suficientes? }\end{array}$ & & & & $\mathrm{x}$ & $25 \%$ \\
\hline & É adequado a deflexão ou curva projetada para reduzir a velocidade de aproximação? & & $\mathrm{x}$ & $\mathrm{x}$ & $\mathrm{x}$ & $75 \%$ \\
\hline & $\begin{array}{l}\text { São necessárias ilhass divisoras, elas têm boa distância de visibilidade, comprimento } \\
\text { e capacidade para armazenar os pedestres? }\end{array}$ & & $\mathrm{x}$ & $\mathrm{x}$ & $\mathrm{x}$ & $75 \%$ \\
\hline & Nas rotatórias a ilha central é alta e visível? & & $\mathrm{x}$ & $\mathrm{x}$ & $\mathrm{x}$ & $75 \%$ \\
\hline & O modelo é apropriado para todos os tipos de veículos? & & $\mathrm{x}$ & $\mathrm{x}$ & & $50 \%$ \\
\hline & $\begin{array}{l}\text { Os detalhes são adequados da ilha central? (Como delimitação, elevação, } \\
\text { visibilidade)? }\end{array}$ & & $\mathrm{x}$ & $\mathrm{x}$ & & $50 \%$ \\
\hline & Os motoristas podem ver os pedestres com tempo suficiente? & & $\mathrm{x}$ & $\mathrm{x}$ & & $50 \%$ \\
\hline & $\begin{array}{l}\text { Os pedestres podem determinar se os veículos começam a girar? (Sem obstruções ao } \\
\text { campo de visão) }\end{array}$ & & $\mathrm{x}$ & $\mathrm{x}$ & $\mathrm{x}$ & $75 \%$ \\
\hline & As marcas de direção da pista foram marcadas nas faixas de aproximação? & & $\mathrm{x}$ & $\mathrm{x}$ & $\mathrm{x}$ & $75 \%$ \\
\hline & Na rotatória a iluminação é adequada e os postes estão em locais seguros? & & $\mathrm{x}$ & $\mathrm{x}$ & $\mathrm{x}$ & $75 \%$ \\
\hline $\begin{array}{l}\text { Outras interseções ou layout } \\
\text { (4) }\end{array}$ & Considerou a necessidade de pintar as bordas das ilhas e refugios? & & $\mathrm{x}$ & $\mathrm{x}$ & & $50 \%$ \\
\hline
\end{tabular}




\begin{tabular}{|c|c|c|c|c|c|}
\hline & $\begin{array}{l}\text { As interseções tem comprimento adequado para acomodar os veículos? As } \\
\text { interseções tem capacidade para acomodar veículos que efetuam movimentos } \\
\text { disponíveis? }\end{array}$ & & $\mathrm{x}$ & $\mathrm{x}$ & $50 \%$ \\
\hline \multicolumn{6}{|l|}{$\begin{array}{l}3.2 \text { Interseção em Desnível } \\
\text { (1) }\end{array}$} \\
\hline \multirow{2}{*}{$\begin{array}{l}\text { Localização e espaçmento } \\
\text { (1) }\end{array}$} & $\begin{array}{l}\text { Será que o local das interseções em desníveis atendem às necessidades da } \\
\text { comunidade adjacente? }\end{array}$ & $\mathrm{x}$ & & & $25 \%$ \\
\hline & Verificar se o espaçamento entre as interseções em desníveis na rede é suficiente. & $\mathrm{x}$ & & & $25 \%$ \\
\hline Faixas de entrelaçamento & $\begin{array}{l}\text { Certifique-se que o comprimento e o número de faixas de entrelaçamemento é } \\
\text { apropriado? }\end{array}$ & $x$ & & & $25 \%$ \\
\hline \multirow{3}{*}{ Rampas } & $\begin{array}{l}\text { A velocidade de projeto é adequada para limitações do local, configurações de } \\
\text { rampa, e vários tipos veículos? }\end{array}$ & $\mathrm{x}$ & & & $25 \%$ \\
\hline & A distância entre sucessivos pontos de entrada e saída é adequada? & $\mathrm{x}$ & & & $25 \%$ \\
\hline & O projeto da faixa principal é adequado em terminais de saída e entrada? & $\mathrm{x}$ & & & $25 \%$ \\
\hline \multirow{3}{*}{ Terminais de saída } & O comprimento é adequado para desaceleração? & $\mathrm{x}$ & & & $25 \%$ \\
\hline & São providas adequadamente as distâncias de visibilidade e distâncias de decisão? & $\mathrm{x}$ & & & $25 \%$ \\
\hline & $\begin{array}{l}\text { As curvas em espiral são necessárias? Se sim, as espirais começam e terminam em } \\
\text { locais apropriados? }\end{array}$ & $\mathrm{x}$ & & & $25 \%$ \\
\hline \multirow{5}{*}{ Terminais de entrada } & $\begin{array}{l}\text { O comprimento é apropriado para aceleração e inserção segura e conveniente com o } \\
\text { tráfego de passagem? }\end{array}$ & $\mathrm{x}$ & & & $25 \%$ \\
\hline & $\begin{array}{l}\text { As curvas em espiral são necessárias? Se forem, as espirais começam e terminam em } \\
\text { locais apropriados? }\end{array}$ & $\mathrm{x}$ & & & $25 \%$ \\
\hline & $\begin{array}{l}\text { O comprimento de aceleração é adequado para a composição de tráfego ( isto é, } \\
\text { caminhões, ônibus, etc.) }\end{array}$ & $\mathrm{x}$ & & & $25 \%$ \\
\hline & Existe uma visão adequada da faixa de mudança de velocidade? & $\mathrm{x}$ & & & $25 \%$ \\
\hline & A visibilidade está atrapalhada por barreiras de segurança ou outras obstruções? & $\mathrm{x}$ & & & $25 \%$ \\
\hline \multirow{4}{*}{ Vias de Serviço } & $\begin{array}{l}\text { Existe distância adequada entre a rodovia e a via de serviço para permitir futuras } \\
\text { ampliaçôes? }\end{array}$ & $\mathrm{x}$ & & & $25 \%$ \\
\hline & O tráfego na via de serviço afeta desfavoravelmente o fluxo ao longo da rodovia? & $\mathrm{x}$ & & & $25 \%$ \\
\hline & Existem acessos suficientes para via de serviço? & $\mathrm{x}$ & & & $25 \%$ \\
\hline & $\begin{array}{l}\text { O número de faixas são adequadas para as operações seguras e acomodações devido } \\
\text { as variações nos padrões de tráfego? }\end{array}$ & $\mathrm{x}$ & & & $25 \%$ \\
\hline
\end{tabular}




\begin{tabular}{|c|c|c|c|c|c|}
\hline \multirow{2}{*}{$\begin{array}{l}\text { Balanceamento de faixas / } \\
\text { faixa básica e continuidade } \\
\text { de faixa (1) }\end{array}$} & Existe coordenação entre o balanceamento das pistas e as pistas básicas? & $\mathrm{x}$ & & & $25 \%$ \\
\hline & A continuidade das faixas é mantida? & $\mathrm{x}$ & & & $25 \%$ \\
\hline \multirow{5}{*}{$\begin{array}{l}\text { Faixas auxiliares ou de } \\
\text { conversão }\end{array}$} & Elas possuem comprimento adequado? & $\mathrm{x}$ & & & $25 \%$ \\
\hline & Existe advertência prévia quanto à aproximação das faixas auxiliares? & $\mathrm{x}$ & & & $25 \%$ \\
\hline & A distância de visibilidade de entrada e saída de veículos está adequada? & $\mathrm{x}$ & & & $25 \%$ \\
\hline & Estreitamentos estão instalados onde necessário? Eles estão corretamente alinhados? & $\mathrm{x}$ & & & $25 \%$ \\
\hline & As vias de serviço estão sendo utilizadas para seu propósito original? & $\mathrm{x}$ & & & $25 \%$ \\
\hline 4. Objetos Físicos (1) & 4. Objetos Físicos & \multicolumn{3}{|c|}{ 4. Objetos Físicos } & Frequência \\
\hline \multirow{9}{*}{ Postes e outras obstruções } & $\begin{array}{l}\text { As larguras dos canteiros centrais não protegidos são apropriadas para os postes de } \\
\text { iluminação? }\end{array}$ & $\mathrm{x}$ & & & $25 \%$ \\
\hline & $\begin{array}{l}\text { Os postes de semáforos ou de outros dispositivos de serviços estão posicionados } \\
\text { adequadamente? }\end{array}$ & $\mathrm{x}$ & $\mathrm{x}$ & $\mathrm{x}$ & $75 \%$ \\
\hline & $\begin{array}{l}\text { Foi considerada localização de serviços e outras utilidades em relação ao projeto (ou } \\
\text { seja, enterrado ou subterrâneo) como vão para cabos aéreos? }\end{array}$ & $\mathrm{x}$ & & & $25 \%$ \\
\hline & Todos os postes estão localizados distante o suficiente do fluxo de tráfego? & & $\mathrm{x}$ & $\mathrm{x}$ & $50 \%$ \\
\hline & Postes frágeis ou flexiveis foram previstos quando necessários? & & $\mathrm{x}$ & $\mathrm{x}$ & $50 \%$ \\
\hline & $\begin{array}{l}\text { A largura dos canteiros centrais é adequado para a instalação dos postes de } \\
\text { iluminação ou árvores? }\end{array}$ & & $\mathrm{x}$ & $\mathrm{x}$ & $50 \%$ \\
\hline & $\begin{array}{l}\text { A margem da rodovia está livre de outras obstruções que poderiam criar um risco de } \\
\text { segurança? }\end{array}$ & & $\mathrm{x}$ & $\mathrm{x}$ & $50 \%$ \\
\hline & $\begin{array}{l}\text { foram tomado todas as medidas para remover, mover ou proteger todos os objetos } \\
\text { que podem ser perigosos? }\end{array}$ & & $\mathrm{x}$ & $\mathrm{x}$ & $50 \%$ \\
\hline & $\begin{array}{l}\text { Os bueiros na margem da rodovia e canais podem ser atravessados com segurança } \\
\text { por qualquer veículo que possa sair da rodovia? }\end{array}$ & & $\mathrm{x}$ & $\mathrm{x}$ & $50 \%$ \\
\hline \multirow{4}{*}{ Divisórias centrais } & O tipo de divisória central selecionado é apropriado para a largura disponível? & $\mathrm{x}$ & & & $25 \%$ \\
\hline & As barreiras possuem configuração geométrica adequada? & $\mathrm{x}$ & & & $25 \%$ \\
\hline & As inclinações dos canteiros de grama estão adequadas? & $\mathrm{x}$ & & & $25 \%$ \\
\hline & As barreiras centrais estão suficientemente afastadas da rodovia? & $\mathrm{x}$ & & & $25 \%$ \\
\hline
\end{tabular}




\begin{tabular}{|c|c|c|c|c|c|}
\hline & O afastamento entre as barreiras centrais está dentro dos limites corretos? & $\mathrm{x}$ & & & $25 \%$ \\
\hline & $\begin{array}{l}\text { As barreiras laterais e das pontes estão de acordo com o nível de desempenho dos } \\
\text { testes de impacto para a classificação da rodovia? }\end{array}$ & $\mathrm{x}$ & & & $25 \%$ \\
\hline & $\begin{array}{l}\text { Existe largura suficiente para pilares dos viadutos, passagem subterrânea e } \\
\text { iluminação? }\end{array}$ & $\mathrm{x}$ & & & $25 \%$ \\
\hline & Verificar o espaçamento apropriado entre travessias de divisórias centrais? & $\mathrm{x}$ & & & $25 \%$ \\
\hline & As barreiras centrais foram consideradas adequadamente e detalhada? & & $\mathrm{x}$ & $\mathrm{x}$ & $50 \%$ \\
\hline & Os tratamentos finais e terminais foram considerados? & & $\mathrm{x}$ & $\mathrm{x}$ & $50 \%$ \\
\hline \multirow{7}{*}{$\begin{array}{l}\text { Proteção de objetos } \\
\text { perigosos }\end{array}$} & $\begin{array}{l}\text { É provida protecção adequada quando necessário? (isto é, barreiras, atenuadores de } \\
\text { impacto) }\end{array}$ & $\mathrm{x}$ & & & $25 \%$ \\
\hline & A proteção é vísivel em todas as condições de operação? & $\mathrm{x}$ & & & $25 \%$ \\
\hline & Os terminais das defensas estão tratados adequadamente? & $\mathrm{x}$ & & & $25 \%$ \\
\hline & As dimensões (isto é, comprimento) da proteção está adequada? & $\mathrm{x}$ & & & $25 \%$ \\
\hline & O tratamento de barreiras é considtente em toda a sua extensão? & $\mathrm{x}$ & & & $25 \%$ \\
\hline & Existe transição apropriada de uma defensa para a outra? & $\mathrm{x}$ & & & $25 \%$ \\
\hline & são usadaos sinais reflexivos para delinear as defensas? & $\mathrm{x}$ & & & $25 \%$ \\
\hline \multirow{2}{*}{ Zona Livre } & $\begin{array}{l}\text { Assegurar que os objetos desprotegidos (temporária ou permanentemente) dentro da } \\
\text { zona de livre obrigatória. }\end{array}$ & $\mathrm{x}$ & & & $25 \%$ \\
\hline & Verificar se a zona livre posui dimensões adequadas & $\mathrm{x}$ & & & $25 \%$ \\
\hline bueiros & $\begin{array}{l}\text { Verificar se a proteção está adequada dos bueiros no encontros com as calçadas e as } \\
\text { interseções com as rodovias.. }\end{array}$ & $\mathrm{x}$ & & & $25 \%$ \\
\hline \multirow{2}{*}{ Cruzamentos com ferrovias } & Assegurar a sinalização vertical e horizontal passiva / ativa apropriada. & $\mathrm{x}$ & & & $25 \%$ \\
\hline & $\begin{array}{l}\text { Verificar a distância de visibilidade para a sinalização e também para a aproximação } \\
\text { de trens. }\end{array}$ & $\mathrm{x}$ & & & $25 \%$ \\
\hline \multirow{3}{*}{ Barreiras de contenção } & $\begin{array}{l}\text { Sempre que necessário, foram previstas adqudamente barreirass de contenção? (por } \\
\text { exemplo, em aterros, estruturas, árvores, postes, canais de drenagem, pontes0 }\end{array}$ & & $\mathrm{x}$ & $\mathrm{x}$ & $50 \%$ \\
\hline & $\begin{array}{l}\text { a barreira de contenção é segura? (Ou seja, não cria perigo para os usuários da } \\
\text { rodovia, incluindo pedestres, ciclistas, etc.) }\end{array}$ & & $\mathrm{x}$ & $\mathrm{x}$ & $50 \%$ \\
\hline & As extremidades das barreiras de contenção são seguras e satisfatórias? & & $\mathrm{x}$ & $\mathrm{x}$ & $50 \%$ \\
\hline
\end{tabular}




\begin{tabular}{|c|c|c|c|c|c|}
\hline & $\begin{array}{l}\text { A barreira de contenção foi projetado considerando: tratamentos finais? Largura de } \\
\text { trabalho? Âncoras? Espaçamentos dos postes? Profundidade dos postes? } \\
\text { sobreposição da barreira? }\end{array}$ & & $\mathrm{x}$ & $\mathrm{x}$ & $50 \%$ \\
\hline & $\begin{array}{l}\text { É necessária a barreira de contenção (não representa um risco maior qunado o objeto } \\
\text { está protegido?) }\end{array}$ & & $\mathrm{x}$ & $\mathrm{x}$ & $50 \%$ \\
\hline & $\begin{array}{l}\text { Se existir a circulação de pedestres e ciclistas detrás das barreiras de contenção, é um } \\
\text { lugar seguro para esses usuários? }\end{array}$ & & $\mathrm{x}$ & $\mathrm{x}$ & $25 \%$ \\
\hline \multirow{6}{*}{$\begin{array}{l}\text { Áreas de pontes, inundações } \\
\text { e cursos d'água }\end{array}$} & $\begin{array}{l}\text { As barreiras da pontes e extremidades das paredes de bueiros são seguros em termos } \\
\text { de visibilidade? Tipo com facilidade de reconhecimento? Proximidade com o fluxo } \\
\text { de tráfego? Possibilidade de causar acidentes ou danos? Terminações colapsiveis ou } \\
\text { frageis? sinalização e demarcações? Conexão com as barreiras de proteção? proteção } \\
\text { contra os riscos da margem da rodovia? }\end{array}$ & & $\mathrm{x}$ & $\mathrm{x}$ & $25 \%$ \\
\hline & Os corrimãos das pontes está a um nível correto e bastante firme? & & $\mathrm{x}$ & $\mathrm{x}$ & \\
\hline & A largura doa acostamentos das pontes ígual ao resto das faixas da rodovia? & & $\mathrm{x}$ & $\mathrm{x}$ & \\
\hline & $\begin{array}{l}\text { É seguro o espaço para o trânsito de veiculos não motorizado sobre a ponte? (por } \\
\text { exemplo, pedestres, bicicletas, cavalos, etc.) }\end{array}$ & & $\mathrm{x}$ & $\mathrm{x}$ & \\
\hline & $\begin{array}{l}\text { As saídas dos bueiros representam algum risco para os condutores que podem sair } \\
\text { da rodovia? }\end{array}$ & & $\mathrm{x}$ & $\mathrm{x}$ & \\
\hline & $\begin{array}{l}\text { As rodoviass propicias a inundações têm adequada sinalização e distância de } \\
\text { visibilidade? }\end{array}$ & & $\mathrm{x}$ & $\mathrm{x}$ & $25 \%$ \\
\hline 5. Aspectos ambientais & 5. Aspectos ambientais & 5. Aspectos ambientais & & & Frequência \\
\hline \multirow{3}{*}{ Clima (1) } & $\begin{array}{l}\text { Verifique os efeitos da chuva, neblina, neve, gelo, vento sobre características na } \\
\text { concepção do projeto. }\end{array}$ & $\mathrm{x}$ & & & $25 \%$ \\
\hline & $\begin{array}{l}\text { Tem acumulação da queda de neve e foi considerada no projeto? (isto é, } \\
\text { armazenamento, distância de visibilidade no entotno de bancos de neve, etc.) }\end{array}$ & $\mathrm{x}$ & & & $25 \%$ \\
\hline & $\begin{array}{l}\text { Verifique as medidas mitigadoras para efeitos de neve no que diz respeito a: ventos } \\
\text { predominantes; neve a aderiva; terreno aberto; }\end{array}$ & $\mathrm{x}$ & & & $25 \%$ \\
\hline Animais (1) & $\begin{array}{l}\text { Existem animais nas rotas de viagens / ou migração conhecidas em áreas que } \\
\text { poderiam afetar o entorno com o projeto? }\end{array}$ & $\mathrm{x}$ & & & $25 \%$ \\
\hline
\end{tabular}




\begin{tabular}{|c|c|c|c|c|c|c|}
\hline & Cercas e passagens inferiores estão projetadas onde é necessário? & $\mathrm{x}$ & & & & $25 \%$ \\
\hline & $\begin{array}{l}\text { Certifique-se se há sinalização apropriada onde for necessário. (ou seja, passagem } \\
\text { de gado, aviso de animais silvestres (veados), etc) }\end{array}$ & $\mathrm{x}$ & & & & $25 \%$ \\
\hline & $\begin{array}{l}\text { A segurança rodoviária foi considerada na redução dos impactos ambientais? (por } \\
\text { exemplo, painel anti-ruído) }\end{array}$ & & $\mathrm{x}$ & & & $25 \%$ \\
\hline 6. Usuários da rodovia & 6. Usuários da rodovia & \multicolumn{4}{|l|}{ 6. Usuários da Rodovia } & Frequência \\
\hline motorizados & & & & & & \\
\hline \multirow{9}{*}{$\begin{array}{l}\text { Veículos pesados e } \\
\text { transporte público }\end{array}$} & $\begin{array}{l}\text { A instalação pode acomodar movimentos de veículos pesados/transporte público } \\
\text { quando necessário? (vãos, raios de giro, largura do acostamento, capacidade } \\
\text { operacional? }\end{array}$ & $\mathrm{x}$ & $\mathrm{x}$ & $\mathrm{x}$ & & $75 \%$ \\
\hline & $\begin{array}{l}\text { Existe sinalização adequada para as atividades de veículos pesados / transporte } \\
\text { público? }\end{array}$ & $\mathrm{x}$ & $\mathrm{x}$ & $\mathrm{x}$ & & $75 \%$ \\
\hline & $\begin{array}{l}\text { O projeto prever as limitações de veículos pesados? (por exemplo, nas distâncias de } \\
\text { paradas, etc). }\end{array}$ & & & & $\mathrm{x}$ & $25 \%$ \\
\hline & O projeto considera as seções transversais seguras para os veículos pesados? & & & & $\mathrm{x}$ & $25 \%$ \\
\hline & $\begin{array}{l}\text { No terrenos montanhosos, as instalações de escape necessária no projeto? São } \\
\text { projetadas ou pode haver modificação no projeto para eliminar, se necessário? }\end{array}$ & & & & $\mathrm{x}$ & $25 \%$ \\
\hline & $\begin{array}{l}\text { Se houver restrições de altura, têm rotas alternativas e foram devidamente sinalizadas } \\
\text { para uso por esses veículos? }\end{array}$ & & & & $\mathrm{x}$ & $25 \%$ \\
\hline & Há áreas de descando projetadas? Se planejado, podem ser usadas com segurança? & & & & $\mathrm{x}$ & $25 \%$ \\
\hline & são seguras as instalações de carregamento dos veículos pesados quando necessário? & & & & $\mathrm{x}$ & $25 \%$ \\
\hline & Há previsão para as manobras seguras dos veículos pesados quando necessárias? & & & & $\mathrm{x}$ & $25 \%$ \\
\hline \multirow{5}{*}{ Transporte público } & Foram atendidos os serviços de transporte público? & & & $\mathrm{x}$ & $\mathrm{x}$ & $50 \%$ \\
\hline & $\begin{array}{l}\text { Há previsão para a circulação segura dos pedestres, que usam os serviços do } \\
\text { transporte público? (por exemplo, espaços suficientes para os passageiros que } \\
\text { descem dos onnibus?) }\end{array}$ & & & & $\mathrm{x}$ & $25 \%$ \\
\hline & Foram consideradas as necessidades dos usuários de transporte público? & & $\mathrm{x}$ & $\mathrm{x}$ & & $50 \%$ \\
\hline & Foram considerados os movimentos dos transportes públicos? & & $\mathrm{x}$ & $\mathrm{x}$ & & $50 \%$ \\
\hline & As paradas de ônibus estão localizadas de forma segura? & & $\mathrm{x}$ & $\mathrm{x}$ & & $50 \%$ \\
\hline
\end{tabular}




\begin{tabular}{|c|c|c|c|c|c|c|}
\hline \multirow{7}{*}{$\begin{array}{l}\text { Veículos de manutenção e } \\
\text { veículos de emergência }\end{array}$} & $\begin{array}{l}\text { A instalação pode acomodar movimentos de veículos de manutenção da rodovia e de } \\
\text { emergência (vãos, raio de giro, largura do acostamento). Após a implementação do } \\
\text { projeto? }\end{array}$ & $\mathrm{x}$ & & & & $25 \%$ \\
\hline & $\begin{array}{l}\text { As divisórias centrais e cruzamentos estão visíveis e em locais adequados para estes } \\
\text { veículos? }\end{array}$ & $\mathrm{x}$ & & & & $25 \%$ \\
\hline & $\begin{array}{l}\text { Pode veículos de manutenção e equipes ser acomodados com segurança após a } \\
\text { implementação do projeto? }\end{array}$ & & & & $\mathrm{x}$ & $25 \%$ \\
\hline & $\begin{array}{l}\text { Existe necessidade de considerar os veículos com instalações e sinalização } \\
\text { adequada? }\end{array}$ & & $\mathrm{x}$ & $\mathrm{x}$ & & $50 \%$ \\
\hline & Veículos de manutenção pode ser localizado com segurança? & & & $\mathrm{x}$ & & $25 \%$ \\
\hline & $\begin{array}{l}\text { Veículos que realizam a manutenção da estrada, podem ser estacionados de forma } \\
\text { segura? }\end{array}$ & & $\mathrm{x}$ & & & $25 \%$ \\
\hline & O trabalho de manutenção pode ser realizada com segurança? & & $\mathrm{x}$ & & & $25 \%$ \\
\hline \multirow{2}{*}{ Veículos lentos } & $\begin{array}{l}\text { Os acostamentos podem acomodar veículos lentos quando necessário? Em temos de } \\
\text { largura, capacidade estrutural, continuidade. }\end{array}$ & $\mathrm{x}$ & & & & $25 \%$ \\
\hline & Existe sinalização apropriada a respeito de veículos lentos quando necessários? & $\mathrm{x}$ & & & & $25 \%$ \\
\hline \multirow{4}{*}{ veículos de neve } & $\begin{array}{l}\text { Verificar a visibilidade da sinalização de trilhas adjacentes. Ela poderia causar } \\
\text { confusão para os usuários da rodovia? }\end{array}$ & $\mathrm{x}$ & & & & $25 \%$ \\
\hline & verificar a sinalização e a visibilidade de pontos onde as trilhas atravessam a rodovia & $\mathrm{x}$ & & & & $25 \%$ \\
\hline & distância de visibilidade de parada foi considerada onde trilhas atravessam a rodovia? & $\mathrm{x}$ & & & & $25 \%$ \\
\hline & o farol dianteiro do carro para neve / ATV pod ofuscar o motorista? & $\mathrm{x}$ & & & & $25 \%$ \\
\hline \multicolumn{7}{|l|}{ Não motorizados } \\
\hline \multirow{3}{*}{ Ciclista e pedestre } & $\begin{array}{l}\text { Os acostamentos possuem larguras suficientes para acomodar ciclistas / pedestres } \\
\text { onde são necessários? }\end{array}$ & $\mathrm{x}$ & & & & $25 \%$ \\
\hline & acostamento / passeios estão previstos nas pontes? & $\mathrm{x}$ & & & & $25 \%$ \\
\hline & o acumulo de neve prejudica o acesso ou a visibilidade dos pedestres? & $\mathrm{x}$ & & & & $25 \%$ \\
\hline \multirow{3}{*}{ Ciclistas (2) } & $\begin{array}{l}\text { As necessidade dos ciclistas foram consideradas de forma satisfatória, especialmente } \\
\text { nas interseçôes? }\end{array}$ & & $\mathrm{x}$ & $\mathrm{x}$ & $\mathrm{x}$ & $75 \%$ \\
\hline & $\begin{array}{l}\text { Onde existe a necessidade de compartilhar as instalações para os uso dos pedestres e } \\
\text { ciclistas, foram tratadas de forma segura? (incluindo metrô e ponte) }\end{array}$ & & & $\mathrm{x}$ & $\mathrm{x}$ & $50 \%$ \\
\hline & $\begin{array}{l}\text { Quando uma ciclovia termina em interseção ou rodovia adjacente, foi prevista uma } \\
\text { transição com segurança? }\end{array}$ & & $\mathrm{x}$ & & & $25 \%$ \\
\hline
\end{tabular}




\begin{tabular}{|c|c|c|c|c|c|}
\hline \multirow{21}{*}{ Pedestre $(2,3)$} & $\begin{array}{l}\text { Os pedestres podem atravessar de forma segura as interseções? Nas faixas de } \\
\text { pedestres marcadas? Refugios? Extensões de calçadas? Pontes e bueiros? Ou outras } \\
\text { situações? }\end{array}$ & $\mathrm{x}$ & $\mathrm{x}$ & & $50 \%$ \\
\hline & $\begin{array}{l}\text { Cada cruzamento é satisfatório em termos de: Visibilidade para ambas as direções? } \\
\text { Utilização por pessoas com deficiências? Por pessoa idosa? E usado por crianças em } \\
\text { idade escolar? }\end{array}$ & $\mathrm{x}$ & $\mathrm{x}$ & & $50 \%$ \\
\hline & $\begin{array}{l}\text { Os gradis de pedestres estão instalados nos cruzamentos quando necessário? (na } \\
\text { margem da rodovia e de canteiros centrais)? }\end{array}$ & $\mathrm{x}$ & $\mathrm{x}$ & & $50 \%$ \\
\hline & Os gradis de pedestres são adequados para auto-estradas? & $\mathrm{x}$ & $\mathrm{x}$ & & $50 \%$ \\
\hline & Os pedestres são impedidos de atravessar a rodovia em locais não seguros? & $\mathrm{x}$ & $\mathrm{x}$ & & $50 \%$ \\
\hline & Os sinais de trânsito para os pedestres são adequados? & $\mathrm{x}$ & $\mathrm{x}$ & & $50 \%$ \\
\hline & A largura e a inclinação das faixas de pedestres são satisfatória? & $\mathrm{x}$ & $\mathrm{x}$ & & $50 \%$ \\
\hline & A área de travessia de pedestre é satisfatória? & $\mathrm{x}$ & $\mathrm{x}$ & & $50 \%$ \\
\hline & É previsto faixa de retenção para a travessia dos pedestres? & $\mathrm{x}$ & $\mathrm{x}$ & & $50 \%$ \\
\hline & Nos cruzamentos de pedestres têm evitado canais e ravinas? & $\mathrm{x}$ & $\mathrm{x}$ & & $50 \%$ \\
\hline & A iluminção é adequada para cada interseção? & $\mathrm{x}$ & $\mathrm{x}$ & & $50 \%$ \\
\hline & Os cruzamentos estão localizados em lugares onde se maximiza o seu uso? & $\mathrm{x}$ & $\mathrm{x}$ & & $50 \%$ \\
\hline & $\begin{array}{l}\text { é possivel evitar o cruzamento? (por exemplo, alternativa mais direta, porém menos } \\
\text { seguro) }\end{array}$ & $\mathrm{x}$ & $\mathrm{x}$ & & $50 \%$ \\
\hline & A concepção do projeto é segura para os pedestres? & & & $\mathrm{x}$ & $25 \%$ \\
\hline & Existe necessidade de implantar travessia de pedestre? & & & $\mathrm{x}$ & $25 \%$ \\
\hline & As travessias de pedestres foram consideradas ao longo das linhas de desejo? & & & $\mathrm{x}$ & $25 \%$ \\
\hline & $\begin{array}{l}\text { As passagens para os pedestres é satisfatório para: Visibilidade (em cada sentido? A } \\
\text { utilização por pessoas com deficiência? Utilização de idosos? Utilização por crianças } \\
\text { nas aréas escolares? }\end{array}$ & & & $\mathrm{x}$ & $25 \%$ \\
\hline & $\begin{array}{l}\text { Se o projeto não contempla áreas pavimentadas para os pedestres, onde os pedestres } \\
\text { andam é seguro suficiente? As travessias são seguras nas pontes e bueiros? }\end{array}$ & & & $\mathrm{x}$ & $25 \%$ \\
\hline & $\begin{array}{l}\text { Foi prevista gradis para pedestres nos canteiros centrias ou em projetos complexos } \\
\text { de interseção para reduzir a travessia? }\end{array}$ & & & $\mathrm{x}$ & $25 \%$ \\
\hline & Os locais de passarelas de pedestres são apropriados? & & & $\mathrm{x}$ & $25 \%$ \\
\hline & $\begin{array}{l}\text { Nas travessias de pedestres está previsto piso tátil, que servirá para ajudar as pessoas } \\
\text { com deficiência? }\end{array}$ & & & $\mathrm{x}$ & $25 \%$ \\
\hline
\end{tabular}




\begin{tabular}{|c|c|c|c|c|c|c|}
\hline & $\begin{array}{l}\text { Existe uma necessidade de ilhas de refúgio de pedestres e são largas o suficiente para } \\
\text { garantir a segurança? }\end{array}$ & & & & $\mathrm{x}$ & $25 \%$ \\
\hline & $\begin{array}{l}\text { Onde houve alaargamento das faixas foi previsto o movimento dos pedestres, e os } \\
\text { pedestres poderá utilizar com segurança? }\end{array}$ & & & & $\mathrm{x}$ & $25 \%$ \\
\hline & $\begin{array}{l}\text { A velocidade operacional esperada é apropriada para as instalações fornecidas aos } \\
\text { pedestres? }\end{array}$ & & & & $\mathrm{x}$ & $25 \%$ \\
\hline \multirow{2}{*}{ areas adjacentes $(2,3)$} & Todos os acessos, para as propriedades e / ou propriedade adjacentes são seguros? & & $\mathrm{x}$ & $\mathrm{x}$ & & $50 \%$ \\
\hline & $\begin{array}{l}\text { Há necesidade de considerar os movimentos relacionados com a atividade agrícola } \\
\text { na região? }\end{array}$ & & $\mathrm{x}$ & $\mathrm{x}$ & & $50 \%$ \\
\hline \multirow{8}{*}{ Motociclistas } & Foram levadas em consideração as necessidades dos motociclistas? & & & & $\mathrm{x}$ & $25 \%$ \\
\hline & $\begin{array}{l}\text { Existem dispositivos na rodovia ou objetos que podem desestabilizar uma } \\
\text { motocicleta? }\end{array}$ & & $\mathrm{x}$ & $\mathrm{x}$ & $\mathrm{x}$ & $75 \%$ \\
\hline & $\begin{array}{l}\text { A borda está livre de obstruções de forma que uma motocicleta consiga inclinar-se } \\
\text { em uma curva de forma segura? }\end{array}$ & & $\mathrm{x}$ & $\mathrm{x}$ & $\mathrm{x}$ & $75 \%$ \\
\hline & Existem advertências ou delineação adequados para os motociclistas? & & $\mathrm{x}$ & $\mathrm{x}$ & & $50 \%$ \\
\hline & $\begin{array}{l}\text { Existe extremidades de barreiras de contenção expostas, desprotegida ou terminal } \\
\text { em áreas de alta velocidade? }\end{array}$ & & $\mathrm{x}$ & $\mathrm{x}$ & & $50 \%$ \\
\hline & $\begin{array}{l}\text { Onde as áreas que existem maiores probabilidades das motocicletas sairem da } \\
\text { rodovia, há alguma medida de segurança? }\end{array}$ & & $\mathrm{x}$ & $\mathrm{x}$ & $\mathrm{x}$ & $75 \%$ \\
\hline & $\begin{array}{l}\text { São todos os postes e dispositivos necessários? Se assim for, existe opção para } \\
\text { protegê-los? }\end{array}$ & & $\mathrm{x}$ & $\mathrm{x}$ & & $50 \%$ \\
\hline & área de drenagem e bueiros podem ser superados com satisfação pelos motociclistas? & & $\mathrm{x}$ & $\mathrm{x}$ & $\mathrm{x}$ & $75 \%$ \\
\hline \multirow{2}{*}{ Cavaleiros e gado } & $\begin{array}{l}\text { Foram considerados o tráfego de cavaleiros, incluindo a utilização das bordas e } \\
\text { acostamentos, e o regulamento para a utilização da faixa da rodovia? }\end{array}$ & & $\mathrm{x}$ & $\mathrm{x}$ & & $50 \%$ \\
\hline & Existem passagem em inferiores para ser usado pelos cavaleiros e gados? & & $\mathrm{x}$ & $\mathrm{x}$ & $\mathrm{x}$ & $75 \%$ \\
\hline \multicolumn{7}{|c|}{ 7. Sinalização e iluminação } \\
\hline \multirow{5}{*}{ Marcas no pavimento } & $\begin{array}{l}\text { As linhas de eixo e de bordo estão claramente visíveis, em considçoes diurnas e } \\
\text { nortunas? }\end{array}$ & $\mathrm{x}$ & & & & $25 \%$ \\
\hline & antigas marcas do pavimento forão removidas? & $\mathrm{x}$ & & & & $25 \%$ \\
\hline & Verificar a retrorefletividade da sinalização horizontal existente & $\mathrm{x}$ & & & & $25 \%$ \\
\hline & Estimar o apagamento. & $\mathrm{x}$ & & & & $25 \%$ \\
\hline & Sinalizações de bordo em relevo são necessárias? & $\mathrm{x}$ & & & & $25 \%$ \\
\hline
\end{tabular}




\begin{tabular}{|c|c|c|c|c|c|c|}
\hline & O delineamento é adequado? Eficaz com todas as condições? & $\mathrm{x}$ & & & & $25 \%$ \\
\hline & $\begin{array}{l}\text { Os marcadores de alinhamento estão colocados corretamente? Retrorefletividade } \\
\text { tem sido avaliada? }\end{array}$ & $\mathrm{x}$ & & & & $25 \%$ \\
\hline & As formas das demarcações e símbolos são consistentes o manual de sinalização? & & $\mathrm{x}$ & $\mathrm{x}$ & & $50 \%$ \\
\hline & $\begin{array}{l}\text { Foi identificado e tratado algum lugar de demarcações que poderia ser confuso ou } \\
\text { mal interpretado, de modo a considerar as respostas dos usuários? }\end{array}$ & & $\mathrm{x}$ & $\mathrm{x}$ & & $50 \%$ \\
\hline & As linhas contínuas (de proíbido ultrapassar) prevstas quando necessárias? & & $\mathrm{x}$ & $\mathrm{x}$ & $\mathrm{x}$ & $75 \%$ \\
\hline & As tachas retroreflectivas estão previstas onde necessárias? & & $\mathrm{x}$ & $\mathrm{x}$ & & $50 \%$ \\
\hline & $\begin{array}{l}\text { As sinalizações de advertência de perigo nas curvas, placas de velocidade ou marcas } \\
\text { no alinhamento estão previstas onde necessárias? }\end{array}$ & & $\mathrm{x}$ & $\mathrm{x}$ & & $50 \%$ \\
\hline & $\begin{array}{l}\text { As demarcações do novo projeto estão consistentes com as seções da rodovia de via } \\
\text { adjacente (ou as demarcaçôes poderá ser melhorada)? }\end{array}$ & & $\mathrm{x}$ & $\mathrm{x}$ & & $50 \%$ \\
\hline & A demarcação diagonal ou de divisa é prevista onde necessária? & & $\mathrm{x}$ & $\mathrm{x}$ & & $50 \%$ \\
\hline & A demarcação e delimitação também ser visível à noite? & & $\mathrm{x}$ & $\mathrm{x}$ & & $50 \%$ \\
\hline Demarcações e delineamento & A demarcação e delimitação sejam visíveis também com a rodovia molhada? & & $\mathrm{x}$ & $\mathrm{x}$ & & $50 \%$ \\
\hline & Foi considerada a necessidade de uma borda de alerta sobre a demarcação? & & $\mathrm{x}$ & $\mathrm{x}$ & & $50 \%$ \\
\hline & Foram consideradas as luzes baixas e altas dos veículos? & & $\mathrm{x}$ & $\mathrm{x}$ & & $50 \%$ \\
\hline & Os postes das mensagens variaveis são frágeis? & & $\mathrm{x}$ & $\mathrm{x}$ & & $-50 \%$ \\
\hline & São as marcas rodoviárias planejadas adequada em termos de segurança? & & & & $\mathrm{x}$ & $-75 \%$ \\
\hline & $\begin{array}{l}\text { Será que as marcações está em conformidade com as normas prescritas nos } \\
\text { Regulamentos de Tráfego do ato e National Road? }\end{array}$ & & & & $\mathrm{x}$ & $-75 \%$ \\
\hline & $\begin{array}{l}\text { As marcas de orientação e ilhas foram pintadas para esclarecer os movimentos em } \\
\text { projetos complexos? }\end{array}$ & & & & $\mathrm{x}$ & $25 \%$ \\
\hline & As marcações nas áreas de tempo úmido foram realizadas melhorias da visibilidade? & & & & $\mathrm{x}$ & $25 \%$ \\
\hline & As marcações de perfil foram consideradas no projeto? & & & & $\mathrm{x}$ & $25 \%$ \\
\hline & $\begin{array}{l}\text { Há locais do projeto que tem necessidades de tachas refletivas, locais como ilhas, } \\
\text { que pode gerar perigo ao usuário no período da noite? }\end{array}$ & & & & $\mathrm{x}$ & $25 \%$ \\
\hline & $\begin{array}{l}\text { As marcaçôes nos locais de transição entre o projeto da rodovia com rodovias } \\
\text { adjacentes, cruzamentos é segura? }\end{array}$ & & & & $\mathrm{x}$ & $25 \%$ \\
\hline
\end{tabular}




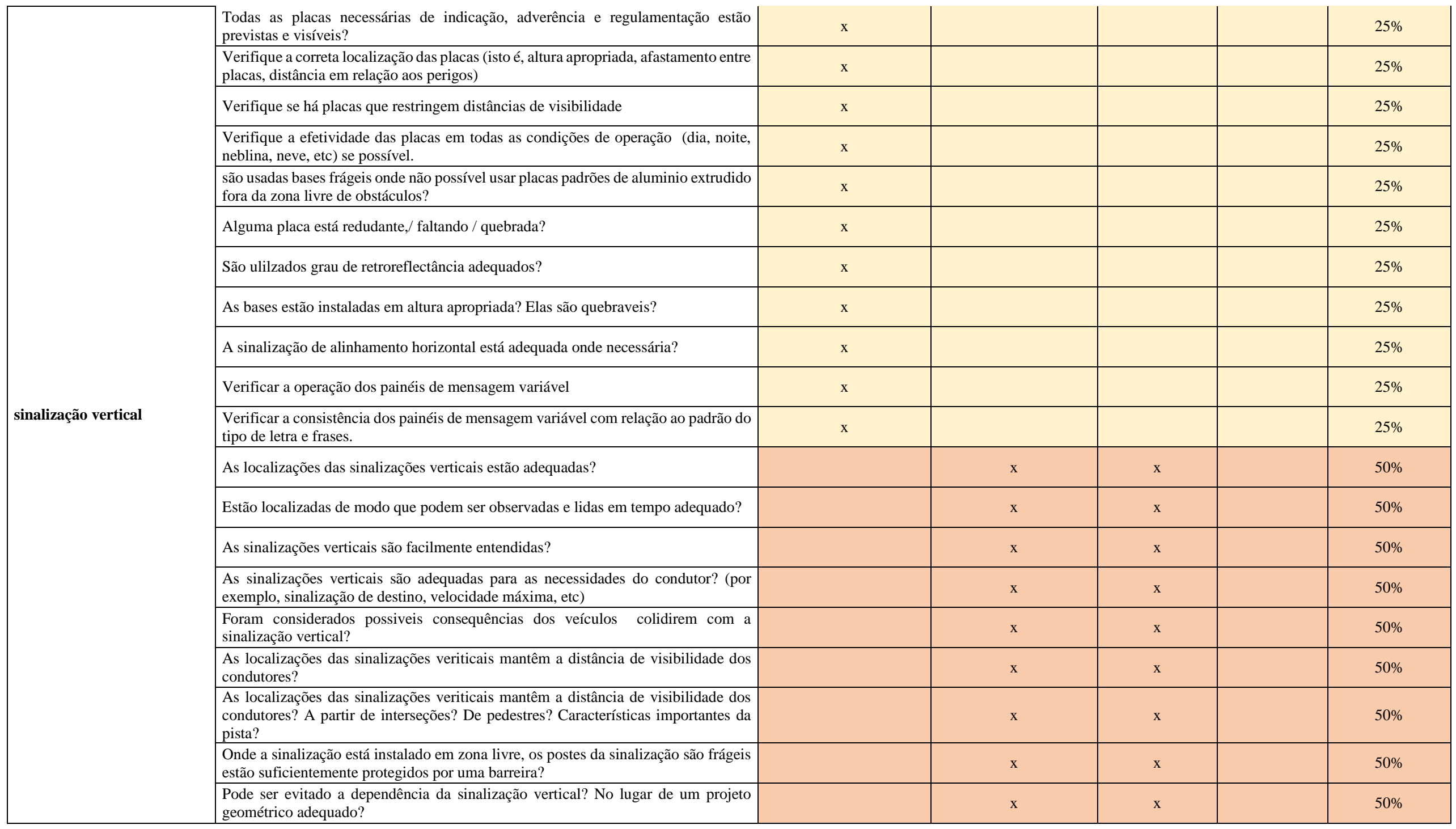




\begin{tabular}{|c|c|c|c|c|c|c|}
\hline & $\begin{array}{l}\text { A nova sinalização é compatível com a da rede de rodovias adjacentes? (Ou a } \\
\text { sinalização antiga deverá ser melhorada) }\end{array}$ & & $\mathrm{x}$ & $\mathrm{x}$ & & $50 \%$ \\
\hline \multirow{19}{*}{ Iluminação } & É necessária iluminação para o projeto? é fornecido de forma adequada? & & $\mathrm{x}$ & $\mathrm{x}$ & $\mathrm{x}$ & $75 \%$ \\
\hline & $\begin{array}{l}\text { Se o projeto for iluminado, será mantida a segurança nos casos da ruptura no } \\
\text { fornecimento de energia? }\end{array}$ & & & & $\mathrm{x}$ & $25 \%$ \\
\hline & $\begin{array}{l}\text { Foi levado em conta as características como árvores, pontes, etc que pode afetar a } \\
\text { instalação de iluminação rodoviária? }\end{array}$ & & & & $\mathrm{x}$ & $25 \%$ \\
\hline & $\begin{array}{l}\text { O projeto terá seções com problemas de iluminação? (por exemplo, sombras de } \\
\text { árvores ou pontes). }\end{array}$ & & $\mathrm{x}$ & $\mathrm{x}$ & & $50 \%$ \\
\hline & Algum poste de iluminação representa perigo na margem da rodovia? & & $\mathrm{x}$ & $\mathrm{x}$ & & $50 \%$ \\
\hline & $\begin{array}{l}\text { Os postes a serem utilizados são frágeis (quebradiços) ou com base dobrável ou } \\
\text { deslizantes? }\end{array}$ & $\mathrm{x}$ & $\mathrm{x}$ & & & $50 \%$ \\
\hline & $\begin{array}{l}\text { O projeto de iluminação pode confundir ou causar efeitos enganosos sobre a } \\
\text { sinalização ou semáforos? }\end{array}$ & & $\mathrm{x}$ & $\mathrm{x}$ & & $50 \%$ \\
\hline & $\begin{array}{l}\text { Existem locais onde a iluminação pode interferir com semáforos ou sinalização } \\
\text { vertical? }\end{array}$ & $\mathrm{x}$ & & & & $25 \%$ \\
\hline & $\begin{array}{l}\text { Há necessidade de requisitos especiais para iluminação ambiente? A segurança será } \\
\text { mantida casos as medidas especiais não forem realizadas? }\end{array}$ & & & $\mathrm{x}$ & $\mathrm{x}$ & $50 \%$ \\
\hline & $\begin{array}{l}\text { foi mantida a segurança do usuário da rodovia que pode colidir com postes de } \\
\text { iluminação? }\end{array}$ & & & & $\mathrm{x}$ & $25 \%$ \\
\hline & $\begin{array}{l}\text { As barreiras de contenção são utilizadas para proteger o usuário da rodovia não } \\
\text { colidir com obejtos fixos, no projeto foram previstas e localizadas adequadamente } \\
\text { para garantir a segurança? }\end{array}$ & & & & $\mathrm{x}$ & $25 \%$ \\
\hline & Todas as articulações (juntas) das áreas foram iluminados adequadamente? & & & & $\mathrm{x}$ & $25 \%$ \\
\hline & Algum poste de iluminação representa perigo na margem da rodovia? & & & & $\mathrm{x}$ & $25 \%$ \\
\hline & Áreas com histórico de acidentes o projeto prevê iluminação? & & & & $\mathrm{x}$ & $25 \%$ \\
\hline & \begin{tabular}{|l} 
A iluminação vai permitir adequadamente iluminação de cruzamentos, as \\
estradas adjacentes, refúgios, etc.?
\end{tabular} & & $\mathrm{x}$ & $\mathrm{x}$ & & $50 \%$ \\
\hline & Todas as articulações (juntas) das áreas foram iluminados adequadamente? & & $\mathrm{x}$ & $\mathrm{x}$ & & $50 \%$ \\
\hline & Existem alguma área não iluminada no projeto? & & $\mathrm{x}$ & $\mathrm{x}$ & & $50 \%$ \\
\hline & $\begin{array}{l}\text { Existem locais de conflito de acidentes, que pode ser vantajoso tratar com a melhoria } \\
\text { da iluminação ou instalar o projeto de iluminação? }\end{array}$ & & $\mathrm{x}$ & $\mathrm{x}$ & & $50 \%$ \\
\hline & O projeto é livre de iluminação em áreas escuras? & & $\mathrm{x}$ & $\mathrm{x}$ & & $50 \%$ \\
\hline
\end{tabular}




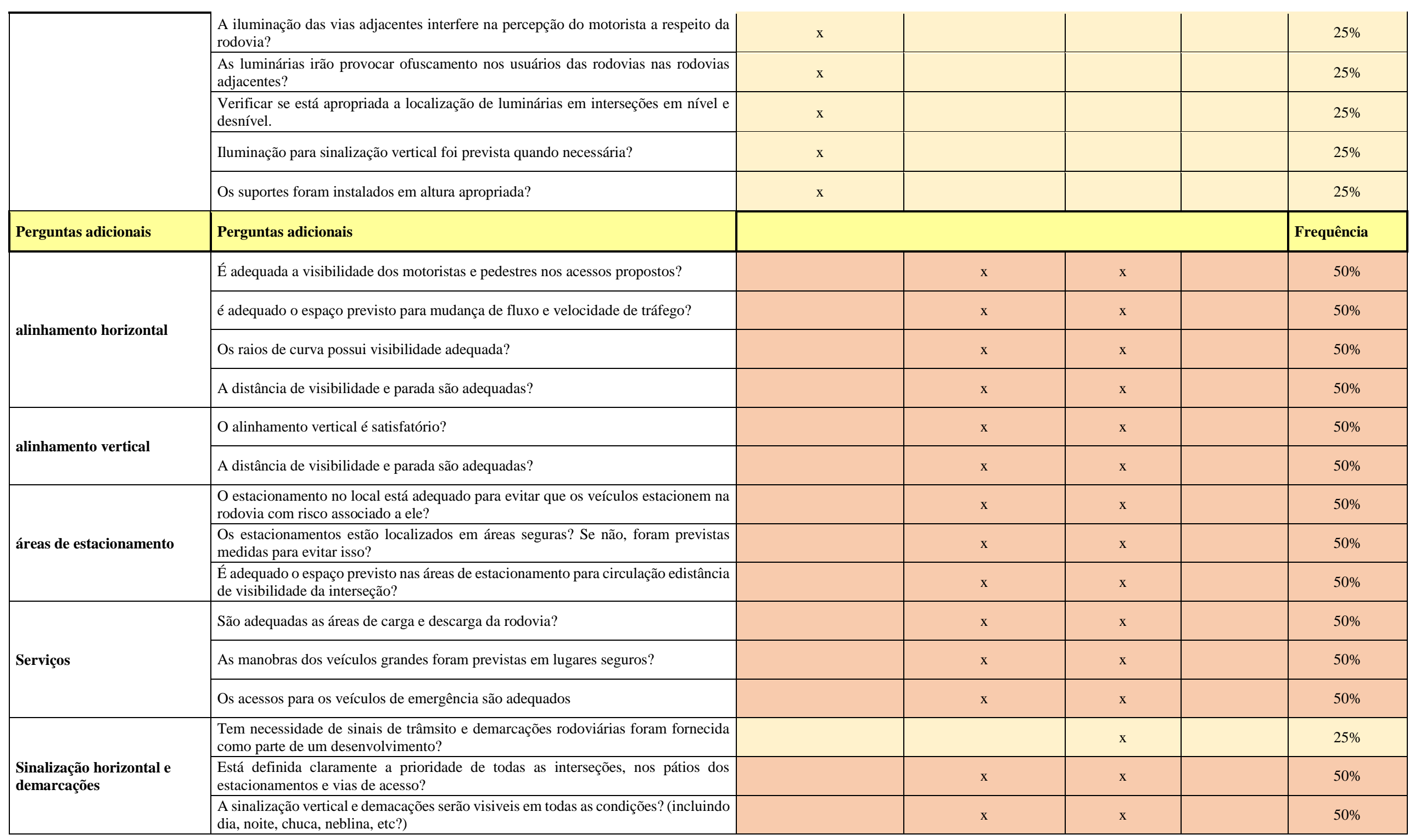




\begin{tabular}{|c|c|c|c|c|c|c|}
\hline \multirow{2}{*}{ Paisagismo } & $\begin{array}{l}\text { A paisagem mantém a visibilidade nas interseções, curvas, acessos e localizações de } \\
\text { pedestres? }\end{array}$ & & $\mathrm{x}$ & $\mathrm{x}$ & & $50 \%$ \\
\hline & $\begin{array}{l}\text { foi evitado a plantação de vegetação em lugares onde os veículos podem sair da } \\
\text { rodovia? }\end{array}$ & & $\mathrm{x}$ & $\mathrm{x}$ & & $50 \%$ \\
\hline \multirow{6}{*}{ Gestão de tráfego (2) } & Foi considerado efeitos adversos em alguma área do projeto? & & & $\mathrm{x}$ & & $25 \%$ \\
\hline & O projeto vai manter a velocidade de projeto de forma segura? & & $\mathrm{x}$ & $\mathrm{x}$ & & $50 \%$ \\
\hline & O número e a localização dos acessos são adequados? & & $\mathrm{x}$ & $\mathrm{x}$ & & $50 \%$ \\
\hline & $\begin{array}{l}\text { Há instalações para os serviços de transporte públicos? E estão localizados em } \\
\text { lugares seguros e justificados? }\end{array}$ & & $\mathrm{x}$ & $x$ & & $50 \%$ \\
\hline & $\begin{array}{l}\text { Existem instalações para os ciclistas? Estão localizados de forma segura a respeito } \\
\text { dos movimentos dos veiculos? }\end{array}$ & & $x$ & $\mathrm{x}$ & & $50 \%$ \\
\hline & $\begin{array}{l}\text { Existem instalações para os pedestres? Estão localizadas em lugares seguros e } \\
\text { adequados? }\end{array}$ & & $x$ & $x$ & & $50 \%$ \\
\hline \multirow{3}{*}{ Outros } & No projeto está prevista iluminação pública? É adequada? & & $\mathrm{x}$ & $\mathrm{x}$ & & $50 \%$ \\
\hline & Há riscos na margem da rodovia? Foram tratados corretamente? & & $\mathrm{x}$ & $\mathrm{x}$ & & $50 \%$ \\
\hline & Os pedestres podem acessar de forma segura o desenvolvimento urbano proposto? & & $\mathrm{x}$ & $\mathrm{x}$ & & $50 \%$ \\
\hline Outras considerações & Outras considerações $(2,3$ e 4$)$ & \multicolumn{4}{|l|}{ Outras considerações $(2,3$ e 4$)$} & Frequência \\
\hline \multirow{4}{*}{$\begin{array}{l}\text { Aspectos de segurança (2 e 3) } \\
\text { e outras características }\end{array}$} & há situações especiais? Foram consideradas situações incomuns ou de perigo? & & $\mathrm{x}$ & $\mathrm{x}$ & & $50 \%$ \\
\hline & $\begin{array}{l}\text { A rodovia é capaz de suportar com segurança a circulação de veículos de grande } \\
\text { porte, caminhões, ônibus, veiculos de emergência, veículos de manutenção da } \\
\text { rodovia? }\end{array}$ & & $\mathrm{x}$ & $\mathrm{x}$ & & $50 \%$ \\
\hline & Se necessário, a rodovia pode ser fechada para eventos especiais de forma segura? & & $\mathrm{x}$ & $\mathrm{x}$ & & $50 \%$ \\
\hline & Se for o caso, os requisitos especiais de paisagem e rotas turisticas são satisfeitos? & & $\mathrm{x}$ & $\mathrm{x}$ & & $50 \%$ \\
\hline \multirow{2}{*}{ Turistas / recreação } & Há requisitos de segurança para instalações de alojamento turisticos ou de lazer? & & & & $\mathrm{x}$ & $25 \%$ \\
\hline & $\begin{array}{l}\text { Foram consideradas perigos incomuns ou com potencialmente associadas com } \\
\text { eventos especiais? Se necessário, a rodovia pode ser fechada com segurança? }\end{array}$ & & & & $\mathrm{x}$ & $25 \%$ \\
\hline
\end{tabular}




\section{APÊNDICE D1 - INSTRUMENTO DE ASV- ESTUDO DE VIABILIDADE - VERSÃO PRELIMINAR}

\begin{tabular}{|c|c|c|c|c|c|c|}
\hline \multirow[t]{2}{*}{$\begin{array}{c}\text { Nível - } \\
\text { Macrocategorias }\end{array}$} & \multirow[t]{2}{*}{$\begin{array}{c}\text { Nível - } \\
\text { Mesocategorias }\end{array}$} & \multirow[t]{2}{*}{ Nível Microcategorias } & \multicolumn{3}{|c|}{$\begin{array}{l}\text { Os itens dos níveis } \\
\text { correspondem ao Estudo de } \\
\text { Viabilidade e com a segurança } \\
\text { viária, e tem clareza dos itens. } \\
\text { Ou necessitam de adequações? }\end{array}$} & \multirow[t]{2}{*}{$\begin{array}{l}\text { Sugestões de adequações e/ou } \\
\text { outras considerações }\end{array}$} \\
\hline & & & $\begin{array}{l}(\mathbf{X}) \\
\text { Sim }\end{array}$ & $\begin{array}{l}\text { (X) } \\
\text { Não }\end{array}$ & \begin{tabular}{|c|}
$\mathrm{X})$ necessita \\
de adequações
\end{tabular} & \\
\hline \multirow{11}{*}{ 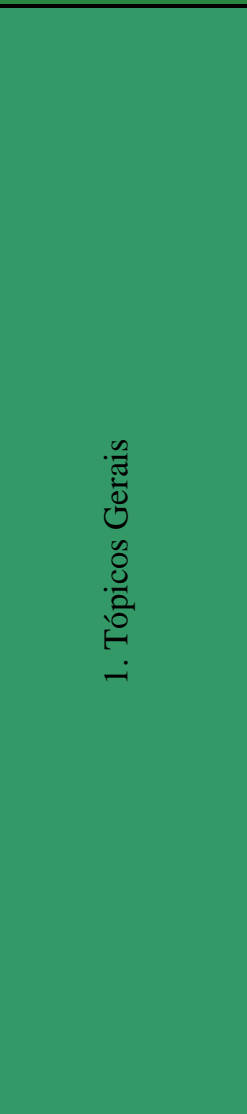 } & \multirow{9}{*}{$\begin{array}{l}1.1 \text { Finalidade } \\
\text { do projeto }\end{array}$} & $\begin{array}{l}\text { Verificar toda documentação pertinente do escopo do projeto, } \\
\text { destacando os objetivos do projeto, características do usuário, veículos de } \\
\text { projetos, projetos de acessos, características das áreas adjacentes, } \\
\text { informações de redes existentes e projetos de futuras expansões. }\end{array}$ & & & & \\
\hline & & Qual é a função do projeto previsto? & & & & \\
\hline & & O projeto é compatível com a função da rodovia? & & & & \\
\hline & & $\begin{array}{l}\text { O projeto proposto (ou reprojeto) enfatiza a segurança adequadamente } \\
\text { dos automóveis - motociclistas - ciclistas - pedestres - veículos pesados e } \\
\text { ônibus? }\end{array}$ & & & & \\
\hline & & Foi considerada adequadamente a composição do tráfego esperado? & & & & \\
\hline & & $\begin{array}{l}\text { Será que o projeto proposto está compatível com as rodovias adjacentes, } \\
\text { topografia e a gestão de trânsito? }\end{array}$ & & & & \\
\hline & & O projeto será implementado em uma única etapa de construção? & & & & \\
\hline & & $\begin{array}{l}\text { Se o projeto for implementado em mais de uma etapa, foi dada a } \\
\text { prioridade de segurança: nas transições de etapas; e nas transições com } \\
\text { rodovias existentes. }\end{array}$ & & & & \\
\hline & & $\begin{array}{l}\text { O trabalho irá evitar problemas com as normas de segurança durante a } \\
\text { construção? }\end{array}$ & & & & \\
\hline & \multirow{2}{*}{$\begin{array}{l}1.2 \\
\text { Características } \\
\text { técnicas do } \\
\text { projeto }\end{array}$} & $\begin{array}{l}\text { Os principais geradores de tráfego (incluindo a habitação ou centros } \\
\text { comerciais) estão longe o suficiente para evitar influências de insegurança } \\
\text { sobre a forma do traçado? Se sim, foram previstos ações mitigadoras? }\end{array}$ & & & & \\
\hline & & $\begin{array}{l}\text { Está previsto acessos alternativos para assegurar que subúrbios ou } \\
\text { subáreas existentes não ficaram isolados / devidos as áreas não serem } \\
\text { cortadas pelo desenvolvimento do trabalho / obras? }\end{array}$ & & & & \\
\hline
\end{tabular}




\begin{tabular}{|c|c|c|c|c|c|c|}
\hline & & $\begin{array}{l}\text { Os acessos para os geradores de tráfego estão significativamente longe } \\
\text { das interseções para fornecer a segurança? }\end{array}$ & & & & \\
\hline & & $\begin{array}{l}\text { A distância de visibilidade dos acessos para os geradores de tráfego estão } \\
\text { adequadas? }\end{array}$ & & & & \\
\hline & & $\begin{array}{l}\text { Será que o projeto proposto é coerente com as estradas adjacentes, } \\
\text { formas do relevo (topografia) e gestão de tráfego? }\end{array}$ & & & & \\
\hline & \multirow{6}{*}{$\begin{array}{l}1.3 \text { Acesso e } \\
\text { áreas adjacentes }\end{array}$} & Existem fatores a montante ou a jusante que poderão afetar o acesso? & & & & \\
\hline & & $\begin{array}{l}\text { Existe poluição visual (outdoor com propagandas comerciais ou } \\
\text { iluminação excessiva) próximo a linhas de passagens? }\end{array}$ & & & & \\
\hline & & $\begin{array}{l}\text { O controle dos acessos é compatível com a função e com outras seções } \\
\text { da rodovia? }\end{array}$ & & & & \\
\hline & & $\begin{array}{l}\text { A distância de visibilidade é satisfatória: nas interseções e acesso ás } \\
\text { propriedades? }\end{array}$ & & & & \\
\hline & & $\begin{array}{l}\text { A velocidade de projeto (ou a velocidade de operação dos veículos) é } \\
\text { compatível com número e o tipo de interseções / e acessos a propriedades } \\
\text { adjacentes? }\end{array}$ & & & & \\
\hline & & $\begin{array}{l}\text { A largura da faixa de direito de passagem atende aos requisitos } \\
\text { necessários a acessibilidade? }\end{array}$ & & & & \\
\hline & $\begin{array}{l}1.4 \text { Impactos do } \\
\text { projeto proposto }\end{array}$ & \begin{tabular}{|lll} 
Efeitos negativos do projeto sobre as vias adjacentes, foram \\
identificados? E foram tratados adequadamente?
\end{tabular} & & & & \\
\hline & $\begin{array}{l}1.5 \text { Obras de } \\
\text { Melhoramentos }\end{array}$ & $\begin{array}{l}\text { O traçado não afetará o nível de segurança, se houver: futuro } \\
\text { alargamento?; a adição de um segunda faixa de sentido completo?; Após } \\
\text { alinhamento?; Principais alterações geométricas nas interseções? E } \\
\text { extensões lineares do projeto?. }\end{array}$ & & & & \\
\hline $\begin{array}{l}\text { Nível - } \\
\text { Macrocategoria } \\
\quad \text { s }\end{array}$ & $\begin{array}{c}\text { Nível - } \\
\text { Mesocategorias }\end{array}$ & Nível Microcategorias & $\begin{array}{l}(\mathbf{X}) \\
\text { Sim }\end{array}$ & $\begin{array}{l}(\mathbf{X}) \\
\text { Não }\end{array}$ & $\begin{array}{c}(X) \text { necessita } \\
\text { de adequações }\end{array}$ & $\begin{array}{l}\text { sugestões de adequações e/ou outras } \\
\text { considerações }\end{array}$ \\
\hline \multirow{3}{*}{ 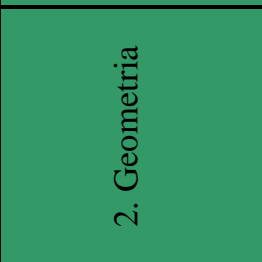 } & \multirow{3}{*}{$\begin{array}{l}2.1 \text { Traçado e } \\
\text { alinhamento }\end{array}$} & $\begin{array}{l}\text { Verificar a adequação da classificação e traçado do projeto para o volume } \\
\text { e composição do tráfego do projeto proposto. }\end{array}$ & & & & \\
\hline & & $\begin{array}{l}\text { A concepção do projeto é flexível para acomodar os imprevistos no } \\
\text { aumento do tráfego ou alterações nas características do tráfego? }\end{array}$ & & & & \\
\hline & & $\begin{array}{l}\text { São seguros todos os aspectos relacionados com a localização do traçado } \\
\text { e/ou alinhamento? }\end{array}$ & & & & \\
\hline
\end{tabular}




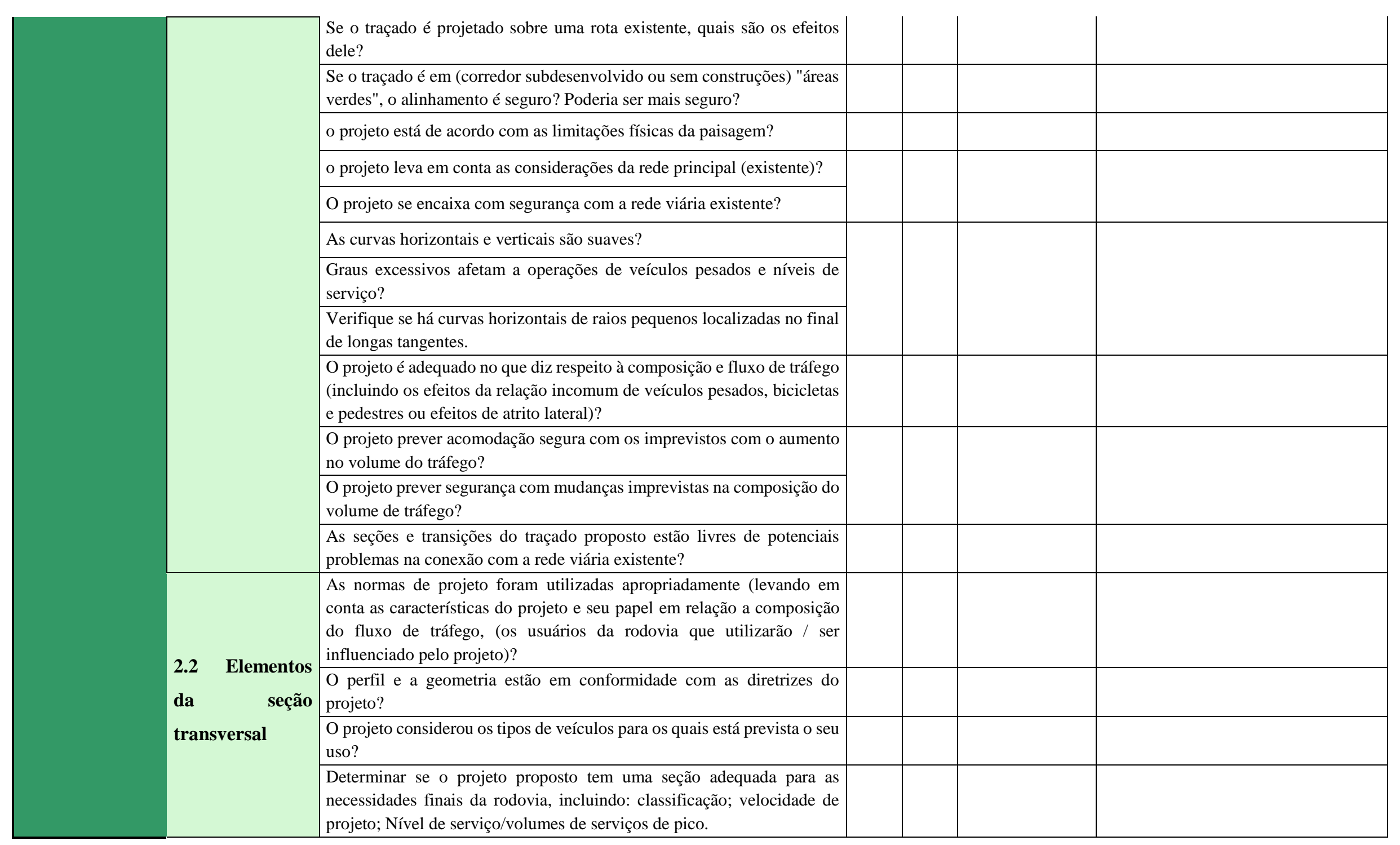




\begin{tabular}{|c|c|c|c|c|c|c|}
\hline & & $\begin{array}{l}\text { Determinar se os ajustes nas dimensões podem ser feitos para futuras } \\
\text { possibilidades de expansão. }\end{array}$ & & & & \\
\hline & \multirow{5}{*}{ 2.3 Velocidades } & $\begin{array}{l}\text { A velocidade de projeto está adequada com: Alinhamento vertical, } \\
\text { horizontal, visibilidade, acessos, entre cruzamentos, aceleração e } \\
\text { desaceleração do fluxo de veículos nos cruzamento, composição do } \\
\text { tráfego previsto? }\end{array}$ & & & & \\
\hline & & $\begin{array}{l}\text { A distância de visibilidade é satisfatória para: interseções? Entrada e saída } \\
\text { das rampas? Entradas de propriedades adjacentes? Em entradas de acesso } \\
\text { de veículos de emergência? }\end{array}$ & & & & \\
\hline & & Pode haver qualquer mudança no limite de velocidade com segurança? & & & & \\
\hline & & $\begin{array}{l}\text { A velocidade de projeto e o limite de velocidade são adequados para a } \\
\text { rodovia ou parte dela? }\end{array}$ & & & & \\
\hline & & $\begin{array}{l}\text { O limite de velocidade projeto está de acordo com a velocidade de } \\
\text { sinalizada? }\end{array}$ & & & & \\
\hline $\begin{array}{l}\text { Nível - } \\
\text { Macrocategoria } \\
\text { S }\end{array}$ & $\begin{array}{c}\text { Nível - } \\
\text { Mesocategorias }\end{array}$ & Nível Microcategorias & $\begin{array}{l}(\mathbf{X}) \\
\text { Sim }\end{array}$ & $\begin{array}{l}(\mathbf{X}) \\
\text { Não }\end{array}$ & $\begin{array}{l}\text { (X) necessita } \\
\text { de adequações }\end{array}$ & $\begin{array}{l}\text { sugestões de adequações e/ou } \\
\text { outras considerações }\end{array}$ \\
\hline \multirow{7}{*}{ 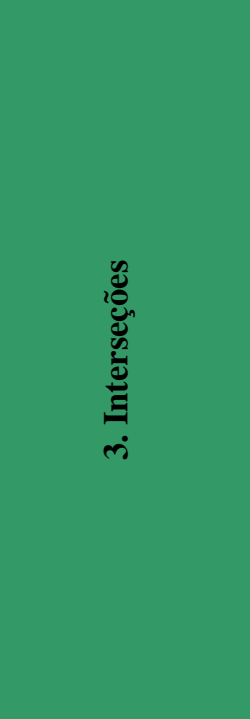 } & \multirow{7}{*}{$\begin{array}{l}\text { 3.1 Quantidade, } \\
\text { tipo e } \\
\text { localização }\end{array}$} & O número de interseções é apropriado para o entorno da rede viária? & & & & \\
\hline & & $\begin{array}{l}\text { Os tipos de interseções selecionadas são adequados para tráfego e } \\
\text { aspectos de segurança do projeto? }\end{array}$ & & & & \\
\hline & & $\begin{array}{l}\text { Os projetos de intersecção acomodam todas as classes de veículos de } \\
\text { projeto? }\end{array}$ & & & & \\
\hline & & $\begin{array}{l}\text { Todos os aspectos das interseções são (por exemplo, o espaçamento, tipo, } \\
\text { layout, etc.) adequados no que diz respeito a: ao conceito geral do projeto; } \\
\text { função do projeto desta rodovia e das rodovias que cruzam o projeto; } \\
\text { compatíveis com a seção adjacente; e aos usuários da rodovia? }\end{array}$ & & & & \\
\hline & & $\begin{array}{l}\text { O número de interseções é apropriado (Não é muito alta ou muito baixa): } \\
\text { para garantir o acesso seguro? para evitar impactos na rede rodoviária } \\
\text { adjacente? E para o acesso de veículos de emergências? }\end{array}$ & & & & \\
\hline & & $\begin{array}{l}\text { As restrições físicas, visibilidade ou gestão do tráfego, que podem } \\
\text { influenciar na escolha do tipo ou o espaçamento das interseções propostas } \\
\text { foram consideradas? }\end{array}$ & & & & \\
\hline & & Todas as propostas de interseções são necessárias ou essenciais? & & & & \\
\hline
\end{tabular}




\begin{tabular}{|c|c|c|c|c|c|c|}
\hline & & $\begin{array}{l}\text { Algumas interseções que foram estimadas desnecessárias podem ser } \\
\text { removidas para melhorar a segurança? E o acesso pode ser conectado de } \\
\text { forma segura por meio de alterações da rede rodoviária adjacente? }\end{array}$ & & & & \\
\hline & & $\begin{array}{l}\text { Os ângulos das faixas da rodovia que cruzam o projeto e linha de } \\
\text { visibilidade são adequados para a segurança de todos os usuários? }\end{array}$ & & & & \\
\hline & & O movimento dos usuários vulneráveis é seguro em todas as interseções? & & & & \\
\hline & & a circulação de veículos pesados é segura nas interseções? & & & & \\
\hline & & $\begin{array}{l}\text { Os alinhamentos verticais e/ou horizontais foram considerados para } \\
\text { determinar o tipo e o espaçamento das intersecções? }\end{array}$ & & & & \\
\hline $\begin{array}{l}\text { Nível - } \\
\text { Macrocategoria } \\
\text { s } \\
\end{array}$ & $\begin{array}{c}\text { Nível - } \\
\text { Mesocategorias }\end{array}$ & Nível Microcategorias & $\begin{array}{l}(\mathbf{X}) \\
\text { Sim }\end{array}$ & $\begin{array}{l}(\mathbf{X}) \\
\text { Não }\end{array}$ & $\begin{array}{l}(X) \text { necessita } \\
\text { de adequações }\end{array}$ & $\begin{array}{l}\text { sugestões de adequações e/ou } \\
\text { outras considerações }\end{array}$ \\
\hline \multirow{11}{*}{ 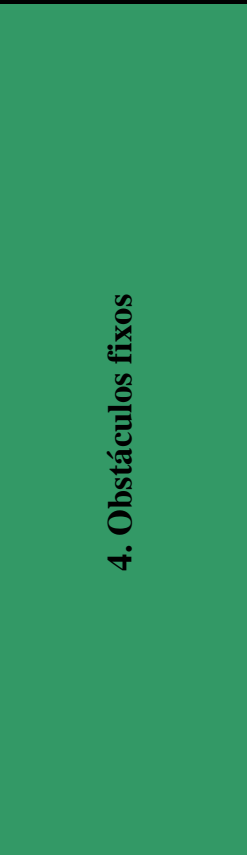 } & \multirow{3}{*}{$\begin{array}{l}4.1 \text { Postes ou } \\
\text { outras } \\
\text { obstruções }\end{array}$} & $\begin{array}{l}\text { As larguras dos canteiros centrais não protegidos são apropriadas para os } \\
\text { postes de iluminação? }\end{array}$ & & & & \\
\hline & & $\begin{array}{l}\text { Os postes de semáforos e outros postes de serviço estão posicionados } \\
\text { adequadamente? }\end{array}$ & & & & \\
\hline & & $\begin{array}{l}\text { Foi considerada localização de serviços e outras utilidades em relação ao } \\
\text { projeto (ou seja, enterrado ou subterrâneo) com vão para cabos aéreos? }\end{array}$ & & & & \\
\hline & \multirow{8}{*}{$\begin{array}{l}\text { 4.2 Dispositivos } \\
\text { centrais }\end{array}$} & $\begin{array}{l}\text { O tipo de divisória central escolhido é apropriado para a largura } \\
\text { disponível? }\end{array}$ & & & & \\
\hline & & As barreiras possuem configuração geométrica adequada? & & & & \\
\hline & & As inclinações dos canteiros de grama estão adequadas? & & & & \\
\hline & & As barreiras centrais estão suficientemente afastadas da rodovia? & & & & \\
\hline & & O afastamento entre as barreiras centrais está dentro dos limites corretos? & & & & \\
\hline & & $\begin{array}{l}\text { As barreiras laterais e das pontes estão de acordo com o nível de } \\
\text { desempenho dos testes de colisões para a classificação da rodovia? }\end{array}$ & & & & \\
\hline & & $\begin{array}{l}\text { Existe largura suficiente para pilares dos viadutos, passagem subterrânea } \\
\text { e iluminação? }\end{array}$ & & & & \\
\hline & & $\begin{array}{l}\text { Verificar o espaçamento apropriado entre travessias de divisórias } \\
\text { centrais? }\end{array}$ & & & & \\
\hline
\end{tabular}




\begin{tabular}{|c|c|c|c|c|c|c|}
\hline $\begin{array}{l}\text { Nível - } \\
\text { Macrocategoria } \\
\text { S }\end{array}$ & $\begin{array}{l}\text { Nível - } \\
\text { Mesocategorias }\end{array}$ & Nível Microcategorias & $\begin{array}{l}(\mathbf{X}) \\
\text { Sim }\end{array}$ & $\begin{array}{l}(\mathbf{X}) \\
\text { Não }\end{array}$ & $\begin{array}{l}(X) \text { necessita } \\
\text { de adequações }\end{array}$ & $\begin{array}{l}\text { sugestões de adequações e/ou } \\
\text { outras considerações }\end{array}$ \\
\hline \multirow{8}{*}{ 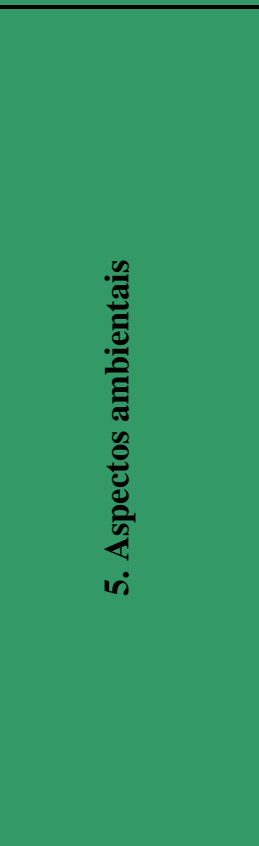 } & \multirow{8}{*}{$\begin{array}{l}5.1 \quad \text { Clima e } \\
\text { outros aspectos }\end{array}$} & $\begin{array}{l}\text { Existem animais nas rotas de viagens / ou migração conhecida em áreas } \\
\text { que poderiam afetar o entorno com o projeto? }\end{array}$ & & & & \\
\hline & & Cercas e passagens inferiores estão implantadas onde é necessário? & & & & \\
\hline & & $\begin{array}{l}\text { Certifique-se se há sinalização apropriada onde for necessário. (ou seja, } \\
\text { passagem de gado, aviso de animais silvestres (veados), etc.) }\end{array}$ & & & & \\
\hline & & $\begin{array}{l}\text { O terreno do entorno da rodovia está livre de objetos físicos ou vegetação } \\
\text { que poderiam afetar a segurança do projeto? ( por exemplo, grandes } \\
\text { cultivos, florestas, cortes profundos (barrancos) cortes elevados, ou áreas } \\
\text { rochosas que podem restringir o projeto. }\end{array}$ & & & & \\
\hline & & $\begin{array}{l}\text { A segurança foi considerada em lugares com determinadas características } \\
\text { ambientais? (por exemplo, cercas de ruídos) }\end{array}$ & & & & \\
\hline & & $\begin{array}{l}\text { Projeto irá operar com segurança em condições ambientais adversas, } \\
\text { como a noite, com neblina ou estrada molhada? }\end{array}$ & & & & \\
\hline & & $\begin{array}{l}\text { Existem distrações visuais (como por exemplo, uma paisagem } \\
\text { panorâmica) e foram tratados adequadamente (por exemplo, } \\
\text { proporcionando áreas para as pessoas estacionar seus veículos com } \\
\text { segurança)? }\end{array}$ & & & & \\
\hline & & $\begin{array}{l}\text { Foram considerados aspectos incomuns? (por exemplo, terrenos com } \\
\text { atividades de mineração) }\end{array}$ & & & & \\
\hline $\begin{array}{l}\text { Nível - } \\
\text { Macrocategoria } \\
\text { S } \\
\end{array}$ & $\begin{array}{l}\text { Nível - } \\
\text { Mesocategorias }\end{array}$ & Nível Microcategorias & $\begin{array}{l}(\mathbf{X}) \\
\text { Sim }\end{array}$ & $\begin{array}{l}(\mathbf{X}) \\
\text { Não }\end{array}$ & $\begin{array}{l}(X) \text { necessita } \\
\text { de adequações }\end{array}$ & $\begin{array}{l}\text { Sugestões de adequações e/ou } \\
\text { outras considerações }\end{array}$ \\
\hline \multirow{4}{*}{ 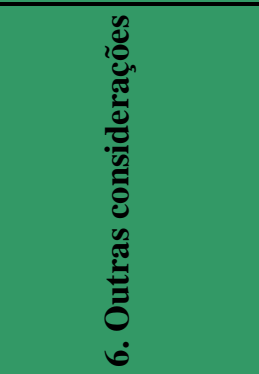 } & \multirow{4}{*}{$\begin{array}{lr}6.1 & \text { Outros } \\
\text { aspectos } & \text { de } \\
\text { segurança } & \text { não } \\
\text { considerados }\end{array}$} & Foi considerada a possibilidade de inundações? & & & & \\
\hline & & $\begin{array}{l}\text { Os cruzamentos ferroviários foram identificados e tratados de forma } \\
\text { adequada? }\end{array}$ & & & & \\
\hline & & $\begin{array}{l}\text { Foram consideradas outras distrações visuais (por exemplo, publicidade, } \\
\text { aviões voando baixo etc.). }\end{array}$ & & & & \\
\hline & & $\begin{array}{l}\text { Considerou a necessidade de áreas de descanso ou estacionamentos (por } \\
\text { exemplo, rotas turísticas, parada de caminhões, áreas para piquenique ou } \\
\text { outras áreas)? }\end{array}$ & & & & \\
\hline
\end{tabular}




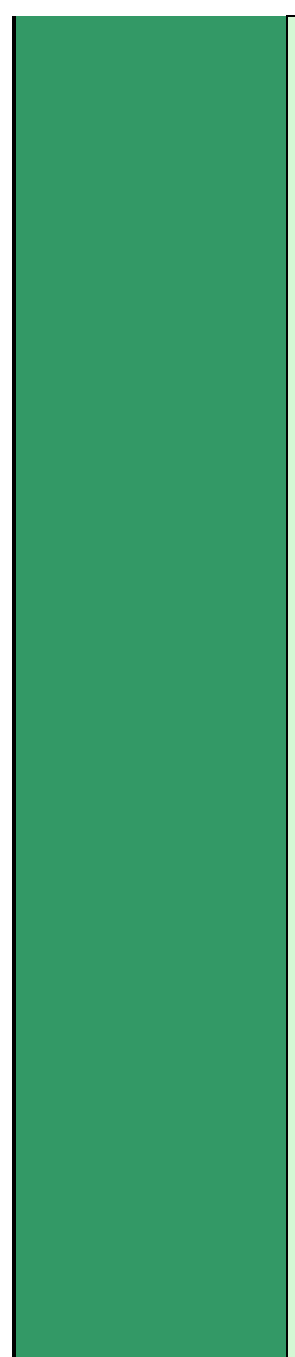

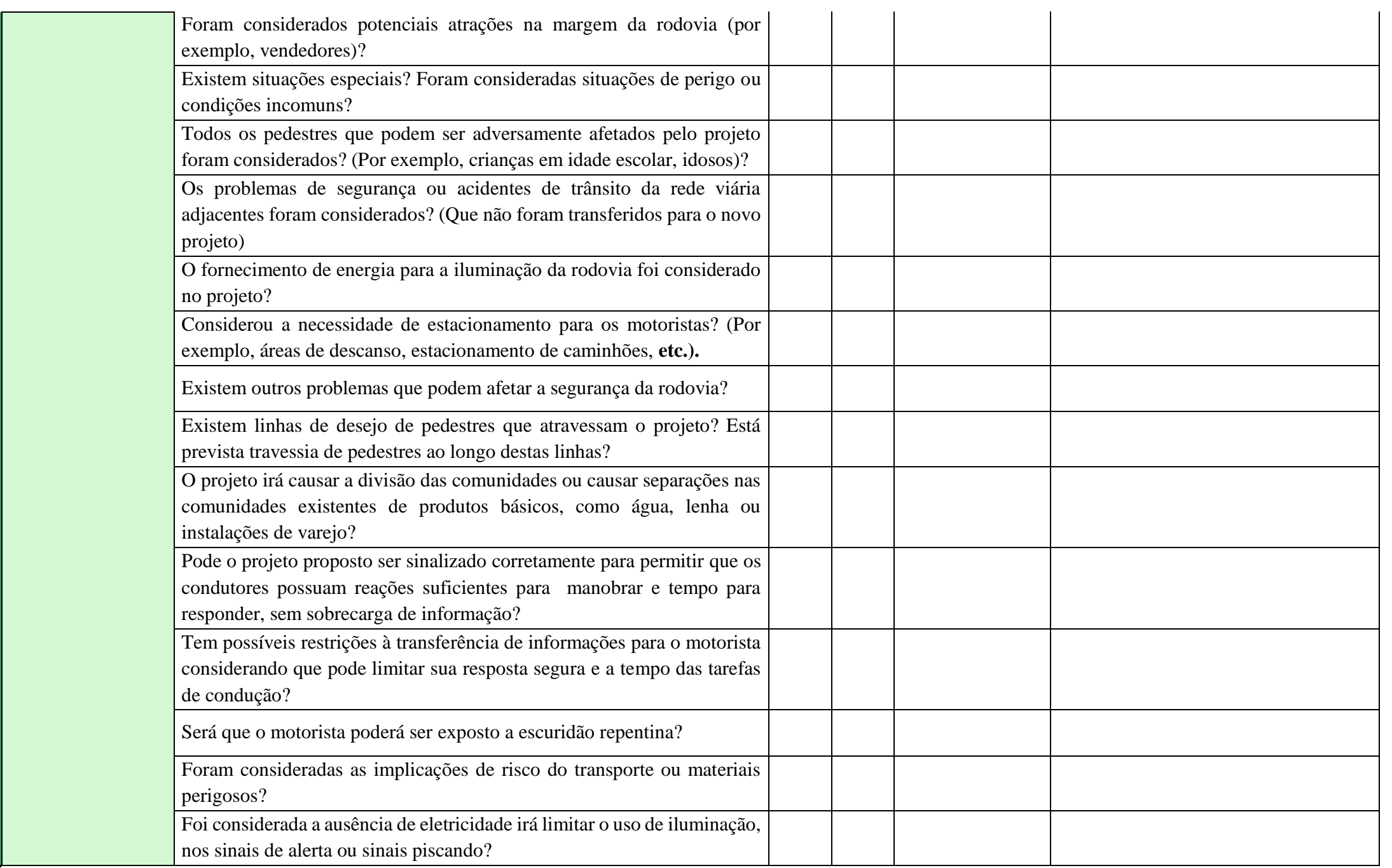




\section{APÊNDICE D2 - INSTRUMENTO DE ASV - PROJETO BÁSICO - VERSÃO PRELIMINAR}

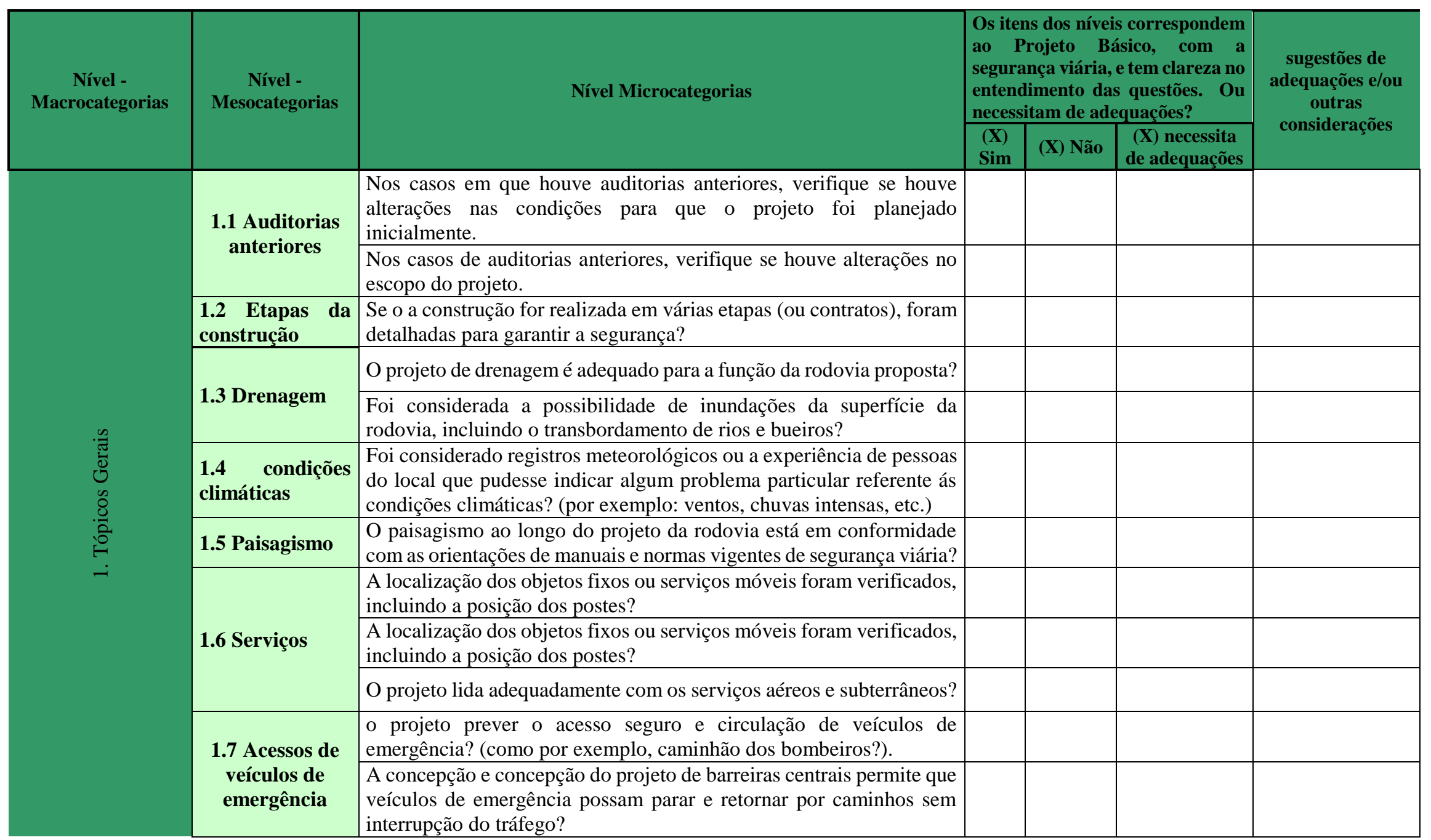


Existem fatores a montante ou a jusante que poderão afetar o acesso à rodovia, principalmente próximo a interseções?

Os futuros acessos poderão ser usados com segurança, considerando

1.8 Acesso e as entradas, saídas e junções com a rodovia?

áreas adjacentes $\mathrm{O}$ acesso ás áreas para descanso e estacionamento de caminhões tem distância de visibilidade adequada?

A percepção dos motoristas poderá ser afetada pelos efeitos de luze refletidas a partir das rodovias adjacentes?

Se o projeto representa a ampliação de uma seção da rodovia, no

1.9 ampliações sentido de via dupla, o projeto é adequado e seguro para ser entendido futuras

\begin{tabular}{l|l} 
futuras & É segura a transição entre uma rodovia de pista simples e de pista
\end{tabular} dupla e vice-versa?

Será que os planos e programas de construção podem ser modificados 1.10 Etapas do para melhorar o nível de segurança do projeto?

projeto especificas como sinalização, transições geometrias adequadas, etc. para um plano temporário?

1.11

Os veículos de manutenção podem ser localizados de forma segura?

Manutenção

Nível -

Nível -

Mesocategorias

2.1 Padrões A velocidade de projeto e a velocidade a ser regulamentada são gerais do apropriadas para o projeto proposto?

do O projeto considerou os tipos de veículos para os quais está previsto o seu uso?

$\mathrm{O}$ veiculo de projeto foi utilizado e apropriado para o projeto proposto?

2.2 Seleção do As características da gestão do tráfego estão destinadas para evitar traçado

O layout das demarcações e materiais reflexivos da rodovia é capaz

de advertir de forma satisfatória as mudanças de alinhamento? (principalmente quando alinhamento for deficiente)

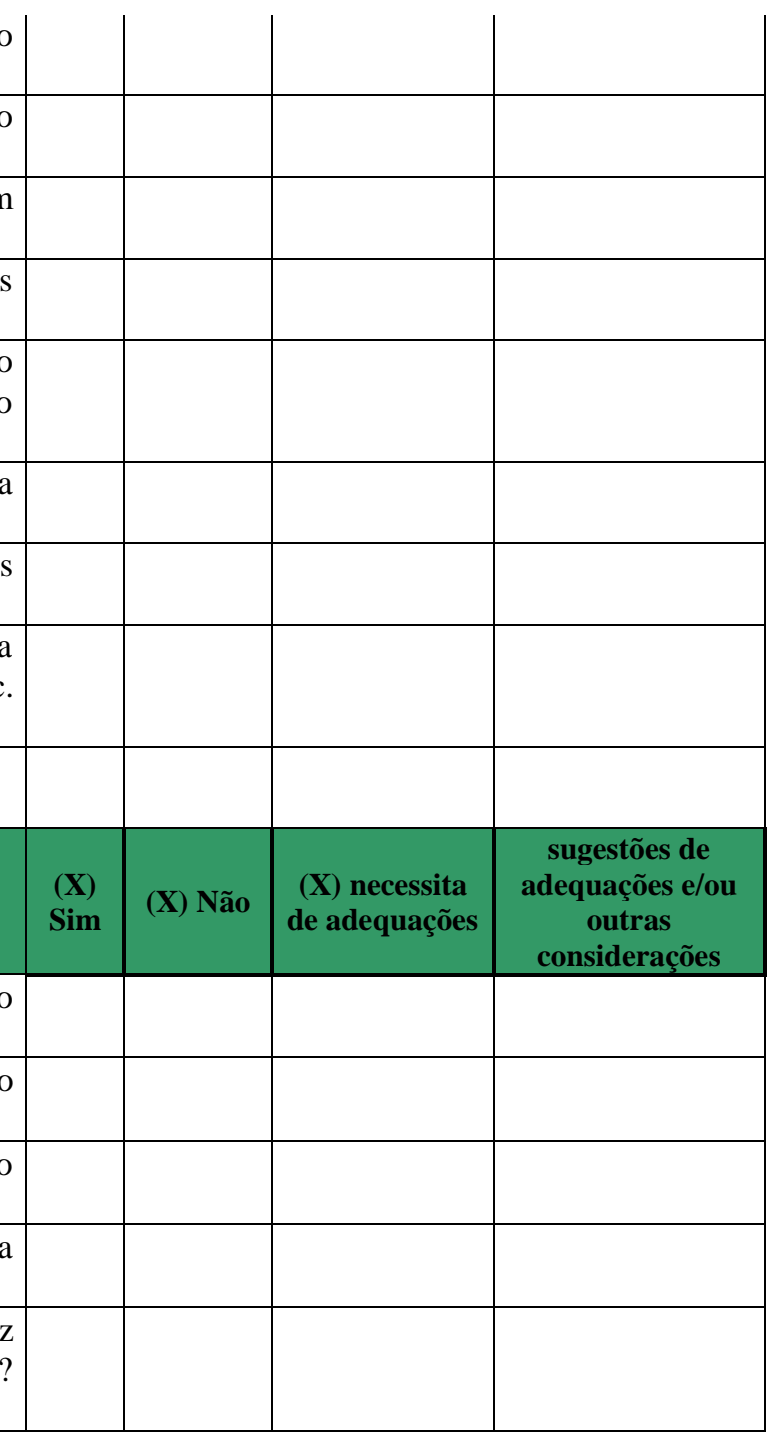


As larguras das faixas da rodovia, acostamentos, canteiro central e outros elementos da seção transversal são adequados para a função da rodovia?

A largura das faixas das rodovias é adequada a respeito do: alinhamentos? Fluxo de tráfego? Dimensões dos veículos? Velocidade de projeto? Combinações de veículos com o fluxo de tráfego?

2.3 Elementos Nas subidas longas estão previstas faixas auxiliares (terceira faixas) da seção seção

para ultrapassagens, nos casos que julgar necessário?

transversal No projeto possui zonas livres?

Existem variações inesperadas da seção transversal que pode influenciar negativamente a segurança?

As inclinações transversais são seguras? (particularmente quando as seções da rodovia existente foram utilizadas ou será utilizada para implantação de acesso nos casos de melhoramento)

A largura da seção transversal é segura nos casos de estreitamento nas pontes?

Os aspectos de segurança são previstos nos acostamentos de forma satisfatória como: previsão de revestimento/ Largura e tratamentos de aterros? Inclinação transversal do acostamento para drenagem?

2.4 Acostamento Os acostamentos são seguros para acomodar veículos em movimento lento ou bicicletas?

Foram projetadas com segurança áreas de descanso e paradas de caminhões?

O projeto do alinhamento horizontal e vertical está adequadamente alinhados?

2.5

O projeto da sinalização vertical nos alinhamentos horizontal e

alinhamentos vertical, permite aos motoristas fazer boa leitura da projeto? (por exemplo, delimitações de vegetação, postes, cercas, etc.)

O alinhamento horizontal e vertical é consistente com a velocidade?

2.6 Distância de Os alinhamentos verticais e horizontais fornecem distância de visibilidade

visibilidade e visibilidade necessária?

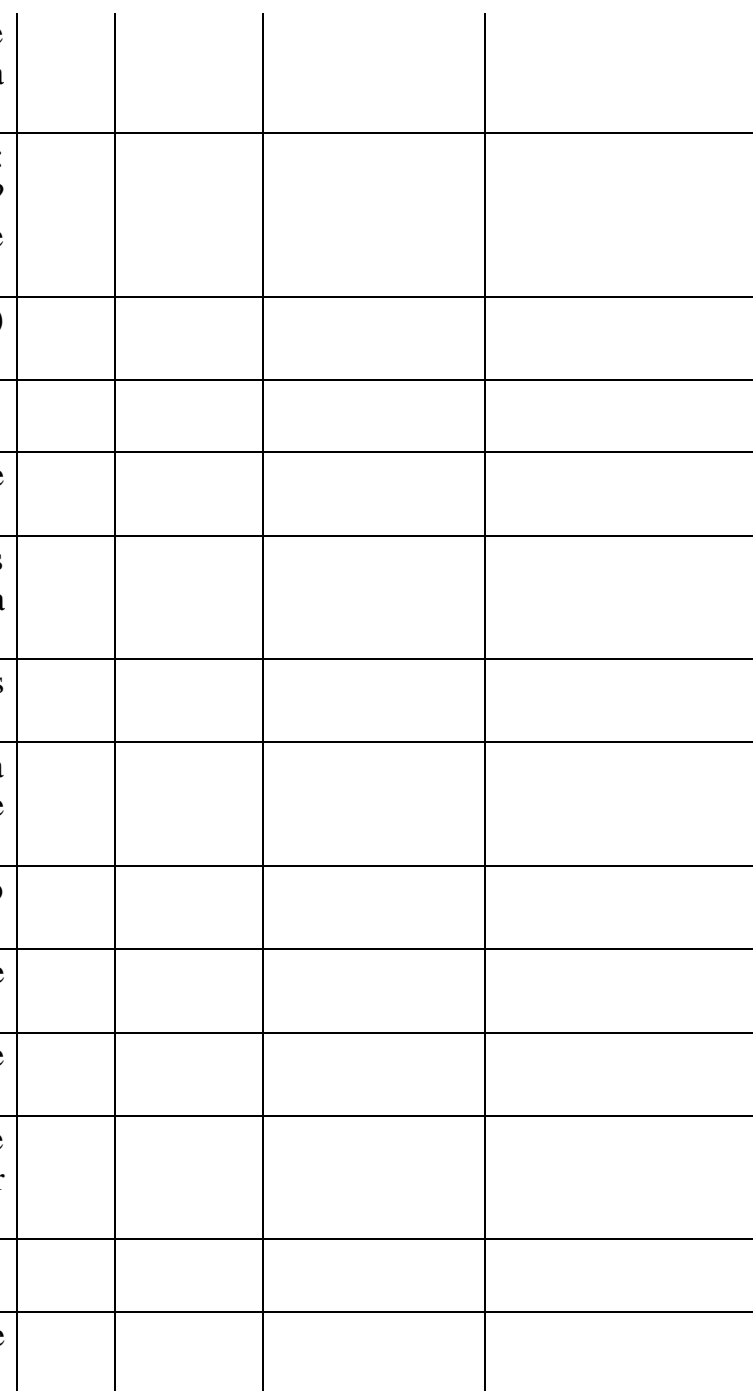




\begin{tabular}{|c|c|c|c|c|c|c|}
\hline & & $\begin{array}{l}\text { A linha de visibilidade do projeto está desobstruída de elementos } \\
\text { como: defensas, cercas ou divisórias; estrutura de obras de arte; } \\
\text { vegetação, etc. }\end{array}$ & & & & \\
\hline & & $\begin{array}{l}\text { Os cruzamentos ferroviários, pontes e outros riscos estão totalmente } \\
\text { visíveis? }\end{array}$ & & & & \\
\hline & & $\begin{array}{l}\text { No projeto existe alguma outra característica local que possam afetar } \\
\text { a visibilidade? }\end{array}$ & & & & \\
\hline & $\begin{array}{l}2.7 \quad \text { Não } \\
\text { conformidade }\end{array}$ & $\begin{array}{l}\text { Foi adotado algum aspecto particular no projeto que não corresponde } \\
\text { as normas? Porém a segurança foi mantida? }\end{array}$ & & & & \\
\hline & $\begin{array}{l}\text { com as normas } \\
\text { ou diretrizes }\end{array}$ & $\begin{array}{l}\text { Se for detectado algum projeto que não atende as normas? Manteve a } \\
\text { segurança? }\end{array}$ & & & & \\
\hline & 2.8 interface & $\begin{array}{l}\text { A ligação ocorre em zonas de perigo como parte superior de curva } \\
\text { vertical, eixo horizontal, perigos na margem da rodovia ou áreas de } \\
\text { baixa visibilidade? }\end{array}$ & & & & \\
\hline & $\begin{array}{l}\text { entre o projeto } \\
\text { proposto } \quad \text { e }\end{array}$ & $\begin{array}{l}\text { Nos casos em que as características das faixas da rodovia possui } \\
\text { variação, a mudança é efetuada com segurança? }\end{array}$ & & & & \\
\hline & $\begin{array}{l}\text { rodovia } \\
\text { existente }\end{array}$ & $\begin{array}{l}\text { É segura a transição entre as ambientes rodoviário como áreas rurais } \\
\text { e urbanas, ou lugares sem iluminação? }\end{array}$ & & & & \\
\hline & & $\begin{array}{l}\mathrm{Na} \text { ligação da rodovia projetada com a existente, considerou a } \\
\text { necessidade de aviso prévio? }\end{array}$ & & & & \\
\hline & 2.9 Legibilidade & $\begin{array}{l}\text { O traçado, função e outras características da rodovia será reconhecido } \\
\text { pelos usuários com antecedência? }\end{array}$ & & & & \\
\hline & do alinhamento & $\begin{array}{l}\text { As velocidades de aproximação são adequadas e os motoristas podem } \\
\text { ser guiados corretamente pela rodovia? }\end{array}$ & & & & \\
\hline $\begin{array}{l}\text { Nível - } \\
\text { Macrocategorias }\end{array}$ & $\begin{array}{l}\text { Nível - } \\
\text { Mesocategorias }\end{array}$ & Nível Microcategorias & $\begin{array}{l}(\mathbf{X}) \\
\text { Sim }\end{array}$ & (X) Não & $\begin{array}{c}\text { (X) necessita } \\
\text { de } \\
\text { adequações }\end{array}$ & $\begin{array}{c}\text { sugestões de } \\
\text { adequações e/ou } \\
\text { outras } \\
\text { considerações }\end{array}$ \\
\hline$\Xi$ & & $\begin{array}{l}\text { Os tipos de interseções selecionadas são adequados para a função da } \\
\text { rodovia projetada? }\end{array}$ & & & & \\
\hline 言育 & 3.1 Tipo & $\begin{array}{l}\text { A proposta de controles da interseção (Dê a preferência e sinal de } \\
\text { Pare) é adequada para o tipo de interseção selecionada? }\end{array}$ & & & & \\
\hline$\frac{w_{0}^{2}}{20}$ & distribuição & $\begin{array}{l}\text { As dimensões das junções são adequadas para todos os movimentos } \\
\text { dos veículos? }\end{array}$ & & & & \\
\hline 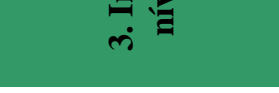 & & $\begin{array}{l}\text { As interseções estão livres de alguma característica incomum que } \\
\text { pode afetar a segurança rodoviária? }\end{array}$ & & & & \\
\hline
\end{tabular}


Nas interseções as larguras e extensões das faixas estão adequadas para todos os tipos de veículos?

$\mathrm{O}$ projeto esta livre, a montante ou a jusante de alguma característica geométrica que possam afetar a segurança (por exemplo, combinação entre faixas)?

As velocidades de aproximação são compatíveis com o projeto da interseção?

Onde foi proposta uma rotatória, foram considerados os movimentos dos ciclistas e os movimentos dos pedestres e as faixas são suficientes?

O tipo, função e características gerais da interseção podem ser percebidos pelos motoristas adequadamente?

3.2 Legibilidade As velocidades de aproximação das interseções são adequadas e os pelos motoristas motoristas podem ser guiados corretamente pela rodovia?

Foram considerados de forma adequada os efeitos dos ângulos do nascer do sol e pôr do sol que poderia acarretar riscos para os motoristas? 3.3 desenho

Existem características a montante ou a jusante que possam afetar a segurança (obstruções visuais, estacionamentos oblíquos, alto volume de entrada de automóveis)?

Linhas de visibilidade estão obstruídas por placas, edifícios, vegetação, etc.?

Os alinhamentos horizontais e verticais nas interseções ou nas proximidades das interseções estão de acordo com as condições necessárias de visibilidade?

Os motoristas podem observar claramente a presença da interseção?

3.4 Distância de (especialmente quando se aproxima de rodovias secundárias)

visibilidade

A linha de visibilidade do projeto da interseção está desobstruída de:

Barreiras de segurança e cercas, divisórias; mobiliário na rodovia

Estacionamentos, sinalização vertical, vegetação e paisagismo, estrutura de pontes.

Os cruzamentos ferroviários, pontes e outros riscos próximos da interseções estão totalmente visíveis?

O projeto está livre de outras características locais que podem afetar negativamente a visibilidade da interseção?

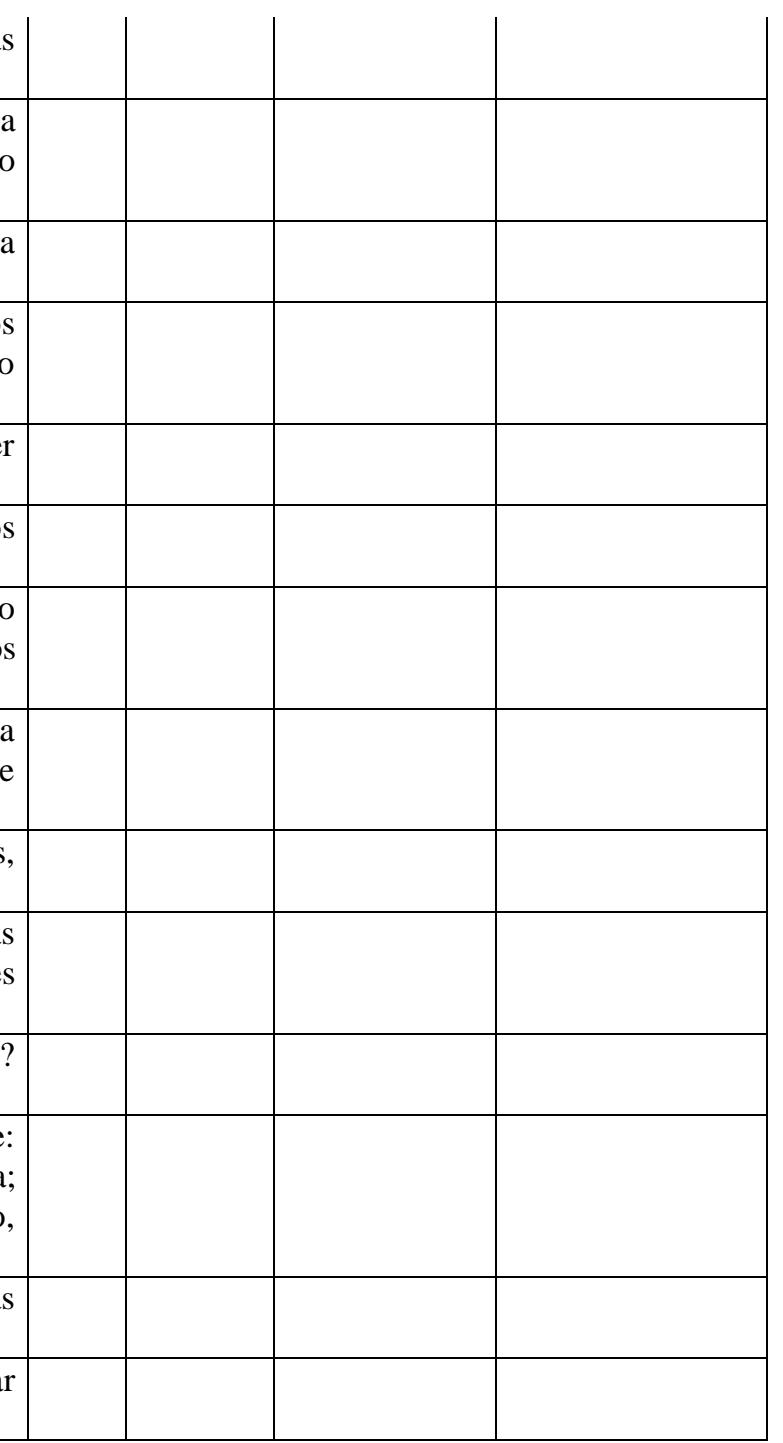




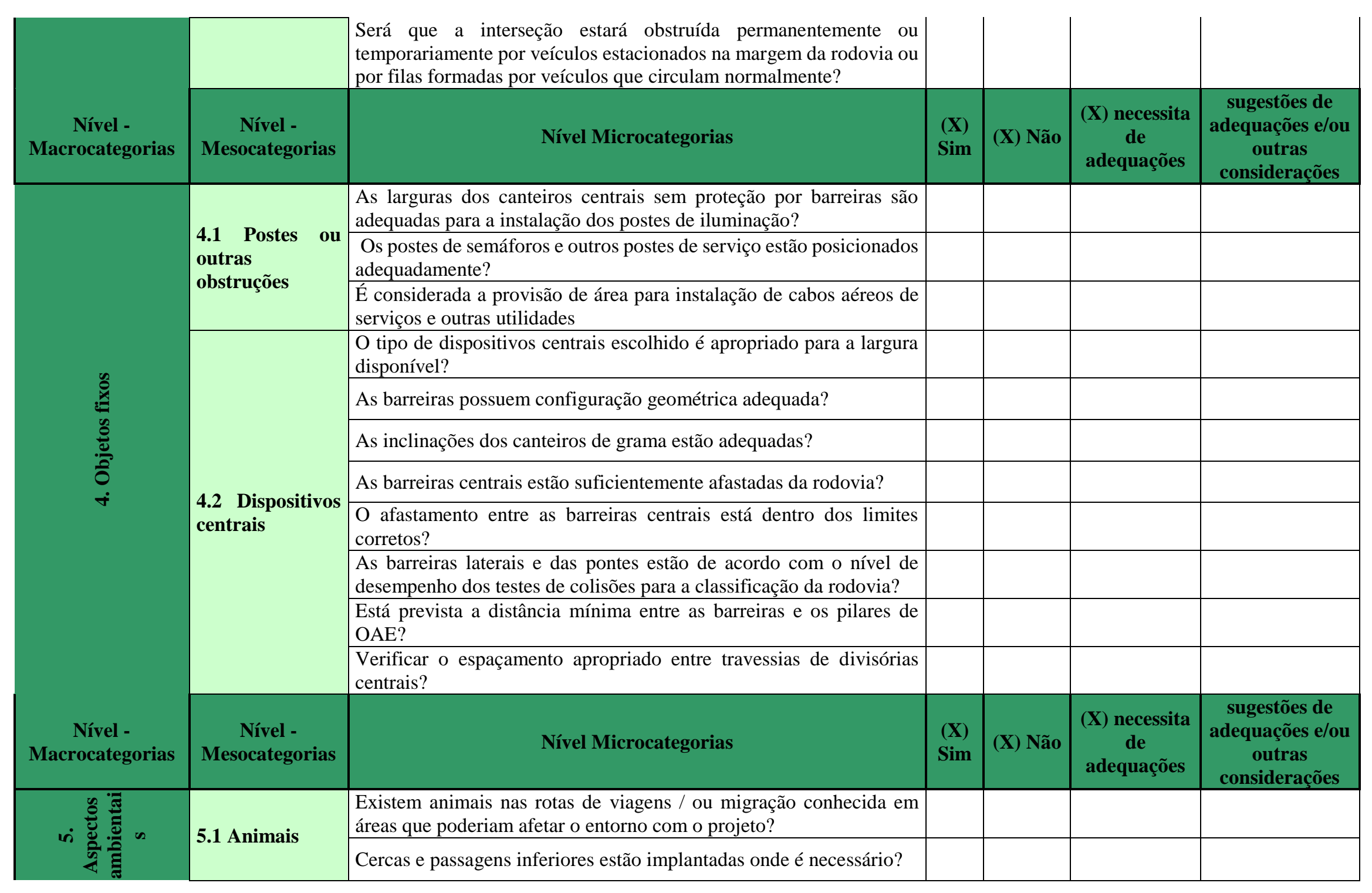




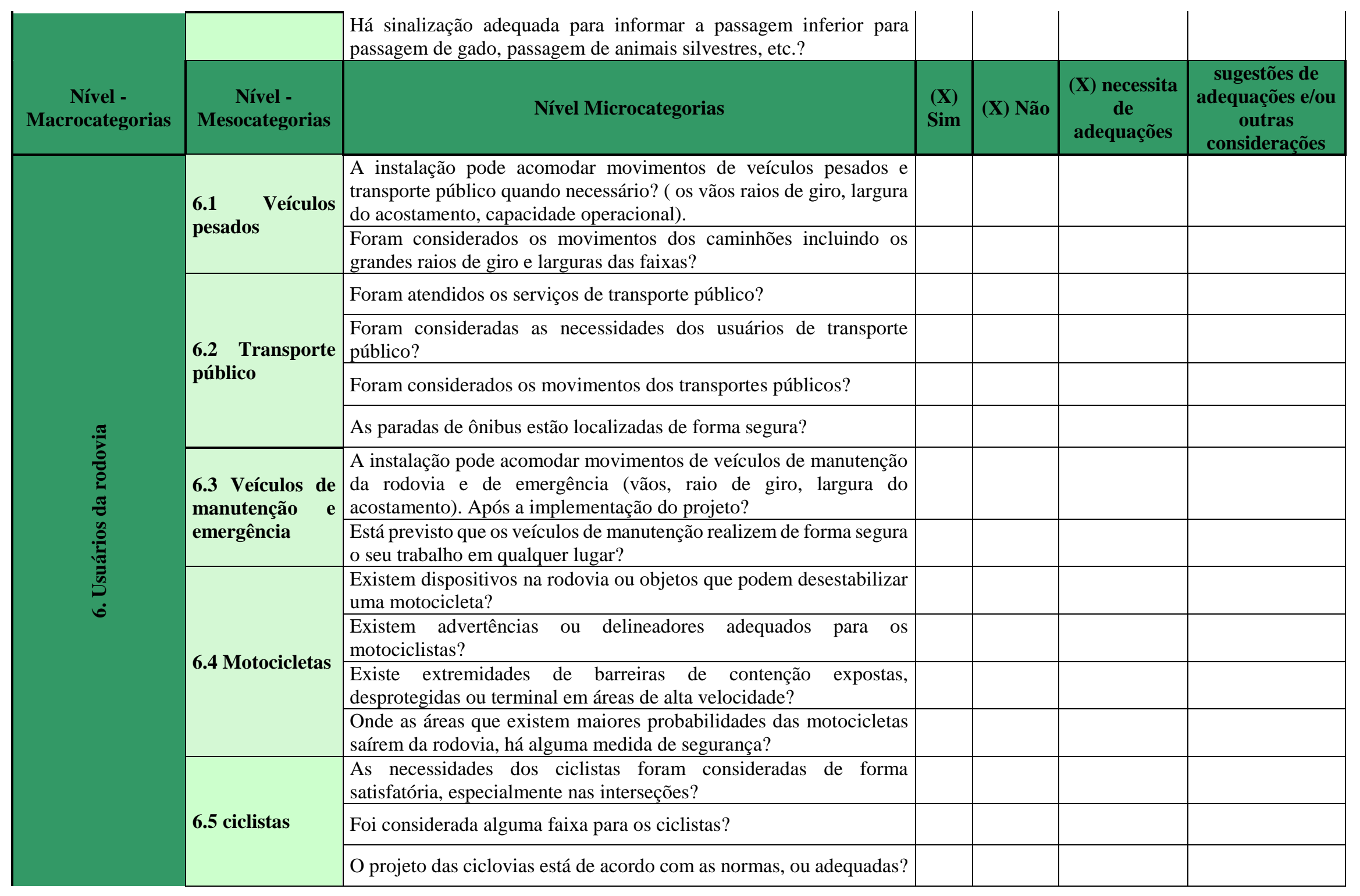




\begin{tabular}{|c|c|c|c|c|c|c|}
\hline & & $\begin{array}{l}\text { Onde existe a necessidade de compartilhar as instalações para o uso } \\
\text { dos pedestres e ciclistas, foram tratadas de forma segura? }\end{array}$ & & & & \\
\hline & & $\begin{array}{l}\text { Quando uma ciclovia termina em interseção ou rodovia adjacente, foi } \\
\text { prevista uma transição com segurança? }\end{array}$ & & & & \\
\hline & & $\begin{array}{l}\text { Existe a necessidade de incorporar algum elemento especial nas } \\
\text { ciclovias? (por exemplo, semáforos para ciclistas) }\end{array}$ & & & & \\
\hline & & As necessidades dos pedestres foram consideradas satisfatoriamente? & & & & \\
\hline & & $\begin{array}{l}\text { Se o projeto não contempla calçadas de pedestres, a disposição da } \\
\text { rodovia é segura para o tráfego dos pedestres? (particularmente em } \\
\text { curvas com baixa visibilidade e em pontes). }\end{array}$ & & & & \\
\hline & & $\begin{array}{l}\text { As passagens subterrâneas ou elevadas (passarelas) para os pedestres } \\
\text { estão localizadas de forma a maximizar o seu uso? ( ou seja, a } \\
\text { probabilidade dos pedestres atravessarem a rodovia perto dos } \\
\text { cruzamentos) }\end{array}$ & & & & \\
\hline & 6.6 Pedestres & $\begin{array}{l}\text { Estão dispostas as travessias específicas de pedestres em cruzamento } \\
\text { com zonas escolares ou semáforos para pedestres? }\end{array}$ & & & & \\
\hline & & $\begin{array}{l}\text { Onde estão previstas as travessias de pedestre essas instalações estão } \\
\text { localizadas de modo a proporcionar o uso com maior segurança } \\
\text { possível? }\end{array}$ & & & & \\
\hline & & $\begin{array}{l}\text { Os refúgios de pedestres e baias são adequados e estão localizadas } \\
\text { onde são necessárias? }\end{array}$ & & & & \\
\hline & & $\begin{array}{l}\text { Todos os pedestres que podem ser adversada mente afetados pelo } \\
\text { projeto foram considerados (grupos vulneráveis) ? (Por exemplo, } \\
\text { crianças em idade escolar, idosos, surdos, cegos,)? }\end{array}$ & & & & \\
\hline & $\begin{array}{l}\text { 6.8 Cavaleiros e } \\
\text { gado }\end{array}$ & $\begin{array}{l}\text { Foi considerado o tráfego de cavaleiros, incluindo a utilização das } \\
\text { bordas e acostamentos, e o regulamento para a utilização da faixa da } \\
\text { rodovia? }\end{array}$ & & & & \\
\hline & & Existe passagem em desnível para ser usado pelos cavaleiros e gados? & & & & \\
\hline $\begin{array}{l}\text { Nível - } \\
\text { Macrocategorias }\end{array}$ & $\begin{array}{c}\text { Nível - } \\
\text { Mesocategorias }\end{array}$ & Nível Microcategorias & $\begin{array}{l}(\mathbf{X}) \\
\text { Sim }\end{array}$ & (X) Não & $\begin{array}{l}\text { (X) necessita } \\
\text { de } \\
\text { adequações }\end{array}$ & $\begin{array}{l}\text { Sugestões de } \\
\text { adequações e/ou } \\
\text { outras } \\
\text { considerações }\end{array}$ \\
\hline 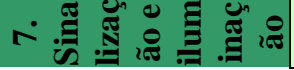 & & A demarcação e delimitação estão padronizadas adequadamente? & & & & \\
\hline
\end{tabular}




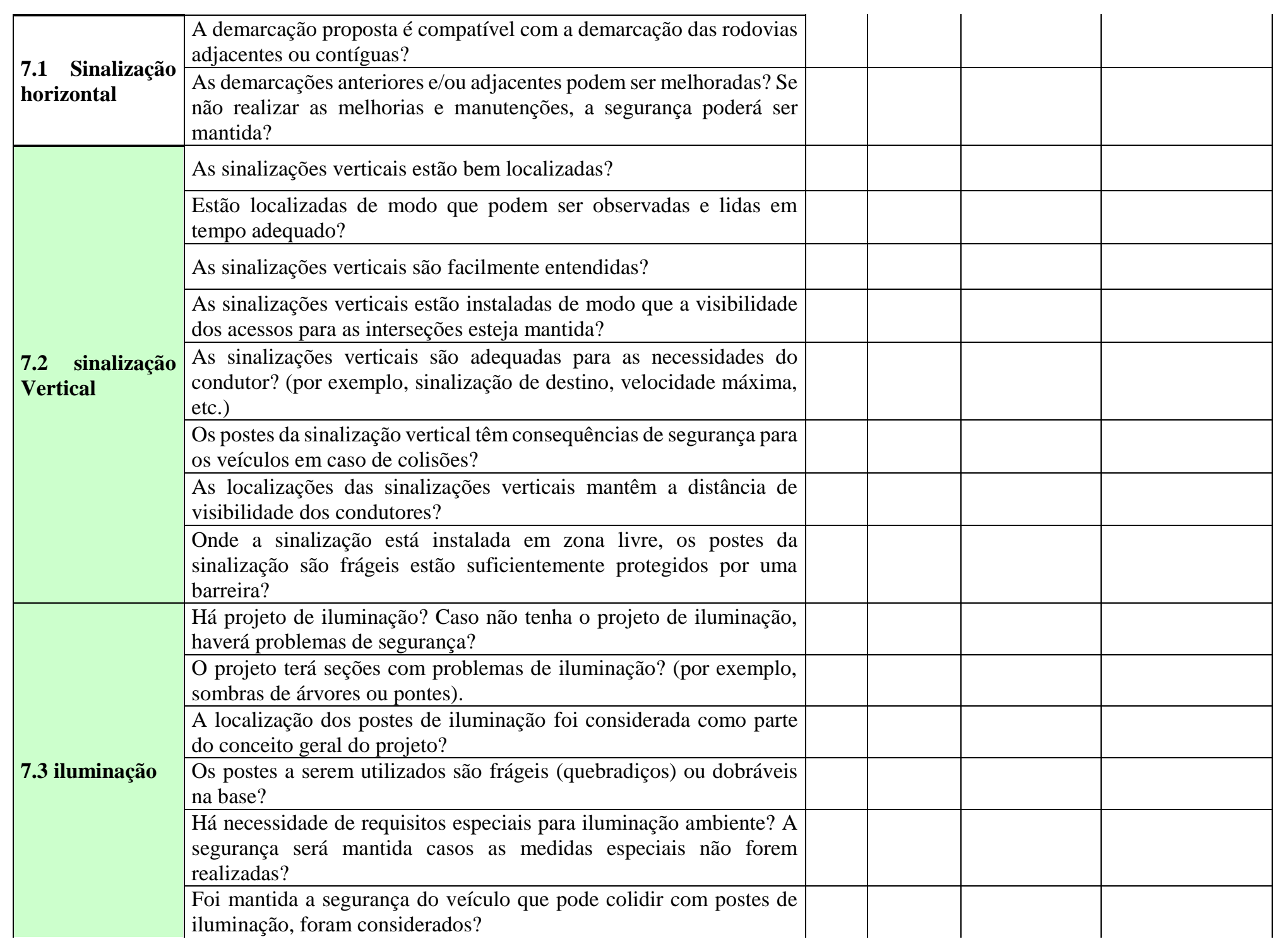




\begin{tabular}{|c|c|c|c|c|c|c|}
\hline $\begin{array}{l}\text { Nível - } \\
\text { Macrocategorias }\end{array}$ & $\begin{array}{l}\text { Nível - } \\
\text { Mesocategorias }\end{array}$ & Nível Microcategorias & $\begin{array}{l}(\mathbf{X}) \\
\text { Sim }\end{array}$ & (X) Não & $\begin{array}{l}\text { (X) necessita } \\
\text { de } \\
\text { adequações }\end{array}$ & $\begin{array}{l}\text { sugestões de } \\
\text { adequações e/ou } \\
\text { outras } \\
\text { considerações } \\
\end{array}$ \\
\hline \multirow{14}{*}{ 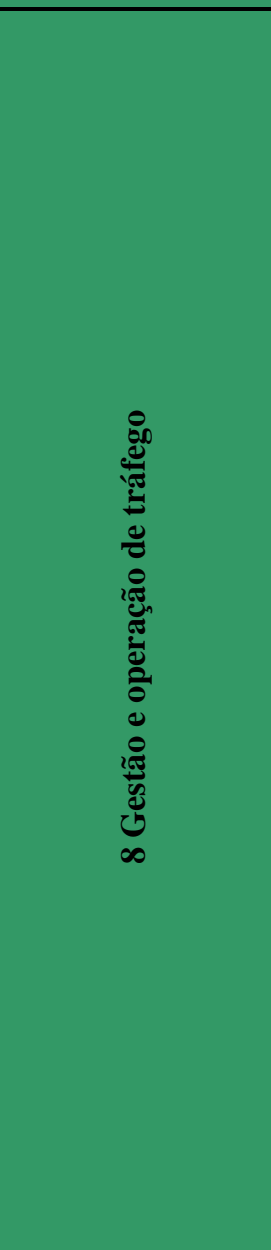 } & \multirow{5}{*}{$\begin{array}{l}\text { 8.1 Fluxo de } \\
\text { tráfego e } \\
\text { gerenciamento } \\
\text { de acesso }\end{array}$} & $\begin{array}{l}\text { Pode o fluxo de tráfego do projeto proposto, ser acomodado com } \\
\text { segurança em seções existentes da rodovia? }\end{array}$ & & & & \\
\hline & & $\begin{array}{l}\text { A disposição de estacionamentos e controle de estacionamentos foi } \\
\text { considerada corretamente? }\end{array}$ & & & & \\
\hline & & $\begin{array}{l}\text { Podem ser implementadas proibições de deslocamento sem causar } \\
\text { problemas nas interseções adjacentes? }\end{array}$ & & & & \\
\hline & & Foram considerados os efeitos de acessos a futuros desenvolvimento? & & & & \\
\hline & & $\begin{array}{l}\text { Ao realizar algum desvio de tráfego para outras rodovias: (por } \\
\text { exemplo, para evitar algum dispositivo de controle de tráfego). } \\
\text { Manteve-se a segurança? }\end{array}$ & & & & \\
\hline & \multirow{4}{*}{$\begin{array}{l}8.2 \\
\text { ultrapassagens e } \\
\text { fusões }\end{array}$} & $\begin{array}{l}\text { As ultrapassagens, distância de visibilidade e de parada são } \\
\text { adequadas? }\end{array}$ & & & & \\
\hline & & $\begin{array}{l}\text { As larguras dos acostamentos são adequadas durante e após as fusões } \\
\text { de pistas? }\end{array}$ & & & & \\
\hline & & $\begin{array}{l}\text { Existe a adequada distância de visibilidade para as reduções de pistas } \\
\text { nas fusões? }\end{array}$ & & & & \\
\hline & & $\begin{array}{l}\text { Os acostamentos são amplos nos pontos de acessos opostos e } \\
\text { interseções? }\end{array}$ & & & & \\
\hline & \multirow{2}{*}{$\begin{array}{l}8.3 \text { áreas de } \\
\text { descanso }\end{array}$} & $\begin{array}{l}\text { Estão previstas áreas nas bordas da rodovia para paradas, áreas de } \\
\text { descanso e área de estacionamentos de caminhões? }\end{array}$ & & & & \\
\hline & & $\begin{array}{l}\text { são seguras as entradas e saídas das áreas de descanso ou } \\
\text { estacionamento de caminhão? }\end{array}$ & & & & \\
\hline & \multirow{3}{*}{$\begin{array}{l}8.4 \text { construção e } \\
\text { operação }\end{array}$} & $\begin{array}{l}\text { Se o projeto for construído "sob tráfego", pode ser feito com } \\
\text { segurança? }\end{array}$ & & & & \\
\hline & & $\begin{array}{l}\text { O projeto pode ser construído de forma segura? Os requisitos de } \\
\text { manutenção foram considerados adequadamente? }\end{array}$ & & & & \\
\hline & & É seguro o acesso de veículos para executar os trabalhos (obras)? & & & & \\
\hline
\end{tabular}




\begin{tabular}{|c|c|c|c|c|c|c|}
\hline $\begin{array}{l}\text { Nível - } \\
\text { Macrocategorias }\end{array}$ & $\begin{array}{l}\text { Nível - } \\
\text { Mesocategorias }\end{array}$ & Nível Microcategorias & $\begin{array}{l}(\mathbf{X}) \\
\text { Sim }\end{array}$ & (X) Não & $\begin{array}{c}\text { (X) necessita } \\
\text { de } \\
\text { adequações }\end{array}$ & $\begin{array}{c}\text { sugestões de } \\
\text { adequações e/ou } \\
\text { outras } \\
\text { considerações }\end{array}$ \\
\hline \multirow{17}{*}{ 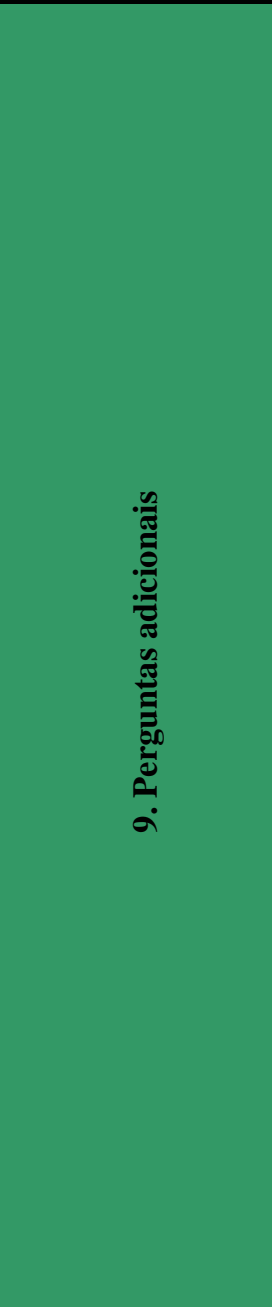 } & \multirow{4}{*}{$\begin{array}{l}\text { 9.1 Alinhamento } \\
\text { horizontal }\end{array}$} & $\begin{array}{l}\text { É adequada a visibilidade dos motoristas e pedestres nos acessos } \\
\text { propostos? }\end{array}$ & & & & \\
\hline & & $\begin{array}{l}\text { é adequado o espaço previsto para mudança de fluxo e velocidade de } \\
\text { tráfego? }\end{array}$ & & & & \\
\hline & & Os raios de curva possui visibilidade adequada? & & & & \\
\hline & & A distância de visibilidade e parada é adequada? & & & & \\
\hline & \multirow{2}{*}{$\begin{array}{l}9.2 \text { Alinhamento } \\
\text { vertical }\end{array}$} & O alinhamento vertical é satisfatório? & & & & \\
\hline & & A distância de visibilidade e parada é adequada? & & & & \\
\hline & \multirow{3}{*}{$\begin{array}{l}9.3 \text { áreas de } \\
\text { estacionamento }\end{array}$} & $\begin{array}{l}\text { O estacionamento no local está adequado para evitar que os veículos } \\
\text { estacionem na rodovia com risco associado a ele? }\end{array}$ & & & & \\
\hline & & $\begin{array}{l}\text { Os estacionamentos estão localizados em áreas seguras? Se não, } \\
\text { foram previstas medidas para evitar isso? }\end{array}$ & & & & \\
\hline & & $\begin{array}{l}\text { É adequado o espaço previsto nas áreas de estacionamento para } \\
\text { circulação e interseção da distância de visibilidade? }\end{array}$ & & & & \\
\hline & \multirow{3}{*}{ 9.4 Serviços } & São adequadas as áreas de carga e descarga da rodovia? & & & & \\
\hline & & $\begin{array}{l}\text { As manobras dos veículos grandes foram previstas em lugares } \\
\text { seguros? }\end{array}$ & & & & \\
\hline & & Os acessos para os veículos de emergência são adequados & & & & \\
\hline & \multirow{2}{*}{$\begin{array}{l}9.5 \text { Sinalização } \\
\text { vertical } \\
\text { sinalização } \\
\text { horizontal }\end{array}$} & $\begin{array}{l}\text { Está definida claramente a prioridade de todas as interseções, nos } \\
\text { pátios dos estacionamentos e vias de acesso? }\end{array}$ & & & & \\
\hline & & $\begin{array}{l}\text { A sinalização vertical e demarcações serão visíveis em todas as } \\
\text { condições? (incluindo dia, noite, chuva, neblina, etc.?) }\end{array}$ & & & & \\
\hline & \multirow{3}{*}{ 9.6 Paisagismo } & $\begin{array}{l}\text { A paisagem mantém a visibilidade nas interseções, curvas, acessos e } \\
\text { localizações de pedestres? }\end{array}$ & & & & \\
\hline & & $\begin{array}{l}\text { Foi evitado a plantação de vegetação em lugares onde os veículos } \\
\text { podem sair da rodovia? }\end{array}$ & & & & \\
\hline & & Foram considerados efeitos adversos em alguma área do projeto? & & & & \\
\hline
\end{tabular}




\begin{tabular}{|c|c|c|c|c|c|c|}
\hline & \multirow{5}{*}{$\begin{array}{l}9.7 \text { gestão de } \\
\text { tráfego }\end{array}$} & O projeto vai manter a velocidade de projeto de forma segura? & & & & \\
\hline & & O número e a localização dos acessos são adequados? & & & & \\
\hline & & $\begin{array}{l}\text { Há instalações para os serviços de transporte públicos? E estão } \\
\text { localizados em lugares seguros e justificados? }\end{array}$ & & & & \\
\hline & & $\begin{array}{l}\text { Existem instalações para os ciclistas? Estão localizados de forma } \\
\text { segura a respeito dos movimentos dos veículos? }\end{array}$ & & & & \\
\hline & & $\begin{array}{l}\text { Existem instalações para os pedestres? Estão localizadas em lugares } \\
\text { seguros e adequados? }\end{array}$ & & & & \\
\hline & \multirow{3}{*}{9.8 Outros } & No projeto está prevista iluminação pública? É adequada? & & & & \\
\hline & & Há riscos na margem da rodovia? Foram tratados corretamente? & & & & \\
\hline & & $\begin{array}{l}\text { Os pedestres podem acessar de forma segura o desenvolvimento } \\
\text { urbano proposto? }\end{array}$ & & & & \\
\hline $\begin{array}{c}\text { Nível - } \\
\text { Macrocategorias }\end{array}$ & $\begin{array}{c}\text { Nível - } \\
\text { Mesocategorias }\end{array}$ & Nível Microcategorias & $\begin{array}{l}(\mathbf{X}) \\
\text { Sim }\end{array}$ & (X) Não & $\begin{array}{c}\text { (X) necessita } \\
\text { de adequações }\end{array}$ & $\begin{array}{l}\text { sugestões de } \\
\text { adequações e/ou } \\
\text { outras } \\
\text { considerações }\end{array}$ \\
\hline \multirow{4}{*}{ 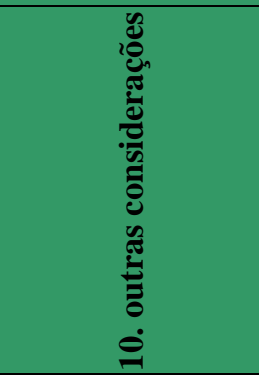 } & \multirow{4}{*}{$\begin{array}{lr}10.1 & \text { Outros } \\
\text { aspectos } & \text { de } \\
\text { segurança } & \text { não } \\
\text { abordado } & \end{array}$} & $\begin{array}{l}\text { Há situações especiais? Foram consideradas situações incomuns ou } \\
\text { de perigo? }\end{array}$ & & & & \\
\hline & & $\begin{array}{l}\text { A rodovia é capaz de suportar com segurança a circulação de veículos } \\
\text { de grande porte, caminhões, ônibus, veículos de emergência, veículos } \\
\text { de manutenção da rodovia? }\end{array}$ & & & & \\
\hline & & $\begin{array}{l}\text { Se necessário, a rodovia pode ser fechada para eventos especiais de } \\
\text { forma segura? }\end{array}$ & & & & \\
\hline & & $\begin{array}{l}\text { Se for o caso, os requisitos especiais de paisagem e rotas turísticas são } \\
\text { satisfeitos? }\end{array}$ & & & & \\
\hline
\end{tabular}




\section{INSTRUMENTO DE ASV - PROJETO EXECUTIVO - VERSÃO PRELIMINAR}

\begin{tabular}{|c|c|c|c|c|c|c|}
\hline \multirow[t]{2}{*}{$\begin{array}{l}\text { Nível - } \\
\text { Macrocategorias }\end{array}$} & \multirow[t]{2}{*}{$\begin{array}{l}\text { Nível - } \\
\text { Mesocategorias }\end{array}$} & \multirow[t]{2}{*}{ Nível Microcategorias } & \multicolumn{3}{|c|}{$\begin{array}{l}\text { Os itens dos níveis correspondem } \\
\text { ao Projeto Básico, com a } \\
\text { segurança viária, e tem clareza } \\
\text { no entendimento das questões. } \\
\text { Ou necessitam de adequações? }\end{array}$} & \multirow{2}{*}{$\begin{array}{l}\text { sugestões de } \\
\text { adequações } \\
\text { e/ou outras } \\
\text { considerações }\end{array}$} \\
\hline & & & (X) Sim & (X) Não & $\begin{array}{c}\text { (X) necessita } \\
\text { de } \\
\text { adequações }\end{array}$ & \\
\hline \multirow{13}{*}{ 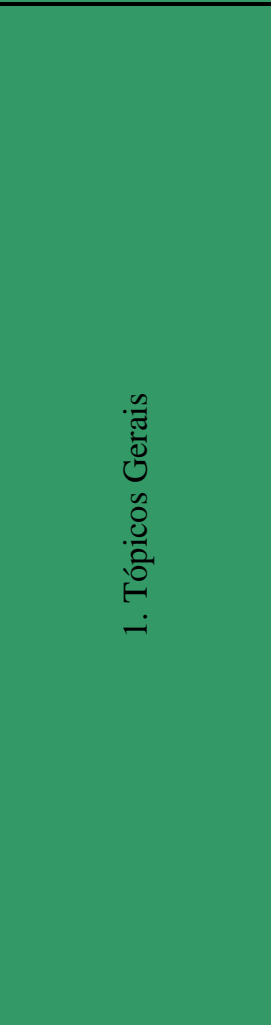 } & \multirow{2}{*}{$\begin{array}{l}\text { 1.1 Auditorias } \\
\text { anteriores }\end{array}$} & $\begin{array}{l}\text { Nos casos em que houve auditorias anteriores, verifique se existiram alterações nas condições } \\
\text { para que o projeto foi planejado inicialmente. }\end{array}$ & & & & \\
\hline & & Nos casos de auditorias anteriores, verifique se houve alterações no escopo do projeto. & & & & \\
\hline & \multirow{2}{*}{$\begin{array}{l}1.2 \text { Etapas da } \\
\text { construção }\end{array}$} & $\begin{array}{l}\text { Se o projeto for ser construído ou implementado em diferentes fases: a) Foram detalha } \\
\text { adequadamente para garantir a segurança? b) As fases de construção é segura? c) Existem } \\
\text { medidas para acomodar a gestão de tráfego temporário entra as diferentes fases? }\end{array}$ & & & & \\
\hline & & Se a construção for realizada em vários contratos, eles serão realizados de forma segurança? & & & & \\
\hline & \multirow{4}{*}{ 1.3 Drenagem } & O projeto proposto de drenagem da rodovia está de forma adequado? & & & & \\
\hline & & A inclinação longitudinal e transversal está adequada para drenagem satisfatória? & & & & \\
\hline & & $\begin{array}{l}\text { Seções planas são evitadas ou adequadamente distribuídas no início ou no final de uma } \\
\text { curvatura? }\end{array}$ & & & & \\
\hline & & $\begin{array}{l}\text { Foi considerada a possibilidade de inundações da superfície da rodovia, incluindo o } \\
\text { transbordamento dos rios e bueiros? }\end{array}$ & & & & \\
\hline & $\begin{array}{l}1.4 \text { Condições } \\
\text { climáticas }\end{array}$ & $\begin{array}{l}\text { Foi considerado registros meteorológicos ou experiência local que pudesse indicar algum } \\
\text { problema particular das condições climáticas? (por exemplo, neve, gelo vento nevoeiro). }\end{array}$ & & & & \\
\hline & 1.5 Paisagismo & $\begin{array}{l}\text { Será que a segurança rodoviária ser adequada quando as árvores frutifera ou plantações (sem } \\
\text { perigo na margem da rodovia)? }\end{array}$ & & & & \\
\hline & 1.6 Serviços & $\begin{array}{l}\text { A localização de objetos fixos ou serviços móveis foram verificados, incluindo a posição dos } \\
\text { postes? }\end{array}$ & & & & \\
\hline & \multirow{2}{*}{$\begin{array}{l}1.7 \text { Acessos de } \\
\text { veículos de } \\
\text { emergência }\end{array}$} & $\begin{array}{l}\text { o projeto prever o acesso seguro e circulação de veículos de emergência? (como por exemplo, } \\
\text { caminhão dos bombeiros) }\end{array}$ & & & & \\
\hline & & $\begin{array}{l}\text { A concepção e execução no projeto das barreiras centrais que permite que veículos de } \\
\text { emergência posam parar e retornar por outros caminhos sem interromper o tráfego? }\end{array}$ & & & & \\
\hline
\end{tabular}




\begin{tabular}{|c|c|c|c|c|c|c|}
\hline & & $\begin{array}{l}\text { Os veículos com deficiência ou veículos de emergência parados, eles foram considerados de } \\
\text { forma adequada? }\end{array}$ & & & & \\
\hline & & A disposição dos telefones de emergência é satisfatória? & & & & \\
\hline & & $\begin{array}{l}\text { As aberturas nas divisórias dos canteiros centrais de vias duplicadas estão localizadas em locais } \\
\text { seguros? (isto é frequência, visibilidade) }\end{array}$ & & & & \\
\hline & 1.8 ampliações & $\begin{array}{l}\text { Se o projeto representa a ampliação de uma seção da rodovia, no sentido de via dupla, o projeto } \\
\text { é adequado e seguro para ser entendido pelos motoristas? }\end{array}$ & & & & \\
\hline & futuras & A transição é segura entre uma rodovia de pista simples e de pista dupla e vice-versa? & & & & \\
\hline & 1.9 Etapas do & $\begin{array}{l}\text { O projeto pode ser desenvolvido por etapas, ou construídos em épocas diferentes: será que os } \\
\text { planos e programas de construção podem ser modificados para melhorar o nível de segurança } \\
\text { do projeto? }\end{array}$ & & & & \\
\hline & & $\begin{array}{l}\text { Os planos e programas de construção incluem medidas de segurança especificas como } \\
\text { sinalização, transições geométricas adequadas, etc. para um plano temporário? }\end{array}$ & & & & \\
\hline & & Existem fatores a montante ou a jusante que poderão afetar o acesso à rodovia? & & & & \\
\hline & & $\begin{array}{l}\text { Todos os acessos podem ser usados com segurança? (considerando as entradas, saídas e } \\
\text { junções) }\end{array}$ & & & & \\
\hline & 1.8 Acesso e áreas & $\begin{array}{l}\mathrm{O} \text { acesso às áreas para descanso e estacionamento de caminhões tem distância de visibilidade } \\
\text { adequada? }\end{array}$ & & & & \\
\hline & adjacentes & $\begin{array}{l}\text { O projeto considera o acesso aos maiores geradores de tráfego e de desenvolvimento urbano } \\
\text { adjacente com segurança? }\end{array}$ & & & & \\
\hline & & $\begin{array}{l}\text { A percepção dos motoristas poderia ser afetada pelos efeitos de luzes refletidas ou de trânsito } \\
\text { a partir das rodovias adjacentes? }\end{array}$ & & & & \\
\hline & & $\begin{array}{l}\text { A necessidade de telas antiofuscante por causa da iluminação das propriedades adjacentes } \\
\text { considerou-se de forma adequada? }\end{array}$ & & & & \\
\hline & $\begin{array}{l}1.11 \text { Estabilidade } \\
\text { de corte e aterro }\end{array}$ & $\begin{array}{l}\text { A estabilidade das encostas é adequada? (Por exemplo, sem o risco de material solto para afetar } \\
\text { os usuários da rodovia) }\end{array}$ & & & & \\
\hline & $\begin{array}{l}\text { 1.12 Resistência a } \\
\text { derrapagem }\end{array}$ & $\begin{array}{l}\text { foi considerada a necessidade de um revestimento antiderrapante em áreas onde a frenagem exige boa } \\
\text { aderência da rodovia? (por exemplo, inclinações, curvas, e quando se aproxima de cruzamentos e } \\
\text { semáforos). }\end{array}$ & & & & \\
\hline $\begin{array}{l}\text { Nível - } \\
\text { Macrocategorias }\end{array}$ & $\begin{array}{l}\text { Nível - } \\
\text { Mesocategorias }\end{array}$ & Nível Microcategorias & (X) Sim & $\begin{array}{l}(\mathbf{X}) \\
\text { Não }\end{array}$ & $\begin{array}{l}\text { (X) necessita } \\
\text { de adequações }\end{array}$ & $\begin{array}{l}\text { Sugestões de } \\
\text { adequações } \\
\text { e/ou outras } \\
\text { considerações }\end{array}$ \\
\hline 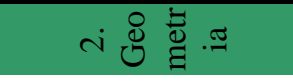 & 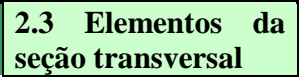 & $\begin{array}{l}\text { As larguras das faixas, acostamentos, canteiro central e outros elementos da seção transversal são } \\
\text { adequados para a função da rodovia? (seção típica) }\end{array}$ & & & & \\
\hline
\end{tabular}


A largura das faixas das rodovias e dos acostamentos é adequada a respesito de: alinhamentos? Fluxo de tráfego? Dimensões dos veículos? Velocidade de projeto? Combinações de veículos com o fluxo de tráfego?

A largura dos acostamentos estão adequados para acomodar veículos quebrados ou de emergência?

A largura do canteiro central é adequado para localizar os mobiliários da rodovia?

A superelevação é consistente com ambiente e velocidade da rodovia?

A inclinação dos acostamentos é segura para a circulação dos veículos?

As inclinações dos taludes são manobráveis para automóveis e caminhões?

Existem instalações para os pedestres e ciclistas?

O projeto está livre de variações imprevistas em relação a seção transversal?

As seções transversais são seguros (especialmente onde as seções da rodovia existentes foram utilizadas ou serão utilizados para gerar acesso a estreitamentos em pontes, etc.)

todas as curvas com inclinação transversal adversa, estão dentro dos limites adequados?

A superelevação é adequada e suficiente em todos os lugares onde é necessária?

Existem variações inesperadas da seção transversal que pode influenciar negativamente a segurança?

A largura da seção transversal é segura nos casos de estreitamento em pontes?

Os recursos da gestão do tráfego estão destinados para evitar a criação de condições inseguras e fornecer orientações adequadas?

O layout das demarcações e materiais reflexivos da rodovia são capazes de advertir de forma satisfatória as mudanças de alinhamento? (principalmente quando alinhamento for deficiente)

As faixas de ultrapassagem foram contempladas adequadamente?

As faixas de ultrapassagem são previstas com segurança no início e ao término das manobras?

E estão devidamente sinalizadas?

Os requisitos para ultrapassagem são satisfatórios?

O projeto pode criar problema de visibilidade para o motorista produzido pelo nascer do sol ou pôr do sol?

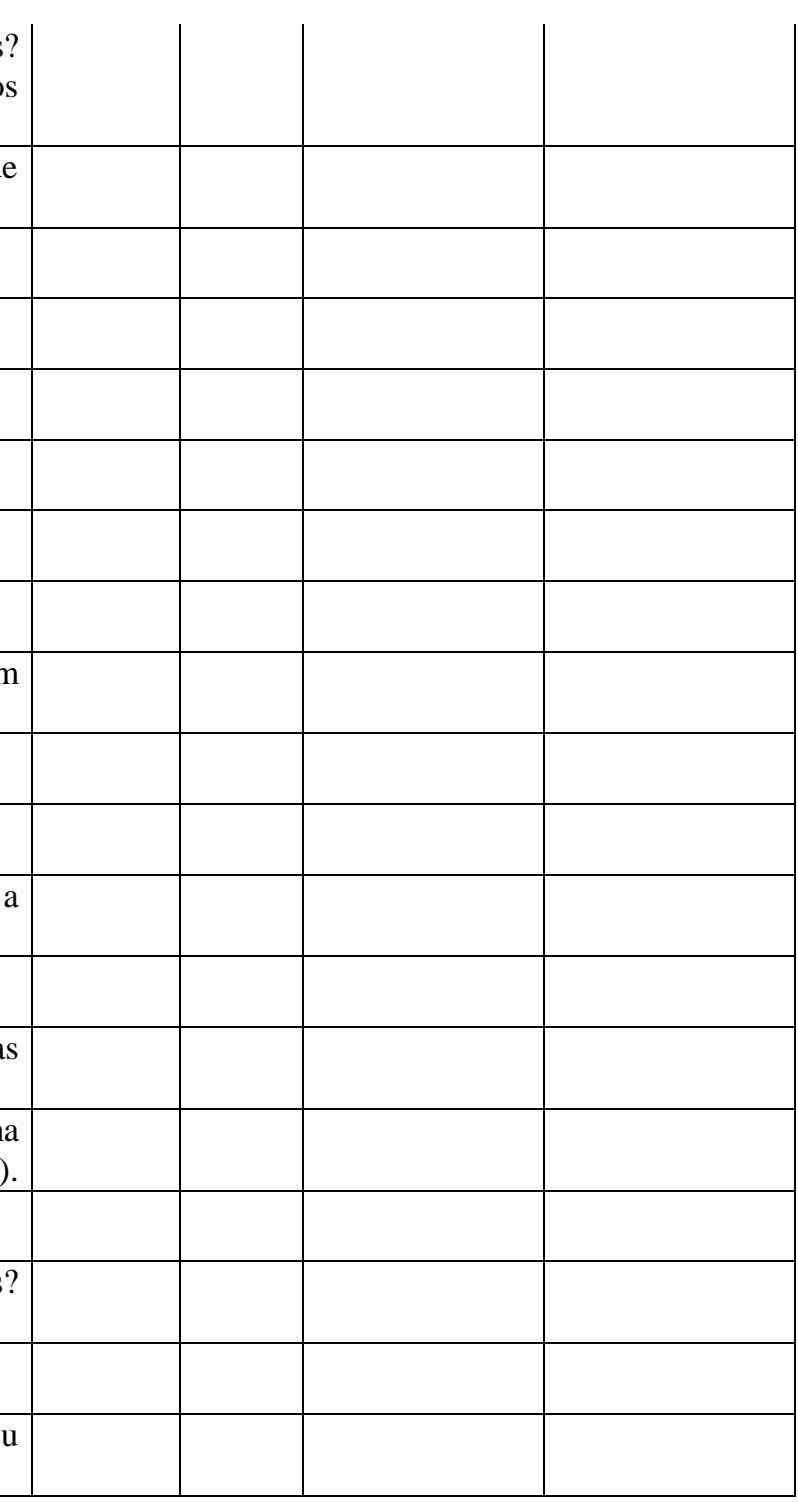


Os requisitos de transporte público foram devidamente atendidos?

As normas de projeto são apropriadas para todos os requisitos do projeto?

A largura das faixas e inclinação transversal é consistente com as normas e orientações gerai do projeto?

Os seguintes aspectos de segurança são previstos nos acostamentos de forma satisfatória: previsão de revestimento/ Largura e tratamentos de aterros? Inclinação transversal do

2.3 Acostamentos acostamento?

Os acostamentos são seguros para os veículos em movimento lento ou bicicletas?

O projeto de alinhamento horizontal e vertical está alinhado corretamente?

alinhamento vertical é constante e adequado em todos os lugares?

\subsection{Alinhamento}

\section{vertica}

horizontal

O alinhamento horizontal é constante em todos os lugares?

O alinhamento é compatível com a função da estrada?

O projeto pode causar sugestões visuais enganosas para os motoristas (por exemplo, ilusões visuais, com delimitação de linhas subliminar como dos postes?

Os alinhamentos verticais e horizontais fornece distância de visibilidade e visibilidade necessária?

Os alinhamentos horizontal e vertical são consistente com a visibilidade necessária?

A linha de visibilidade e redução da distância de visibilidade do projeto obstruída por: defensas, outdoors na margem da rodovia: cercas ou divisórias; mobiliário na rodovia; Estacionamentos, sinalização vertical, vegetação e paisagismo, estrutura de pontes, veículos estacionados na

2.5 Distância de margem da rodovia, ou filas formadas pelos veículos.

visibilidade

Os cruzamentos ferroviários, pontes e outros riscos estão totalmente visíveis?

Existem obstruções elevadas (tais como passagens superiores ou ferroviárias, pórticos de sinalização, galhos das árvores), que pode limitar a distância de visibilidade, especialmente na parte inferior de uma curva vertical?

A rodovia pode ser usada por veículos de grande altura, ou se não, foi considerado um desvio para uma rota alternativa quando necessário?

A visibilidade está adequada para: pedestre, bicicletas ou travessia de animais,? Acesso a rodovia, vias de acesso e no acesso a desníveis

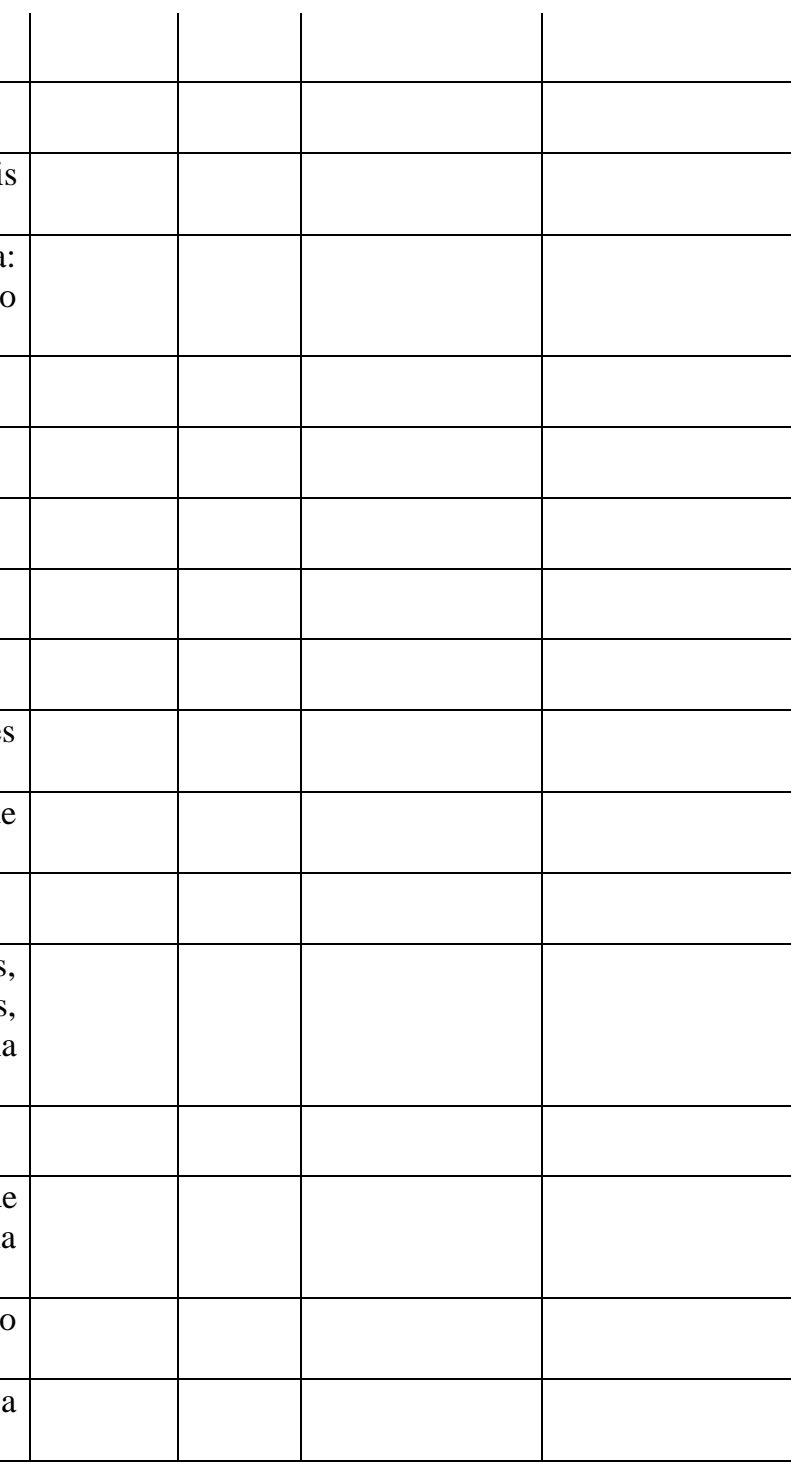


O projeto está livre de alguma outra característica do local que possam afetar a visibilidade?

Foi considerado a visão mínima do triângulo de visibilidade: nas entradas e saídas de rampas? áreas de minas? nas interseções? rotatórias? ou outros pontos de conflitos?

2.6 Efeitos da não No caso de adoção de algum aspecto particular no projeto não cumprir as normas? A segurança conformidade foi mantida?

com as normas ou

diretrizes

Se for detectado algum projeto que não atende as normas: A segurança foi mantida?

É segura a transição, em áreas onde o ambiente rodoviário muda (por exemplo, quando se desloca da área urbana para rural, de um lugar restrito a irrestrito, de uma via iluminada para uma sem iluminação)?

$\mathrm{Na}$ transição da rodovia projetada com a existente, considerou a necessidade de aviso prévio? Foi considerado as implicações de segurança nas transições?

2.7 interface entre A transição entre o projeto antigo e o novo projeto é satisfatório?

o projeto proposto Se a rodovia existente possui padrão inferior ao novo projeto, a advertência da redução é clara e rodovia

existente

e inequívoca?

Foram tomados medidas de segurança adequadas quando necessárias mudança súbita de velocidade?

Acesso ou atrito lateral são tratados de forma segura?

Se o padrão das faixas varia, a alteração é realizada com segurança?

A transição ocorre quando a mudança de ambiente é seguro? (Por exemplo, urbana para rural, área com restrição ou sem restrições, uma área iluminada, ou sem iluminação)

O traçado geral, função e características gerais da rodovia será reconhecido pelos motoristas

2.8 Legibilidade com antecedência?

\begin{tabular}{l|l} 
do alinhamento & As velocidades de aproximação são adequadas e os motoristas podem ser guiados corretamente
\end{tabular} pela rodovia?

2.9 Tratamento de A transição geométrica da seção transversal ao entrar na ponte pode ser realizada com pontes e bueiros $\quad$ segurança?

2.10 Tratamento A segurança rodoviária foi considerada em lugares com determinadas características

ambientais

Nível -

ambientais? (por exemplo, painel antirruído) 


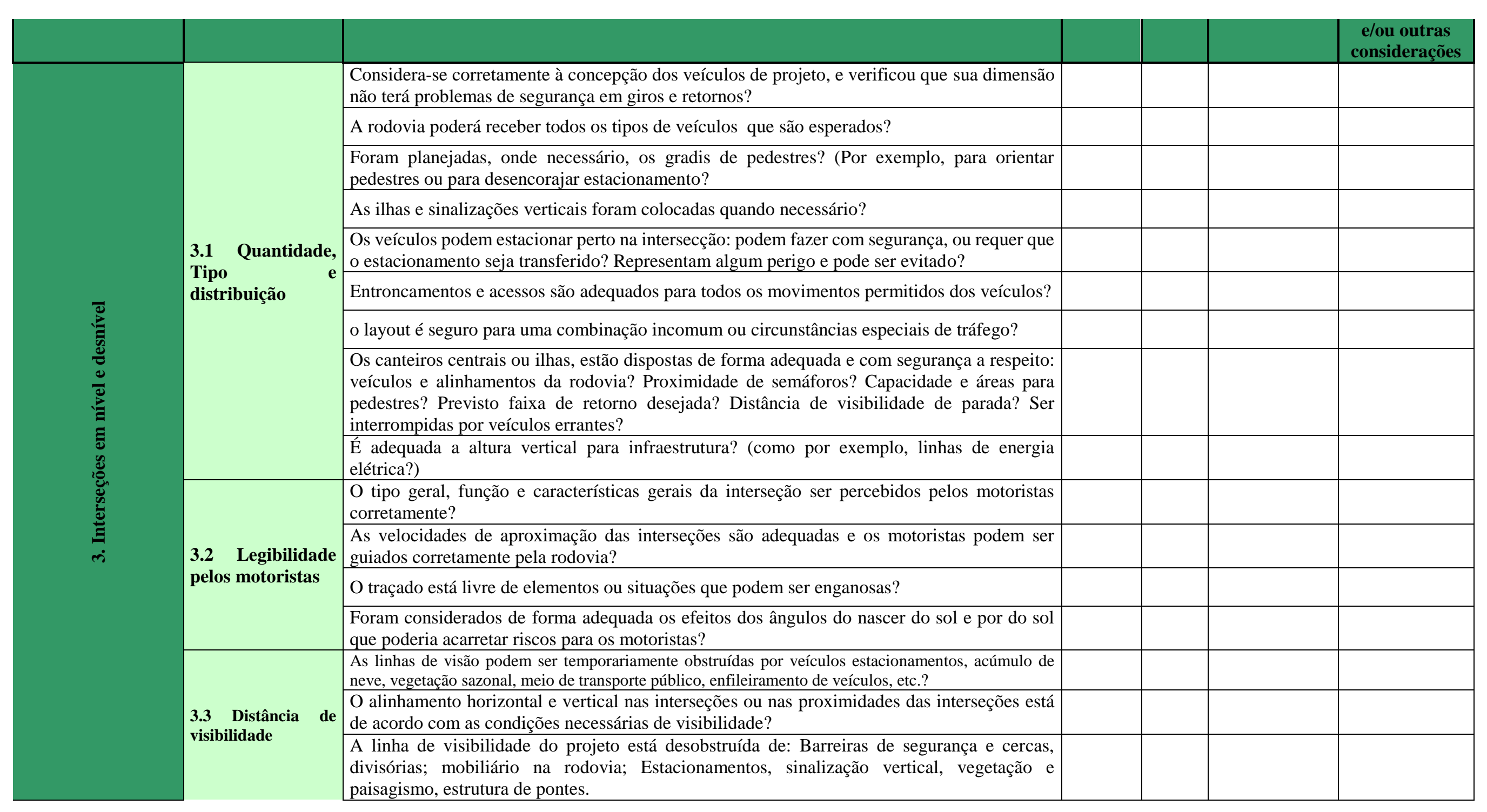


Os cruzamentos ferroviários, pontes e outros riscos próximos das interseções estão totalmente visíveis?

O projeto está livre de outras características locais que podem afetar negativamente a visibilidade?

As normas adotadas permite uma boa visibilidade para velocidade de tráfego e composição do tráfego incomum?

Os semáforos estão operando em fases e/ou sequências com segurança?

O tempo é suficiente para o movimento do fluxo de veículos e pedestres?

As luzes dos semáforos são visíveis? (por exemplo, elas não estão obstruídas por árvores, postes, sinais de trânsito ou veículos de grande porte).

As lâmpadas orientadas em outra direção de atuação estão suficientemente protegidas de modo a ser vistas apenas pelo tráfego que a enfrenta?

As lâmpadas tem uma intensidade de luz suficiente, de modo de, se for o caso, não ser afetadas pelo nascer do sol ou pôr do sol?

3.4 Controle

$\mathrm{O}$ alinhamento vertical proporciona uma adequada distância de visibilidade de parada para a

semafórico

interseção ou filas atrás do veículo?

Quando necessária são proporcionada instalações para o pedestre?

Os condutores que se aproximam da interseção ver claramente os pedestres?

As fases do semáforo são controladas parcial ou totalmente?

Os postes dos semáforos estão localizados em lugares que não geram risco?

É adequada as demarcações para o desvio do tráfego?

Existe una fase exclusiva para pedestres? É conveniente?

É adequada a deflexão ou curva projetada para reduzir a velocidade de aproximação?

São necessárias ilhas divisoras, elas têm boa distância de visibilidade, comprimento e capacidade para armazenar os pedestres?

3.5 Rotatórias

Nas rotatórias a ilha central é alta e visível?

O modelo é apropriado para todos os tipos de veículos?

Os detalhes são adequados da ilha central? (Como delimitação, elevação, visibilidade)? 
Os motoristas podem ver os pedestres com tempo suficiente?

Os pedestres podem determinar se os veículos começam a girar? (Sem obstruções ao campo de visão)

As marcas de direção da pista foram marcadas nas faixas de aproximação?

Na rotatória a iluminação é adequada e os postes estão em locais seguros?

3.6 Outras

Considerou a necessidade de pintar as bordas das ilhas e refúgios?

interseções

As interseções tem comprimento adequado para acomodar os veículos? As interseções tem capacidade para acomodar veículos que efetuam movimentos disponíveis?

Nível Macrocategorias

\section{Nível - \\ Mesocategorias}

4.1 Postes ou outras obstruções

Os postes de semáforos e outros postes de serviço estão posicionados adequadamente?

Todos os postes estão localizados distantes o suficiente do fluxo de tráfego?

Postes frágeis ou flexíveis foram previstos quando necessários?

A largura dos canteiros centrais é adequado para a instalação dos postes de iluminação ou árvores?

A margem da rodovia está livre de outras obstruções que poderiam criar um risco de segurança?

Foram tomadas todas as medidas para remover, mover ou proteger todos os objetos que podem ser perigosos?

Os bueiros na margem da rodovia e canais podem ser atravessados com segurança por qualquer veículo que possa sair da rodovia?

4.2 Dispositivos

centrais

As barreiras centrais foram consideradas adequadamente e detalhada?

4.3 Barreiras de

Os tratamentos finais e terminais foram considerados?

Sempre que necessário, foram previstas adequadamente barreiras de contenção? (por exemplo,

segurança

em aterros, estruturas, árvores, postes, canais de drenagem, pontes)

a barreira de contenção é segura? (Ou seja, não cria perigo para os usuários da rodovia,

incluindo pedestres, ciclistas, etc.)

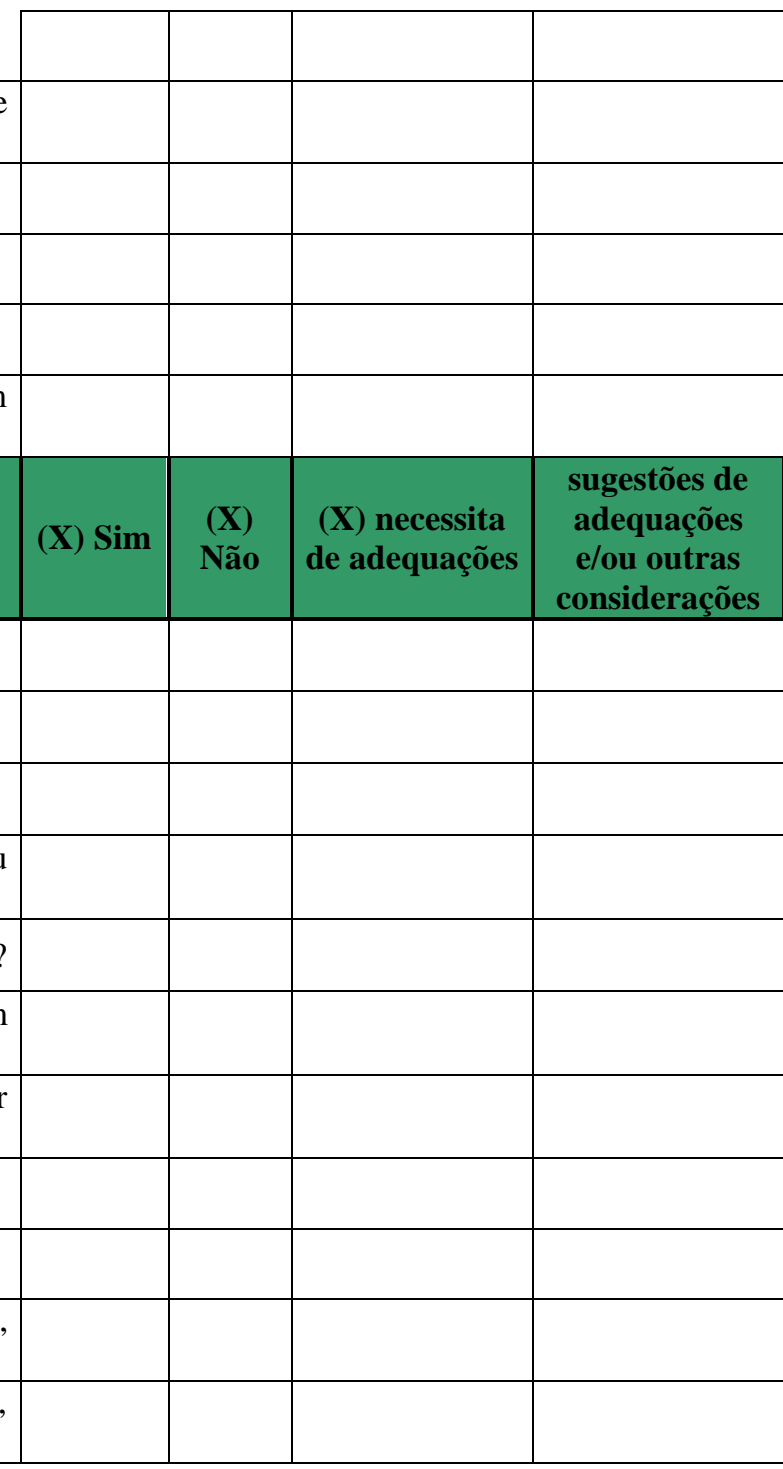


As extremidades das barreiras de contenção são seguras e satisfatórias?

A barreira de contenção foi projetado considerando: tratamentos finais? Largura de trabalho?

Âncoras? Espaçamentos dos postes? Profundidade dos postes? sobreposição da barreira?

É necessária a barreira de contenção (não representa um risco maior quando o objeto está protegido?)

Se existir a circulação de pedestres e ciclistas detrás das barreiras de contenção, é um lugar seguro para esses usuários?

As barreiras da pontes e extremidades das paredes de bueiros são seguros em termos de visibilidade? Tipo com facilidade de reconhecimento? Proximidade com o fluxo de tráfego?

Possibilidade de causar acidentes ou danos? Terminações colapsáveis ou frágeis? sinalização e demarcações? Conexão com as barreiras de proteção? proteção contra os riscos da margem da rodovia?

4.4 OAE, Bueiros

Os corrimãos das pontes está a um nível correto e bastante firme?

e outros

A largura doa acostamentos das pontes iguais ao resto das faixas da rodovia?

É seguro o espaço para o trânsito de veículos não motorizado sobre a ponte? (por exemplo, pedestres, bicicletas, cavalos, etc.)

As saídas dos bueiros representam algum risco para os condutores que podem sair da rodovia?

As rodovias propicias a inundações têm adequada sinalização e distância de visibilidade?

Nível -

Macrocategorias

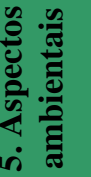

Nível -

Macrocategorias
Nível -

Mesocategorias
Nível Microcategorias

\section{Nível Microcategorias}

Existem animais nas rotas de viagens / ou migração conhecidas em áreas que poderiam afetar o entorno com o projeto?

Cercas e passagens inferiores estão implantadas onde é necessário?

Há sinalização adequada para informar a passagem inferiores para passagem de gado, passagem de animais silvestres, etc.?

A segurança rodoviária foi considerada na redução dos impactos ambientais? (por exemplo, painel antirruído)

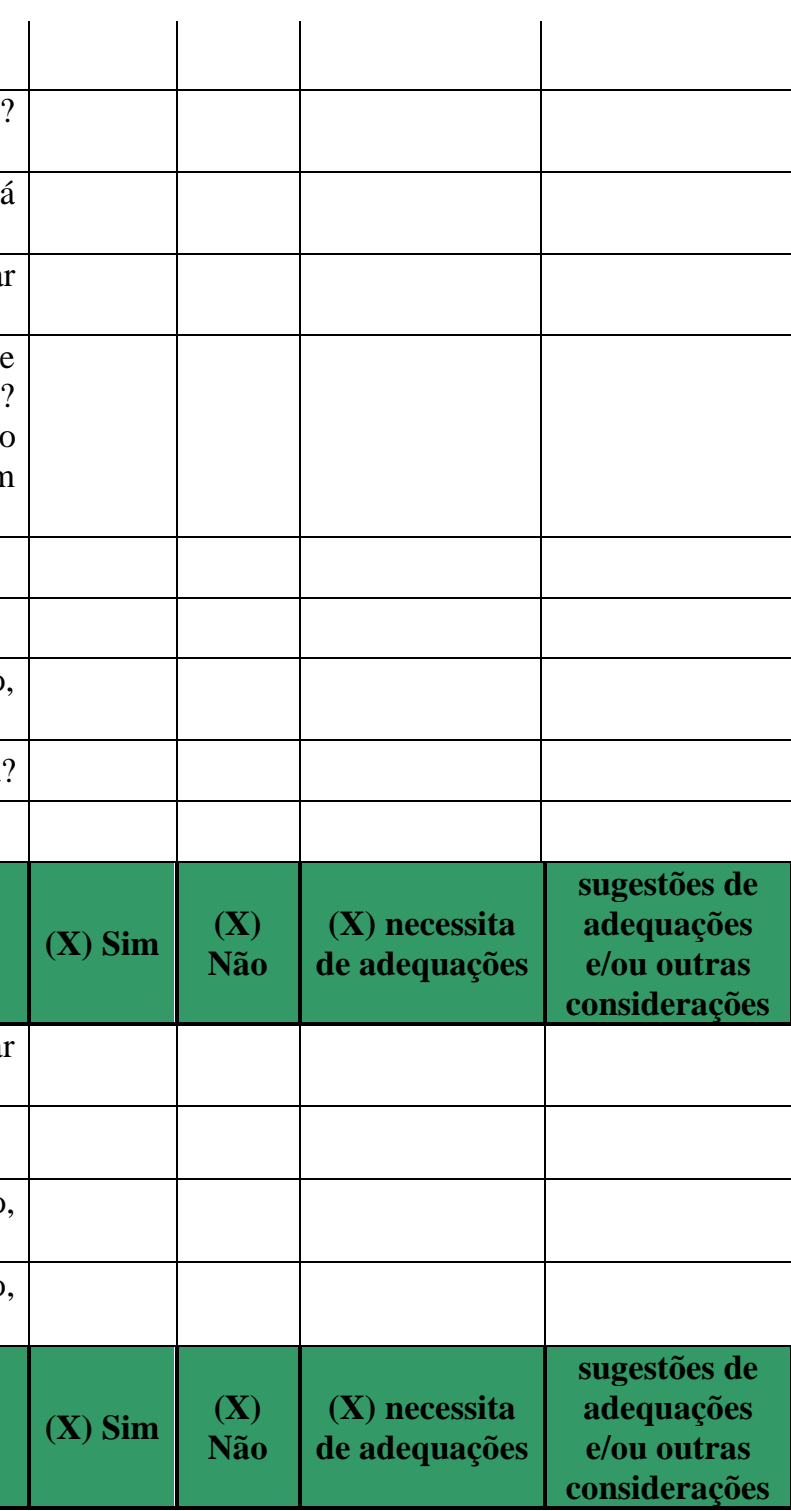




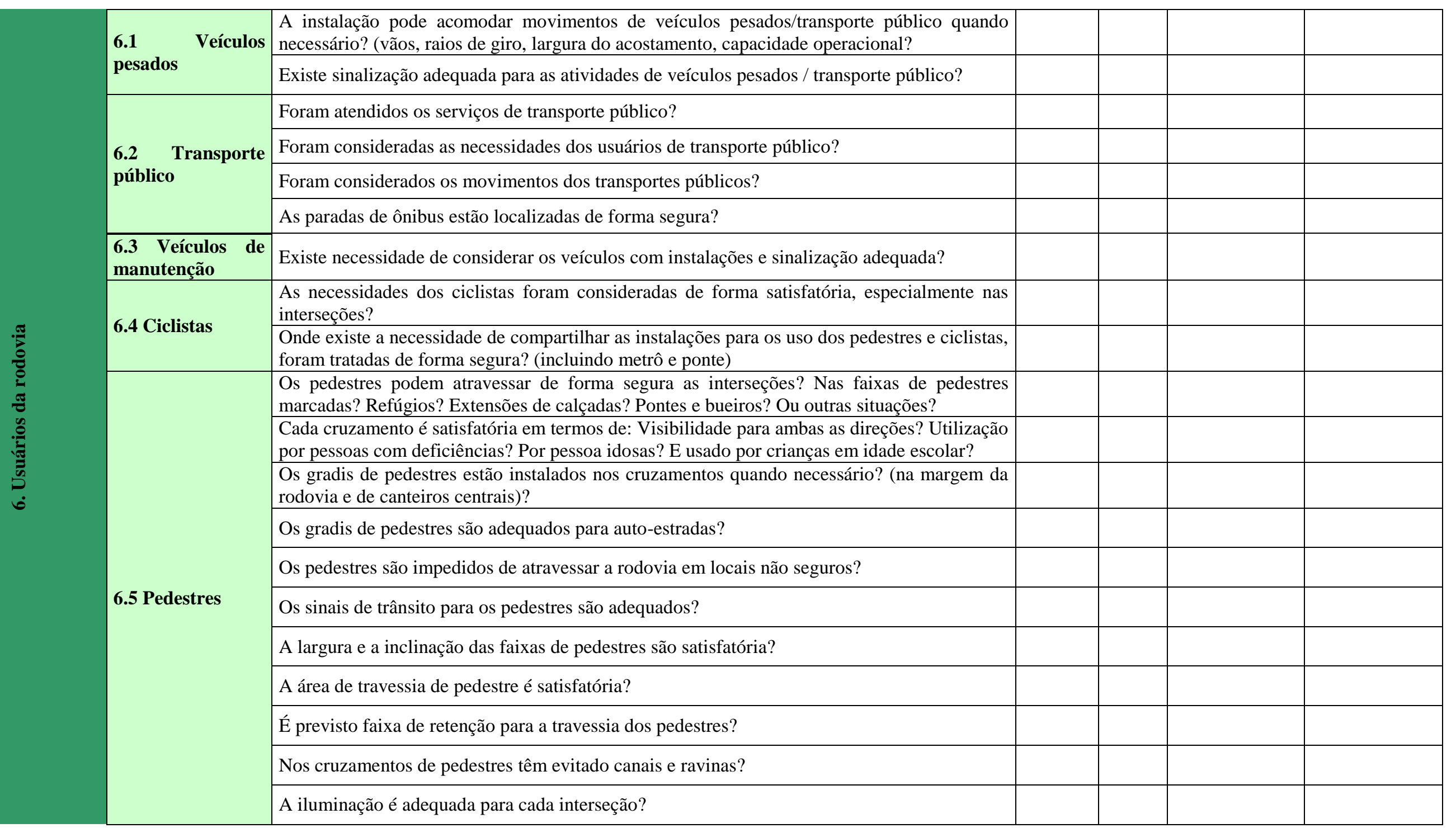


Os cruzamentos estão localizados em lugares onde se maximiza o seu uso?

é possível evitar o cruzamento? (por exemplo, alternativa mais direta, porém menos seguro)

6.6 Entorno da

rodovia

Todos os acessos, para as propriedades e / ou propriedade adjacentes são seguros?

(r)

Há necessidade de considerar os movimentos relacionados com a atividade agrícola na região?

Existem dispositivos na rodovia ou objetos que podem desestabilizar uma motocicleta?

A borda está livre de obstruções de forma que uma motocicleta consiga inclinar-se em uma curva de forma segura?

Existem advertências ou delineação adequados para os motociclistas?

6.7 motocicletas

Existe extremidades de barreiras de contenção expostas, desprotegida ou terminal em áreas de alta velocidade?

Onde as áreas que existem maiores probabilidades das motocicletas saírem da rodovia, há alguma medida de segurança?

São todos os postes e dispositivos necessários? Se assim for, existe opção para protegê-los? área de drenagem e bueiros podem ser superados com satisfação pelos motociclistas?

Foram considerados o tráfego de cavaleiros, incluindo a utilização das bordas e acostamentos,

6.8 Cavaleiros

Foram considerados o tráfego de cavaleiros, incluindo
e o regulamento para a utilização da faixa da rodovia?

gado

Existe passagem em inferiores para ser usado pelos cavaleiros e gados?

Nível -

Macrocategorias

Nível -

Mesocategorias

\section{Nível Microcategorias}

As formas das demarcações e símbolos são consistentes o manual de sinalização?

Foi identificado e tratado algum lugar de demarcações que poderia ser confuso ou mal horizontal

As linhas contínuas (de proibido ultrapassar) previstas quando necessárias?

As tachas retroreflectivas estão previstas onde necessárias? 


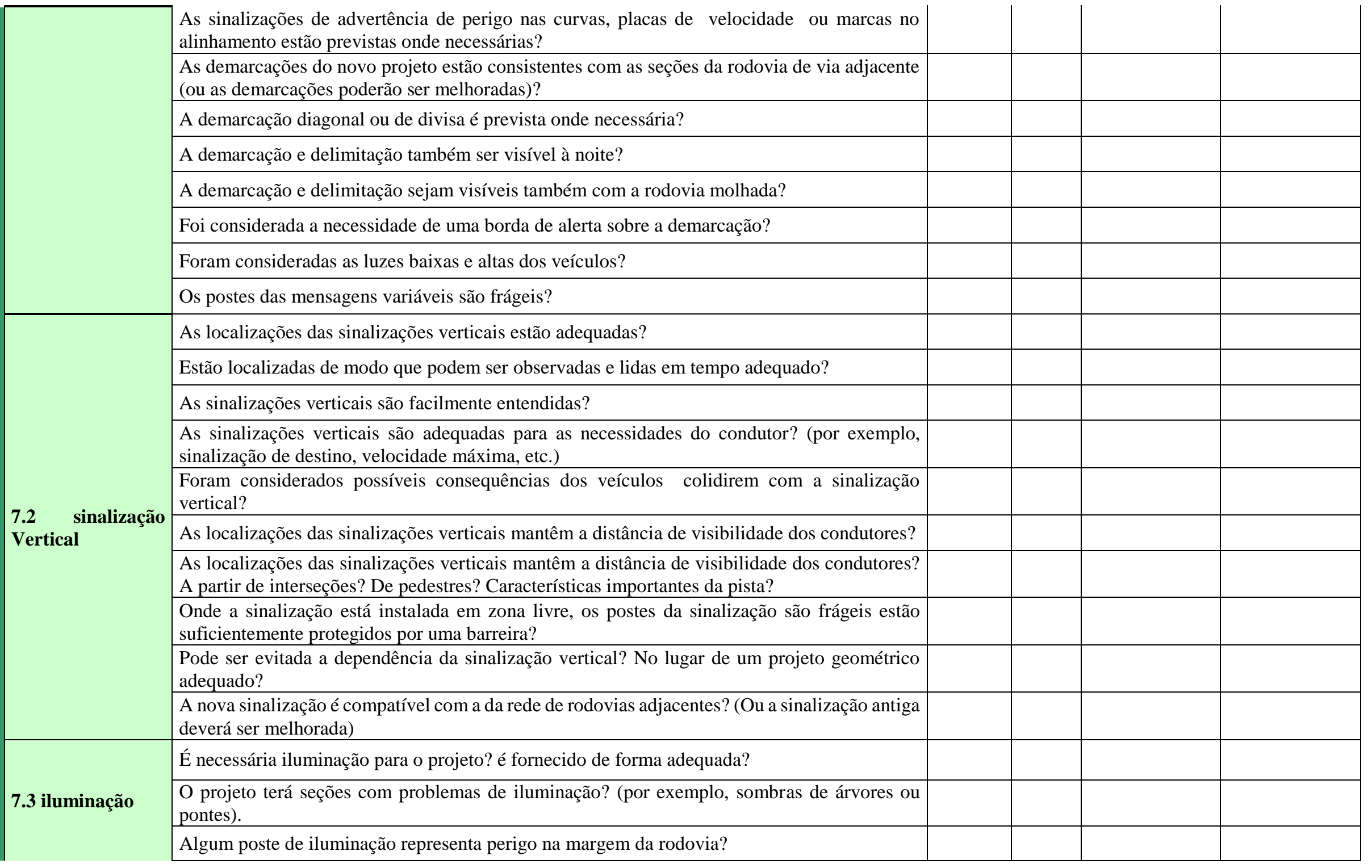




\begin{tabular}{|c|c|c|c|c|c|c|}
\hline & & Os postes a serem utilizados são frágeis (quebradiços) ou com base dobrável ou deslizantes? & & & & \\
\hline & & $\begin{array}{l}\text { O projeto de iluminação pode confundir ou causar efeitos enganosos sobre a sinalização ou } \\
\text { semáforos? }\end{array}$ & & & & \\
\hline & & $\begin{array}{l}\text { Há necessidade de requisitos especiais para iluminação ambiente? A segurança será mantida } \\
\text { casos as medidas especiais não forem realizadas? }\end{array}$ & & & & \\
\hline & & $\begin{array}{l}\text { A iluminação vai permitir adequadamente iluminação de cruzamentos, as estradas adjacentes, } \\
\text { refúgios, etc.? }\end{array}$ & & & & \\
\hline & & Todas as articulações (juntas) das áreas foram iluminados adequadamente? & & & & \\
\hline & & Existem alguma área não iluminada no projeto? & & & & \\
\hline & & $\begin{array}{l}\text { Existem locais de conflito de acidentes, que pode ser vantajoso tratar com a melhoria da } \\
\text { iluminação ou instalar o projeto de iluminação? }\end{array}$ & & & & \\
\hline & & O projeto é livre de iluminação em áreas escuras? & & & & \\
\hline $\begin{array}{l}\text { Nível - } \\
\text { Macrocategorias }\end{array}$ & $\begin{array}{l}\text { Nível - } \\
\text { Mesocategorias }\end{array}$ & Nível Microcategorias & (X) Sim & $\begin{array}{l}(\mathbf{X}) \\
\text { Não }\end{array}$ & $\begin{array}{l}\text { (X) necessita de } \\
\text { adequações }\end{array}$ & $\begin{array}{c}\text { sugestões de } \\
\text { adequações e/ou } \\
\text { outras } \\
\text { considerações } \\
\end{array}$ \\
\hline \multirow{11}{*}{ 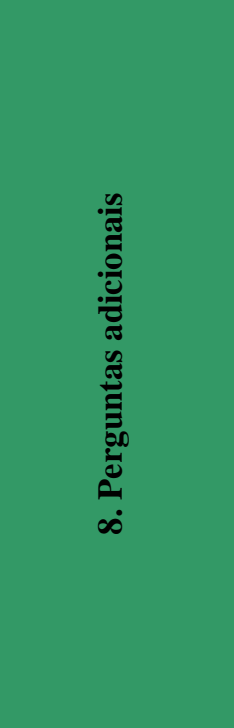 } & \multirow{4}{*}{$\begin{array}{l}\text { 8.1 Alinhamento } \\
\text { horizontal }\end{array}$} & É adequada a visibilidade dos motoristas e pedestres nos acessos propostos? & & & & \\
\hline & & é adequado o espaço previsto para mudança de fluxo e velocidade de tráfego? & & & & \\
\hline & & Os raios de curva possui visibilidade adequada? & & & & \\
\hline & & A distância de visibilidade e parada são adequadas? & & & & \\
\hline & \multirow{2}{*}{$\begin{array}{l}\text { 8.2 Alinhamento } \\
\text { vertical }\end{array}$} & O alinhamento vertical é satisfatório? & & & & \\
\hline & & A distância de visibilidade e parada são adequadas? & & & & \\
\hline & \multirow{3}{*}{$\begin{array}{l}8.3 \text { áreas de } \\
\text { estacionamento }\end{array}$} & $\begin{array}{l}\text { O estacionamento no local está adequado para evitar que os veículos estacionem na rodovia } \\
\text { com risco associado a ele? }\end{array}$ & & & & \\
\hline & & $\begin{array}{l}\text { Os estacionamentos estão localizados em áreas seguras? Se não, foram previstas medidas para } \\
\text { evitar isso? }\end{array}$ & & & & \\
\hline & & $\begin{array}{l}\text { É adequado o espaço previsto nas áreas de estacionamento para circulação distância de } \\
\text { visibilidade da interseção? }\end{array}$ & & & & \\
\hline & \multirow{2}{*}{ 8.4 Serviços } & São adequadas as áreas de carga e descarga da rodovia? & & & & \\
\hline & & As manobras dos veículos grandes foram previstas em lugares seguros? & & & & \\
\hline
\end{tabular}


Os acessos para os veículos de emergência são adequados

8.5 Sinalização Está definida claramente a prioridade de todas as interseções, nos pátios dos estacionamentos vertical e e vias de acesso?

sinalização $\quad$ A sinalização vertical e demarcações serão visíveis em todas as condições? (incluindo dia

horizontal

noite, chuva, neblina, etc.?

\subsection{Paisagismo}

A paisagem mantém a visibilidade nas interseções, curvas, acessos e localizações de pedestres? foi evitado a plantação de vegetação em lugares onde os veículos podem sair da rodovia?

O projeto vai manter a velocidade de projeto de forma segura?

O número e a localização dos acessos são adequados?

8.7 gestão de Há instalações para os serviços de transporte públicos? E estão localizados em lugares seguros tráfego e justificados?

Existem instalações para os ciclistas? Estão localizados de forma segura a respeito dos movimentos dos veículos?

Existem instalações para os pedestres? Estão localizadas em lugares seguros e adequados?

No projeto está prevista iluminação pública? É adequada?

8.8 Outros

Há riscos na margem da rodovia? Foram tratados corretamente?

Os pedestres podem acessar de forma segura o desenvolvimento urbano proposto?

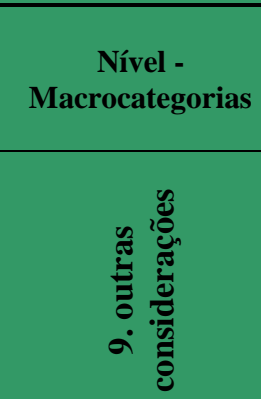

9.1

Nível -

Mesocategorias

Outros

há situações especiais? Foram consideradas situações incomuns ou de perigo?

segurança

A rodovia é capaz de suportar com segurança a circulação de veículos de grande porte,

abordado

caminhões, ônibus, veículos de emergência, veículos de manutenção da rodovia?

Se necessário, a rodovia pode ser fechada para eventos especiais de forma segura?

Se for o caso, os requisitos especiais de paisagem e rotas turísticas são satisfeitos?

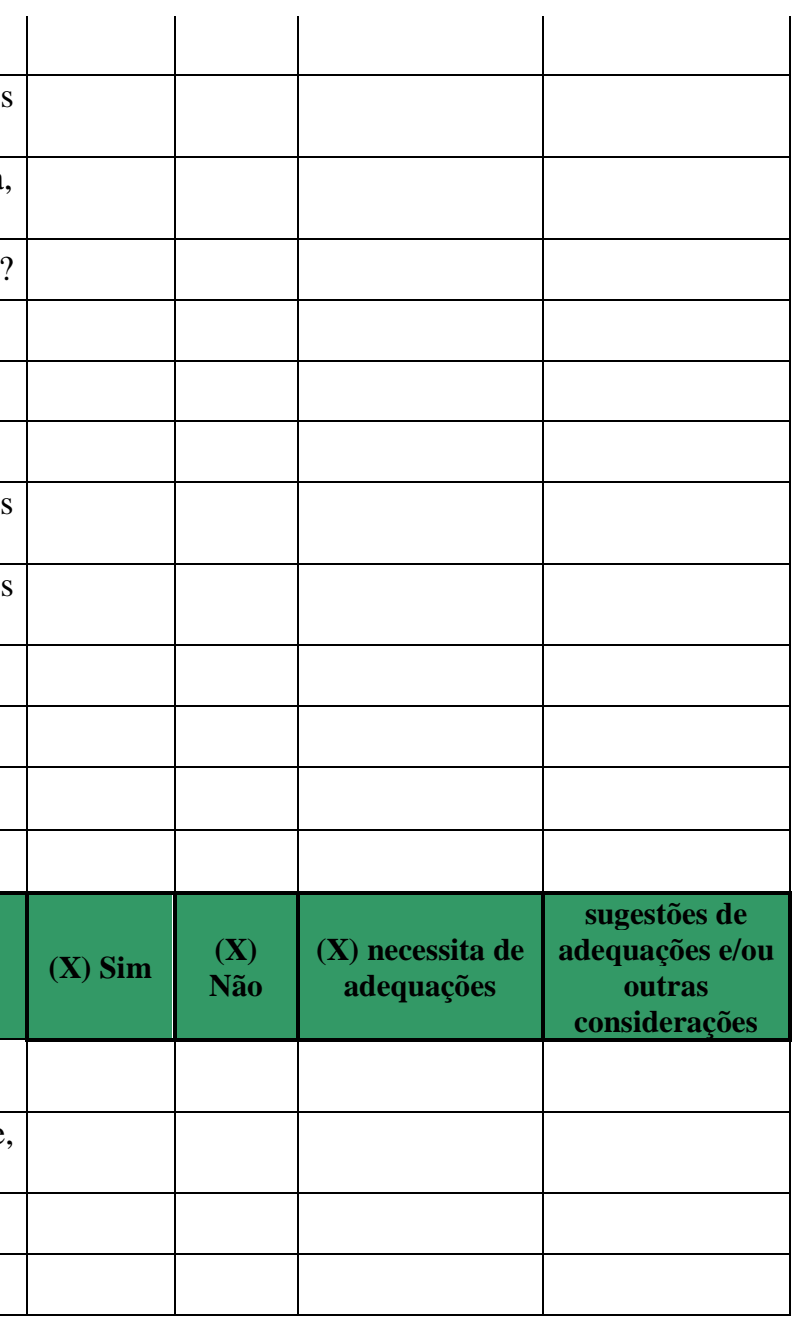




\section{APÊNDICE E1 - INSTRUMENTO DE ASV - ESTUDO DE VIABILIDADE - VERSÃO FINAL}

Identificação do projeto:

Data da auditoria:

Localização do estudo de viabilidade e extensão:

\begin{tabular}{|c|c|c|c|c|c|}
\hline \multicolumn{6}{|c|}{ INSTRUMENTO DE ASV DETALHADO - ESTUDO DE VIABILIDADE } \\
\hline \multirow{2}{*}{\multicolumn{2}{|c|}{ 1. Tópicos Gerais }} & \multicolumn{3}{|c|}{ Verificação pelo auditor } & \multirow[t]{2}{*}{ Comentários/sugestões dos auditores } \\
\hline & & $\begin{array}{c}(\mathbf{X}) \\
\text { Atendido }\end{array}$ & $\begin{array}{l}\text { (X) Não } \\
\text { atendido }\end{array}$ & $\begin{array}{l}\text { (X) Atendido } \\
\text { parcialmente }\end{array}$ & \\
\hline \multirow{8}{*}{$\begin{array}{l}1.1 \text { Finalidade do } \\
\text { projeto }\end{array}$} & $\begin{array}{l}\text { Verificar toda documentação pertinente do escopo do projeto, } \\
\text { destacando os objetivos do projeto, características do usuário, } \\
\text { veículos de projetos, projetos pré-existentes de acessos, } \\
\text { características das áreas adjacentes, informações de redes existentes } \\
\text { e projetos de futuras expansões. }\end{array}$ & & & & \\
\hline & Qual a finalidade do projeto proposto? & & & & \\
\hline & $\begin{array}{l}\text { O projeto proposto é compatível com a finalidade da rodovia } \\
\text { (classificação e classe da rodovia)? }\end{array}$ & & & & \\
\hline & $\begin{array}{l}\text { O projeto proposto enfatiza adequadamente a segurança dos } \\
\text { veículos (carros, motos, ônibus e caminhões), ciclistas e pedestres? }\end{array}$ & & & & \\
\hline & Foi considerada adequadamente a composição do tráfego esperado? & & & & \\
\hline & O projeto será executado em uma única etapa? & & & & \\
\hline & $\begin{array}{l}\text { Se o projeto for executado em mais de uma etapa, houve prioridade } \\
\text { da segurança na transição dessas etapas e/ou nas transições com } \\
\text { rodovias existentes? }\end{array}$ & & & & \\
\hline & $\begin{array}{l}\text { O trabalho irá evitar problemas com as normas de segurança durante } \\
\text { a construção? }\end{array}$ & & & & \\
\hline \multirow{3}{*}{$\begin{array}{l}\text { 1.2 Características } \\
\text { técnicas do projeto }\end{array}$} & $\begin{array}{l}\text { Há trechos da rodovia localizados na área de influência de polos } \\
\text { geradores de viagens? Se sim, foram apresentadas medidas de } \\
\text { gestão de segurança para essas áreas? }\end{array}$ & & & & \\
\hline & $\begin{array}{l}\text { Foram previstos acessos alternativos para assegurar que subúrbios } \\
\text { ou subáreas existentes não fiquem isolados? }\end{array}$ & & & & \\
\hline & $\begin{array}{l}\text { Os acessos aos geradores de viagens estão com distância adequada } \\
\text { de interseções, pontes,, túnel, posto de pesagem e praças de pedágio }\end{array}$ & & & & \\
\hline
\end{tabular}




\begin{tabular}{|c|c|c|c|c|c|}
\hline & $\begin{array}{l}\text { para fornecer segurança na trafegabilidade do tráfego local e } \\
\text { usuários da rodovia? }\end{array}$ & & & & \\
\hline & $\begin{array}{l}\text { A distância de visibilidade dos acessos para geradores de viagens } \\
\text { estão adequadas? }\end{array}$ & & & & \\
\hline & $\begin{array}{l}\text { O projeto proposto é coerente com as rodovias adjacentes, no que } \\
\text { tange a topografia e gestão de tráfego? }\end{array}$ & & & & \\
\hline \multirow{4}{*}{$\begin{array}{l}1.3 \text { Acesso e áreas } \\
\text { adjacentes }\end{array}$} & $\begin{array}{l}\text { O controle dos acessos é compatível com a função e com outras } \\
\text { seções da rodovia? }\end{array}$ & & & & \\
\hline & $\begin{array}{l}\text { A distância de visibilidade é satisfatória: nas interseções e acesso ás } \\
\text { propriedades? }\end{array}$ & & & & \\
\hline & $\begin{array}{l}\text { A velocidade de projeto (ou a velocidade de operação) é compatível } \\
\text { com número e o tipo de interseções e/ou acessos a propriedades } \\
\text { adjacentes e marginais? }\end{array}$ & & & & \\
\hline & $\begin{array}{l}\text { A largura da faixa de direito de passagem atende aos requisitos } \\
\text { necessários a acessibilidade? }\end{array}$ & & & & \\
\hline $\begin{array}{l}1.4 \text { Impactos do } \\
\text { projeto proposto }\end{array}$ & $\begin{array}{l}\text { Efeitos negativos do projeto sobre as vias adjacentes foram } \\
\text { identificados? E foram tratados adequadamente? }\end{array}$ & & & & \\
\hline $\begin{array}{l}1.5 \text { Obras de } \\
\text { Melhoramentos }\end{array}$ & $\begin{array}{l}\text { O traçado não afetará o nível de segurança, se houver futuros } \\
\text { alargamentos, realinhamentos, adição de novas faixas, alterações na } \\
\text { geometria das interseções ou nas extensões lineares do projeto? }\end{array}$ & & & & \\
\hline \multirow{2}{*}{ 2. Geometria } & & \multicolumn{3}{|c|}{ Verificação pelo auditor } & Comentários / sugestões dos auditores \\
\hline & & $\begin{array}{c}\mathbf{X}) \\
\text { Atendido } \\
\end{array}$ & $\begin{array}{l}\text { (X) Não } \\
\text { atendido }\end{array}$ & $\begin{array}{l}\text { (X) Atendido } \\
\text { parcialmente } \\
\end{array}$ & \\
\hline \multirow{5}{*}{$\begin{array}{l}2.1 \quad \text { Traçado e } \\
\text { alinhamento }\end{array}$} & $\begin{array}{l}\text { São seguros todos os aspectos relacionados com a localização do } \\
\text { traçado e/ou alinhamento? }\end{array}$ & & & & \\
\hline & $\begin{array}{l}\text { Nos casos em que um novo traçado é proposto sobre um traçado } \\
\text { existente, quais os efeitos desse traçado referente a segurança viária? }\end{array}$ & & & & \\
\hline & $\begin{array}{l}\text { Verificar se o traçado proposto é seguro, e se poderia ser mais } \\
\text { seguro, principalmente, quando tratar de traçado em áreas } \\
\text { subdesenvolvidas ou em áreas de vegetação densa. }\end{array}$ & & & & \\
\hline & $\begin{array}{l}\text { O traçado proposto está de acordo com as limitações físicas da } \\
\text { vegetação? }\end{array}$ & & & & \\
\hline & $\begin{array}{l}\text { O projeto é adequado no que diz respeito à composição e fluxo de } \\
\text { tráfego (incluindo os efeitos da relação incomum de veículos } \\
\text { pesados, bicicletas e pedestres ou efeitos de atrito lateral)? }\end{array}$ & & & & \\
\hline
\end{tabular}




\begin{tabular}{|c|c|c|c|c|c|}
\hline & $\begin{array}{l}\text { O projeto prevê acomodação e contempla a segurança com } \\
\text { imprevistos com o aumento e mudança na composição do volume } \\
\text { de tráfego? }\end{array}$ & & & & \\
\hline & $\begin{array}{l}\text { As seções e transições do traçado proposto estão livres de potenciais } \\
\text { problemas na conexão com a rede viária existente? }\end{array}$ & & & & \\
\hline \multirow{3}{*}{$\begin{array}{l}2.2 \text { Elementos da } \\
\text { seção transversal }\end{array}$} & $\begin{array}{l}\text { As normas de projeto foram utilizadas apropriadamente, levando em } \\
\text { conta as características do projeto, composição do fluxo de tráfego } \\
\text { e usuários da rodovia? }\end{array}$ & & & & \\
\hline & $\begin{array}{l}\text { O perfil e a geometria estão em conformidade com as diretrizes do } \\
\text { projeto? }\end{array}$ & & & & \\
\hline & $\begin{array}{l}\text { O projeto considerou os tipos de veículos para os quais está previsto } \\
\text { o seu uso? }\end{array}$ & & & & \\
\hline \multirow{5}{*}{2.3 Velocidades } & $\begin{array}{l}\text { A velocidade de projeto está adequada com: alinhamento vertical, } \\
\text { horizontal, visibilidade, acessos, entre cruzamentos, aceleração e } \\
\text { desaceleração do fluxo de veículos nos cruzamento e composição do } \\
\text { tráfego previsto? }\end{array}$ & & & & \\
\hline & $\begin{array}{l}\text { A distância de visibilidade é satisfatória para: interseções? Entrada } \\
\text { e saída das rampas? Entradas de propriedades adjacentes? Entradas } \\
\text { de acesso de veículos de emergência? }\end{array}$ & & & & \\
\hline & $\begin{array}{l}\text { Pode haver qualquer mudança no limite de velocidade com } \\
\text { segurança? }\end{array}$ & & & & \\
\hline & $\begin{array}{l}\text { A velocidade de projeto e o limite de velocidade são adequados para } \\
\text { a rodovia ou parte dela? }\end{array}$ & & & & \\
\hline & $\begin{array}{l}\text { O limite de velocidade de projeto está de acordo com a velocidade } \\
\text { de sinalizada? }\end{array}$ & & & & \\
\hline \multirow{2}{*}{ 3. Interseções } & & \multicolumn{3}{|c|}{ Verificação pelo auditor } & Comentários/ sugestões dos auditores \\
\hline & & $\begin{array}{c}(\mathrm{X}) \\
\text { Atendido }\end{array}$ & $\begin{array}{l}\text { (X) Não } \\
\text { atendido }\end{array}$ & $\begin{array}{l}\text { (X) Atendido } \\
\text { parcialmente }\end{array}$ & \\
\hline \multirow[t]{2}{*}{$\begin{array}{l}\text { 3.1 Quantidade, } \\
\text { tipo e localização }\end{array}$} & $\begin{array}{l}\text { Todos os aspectos das interseções são (por exemplo, o espaçamento, } \\
\text { tipo, layout, etc.) adequados no que diz respeito: ao conceito geral } \\
\text { do projeto; a função do projeto desta rodovia e das rodovias que } \\
\text { cruzam o projeto; compatíveis com a seção adjacente; e aos usuários } \\
\text { da rodovia? }\end{array}$ & & & & \\
\hline & $\begin{array}{l}\mathrm{O} \text { número de interseções proposto e gabarito vertical atendem as } \\
\text { necessidades de conexão entre o projeto proposto e as rodovias }\end{array}$ & & & & \\
\hline
\end{tabular}




\begin{tabular}{|c|c|c|c|c|c|}
\hline & $\begin{array}{l}\text { adjacentes, assim como, acesso seguro para os veículos de } \\
\text { emergências? }\end{array}$ & & & & \\
\hline & $\begin{array}{l}\text { Foram consideradas na escolha do tipo e espaçamento das } \\
\text { interseções propostas eventuais restrições físicas, visibilidade ou a } \\
\text { operação do tráfego para garantir a segurança dos usuários da } \\
\text { rodovia? }\end{array}$ & & & & \\
\hline & $\begin{array}{l}\text { Todas as propostas de interseções são realmente necessárias para o } \\
\text { projeto proposto? }\end{array}$ & & & & \\
\hline & $\begin{array}{l}\text { Algumas interseções projetadas desnecessárias podem ser } \\
\text { removidas para melhorar a segurança? E o acesso a rodovia pode ser } \\
\text { conectado de forma segura com eventuais mudanças em torno da } \\
\text { rede rodoviária adjacente? }\end{array}$ & & & & \\
\hline & $\begin{array}{l}\text { Os ângulos das faixas das rodovias existentes que cruzam o } \\
\text { alinhamento principal do projeto proposto, bem como a linha de } \\
\text { visibilidade estão adequados para a segurança dos usuários da } \\
\text { rodovia? }\end{array}$ & & & & \\
\hline & $\begin{array}{l}\text { O movimento dos usuários vulneráveis é seguro em todas as } \\
\text { interseções? }\end{array}$ & & & & \\
\hline & $\begin{array}{l}\text { Os projetos propostos das interseções acomodam de forma segura a } \\
\text { circulação dos veículos de projeto, inclusive os veículos pesados? }\end{array}$ & & & & \\
\hline & $\begin{array}{l}\text { O alinhamento horizontal e vertical do eixo principal foi } \\
\text { considerado para determinar o tipo e a localização das interseções? }\end{array}$ & & & & \\
\hline \multirow[b]{2}{*}{ 4. Obstáculos Fixos } & & \multicolumn{3}{|c|}{ Verificação pelo auditor } & \\
\hline & & $\begin{array}{c}\text { (X) } \\
\text { Atendido } \\
\end{array}$ & $\begin{array}{l}\text { (X) Não } \\
\text { atendido }\end{array}$ & $\begin{array}{l}\text { (X) Atendido } \\
\text { parcialmente }\end{array}$ & Comentários / sugestões dos auditores \\
\hline \multirow{3}{*}{$\begin{array}{l}\text { 4.1 Postes ou } \\
\text { outras obstruções }\end{array}$} & $\begin{array}{l}\text { As larguras dos canteiros centrais sem proteção por barreiras são } \\
\text { adequadas para as instalações dos postes de iluminação? }\end{array}$ & & & & \\
\hline & $\begin{array}{l}\text { Os postes de semáforos e outros postes de serviço estão } \\
\text { posicionados adequadamente e com alturas adequadas para o } \\
\text { trânsito? }\end{array}$ & & & & \\
\hline & $\begin{array}{l}\text { Foi considerada localização de serviços e outras utilidades } \\
\text { referentes a cabos subterrâneos ou aéreos na elaboração do projeto? }\end{array}$ & & & & \\
\hline \multirow{2}{*}{$\begin{array}{l}\text { 4.2 Dispositivos } \\
\text { centrais }\end{array}$} & $\begin{array}{l}\text { O tipo de dispositivos de contenção viária escolhido é apropriado } \\
\text { para a largura dos canteiros centrais? }\end{array}$ & & & & \\
\hline & As barreiras rígidas possuem configuração geométrica adequada? & & & & \\
\hline
\end{tabular}




\begin{tabular}{|c|c|c|c|c|c|}
\hline & \multicolumn{5}{|l|}{ As inclinações dos canteiros de grama estão adequadas? } \\
\hline & \multicolumn{5}{|l|}{ As barreiras centrais estão suficientemente afastadas da rodovia? } \\
\hline & \multicolumn{5}{|l|}{$\begin{array}{l}\text { Está prevista a distância mínima entre os dispositivos de contenção } \\
\text { e os pilares das obras de artes especiais (OAE) e postes de } \\
\text { iluminação? }\end{array}$} \\
\hline & \multicolumn{5}{|l|}{$\begin{array}{l}\text { O espaçamento é apropriado entre as travessias de divisórias } \\
\text { centrais? }\end{array}$} \\
\hline & \multicolumn{5}{|l|}{$\begin{array}{l}\text { As travessias de linhas de transmissão e/ou telecomunicações estão } \\
\text { com as alturas adequadas para o trânsito da via? }\end{array}$} \\
\hline & \multicolumn{5}{|l|}{$\begin{array}{l}\text { Há interferências transversal e/ou longitudinal do projeto com os } \\
\text { equipamentos de energia, saneamento e telecomunicações } \\
\text { (telefonia, fibras ópticas, rede de água e esgoto, gasodutos, } \\
\text { oleodutos, etc...)? }\end{array}$} \\
\hline \multirow{2}{*}{\multicolumn{2}{|c|}{ 5. Aspectos ambientais }} & \multicolumn{3}{|c|}{ Verificação pelo auditor } & Comentários / sugestões dos auditores \\
\hline & & \begin{tabular}{c|c}
$\mathbf{X})$ \\
Atendido \\
\end{tabular} & \begin{tabular}{|c|} 
(X) Não \\
atendido
\end{tabular} & \begin{tabular}{|l|} 
(X) Atendido \\
parcialmente
\end{tabular} & \\
\hline \multirow{6}{*}{$\begin{array}{l}5.1 \text { Clima e outros } \\
\text { aspectos }\end{array}$} & \begin{tabular}{|l|} 
Existem animais nas rotas de viagens / ou migração conhecida em \\
áreas que poderiam afetar o entorno com o projeto?
\end{tabular} & & & & \\
\hline & $\begin{array}{l}\text { O terreno do entorno da rodovia está livre de objetos fíxos ou } \\
\text { vegetação que poderiam afetar a segurança do projeto? (por } \\
\text { exemplo, grandes cultivos, florestas, cortes profundos (barrancos) } \\
\text { cortes elevados, ou áreas rochosas que podem restringir o projeto. }\end{array}$ & & & & \\
\hline & $\begin{array}{l}\text { Foram consideradas as condições de tempo e ambientais para os } \\
\text { projetos dos declives (rampas) e curvas? }\end{array}$ & & & & \\
\hline & $\begin{array}{l}\text { Projeto irá operar com segurança em condições ambientais } \\
\text { adversas, como a noite, com neblina ou estrada molhada? }\end{array}$ & & & & \\
\hline & $\begin{array}{l}\text { Existem distrações visuais, como por exemplo, paisagem } \\
\text { panorâmica que podem proporcionar insegurança aos usuários da } \\
\text { rodovia? }\end{array}$ & & & & \\
\hline & $\begin{array}{l}\text { Foram considerados aspectos incomuns? (como por exemplo, } \\
\text { terrenos com atividades de mineração) }\end{array}$ & & & & \\
\hline \multicolumn{2}{|c|}{ 6. Outras considerações } & \multicolumn{3}{|c|}{ Verificação pelo auditor } & Comentários/sugestões dos auditores \\
\hline
\end{tabular}




\begin{tabular}{|c|c|c|c|c|c|}
\hline & & $\begin{array}{c}(\mathbf{X}) \\
\text { Atendido }\end{array}$ & $\begin{array}{c}(\mathbf{X}) \\
\text { Atendido }\end{array}$ & $\begin{array}{l}\text { (X) Atendido } \\
\text { parcialmente }\end{array}$ & \\
\hline \multirow{10}{*}{$\left|\begin{array}{lr}6.1 & \text { Outras } \\
\text { aspectos } & \text { de } \\
\text { segurança } & \text { não } \\
\text { considerações } & \end{array}\right|$} & Foi considerada a possibilidade de inundações? & & & & \\
\hline & $\begin{array}{l}\text { Os cruzamentos ferroviários foram identificados e tratados de forma } \\
\text { adequada? }\end{array}$ & & & & \\
\hline & $\begin{array}{l}\begin{array}{l}\text { Foram consideradas outras distrações visuais (por exemplo, } \\
\text { publicidade, aviões voando baixo etc.). }\end{array} \\
\end{array}$ & & & & \\
\hline & $\begin{array}{l}\text { Considerou a necessidade de áreas de descanso ou estacionamentos } \\
\text { (por exemplo, rotas turísticas, parada de caminhões, áreas para } \\
\text { piquenique ou outras áreas)? }\end{array}$ & & & & \\
\hline & $\begin{array}{l}\text { Foram considerados potenciais atrações na margem da rodovia (por } \\
\text { exemplo, vendedores)? }\end{array}$ & & & & \\
\hline & $\begin{array}{l}\text { Existem situações especiais de perigo, que podem afetar aa } \\
\text { segurança do projeto proposto? }\end{array}$ & & & & \\
\hline & $\begin{array}{l}\text { Todos os pedestres que podem ser adversamente afetados pelo } \\
\text { projeto foram considerados? (Por exemplo, crianças em idade } \\
\text { escolar, idosos)? }\end{array}$ & & & & \\
\hline & $\begin{array}{l}\text { Os problemas de segurança ou acidentes de trânsito da rede } \\
\text { rodoviária adjacentes foram considerados no projeto proposto? }\end{array}$ & & & & \\
\hline & $\begin{array}{l}\text { O fornecimento de energia para a iluminação da rodovia foi } \\
\text { considerado no projeto? }\end{array}$ & & & & \\
\hline & Existem outros problemas que podem afetar a segurança da rodovia? & & & & \\
\hline
\end{tabular}




\section{APÊNDICE E2 - INSTRUENTO DE ASV - PROJETO BÁSICO - VERSÃO FINAL}

\section{Identificação do projeto:}

\section{Data da auditoria:}

\section{Localização do estudo de viabilidade e extensão:}

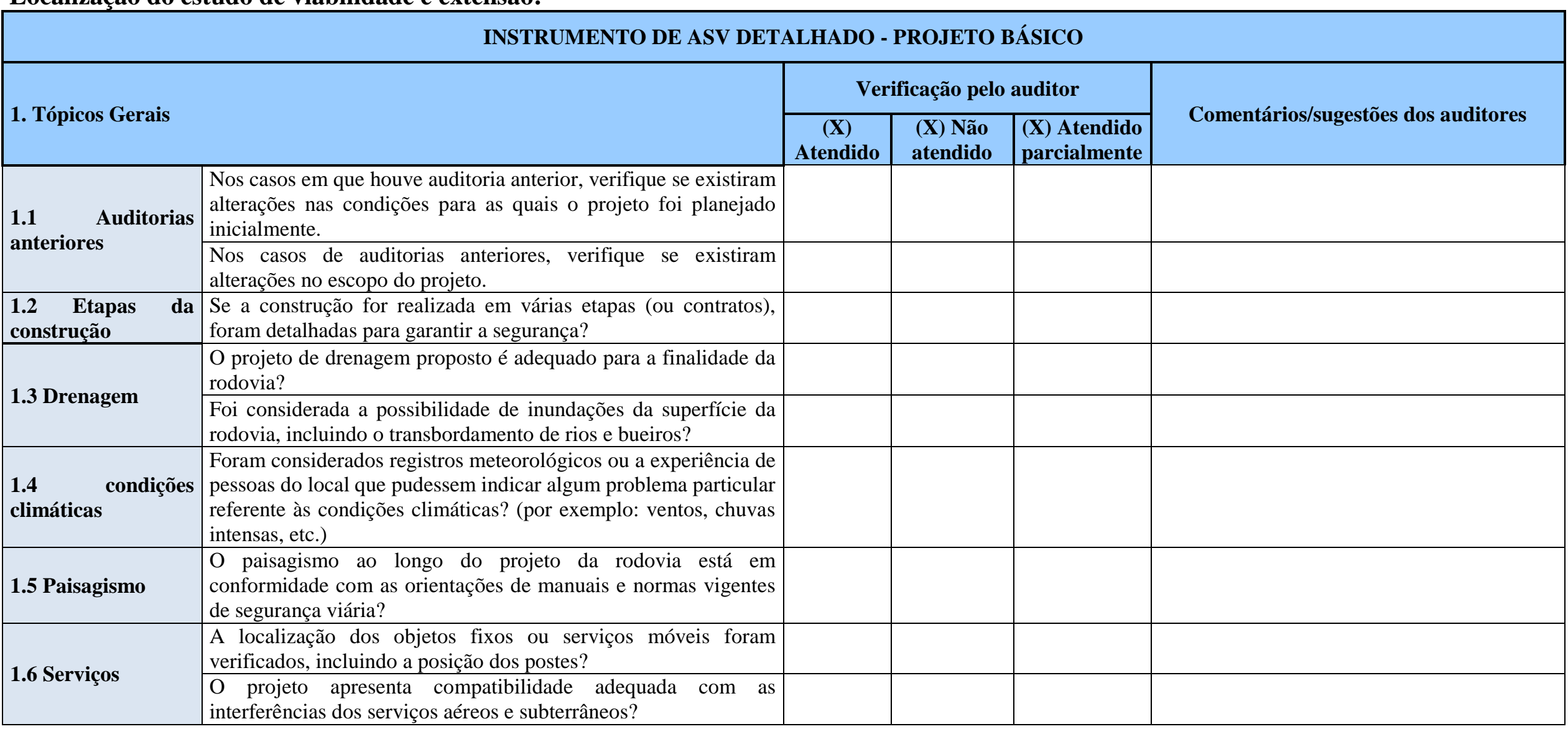




\begin{tabular}{|c|c|c|c|c|c|}
\hline \multirow{2}{*}{$\begin{array}{ll}1.7 \quad \text { Acessos } & \text { de } \\
\text { veículos } & \text { de } \\
\text { emergência } & \end{array}$} & $\begin{array}{l}\text { o projeto prevê o acesso seguro e circulação de veículos de } \\
\text { emergência? (como por exemplo, caminhão dos bombeiros?). }\end{array}$ & & & & \\
\hline & $\begin{array}{l}\text { A concepção e execução do projeto de barreiras de canteiros } \\
\text { centrais permitem que veículos de emergência possam parar e } \\
\text { retornar por caminhos sem interrupção do tráfego? }\end{array}$ & & & & \\
\hline \multirow{4}{*}{$\begin{array}{l}1.8 \text { Acesso e áreas } \\
\text { adjacentes }\end{array}$} & $\begin{array}{l}\text { Existem fatores à montante ou à jusante que poderão afetar o } \\
\text { acesso à rodovia, principalmente próximo à interseções? }\end{array}$ & & & & \\
\hline & $\begin{array}{l}\text { Os futuros acessos poderão ser usados com segurança, } \\
\text { considerando as entradas, saídas e junções com a rodovia? }\end{array}$ & & & & \\
\hline & $\begin{array}{l}\text { Os acessos às áreas para descanso e estacionamento de caminhões } \\
\text { têm distância de visibilidade adequada? }\end{array}$ & & & & \\
\hline & $\begin{array}{l}\text { A percepção dos motoristas poderá ser afetada pelos efeitos de } \\
\text { luzes refletidas a partir das rodovias adjacentes? }\end{array}$ & & & & \\
\hline \multirow{2}{*}{$\begin{array}{l}1.9 \text { ampliações } \\
\text { futuras }\end{array}$} & $\begin{array}{l}\text { Se o projeto representa ampliação de uma seção da rodovia, o } \\
\text { projeto é adequado e seguro para ser entendido pelos motoristas? } \\
\text { (casos de obras de melhoramentos) }\end{array}$ & & & & \\
\hline & $\begin{array}{l}\text { É segura a transição entre uma rodovia de pista simples e de pista } \\
\text { dupla e vice-versa? }\end{array}$ & & & & \\
\hline \multirow[b]{2}{*}{$\begin{array}{l}1.10 \text { Etapas do } \\
\text { projeto }\end{array}$} & $\begin{array}{l}\text { Será que os planos e programas de construção podem ser } \\
\text { modificados para melhorar o nível de segurança do projeto? }\end{array}$ & & & & \\
\hline & $\begin{array}{l}\text { Os planos e programas de construção incluem medidas de } \\
\text { segurança especificas como sinalização, transições geométricas } \\
\text { adequadas, etc. para um plano temporário? }\end{array}$ & & & & \\
\hline 1.11 Manutenção & $\begin{array}{l}\text { Os veículos de manutenção podem ser localizados de forma } \\
\text { segura? }\end{array}$ & & & & \\
\hline \multirow[b]{2}{*}{ 2. Geometria } & & \multicolumn{3}{|c|}{ Verificação pelo auditor } & Comentários / sugestões dos auditores \\
\hline & & $\begin{array}{c}\mathbf{X}) \\
\text { Atendido }\end{array}$ & $\begin{array}{l}\text { (X) Não } \\
\text { atendido }\end{array}$ & \begin{tabular}{|l|} 
(X) Atendido \\
parcialmente
\end{tabular} & \\
\hline \multirow{2}{*}{$\begin{array}{l}2.1 \text { Padrões gerais } \\
\text { do projeto }\end{array}$} & $\begin{array}{l}\text { A velocidade de projeto e a velocidade a ser regulamentada são } \\
\text { apropriadas para o projeto proposto? }\end{array}$ & & & & \\
\hline & $\begin{array}{l}\text { O projeto considerou os tipos de veículos para os quais está } \\
\text { previsto o seu uso? }\end{array}$ & & & & \\
\hline $\begin{array}{l}2.2 \text { Seleção do } \\
\text { traçado }\end{array}$ & $\begin{array}{l}\text { O veiculo de projeto foi utilizado e apropriado para o projeto } \\
\text { proposto? }\end{array}$ & & & & \\
\hline
\end{tabular}




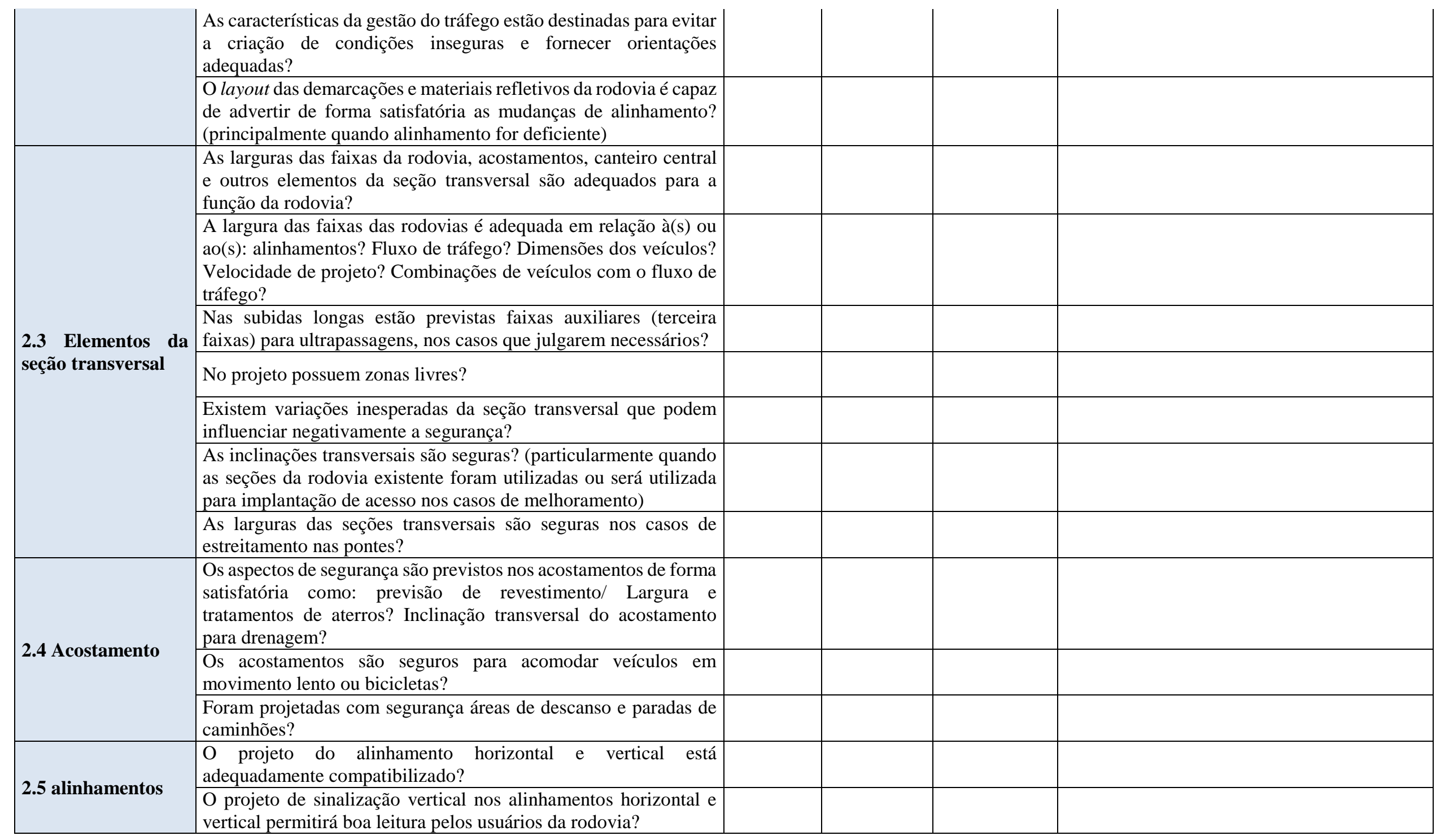




\begin{tabular}{|c|c|c|c|c|c|}
\hline & $\begin{array}{l}\text { O alinhamento horizontal e vertical é compatível com a velocidade } \\
\text { regulamentada?". }\end{array}$ & & & & \\
\hline \multirow{4}{*}{$\begin{array}{l}\text { 2.6 Distância de } \\
\text { visibilidade }\end{array}$} & $\begin{array}{l}\text { Os alinhamentos verticais e horizontais fornecem distância de } \\
\text { visibilidade e visibilidade necessária para a manobra? }\end{array}$ & & & & \\
\hline & $\begin{array}{l}\text { A linha de visibilidade do projeto está desobstruída de elementos } \\
\text { como: defensas, cercas ou divisórias; estrutura de obras de arte; } \\
\text { vegetação, etc. }\end{array}$ & & & & \\
\hline & $\begin{array}{l}\text { Os cruzamentos ferroviários, pontes e outros riscos estão } \\
\text { totalmente visiveis? }\end{array}$ & & & & \\
\hline & $\begin{array}{l}\text { No projeto existe alguma outra característica local que possam } \\
\text { afetar a visibilidade? }\end{array}$ & & & & \\
\hline $\begin{array}{lr}2.7 & \text { Não } \\
\text { conformidade } & \text { com } \\
\text { as normas } & \text { ou } \\
\text { diretrizes } & \\
\end{array}$ & $\begin{array}{l}\text { Foi adotado algum aspecto particular no projeto que não } \\
\text { corresponde às normas, mas com justificativa técnica aceitável? } \\
\text { Porém a segurança foi mantida? }\end{array}$ & & & & \\
\hline \multirow{4}{*}{$\begin{array}{l}2.8 \text { interface entre } 0 \\
\text { projeto proposto e } \\
\text { rodovia existente }\end{array}$} & $\begin{array}{l}\text { A ligação entre o projeto proposto e rodovia existente ocorre em } \\
\text { zonas de perigo como parte superior de curva vertical, eixo } \\
\text { horizontal, perigos na margem da rodovia ou áreas de baixa } \\
\text { visibilidade? }\end{array}$ & & & & \\
\hline & $\begin{array}{l}\text { Nos casos em que as características das faixas da rodovia possuem } \\
\text { variação, a mudança é efetuada com segurança? }\end{array}$ & & & & \\
\hline & $\begin{array}{l}\text { É segura a transição entre os ambientes rodoviários como áreas } \\
\text { rurais e urbanas, ou lugares sem iluminação? }\end{array}$ & & & & \\
\hline & $\begin{array}{l}\text { Na ligação da rodovia projetada com a existente, considerou a } \\
\text { necessidade de pré sinalização? }\end{array}$ & & & & \\
\hline \multirow{2}{*}{$\begin{array}{l}2.9 \text { Legibilidde do } \\
\text { alinhamento }\end{array}$} & $\begin{array}{l}\text { O traçado, função e outras características da rodovia serão } \\
\text { reconhecidos pelos usuários com antencedência? }\end{array}$ & & & & \\
\hline & $\begin{array}{l}\text { As velocidades de aproximação são adequadas e os motoristas } \\
\text { podem ser guiados corretamente pela rodovia? }\end{array}$ & & & & \\
\hline \multirow{2}{*}{\multicolumn{2}{|c|}{ 3. Interseções }} & \multicolumn{3}{|c|}{ Verificação pelo auditor } & Comentários / sugestões dos auditores \\
\hline & & $\begin{array}{c}\mathbf{X}) \\
\text { Atendido } \\
\end{array}$ & $\begin{array}{l}\text { (X) Não } \\
\text { atendido }\end{array}$ & $\begin{array}{l}\text { (X) Atendido } \\
\text { parcialmente }\end{array}$ & \\
\hline 3.1 Tipo e distribuiçã & io $\begin{array}{l}\text { Os tipos de interseções selecionadas são adequados para a } \\
\text { função da rodovia projetada? }\end{array}$ & & & & \\
\hline
\end{tabular}




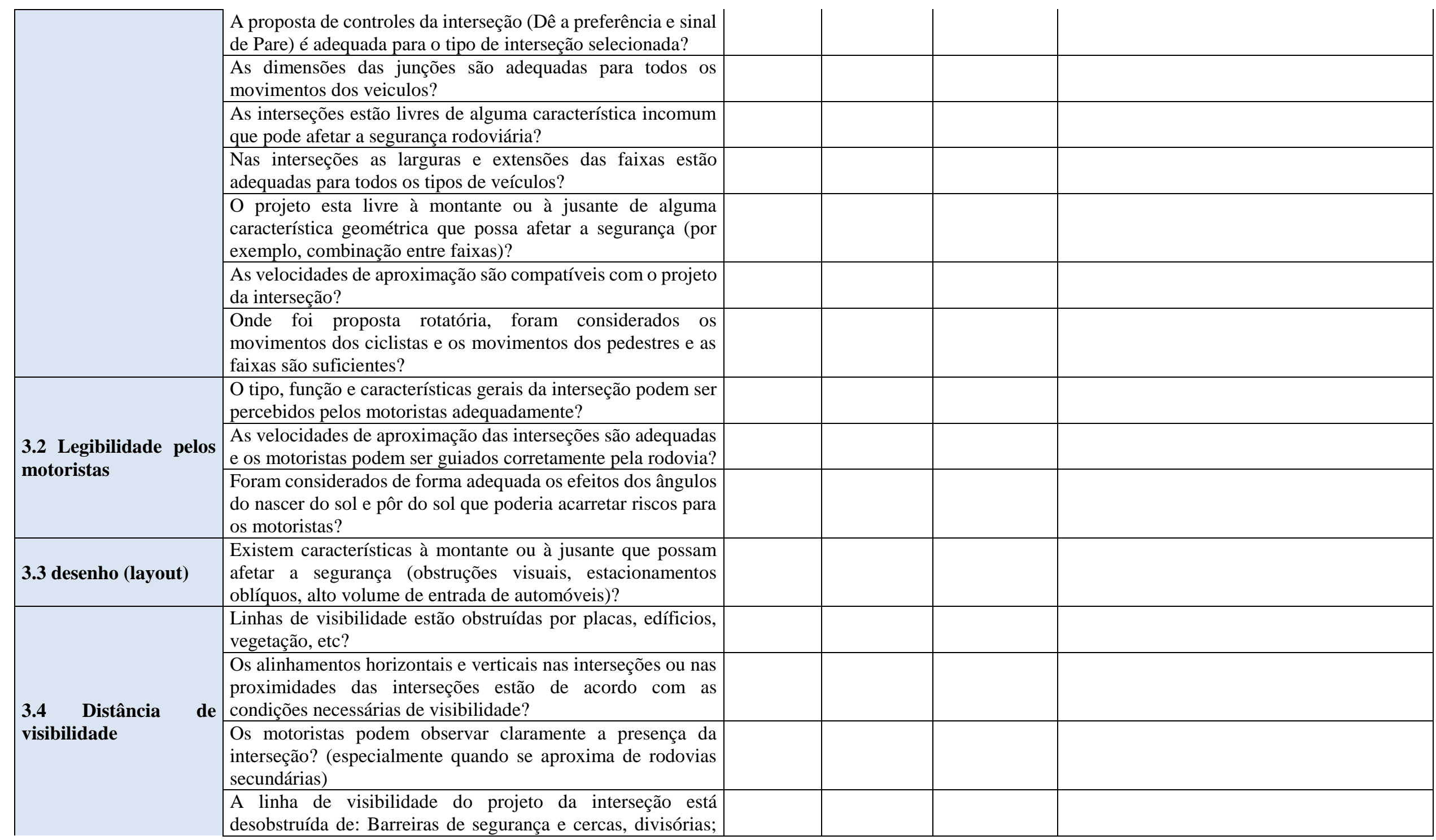




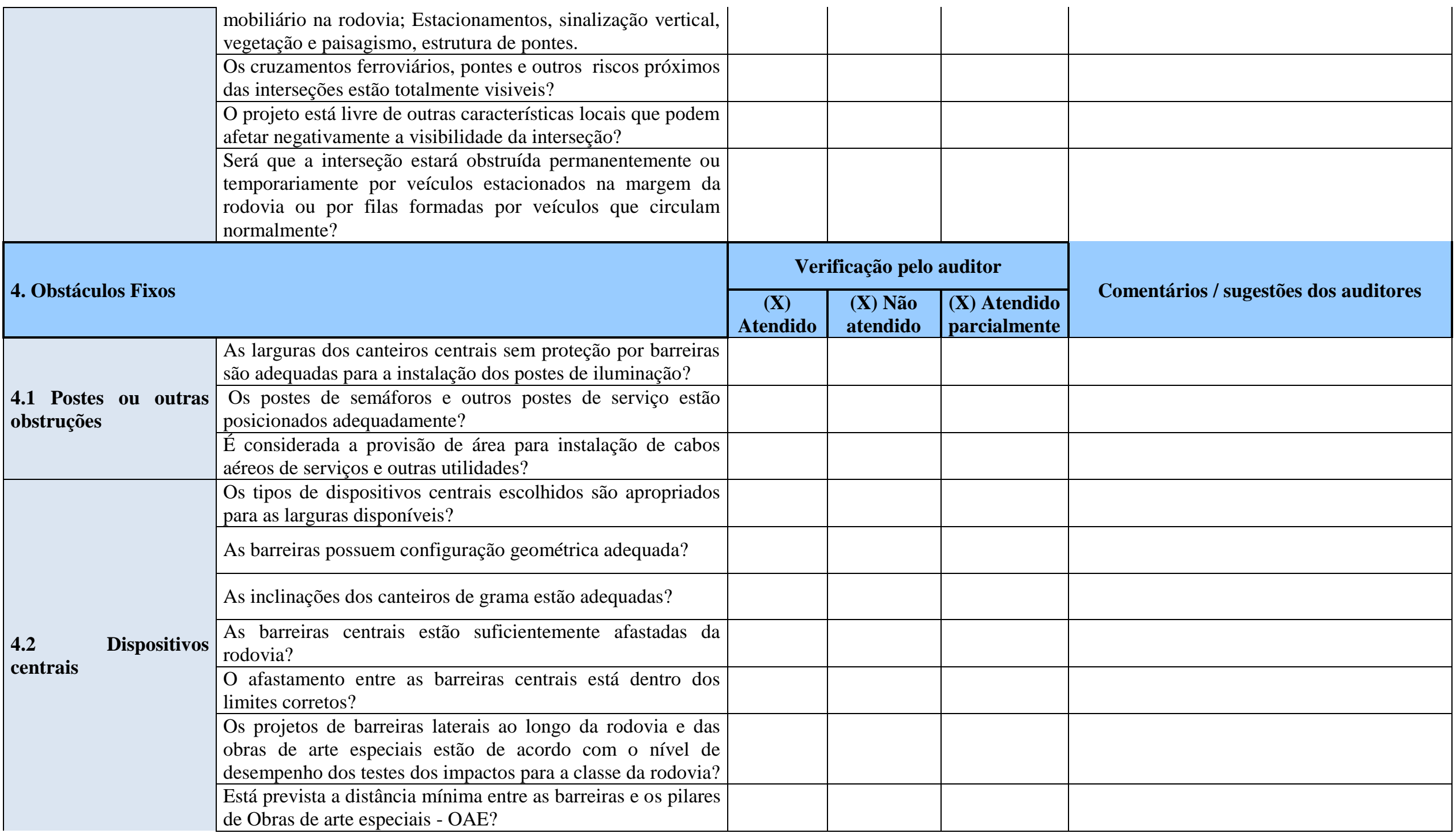




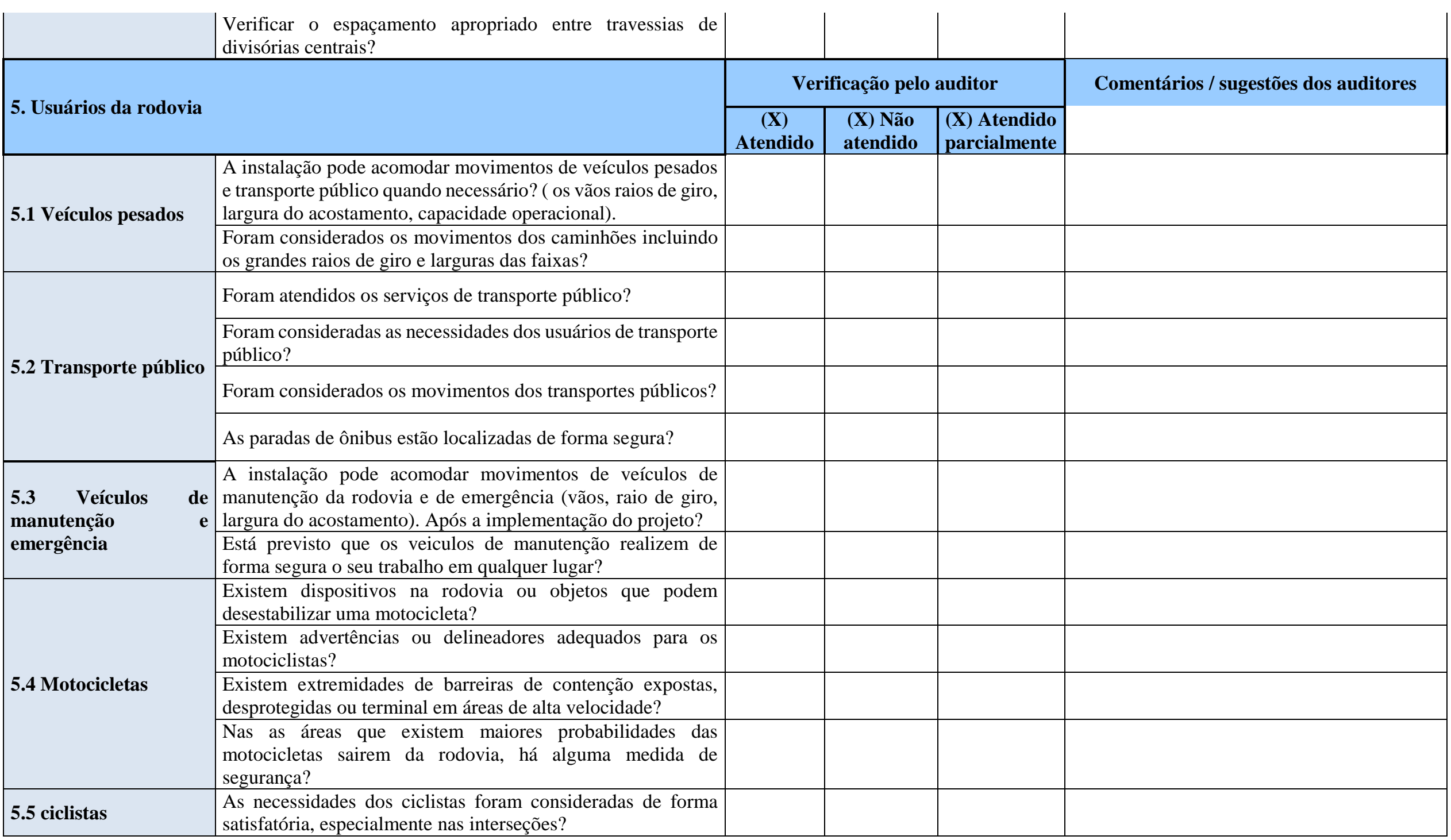




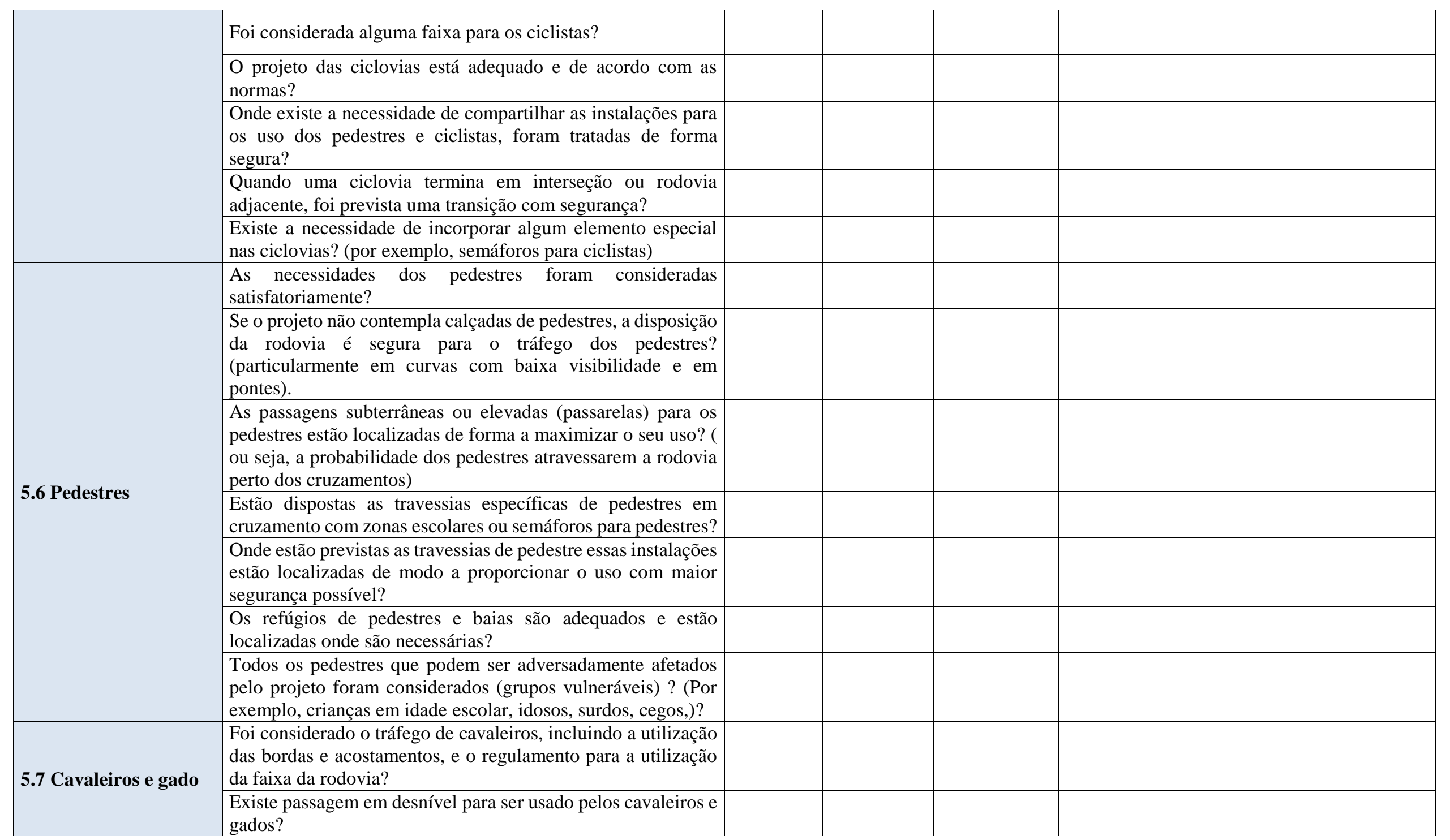




\begin{tabular}{|c|c|c|c|c|c|}
\hline \multirow{2}{*}{\multicolumn{2}{|c|}{ 6. Sinalização e iluminação }} & \multicolumn{3}{|c|}{ Verificação pelo auditor } & \multirow[t]{2}{*}{ Comentários / sugestões dos auditores } \\
\hline & & \multirow[t]{2}{*}{$\begin{array}{c}(\mathrm{X}) \\
\text { Atendido } \\
\end{array}$} & \multirow[t]{2}{*}{$\begin{array}{l}\text { (X) Não } \\
\text { atendido }\end{array}$} & \multirow[t]{2}{*}{\begin{tabular}{|l|} 
(X) Atendido \\
parcialmente \\
\end{tabular}} & \\
\hline \multirow{3}{*}{$\begin{array}{l}\text { 6.1 Sinalização } \\
\text { horizontal }\end{array}$} & $\begin{array}{|lllll|}\begin{array}{l}\text { A demarcação } \\
\text { adequadamente? }\end{array} & \text { e delimitação } & \text { estão } & \text { padronizadas } \\
\end{array}$ & & & & \\
\hline & $\begin{array}{l}\text { A demarcação proposta é compativel com a demarcação das } \\
\text { rodovias adjacentes ou contíguas? }\end{array}$ & & & & \\
\hline & $\begin{array}{l}\text { As demarcações pré-existentes e/ou adjacentes podem ser } \\
\text { melhoradas? Se não realizar as melhorias e manutenções, a } \\
\text { segurança poderá ser mantida? }\end{array}$ & & & & \\
\hline \multirow{8}{*}{ 6.2 Sinalização Vertical } & As sinalizações verticais estão bem posicionadas? & & & & \\
\hline & $\begin{array}{l}\text { Estão localizadas de modo que podem ser observadas e lidas } \\
\text { em tempo adequado? }\end{array}$ & & & & \\
\hline & As sinalizações verticais são facilmente entendidas? & & & & \\
\hline & $\begin{array}{l}\text { As sinalizações verticais estão instaladas de modo que a } \\
\text { visibilidade dos acessos para as interseções esteja mantida? }\end{array}$ & & & & \\
\hline & $\begin{array}{l}\text { As sinalizações verticais são adequadas para as necessidades } \\
\text { do condutor? (por exemplo, sinalização de destino, velocidade } \\
\text { máxima, etc) }\end{array}$ & & & & \\
\hline & $\begin{array}{l}\text { Os postes da sinalização vertical têm consequências de } \\
\text { segurança para os veículos em caso de colisões? }\end{array}$ & & & & \\
\hline & $\begin{array}{l}\text { As localizações das sinalizações veriticais mantêm a distância } \\
\text { de visibilidade dos condutores? }\end{array}$ & & & & \\
\hline & $\begin{array}{l}\text { Nos casos em que a sinalização vertical está instalada em zona } \\
\text { livre, os postes desta sinalização são colpsiveis, há necessidade } \\
\text { de possiveis proteção com barreiras rígidas? }\end{array}$ & & & & \\
\hline \multirow{3}{*}{ 6.3 Iluminação } & $\begin{array}{l}\text { Há projeto de iluminação? Caso não tenha o projeto de } \\
\text { iluminação, haverá problemas de segurança? }\end{array}$ & & & & \\
\hline & $\begin{array}{l}\text { O projeto terá seções com problemas de iluminação? (por } \\
\text { exemplo, sombras de árvores ou pontes). }\end{array}$ & & & & \\
\hline & $\begin{array}{l}\text { A localização dos postes de iluminação foi considerada como } \\
\text { parte do conceito geral do projeto? }\end{array}$ & & & & \\
\hline
\end{tabular}




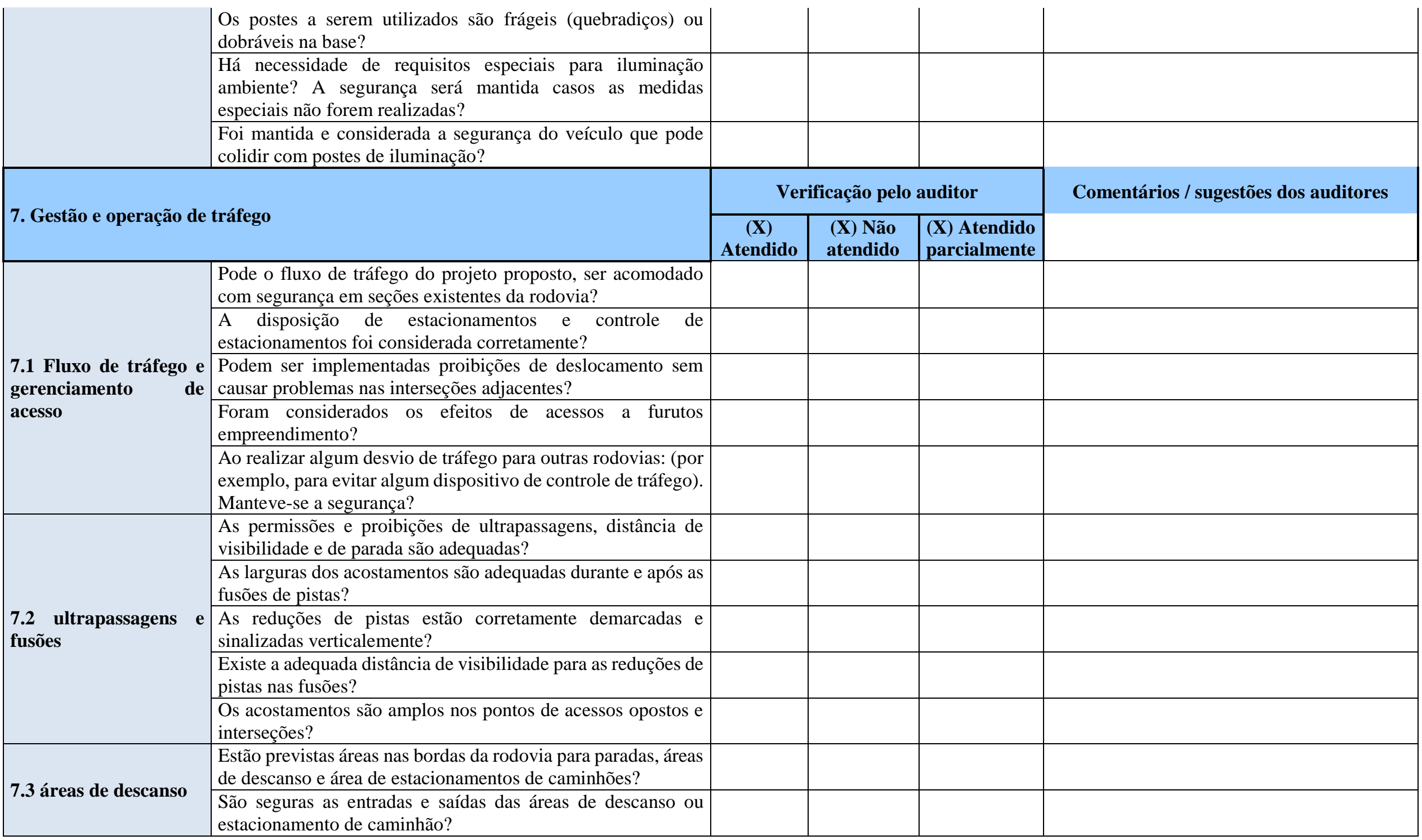




\begin{tabular}{|c|c|c|c|c|c|}
\hline \multirow{3}{*}{$\begin{array}{l}7.4 \text { construção e } \\
\text { operação }\end{array}$} & $\begin{array}{l}\text { Se o projeto for construído "sob tráfego", pode ser feito com } \\
\text { segurança? }\end{array}$ & & & & \multirow{5}{*}{ Comentários / sugestões dos auditores } \\
\hline & $\begin{array}{l}\text { O projeto pode ser construido de forma segura? Os requisitos } \\
\text { de manutenção foram considerados adequadamente? }\end{array}$ & & & & \\
\hline & $\begin{array}{l}\begin{array}{l}\text { É seguro o acesso de veículos para executar os trabalhos } \\
\text { (obras)? }\end{array} \\
\end{array}$ & & & & \\
\hline \multirow{2}{*}{\multicolumn{2}{|c|}{ 8. Perguntas adicionais }} & \multicolumn{3}{|c|}{ Verificação pelo auditor } & \\
\hline & & \begin{tabular}{|c|}
$(\mathbf{X})$ \\
Atendido \\
\end{tabular} & $\begin{array}{l}\text { (X) Não } \\
\text { atendido }\end{array}$ & $\begin{array}{l}\text { (X) Atendido } \\
\text { parcialmente }\end{array}$ & \\
\hline \multirow{4}{*}{$\begin{array}{l}8.1 \quad \text { Alinhamento } \\
\text { horizontal }\end{array}$} & $\begin{array}{l}\text { É adequada a visibilidade dos motoristas e pedestres nos } \\
\text { acessos propostos? }\end{array}$ & & & & \\
\hline & $\begin{array}{l}\text { é adequado o espaço previsto para mudança de fluxo e } \\
\text { velocidade de tráfego? }\end{array}$ & & & & \\
\hline & Os raios de curva possuem visibilidade adequada? & & & & \\
\hline & A distância de visibilidade e parada é adequada? & & & & \\
\hline $\begin{array}{ll}8.2 & \text { Alinhamento } \\
\text { vertical } & \end{array}$ & A distância de visibilidade e parada é adequada? & & & & \\
\hline \multirow{3}{*}{$\begin{array}{l}8.3 \quad \text { áreas } \\
\text { estacionamento }\end{array}$} & $\begin{array}{l}\text { O estacionamento no local está adequado para evitar que os } \\
\text { veículos estacionem na rodovia com risco associado a ele? }\end{array}$ & & & & \\
\hline & $\begin{array}{l}\text { Os estacionamentos estão localizados em áreas seguras? Se } \\
\text { não, foram previstas medidas para evitar isso? }\end{array}$ & & & & \\
\hline & $\begin{array}{l}\text { É adequado o espaço previsto nas áreas de estacionamento } \\
\text { para circulação e distância de visibilidade da interseção? }\end{array}$ & & & & \\
\hline \multirow{3}{*}{ 8.4 Serviços } & São adequadas as áreas de carga e descarga da rodovia? & & & & \\
\hline & $\begin{array}{l}\text { As manobras dos veículos grandes foram previstas em lugares } \\
\text { seguros? }\end{array}$ & & & & \\
\hline & Os acessos para os veículos de emergência são adequados & & & & \\
\hline \multirow{2}{*}{$\begin{array}{l}\text { 8.5 Sinalização vertical } \\
\text { e sinalização horizontal }\end{array}$} & $\begin{array}{l}\text { Está definida claramente a prioridade de todas as interseções, } \\
\text { nos pátios dos estacionamentos e vias de acesso? }\end{array}$ & & & & \\
\hline & $\begin{array}{l}\text { A sinalização vertical e demacações serão visiveis em todas as } \\
\text { condições? (incluindo dia, noite, chuca, neblina, etc?) }\end{array}$ & & & & \\
\hline
\end{tabular}




\begin{tabular}{|c|c|c|c|c|c|}
\hline \multirow{2}{*}{ 8.6 Paisagismo } & $\begin{array}{l}\text { A paisagem mantém a visibilidade nas interseções, curvas, } \\
\text { acessos e localizações de pedestres? }\end{array}$ & & & & \\
\hline & $\begin{array}{l}\text { Foi evitada a plantação de vegetação em lugares onde os } \\
\text { veículos podem sair da rodovia? }\end{array}$ & & & & \\
\hline \multirow{6}{*}{8.7 gestão de tráfego } & $\begin{array}{l}\text { Foram considerados efeitos adversos em alguma área do } \\
\text { projeto? }\end{array}$ & & & & \\
\hline & O projeto vai manter a velocidade de projeto de forma segura? & & & & \\
\hline & $\begin{array}{l}\text { O número e a localização dos acessos são adequados para o } \\
\text { projeto proposto? }\end{array}$ & & & & \\
\hline & $\begin{array}{l}\text { Há instalações para os serviços de transporte públicos? E estão } \\
\text { localizados em lugares seguros e justificados? }\end{array}$ & & & & \\
\hline & $\begin{array}{l}\text { Existem instalações para os ciclistas? Estão localizadas de } \\
\text { forma segura a respeito dos movimentos dos veiculos? }\end{array}$ & & & & \\
\hline & $\begin{array}{l}\text { Existem instalações para os pedestres? Estão localizadas em } \\
\text { lugares seguros e adequados? }\end{array}$ & & & & \\
\hline \multirow{3}{*}{8.8 Outros } & No projeto está prevista iluminação pública? É adequada? & & & & \\
\hline & \begin{tabular}{|l}
$\begin{array}{l}\text { Há riscos na margem da rodovia? } \\
\text { corretamente? }\end{array}$ \\
Foram tratados \\
\end{tabular} & & & & \\
\hline & \begin{tabular}{|lrllll}
$\begin{array}{l}\text { Os pedestres podem acessar de forma } \\
\text { desenvolvimento urbano proposto? }\end{array}$ & segura & o \\
\end{tabular} & & & & \multirow{3}{*}{ Comentários / sugestões dos auditores } \\
\hline \multirow[b]{2}{*}{ 9. Outra considerações } & & \multicolumn{3}{|c|}{ Verificação pelo auditor } & \\
\hline & & $\begin{array}{c}(\mathbf{X}) \\
\text { Atendido } \\
\end{array}$ & $\begin{array}{l}\text { (X) Não } \\
\text { atendido }\end{array}$ & $\begin{array}{l}\text { (X) Atendido } \\
\text { parcialmente }\end{array}$ & \\
\hline \multirow{4}{*}{$\begin{array}{l}9.1 \text { Outros aspectos de } \\
\text { segurança não } \\
\text { abordado }\end{array}$} & \begin{tabular}{|lll} 
Há situações especiais? Foram consideradas situações \\
incomuns ou de perigo?
\end{tabular} & & & & \\
\hline & $\begin{array}{l}\text { A rodovia é capaz de suportar com segurança a circulação de } \\
\text { veículos de grande porte, caminhões, ônibus, veiculos de } \\
\text { emergência, veículos de manutenção da rodovia? }\end{array}$ & & & & \\
\hline & $\begin{array}{l}\text { Se necessário, a rodovia pode ser fechada para eventos } \\
\text { especiais de forma segura? }\end{array}$ & & & & \\
\hline & $\begin{array}{l}\text { Se for o caso, os requisitos especiais de paisagem e rotas } \\
\text { turisticas são satisfeitos? }\end{array}$ & & & & \\
\hline
\end{tabular}




\section{APÊNDICE E3 - INSTRUMENTO DE ASV - PROJETO EXECTIVO - VERSÃO FINAL}

\section{Identificação do Projeto:}

\section{Data da auditoria:}

\section{Localização do estudo de viabilidade e extensão:}

\begin{tabular}{|c|c|c|c|c|c|}
\hline \multirow[b]{2}{*}{ 1. Tópicos Gerais } & & \multicolumn{3}{|c|}{ Verificação pelo auditor } & \multirow[b]{2}{*}{ Comentários / sugestões dos auditores } \\
\hline & & $\begin{array}{c}(\mathbf{X}) \\
\text { Atendido }\end{array}$ & $\begin{array}{l}(\mathbf{X}) \text { Não } \\
\text { atendido }\end{array}$ & $\begin{array}{l}\text { (X) Atendido } \\
\text { parcialmente }\end{array}$ & \\
\hline \multirow{2}{*}{$\begin{array}{l}\text { 1.1 Auditorias } \\
\text { anteriores }\end{array}$} & $\begin{array}{l}\text { Nos casos em que houve auditorias anteriores, verifique se existiram } \\
\text { alterações nas condições para que o projeto foi planejado } \\
\text { inicialmente. }\end{array}$ & & & & \\
\hline & $\begin{array}{l}\text { Nos casos de auditorias anteriores, verifique se existiram alterações } \\
\text { no escopo do projeto. }\end{array}$ & & & & \\
\hline \multirow[t]{2}{*}{$\begin{array}{l}1.2 \text { Etapas da } \\
\text { construção }\end{array}$} & $\begin{array}{l}\text { Se o projeto for ser construído ou implementado em diferentes fases: } \\
\text { a) Foram detalhas adequadamente para garantir a segurança? b) As } \\
\text { fases de construção são seguras? c) Existem medidas para acomodar } \\
\text { a gestão de tráfego temporário entre as diferentes fases? }\end{array}$ & & & & \\
\hline & $\begin{array}{l}\text { Se a construção for realizada em vários contratos, eles serão } \\
\text { realizados de forma segurança? }\end{array}$ & & & & \\
\hline \multirow{4}{*}{ 1.3 Drenagem } & $\begin{array}{l}\text { O projeto de drenagem proposto é adequado para a finalidade da } \\
\text { rodovia? }\end{array}$ & & & & \\
\hline & $\begin{array}{l}\text { A inclinação longitudinal e transversal está adequada para uma } \\
\text { drenagem satisfatória? }\end{array}$ & & & & \\
\hline & $\begin{array}{l}\text { Nas seções em tangentes o projeto de drenagem proposto está } \\
\text { compatível com os projetos de início e final das curvas? }\end{array}$ & & & & \\
\hline & $\begin{array}{l}\text { Foi considerada a possibilidade de inundações da superficie da } \\
\text { rodovia, incluindo o transbordamento dos rios e bueiros? }\end{array}$ & & & & \\
\hline $\begin{array}{l}\text { 1.4 Condições } \\
\text { climáticas }\end{array}$ & $\begin{array}{l}\text { Foram considerados registros meteorológicos ou a experiência de } \\
\text { pessoas do local que pudessem indicar algum problema particular } \\
\text { referente às condições climáticas? (por exemplo: ventos, chuvas } \\
\text { intensas, etc.) }\end{array}$ & & & & \\
\hline
\end{tabular}




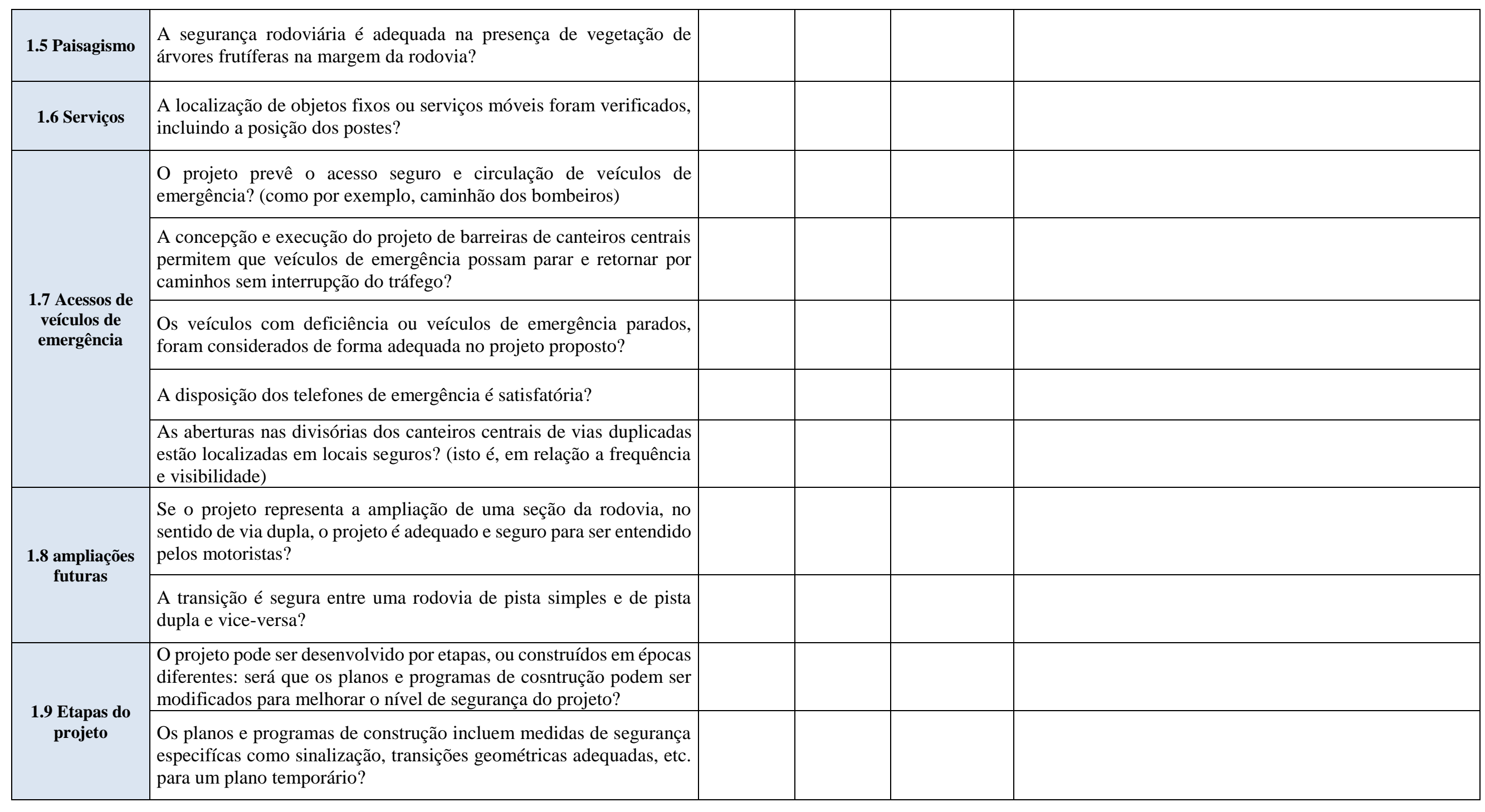




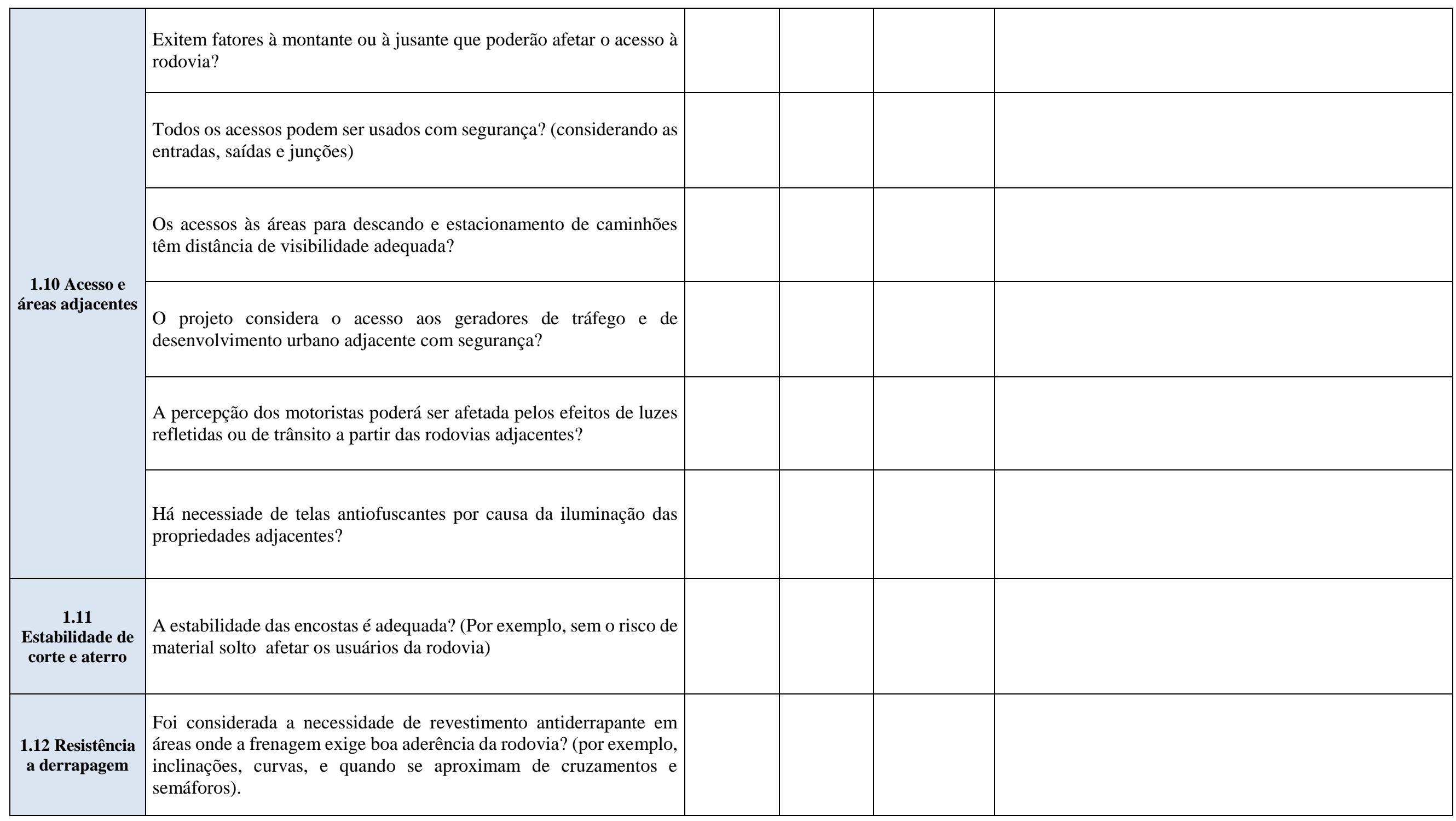




\begin{tabular}{|c|c|c|c|c|c|}
\hline \multirow{2}{*}{ 2. Geometria } & & \multicolumn{3}{|c|}{ Verificação pelo auditor } & \multirow[b]{2}{*}{ Comentários / sugestões dos auditores } \\
\hline & & $\begin{array}{c}(\mathbf{X}) \\
\text { Atendido }\end{array}$ & $\begin{array}{l}\text { (X) Não } \\
\text { atendido }\end{array}$ & $\begin{array}{l}\text { (X) Atendido } \\
\text { parcialmente }\end{array}$ & \\
\hline \multirow{13}{*}{$\begin{array}{l}\text { 2.1 Elementos } \\
\text { da seção } \\
\text { transversal }\end{array}$} & $\begin{array}{l}\text { As larguras das faixas, acostamentos, canteiro central e outros } \\
\text { elementos da seção transversal são adequados para a função da } \\
\text { rodovia? (seção típica) }\end{array}$ & & & & \\
\hline & $\begin{array}{l}\text { A largura das faixas das rodovias e dos acostamentos é adequada a } \\
\text { respesito à(s) ou ao(s): alinhamentos? Fluxo de tráfego? Dimensões } \\
\text { dos veículos? Velocidade de projeto? Combinações de veículos com } \\
\text { o fluxo de tráfego? }\end{array}$ & & & & \\
\hline & $\begin{array}{l}\text { A largura dos acostamentos está adequada para acomodar veículos } \\
\text { quebrados ou de emergência? }\end{array}$ & & & & \\
\hline & $\begin{array}{l}\text { A largura do canteiro central é adequada para localizar os mobiliarios } \\
\text { da rodovia? }\end{array}$ & & & & \\
\hline & $\begin{array}{l}\text { A superelevação é compatível com a velocidade de projeto da } \\
\text { rodovia? }\end{array}$ & & & & \\
\hline & $\begin{array}{l}\text { A inclinação dos acostamentos é segura para a circulação dos } \\
\text { veículos? }\end{array}$ & & & & \\
\hline & $\begin{array}{l}\text { Os veículos (como automóveis e caminhões) manobram de forma } \\
\text { segura devido às inclinações de takudes? }\end{array}$ & & & & \\
\hline & Existem instalações para circulação de pedestres e ciclistas? & & & & \\
\hline & $\begin{array}{l}\text { O projeto proposto está livre de variações em relação à seção } \\
\text { transversal? }\end{array}$ & & & & \\
\hline & $\begin{array}{l}\text { As inclinações transversais são seguras? (particularmente quando as } \\
\text { seções da rodovia existente foram utilizadas ou será utilizada para } \\
\text { implantação de acesso nos casos de melhoramento) }\end{array}$ & & & & \\
\hline & $\begin{array}{l}\text { As curvas com inclinação transversal adversa, estão dentro dos limites } \\
\text { adequados? }\end{array}$ & & & & \\
\hline & A superelevação é compatível em todo o projeto proposto? & & & & \\
\hline & $\begin{array}{l}\text { As larguras das seções transversais são seguras nos casos de } \\
\text { estreitamento nas pontes? }\end{array}$ & & & & \\
\hline
\end{tabular}




\begin{tabular}{|c|c|c|c|c|}
\hline \multirow{7}{*}{$\begin{array}{l}\text { 2.2 Detalhes de } \\
\text { geometria }\end{array}$} & $\begin{array}{l}\text { O layout das demarcações e materiais refletivos da rodovia são } \\
\text { capazes de advertir de forma satisfatória as mudanças de } \\
\text { alinhamento? (principalmente quando alinhamento for deficiente). }\end{array}$ & & & \\
\hline & As faixas de ultrapassagem foram contempladas adequadamente? & & & \\
\hline & $\begin{array}{l}\text { As faixas de ultrapassgens foram previstas e devidamente } \\
\text { sinalizadas? }\end{array}$ & & & \\
\hline & $\begin{array}{l}\text { O projeto pode criar problema de visibilidade para o motorista } \\
\text { produzido pelo nascer do sol ou pôr do sol? }\end{array}$ & & & \\
\hline & Os requisitos de transporte público foram devidamente atendidos? & & & \\
\hline & $\begin{array}{l}\text { As normas de projeto são apropriadas para todos os requisitos do } \\
\text { projeto? }\end{array}$ & & & \\
\hline & $\begin{array}{l}\text { As larguras das faixas e inclinações transversais são consistentes com } \\
\text { as normas e orientações gerais do projeto? }\end{array}$ & & & \\
\hline \multirow{2}{*}{$\begin{array}{c}2.3 \\
\text { Acostamentos }\end{array}$} & $\begin{array}{l}\text { Os aspectos de segurança são previstos nos acostamentos de forma } \\
\text { satisfatória como: previsão de revestimento/ Largura e tratamentos de } \\
\text { aterros? Inclinação transversal do acostamento? }\end{array}$ & & & \\
\hline & $\begin{array}{l}\text { Os acostamentos são seguros para os veículos em movmento lento ou } \\
\text { bicicletas? }\end{array}$ & & & \\
\hline \multirow{4}{*}{$\begin{array}{l}\text { 2.4 Alinhamento } \\
\text { vertical e } \\
\text { horizontal }\end{array}$} & $\begin{array}{l}\text { O projeto de alinhamento horizontal e vertical está compatibilizado } \\
\text { corretamente? }\end{array}$ & & & \\
\hline & Alinhamento vertical é constante e adequado em todos os lugares? & & & \\
\hline & O alinhamento horizontal é constante em todos os lugares? & & & \\
\hline & O alinhamento é compatível com a função da rodovia proposta? & & & \\
\hline
\end{tabular}




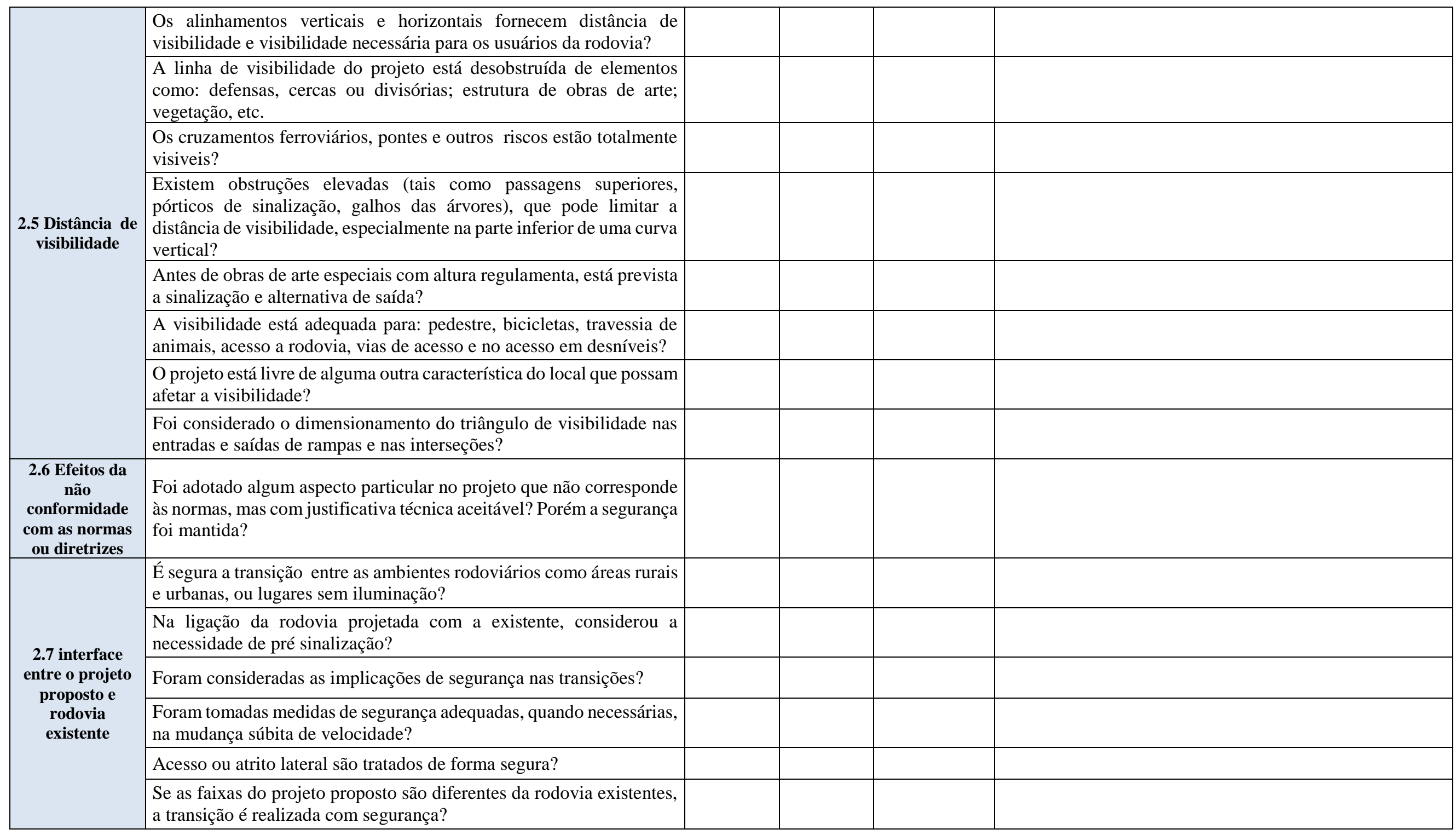




\begin{tabular}{|c|c|c|c|c|c|}
\hline \multirow{2}{*}{$\begin{array}{l}\text { 2.8 Legibilidde } \\
\text { do alinhamento }\end{array}$} & $\begin{array}{l}\text { O traçado, função e características gerais da rodovia será reconhecido } \\
\text { pelos motoristas com antecedência? }\end{array}$ & & & & \\
\hline & $\begin{array}{l}\text { As velocidades de aproximação são adequadas e os motoristas podem } \\
\text { ser guiados corretamente pela rodovia? }\end{array}$ & & & & \\
\hline $\begin{array}{l}2.9 \text { Tratamento } \\
\text { de pontes e } \\
\text { bueiros }\end{array}$ & $\begin{array}{l}\text { A transição geométrica da seção transversal ao entrar na ponte pode } \\
\text { ser realiazada com segurança? }\end{array}$ & & & & \\
\hline $\begin{array}{l}\text { 2.10 Tratamento } \\
\text { ambientais }\end{array}$ & $\begin{array}{l}\text { A segurança rodoviária foi considerada em lugares com determinadas } \\
\text { características ambientais? (por exemplo, painel anti-ruído) }\end{array}$ & & & & \multirow[b]{3}{*}{ Comentários / sugestões dos auditores } \\
\hline \multirow{2}{*}{\multicolumn{2}{|c|}{ 3. Interseções }} & \multicolumn{3}{|c|}{ Verificação pelo auditor } & \\
\hline & & $\begin{array}{c}(\mathbf{X}) \\
\text { Atendido } \\
\end{array}$ & $\begin{array}{r}\text { (X) Não } \\
\text { atendido }\end{array}$ & $\begin{array}{l}\text { (X) Atendido } \\
\text { parcialmente }\end{array}$ & \\
\hline \multirow{9}{*}{$\begin{array}{l}\text { 3.1 Quantidade, } \\
\text { Tipo e } \\
\text { distribuição }\end{array}$} & $\begin{array}{l}\text { Considera-se corretamente à concepção dos veículos de projeto, e } \\
\text { verificou que suas dimensões não terão problemas de segurança em } \\
\text { giros e retornos nas interseções? }\end{array}$ & & & & \\
\hline & $\begin{array}{l}\text { A rodovia projetada poderá receber todos os tipos de veículos que } \\
\text { são esperados? }\end{array}$ & & & & \\
\hline & $\begin{array}{l}\text { Em locais de travessia de pedestres foram previstas os gradis de } \\
\text { pedestres para orientar os pedestres? }\end{array}$ & & & & \\
\hline & $\begin{array}{l}\text { Nas interseções ilhas e sinalização vertical foram projetadas quando } \\
\text { necessárias? }\end{array}$ & & & & \\
\hline & Os veículos podem estacionar perto das interseções com segurança? & & & & \\
\hline & $\begin{array}{l}\text { Entrocamentos e acessos são adequados para todos os movimentos } \\
\text { permitidos dos veículos? }\end{array}$ & & & & \\
\hline & $\begin{array}{l}\text { o layout é seguro para uma combinação incomum ou circunstâncias } \\
\text { especiais de tráfego? }\end{array}$ & & & & \\
\hline & $\begin{array}{l}\text { Os canteiros centrais ou ilhas estão dispostos de forma adequada e } \\
\text { com segurança a respeito dos: veículos e alinhamnetos da rodovia? } \\
\text { Proximidade de semáforos? Capacidade e áreas para pedestres? } \\
\text { Previsto faixa de retorno desejada? Distância de visibilidade de } \\
\text { parada? Ser interrupidas por veículos errantes? }\end{array}$ & & & & \\
\hline & $\begin{array}{l}\text { Nos casos de infraestrutura de linha de transmissão, a alutra dos vãos } \\
\text { foi dimensionado adequadamente? }\end{array}$ & & & & \\
\hline
\end{tabular}




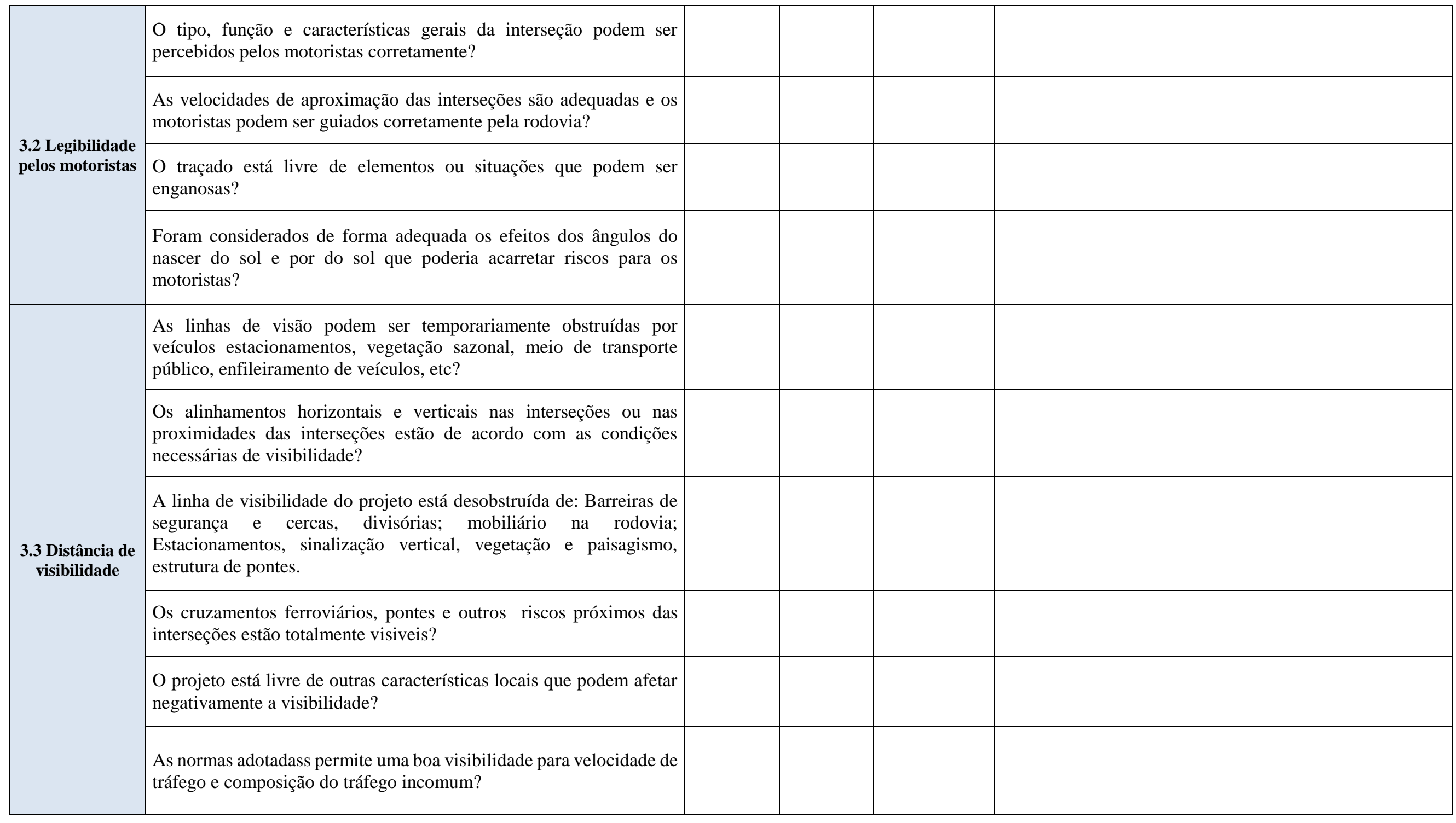




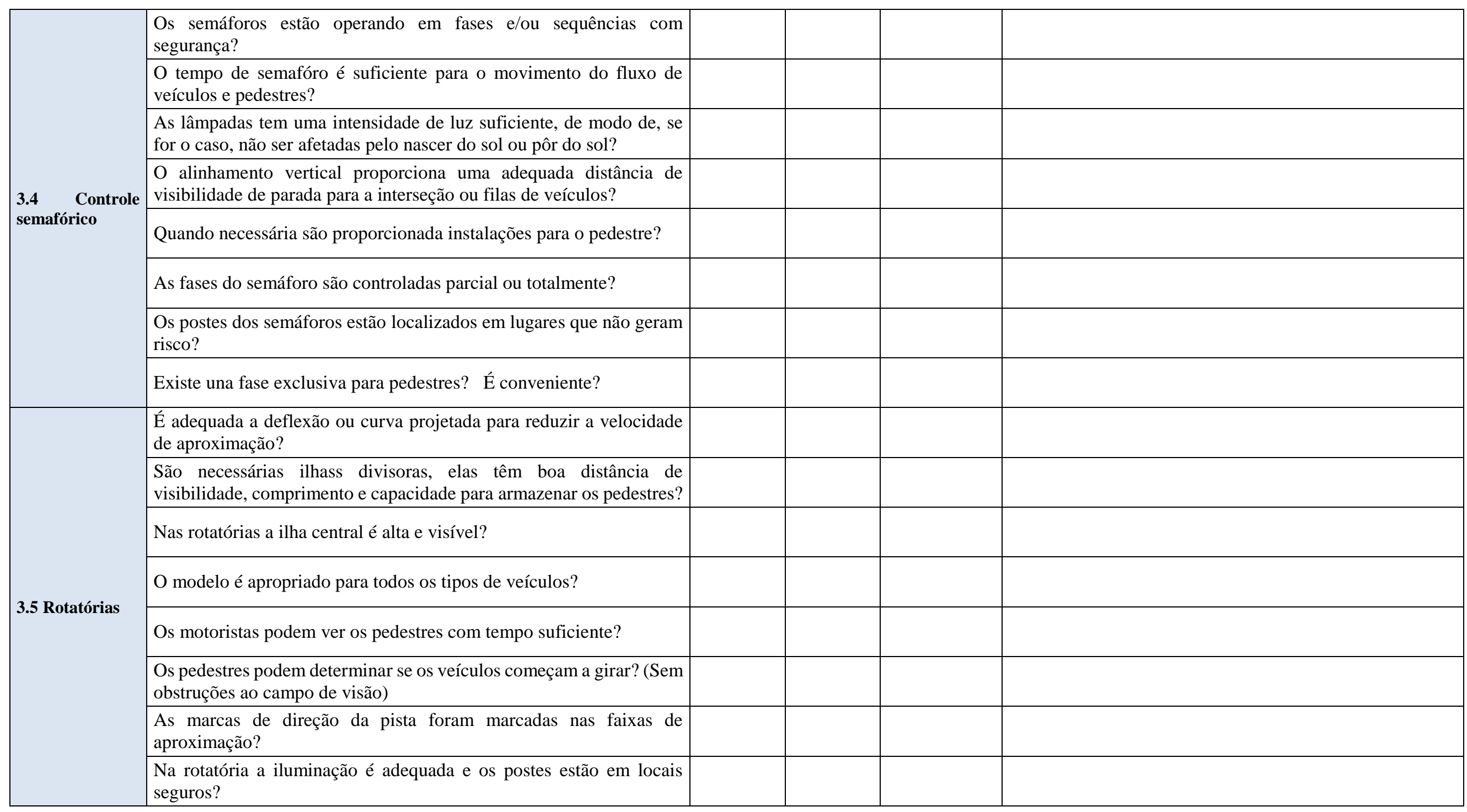




\begin{tabular}{|c|c|c|c|c|c|}
\hline \multirow{2}{*}{$\begin{array}{l}\text { 3.6 Outras } \\
\text { interseções }\end{array}$} & $\begin{array}{l}\text { Nas interseções há necessidade de pintar as bordas das ilhas e } \\
\text { regúgios? }\end{array}$ & & & & \multirow[b]{4}{*}{ Comentários / sugestões dos auditores } \\
\hline & $\begin{array}{l}\text { Os ramos das interseções tem comprimento adequado para acomodar } \\
\text { os veículos? }\end{array}$ & & & & \\
\hline \multirow{2}{*}{\multicolumn{2}{|c|}{ 4. Obstáculos Fixos }} & \multicolumn{3}{|c|}{ Verificação pelo auditor } & \\
\hline & & $\begin{array}{c}(\mathbf{X}) \\
\text { Atendido } \\
\end{array}$ & $\begin{array}{r}\text { (X) Não } \\
\text { atendido }\end{array}$ & $\begin{array}{l}\text { (X) Atendido } \\
\text { parcialmente }\end{array}$ & \\
\hline \multirow{5}{*}{$\begin{array}{l}\text { 4.1 Postes ou } \\
\text { outras } \\
\text { obstruções }\end{array}$} & $\begin{array}{l}\text { Todos os postes estão localizados distantes o suficiente do fluxo de } \\
\text { tráfego? }\end{array}$ & & & & \\
\hline & Postes frágeis ou flexiveis foram previstos quando necessários? & & & & \\
\hline & $\begin{array}{l}\text { A largura dos canteiros centrais é adequada para a instalação dos } \\
\text { postes de iluminação ou árvores? }\end{array}$ & & & & \\
\hline & $\begin{array}{l}\text { A margem da rodovia está livre de outras obstruções que poderiam } \\
\text { criar um risco de segurança? }\end{array}$ & & & & \\
\hline & $\begin{array}{l}\text { Os bueiros na margem da rodovia e canais podem ser atravessados } \\
\text { com segurança por qualquer veículo que possa asair da rodovia? }\end{array}$ & & & & \\
\hline \multirow{2}{*}{$\begin{array}{l}\text { 4.2 Dispositivos } \\
\text { centrais }\end{array}$} & $\begin{array}{l}\begin{array}{l}\text { As barreiras centrais foram consideradas e detalhadas } \\
\text { adequadamente? }\end{array} \\
\end{array}$ & & & & \\
\hline & Os tratamentos finais e terminais foram considerados? & & & & \\
\hline \multirow{5}{*}{$\begin{array}{l}\text { 4.3 Barreiras de } \\
\text { segurança }\end{array}$} & $\begin{array}{l}\text { Sempre que necessário, foram previstas adqudamente barreirass de } \\
\text { contenção? (por exemplo, em aterros, estruturas, árvores, postes, } \\
\text { canais de drenagem, pontes). }\end{array}$ & & & & \\
\hline & $\begin{array}{l}\text { A barreira de contenção é segura? (Ou seja, não cria perigo para os } \\
\text { usuários da rodovia, incluindo pedestres, ciclistas, etc.) }\end{array}$ & & & & \\
\hline & $\begin{array}{l}\text { As extremidades (terminais) das barreiras de contenção são seguras e } \\
\text { satisfatórias? }\end{array}$ & & & & \\
\hline & $\begin{array}{l}\text { A barreira de contenção foi projetada considerando: tratamentos } \\
\text { finais? Largura de trabalho? ancoragem? Espaçamentos dos postes? } \\
\text { Profundidade dos postes? sobreposição da barreira? }\end{array}$ & & & & \\
\hline & $\begin{array}{l}\text { Nos casos em que foram projetadas barreiras de contenção, existe } \\
\text { possivbilidade dessa barreira gerar perigo ao usuário da rodovia? }\end{array}$ & & & & \\
\hline
\end{tabular}




\begin{tabular}{|c|c|c|c|c|c|}
\hline & $\begin{array}{l}\text { Nos locais que está previsto barreiras de contenção, há possibilidade } \\
\text { de circulação de pedestres e ciclistas de forma segura? }\end{array}$ & & & & \\
\hline \multirow{6}{*}{$\begin{array}{l}\text { 4.4 Obra de arte } \\
\text { especial - OAE, } \\
\text { Bueiros e outros }\end{array}$} & $\begin{array}{l}\text { As barreiras de conteção das OAE, extremidades de bueiros são } \\
\text { seguros no que tange a visibilidade? }\end{array}$ & & & & \\
\hline & Os corrimãos das pontes estão a um nível correto e bastante firme? & & & & \\
\hline & $\begin{array}{l}\text { A largura dos acostamentos das pontes é ígual ao resto das faixas da } \\
\text { rodovia? }\end{array}$ & & & & \\
\hline & $\begin{array}{l}\text { É seguro o espaço para o trânsito de veiculos não motorizado sobre a } \\
\text { ponte? (por exemplo, pedestres, bicicletas, cavalos, etc.) }\end{array}$ & & & & \\
\hline & $\begin{array}{l}\text { As saídas dos bueiros representam algum risco para os condutores que } \\
\text { podem sair da rodovia? }\end{array}$ & & & & \\
\hline & $\begin{array}{l}\text { As rodoviass com eminência de inundações têm adequada sinalização } \\
\text { e distância de visibilidade? }\end{array}$ & & & & \\
\hline \multirow{2}{*}{\multicolumn{2}{|c|}{ 5. Usuários da Rodovia }} & \multicolumn{3}{|c|}{ Verificação pelo auditor } & \multirow[b]{2}{*}{ Comentários / sugestões dos auditores } \\
\hline & & $\begin{array}{c}(\mathbf{X}) \\
\text { Atendido }\end{array}$ & $\begin{array}{l}(\mathrm{X}) \mathrm{Não} \\
\text { atendido }\end{array}$ & $\begin{array}{l}\text { (X) Atendido } \\
\text { parcialmente }\end{array}$ & \\
\hline \multirow{2}{*}{$\begin{array}{l}5.1 \text { Veículos } \\
\text { pesados }\end{array}$} & $\begin{array}{l}\text { A instalação pode acomodar movimentos de veículos } \\
\text { pesados/transporte público quando necessário? (vãos, raios de giro, } \\
\text { largura do acostamento, capacidade operacional? }\end{array}$ & & & & \\
\hline & $\begin{array}{l}\text { Existe sinalização adequada para as atividades de veículos pesados / } \\
\text { transporte público? }\end{array}$ & & & & \\
\hline \multirow{4}{*}{$\begin{array}{l}5.2 \text { Transporte } \\
\text { público }\end{array}$} & Foram atendidos os serviços de transporte público? & & & & \\
\hline & $\begin{array}{l}\text { Foram consideradas as necessidades dos usuários de transporte } \\
\text { público? }\end{array}$ & & & & \\
\hline & Foram considerados os movimentos dos transportes públicos? & & & & \\
\hline & As paradas de ônibus estão localizadas de forma segura? & & & & \\
\hline $\begin{array}{l}5.3 \text { Veículos de } \\
\text { manutenção }\end{array}$ & $\begin{array}{l}\text { Existe necessidade de considerar instalações e sinalização para os } \\
\text { veículos de manutenção? }\end{array}$ & & & & \\
\hline
\end{tabular}




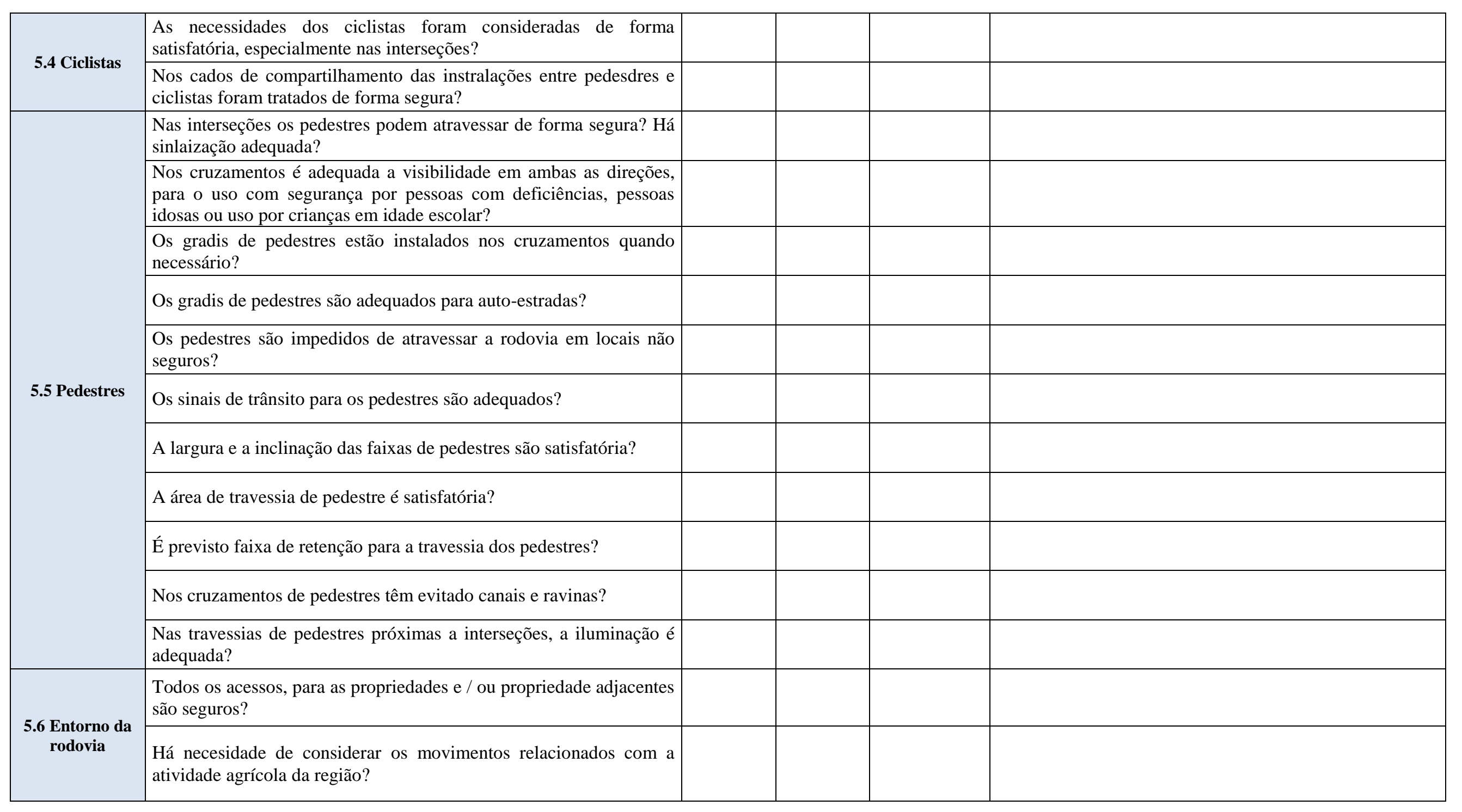




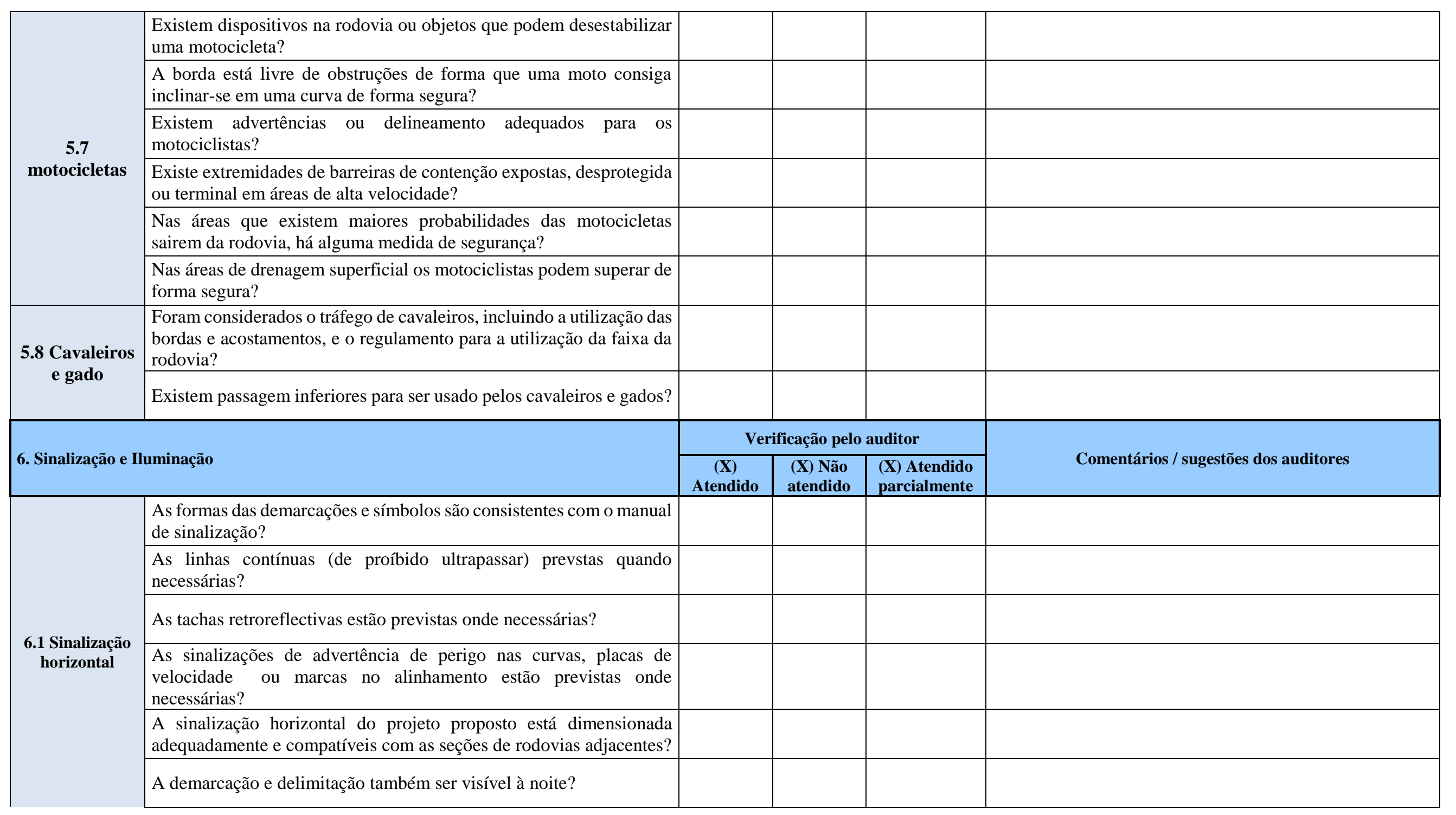




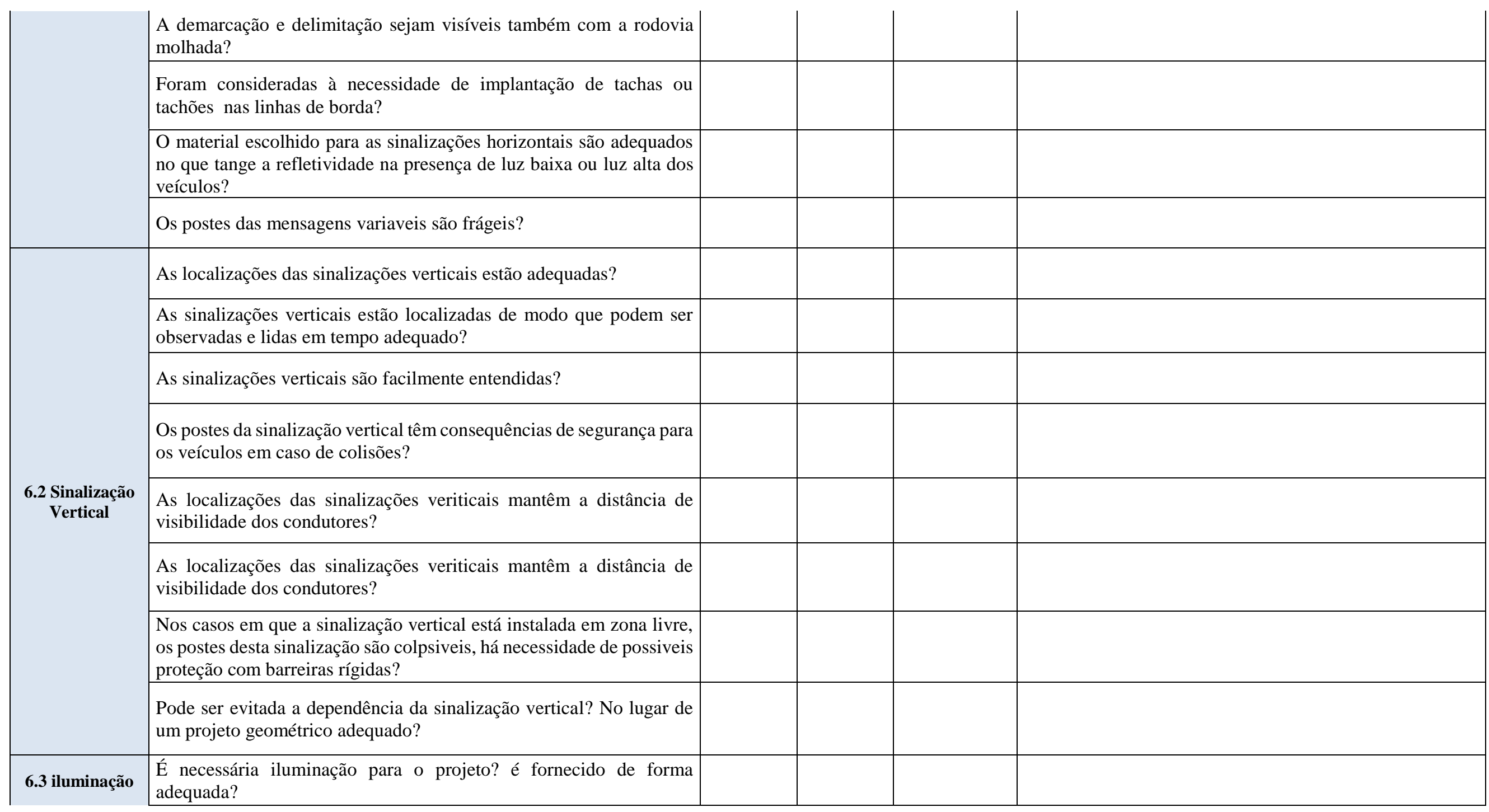




\begin{tabular}{|c|c|c|c|c|c|}
\hline & $\begin{array}{l}\text { O projeto terá seções com problemas de iluminação? (por exemplo, } \\
\text { sombras de árvores ou pontes). }\end{array}$ & & & & \\
\hline & Algum poste de iluminação representa perigo na margem da rodovia? & & & & \\
\hline & $\begin{array}{l}\text { Os postes a serem utilizados são frágeis (quebradiços) ou com base } \\
\text { dobrável ou deslizante? }\end{array}$ & & & & \\
\hline & $\begin{array}{l}\text { O projeto de iluminação pode confundir ou causar efeitos enganosos } \\
\text { sobre a sinalização ou semáforos? }\end{array}$ & & & & \\
\hline & $\begin{array}{l}\text { Há necessidade de requisitos especiais para iluminação ambiente? A } \\
\text { segurança será mantida casos as medidas especiais não forem } \\
\text { realizadas? }\end{array}$ & & & & \\
\hline & $\begin{array}{l}\text { A iluminação vai permitir adequadamente iluminação de } \\
\text { cruzamentos, das estradas adjacentes, refúgios, etc.? }\end{array}$ & & & & \\
\hline & $\begin{array}{l}\text { Todas as articulações (juntas) do projeto foram iluminadas } \\
\text { adequadamente? }\end{array}$ & & & & \\
\hline & Existe alguma área não iluminada no projeto? & & & & \\
\hline & $\begin{array}{l}\text { Existem locais de conflito de acidentes, que pode ser vantajoso tratar } \\
\text { com a melhoria da iluminação ou instalar o projeto de iluminação? }\end{array}$ & & & & \\
\hline & & & icação pelo & uditor & \\
\hline 7. Perguntas Adice & onais & $\begin{array}{c}(\mathbf{X}) \\
\text { Atendido } \\
\end{array}$ & $\begin{array}{l}\text { (X) Não } \\
\text { atendido }\end{array}$ & $\begin{array}{l}\text { (X) Atendido } \\
\text { parcialmente }\end{array}$ & Comentários / sugestões dos auditores \\
\hline & $\begin{array}{l}\text { É adequada a visibilidade dos motoristas e pedestres nos acessos } \\
\text { propostos? }\end{array}$ & & & & \\
\hline 7.1 Alinhamento & $\begin{array}{l}\text { é adequado o espaço previsto para mudança de fluxo e velocidade de } \\
\text { tráfego? }\end{array}$ & & & & \\
\hline & Os raios de curva possuem visibilidade adequada? & & & & \\
\hline & A distância de visibilidade e parada é adequada? & & & & \\
\hline $\begin{array}{c}\text { 7.2 Alinhamento } \\
\text { Vertical }\end{array}$ & A distância de visibilidade e parada é adequada? & & & & \\
\hline $\begin{array}{c}7.3 \text { áreas de } \\
\text { estacionamento }\end{array}$ & $\begin{array}{l}\text { O estacionamento no local está adequado para evitar que os veículos } \\
\text { estacionem na rodovia com risco associado a ele? }\end{array}$ & & & & \\
\hline
\end{tabular}




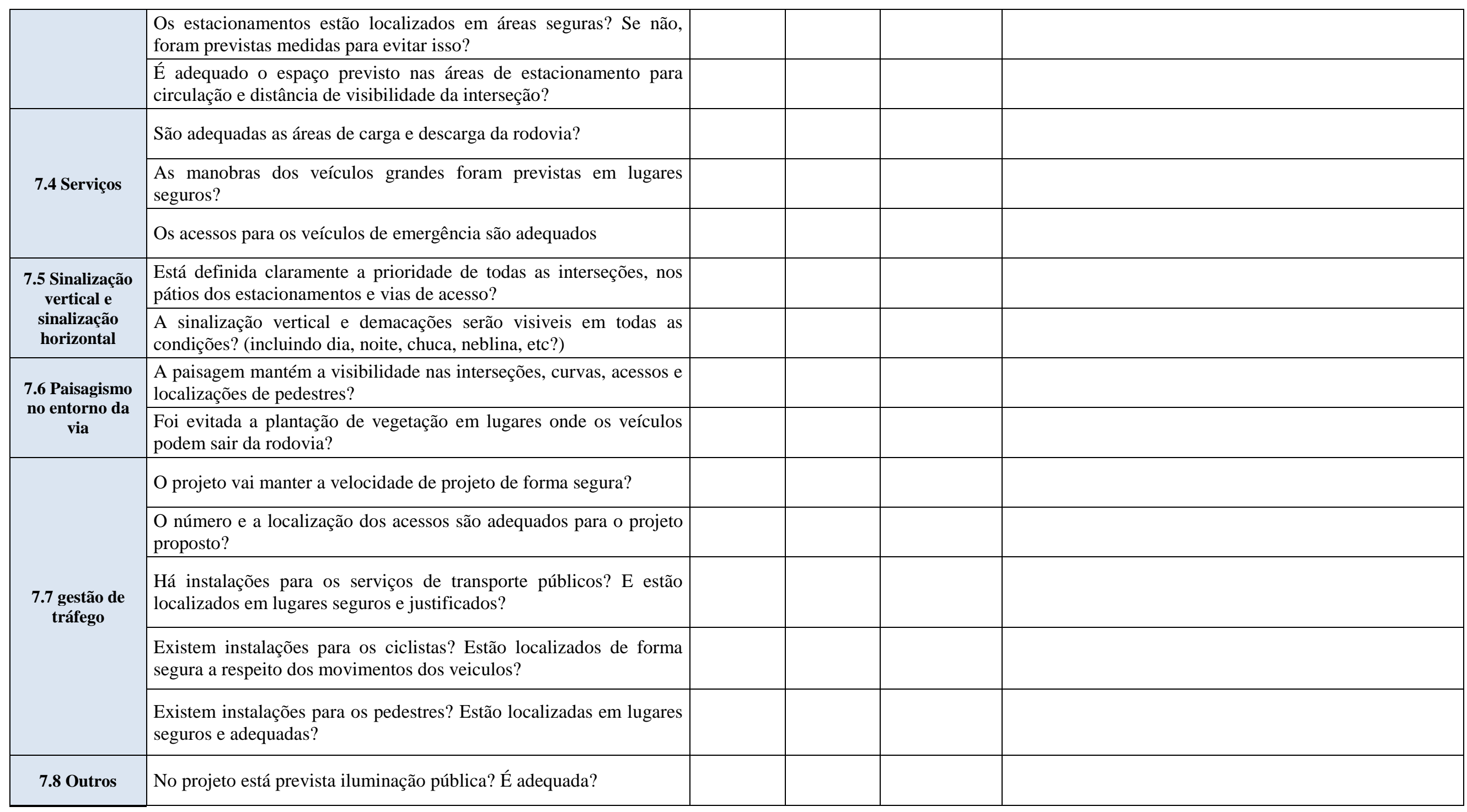




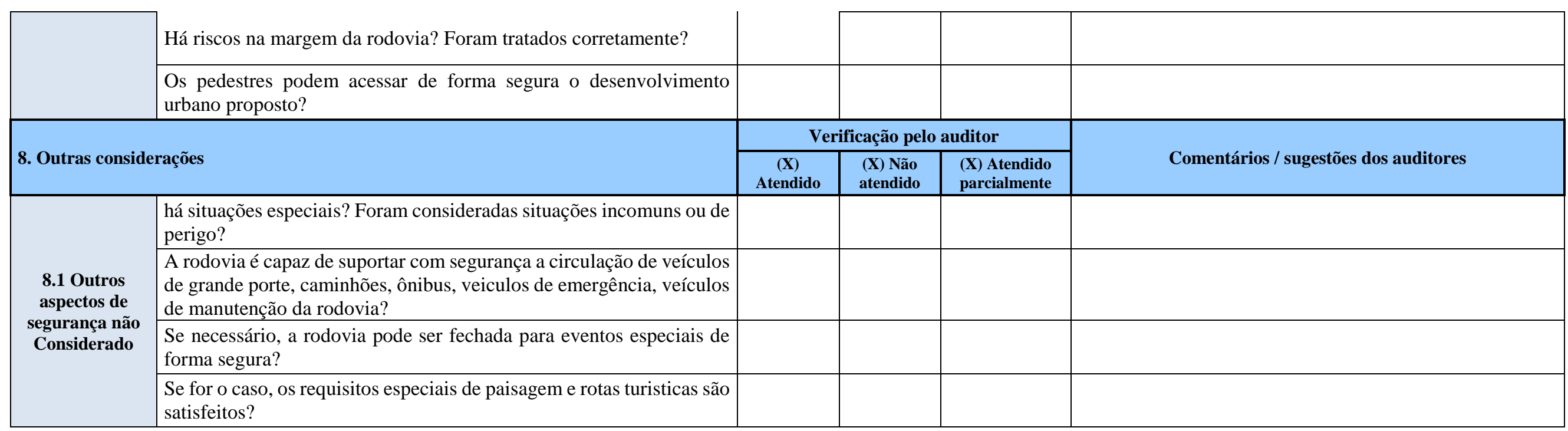

